Editora Poisson

\section{Gestão da Produção em Foco Volume 31}

1ạ Edição

Belo Horizonte

Poisson

2019 
Editor Chefe: Dr. Darly Fernando Andrade

\section{Conselho Editorial}

Dr. Antônio Artur de Souza - Universidade Federal de Minas Gerais

Ms. Davilson Eduardo Andrade

Dr. José Eduardo Ferreira Lopes - Universidade Federal de Uberlândia

Dr. Otaviano Francisco Neves - Pontifícia Universidade Católica de Minas Gerais

Dr. Luiz Cláudio de Lima - Universidade FUMEC

Dr. Nelson Ferreira Filho - Faculdades Kennedy

Ms. Valdiney Alves de Oliveira - Universidade Federal de Uberlândia

Dados Internacionais de Catalogação na Publicação (CIP)

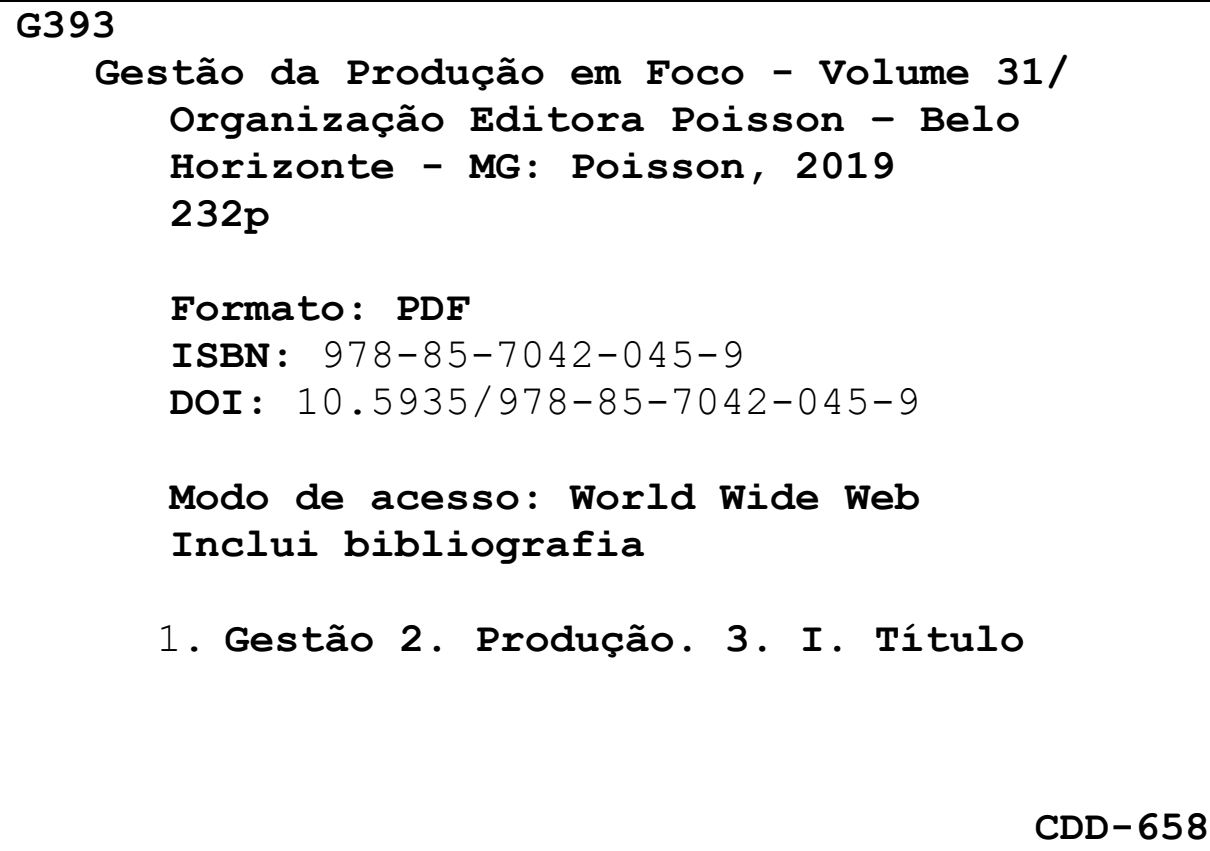

1. Gestão 2. Produção. 3. I. Título

O conteúdo dos artigos e seus dados em sua forma, correção e confiabilidade são de responsabilidade exclusiva dos seus respectivos autores.

Baixe outros títulos gratuitamente em www.poisson.com.br contato@poisson.com.br 


\section{SUMÁRIO}

Capítulo 1: Avaliação da qualidade dos serviços mecânicos sob a perspectiva de clientes de uma empresa no município de Xinguara - PA..... 7

Aline Pereira Santos. Karoline Silva Amorim. Fábia Maria de Souza. Hélio Raymundo Ferreira Filho, Nayara Cristina Ramos

Capítulo 2: Avaliação da eficácia de sistemas de gestão da qualidade de empresas construtoras no atendimento a requisitos técnicos aplicáveis a uma edificação habitacional: Um estudo de caso em Brasília/DF 15

Walter Segond de Vasconcelos

Capítulo 3: Método de Análise e Solução de Problemas (MASP) aplicado a uma empresa de alimentos 25

Luciana Lima Gonçalves Vieira, Paulo Fernandes Sanches Junior, Luciano dos Santos Diniz

Capítulo 4: Utilização da internet das coisas e da plataforma arduino para o controle da qualidade do leite: Uma revisão sistemática 37

Katiane de Oliveira Comachio, Silvana Ligia Vincenzi

Capítulo 5: Aplicação do mapeamento do fluxo de valor em uma empresa fabricante de redutores de velocidade e motorredutores de velocidade. 48

Rodrigo Fredi, Rodrigo Montanari da Cunha, Diego Quinelatto Rossi

Capítulo 6: Indústria 4.0: Uma análise da indústria brasileira perante o mundo.. 57 Anderson Senhoreli, Camila Aparecida Soares de Oliveira, Viviane Yukari Yamada

Capítulo 7: Impulso das tecnologias 4.0 na indústria têxtil 68 Gabriela Maestri, Fernando Ribeiro Oliveira, Fernanda Steffens

Capítulo 8: Design e simulação dos movimentos de um braço robótico de 4 graus de liberdade.....

Matheus Adriano Godoy Ramos

Capítulo 9: Implementação de robôs colaborativos em uma indústria do setor automotivo

Marcela Monique Donadelli, Telma Tamires Barbosa Vieira, Rafael Rodrigues Benelli, Alexandre Carvalho Dantas, Ivan Correr 


\section{SUMÁRIO}

Capítulo 10: Modelo de utilização de sistemas ciber-físicos na implementação da metodologia WCM

Guilherme Louro Brezinski, André Luiz Alcântara Castilho Venâncio, Eduardo de Freitas Rocha Loures, Fernando Deschamps

Capítulo 11: Uso da Blackboard e Sway no desenvolvimento do livro digital no Colégio Marista de Criciúma 107

Tiago Cesconeto Roque, Lucimara Cardoso Nicolau

Capítulo 12: A Prática nas Engenharias: A importância do contato com um Makerspace para engenheiros em formação

Lucas Davis Ribeiro de Paula, Danielle Saranh Galdino Duarte Garcia, Raquel Ferreira de Souza

Capítulo 13: Implementação de interface computacional para determinação do coeficiente de difusividade mássica de corantes em tecidos têxteis

Gylles Ricardo Ströher, Fernando dos Santos Freitas, Gisely Luzia Ströher

Capítulo 14: Os benefícios da aplicação da cronoanálise no processo produtivo: Uma pesquisa-ação em empresa do ramo de puericultura pesada 133

Lucas Eduardo Barbieri, Eduardo Ezequiel Zaniboni, Vanessa Moraes Rocha de Munno, Bianco Gallazzi da Silva Leite, Ivan Correr

Capítulo15: Análise dos modelos matemáticos para o transporte de ajuda humanitária em situações de desastres. 147

Lorena Hernández Mastrapa, Daniel René Tasé Velázquez, Everton Dias de Oliveira, Caroline Kuhl Gennaro, Maria Julia Xavier Belém

Capítulo 16: Previsão de carga elétrica em curto prazo utilizando modelos de Box \& Jenkins especificados via otimização por enxame de partículas 155

Guilherme Guilhermino Neto, Henrique Steinherz Hippert

Capítulo 17: Modelagem da produção industrial alimentícia brasileira (2002-2017) a partir da combinação dos modelos SARIMA e Holt-Winters. 164

Karina Sayuri Ueda, Silvia Maria Martelli, Ícaro Agostino, Renan Mitsuo Ueda, Adriano Mendonça Souza 


\section{SUMÁRIO}

Capítulo 18: Aplicação da programação linear inteira no planejamento dos pedidos de fraldas descartáveis do município de Ouro Preto - MG 176

Luis Guilherme Esteves Leocadio

Capítulo 19: Modelo de progamação inteira para o problema de mix de produção no benefiamento do granito com matrizes de produção

Marcos Wagner Jesus Servare Junior

Capítulo 20: Modelagem matemática para o problema de alocação de pilhas em um pátio de estocagem e porto

Marcos Wagner Jesus Servare Junior, Álvaro Daniel Oliveira Lopes, José Leandro Felix Salles, Helder Roberto de Oliveira Rocha

Capítulo 21: Projeto modelagem bifocal: Buscando melhorias no processo de soldagem utilizando arame tubular

Maria Verônica Macedo de Lima Galm, Peter Jônas Ribeiro Hachmann, Victor de Souza Ribeiro, Simone Cavenati

Capítulo 22: Aplicação da programação linear na maximização dos lucros de uma panificadora 210 Lara Cristine Pereira dos Santos, Natália Cibele de Sousa Santos, Jarbas Ancelmo da Silva Júnior

Autores: 219 


\section{Capítulo 1}

\section{AVALIACÃO DA QUALIDADE DOS SERVIÇOS MECÂNICOS SOB A PERSPECTIVA DE CLIENTES DE UMA EMPRESA NO MUNICIPPIO DE XINGUARA - PA}

\section{Aline Pereira Santos}

Karoline Silva Amorim

\section{Fábia Maria de Souza}

Hélio Raymundo Ferreira Filho

Nayara Cristina Ramos

Resumo: $O$ atendimento das necessidades de clientes está atrelado à qualidade em serviços, desta forma estando em ligação também com o grau de percepção e satisfação quanto ao produto intangível recebido. Logo, dar importância aos serviços de forma planejada e controlada continuamente, pois as percepções entorno deste podem ser facilmente influenciadas por inúmeros fatores de desgosto perante a expectativa inicial. Assim, percebe-se que as empresas precisam estar atentas a métodos que proporcionem possíveis maneiras de identificarem as necessidades de seus clientes quanto aos serviços ofertados. Assim, este artigo objetiva avaliar a qualidade dos serviços sob a perspectiva dos clientes de uma pequena oficina mecânica localizada em Xinguara - PA, uma vez que a qualidade em serviços tem entre seus elementos a busca de fatores diferenciais as empresas, tendo como aspecto o crescimento da competitividade, e abranger as fundamentações para dar maior atenção para os clientes tendo em vista como elemento de suma importância para a organização. Deste modo, por meio de uma abordagem qualitativa, buscou-se conhecer a satisfação dos clientes na obtenção dos serviços mecânicos prestados na empresa. A partir do levantamento de informações quanto a satisfação do consumidor, e consequentemente, os fatores que estão garantindo a fidelização dos mesmos à organização.

Palavras-chave: Qualidade em serviços. Satisfação de Clientes. Oficina Mecânica 


\section{INTRODUÇÃO}

Com o mercado cada dia mais instável, é necessário a busca de resultados eficazes na prestação de serviços, o que faz parte das estratégias de uma gestão ativa que priorize a gestão da qualidade, tornando essa prática crucial para a sobrevivência das corporações no mercado. A eficiência é a mola propulsora da análise e ampliação de conceitos, métodos e ferramentas para aprimorar o processo de abastecimento dos produtos e aprimorar os serviços com qualidade oferecidos pelas empresas.

A satisfação dos clientes é expressa por Santos; Neiva; Andrade-Melo (2013) como sendo definida por um retorno dado pelo usuário sobre os serviços prestados. Desta forma, segundo Altaf; Zancanello; Falco (2016), é importante fazer um estudo quanto o comportamento do consumidor para desenvolver estratégias e ferramentas mercadológicas que possam levar a obtenção de vantagens competitivas no atual ambiente dinâmico, esta estratégia permite conhecer e utilizar a segmentação de mercado como forma de amoldar-se as necessidades e anseios de grupos distintos de clientes.

Para se manter no mercado competitivo uma empresa necessita usar uma estratégia que venha garantir a satisfação dos clientes visando garantir sua fidelização. Cada empresa, independente do seu porte e da sua área de atuação precisa delinear a estratégia que melhor atende suas perspectivas. Quando a área de atuação está no segmento de prestação de serviço, as exigências são mais complexas, pois tratam-se de atuações que envolvem fatores subjetivos, tais como, ações que priorizam gosto, expectativas, preferências, confiança, segurança e outros fatores subjetivos.

Contudo, nem sempre as empresas conseguem atender as exigências da sua clientela, com isso a problemática desta pesquisa consiste em responder a seguinte questão: Qual o grau de satisfação dos clientes de uma oficina mecânica especializada em serviços de manutenção e consertos de motos percebem a qualidade dos serviços ofertados? Assim, este trabalho tem como objetivo conhecer a percepção dos clientes quanto a qualidade dos serviços oferecidos em uma oficina mecânica especializada em serviços de manutenção e consertos de motos, localizada no município de Xinguara.
Para compreender os interesses dos clientes a empresa vem sempre melhorando suas tecnologias de base para a melhor prestação dos serviços alcançando a qualidade do mesmo. Desta forma, foi feito um estudo de caso quanto a qualidade do serviço prestado, com ênfase nas seguintes dimensões: confiabilidade, responsabilidade, segurança, empatia e tangibilidade.

\section{GESTÃO DA QUALIDADE}

Por mais que seja um assunto muito discutido, e a qualidade seja usada no cotidiano, este tema ainda é questionável quanto ao seu real significado dentro da gestão. O termo qualidade é definido por muitos autores sob pontos de vista distintos que podem ser caracterizados pela cultura, pela história, desenvolvimento econômico e social e acerca da abordagem em questão.

Para Martin; Golsby-Smith (2018), "a gestão é uma ciência e que as decisões de negócios devem ser orientadas por uma análise rigorosa dos dados é subjacente à prática e ao estudo de negócios". De acordo com Barbosa; Gambi e Gerolamo (2017), "o programa de gestão da qualidade foi introduzido por Deming (1986), Juran (1989) e Feigenbaum (1986) e preza pelo foco no cliente, melhoria contínua, trabalho em equipe e busca constante pela atualização".

Para Paladini (2012) a qualidade não está totalmente atrelada a algumas estratégias ou técnicas estatísticas, mas a uma forma de decisão que reflete em políticas de funcionamento da empresa, enquanto Jerônimo et al (2015) dizem que a qualidade pode ser entendida por muitos como algo que está à beira da perfeição, e está calcada em princípios quanto a coordenação em meio a funções dentro da organização e defeito zero, referindo-se a gestão.

A gestão da qualidade, para Silvino e Rafalski (2013), possui diversos conceitos, porém não reconhecidos como padrão: a satisfação do cliente, a garantia e a conquista do mercado. Para os autores a gestão da qualidade é uma estratégia de administração com inclinação a designar o conceito de qualidade em todos os processos organizacionais, fazendo com que afete não somente a gestão da empresa, mas todos os setores que trabalharem junto à mesma.

A partir deste raciocínio, Paladini (2012) afirma que por meio da percepção dos 
clientes torna-se possível a tomada de decisões organizacionais, fazendo com que atenda às suas demandas e, por conseguinte possibilita a melhoria contínua dos produtos e serviços. Na visão de Toledo et al (2013) a qualidade para muitos se confunde com outros conceitos como produtividade, eficácia e eficiência.

\subsection{QUALIDADE EM SERVIÇOS}

As empresas, com o passar do tempo começaram a reconhecer o potencial competitivo quanto à melhoria da qualidade de seus produtos e serviços. O cenário de extrema competição atual está fazendo com que conceitos anteriormente utilizados não sejam mais suficientes para capacitar as empresas a competirem neste mercado.

A qualidade em serviços para Costa et al (2015) pode ser considerada como a causa entre a eficácia do serviço e a expectativa do consumidor. Desta forma, atingir as necessidades e as expectativas de um cliente de forma eficaz, promove um serviço de qualidade. Quanto mais serviços de qualidade forem prestados, mais necessidades serão atendidas e as expectativas alcançadas.

Com o objetivo de identificar o que mais se faz influente na qualidade na visão dos clientes, Parasuraman; Zeithaml; Berry (1998; 2014) realizaram estudos onde percebia-se que alguns atributos se repetiam com frequência e sua concentração acontecia em um menor grupo de dimensões, que se dividiam em: confiabilidade, responsabilidade, segurança, empatia e tangíveis.

- Confiabilidade: Habilidade para execução do serviço conforme o prometido de maneira segura e precisa;

- Responsabilidade: Entregar o serviço sem demora e disposição em ajudar o cliente;

- Segurança: Conhecimentos dos colaboradores, ligado à simpatia, os colaboradores passam credibilidade e confiança. Está ligado com a confiança que o cliente tem em fazer negócios com a empresa;

- Empatia: Entendimento das necessidades dos clientes, ou seja, o cuidado, atenção particular dada aos clientes;
- Tangíveis: Aspecto das instalações físicas, equipamento, pessoal e material impresso.

Estas dimensões servem como pontos qualificadores, que podem ser utilizados para mensurar a qualidade de um serviço prestado. Deste modo as informações colhidas por esses itens medem a expectativa do cliente em relação ao serviço ideal ainda não utilizado, e também a qualidade percebida pelo cliente depois de ter o serviço realizado.

\subsubsection{TIPOS DE SERVIÇOS E CARACTERÍSTICAS}

No mundo dos negócios os serviços têm crescido e, algumas características fazem menção de como compreender um serviço. Estes são divididos por Kotler e Keller (2013), em quatro características principais: intangibilidade, indivisibilidade, variabilidade e perecibilidade.

- Intangibilidade: Kotler e Keller (2013) dizem que os serviços não podem ser observados e provados antes de serem obtidos, já Roggia (2010), apregoa que o prestador de serviços deve fornecer evidências tangíveis dos mesmos de alguma maneira para que a insegurança dos compradores seja diminuída. Quando o prestador de serviço quer mostrar agilidade, por exemplo, precisa tornar seu posicionamento estratégico tangível em todos os meios de contato com o consumidor, deixando-o mais claro e objetivo;

- Indivisibilidade: o serviço e o prestador são avaliados como um todo segundo Kotler; Keller (2013) os serviços não podem ser separados do prestador pois a maneira que este é entendido formam a qualidade percebida pelo cliente. Para Loregian e Hoss (2013) a inseparabilidade é um dos atributos da prestação de serviços que a faz se diferenciar da produção de mercadorias, pois o serviço é executado e consumido simultaneamente, com a colaboração do cliente e do fornecedor;

- Variabilidade: em sua construção pode ser classificada em três categorias segundo Cruz; Santos e Mendes (2018): variabilidade de tempo do processamento; variabilidade de fluxo; e variabilidade geométrica, as duas primeiras referem-se "às variações de tempo observadas na execução 
dos processos, tendo como parâmetro comparativo a programação de atividades. [...] já a de fluxo quando uma estação de trabalho afeta o comportamento de outras estações de trabalho [...]";

- Perecibilidade: não é possível a armazenagem dos serviços para a venda ou uso posterior. Conforme afirmam Kotler e Keller (2013) a perecibilidade dos serviços mostra que a organização está vendendo fundamentalmente a sua atuação. É necessário manter um equilíbrio entre a oferta e a demanda. A perecibilidade dos serviços como definem Loregian; Hoss (2013) tem certas implicações. Uma destas implicações é que o prestador do serviço, por exemplo, o mecânico, está vendendo essencialmente seu desempenho.

\subsection{SERVIÇOS NO SEGMENTO MECÂNICO}

O setor mecânico se caracteriza como sendo de alta competitividade, fazendo com que a qualidade na prestação deste serviço seja uma estratégia para a empresa continuar atuando no mercado ao longo prazo. A movimentação e competitividade deste mercado para Carvalho et al (2017) justificase pelo fato da entrada de franquias especializadas na reparação de veículos, com muitas redes de atendimento espalhadas pelo país.

O mercado de reparos segundo o Sebrae (2015) vem ganhando destaque e o nicho de consertos e manutenção de veículos tende a manter-se aquecido. Neste comércio onde a principal atividade são os serviços, é preciso estar atento na qualidade dos reparos, demandando a qualificação da mão de obra, o que se dá pelo fato de o prestador de serviço, mecânico, está vendendo fundamentalmente seu desempenho. No entanto, tem-se também a questão da substituição de peças que também é essencial para que haja entrega do serviço posteriormente.

A esfera dos serviços prestados pelas oficinas mecânicas, como descreve Carvalho et al (2017), é normalmente constituída por proprietários particulares de veículos e donos de frotas, ou seja, aqueles que portam algum tipo de transporte. No Brasil a quantidade de veículos se faz muito intensiva, o que é de suma importância para assegurar aos trabalhadores da área de serviços mecânicos.

\subsubsection{SERVIÇOS MECÂNICOS EM MOTOS}

Assim como em todo serviço, neste tipo de prestação de serviços é necessário que os profissionais tenham plena capacidade para realizar manutenções, que surgem mais facilmente em motos, resultado da facilidade destes veículos têm em quebrar ou dar algum problema. O provedor do reparo para motocicletas deve saber efetuar as atividades afim de eliminar possíveis quebras e defeitos.

De acordo com Loregian e Hoss (2013), as empresas prestadoras de serviços de manutenção de motos devem ter como principal finalidade garantir as condições legais de funcionamento das mesmas, como fazer reparação e substituição de peças, bem como fazer ajustes necessários com a utilização de ferramentas e máquinas adequadas.

\subsection{SATISFAÇÃO E FIDELIZAÇÃO DE CLIENTES}

As experiências vividas pelo cliente são o que geram as expectativas sobre determinado serviço, seja com o prestador de serviços que está contratando no momento ou outros fornecedores. Para Morais; Silva e Veras (2017), quando um cliente tem um bom tratamento, este irá estabelecer um padrão de atendimento que usará como referência sempre que retornar à empresa e empregará de forma inconsciente como base para julgar outros estabelecimentos.

A satisfação do cliente representa o indicador de confiabilidade para os consumidores em relação a organização que disponibiliza produtos e/ou serviços. Como afirmam Antunes e Rita (2007), com a interação consumidor e empresa sendo concretizada, facilita uma possível ligação entre os mesmos, podendo oferecer serviços mais qualificados para atender as necessidades de cada cliente.

Somente a satisfação não será necessária para manter seus clientes quando o mercado está em contáveis mudanças, e com isso as empresas, como profere Kotler (2003) são levadas a expandir suas prioridades para se obter a fidelização e comprometimento dos consumidores. Lafley e Martin (2018) defendem que o desempenho é amparado por oferecer aos consumidores a escolha mais fácil, e não a perfeita. Desta forma, para manter "os clientes fidelizados não é uma questão de adaptar-se continuamente às 
mudanças necessárias para permanecer com o melhor ajuste racional ou emocional. Tratase de ajudar o consumidor a não precisar fazer mais uma escolha".

A fidelização como exprime Souza (2009), é correspondente a ações oferecidas com o aspecto de fidelizar ou reter os clientes que se tornam indispensáveis, restringindo 0 envolvimento de seus consumidores com a concorrência. As instituições organizacionais usam como uma estratégia para fidelização de clientes e como ferramenta, o marketing de relacionamento.

Relacionamentos sólidos entre a empresa e seu cliente, interferem na percepção da qualidade que por fim atuam positivamente na satisfação do cliente e em seguida na lealdade conferida pela a organização. Para Pereira; Bastos (2009), esse ato faz com que os clientes vejam o produto e/ou serviços designados a ele como, sendo de maior qualidade, e por fim acabem tornando-se a sua primeira opção.

\section{METODOLOGIA}

A abordagem utilizou a pesquisa qualitativa, a qual trata os dados visando analisar a satisfação dos clientes quanto aos serviços oferecidos em uma oficina mecânica. Para Ganga (2012) o papel do pesquisador numa pesquisa qualitativa é obter informações do fenômeno por meio da visão dos indivíduos. $\mathrm{Na}$ pesquisa qualitativa como definem Marconi e Lakatos (2017) o pesquisador pode destacar aspectos psicológicos e opiniões de indivíduos, e, por meio disso, busca descrever a complexidade de uma determinada hipótese e interpretar os dados e teorias.

Para alcançar os objetivos utilizou-se técnicas da pesquisa descritiva, descrever a visão dos clientes quanto a prestação de serviço na oficina, buscando compreender o que leva a fidelização dos fregueses, para Gil (2017) visa levantar as opiniões, atitudes e crenças de uma população, já Ganga (2012) diz que esse tipo de pesquisa tem como objetivo descrever as características de determinada população ou fenômeno.

Os procedimentos técnicos deram-se por meio do Estudo de Caso, no qual buscou-se compreender os fatores que envolvem a qualidade nos serviços em mecânicas, fazendo levantamento e coleta de dados, uma vez que estudo de caso para Yin (2015) permite avaliar o objeto de estudo dentro do contexto viabilizando fazer correlações dos fenômenos.

O público-alvo para a obtenção dos dados foram clientes da oficina mecânica, a seleção dos clientes se deu de forma aleatória. Entrevistou-se 30 pessoas, para isso foi utilizado questionários para o levantamento dos dados, com perguntas fechadas com o total de 15 questionamentos, que resultou na observação feita pelas entrevistadoras.

Os instrumentos de coletas de dados foram construídos a partir das características da qualidade dos serviços delineada por Kotler; Keller (2013): intangibilidade, indivisibilidade, variabilidade e perecibilidade. Desta forma, os dados foram analisados de acordo com as orientações estabelecidas sobre as características de qualidade de serviço consideradas por Kotler e Keller (2013).

\section{RESULTADOS E DISCUSSÃO}

Quanto a fidelização e satisfação dos clientes, como também a imagem que os clientes têm do estabelecimento em estudo, existe uma instabilidade quanto ao grau de satisfação, conforme mensurado na Tabela 1, mostrada abaixo (sendo 0 totalmente insatisfeito e 10 totalmente satisfeito) e que representa o grau de afeição dos clientes que se dispõe da seguinte forma: quanto mais próximo de zero mais o assunto desagrada ao cliente, e quanto mais próximo de dez melhor visão o cliente tem sob a questão. 
Tabela 1- Demonstrativo quanto a satisfação e fidelidade dos clientes

INDAGAÇOিES AOS CLIENTES
\begin{tabular}{|l|c|c|c|c|c|c|c|c|c|c|c|c|}
\hline $\begin{array}{l}\text { Satisfeito com os serviços que ofertados } \\
\text { na oficina }\end{array}$ & 0 & & & & & 4 & & 3,33 & 30 & 30 & 30 & 6,67 \\
\hline $\begin{array}{l}\text { Chance de trocar a oficina por outra } \\
\text { futuramente }\end{array}$ & 6,67 & 3,33 & 6,67 & 6,67 & 3,33 & & 13,33 & 16,67 & 30 & 10 & 3,33 \\
\hline $\begin{array}{l}\text { Chance de recomendar a oficina a } \\
\text { alguém }\end{array}$ & & & & & & & 3,33 & 20 & 30 & 30 & 16,67 \\
\hline $\begin{array}{l}\text { Percepçâo quanto a reputaçâo dos } \\
\text { serviços da oficina. }\end{array}$ & & & & & & & & 6,67 & 23,33 & 53,33 & 16,67 \\
\hline
\end{tabular}

Fonte: Dados dos clientes da oficina mecânica (2018)

De acordo com as respostas das indagações feitas foi possível a constatação que os clientes em sua maioria consideram o estabelecimento um bom lugar, contudo, se percebe a necessidade de melhoria na qualidade dos serviços, ou seja:

- 63,33 \% demonstraram que estão satisfeitos com os serviços, mas a qualidade precisa melhorar;

- 3,33\% demonstraram fidelização a empresa, $40 \%$ estão propensos a aderindo esta fidelidade, contudo esperam por melhorias, que não sabem informar quais são, para serem convencidos. Por outro lado, cerca de $26,67 \%$ estão esperando encontrar outra que ofereça melhores serviços;

- $16,67 \%$ demonstraram confiança em recomendar a empresa a outras pessoas de forma espontânea e/ou intencional, $60 \%$ recomendam desde que sejam indagados, caso contrário, ficam quietos;

- $16,67 \%$ demonstraram satisfação total com os serviços, $76,66 \%$ estão satisfeitos, mas esperam melhoria nos serviços de forma geral, gostariam de serem surpreendidos com novidades que agreguem mais valor aos produtos ofertados pela empresa.

Logo, podem recomendar para as demais pessoas ainda não usuárias dos serviços e se sentem essencialmente satisfeitos com os serviços recebidos. Quanto as dimensões da qualidade em serviços que permitem a percepção dos clientes quanto as ações que precisam ser melhoradas foram diagnosticadas o seguinte:

Tabela 2 - Demonstrativo quanto as dimensões da qualidade e satisfação do cliente

\begin{tabular}{c|l|c|c|}
$\begin{array}{c}\text { DIMENSÕES DA } \\
\text { QUALIDADE }\end{array}$ & \multicolumn{1}{c}{ ELEMENTOS DE PERCEPÇÕES DO CLIENTE QUANTO } & $\begin{array}{c}\text { GRAU DE } \\
\text { SATISFAÇÃO }\end{array}$ \\
\multirow{2}{*}{ Variabilidade } & A qualidade do serviço, no geral, vale seu tempo e esforços & $86,67 \%$ & $13,33 \%$ \\
\hline \multirow{2}{*}{ Indivisibilidade } & Equipamentos e tecnologias atualizados e modernos & $53,33 \%$ & $46,67 \%$ \\
\cline { 2 - 4 } & Os serviços prestados são cumpridos conforme o acordado & $83,33 \%$ & $16,67 \%$ \\
\hline \multirow{3}{*}{ Variabilidade } & A capacidade adequada de resoluções dos problemas & $76,67 \%$ & $23,33 \%$ \\
\cline { 2 - 4 } & As facilidades em obter informações sobre os serviços prestados & $56,67 \%$ & $43,33 \%$ \\
\cline { 2 - 4 } & A rapidez quanto as solicitações feitas aos funcionários & $63,33 \%$ & $36,67 \%$ \\
\hline \multirow{2}{*}{ Intangibilidade } & Os funcionários são confiáveis e competentes no atendimento & $90 \%$ & $10 \%$ \\
\hline \multirow{2}{*}{ Perecibilidade } & A atenção adequada dado pelos funcionários às solicitações do cliente & $76,67 \%$ & $23,33 \%$ \\
\cline { 2 - 4 } & Horário de atendimento adequado & $93,33 \%$ & $6,67 \%$ \\
\hline
\end{tabular}

Fonte: Dados dos clientes da oficina mecânica (2018)

A partir dos resultados expostos na Tabela 2, identificou-se que os serviços oferecidos pela oficina mecânica têm boa aceitação pelas pessoas, já que em todos os casos as percentagens de respostas positivas ficaram acima dos $50 \%$. 
Nota-se que o serviço da empresa tem uma imagem bastante receptiva, pois a maioria dos clientes consideraram que os pontos: a) horário de atendimento; b) a qualidade como fator para tempo gasto e, c) serviços cumpridos como prometido, mantiveram taxas altíssimas sendo fatores chave para a satisfação dos utentes.

Constata-se que os dois pontos frágeis: são as atividades inerentes às informações referentes aos serviços oferecidos e aos equipamentos incumbidos da realização dos mesmos. Os clientes estão com problemas que requerem serviços especializados e sabem que a empresa oferece, assim como, não esclarece os procedimentos adotados no decorrer da prestação de serviço que levará a solução do problema do cliente.

Esses fatores que fragilizam a qualidade do serviço são bem pontuais e com soluções viáveis, ou seja, a organização deverá a pensar em soluções para deixar seus clientes a par dos serviços que oferecem, e mais à vontade ao pedir informações. Faz-se importante também fazer observação no que diz respeito aos equipamentos e tecnologias, sempre estando atualizados no mercado, fazendo com que os clientes se sintam ainda mais seguros quanto ao fato de deixarem seus veículos para os devidos reparos e consertos, já que vão contar com aparelhamentos que manterão um padrão de qualidade.

Verificou-se, portanto, que os clientes sentem que a empresa deve investir mais em pessoal e maquinário, pois apresentando um melhor resultado fica mais fácil conquistar a lealdade dos clientes. Por mais que seja uma oficina pequena é importante manter um padrão de qualidade que atenda as expectativas dos

\section{REFERÊNCIAS}

[1] ALTAF, Joyce Gonçalves; ZANCANELLO, Luciana C.; FALCO, Gláucia P. Aspectos Preponderantes para a Satisfação do Cliente: o Caso 25 de Março. Revista de Administração, v. 2, n. 1, p. 67-86, oct./ 2016.

[2] ANTUNES, Joaquim; RITA, Paulo. O marketing relacional e a fidelização de clientes Estudo aplicado ao termalismo português. Economia Global e Gestão, v. 12, n. 2, p. 109-132, ago./ 2007.

[3] BARBOSA, F. M.; GAMBI, L. N.; GEROLAMO, M. C. Leadership and quality management - a correlational study between leadership models and quality management usuários do serviço, pois isso se faz um ponto crucial para todos os envolvidos.

\section{CONSIDERAÇÕES FINAIS}

Notou-se ao decorrer do trabalho que é de suma importância traçar estratégias competitivas para a oficina que facilita a qualidade dos serviços, pois existe pontos frágeis apontados pelos clientes que comprometem sua satisfação, tais como: deixar claro quais equipamentos são utilizados para o serviço, a mão de obra qualificada também são pontos que devem ser estudados, assim como a comunicação, a empresa tem que divulgar mais os seus serviços até por meio dos funcionários mesmo e fazer mais valorosos os seus méritos, e principalmente conhecer o seu público.

Entender as particularidades dos clientes, faz com que haja um retorno em forma de retenção e lealdade. O empresário deve saber exatamente qual o público ao qual presta o serviço e como sendo uma empresa pequena deve procurar visualizar o que 0 cliente gosta, espera ou necessita, tudo atrelado ao preço do serviço e ao atendimento.

É notório que o mercado de oficinas mecânicas, geram grande expectativa aos clientes quanto à qualidade do serviço, e para o trabalho estes foram sublimes fontes de informação. Contudo, vale ressaltar que há uma necessidade de constante melhoria na qualidade de prestação de serviços, pois é indispensável para a multiplicação de clientes, para tanto se faz com grande prestígio o relacionamento entre empresa e consumidor, o que proporcionará a tão almejada

fidelização.

principles. Gestão \& Produção, n. 24, v.3, p. 438 449, jul./set. 2017.

[4] CARVALHO, L.; SANTOS, J. C.; SILVEIRA, F. S.; ALMEIDA, D. M. Avaliação qualiquantitativa dos riscos existentes em uma oficina mecânica localizada em Campo Mourão/PR. Tecnológica Revista do depto. de Química e Física, do depto. de Engenharia, Arquitetura e Ciências Agrárias e do Mestrado em Tecnologia Ambiental, v. 21, n. 2, p. 108-115, jul./dez. 2017.

[5] COSTA, M. R. S. et al. Avaliação da qualidade dos serviços: estudos sobre as expectativas e percepções dos clientes de uma 
empresa de moto peças. Revista Eletrônica Gestão e Serviços, v. 6, n. 2, p. 1333-135, jul./dez. 2015.

[6] CRUZ, H. M.; SANTOS, D. G.; MENDES, L. A. Causas da variabilidade do tempo de execução dos processos em diferentes sistemas construtivos. Ambiente e construção, v.18, n.1, p. 49-65, jan./mar. 2018.

[7] GANGA, G. M. D. Trabalho de conclusão de curso (TCC) na engenharia de produção: um guia prático de conteúdo e forma. São Paulo: Atlas, 2012.

[8] GIL, A. C. Como elaborar projetos de pesquisa. 6. ed. São Paulo: Atlas, 2017.

[9] JERÔNIMO, T. B. et al. Inovando a estratégia de gestão da qualidade pelo uso do Desdobramento da Função Qualidade combinado com SERVPERF em empresas de prestação de serviços. Exacta - EP, São Paulo, v. 13, n. 2, p. 167-176, 2015

[10] KOTLER, Philip; KELLER, Kevin L. Administração de Marketing - 14. ed. São Paulo: Pearson, 2013.

[11] KOTLER, Philip. Marketing de A a 80 conceitos que todo profissional precisa saber. Rio de Janeiro: Campus, 2003.

[12] LAFLEY, A.G.; MARTIN, R. L. A fidelidade do cliente está superestimada. Harvard Business Review Brasil (online), fev/2017. Disponível em $<$ http://hbrbr.uol.com.br/a-fidelidade-do-clienteesta-superestimada/>

[13] LOREGIAN, A. M.; HOSS, O. Marketing de serviços: o atendimento e a qualidade dos serviços prestados como ferramenta estratégica para a competitividade das oficinas mecânicas para motocicletas da cidade de Pato Branco - PR. Portal eduCAPES, nov. de 2013. Disponível em: < https://educapes.capes.gov.br> Acesso em: 06 mar. 2018

[14] MORAIS, M. G; SILVA, A. R; VERAS, G.P; FERREIRA, M. T. M. A gestão da qualidade na prestação de serviços: um estudo em um restaurante localizado em São Luís- MA. In: XXXVII Encontro Nacional de Engenharia de ProduçãoENEGEP, 37, Anais..., Joinville, 2017. Disponível em: < http://www.abepro.org.br>. Acesso em: 28 fev. 2018

[15] MARTIN Roger L.; GOLSBY-SMITH, Tony. Gestão é bem mais que ciência. Harvard Business Review Brasil (online) out/2017. Disponível em $<$ http://hbrbr.uol.com.br/gestao-e-mais-queciencia/>. Acesso em: 07 abr. 2018.
[16] PALADINI, E. P. Gestão da Qualidade: teoria e prática. 2012. São Paulo: Atlas, 2012.

[17] PARASURAMAN, A.; ZEITHAML, V. A.; BERRY, L. L. Servqual: a multiple-item scale for measuring consumer perceptions of service quality. Journal of Retailing, v.64, n. 1, p. 12-40, 1998.

[18] PEREIRA, P.F. P; BASTOS, F.C. Um estudo sobre a fidelização de clientes a partir de estratégias de marketing de relacionamento no segmento de farmácias e drogarias. Simpósio de Excelência em Gestão e Tecnologia - SEGeT, 2009. Disponível em: < http://gpi.aedb.br/seget/artigos>. Acesso em: 02 mar. 2018

[19] MARCONI, M. A.; LAKATOS, E. M. Metodologia científica. 7. ed. São Paulo: Atlas, 2017.

[20] ROGGIA, N. M. Marketing de serviço. Comunidade ADM, 2010. Disponível em: $<$ http://www.administradores.com.br > . Acesso em: 28 fev. 2018.

[21] SANTOS, Juliana N.; NEIVA, Elaine R.; ANDRADE-MELO, E. Antônio. Relação entre clima organizacional, percepção de mudança organizacional e satisfação do cliente. Psicologia: Teoria e Pesquisa, v. 29, n. 1, p. 31-39. 2013.

[22] SEBRAE, Serviço Brasileiro de Apoio às Micro e Pequenas Empresas. Tendências de mercado para consertos de veículos. Ago. 2015. Disponivel em: <http://www.sebrae.com.br>. Acesso em: 06 mar. 2018.

[23] SILVA, E. M.; YUE, G. K.; ROTONDARO, R. G.; LAURINDO, F. J. B. Gestão da qualidade em serviços de TI: em busca de competitividade. Production, v. 16, n. 2, p. 329-340, 2018.

[24] SILVINO, A. S; RAFALSKI, J. P. Gestão de qualidade em serviços nas micro e pequenas empresas do ramo de software: garantia de qualidade MPS.BR. Revesta de Administração da Faculdade Novo Milênio, v. 6, n.1, p. 1-9, nov. 2013

[25] SOUZA, A. A. Satisfação, Lealdade, Fidelização e Retenção de Clientes. V Congresso Nacional de Excelência em Gestão, 2009. Disponível em:< http://files.blogdocallcenter.com/>. Acessado em: 02 mar. 2018

[26] TOLEDO, J. C.; BORRÁS, M. Á. A.; MERGULHÃO, R. C. Qualidade gestão e métodos. Rio de Janeiro: LTC, 2013.

[27] YIN, R. K. Estudo de Caso - Planejamento e Métodos. 5. ed. São Paulo: Bookman, 2015. 


\section{Eapítulo 2}

\section{AVALIACÃO DA EFICÁCIA DE SISTEMAS DE GESTÃO DA QUALIDADE DE EMPRESAS CONSTRUTORAS NO ATENDIMENTO A REQUISITOS TÉCNICOS APLICÁVEIS A UMA EDIFICACÃO HABITACIONAL: UM ESTUDO DE CASO EM BRASÍLIA/DF.}

\section{Walter Segond de Vasconcelos}

Resumo: Dada a obrigatoriedade da edificação habitacional e seus sistemas atenderem aos requisitos de desempenho expressos na Norma ABNT NBR 15575, empresas construtoras veem um Sistema de Gestão da Qualidade como a estratégia para atendimento a esses requisitos, o que nos levou a avaliação da eficácia dos sistemas de três empresas no atendimento a requisitos técnicos aplicáveis a paredes de vedação em alvenaria de blocos cerâmicos, tendo em vista a manifestação, em edificações de reduzido tempo de vida útil, de patologias que impactam de forma negativa o atendimento aos requisitos do usuário do ambiente construído e a imagem da empresa em seu mercado de atuação. Para tal, avaliouse 'o que se diz que é feito' e 'o que de fato é feito' pelas empresas pesquisadas, a partir de critérios de referência, tidos como 'o que deveria ser feito', chegando a resultados que demonstram que 'o que se diz que é feito' não é 'o que de fato é feito' e 'o que de fato é feito' não é 'o que deveria ser feito', os quais confirmam a possibilidade da ocorrência em edificações habitacionais de manifestações patológicas motivadas pela ineficácia de sistemas de gestão da qualidade de empresas construtoras.

Palavras-chave: Eficácia; Gestão; Qualidade. 


\section{INTRODUÇÃO}

Não raro, encontramos em nossas cidades edifícios habitacionais multifamiliares, de pouco tempo de vida útil, construídos por empresas mantenedoras de sistemas de gestão da qualidade, apresentando manifestações patológicas nos sistemas da edificação, decorrentes de uma ou mais causas.

Diante do exposto, formula-se o seguinte problema a ser investigado: pode a ineficácia de sistemas de gestão da qualidade implantados por empresas construtoras contribuir para o surgimento de manifestações patológicas?

Tal possibilidade, levou-nos ao estudo da eficácia de sistemas de gestão da qualidade de empresas construtoras, tendo em vista que um sistema de gestão tem como função, entre outras, o direcionamento da organização no atendimento aos requisitos de desempenho de uma edificação e seus sistemas, fixados pela NBR 15575, (ABNT, 2013), conforme determina o Referencial Normativo do SiAC, de 2017.

O estudo, tendo como escopo paredes de vedação em alvenaria de blocos cerâmicos, elementos de sistemas de vedação vertical interno e externo de edificações, desenvolveu-se em obras de 3(três) empresas construtoras com atuação no mercado imobiliário de Brasília, Distrito Federal.

A NBR ISO 9001 (ABNT,2015), em sua subseção 7.5 , alerta-nos para a importância da informação documentada na eficácia de sistemas de gestão da qualidade, o que nos levou, inicialmente, a avaliação do 'o que se diz que é feito', expresso em procedimentos documentados elaborados pelas empresas construtoras, com base em critérios de referência, tidos como 'o que deveria ser feito', definidos a partir de documentos técnicos reconhecidos a nível nacional, específicos para as etapas dos fatores de produção método, projeto e material. Em seguida, avaliou-se o 'o que de fato é feito', evidenciado in loco quando da elevação de paredes de vedação em alvenaria de blocos cerâmicos, tendo como base também os critérios de referência, ' o que deveria ser feito'. Definiu-se notas de 1 a 5, para os resultados das avaliações, 'o que se diz que é feito' e 'o que de fato é feito', as quais variam em função da extensão da aderência do conteúdo dos procedimentos documentados e das práticas de execução das empresas pesquisadas ao 'o que deveria ser feito'.

Os resultados das avaliações encontram-se consolidados em Tabela, identificados por cores e expressos em porcentagem, que traduzem $O$ quanto os procedimentos documentados e práticas de execução mantidas pelas empresas construtoras estão aderentes aos critérios de referência.

\section{METODOLOGIA}

\subsection{DESENVOLVIMENTO DA PESQUISA}

Do ponto de vista da sua natureza, esta pesquisa pode ser classificada como pesquisa aplicada, pois objetiva gerar conhecimento para aplicação prática e na solução de problemas. A pesquisa desenvolveu-se em quatro etapas, conforme Figura 2.1.1, fundamentada no CICLO PDCA. 
Figura 2.1.1 - Representação esquemática da metodologia de desenvolvimento da pesquisa

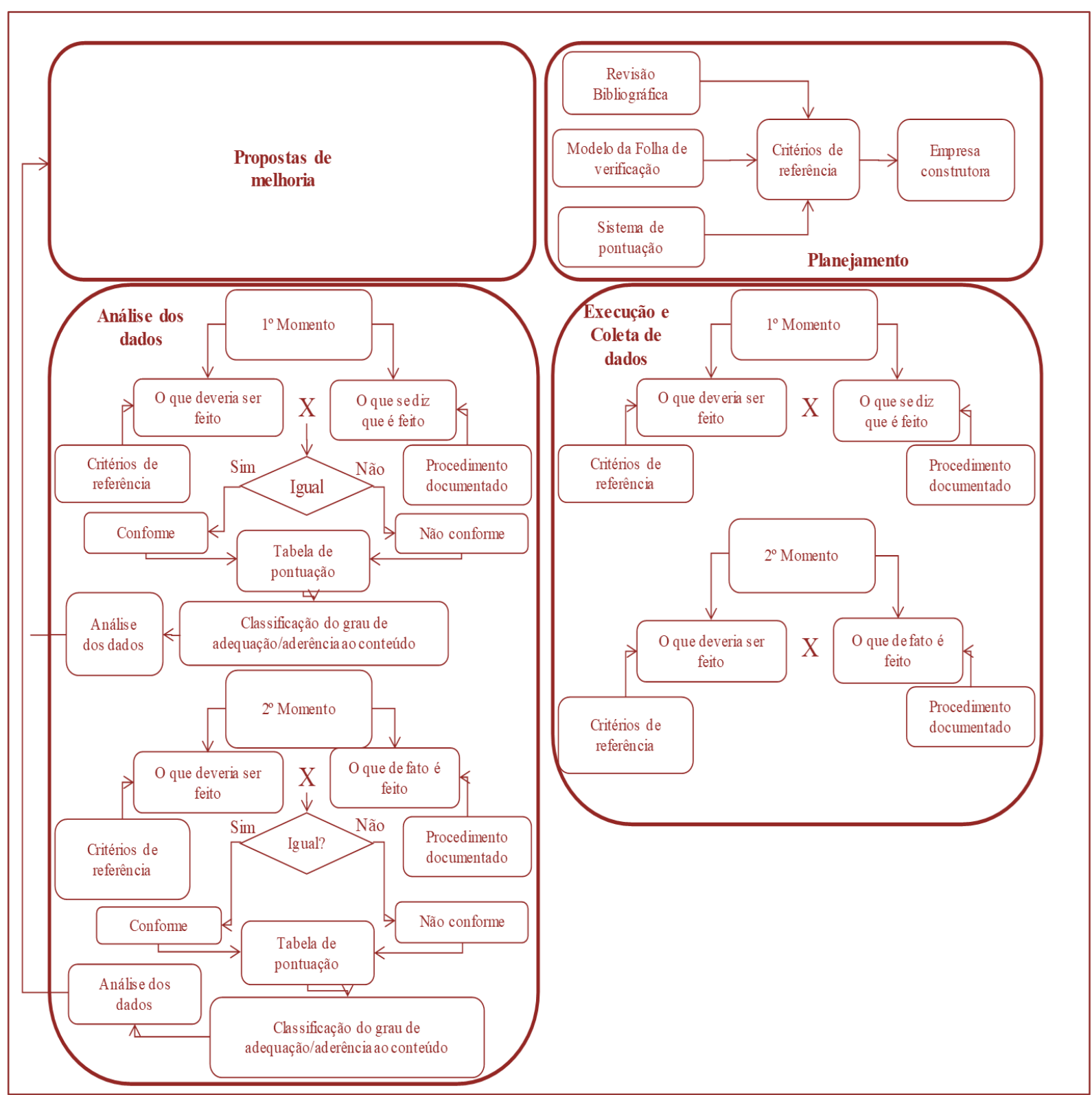

Elaboração: Autor

A etapa de planejamento, constituiu-se das seguintes atividades:

a- seleção de três empresas construtoras, caracterizadas na Tabela 2.1.1, identificadas pelas letras $A, B$ e $C$, com obras de edificações habitacionais multifamiliares em andamento e sistemas verticais de vedação interna e externa de mesma tipologia construtiva; 
Tabela 2.1.1 - Caracterização das obras pesquisadas

\begin{tabular}{|c|c|c|c|}
\hline \multirow{2}{*}{ Caracterização das obras } & \multicolumn{3}{|c|}{ Empresa } \\
\hline & A & $\mathrm{B}$ & $\mathrm{C}$ \\
\hline Área construída & $14.479,12 \mathrm{~m}^{2}$ & $22.000 \mathrm{~m}^{2}$ & $14.442,69 \mathrm{~m}^{2}$ \\
\hline Número de pavimentos & 10 pavimentos & 10 pavimentos & 11 pavimentos \\
\hline Número de unidades residenciais & 96 unidades & 120 unidades & 84 unidades \\
\hline Área privativa da unidade habitacional & $82,55 \mathrm{~m}^{2}$ & $91,60 \mathrm{~m}^{2}$ & 73 a $91 \mathrm{~m}^{2} ; 150$ a $160 \mathrm{~m}^{2}$ \\
\hline $\begin{array}{l}\text { Total de elevação de alvenaria de } \\
\text { vedação }\end{array}$ & $16.875,00 \mathrm{~m}^{2}$ & $23.200 \mathrm{~m}^{2}$ & $18.524,52 \mathrm{~m}^{2}$ \\
\hline
\end{tabular}

Elaboração: Autor

b- elaboração do modelo da folha de verificação para a coleta de dados, ver Tabela 2.1.2;

Tabela 2.1.2 - Modelo da folha de verificação

\begin{tabular}{|c|c|c|c|c|}
\hline \multicolumn{5}{|c|}{ Folha de verificação- Identificação da empresa pesquisada } \\
\hline \multicolumn{5}{|c|}{ Des crição do Fator de produção / Etapa } \\
\hline $\begin{array}{l}\text { Critério de referência } \\
\text { O que deveria ser feito }\end{array}$ & O que se diz que é feito & $\begin{array}{c}\text { Avalia } \\
\text { ção }\end{array}$ & O que de fato é feito & $\begin{array}{c}\text { Avalia } \\
\text { ção }\end{array}$ \\
\hline Descrição da prática recomendada & $\begin{array}{l}\text { Descrição do procedimento documentado } \\
\text { pela empresa construtora }\end{array}$ & Nota & $\begin{array}{c}\text { Prática evidenciada no local de execução da } \\
\text { alvenaria de vedação }\end{array}$ & Nota \\
\hline
\end{tabular}

Elaboração: Autor

c- identificação de boas práticas aplicáveis a execução de paredes de vedação em alvenaria de blocos cerâmicos, recomendadas no Código de Práticas n. 01: alvenaria de vedação em blocos cerâmicos, elaborado pelo Instituto de Pesquisas Tecnológicas (IPT) (Thomaz et al., 2009), entre outros documentos técnicos pesquisados, para definição dos critérios de referência aplicáveis as etapas dos fatores de produção, a saber: fator de produção método, etapas estudadas: marcação, elevação e fixação; fator de produção projeto, etapas estudadas: seleção de materiais, verificação da estabilidade de paredes, reforço de vergas e contravergas, ligações entre elementos e fixação (encunhamento) em lajes e vigas e fator de produção material, etapas estudadas: seleção e preservação de materiais ;

d- definição do sistema de pontuação de avaliação dos critérios de referência definidos para as etapas de cada fator de produção, notas de 1 a 5 , para os resultados das avaliações no $1^{\circ}$ e $2^{\circ}$ momentos, respectivamente, 'o que deveria ser feito' $X$ 'o que se diz que é feito' e 'o que deveria ser feito' $X$ 'o que de fato é feito', conforme Tabela 2.1.3. 
Tabela 2.1.3 - Tabela de Pontuação

\begin{tabular}{|c|c|}
\hline \multicolumn{2}{|r|}{ Tabela de pontuação } \\
\hline $\begin{array}{c}\text { 'O que deveria ser feito' } \\
\mathrm{X} \\
\text { 'O que se diz que é feito' }\end{array}$ & $\begin{array}{l}\text { NA- A prática recomendada não se aplica. } \\
\text { 1- Alguma ou nenhuma das práticas recomendadas estão documentadas }(<1 / 4) \text {; } \\
\text { 2- Muitas das práticas recomendadas estão documentadas }(\geq 1 / 4) \text {. } \\
\text { 3- A maioria das práticas recomendadas es tão documentadas }(\geq 1 / 2) \text {; } \\
\text { 4- Quas e todas as práticas recomendadas es tão documentadas }(\geq 3 / 4) \text {; } \\
\text { 5- Todas as práticas recomendadas es tão documentadas }(=100 \%) \text {. }\end{array}$ \\
\hline $\begin{array}{l}\text { 'O que deveria ser feito' } \\
\mathrm{X} \\
\text { 'O que de fato é feito' }\end{array}$ & $\begin{array}{l}\text { NA- A prática recomendada não se aplica; } \\
\text { 1- Alguma ou nenhuma das práticas recomendadas estão implementadas }(<1 / 4) \text {; } \\
\text { 2- Muitas das práticas recomendadas estão implementadas }(\geq 1 / 4) \text {. } \\
\text { 3- A maioria das práticas recomendadas es tão implementadas }(\geq 1 / 2) \text {; } \\
\text { 4- Quase todas as práticas recomendadas es tão implementadas }(\geq 3 / 4) \text {; } \\
\text { 5- Todas as práticas recomendadas estão implementadas }(=100 \%) \text {. }\end{array}$ \\
\hline
\end{tabular}

Elaboração: Autor

Após a avaliação dos critérios de referência definidos para as etapas dos fatores de produção, calculou-se o grau de aderência de cada uma das etapas dos fatores de produção aos critérios de referência, dividindo a somatória das notas obtidas pela empresa construtora em cada momento, pelo número de critérios avaliados vezes 5, numeral equivalente a nota máxima da tabela de pontuação.
Definiu-se uma escala de tipificação do grau de aderência, podendo ser ele classificado em mínimo, baixo, médio e alto, conforme Tabela 2.1.4. O porcentual indica a extensão da aderência do conteúdo dos procedimentos documentados e das práticas de execução das empresas pesquisadas ao 'o que deveria ser feito'.

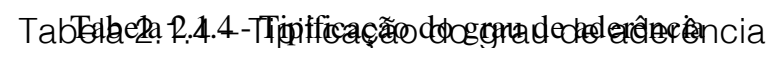

\begin{tabular}{|c|c|c|c|c|}
\hline 0 & $\leq 25 \%$ & $\leq 50 \%$ & $\leq 75 \%$ & $\leq 100 \%$ \\
\hline & $\begin{array}{l}\text { Grau de } \\
\text { aderência } \\
\text { mínimo }\end{array}$ & $\begin{array}{c}\text { Grau de } \\
\text { aderência } \\
\text { baixo }\end{array}$ & $\begin{array}{c}\text { Grau de } \\
\text { aderência } \\
\text { médio }\end{array}$ & $\begin{array}{c}\text { Grau de } \\
\text { aderência } \\
\text { alto }\end{array}$ \\
\hline
\end{tabular}

A etapa de coleta de dados foi conduzida em dois momentos, a saber: 1ํ Momento: verificação da adequação do 'o que se diz que é feito', expresso em procedimentos de execução documentados pelas empresas investigadas, com 'o que deveria ser feito', conforme critérios de referência; $2^{\circ}$ Momento: verificação da conformidade do 'o que de fato é feito', constatação in loco da prática de execução implantada pela empresa investigada, com "o que deveria ser feito', conforme critérios de referência.
No item 4. Conclusões, deste estudo, encontram-se os resultados, as análises realizadas e as conclusões.

\section{REVISÃO BIBLIOGRÁFICA}

\subsection{PROGRAMA BRASILEIRO DA QUALIDADE E PRODUTIVIDADE DO HABITAT- PBQP-H}

O PBQP-H é um instrumento do Governo Federal para cumprimento dos compromissos firmados pelo Brasil quando da assinatura da Carta de Istambul, na Conferência do Habitat 
Il em 1996. A sua meta é organizar o setor da construção civil em torno de duas questões principais: a melhoria da qualidade do habitat e a modernização produtiva. Integram o Programa projetos voltados para a qualidade da construção civil, são eles, o Sistema de Qualificação de Empresas de Materiais, Componentes e Sistemas Construtivos (SiMaC), o Sistema Nacional de Avaliação Técnica de Produtos Inovadores (SiNAT) e o Sistema de Avaliação da Conformidade de Empresas de Serviços e Obras da Construção Civil (SiAC).

\subsection{SISTEMA DE AVALIAÇÃO DA CONFORMIDADE DE EMPRESAS DE SERVIÇOS E OBRAS DA CONSTRUÇÃO CIVIL- SIAC}

O SiAC foi instituído pela Portaria n. 118, de 5 de março de 2005, alterada pela Portaria $n$. 13, de 6 de janeiro de 2017, ambas do Ministério das Cidades. Este Sistema é um dos projetos mais importantes do PBQP-H e contribui para a melhoria da qualidade do setor da construção civil a partir da certificação de sistemas de gestão da qualidade de empresas construtoras de diversas especialidades técnicas e subsetores.

\subsection{REFERENCIAL NORMATIVO DO SIAC- GESTÃO DA QUALIDADE}

Os requisitos do Referencial Normativo do SiAC encontram-se organizados em 5 Seções, assim identificadas, Seção 4 - Sistema de Gestão da Qualidade, Seção 5 Responsabilidade da direção da empresa, Seção 6 - Gestão de recursos, Seção 7 Execução da obra e Seção 8 - Medição, análise e melhoria, as quais expressam um conjunto de atividades coordenadas voltadas a gestão da qualidade e apresentadas na Tabela

3.3.

Tabela 3.3 - Atividades coordenadas relativas a gestão da qualidade

\begin{tabular}{|c|c|c|c|c|c|c|}
\hline \multicolumn{7}{|c|}{ GESTÃO DA QUALIDADE } \\
\hline $\begin{array}{l}\text { REFERENCIAL } \\
\text { NORMATIVO }\end{array}$ & $\begin{array}{l}\text { POLÍTICA DA } \\
\text { QUALIDADE }\end{array}$ & $\begin{array}{l}\text { OBJETIVOS DA } \\
\text { QUALIDADE }\end{array}$ & $\begin{array}{c}\text { PLANEJAMENTO DA } \\
\text { QUALIDADE }\end{array}$ & $\begin{array}{l}\text { CONTROLE DA } \\
\text { QUALIDADE }\end{array}$ & $\begin{array}{l}\text { GARANTIA DA } \\
\text { QUALIDADE }\end{array}$ & $\begin{array}{l}\text { MELHORIA DA } \\
\text { QUALIDADE }\end{array}$ \\
\hline SEÇÃO 4 & & & $\begin{array}{c}4.1 ; 4.2 .1 ; 4.2 .2 ; 4.2 .3 ; \\
4.2 .4\end{array}$ & & & \\
\hline SEÇÃO 5 & 5.3 & 5.4 .1 & $\begin{array}{c}5.4 .2 ; 5.5 .1 ; 5.5 .2 \\
5.5 .3\end{array}$ & $5.1 ; 5.2 ; 5.6$ & & \\
\hline SEÇÃO 6 & & & $6.1 ; 6.2 ; 6.3 ; 6.4$ & & & \\
\hline SEÇÃO 7 & & & $\begin{array}{c}\text { 7.1.1; 7.1.2; 7.3.1; } \\
\text { 7.3.2; 7.4.1; 7.4.2; } \\
\text { 7.5.1 }\end{array}$ & $\begin{array}{c}\text { 7.2.1; 7.2.2; 7.3.3; } \\
7.3 .4 ; 7.3 .5 ; 7.3 .7 ; 7.4 .3 ; \\
7.5 .3 ; 7.5 .4 ; 7.5 .5 ; 7.6\end{array}$ & $\begin{array}{l}7.2 .3 ; 7.3 .6 \\
7.3 .8 ; 7.5 .2\end{array}$ & \\
\hline SEÇÃO 8 & & & 8.1 & $8.2 .1 ; 8.2 .2 ; 8.2 .4 ; 8.3$ & 8.2 .3 & $\begin{array}{l}8.4 ; 8.5 .1 \\
8.5 .2 ; 8.5 .3\end{array}$ \\
\hline
\end{tabular}

Fonte: Referencial Normativo Nível "A"do SiAC

Elaboração: Autor

As atividades coordenadas de gestão da qualidade foram definidas pela NBR ISO 9000 (ABNT, 2015), sendo:

a- Política da qualidade: "intenções e diretizes globais de uma organização (3.3.1), relativas à qualidade (3.1.1), formalmente expressas pela Alta Direção (3.2.7)" (ABNT, 2015). Este é um documento estratégico que estabelece unidade e o rumo da organização e deve ser apropriado aos propósitos da empresa. Havendo replanejamento dos rumos da organização pela alta direção, nova política da qualidade pode ser estabelecida.

b- Objetivos da qualidade: "aquilo que é buscado ou almejado, no que diz respeito à qualidade (3.1.1)" (ABNT, 2015). Cabe a alta direção a definição dos mesmos, trata-se também de um documento estratégico. Os objetivos são definidos a partir da política da qualidade e devem ser mensuráveis, entre eles, aqueles necessários para atendimento aos requisitos aplicados à execução das obras da empresa. 
c- Planejamento da qualidade: "parte da gestão da qualidade (3.2.8) focada no estabelecimento dos objetivos da qualidade (3.2.5) e que especifica os recursos e processos (3.4.1) operacionais necessários para atender a estes objetivos" (ABNT, 2015). A eficácia do Sistema de Gestão da Qualidade em atender aos objetivos da qualidade decorre da capacidade da organização na identificação, determinação da sequência e interação dos processos operacionais, como também, na determinação dos métodos necessários para operação desses processos.

d- Controle da qualidade: "parte da gestão da qualidade (3.2.8) focada no atendimento dos requisitos (3.1.2) da qualidade" (ABNT, 2015). Uma das atividades coordenadas é a inspeção para verificação do atendimento aos requisitos especificados. Segundo SOUZA (1995, p. 175): "A checagem do serviço executado ou em execução evita o desvio de rumos e garante $o$ andamento normal da obra sem a ocorrência de problemas que podem repercutir nas etapas posteriores".

e- Garantia da qualidade: "parte da gestão da qualidade (3.2.8) focada em prover confiança de que os requisitos (3.1.2) da qualidade serão atendidos" (ABNT, 2015). Para garantia da qualidade faz-se necessário o estabelecimento de métodos de medição dos processos do Sistema de Gestão da Qualidade para demonstração da eficácia do mesmo em alcançar os resultados planejados.

f- Melhoria da qualidade: "parte da gestão da qualidade (3.2.8) focada no aumento da capacidade de atender os requisitos (3.1.2) da qualidade" (ABNT, 2015). A melhoria da qualidade decorre da capacidade da organização em analisar registros/dados gerados pelo Sistema de Gestão da Qualidade e, como resultado da análise, a implementação de ações de melhoria, entre elas, ações corretivas e preventivas.

\subsection{REFERENCIAL NORMATIVO DO SIAC- ABORDAGEM DE PROCESSO}

De acordo com a NBR ISO 9000 (ABNT, 2015) o "processo é o conjunto de atividades interativas que transformam insumos em produtos". Campos (2004) define processo como sendo um conjunto de causas que provoca um ou mais efeitos. Para Cardoso (1998) a gestão de um processo envolve um conjunto de ações de diversas naturezas: planificação, organização, direção ou condução e controle.

O Referencial Normativo do SiAC adota a abordagem de processo para implantação e melhoria da eficácia do sistema de gestão da qualidade de uma empresa construtora. Para melhor assegurar os resultados desejados pela organização o Referencial Normativo propõe que as atividades e os recursos aplicáveis aos produtos e serviços da empresa construtora sejam gerenciados como um processo, ou seja, implementando em cada etapa do processo a metotologia conhecida como CICLO PDCA, do inglês Plan, Do, Check e Act.

Abaixo, a Tabela 3.4 demonstra a correlação entre os requisitos do Referencial Normativo SiAC e os quadrantes do CICLO PDCA.

Tabela 3.4 - Correlação entre os Requisitos Normativos e quadrantes do CICLO PDCA

\begin{tabular}{|c|c|c|c|c|}
\hline \multicolumn{5}{|c|}{ CICLO PDCA } \\
\hline REFERENCIAL NORMATIVO & PLANEJAMENTO-PLAN & FAZER-DO & CHECAR- CHECK & AGIR-ACT \\
\hline SEÇÃO 4 & $4.1 ; 4.2$ & & & \\
\hline SEÇÃO 5 & $5.3 ; 5.4$ & $5.1 ; 5.2 ; 5.5$ & 5.6 & \\
\hline SEÇÃO 6 & & $6.1 ; 6.2 ; 6.3 ; 6.4$ & & \\
\hline SEÇÃO 7 & 7.1 & $7.2 ; 7.3 ; 7.4 ; 7.5 ; 7.6$ & & \\
\hline SEÇÃO 8 & & & $8.1 ; 8.2 ; 8.3 ; 8.4$ & 8.5 \\
\hline \multicolumn{5}{|c|}{ Fonte: Referencial Normativo Nível "A " do SiA C } \\
\hline Elaboração: A utor & & D) & C & \\
\hline
\end{tabular}




\subsection{REFERENCIAL NORMATIVO DO SIAC- FATORES DE PRODUÇÃO DE OBRAS E SERVIÇOS}

$\mathrm{Na}$ economia, segundo Rossetti (2003), insumos são também chamados de fatores de produção. O mesmo autor entende que uma empresa é a soma desses fatores, os quais, devidamente organizados, geram bens ou serviços. Conclui-se que a organização dos fatores de produção se faz importante no atendimento aos objetivos e metas organizacionais. Observa-se que a palavrachave é organização.

O Referencial Normativo do SiAC contém requisitos voltados para os recursos e processos operacionais necessários para a produção de obras e serviços, os quais serão nomeados pela expressão 'fator de produção', entre outros, os requisitos: 7.3: Projeto; 7.4: Aquisição (material) e 7.5: Operações de produção de fornecimento de serviço (método).

O requisito normativo 7.3 (Projeto) se aplica à obra como um todo ou parte dela. A NBR ISO 9000 (ABNT, 2015) assim define o termo projeto e desenvolvimento: "conjunto de processos (3.4.1) que transformam requisitos (3.1.2) em características (3.5.1) especificadas ou na especificação (3.7.3) de um produto (3.4.2), processo (3.4.1) ou sistema (3.2.1)" (ABNT, 2015). Integram esse conjunto de processos as seguintes atividades coordenadas: planejamento da elaboração do projeto, entradas de projeto, saídas de projeto, análise crítica de projeto, verificação de projeto, validação de projeto, controle de alterações de projeto e análise crítica de projetos fornecidos pelo cliente, se pertinente.

O requisito normativo 7.4 (Aquisição) tem como escopo a compra de materiais e a contratação de serviços. Visando a garantia de que o material adquirido ou o serviço contratado estejam em conformidade aos documentos de aquisição, algumas atividades coordenadas são implantadas na empresa, sendo elas: de qualificação de fornecedores; de avaliação de fornecedores; de informações para aquisição e de verificação do produto adquirido.

O requisito normativo 7.5 (Operações de produção e fornecimento de serviço) estabelece que a empresa construtora deve planejar e realizar a produção e o fornecimento de serviço sob condições controladas. Entre as condições controladas incluem-se as seguintes atividades coordenadas, a saber: a disponibilidade de informações que descrevam as características do produto; a disponibilidade de procedimentos de execução documentados; quando necessário, o uso de equipamentos adequados; a disponibilidade e uso de dispositivos para monitoramento e medição; a implementação de minitoramento e medição; a implementação da liberação, entrega e atividades pós-entrega e a manutenção de equipamentos considerados críticos para o atendimento das exigências dos clientes.

\section{CONCLUSÕES}

Para o termo 'Qualidade' muitos são os conceitos, nem sempre claros e objetivos. $\mathrm{Na}$ engenharia civil, no setor de Construção Civil, o termo 'Qualidade' não é subjetivo, expressa - grau de atendimento, pela empresa construtora, aos requisitos prescritos por normas técnicas aplicáveis as edificações e seus sistemas.

A Tabela 4.0, apresentada abaixo, consolida os dados coletados nas empresas investigadas. Foram investigadas nas 3 (três) empresas um total de trinta etapas relativas aos fatores de produção projeto, material e método, considerando os dois momentos, 'o que se diz que é feito' e 'o que de fato é feito'.

Observando a coluna 'o que se diz que é feito', das etapas investigadas relativas aos fatores de produção projeto, material e método, 26,67\% encontram-se no vermelho, $43,33 \%$ no amarelo, $23,33 \%$ no verde e $6,67 \%$ no azul. Dos 203 critérios de referência avaliados, os quais totalizam 1015 pontos, as 3 (três) empresas totalizaram 396 pontos, ou seja, $39,01 \%$ do total possível de pontos, individualmente, assim pontuadas: empresa A- 32,40\%; empresa B- 31,30\% e empresa C$53,50 \%$. O fator de produção método é o menos aderente às práticas recomendadas (35,03\%), sendo a etapa "Marcação" a mais crítica, seguido dos fatores de produção projeto (41,37\%), a etapa "Fixação em lajes e vigas" sendo a mais crítica, e material( 42,23\%), com a etapa "Seleção de materiais".

Analisando a coluna 'o que de fato é feito', das etapas investigadas relativas aos fatores de produção projeto, material e método, $13,33 \%$ encontram-se no vermelho, $13,33 \%$ no amarelo, $46,67 \%$ no verde e $26,67 \%$ no 
azul, percentuais que expressam resultados melhores que os da coluna 'o que se diz que é feito'. Dos 199 critérios estabelecidos como de referência, os quais totalizam 995 pontos, as 3 (três) empresas totalizaram 628 pontos, ou seja, $63,13 \%$ do total possível de pontos, individualmente, assim pontuadas: empresa A- 58,90\%; empresa B- 57,40\% e empresa C$73,10 \%$. O fator de produção projeto é o menos aderente às práticas recomendadas (43,90\%), sendo a etapa "Seleção de materiais" a mais crítica, seguido dos fatores de produção material (65,13\%), a etapa "Seleção de materiais" sendo a mais crítica e método ( 77,27\%), com a etapa "Elevação".

Na comparação da coluna 'o que se diz que é feito' com a 'o que de fato é feito', constata-se que o fator de produção projeto apresenta a menor evolução do grau de aderência, de $41,37 \%$ para $43,90 \%$, seguido dos fatores de produção material, de $42,23 \%$ para $65,13 \%$, e método, de $35,03 \%$ para $77,27 \%$.

Quanto a etapa "Seleção de materiais", do fator de produção projeto, observa-se que o grau de aderência involuiu, de $38 \%$ para $35,33 \%$. Para essa etapa definiu-se critérios de referência relativos a requisitos dimensionais, físicos e mecânicos aplicáveis a blocos cerâmicos. Tal fato sugere uma não conformidade ao estabelecido pela Norma ABNT NBR 15575, Parte 1, no tocante a incumbência técnica do projetista, pois, conforme a referida Norma, cabe ao projetista o papel de especificar materiais, produtos e processos que assegurem o desempenho da edificação e seus sistemas. Já a etapa "Seleção de materiais", do fator de produção material, apresentou o menor grau de aderência, 32\%, como resultado da avaliação com base em critérios de referência aplicáveis a verificação da qualidade de blocos cerâmicos e argamassa de assentamento dos mesmos.

Constata-se uma evolução do grau médio de aderência dos fatores de produção, de $39,54 \%$ para $62,10 \%$, quando da comparação do 'o que se diz que é feito' com 'o que de fato é feito', o que demonstra que as práticas de execução mantidas pelas empresas construtoras estão mais em conformidade com os critérios de referência do que os procedimentos por elas documentados para o produto em estudo "paredes de vedação em alvenaria de blocos cerâmicos", o que vai de encontro ao alerta da NBR ISO 9001 (ABNT, 2015), subseção 7.5, quanto a importância da informação documentada na eficácia de sistemas de gestão da qualidade. Essa deficiência em procedimentos documentados causa alguns efeitos, tais como, treinamentos ineficazes, gerando custos sem agregação de valor, despadronização dos serviços de execução, elevados desperdícios e baixa produtividade, entre outros, comprometendo assim a eficácia do SGQ em atender os objetivos da qualidade, entre eles, o atendimento aos requisitos técnicos aplicáveis ao produto paredes de vedação em alvenaria de blocos cerâmicos.

O presente estudo demonstra deficiências no planejamento da qualidade pelas empresas construtoras, o que pode ser evidenciado pelos resultados obtidos. Os fatores de produção projeto, material e método apresentaram um percentual de aderência aos critérios de referência considerados baixos, a saber, respectivamente, 41,37\%, $42,23 \%$ e $35,03 \%$, tendo em vista que os projetos executivos e procedimentos documentados pelas empresas investigadas não fornecem informações técnicas necessárias para a execução das paredes de vedação em alvenaria de blocos cerâmicos, impedindo a determinação de recursos e processos operacionais necessários para atendimento aos requisitos de desempenho de uma edificação e seus sistemas e, assim sendo, eliminando, ou mesmo, reduzindo o surgimento de manifestações patológicas

Constatou-se que 'o que se diz que é feito' não é 'o que de fato é feito' e 'o que de fato é feito' não é 'o que deveria ser feito'. Tal cenário demonstra deficiências no controle da qualidade, parte da gestão da qualidade focada no atendimento dos requisitos da qualidade por meio da verificação do atendimento aos requisitos especificados.

Face aos resultados obtidos, conclui-se que manifestações patológicas podem surgir em edifícios habitacionais multifamiliares, de pouco tempo de vida útil, construídos por empresas construtoras mantenedoras de sistemas de gestão da qualidade ineficazes. 


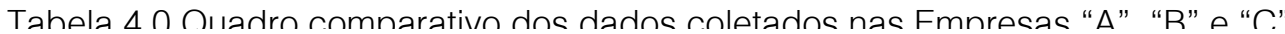
Tabela 4.0- Quadro comparativo dos dados coletados nas Empresas "A", "B" e "C"

\begin{tabular}{|c|c|c|c|c|c|c|c|c|c|}
\hline \multirow{2}{*}{$\begin{array}{l}\text { Fator de } \\
\text { produção }\end{array}$} & \multirow{2}{*}{ Etapa } & \multicolumn{4}{|c|}{ O que se diz que é feito $(\%)$} & \multicolumn{4}{|c|}{$\mathrm{O}$ que de fato é feito $(\%)$} \\
\hline & & "A" & "B" & "C" & Média & "A" & "B" & "C" & Média \\
\hline \multirow{6}{*}{ Projeto } & Seleção de materiais & 20,00 & 28,00 & 66,00 & 38,00 & 20,00 & 20,00 & 66,00 & 35,33 \\
\hline & Verificação da estabilidade & 20,00 & 37,10 & 60,00 & 39,00 & 20,00 & 42,80 & 60,00 & 40,93 \\
\hline & $\begin{array}{c}\text { Reforço com vergas e } \\
\text { contravergas }\end{array}$ & 80,00 & 20,00 & 90,00 & 63,30 & 100,00 & 60,00 & 60,00 & 73,33 \\
\hline & Ligações entre elementos & 60,00 & 46,70 & 40,00 & 48,90 & 60,00 & 73,30 & 40,00 & 57,77 \\
\hline & Fixação em lajes e vigas & 60,00 & 20,00 & 20,00 & 33,33 & 60,00 & 60,00 & 20,00 & 46,67 \\
\hline & Média & 33,30 & 31,70 & 59,10 & 41,37 & 35,20 & 40,00 & 56,50 & 43,90 \\
\hline \multirow{3}{*}{ Material } & Seleção de materiais & 20,00 & 20,00 & 56,30 & 32,10 & 28,90 & 34,50 & 78,10 & 47,17 \\
\hline & Preservação de materiais & 62,80 & 45,7 & 65,70 & 58,07 & 100,00 & 80,00 & 100,00 & 93,33 \\
\hline & Média & 36,70 & 30,00 & 60,00 & 42,23 & 57,30 & 52,20 & 85,90 & 65,13 \\
\hline \multirow{4}{*}{ Método } & Marcação & 27,50 & 32,50 & 42,50 & 34,16 & 97,50 & 100,00 & 100,00 & 99,17 \\
\hline & Elevação & 26,20 & 33,70 & 45,00 & 34,97 & 66,20 & 65,00 & 70,00 & 67,06 \\
\hline & Fixação & 46,70 & 20,00 & 46,70 & 37,80 & 73,30 & 73,30 & 73,30 & 73,30 \\
\hline & Média & 28,90 & 31,80 & 44,40 & 35,03 & 76,30 & 76,30 & 79,20 & 77,27 \\
\hline \multirow{3}{*}{ Consolidado } & Empresa 'A' & 32,40 & & & & 58,90 & & & \\
\hline & Empresa 'B' & & 31.30 & & & & 57,40 & & \\
\hline & Empresa 'C' & & & 53,50 & & & & 73,10 & \\
\hline \multirow{3}{*}{$\begin{array}{c}\text { O que se diz } \\
\text { que é feito + o } \\
\text { que de fato é } \\
\text { feito }\end{array}$} & Empresa 'A' & \multicolumn{8}{|c|}{ 44,96- Aderência baixa } \\
\hline & Empresa 'B' & \multicolumn{8}{|c|}{ 44,30- Aderência baixa } \\
\hline & Empresa 'C' & \multicolumn{8}{|c|}{ 62,80- Aderência média } \\
\hline
\end{tabular}

Elaboração: Autor

\section{REFERÊNCIAS}

[1] ASSOCIAÇÃO BRASILEIRA DE NORMAS TÉCNICAS. NBR 9000: Sistemas de gestão da qualidade- Fundamentos e vocabulário - Rio de Janeiro: ABNT, 2015.

[2] ASSOCIAÇÃO BRASILEIRA DE NORMAS TÉCNICAS. NBR 9001: Sistemas de gestão da qualidade- Requisitos. Rio de Janeiro: ABNT, 2015.

[3] ASSOCIAÇÃO BRASILEIRA DE NORMAS TÉCNICAS. NBR 15575-1: Edificações habitacionais- Desempenho. Rio de Janeiro: ABNT, 2013.

[4] BRASIL. Ministério das Cidades. Secretaria Nacional de Habitação. Programa Brasileiro da Qualidade e Produtividade do Habitat. PBQP-H. Apresentação. Brasília: MC. Disponível em: $<$ http://pbqp-

h.cidades.gov.br/pbqp_apresentacao.php $>$.

Acesso em: 01 jul. 2018.

[5] (2017). Sistema de Avaliação da conformidade de Empresas de Serviços e Obras da Construção Civil. Brasília: MC. Disponível em: <http://www4.cidades.gov.br/pbqp-

h/projetos_siac.php>. Acesso em: 01 jul. 2018.

[6] CAMPOS, V. F. TQC - Controle Total da Qualidade (no estilo japonês). Nova Lima: INDG Tecnologia e Serviços Ltda, 2004.

[7] CARDOSO, F. F. A gestão da produção de vedações verticais: alternativas para a mudança necessária. São Paulo. In: Seminário Tecnologia e Gestão na produção de Edifícios: vedações verticais. Artigo Técnico, 1998.

[8] ROSSETTI, J. P. Introdução à economia. 20 ed. São Paulo: Atlas, 2003.

[9] SOUZA, R.; MEKBEKIAN, G.; SILVA, M. Sistema de gestão da qualidade para empresas construtoras. São Paulo: Pini, 1995.

[10] THOMAZ, E.; MITIDIERI FILHO, C. V.; CLETO, F. R. et al. Código de práticas n. 01: alvenaria de vedação em blocos cerâmicos. São Paulo: IPT, 2009 Disponível em $<$ http://www.ipt.br/projeto/2-

codigos_de_praticas_na_construcao_civil.htm>

Acesso em: 10 jun. 2018. 


\section{Bapítulo 3}

\section{MÉTODO DE ANÁLISE E SOLUCÃO DE PROBLEMAS (MASP) APLICADO A UMA EMPRESA DE ALIMENTOS}

\section{Luciana Lima Gonçalves Vieira}

Paulo Fernandes Sanches Junior

Luciano dos Santos Diniz

Resumo: O objetivo principal desta pesquisa é analisar a aplicação do Método de Análise e Solução de Problemas (MASP) na área comercial de uma empresa do ramo alimentício. A discussão teórica abrangeu as definições e teorias a respeito do MASP. O percurso metodológico se deu a partir da aplicação das etapas do MASP para solucionar o problema das oscilações das vendas da empresa AMD Alimentos. A discussão dos resultados demonstrou a alavancagem das vendas após a aplicação do método. As considerações finais explicitam vantagens na utilização do MASP e os gargalos que deverão ser solucionados para o crescimento da empresa AMD Alimentos.

Palavras-chave: Masp, Ferramentas da Qualidade, Ciclo PDCA 


\section{INTRODUÇÃO}

Gerir custos e aperfeiçoar os processos são esforços necessários a qualquer organização como forma de obtenção de maiores lucros. Segundo Martins e Laugeni (2000), as empresas têm sofrido pressão do mercado no sentido de baixarem os preços de venda forçando-as a encontrar soluções eficazes para redução de custos. Cada vez mais as organizações precisam ser rápidas em responder aos estímulos, exigências e alterações de cenário apresentadas pelo mercado.

O Método de Análise e Solução de Problemas (MASP) tem se mostrado bastante eficiente na elaboração de ações corretivas quando as empresas necessitam investigar o impacto de problemas relacionados a riscos, custos e benefícios (CERQUEIRA, 1995). A AMD Alimentos é uma empresa de distribuição de alimentos que atua nas áreas de panificação, confeitaria, restaurantes e lanchonetes. Fundada em 19 de dezembro de 2006 com apenas um funcionário e fazendo entregas em uma caminhonete particular, distribuía apenas farinha de trigo. Atualmente, a empresa já conta com colaboração de 57 funcionários e um mix de aproximadamente 400 produtos ativos. A empresa possui sua sede na cidade de Contagem, trabalhando com foco de venda em Belo Horizonte, Contagem e Betim. O rápido crescimento da empresa trouxe vários problemas administrativos, mas o principal diz respeito às oscilações nas vendas que tem impacto direto no faturamento bruto da empresa. Desta forma, este estudo irá analisar o histórico do faturamento da empresa e propor um Plano de Ação através da aplicação do Método de Análise e Solução de Problemas (MASP).

\section{MÉTODO DE ANÁLISE DE SOLUÇÃO DE PROBLEMAS (MASP)}

O Método de Análise e Solução de Problemas - MASP é a denominação que o QC-Story, método de solução de problemas de origem japonesa, acabou recebendo no Brasil figura 1 (CAMPOS, 1999; RIBEIRO NETO, 2013). O QC-Story foi inicialmente utilizado na fábrica da Komatsu no Japão como um procedimento para elaboração de relatórios, através dos quais os funcionários reportavam os resultados das melhorias que obtinham no âmbito da qualidade, denominando-os de "the quality control story".

Segundo Pires (2014), MASP (método de análise e solução de problemas) é uma metodologia utilizada para identificar, analisar e solucionar problemas, impedindo que eles se repitam, mediante a utilização do PDCA e das ferramentas de qualidade.

O MASP como método de "controle" por excelência é o PDCA (Plan, do, check, action) aplicado. Segundo Toledo (2010), o MASP é o método de soluções de problemas mais difundido no Brasil.

FIGURA 01 - PDCA.

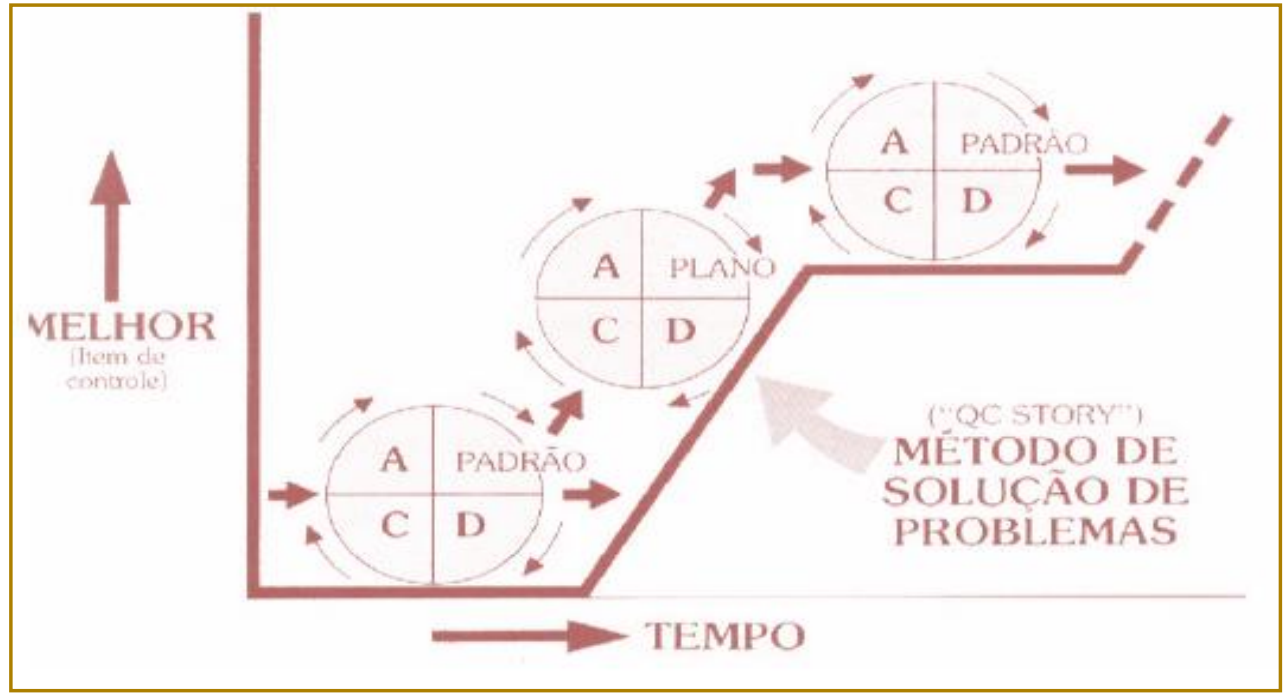

Fonte: Campos (1999). 
Para a aplicação eficiente do MASP é necessário a utilização de ferramentas de qualidade que preveem formas padrão de análise de problemas e levantamentos qualitativos e quantitativos das falhas de um processo, produto ou serviço. Seleme e Stadler (2008) destacam que a importância das ferramentas está na sua efetiva utilização para a identificação e a eliminação das falhas.

O MASP, segundo Carpinetti (2012) é composto de oito fases, de acordo com a Figura 2, sendo elas:

Identificação do Problema: Nessa fase, procura-se identificar os problemas mais críticos e, portanto, mais prioritários;

Observação: objetiva a caracterização completa do problema para aumentar a chance de se identificar as causas do problema;

Análise: nessa fase, busca-se levantar as causas raízes ou fundamentais do problema em questão;

Plano de ação: depois de
identificadas as supostas causas

fundamentais; o objetivo desta fase é elaborar e detalhar um plano de ação para a eliminação dos efeitos indesejáveis das causas fundamentais. Ou seja, objetiva-se bloquear as causas fundamentais;

- Ação: consiste na implementação do plano de ação;

- Verificação: Consiste na avaliação de resultados para a verificação se ação foi eficaz na eliminação ou minimização do problema. Caso o resultado não tenha sido satisfatório, o processo é reiniciado pela observação e análise do problema. Caso contrário, segue-se para a próxima etapa;

Padronização: visa introduzir as ações implementadas na rotina de operação do processo ou atividade, de forma a prevenir o reaparecimento do problema;

- Conclusão: o processo é finalizado com o registro de todas as ações empreendidas e resultados obtidos, para posterior recuperação de informações e históricos.

Figura 02 - As 08 Etapas do MASP

\begin{tabular}{|c|c|c|c|}
\hline PDCA & FLUXOGRAMA & FASE DO MASP & OBJETIVO \\
\hline & & $\begin{array}{l}\text { Identificaçäo do } \\
\text { problema }\end{array}$ & $\begin{array}{l}\text { Definir claramente o problema e } \\
\text { reconhecer a sua importância. }\end{array}$ \\
\hline & & Observaçẫo & $\begin{array}{l}\text { Investigar as características específicas } \\
\text { do problema com uma visấo ampla e } \\
\text { sob vários pontos de vista. }\end{array}$ \\
\hline & & Análise & Descobrir as causas fundamentais. \\
\hline & & Plano de açăo & $\begin{array}{l}\text { Conceber um plano para bloquear as } \\
\text { causas fundamentais. }\end{array}$ \\
\hline \multirow{3}{*}{ D } & & Açăo & Bloquear as causas fundamentais. \\
\hline & & Verificaçăo & Verificar se o bloqueio foi efetivo. \\
\hline & & $\begin{array}{l}\text { O bloqueio foi } \\
\text { efetivo? }\end{array}$ & \\
\hline \multirow{2}{*}{$\mathbf{A}$} & & Padronizaçăo & $\begin{array}{l}\text { Prevenir contra o reaparecimento do } \\
\text { problema. }\end{array}$ \\
\hline & & Conclusăo & $\begin{array}{l}\text { Recaptular todo o processo de soluçăo } \\
\text { do problema para trabalho futuro. }\end{array}$ \\
\hline
\end{tabular}

Fonte: Campos (2004)

Ainda na figura 02, pode-se identificar como as 08 etapas do MASP estão inseridas no ciclo do PDCA. Também é possível observar como todo o processo segue uma sequência até a fase de verificação do bloqueio e, se os resultados obtidos foram os esperados, segue-se para a padronização das rotinas executadas. Caso contrário, se na verificação do bloqueio for evidenciado que os resultados não foram alcançados conforme previsto, não é possível prosseguir na sequencia determinada. É necessário retornar e refazer 
todos os passos, pois certamente houve falha em algumas das etapas anteriores.

Evidentemente, para que seja efetivo, as etapas do MASP devem ser seguidas e aplicadas na ordem em que se apresentam.

\section{INVESTIGAÇÃO E CORREÇÃO DE CAUSAS DOS PROBLEMAS}

Todo problema encontrado em um sistema organizacional deve ser solucionado de forma a eliminar o seu fato gerador. Uma ação corretiva pode ser definida como ação tomada para eliminar a causa da não conformidade detectada ou outra situação indesejável no sentido de prevenir sua recorrência.

De acordo com Vivone, Giusti e Albieri (2005) é muito importante em um processo eficaz de ação corretiva que a abordagem formal seja utilizada. Segundo os autores uma abordagem formal permite que a equipe de análise certifique-se que 0 esforço foi despendido de forma eficaz com o registro da troca de perguntas e respostas, bem como da manutenção do histórico das ações corretivas disponíveis. Usualmente, os formulários de ações corretivas são devidamente preenchidos e arquivados (após validação da eficácia), e mantido um histórico para consultas futuras.

Schmenner (1999) define vários pontos a considerar neste aspecto incluindo a coleta de dados e a investigação sistemática. Segundo o autor, a coleta de dados apropriados pode requerer a avaliação de aspectos do processo, o monitoramento dos defeitos ou situações que se está investigando e suas características, a relação das ocorrências com tempos ou locais e a observação de qualquer mudança ou condição do processo, materiais, equipamentos e mão de obra utilizada.
A investigação sistemática envolve uma série de métodos ou instrumentos estatísticos e de análise para encontrar o ponto de falha do sistema. O conjunto destas ferramentas de qualidade, usadas de forma ortodoxa fazem parte da aplicação do MASP. Segundo Leite (2010) o MASP baseia-se na obtenção de dados que justifiquem ou comprovem fatos previamente levantados e que, comprovadamente, causem problemas.

Para Toledo (2010), ao adotar um método há uma padronização na empresa, ou seja, todos devem seguir o mesmo método para, por exemplo tomar ações corretivas. Assim, o ataque aos problemas deve ser planejado e implementado de modo a impedir o reaparecimento dos fatores causadores do mesmo.

\section{APLICAÇÃO DO MASP}

A primeira etapa do MASP, diz respeito à identificação ou apresentação do problema. $\mathrm{Na}$ AMD Alimentos, para se chegar na proposição inicial de problema, foi realizada uma reunião com o dono da empresa, que responde como responsável por todos os setores. Na reunião ele expôs sua dificuldade em manter uma frequência no volume das vendas que, mensalmente, tinham grande oscilação e não chegavam a um patamar satisfatório. As vendas estavam, em média, $15 \%$ abaixo do ponto de equilíbrio financeiro da empresa e, por isso, os problemas da área comercial eram vistos como o ponto crítico que precisava ser melhorado urgentemente já que comprometia a sobrevivência da organização. Deste modo, foi estabelecido que o problema seria a grande oscilação mensal no faturamento bruto da empresa.

Após a definição do problema foi realizado um levantamento histórico do faturamento da empresa. Para tanto, foi elaborado o gráfico de vendas referente ao ano de 2015 (Figura $3)$. 
Figura 3 - Vendas Brutas 2015

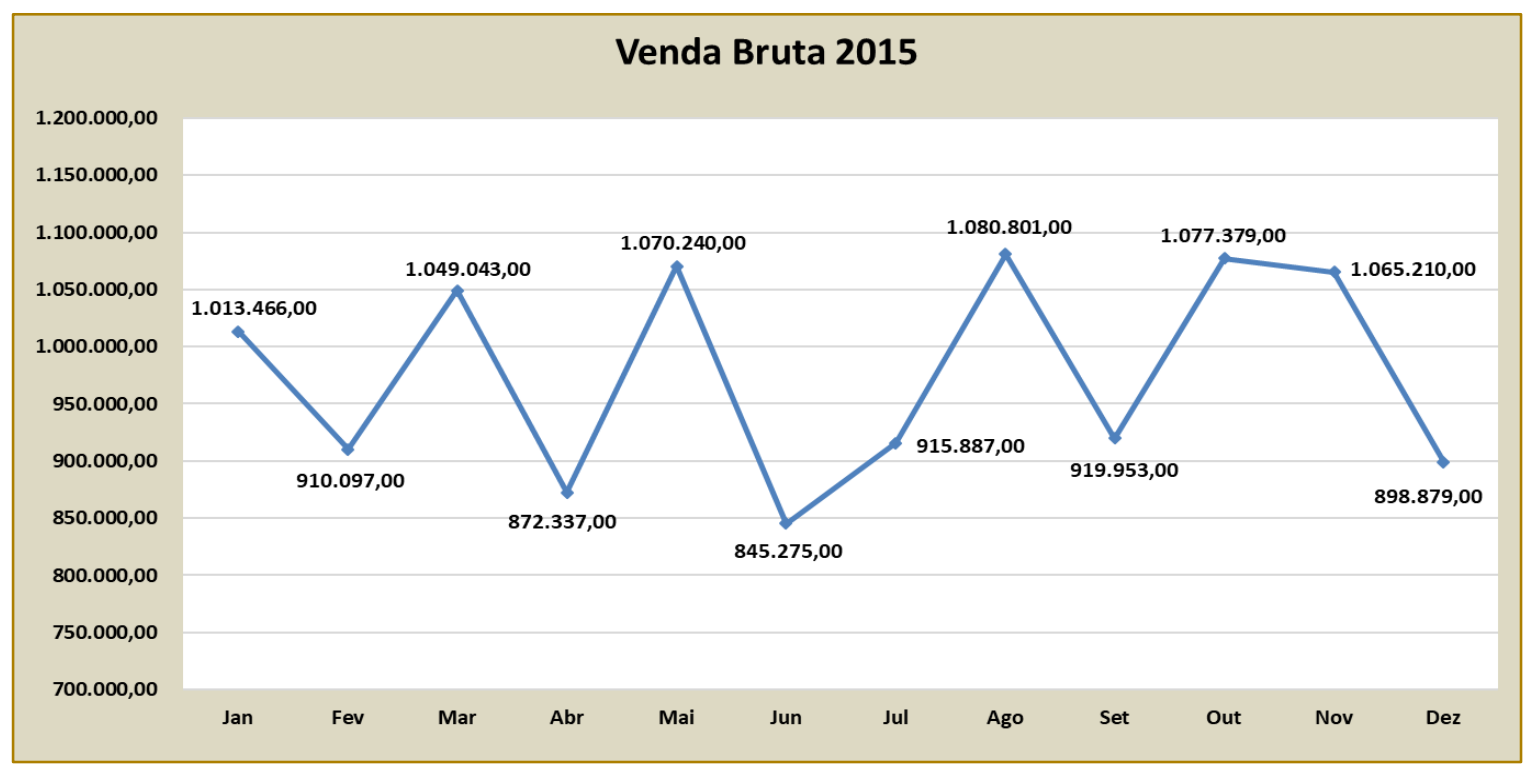

Fonte: Dados da Pesquisa (2015)

A análise gráfica das vendas de 2015 deixa evidente a oscilação existente nas vendas ao longo dos meses. Conforme know-how do dono da empresa, essa variação não é decorrente de nenhuma sazonalidade do mercado. Os únicos períodos em que a sazonalidade pode ocorrer são meses de: (1) janeiro e julho que em função às férias escolares alguns clientes, como cantinas de escolas e faculdades, não realizam compras e (2) agosto e setembro quando é a época da entressafra do trigo podendo ocorrer a alta de preço na farinha ou algum problema na safra daquele ano.

Sendo assim, se considerados o mês de maior venda do ano de 2015 (Agosto), e subtrair pelo mês de menor venda (Junho $\mathrm{R} \$ 1.080 .801,00$ - RS 845.275,00) obtem-se um gap de $R \$ 235.562,00$ que será tratado como oportunidade de melhoria. O mês de junho remete a perda máxima de faturamento dentro do ano e serve como referência para a busca das melhores práticas a serem introduzidas na empresa.

Solicitou-se então que cada vendedor entrasse em contato com os seus clientes para perguntar o motivo que deixaram de comprar da empresa nos meses de janeiro e fevereiro de 2016. Foi então realizada uma folha de verificação com os motivos listados pelos clientes e partiu-se para a análise de Pareto das vendas não efetuadas (Figura 4). Do total de 700 clientes, em média 120 deixavam de ser atendidos por mês. Destes 120 clientes, 42 não eram sequer contatados pelos vendedores durante o mês. 
Figura 4 - Estratificação da perda de vendas

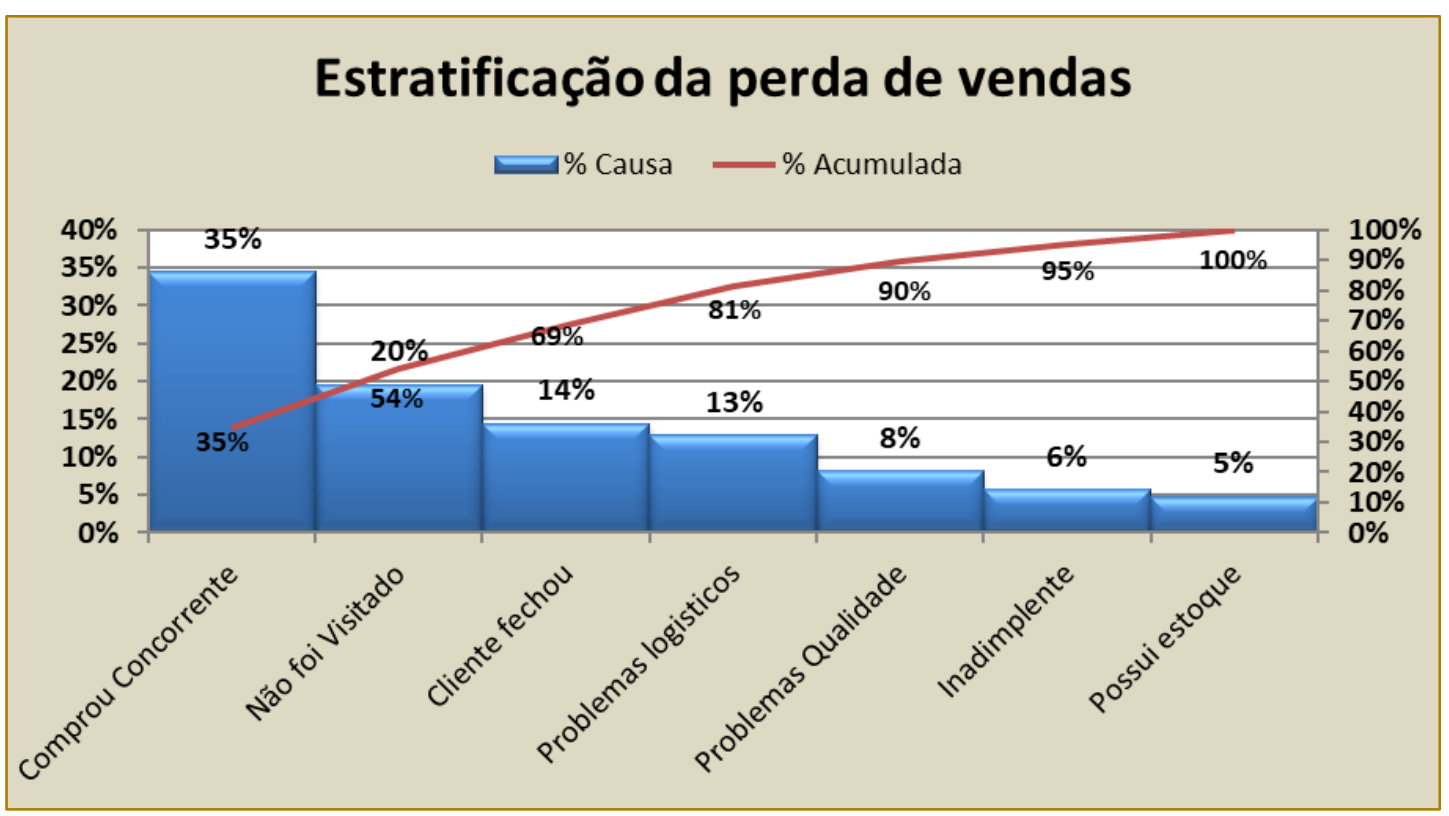

Fonte: Dados da Pesquisa (2015)

\subsection{OBSERVAÇÃO}

Nesta etapa elaborou-se um esquema de acompanhamento, com reuniões semanais para entender o trabalho dos vendedores, com visitas in loco junto aos clientes para observar como os vendedores procediam com a execução da rota de vendas, qual era abordagem utilizada, a apresentação feita por cada um, a forma como ofereciam os produtos.

Foi evidenciada a falta de rotina comercial na área de vendas porque um número grande de clientes era simplesmente ignorado. Em geral, os clientes fazem compras periódicas, todas as semanas ou quinzenais. Observou-se que o primeiro critério que o Cliente leva em consideração para decidir sobre qual empresa comprar (AMD Alimentos ou concorrente), é o contato e suporte periódico que o vendedor dá a ele. Mesmo que o cliente não tenha comprado no primeiro contato do vendedor, esta prática estabelece uma relação de confiança com o cliente que passa a confiar na empresa e no produto ofertado. Porém, o que foi verificado era o vendedor descartava o cliente caso ele não efetuasse uma compra na sua primeira visita/contato.

Observou-se também que o mix de produtos não era potencialmente trabalhado. Os vendedores ofereciam apenas aqueles produtos que os clientes já tinham o hábito de comprar e não ofereciam nenhum produto diferente para tentar aumentar o ticket médio de produtos.

Outro fator relevante para o cliente era o preço, principalmente dos produtos básicos, como açúcar cristal, polvilho e fermento. Se durante uma cotação o cliente observar que estes produtos possuem um melhor preço na mão de um determinado vendedor, ele tem a tendência de comprar todos os demais produtos dos quais precisava com o mesmo vendedor. Ou seja, reduzir o preço destes produtos chaves para o cliente e consequentemente sua margem de contribuição, não era de forma geral um ponto negativo, pois abriria oportunidades para os outros 400 produtos que a AMD possuía em seu portfólio.

Outro ponto fundamental no processo de venda era o tipo ou marca de farinha de trigo utilizado nas receitas das padarias. A decisão da farinha de trigo é do padeiro. Este é fiel a marca que utiliza, uma vez que a substituição da matéria prima, poderia mudar as receitas que estava habituado a fazer. Neste caso, o importante era nunca deixar o faltar a mercadoria ao cliente, ou seja, sempre garantir a quantidade adequada, no prazo solicitado. Se a empresa perdesse os clientes que consumiam a farinha, provavelmente deixaria de vender a ele todos os outros produtos do portfólio. 
Realizada a etapa de observação, partiu-se para a definição da meta almejada, dentro das possibilidades de melhoria observadas.

$\mathrm{Na}$ ADM a meta definida com base nas observações e levantamentos anteriores, foi de atingir um crescimento anual de $20 \%$ nas vendas brutas até 31/12/2016. A meta de crescimento da organização foi rateada de forma ponderada entre os vendedores, gerando metas individuais de vendas para cada um, que seriam acompanhadas para garantir o alcance da meta global da empresa.

\subsection{ANÁLISE PARA DESCOBERTA DAS CAUSAS}

Nesta etapa, deve-se definir as causas que influenciam o problema definido, escolher as mais prováveis e efetuar a verificação das hipóteses. Foi uma sessão de brainstorming com a presença do dono da empresa, o supervisor de vendas externas, a supervisora de vendas do telemarketing, a gerente financeira, supervisor logístico, o líder de projetos e a consultoria contratada para direcionar as aplicações do método. Nesta reunião foram expostas as possíveis causas do problema e alocadas na estrutura do Diagrama de Ishikawa. Na Figura 05, pode-se observar a estruturação das ideias obtidas no Diagrama de Ishikawa.

O diagrama pode ser elaborado através da determinação do problema a ser estudado (identificação do efeito), o registro das possíveis causas no diagrama agrupadas de forma relacionada com os "6M" (mão-de-obra, método, matéria-prima, medida e meio ambiente).

Uma vez realizado o levantamento das possíveis causas, foi utilizada uma ferramenta de priorização, conhecida como GUT (abreviação de Gravidade, Urgência e Tendência) para definir quais causas atacar primeiro. A matriz GUT é uma ferramenta muito utilizada pelas empresas para priorizar os problemas que devem ser atacados pela gestão, bem como para analisar a prioridade que certas atividades devem ser realizadas e desenvolvidas (MARSHALL, 2008). Esta ferramenta consiste em listar as causas levantadas e dar notas de 1 a 5 , para as situações de gravidade, urgência e tendência das causas elencadas, onde a nota 1 remete as situações menos graves, urgentes ou tendenciosas, e a nota 5 remete as situações mais graves, urgentes ou tendenciosas. Essas notas são multiplicadas, e através do produto destas notas identificaremos nos maiores valores as causas a serem tratadas como prioridade.

FIGURA 5 - Diagrama de Ishikawa

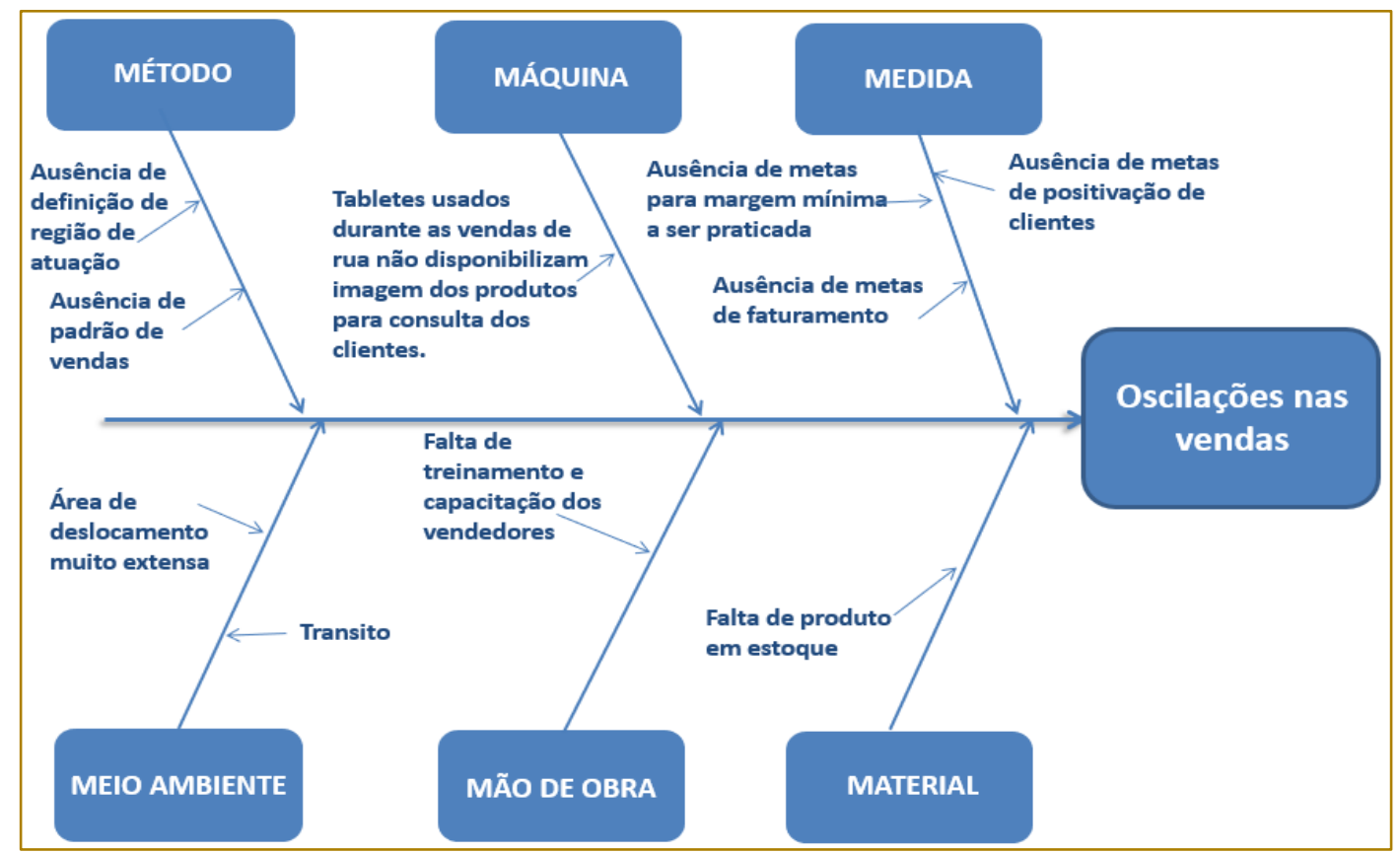

Fonte: Dados da Pesquisa (2015) 
QUADRO 01 - Realização GUT

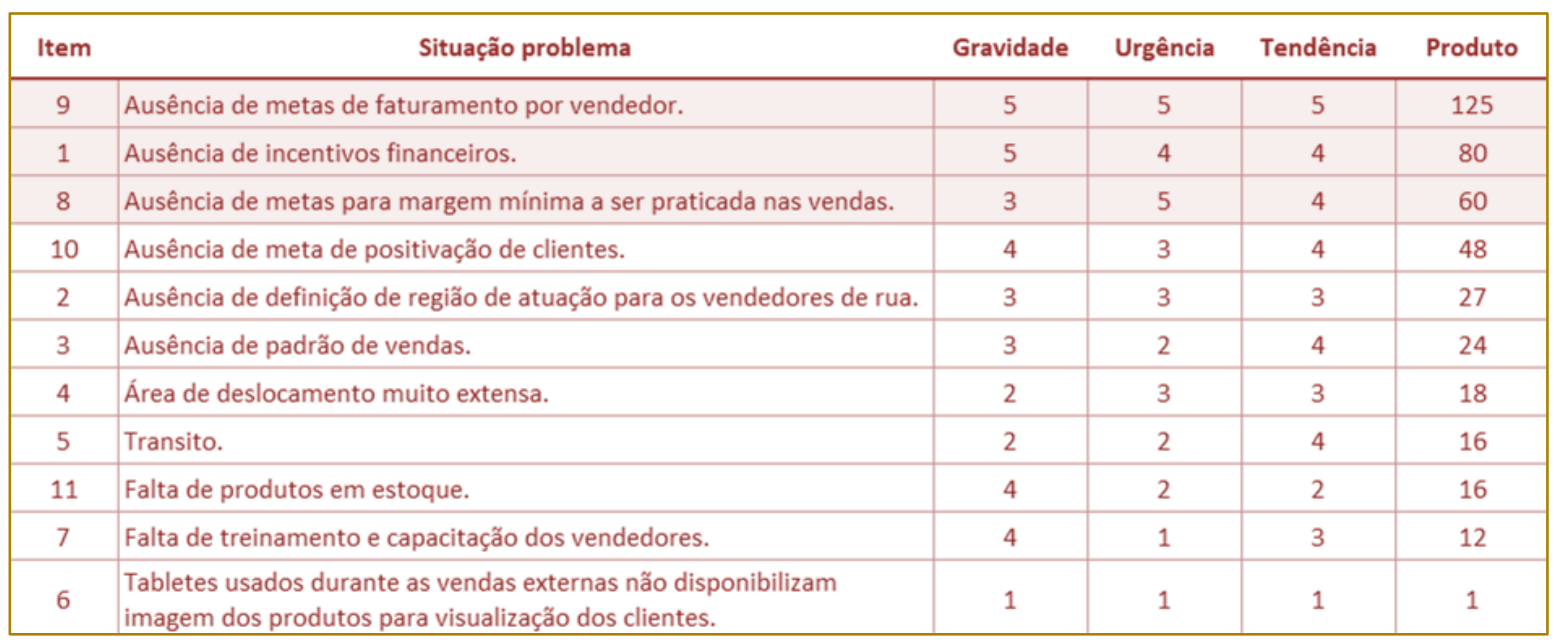

Fonte: Dados da Pesquisa (2015)

Com o auxílio da ferramenta de priorização, foram determinadas as causas a serem tratadas. Sendo elas os itens 1, 8, 9 do quadro 01.

\subsection{PLANO DE AÇÃO}

Após a identificação do problema, a definição da meta e a identificação das principais causas, é necessário a elaboração do Plano de Ação a ser implantado. Nesta etapa utilizou-se a ferramenta $5 \mathrm{~W} 1 \mathrm{H}$ que consiste em responder as perguntas: $O$ quê? Por quê? Como? Quando? Onde? Quem? (quadro 02).

QUADRO 02 - Plano de Ação

\begin{tabular}{|c|c|c|c|c|c|}
\hline № & O QUE & POR QUÊ & СОМО & QUEM & QUANDO \\
\hline 1 & Definir meta individual de vendas por vendedor & $\begin{array}{l}\text { Para que o vendedor saiba que será cobrado com } \\
\text { base na meta estipulada. }\end{array}$ & $\begin{array}{l}\text { Analisando o histórico de vendas, e protencial real } \\
\text { para projeção do percentual a ser encrementado. }\end{array}$ & Marcelo & $05 / 03 / 2016$ \\
\hline 2 & $\begin{array}{l}\text { Divulgar as metas definidas para o mês } \\
\text { subsequente, no último dia útil do mês vigente. }\end{array}$ & $\begin{array}{l}\text { Para que o vendedor programe a rotina de } \\
\text { vendas do mês. }\end{array}$ & $\begin{array}{l}\text { Convovando uma reunião individual e informando } \\
\text { o valor estipulado. }\end{array}$ & Ricardo & $07 / 03 / 2016$ \\
\hline 3 & $\begin{array}{l}\text { Elaborar uma ferramenta para efetuar o check de } \\
\text { metas semanal e mensal. }\end{array}$ & $\begin{array}{l}\text { Para permirtir o acompanhamento semanal e } \\
\text { mensal das vendas do período. }\end{array}$ & $\begin{array}{l}\text { Desenvolvendo uma planilha de acompanhamento } \\
\text { das vendas. }\end{array}$ & Luciana & $14 / 03 / 2016$ \\
\hline 4 & $\begin{array}{l}\text { Elaborar uma política de bonificação e } \\
\text { comissionamento. }\end{array}$ & $\begin{array}{l}\text { Para definir quais serão os incentivos financeiros } \\
\text { dos vendedores. }\end{array}$ & $\begin{array}{l}\text { Definindo as premissas necessárias para a } \\
\text { binificação. }\end{array}$ & Luciana & $15 / 03 / 2016$ \\
\hline 5 & Divulgar toda política comercial estabelecida. & Para que todos tenham ciencia. & $\begin{array}{l}\text { Alugandi uma sala de reuniões fora da empresa } \\
\text { para realização de um WorkShop. }\end{array}$ & Marcelo & $21 / 03 / 2016$ \\
\hline 6 & $\begin{array}{l}\text { Efetuar check de metas semanal para os } \\
\text { vendedores. }\end{array}$ & $\begin{array}{l}\text { Para que o vendedor possa ver seu resultado } \\
\text { parcial, e corrigir os desvios verificados. }\end{array}$ & $\begin{array}{l}\text { Convocando uma reunião individual e informando } \\
\text { os valores auferidos até o momento. }\end{array}$ & Luciana & $31 / 12 / 2016$ \\
\hline 7 & Elaborar lista semanal de produtos promocionais. & $\begin{array}{l}\text { Para ser praticads nas aboragenens de reconquistá } \\
\text { de clientes inativos. }\end{array}$ & $\begin{array}{l}\text { Escoolhendo produtos que possam interessar àos } \\
\text { clientes inativos. }\end{array}$ & Marcelo & $31 / 12 / 2016$ \\
\hline
\end{tabular}

Fonte: Dados da Pesquisa (2016)

\subsection{AÇÃO}

Para dar início a execução das ações propostas, foi realizado um workshop fora do ambiente interno da empresa para todos os vendedores. A escolha do ambiente externo foi uma decisão estratégica visando gerar melhores expectativas nos vendedores quanto à nova rotina que seria proposta.

No workshop realizou-se o treinamento da equipe de vendas e foi apresentada a nova política comercial, a proposta de metas e bonificação. Foi informado também que o programa teria início a partir do dia 
01/04/2016 e as metas de cada vendedor seriam divulgadas em reunião individual. A política de bonificação e comissionamento foi formulada para premiar os vendedores conforme o desempenho de faturamento global das vendas, a venda de produtos próprios (aqueles produzidos na empresa e que oferecem maior margem de contribuição) e a venda de produtos nobres (que eram os produtos fornecidos pelos fornecedores parceiros da AMD Alimentos). Desta forma estaria sendo trabalhada simultaneamente a necessidade de estipular metas de vendas, de forma a direcioná-las para os produtos mais rentáveis pela empresa, oferecendo incentivo financeiro para motivar o desempenho dos vendedores.

Com intuito de resgatar clientes que deixaram de comprar na AMD, foi criada uma lista de promoção com produtos diferentes a cada semana. Essa lista era composta por um produto chave (aqueles que os clientes observam o preço antes de qualquer outro produto), dois produtos de produção própria (que eram os que garantiam maior margem a empresa) e algum produto dos fornecedores que eram parceiros da ADM. Foi solicitado aos vendedores, que focassem a oferta destes produtos para aumentar o mix de produtos nos clientes e reativar os clientes que haviam deixado de comprar.

\subsection{VERIFICAÇÃO}

$\mathrm{Na}$ etapa de Verificação iniciou-se uma fase de acompanhamento periódico do plano de ação, e das vendas da empresa, para constatar se obteve retorno esperado.

Toda sexta-feira era feita uma reunião individual com cada vendedor para acompanhamento das vendas realizadas durante a semana até o fechamento do mês e divulgação dos resultados finais.

A proposta de acompanhar as vendas semanalmente gerava uma possibilidade de recuperação das vendas, caso o vendedor não estivesse dentro de um patamar esperado até aquele momento do mês. Ou seja, permitia a ele ter uma informação parcial do seu desempenho e assim saber o quando precisaria se esforçar para chegar ao seu objetivo final.

Deste modo, criou-se um arquivo que era atualizado semanalmente com os resultados apresentados a cada um separadamente. Este arquivo possuía o resultado consolidado das vendas conforme modelo apresentado no Quadro 3, sendo possível visualizar a venda acumulada, a tendência de vendas e o desvio efetivo, ou seja, quanto ainda era preciso vender para bater as metas. Neste arquivo eram incluídas orientações individuais que ajudariam o vendedor a atingir suas metas de forma direcionada.

\subsection{EFETIVIDADE DO BLOQUEIO}

Nesta etapa da aplicação do Método de Análise a Solução de Problemas, deve ser efetuada uma comparação entre os números levantados no início do estudo, e o os resultados apurados ao final do período definido para comprimento da meta estipulada.

Para tanto, o Figura 6, apresenta o comparativo entre as vendas brutas de $2015 \mathrm{x}$ 2016.

Fica evidenciada através de números, que as vendas tiveram uma evolução satisfatória em relação ao período anterior, onde se trabalhava de maneira arbitrária, sem aplicação de qualquer tipo de metodologia.

A implantação de rotinas de vendas, de acompanhamento das vendas, definição de metas por vendedor e elaboração de uma política de bonificação e comissionamento, geraram a alavancagem das vendas brutas. 
QUADRO 03 - Check de Metas Global

\begin{tabular}{|c|c|c|c|c|c|}
\hline \multicolumn{6}{|c|}{ FECHAMENTO MAIO DE 2016} \\
\hline CATEGORIA & PREVISTO & REALIZADO & DESVIO & \multicolumn{2}{|c|}{ TENDÊNDCIA } \\
\hline FATURAMENTO & $42.500,00$ & $44.237,70$ & $1.737,70$ & & $44.237,70$ \\
\hline PRÓPRIA & $5.950,00$ & $3.209,36$ & $2.740,64$ & & $3.209,36$ \\
\hline NOBRE & $12.750,00$ & $8.583,18$ & $4.166,82$ & & $8.583,18$ \\
\hline \multicolumn{6}{|c|}{ PLANO DE AÇÃO } \\
\hline CATEGORIA & \multicolumn{4}{|c|}{ AÇÃO } & PRAZO \\
\hline FATURAMENTO & \multicolumn{4}{|c|}{$\begin{array}{l}\text { CONFEITARIA CABRAL LTDA, efetuar levantamento dos produtos que } \\
\text { deixou de comprar por preço e quais os preços tem com comcorrente. }\end{array}$} & $18 / 04 / 2016$ \\
\hline PRÓPRIA & \multicolumn{4}{|c|}{ Focar nos produto OLEO A MONTANNA EMULSIFICANTE 5LT. } & $12 / 04 / 2016$ \\
\hline NOBRE & \multicolumn{4}{|c|}{ Focar venda POLVILHO PARANAENSE AZEDO $25 \mathrm{KG}$. } & $12 / 04 / 2016$ \\
\hline
\end{tabular}

Fonte: Dados da Pesquisa (2016)

Figura 6 - Venda Consolidada

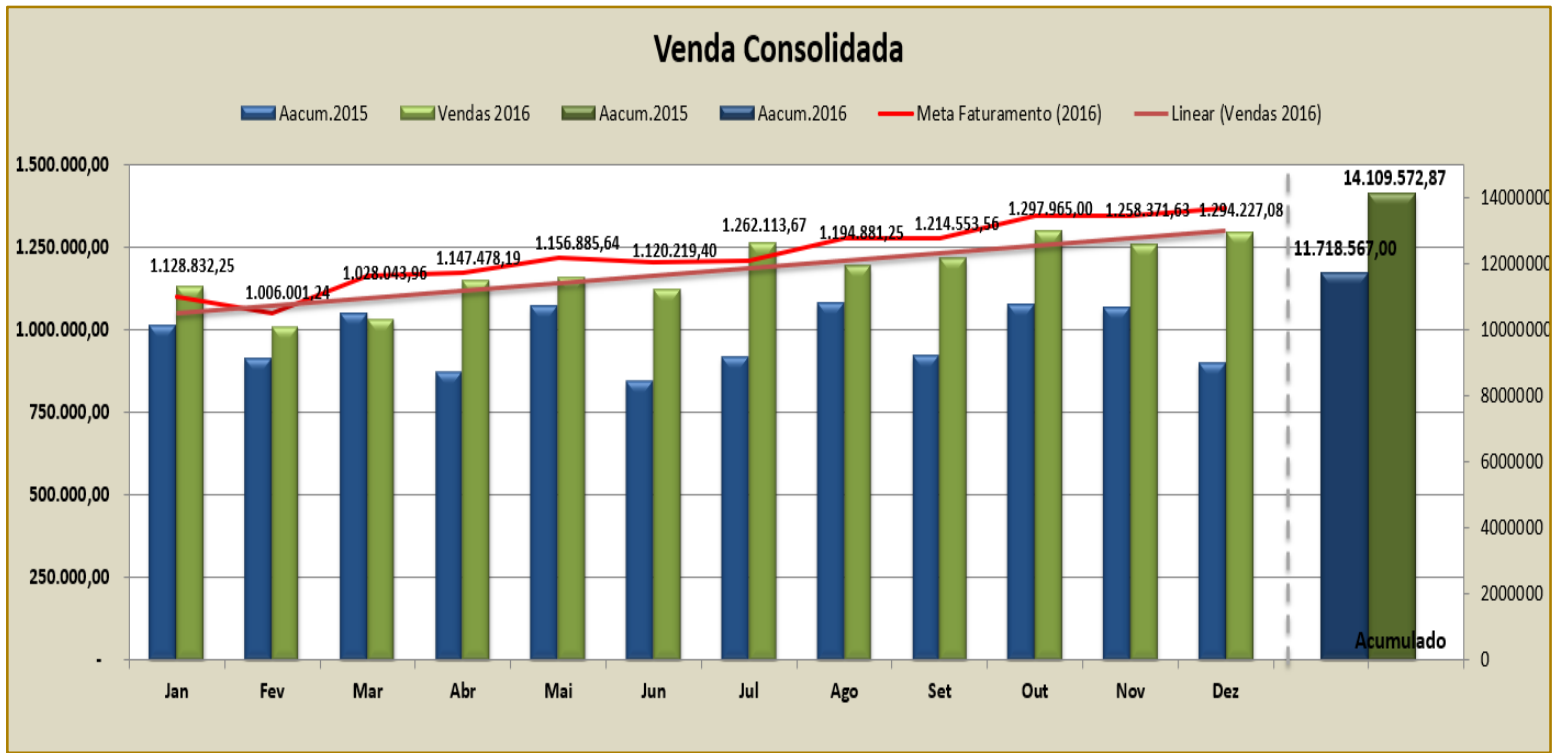

Fonte: Dados da Pesquisa (2016)

É possível observar ainda, que existe uma tendência de crescimento, diferente da inconstância das vendas observada no período passado.

Porém, pode-se perceber também, que as metas de venda não foram $100 \%$ atingidas no decorrer dos meses de 2016, devido a eventos pontuais ocorridos durante o ano. Desta forma, foram feitas reunião, para verificar as causas que levaram ao não atingimento das metas, bem como para definição de ações que ajudassem na recuperação das vendas no mês posterior, permitindo que a meta final de faturamento de 14 milhões ao final de 2016 fosse atingida.

O mês de março, por exemplo, foi identificada queda no faturamento devido falta de produto em estoque, justamente a farinha de trigo que é o principal produto da empresa. O atraso ocorreu, porque o pedido da farinha não foi efetuado em tempo hábil pela AMD Alimentos. Para evitar que o fato ocorresse novamente, foi elaborada uma tabela contendo o Ponto de Pedido de todos os produtos e inserido no sistema. Desta forma, o próprio sistema alertaria quando o estoque chegasse no nível 
se segurança sendo necessário efetuar um novo pedido.

O Quadro 04, refere-se a um painel criado para acompanhamento das vendas, ele apresenta o faturamento bruto obtido no ano anterior e no ano em que decorreu o estudo, fazendo o comparativo percentual do crescimento efetivo obtido mês a mês, o crescimento percentual estimado em relação a meta estipulada, e o percentual atingido da meta estipulada que representa o crescimento estipulado.

QUADRO 04 - Painel de Vendas

\begin{tabular}{|c|c|c|c|c|c|c|c|c|c|c|c|c|c|}
\hline \multicolumn{14}{|c|}{ Análise Consolidado Geral - Todas as Regionais } \\
\hline TODAS REGIONAIS & Jan & Fev & Mar & Abr & Mai & Jun & Jul & Ago & Set & Out & Nov & Dez & Acumulado \\
\hline Vendas 2015 & 1.013 .466 & 910.097 & 1.049 .043 & 872.337 & 1.070 .240 & 845.275 & 915.887 & 1.080 .801 & 919.953 & 1.077 .379 & 1.065 .210 & 898.879 & 11.718 .567 \\
\hline Vendas 2016 & 1.128.832 & $1.006,001$ & 1.028 .044 & $1,147,478$ & 1.156 .886 & 1.120 .219 & 1.262 .114 & 1.194.881 & 1.214 .554 & 1.297 .965 & 1.258 .372 & 1.294 .227 & 14.109.57: \\
\hline Crescimento (2015-2016) & $11,4 \%$ & $10,5 \%$ & $\cdot 2,0 \%$ & $31,5 \%$ & $8,1 \%$ & $32,5 \%$ & $37,8 \%$ & $10,6 \%$ & $32,0 \%$ & $20,5 \%$ & $18,1 \%$ & 44,0\% & $20,4 \%$ \\
\hline Meta Faturamento (2016) & 1.100 .227 & 1.049 .600 & 1.165 .500 & 1.171 .500 & $\mid$\begin{tabular}{|l|}
1.217 .000 \\
\end{tabular} & 1.204 .500 & 1.207 .500 & 1.278 .600 & 1.277 .787 & 1.347 .000 & 1.347 .800 & 1.367 .104 & 14.734.11 \\
\hline Crescimento (Meta X 2015) & $8,6 \%$ & $15,3 \%$ & $11,1 \%$ & $34,3 \%$ & $13,7 \%$ & $42,5 \%$ & $31,8 \%$ & $18,3 \%$ & $38,9 \%$ & $25,0 \%$ & $26,5 \%$ & $52,1 \%$ & $25,7 \%$ \\
\hline PERCENTUAL DA META & $102,6 \%$ & $95,8 \%$ & $88,2 \%$ & $97,9 \%$ & $95,1 \%$ & $93,0 \%$ & $104,5 \%$ & $93,5 \%$ & $95,1 \%$ & $96,4 \%$ & $93,4 \%$ & $94,7 \%$ & $95,8 \%$ \\
\hline
\end{tabular}

Fonte: Dados da Pesquisa (2016)

\subsection{PADRONIZAÇÃO}

Foram elaboradas as rotinas de padronização que serviu como base para o planejamento comercial do 2017, pautado nas mesmas aplicações práticas efetuadas no ano de 2016.

Visando a consolidação dos procedimentos, definiu-se que as rotinas de definição de metas e, o check (ou verificação) de metas semanais com os vendedores e a política de bonificação e comissionamento, juntamente com as listas de produtos promocionais que eram divulgadas semanalmente, continuariam a ser realizados para o ano de 2017, porém a meta era manter o resultado alcançado em 2016. Estimular uma meta de crescimento em 2017 poderia trazer problemas que ainda não haviam sido enfrentados pela empresa $e$ prejudicar o desempenho da área de vendas. Por isso, entendeu-se que seria melhor um crescimento sólido aliado à consolidação das novas práticas organizacionais.

\section{CONSIDERAÇÕES FINAIS}

Tradicionalmente, a aplicação do MASP é realizada em áreas relacionadas a produção e qualidade de industrias. A realização do estudo, com a utilização do método em uma área diferente da industrial mostrou-se extremamente eficiente para que os gestores possam identificar problemas e resolvê-los, de forma sistemática, melhorando a performance das empresas. Tanto a aplicação do MASP na área de produção, quanto no setor comercial enfrentam dificuldades similares quando se trata da execução dos planos de ação.

Toda mudança proposta tira as pessoas da zona de conforto e gera um certo receio, fazendo com que assumam uma posição defensiva que pode prejudicar todo andamento do trabalho que está sendo proposto, por isso, o grande desafio desse trabalho foi a dificuldade para envolver todos os vendedores no processo. Entretanto, a apresentação do método e, principalmente, dos dados coletados de maneira objetiva, proporcionou maior envolvimento da equipe para a solução do problema. O MASP tirou a subjetividade da interpretação do problema.

Com a aplicação do MASP foi possível concluir, que o objetivo de atingir $20 \%$ de aumento no faturamento bruto até a data de 31 de dezembro de 2016 foi atingido.

Apesar do efeito positivo em relação ao atingimento da meta, alguns efeitos colaterais foram observados. O crescimento do faturamento bruto da empresa está diretamente atrelado ao aumento do volume de vendas, com isso, foram identificados alguns pontos críticos que certamente serão 
gargalos futuros. Dentre eles, o principal problema diz respeito à estrutura. O aumento das vendas gera uma necessidade maior de estoque e o atual espaço físico da AMD está completamente saturado. Outra necessidade eminente será o aumento da frota de caminhões que fazem as entregas. Por isso, a aplicação do MASP demonstrou que a empresa precisará realizar investimentos que não pode arcar no momento se quiser crescer. Deste modo, a aplicação do MASP

\section{REFERÊNCIAS}

[1] CAMPOS, Vicente Falconi. TQC - Controle da qualidade total: no estilo japonês. 8.ed. Belo Horizonte: Editora DG, 1999.

[2] CAMPOS, Vicente Falconi..TQC - Controle da qualidade total no estilo japonês. Nova Lima: INDG, 2004.

[3] CARPINETTI, L. C. R. Gestão da Qualidade ISO 9001:2008: Princípios e requisitos. São Paulo: Atlas, 2011.

[4] CERQUEIRA. J. P. A Metodologia de Análise e Solução de Problemas. 1. ed. São Paulo: Pioneira, 1995

[5] LEITE, Prof.Ms. Osni Paula. MASP Metodologia de análise e solução de problemas. FATEC Sorocaba. Disponível em: $<$ http://www.fatecsorocaba.edu.br/metrologia/apost ilas/masp.ppt>Acesso em: 24/08/17

[6] MARSHALL JR, I.; CIERCO, A. A.; ROCHA; A. V.; MOTA, E. B.; LEUSIN, S. Gestão da qualidade. 9. ed. Rio de Janeiro: editora FGV, 2008.

[7] MARTINS, Petrônio Garcia; LAUGENI, Fernando P. Administração da produção. São Paulo: Saraiva, 2000. proporcionou não só o aumento crescimento a curto prazo da empresa AMD de forma sustentado, como também evidenciou as variáveis que deverão ser equacionadas a longo prazo caso queiram aumentar, ainda mais, o faturamento. Restou evidente que o MASP é uma forte ferramenta para a identificação de problemas mesmo aqueles aplicados nas áreas mais administrativas ou gerenciais.

[8] PIRES, J. G. C. Aprendizagem Organizacional através da Metodologia de Solução de Problemas - MASP. Revista de Administração da Fatea, v. 9, n. 9, p. 84-100, 2014.

[9] RIBEIRO NETO, A. F. Aplicação do método de análise e solução de problemas MASP. Especialize Revista Online, v. 4 p. 1-15, 2013.

[10] SCHMENNER, Roger W. Administração de operações em serviços. São Paulo: Futura, 1999.

[11] SELEME, Robson; STADLER, Humberto. Controle da qualidade: as ferramentas essenciais. Curitiba: Ibpex, 2008.

[12] TOLEDO, José Carlos de. Melhoria da Qualidade e MASP. São Paulo: GEPEQ/DEPUFSCar, 2010.

[13] VIVONE, Marcus Vinícius; GIUSTI, Paulo Sérgio; ALBIERI, José Geraldo. Uma Abordagem 8D para tomada de ação corretiva eficaz. São Paulo: InteractionPlexus, 2005. 


\section{Bapítulo 4}

\section{UTILIZACÃO DA INTERNET DAS COISAS E DA PLATAFORMA ARDUINO PARA O CONTROLE DA QUALIDADE DO LEITE: UMA REVISÃO SISTEMÁTICA}

\section{Katiane de Oliveira Comachio}

Silvana Ligia Vincenzi

Resumo: A crescente oferta de sensores para as mais diversas aplicações tem impulsionado o estudo de tecnologias de baixo custo e o fortalecimento do conceito de Internet Of Things (Internet das Coisas). Com tecnologias mais acessíveis, o mercado exige melhoria e garantia da qualidade de produtos, com isso a Internet das Coisas se torna aliada na busca dos padrões. Assim, o objetivo deste trabalho foi comparar a metodologia e evolução dos estudos já realizados sobre a utilização da Internet das Coisas e da Plataforma Arduino para controle da qualidade do leite, a partir de uma revisão sistemática. Para tanto, utilizou-se um protocolo de pesquisa, onde foram pesquisados artigos indexados no período de 2000 a 2019 (aprovados na revisão) em seis bases eletrônicas: Plataforma Capes, Scopus, Web of Science, ScienceDirect, Scielo e Google acadêmico. Este procedimento resultou na seleção de 25 artigos científicos, extraídos do montante de 4978 resultados computados nos mecanismos de pesquisa selecionados, alcançando assim um índice de aproveitamento de 0,5\%. Foi possível constatar um maior número de artigos selecionados escritos na língua inglesa e oriundos da Plataforma Capes e Scopus, como também uma certa evolução das técnicas empregadas para estudos na agricultura e automação industrial. Além disso, há um crescimento considerável no número de artigos a partir de 2010, tendo como um dos fatores associados, a utilização de sensores diversos nas mais diversas aplicações (casa, agricultura, indústria). No entanto, é necessário um maior esforço da comunidade científica para a melhoria das metodologias empregadas na indústria, visando o controle e segurança dos alimentos.

Palavras-chave: Automação Industrial. Sensores. IoT. 


\section{INTRODUÇÃO}

O leite é considerado um alimento de alto valor nutricional, pois em sua composição apresenta elevado teor de gordura, proteína, carboidrato, minerais e vitaminas. Em contrapartida, devido a ação de microrganismos advindos da manipulação na coleta, o leite sofre alterações nas suas propriedades organolépticas, físico-químicas e microbiológicas muito rapidamente se não for conservado de maneira adequada (RECHE, 2013).

No início do século XXI, impulsionado pelo cenário competitivo, o setor de produção leiteira no Brasil ganhou incentivo da indústria para aderir às novas tecnologias. Para Cortinhas (2013), foi uma maneira de manter a produtor rural no mercado competitivo de leite, melhorar a qualidade do leite cru e aumentar a produtividade. Dessa forma, o Ministério da Agricultura e Abastecimento publicou a Instrução Normativa no51 de 18 de setembro de 2002 para monitorar a qualidade do leite por meio da determinação do resfriamento obrigatório na propriedade rural em que é produzido e resíduos de antibiótico no leite (BRASIL, 2002). Em 2011, entrou em vigor a Instrução Normativa no62 que define novos parâmetros de qualidade e critérios de avaliação do leite cru refrigerado, estabelecendo prazos para a implantação de limites legais de Contagem de Células Somáticas (CCS) e Contagem Bacteriana Total (CBT) (BRASIL, 2011). Segundo Pinto et al. (2006) é possível minimizar o crescimento microbiano e de bactérias psicotrópicas quando se tem condições higiênicas adequadas de produção, armazenamento e transporte, bem como refrigeração em todas as etapas antes da industrialização.

Entretanto, não é apenas a composição microbiológica que afeta a qualidade do leite, mas também a composição físico-química. Assim como a microbiológica, a físico-química varia de acordo com diversos fatores, como raça do animal, genética individual, gestação, ciclo estral, estações do ano, temperatura, idade, lactação, tamanho do animal, alimentação e condição patológica (principalmente mastite) (RECHE, 2013). Além disso, elevados índices de contaminação microbiana afetam diretamente a composição físico-química do leite, como acidificação, coagulação, alteração da cor, viscosidade, dentre outros (MARTINS et al., 2008).
Os produtos de origem animal são substanciais à saúde pública, por isso o monitoramento da qualidade por meio de parâmetros físico-químicos e microbiológicos tornam-se obrigatórios (MARTINS et al., 2008). De acordo com a IN no62 de 2011, a periodicidade das análises físico-químicas do leite (gordura, acidez titulável, densidade relativa, índice crioscópico, sólidos não gordurosos e alizarol) deve ser diária, quantas vezes forem necessárias e a periodicidade das análises microbiológicas (CBT, CSS e resíduo de antibiótico) deve ser pelo menos uma vez ao mês (BRASIL, 2011).

Devido às exigências dos mercados nacional e internacional, muitos laticínios se adequaram às normas de qualidade e segurança alimentar, mas o grande problema é garantir qualidade do leite que chega a essas unidades de beneficiamento. Por isso, os produtores são pressionados a melhorarem a qualidade do leite fornecido aos laticínios, seja para atender a legislação ou pela remuneração por critério de qualidade que ocorre em algumas regiões brasileiras (SILVEIRA et al., 2017). Porém, prover alimentos seguros, de qualidade e com uso sustentável da base de recursos naturais é o grande desafio do agronegócio.

Nos últimos anos, impulsionados pela necessidade de automação de processos, muitos pesquisadores têm se dedicado à pesquisa e implantação de dispositivos e equipamentos que garantam a qualidade e segurança dos alimentos antes e depois do processamento (ARAÚJO, 2012; GIMENES e PEREIRA, 2015; BABU et al, 2018; FATANI et al., 2018). Um dos conceitos desenvolvidos e amplamente utilizado é Internet of Things, Internet das Coisas em Português, mencionada pela primeira vez em 1999, por Kevin Ashton. Define-se como um "sistema de computação de dispositivos interrelacionados", onde os objetos em questão, sejam eles mecânicos, digitais, objetos inanimados ou pessoas, são equipados com identificadores únicos, assim contribuindo para a transferência de dados através de uma rede sem a interferência de humanos ou computadores (COSTA, 2018).

O conceito de IOT proporcionou a criação e utilização de plataformas de programação, que contribuem para a transferência de dados entre os dispositivos relacionados. Um exemplo é a plataforma Arduino. A plataforma Arduino é um sistema "aberto", tanto em hardware como em software, ou seja, ela 
apresenta fácil integração com os diversos dispositivos e isso alavancou a oferta de sensores para as mais diversas aplicações. Além disso, a plataforma Arduino está disponível em grande especificidade e com custos relativamente baixos. Embora o setor industrial seja relutante à essa tecnologia, a plataforma Arduino tem conquistado o desenvolvimento de muitas aplicações e se mostrado eficaz na tomada de decisões, já que apresenta facilidade na comunicação e interligação com diferentes tipos de sensores, permite a programação nas linguagens $\mathrm{C} \mathrm{e}$ $\mathrm{C}++$, possui diversidade de protocolos facilitando o desenvolvimento de projetos de grande complexidade, permite a transferência do programa para o Arduino através de um cabo USB e apresenta resultados imediatos (ARAÚJO, 2012).

\section{METODOLOGIA}

A sistemática da pesquisa foi baseada na metodologia proposta por Kitchenham et al. (2009) com a formulação de um protocolo de pesquisa e definição da busca eletrônica em sites e bases indexadas. Para conduzir a pesquisa foram elaboradas as questões abaixo:

- Quais razões podem ter influenciado o maior ou menor número de publicações?

- Quais são as medidas mitigatórias apontadas pelos autores estudados com relação à qualidade do leite?

- Quais foram as metodologias aplicadas à indústria alimentícia que utilizaram a plataforma Arduino?

- Quais as limitações encontradas pelos autores relacionadas ao uso da plataforma Arduino?

Após a elaboração das questões norteadoras, adotou-se algumas estratégias de pesquisa, como a fonte de pesquisa (site e bases de busca), idioma dos trabalhos, os tipos de documentos, ano de publicação, palavraschaves e a aplicabilidade dos trabalhos.

Para a fonte de pesquisa, foram selecionadas seis principais bases de busca e sites relacionados às universidades e eventos, conforme $\quad 0 \quad$ Quadro 1.

Quadro 1 - Bases de busca e endereços eletrônicos pesquisados.

\begin{tabular}{|c|c|}
\hline Bases de Busca & Endereço Eletrônico \\
\hline Plataforma Capes & http://www.periodicos.capes.gov.br/ \\
\hline Scopus & https://www.scopus.com/ \\
\hline Web of Science & $\begin{array}{l}\text { http://apps- } \\
\text { webofknowledge.ez48.periodicos.capes.gov.br/WOS_GeneralSearch_input.do?pr } \\
\text { oduct=WOS\&search_mode=GeneralSearch\&SID=6AFi9qW3F8JY9hXFacc\&prefer } \\
\text { encesSaved= }\end{array}$ \\
\hline Science Direct & https://www.sciencedirect.com/ \\
\hline Google Acadêmico & https://scholar.google.com.br/ \\
\hline Plataforma Scielo & http://www.scielo.br/ \\
\hline
\end{tabular}

Fonte: Autoria Própria.

A Plataforma Capes, o Scopus, o Web of Science e o Science Direct foram escolhidos para otimizar o número de artigos sobre o tema, já que é possível ampliar o alcance das palavras-chave e são ferramentas de buscas utilizadas em sua grande maioria por pesquisadores. Conforme Miranda et al. (2017), o Google Acadêmico é uma ferramenta que proporciona comparar a quantidade de trabalhos acadêmicos, artigos científicos e pesquisas disponibilizados ao público não especializado. A Plataforma Scielo é uma plataforma iniciada no Brasil e que contém artigos escritos em português.

A escolha dos idiomas foi de acordo com a linguagem materna e com a linguagem científica universal, português e inglês, respectivamente. O intervalo de tempo compreende a 19 anos, incluídos os artigos publicados entre 2000 e 2019. As palavraschave estão dispostas no quadro 2. 
Quadro 2 - Palavras utilizadas na busca dos trabalhos.

\begin{tabular}{|l|l|}
\hline \multicolumn{2}{|c|}{ Palavras-Chave } \\
\hline Português & Inglês \\
\hline Qualidade do leite & Milk Quality \\
\hline Fraudes no leite & Milk Frauds \\
\hline Adulteração do leite & Milk Adulteration \\
\hline Arduino e internet das Coisas & Arduino, iot \\
\hline Arduino, internet das coisas e agricultura & Arduino, iot, agriculture \\
\hline Sensores, internet das coisas e agricultura & Sensors, iot, agriculture \\
\hline Arduino, sensores e internet das coisas & Arduino, sensors, iot \\
\hline
\end{tabular}

Fonte: Autoria Própria.

Para otimizar a pesquisa e facilitar a busca por combinação entre as palavras, optou-se por utilizar os operadores "OR" ou "AND" para as palavras-chave mencionadas no Quadro 2. Além disso, alguns critérios de inclusão foram adotados para filtrar a pesquisa, tais como artigos científicos disponíveis na íntegra, metodologias claras, publicações em revistas/periódicos classificadas pelas Qualis Capes.

Os artigos foram selecionados observando a seguinte sistemática: Primeiro, selecionou-se o artigo por meio do título, sempre considerando a relevância com o tema. Depois, em cada artigo selecionado, foi feita a leitura do resumo. E, por fim, os artigos foram selecionados considerando a classificação na Qualis Capes, na qual acarretou na escolha de apenas 25 artigos.

\section{RESULTADOS E DISCUSSÕES}

Com elevado valor nutricional para a saúde humana, o consumo de leite tem aumentado rapidamente em várias regiões do mundo e isso tem motivado ações fraudulentas $e$ adulteração do leite. Para GhasemiVarnamkhasti et al. (2017) a fraude no leite inclui atividades ilegais, como excesso de execução, roubo, desvio, falsificação e também adulteração. Já a adulteração é uma subcategoria de fraude, que pode ser definida como a adição ilegítima de compostos químicos ao leite com o objetivo de aumentar o peso para a venda, aumentar a vida útil e/ou melhorar a aparência do leite. Nascimento et al. (2017) acrescenta que "o leite pode ser adulterado para ganho financeiro ou devido a más condições de higiene de processamento, armazenamento, transporte e comercialização".
Para Nascimento et al. (2017), em algumas situações, especialmente naquelas onde há mistura de adulterantes, os métodos recomendados para avaliar a qualidade do leite demonstram falha na detecção. Devido ao aumento dos esforços em impedir que as fraudes e adulterações aconteçam e, como consequência, reduzam a qualidade do leite, várias pesquisas apontam para melhoria nos equipamentos. Além de elaborar equipamentos que sejam capazes de detectar esse tipo de acontecimento, as pesquisas mostram que essas inovações devem apresentar baixo custo de compra e manutenção e que sejam de fácil manuseio.

Babu et al. (2018) destacam que muitas revisões de literatura estão abordando a qualidade e segurança de alimentos, principalmente quando se refere ao processo de transporte e serviço de alimentos. Graças aos avanços da tecnologia no campo da Internet das Coisas é possível testar a qualidade dos alimentos considerando vários fatores integrados. A popularização da placa Arduino é um dos avanços tecnológicos em questão. Segundo Amorin et al. (2015), nos últimos anos, a placa Arduino conquistou diversas aplicações e, com ela, houve um aumento expressivo na oferta de sensores. Alguns motivos que levaram à popularização se deve ao fato de que a placa apresenta fácil integração com demais softwares e hardwares, exemplo são os diversos sensores encontrados no mercado nacional e internacional, denominados dispositivos loT.

A utilização da plataforma Arduino ainda está em ascensão e muitos trabalhos estão voltados à inclusão desse item como uma ferramenta educacional. Assim, a busca limitou-se aos trabalhos relacionados a qualidade e segurança dos alimentos com ou sem a utilização da plataforma Arduino, a utilização da internet das coisas voltada à 
automação e a utilização da plataforma na elaboração de equipamentos diversos.

No primeiro momento, a pesquisa de trabalhos limitou-se as palavras-chave de maneira individual, sem relacionar umas com as outras, mas considerando apenas trabalhos dos últimos 5 anos. Com relação a palavra-chave Qualidade do Leite ou Milk Quality, foram encontrados cerca de 365369 $(68,22 \%)$ artigos na Plataforma Capes, 145822 no Science Direct (27,22\%), 18211 $(3,4 \%)$ artigos no Scopus, 5354 (1\%) advindos do Web of Science, $743(0,14 \%)$ no Google Acadêmico e 47 (0,0088\%) no Scielo, totalizando 535546 artigos referentes à temática, nos quais estavam incluídos diversos trabalhos que não condiziam com o escopo definido.

Considerando a palavra-chave Adulteração e Fraudes do Leite ou Milk Frauds e Milk Adulterations, 66730 (74,37\%) trabalhos foram encontrados no Google Acadêmico, 13186 (14,7\%) na Plataforma Capes, 8487 (9,46\%) no Science Direct, 890 (0,99\%) no Scopus, $430(0,48 \%)$ do Web of Science, totalizando 89723 trabalhos relacionados ao tema, nos quais diversos trabalhos não atendiam 0 escopo.

Para a palavra-chave Plataforma Arduino, Arduino e Arduino Platform foram encontrados 440504 trabalhos referentes ao tema, dos quais 408200 (92,67\%) foram no Google Acadêmico, 19741 (4,48\%) da Plataforma Capes, $6312(1,43 \%)$ do Scopus, 5541 $(1,26 \%)$ no Science Direct, $632(0,14 \%)$ do
Web of Science e $78(0,018 \%)$ do Scielo, mas muitos não condiziam com o tema.

Dentre os 585721 trabalhos encontrados com a palavra-chave Sensores ou Sensors, 475811 $(81,24 \%)$ advém da Plataforma Capes, 45086 $(7,7 \%)$ do Web of Science, $42500(7,26 \%)$ do Google Acadêmico, 19768 (3,37\%) da Base Scopus, 1931 (0,33\%) do Science Direct, 625 $(0,11 \%)$ no Scielo.

Quanto à palavra-chave Internet of Things ou Internet das Coisas foram encontrados 466476 trabalhos, dos quais 337000 (72,24\%) são do Google Acadêmico, 101830 (21,83\%) são da Plataforma Capes, 20354 (4,36\%) da Web of Science, $6099(1,31 \%)$ são do Science Direct, $1185(0,25 \%)$ no Scopus e apenas 8 $(0,0017 \%)$ trabalhos foram encontrados no Scielo.

É possível notar que todas as palavras-chave pesquisadas apresentaram um crescente número de publicações ao longo dos anos, independente da base de busca utilizada. Para demonstrar esse gradativo aumento, optou-se apenas pelos dados da base de busca do Scopus, pois ela disponibiliza ferramenta que permite gerar gráficos de acordo com os anos. Para melhor visualização dos números de publicações, optou-se por separar as palavras-chave conforme a semelhança. No Gráfico 1 estão os números de publicações relacionados às palavraschave Qualidade do Leite e Milk Quality e Fraudes e Adulterações do Leite (ou Milk Frauds e Milk Adulterations).

Gráfico 1 - Número de publicações entre os anos 2000 e 2019 relacionados à palavra-chave Leite.

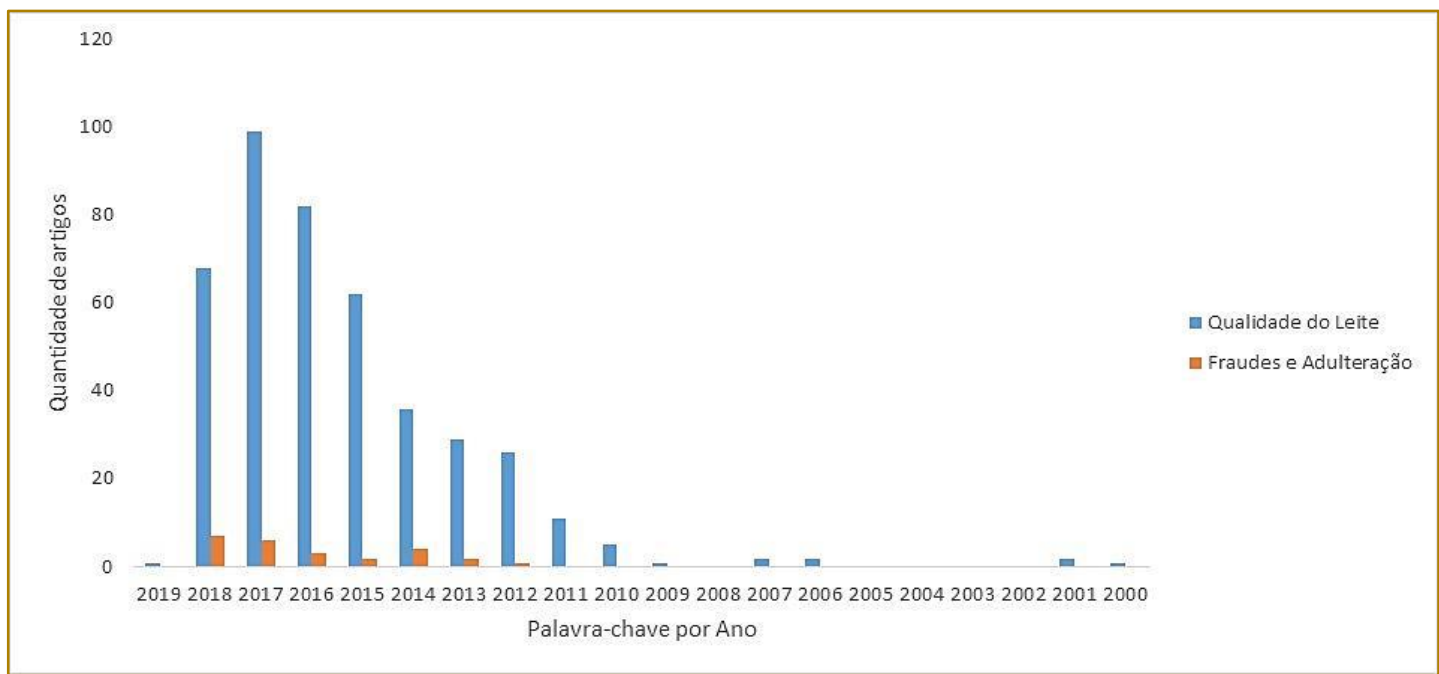

Fonte: Base de Busca Scopus. 
Nota-se que as pesquisas sobre Fraudes e Adulteração de Leite obtiveram aumento a partir de 2012 e que as pesquisas sobre qualidade do leite a partir de 2010. Desde muito tempo, as empresas buscam certificações de qualidade para seus produtos, mas somente a partir de 2010, as indústrias de beneficiamento do leite é que resolveram investir nesse aspecto, com o objetivo de aumentar a vida útil dos produtos, ganhar mercado e se tornar competitivas.

No Gráfico 2, agrupou-se as palavras-chave voltadas à tecnologia Plataforma Arduino (ou Arduino ou Arduino Platform), Internet das Coisas (Internet of Things) e Sensores (Sensors).

Gráfico 2 - Número de publicações entre os anos de 2000 e 2019 relacionados à tecnologia.

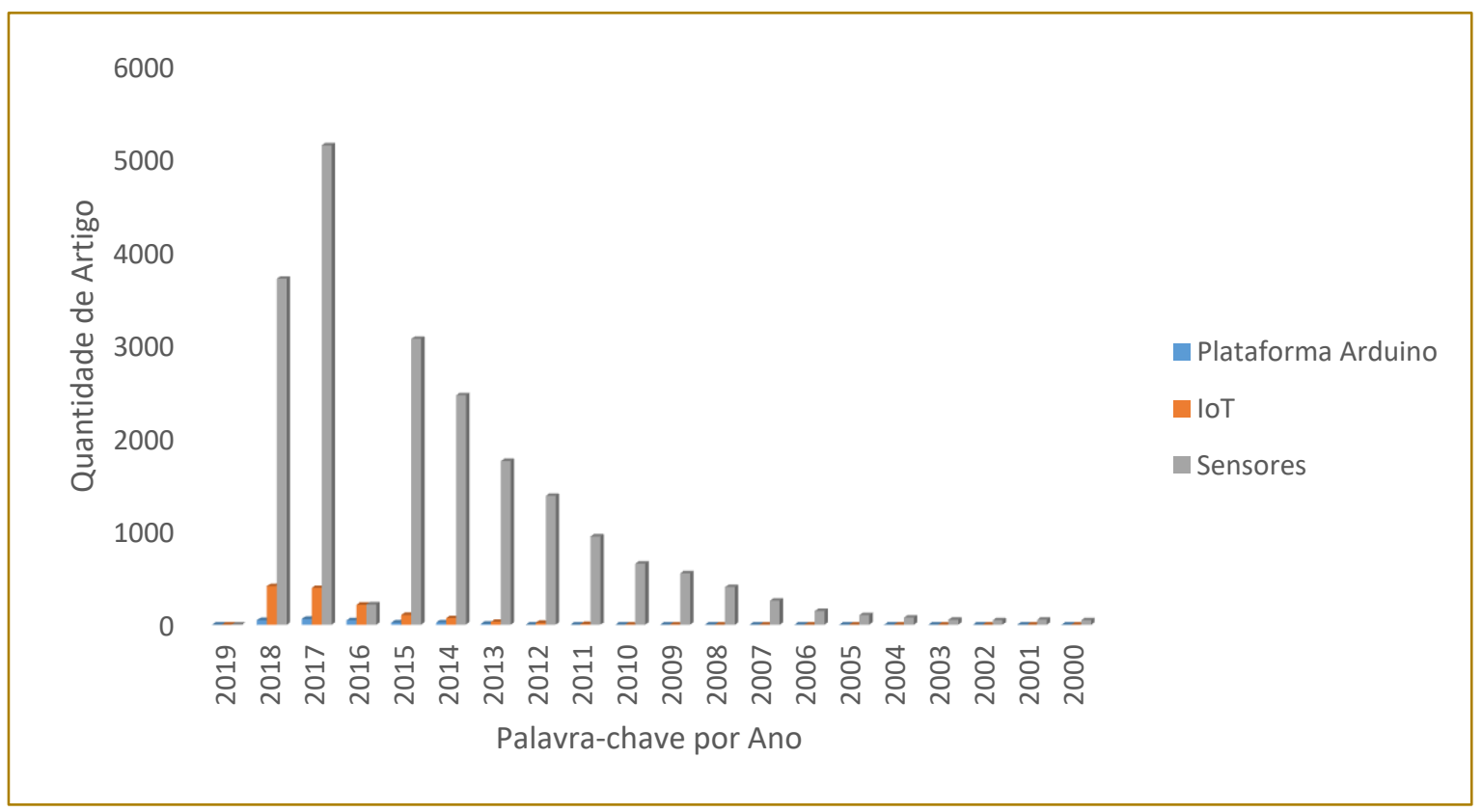

Fonte: Base de Busca Scopus.

O Gráfico 2 mostra que a pesquisa sobre sensores está sobressaindo sobre Internet das Coisas e Plataforma Arduino. A busca por melhoria nos processos, fez com que muitos pesquisadores pensassem em maneiras de substituir trabalhos manuais por automáticos. $\mathrm{O}$ ano de 2017, foi o ano com maior número de publicações relacionados à sensores. Quanto à Internet das Coisas e a Plataforma Arduino, ainda são temas pouco explorados, mas com grande possibilidade de ascensão, devido ao uso genérico.

Vega et al. (2014) se apropriaram do conceito de Internet das Coisas e montaram um sistema de gestão elétrica domiciliar com o auxílio da Plataforma Arduino, onde o usuário faz o acionamento ou desligamento da energia por um sistema. Os autores afirmam que a Plataforma Arduino simplifica $\mathrm{O}$ processo de trabalho com eletrônica digital, exige baixos custos de aquisição, trabalha com diferentes sistemas operacionais (multiplataforma) e seu software é aberto facilitando a programação em $\mathrm{C}$ ou $\mathrm{C}++$.

Já Rajkumar et al. (2017) elaboraram um recurso de controle automatizado usando microcontroladores para ligar e desligar o motor de bombeamento ao detectar nível de umidade abaixo ou acima do esperado, respectivamente.

Há muitos trabalhos sobre os temas pesquisados, mas quando relacionados uns com os outros, o resultado foi bem diferente. Ao aplicar filtros de publicações com no máximo 5 anos, escolher apenas artigo como tipo de trabalho e somente artigos com acesso livre, notou-se que o número publicações diminuiu consideravelmente. Como forma de melhorar a busca por trabalhos que condizem com o tema, além dos filtros aplicados, as palavras-chave foram relacionadas, como mostra o Quadro 3. 
Quadro 3 - Palavras-chave correlacionadas.

\begin{tabular}{|c|c|c|c|c|}
\hline & Scopus & Web of Science & Science Direct & $\begin{array}{c}\text { Plataforma } \\
\text { Capes }\end{array}$ \\
\hline Arduino, iot & 439 & 279 & 279 & 627 \\
\hline Arduino, iot, agriculture & 32 & 16 & 46 & 96 \\
\hline Arduino, sensors, iot & 94 & 18 & 269 & 504 \\
\hline Sensors, iot, agriculture & 381 & 186 & 561 & 98 \\
\hline Sensors, iot, livestock & 20 & 6 & 54 & 114 \\
\hline Sensors, iot, milk & 6 & 7 & 57 & 789 \\
\hline
\end{tabular}

Fonte: Autoria própria

Ao verificar os resultados, excluiu-se a base de busca Google Acadêmico, pois não tem como filtrar apenas artigos e a base de busca Scielo, pois não apresentou nenhum artigo a partir de 2014 com as palavras-chave descritas.

Conclui-se que a Plataforma Capes e o Scopus, apresentam melhor retorno de material conceituado (Gráfico 3). Entretanto, um aspecto negativo é o fato destes não permitirem o acesso à informação de maneira ampla, limitando parte do conteúdo a pesquisadores filiados a instituições públicas, ou mediante pagamento do material selecionado.

Gráfico 3: Porcentagem de artigos encontrados em cada base de busca, triagem final.

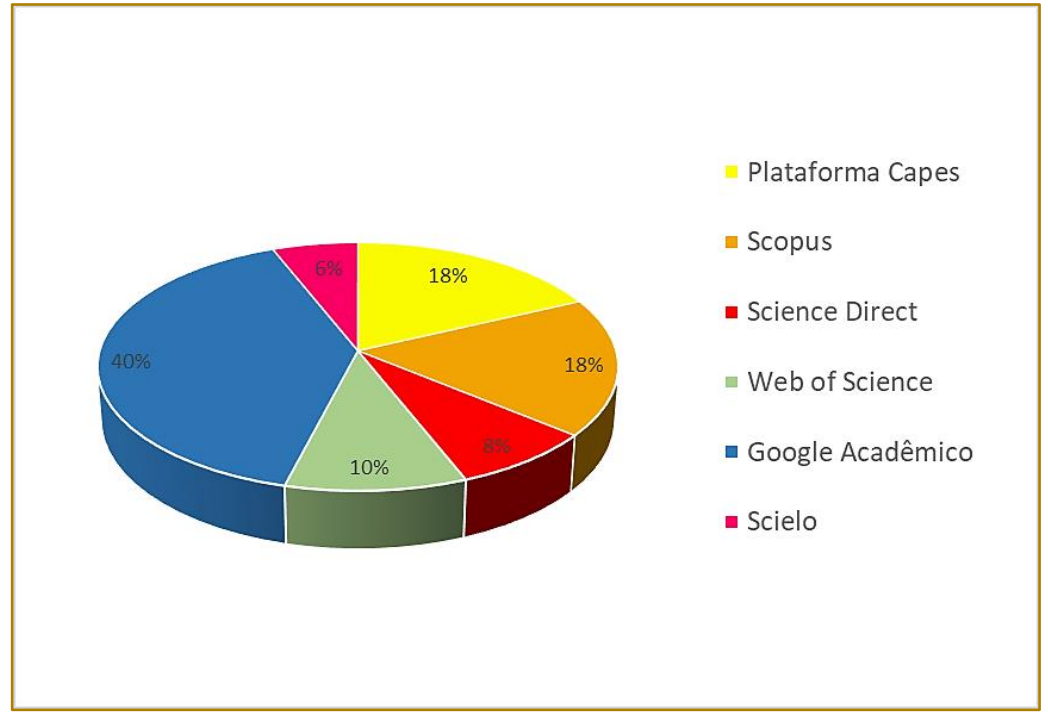

Fonte: Autoria própria.

Ao se analisar o Google acadêmico, ferramenta com maior utilização pelo público não especializado, apresentou o maior número de publicações (Gráfico 3), fato este atribuído pela falta de critério da base ao se colocar artigos não indexados e anais de evento. A seleção de artigos que atendem ao escopo definido é exaustiva, principalmente pela ampla busca, que demonstra resultados muitas vezes não condizentes a temática selecionada.
A partir dos artigos que abrangiam o critério de inclusão, foi avaliada a classificação dos artigos de acordo com o Qualis Capes. Este índice resultou em 24\% de artigos A1, $12 \%$ em A2, 36\% classificados como B1, $4 \%$ como B3 e $24 \%$ dos artigos eram de conferências e não apresentaram Qualis, como mostra o Quadro
4. 
Quadro 4 - Relação dos trabalhos selecionados de acordo com o ano e o Qualis.

\begin{tabular}{|c|c|c|c|}
\hline Autor & País & Qualis & Título \\
\hline Brandão et al. (2017) & Brasil & A1 & $\begin{array}{l}\text { Detection of adulteration of goat milk powder with bovine milk } \\
\text { powder by front-face and time resolved fluorescence. }\end{array}$ \\
\hline $\begin{array}{l}\text { Breitenbach et al. } \\
\qquad(2018)\end{array}$ & Brasil & A1 & $\begin{array}{l}\text { Whose fault is it? Fraud scandal in the milk industry and its } \\
\text { impact on product image and consumption - The case of } \\
\text { Brazil. }\end{array}$ \\
\hline Esteki et al. (2017) & Irã/Bélgica & A1 & $\begin{array}{l}\text { Qualitative and quantitative analysis of peanut adulteration in } \\
\text { almond powder samples using multi-elemental fingerprinting } \\
\text { combined with multivariate data analysis methods. }\end{array}$ \\
\hline $\begin{array}{l}\text { Guerreiro et al. } \\
\qquad(2018)\end{array}$ & Brasil & A1 & $\begin{array}{l}\text { Evaluating the effects of the adulterants in milk using direct- } \\
\text { infusion high resolution mass spectrometry }\end{array}$ \\
\hline $\begin{array}{l}\text { Handford et al. } \\
\text { (2016) }\end{array}$ & - & A1 & $\begin{array}{l}\text { Impacts of Milk Fraud on Food Safety and Nutrition with } \\
\text { Special Emphasis on Developing Countries. }\end{array}$ \\
\hline Liu et al. (2018) & $\begin{array}{l}\text { Holanda e } \\
\text { França }\end{array}$ & A1 & $\begin{array}{l}\text { Evaluation of portable near-infrared spectroscopy for organic } \\
\text { milk authentication. }\end{array}$ \\
\hline $\begin{array}{l}\text { Ghasemi- } \\
\text { Varnamkhasti et al. } \\
(2017)\end{array}$ & Irã/Itália & A2 & $\begin{array}{l}\text { Development of two dielectric sensors coupled with } \\
\text { computational techniques for detecting milk adulteration. }\end{array}$ \\
\hline $\begin{array}{l}\text { Hansen e Ferrão } \\
(2018)\end{array}$ & Brasil & A2 & $\begin{array}{l}\text { Identification of Possible Milk Adulteration Using } \\
\text { Physicochemical Data and Multivariate Analysis. }\end{array}$ \\
\hline Sezer et al. (2018) & Turquia & A2 & $\begin{array}{l}\text { Identification of milk fraud using laser-induced breakdown } \\
\text { spectroscopy (LIBS). }\end{array}$ \\
\hline Amorin et al. (2015) & Brasil & B1 & $\begin{array}{l}\text { Sensores digitais de temperatura com tecnologia one-wire: } \\
\text { Um exemplo de aplicação didática na área de condução } \\
\text { térmica. }\end{array}$ \\
\hline $\begin{array}{l}\text { Cordova e Tort } \\
\text { (2016) }\end{array}$ & Brasil & B1 & $\begin{array}{l}\text { Medida de g com a placa Arduino em um experimento } \\
\text { simples de queda livre. }\end{array}$ \\
\hline Jo e Baloch (2017) & $\begin{array}{l}\text { Coreia do } \\
\text { Sul e } \\
\text { Paquistão }\end{array}$ & B1 & $\begin{array}{l}\text { Internet of Things-Based Arduino Intelligent Monitoring and } \\
\text { Cluster Analysis of Seasonal Variation in Physicochemical } \\
\text { Parameters of Jungnangcheon, an Urban Stream. }\end{array}$ \\
\hline $\begin{array}{l}\text { Kamogawa e } \\
\text { Miranda (2013) }\end{array}$ & Brasil & B1 & $\begin{array}{l}\text { Uso de Hardware de Código Fonte Aberto "Arduino" para } \\
\text { Acionamento de Dispositivo Solenoide em Sistemas de } \\
\text { Análises em Fluxo }\end{array}$ \\
\hline $\begin{array}{l}\text { Nascimento et al. } \\
(2017)\end{array}$ & Brasil & B1 & $\begin{array}{l}\text { Results from portable and of low cost equipment developed } \\
\text { for detection of milk adulterations }\end{array}$ \\
\hline Pereira et al. (2016) & Brasil & B1 & Estatística de contagem com a plataforma Arduino \\
\hline Santos et al. (2017) & Brasil & B1 & $\begin{array}{l}\text { Investigação do fenômeno ilha de calor urbana através da } \\
\text { utilização da placa Arduino e de um sítio oficial de } \\
\text { meteorologia. }\end{array}$ \\
\hline Szmoski et al. (2018) & Brasil & B1 & $\begin{array}{l}\text { Desenvolvimento de um aparato experimental de baixo custo } \\
\text { para o estudo de objetos em queda: análise do movimento de } \\
\text { magnetos em tubos verticalmente orientados. }\end{array}$ \\
\hline Vega et al. (2014) & Colômbia & B1 & $\begin{array}{l}\text { Internet de los objetos empleando arduino para la gestión } \\
\text { eléctrica domiciliaria. }\end{array}$ \\
\hline Babu et al. (2018) & Índia & B3 & $\begin{array}{l}\text { Milk quality testing using intelligent inference performance } \\
\text { evaluation system integrated with loT. }\end{array}$ \\
\hline $\begin{array}{l}\text { Crisnapati et al. } \\
(2017)\end{array}$ & Indonésia & - & $\begin{array}{l}\text { Hommons: Hydroponic Management and Monitoring System } \\
\text { for an IOT Based NFT Farm Using Web Technology }\end{array}$ \\
\hline Fatani et al. (2018) & $\begin{array}{l}\text { Arábia } \\
\text { Saudita e } \\
\text { Argélia }\end{array}$ & - & Dual pH Level Monitoring and Control using IoT Application. \\
\hline Kumar et al. (2017) & Índia & - & $\begin{array}{l}\text { Implementation Of lot In Smart Irrigation System Using } \\
\text { Arduino Processor. }\end{array}$ \\
\hline Maina (2017) & Quênia & - & $\begin{array}{l}\text { loT at the Grassroots - Exploring the Use of Sensors for } \\
\text { Livestock Monitoring. }\end{array}$ \\
\hline $\begin{array}{l}\text { Rajkumar et al. } \\
\text { (2017) }\end{array}$ & Índia & - & Intelligent Irrigation System - An lot Based Approach \\
\hline $\begin{array}{l}\text { Sneha e Rakesh } \\
\text { (2017) }\end{array}$ & Índia & - & $\begin{array}{l}\text { Automatic Monitoring and Control of Shrimp Aquaculture and } \\
\text { Paddy Field Based on Embedded System and IoT. }\end{array}$ \\
\hline
\end{tabular}


Para embasar a pesquisa algumas perguntas foram elaboradas, sendo a primeira pergunta citada na metodologia: "Quais razões podem ter influenciado o maior ou menor número de publicações?". Vega et al. (2014) apontam que a Internet das Coisas está emergindo como principal tendência para o desenvolvimento da tecnologia das comunicações, pois permite implementar os objetos com os quais as pessoas interagem, de forma a aumentar a comunicação em tempo real.

Ainda de forma sutil, a Internet das Coisas está ampliando suas aplicações, bem como a utilização da Plataforma Arduino. Para Kamogawa e Miranda (2013), a plataforma Arduino surge como uma alternativa à principal dificuldade das pesquisas em microcontroladores, que é a necessidade de construir os circuitos eletrônicos e desenvolver a programação. Esse hardware possui baixo custo, portabilidade USB, software livre, é de fácil operação, além de possuir componentes que facilitam a programação e a interligação com outros circuitos.

Devido à grande preocupação com a qualidade de alimentos, não só o leite, autores como Rajkumar et al. (2017) e Crisnapati et al. (2017) apontam que a elaboração de equipamentos de baixo custo e fácil manutenção podem facilitar o controle de processo e a detecção de falhas. Então, "Quais são as medidas mitigatórias apontadas pelos autores estudados com relação à qualidade do leite? ", Ghasemi-Varnamkhasti et al. (2017) salienta que uma das maneiras de detectar a adulteração do leite é a fabricação e o desenvolvimento de ferramentas e técnicas de de medição confiáveis, como Nariz e Língua Eletrônico, medição por admissão elétrica, biossensores, medição de condutância e frequência, espectroscopia, processamento de imagem e avaliação ultra-som.

Quanto às perguntas "Quais foram as metodologias aplicadas à indústria alimentícia que utilizaram a plataforma Arduino?" e "Quais as limitações encontradas pelos autores relacionadas ao uso da plataforma Arduino?", muitos autores mostraram que essa plataforma é de uso genérico, apresentando eficiência em muitos trabalhos e projetos. Os artigos encontrados apresentaram aplicações diversas, como monitoramento de hidroponia com uso da loT (CRISNAPATI et al., 2017), sistema de irrigação inteligente (RAJKUMAR et al., 2017), sensores de temperatura para efeitos didáticos da condutividade térmica (AMORIN et al., 2015), monitoramento e controle de $\mathrm{pH}$ utilizando aplicação loT (FATANI et al., 2018), sensores para detecção de adulteração de leite (GHASEMI-VARNAMKHASTI et al., 2017), estatística de contagem com a plataforma Arduino (PEREIRA et al., 2016), dentre outros. Porém, nenhum dos autores apontou limitações quanto ao uso da Plataforma Arduino, apenas limitações dentro do seu objeto de estudo.

\section{CONCLUSÃO}

A busca por meio de revisão sistemática demonstrou uma ótima ferramenta de análise. Com ela é possivel selecionar os melhores artigos na área, ter conhecimento das metodologias aplicadas e como os autores tratam a temática.

As plataformas escolhidas apresentaram grande número de publicações relacionadas com as palavras-chave listadas. O Google acadêmico foi a plataforma que mais buscou trabalhos, porém muitos não condiziam com o tema e/ou não apresentavam confiabilidade do trabalho. As plataformas Capes e Scopus ficaram empatadas em número de artigos escolhidos e relacionados com o tema. As demais plataformas buscaram muitos artigos repetidos, encontrados nas outras plataformas.

Nota-se a predominância de artigos em inglês, o que demonstra que o Brasil ainda precisa evoluir quanto à utilização da Internet das Coisas. Observou-se também, a crescente publicação de autores cujos sobrenomes eram asiáticos, indicativo de que tecnologia eficiente e de baixo custo tem prioridade nestes países.

Assim, recomenda-se o emprego do conceito de Internet das Coisas voltado à automação de baixo custo de processos industriais, considerando os padrões e metodologias já aplicadas. 


\section{REFERÊNCIAS}

[1] AMORIN, H. S. do; DIAS, M. A.; SOARES, $\checkmark$. Sensores digitais de temperatura com tecnologia one-wire: Um exemplo de aplicação didática na área de condução térmica. Revista Brasileira de Ensino de Física, v. 37, n. 4, 2015. Disponível em: <http://dx.doi.org/10.1590/S1806-11173742009> Acesso em: 15 ago. 2018.

[2] ARAÚJO, J. C. D. A. Sistema de Aquisição e Monitorização de Dados para Indústria Alimentar e Laboratorial. 2012. 104f. Dissertação (Mestrado em Engenharia Eletrotécnica - Energia e Automação Industrial) - Escola Superior de Tecnologia de Viseu, Instituto Superior Politécnico de Viseu, Viseu, Portugal, 2012.

[3] BABU, G. S.; KRISHNA, V. R.; DHARMA TEJA, V.; BALRAJ YADAV, S. Milk Quality Testing Using Intelligent Inference Perfomance Evaluation System Integrated with IoT. International Journal of Engineering \& Technology, n.7, p.74-77, 2018.

[4] BRASIL. Ministério da Agricultura, Pecuária e Abastecimento. Departamento de Inspeção de Produtos de Origem Animal. Instrução Normativa $n \div 51$, de 18 de setembro de 2002. Aprova e oficializa o regulamento técnico de identidade e qualidade de leite cru refrigerado. Diário Oficial da União, Brasília, DF, 20 ago. 2002. Seção 1, p. 13.

[5] BRASIL. Ministério da Agricultura, Pecuária e Abastecimento. Departamento de Inspeção de Produtos de Origem Animal. Instrução Normativa no62, de 29 de dezembro de 2011. Altera o regulamento técnico de identidade e qualidade de leite cru refrigerado. Diário Oficial da União, Brasília, DF, 29 dez. 2011. Seção 1, p. 13.

[6] CORTINHAS, Cristina Simões. Qualidade do leite cru e práticas de manejo em fazendas leiteiras. 2013. 125 f. Tese (Doutorado em Ciências) - Faculdade de Medicina Veterinária e Zootecnia, Universidade de São Paulo, Pirassununga, 2013. Disponível em: <http://www.teses.usp.br/teses/disponiveis/10/1013 5/tde-21082014-111709/en.php>. Acesso em: 23 ago. 2018 .

[7] COSTA, P. M. B. da P. Sistema de Internet das Coisas para o Apoio aos Cuidados de Saúde da População Idosa. 2018. 106 f. Dissertação (Mestrado em Engenharia de Informática) Departamento de Informática, Escola de Ciências e Tecnologia, Universidade de Évora, Portugal, 2018.

[8] CRISNAPATI, P. N.; WARDANA, N.K.; ARYANTO, K. A. A.; HERMAWAN, A. Hommons: Hydroponic Management and Monitoring System for an IOT Based NFT Farm Using Web Technology. IEEE Xplore, 2017.

[9] FATANI, A.; KANAWAI, A.; ALSHAMI, H.; BENSENOUCI, A.; BRAHIMI, T.; BENSENOUCI, M.A. Dual pH Level Monitoring and Control using IoT Application. IEEE Xplore, 2018.
[10] GIMENES, A. H.; PEREIRA, P. R. A. Utilização da Plataforma Arduino como Ferramenta de Controle para um Sistema de Nível de Líquidos. XI Congresso Brasileiro de Engenharia Química em Iniciação Científica. Unicamp, Campinas, São Paulo, 2015. Disponível em: <http://dx.doi.org/10.5151/chemeng-cobeqic2015472-34099-262068>. Acesso em: 14 ago. 2018.

[11] GHASEMI-VARNAMKHASTI, M.; GHATREH-SAMANI, N.; NADERI-BOLDAJI, M.; FORINA, M.; BONYADIAN, M. Development of two dielectric sensors coupled with computational techniques for detecting milk adulteration. Computers and Electronics in Agriculture, n.140, p. 266-278, 2017. Disponível em: <http://dx.doi.org/10.1016/j.compag.2017.06.005>. Acesso em: 14 ago. 2018.

[12] KAMOGAWA, M. Y.; MIRANDA, J. C. Uso de Hardware de Código Fonte Aberto "Arduino" para Acionamento de Dispositivo Solenoide em Sistemas de Análises em Fluxo. Revista Química Nova, v.36, n.8, p.1232-1235, 2013.

[13] KITCHENHAM, B.; BRERETON, O. P.; BUDGEN, D.; TURNER, M.; BAILEY, J.; LINKMAN, S. Systematic literature reviews in software engineering - A systematic literature review. Information and Software Technology, n.51, p.7-15, $2009 . \quad$ Disponível em: <http://dx.doi.org/10.1016/j.infsof.2008.09.009> Acesso em: 18 ago. 2018.

[14] MARTINS, M. E. P.; NICOLAU, E. S.; MESQUITA, A. J. de; NEVES, R. B. S.; ARRUDA, M. T. Qualidade de leite cru produzido e armazenado em tanques de expansão no estado de Goiás. Revista Ciência Animal Brasileira, v. 9, n. 4, p. 1152-1158, 2008. Disponível em: < http://revistas.bvs-vet.org.br/cab/article/view/5136 >. Acesso em: 23 ago. 2018.

[15] MIRANDA,, Y. C.; MARTINS NETO, F. F.; BORTOLI, M. M. Sensoriamento Remoto Aplicado à Detecção de Ilhas de Calor Urbanas: Uma Revisão Sistemática. V Simpósio Nacional de Gerenciamento de Cidades. Várzea Grande, 2017.

[16] NASCIMENTO, W. W. G.; SOUZA, M. P. F. de; VALENTE, A. C. M. M.; ANJOS, V. de C. dos.; FURTADO, M. A. M.; BELL, M. J. V. Results from portable and of low cost equipment developed for detection of milk adulterations. Food Science And Technology, v. 37, p. 38-41, dez. 2017. Disponível em: <http://dx.doi.org/10.1590/1678-457x.06617>. Acesso em: 15 ago. 2018.

[17] PEREIRA, A. M.; SANTOS, A. C. F.; AMORIN, H. S. Estatística de contagem com a plataforma Arduino. Revista Brasileira de Ensino de Física, v. 38, n. 4, p. 4501-4508, mai. 2016. Disponível em: <http://dx.doi.org/10.1590/18069126-RBEF-2016-0079>. Acesso: 17 ago. 2018.

[18] PINTO, C. L. O.; MARTINS, M. L.; VANETTI, M. C. D. Qualidade microbiológica de 
leite cru refrigerado e isolamento de bactérias psicrotróficas proteolíticas. Revista Ciência e Tecnologia de Alimentos, v. 26, n. 3, p. 645-651, 2006. Disponível em: <http://www.scielo.br/pdf/cta/v26n3/31769.pdf>. Acesso em: 23 ago. 2018.

[19] RAJKUMAR, M. N. ABINAYA, S.; KUMAR, V. V. Intelligent Irrigation System - An lot Based Approach. IEEE Xplore, 2017.

[20] RECHE, Natália Luiza Machado. Influência do armazenamento do leite em resfriador por expansão direta sobre a contagem de microorganismos e estabilidade da caseína. 2013. 91 f. Dissertação (Mestrado em Ciência Animal) -
Centro de Ciências Agroveterinárias, Universidade do Estado de Santa Catarina, Lages, 2013.

[21] SILVEIRA, L.; COSTA, C.; SOUSA, F. A. de. Avaliação do impacto de um projeto de extensão em um laticínio de Iraí de Minas - MG, sobre as melhorias na qualidade de leite. Revista Gestão Tecnologia e Ciências, v. 6, n. 14, p. 33-43, $2017 . \quad$ Disponível em: <http://www.fucamp.edu.br/editora/index.php/gete c/article/view/1083/778>. Acesso em: 21 ago. 2018.

[22] VEGA, A. M.; SANTAMARÍA, F.; RIVAS, E. Internet de los objetos empleando arduino para la gestión eléctrica domiciliaria. Revista EAN, n.77, p.22-41, 2014. 


\section{Capítulo 5}

\section{APLICACÃO DO MAPEAMENTO DO FLUXO DE VALOR EM UMA EMPRESA FABRICANTE DE REDUTORES DE VELOCIDADE E MOTORREDUTORES DE VELOCIDADE}

\section{Rodrigo Fredi}

\section{Rodrigo Montanari da Cunha}

\section{Diego Quinelatto Rossi}

Resumo: A abertura de mercado ocasionou o aumento da competitividade nas empresas para atender as exigências dos clientes em qualidade e variedade de produtos. Fabricar produtos com maior eficiência e qualidade requer aplicação de melhoria de proceessos, com foco nas ferramentas lean manufacturing. O mapa de fluxo de valor (MFV) é uma técnica importante que possibilita a implementação de um sistema com pensamento enxuto nas empresas, através da identificação de desperdícios para tomada de decisão com propósito de reduzi-los. O trabalho, considerado como estudo de caso, tem por objetivo aplicar a ferramenta mfv em um fabricante de redutores e motorredutores por meio da definição do estágio atual e sugestão do estágio futuro com proposta de melhorias no lead time, nivelamento de processos de produção e alteração do sistema empurrado para o sistema puxado. Por fim os resultados foram apresentados aos dirigentes da empresa para avaliação, sem ocorrer a implementação de fato.

Palavras-chaves: mapeamento de fluxo de valor; lead time; nivelamento de processo de produção. 


\section{INTRODUÇÃO}

A abertura do mercado mundial foi de extrema importância para o crescimento e desenvolvimento de muitas empresas, que a partir desse momento, começaram a competir pelo mundo de igual para igual (SILVA, 2004).

Em decorrência dessa abertura e aumento da competitividade, os clientes estão cada vez mais exigentes no que diz respeito a qualidade e variedade de produtos. Para que as empresas se adaptem e sobrevivam neste cenário, elas devem avaliar produtividade, qualidade e diversidade. Porém, para que essas avaliações sejam possíveis, torna-se necessária a realização de melhorias nos processos de fabricação, visando produtos com maior eficiência e qualidade (SILVA; OLIVEIRA, 2016).

Existe nas organizações um grande foco nas ferramentas lean e como elas atuam, porém, esquece-se de alterar a forma como o trabalho é realizado e como o mesmo mantém o fluxo, e com isso, não se observa os resultados que podem ser alcançados (GOULART; BOND, 2016).

O Mapa de Fluxo de Valor (MFV) é uma técnica de diagnóstico e planejamento fundamental para o entendimento de todas as etapas dos processos produtivos, compreensão da agregação de valor e identificação de desperdício, sendo capaz de mostrar as oportunidades de melhorias ligadas ao conceito lean (VASCONCELOS; NOBREGA, 2016).

Segundo Goulart e Bond (2016) o MFV é uma ferramenta de extrema importância para o sistema enxuto, sendo capaz de visualizar e identificar o fluxo de materiais e informações, possibilitando que os desperdícios sejam identificados e auxiliando na tomada de decisões sobre o fluxo no qual o mesmo foi aplicado.

Luz e Buiar (2004) mostram as principais vantagens do MFV:

a) Auxiliar na visualização do processo como um todo;

b) auxiliar na identificação da fonte do desperdício;

c) ser de fácil entendimento para se tratar os processos;

d) auxiliar na tomada de decisões

sobre o fluxo; e) estreitar a relação entre conceitos e técnicas enxutas;

f) mostrar a relação entre os fluxos de material e informação, e;

g) por ser uma ferramenta qualitativa, direciona o caminho para se operar em fluxo.

$\mathrm{O}$ artigo tem por objetivo analisar a aplicação da ferramenta MFV na detecção de desperdícios em uma empresa fabricante de redutores e motorredutores. Foi considerado inicialmente um modelo específico de redutor, denominado "Modelo 1", e posteriormente selecionado o setor usinagem do eixo sem fim por ser o componente com maior demanda na linha de produção e com maior número de processos de fabricação.

\section{REFERENCIAL TEÓRICO}

\subsection{LEAN MANUFACTURING}

Womack, Jones e Roos (2004) comentam que Lean Manufacturing surgiu no Japão na década de 50, pós Segunda Guerra Mundial, momento de escassez de recursos, tendo como pioneira a empresa Toyota.

Referente aos mesmos autores acima é possível identificar a diferença do modelo Toyota, que compreende o conceito de produção enxuta baseado na cultura homogênea da população japonesa com alta taxa de poupança e alfabetização, subordinação dos desejos pessoais aos interesses em grupo e comportamento predisposto a trabalhar grande quantidade de horas, como o modelo seguido pela Ford e General Motors (GM).

Este último compreende a produção em massa com objetivos baseados em qualidade tolerável de defeitos, nível máximo de estoques e limitada variedade de produtos versus o almejo da perfeição, nenhum estoque, custos declinantes e ausência de itens defeituosos da produção enxuta. Os autores enfatizam a vitória do modelo Toyota.

No site oficial do Lean Institute Brasil (2017) é possível encontrar a definição de lean como sendo "uma filosofia de gestão inspirada em práticas e resultados do Sistema Toyota". Womack e Jones (1998) comentam que o executivo da Toyota Taiichi Ohno (1912-1990) "foi o maior crítico do desperdício que a história humana já conheceu". Os autores definem desperdício, derivado da palavra japonesa muda, como "qualquer atividade 
humana que absorve recursos, mas não gera valor".

Felizmente, segundo os autores, existe um poderoso antídoto para o desperdício chamado pensamento enxuto, que é a forma de fazer cada vez mais com cada vez menos: menos esforço humano, menos equipamento, menos tempo e menos espaço, com o objetivo de transformar muda em valor.

\subsection{MAPEAMENTO DE FLUXO DE VALOR}

Rother e Shook (1999) definem um fluxo de valor como "toda ação que agrega ou não valor,

necessária para trazer um produto por todos os fluxos essenciais a cada um". Este fluxo inicia- se com a chegada da matéria prima e é finalizado no consumidor, compondo-se de dois mapas: o estado atual, que exibe como o fluxo está hoje; e o estado futuro, que exibe possíveis melhorias a partir da observação do primeiro mapa.

As principais vantagens da ferramenta mapeamento do fluxo de valor são: análise global dos processos a partir dos individuais; identificação dos desperdícios e suas fontes; fornecimento de uma linguagem comum para os processos de manufatura; facilitação da tomada de decisões sobre o fluxo; aproximação de conceitos e técnicas enxutas; formação de uma base para o plano de implantação; mostra da relação entre o fluxo de informação e material; simbologia própria; tem como objetivo o mapeamento do fluxo de materiais e informação da cadeia de valor, descrevendo o estado atual do processo mapeado e propondo uma condição futura (ROTHER e SHOOK, 1999), representado na Figura 1, através de 4 etapas:

Família de produtos: uma família é um grupo de produtos que passa por etapas semelhantes de processamento e utiliza equipamentos comuns nos seus processos;

Desenho do estado atual: é realizado a partir da coleta de dados com as informações necessárias para o desenvolvimento do estado futuro;

Desenho do estado futuro: as setas interligando o estado atual e o estado futuro tem 0 sentido de indicar que o desenvolvimento do estado atual e futuro são superpostos;

Plano de trabalho e implementação: o passo final é elaborar um plano de ação com responsáveis e prazos para que todas as oportunidades de melhoria sejam atingidas. Então, assim que o seu estado futuro se tornar realidade, um novo mapa do estado futuro deverá ser feito, chegando a melhoria contínua no fluxo de valor.

Figura 1: Etapas para elaboração do mapeamento de fluxo de valor.

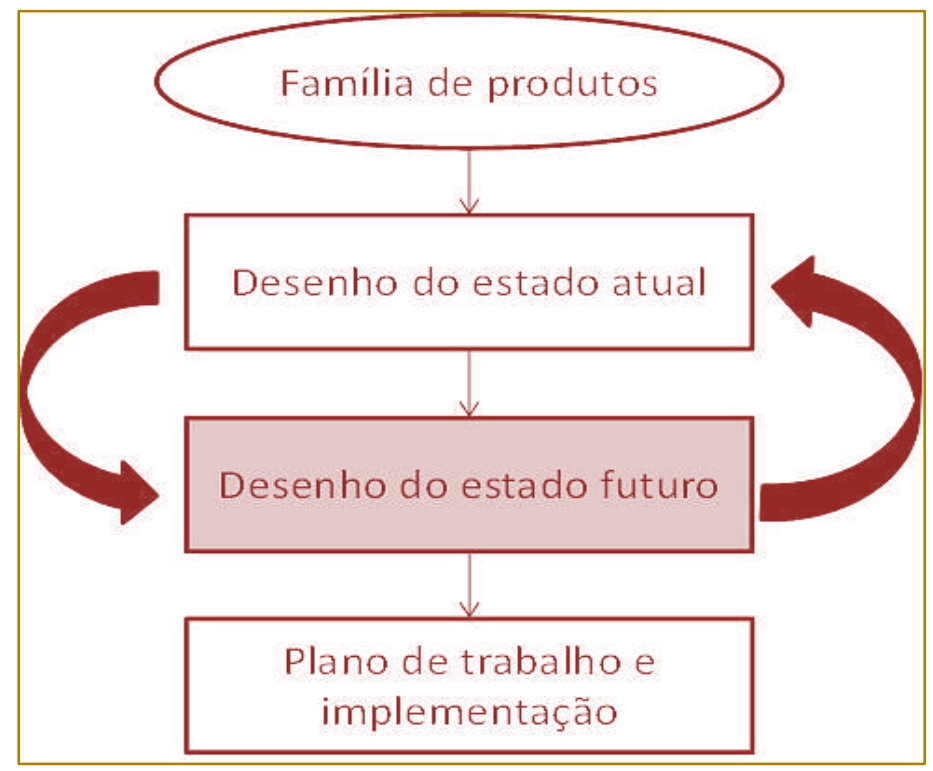

Fonte: Rother e Shook (1999). 
Desenhar o fluxo de valor para uma família de produtos geralmente necessita que as barreiras departamentais das organizações sejam quebradas. É raro encontrar em uma empresa uma pessoa que conheça todo o fluxo de material e informação de uma família de produtos, ou seja, os processos e como eles são programados. Sem isto, partes do fluxo podem ficar desarticuladas, trabalhando com resultados ótimos, porém, desconsiderando o resultado global (LUZ; BUIAR, 2004).

\section{METODOLOGIA}

O presente artigo tem por objetivo analisar a aplicação da ferramenta MFV na detecção de desperdícios em uma empresa fabricante de redutores e motorredutores fundada há mais de 30 anos, com aproximadamente 200 funcionários e instalada em $11 \mathrm{mil} \mathrm{m}^{2}$ de área construída. O procedimento metodológico trata-se de um estudo de caso que utiliza as etapas apresentadas para elaboração do MFV, visualizado na Figura 1, possibilitando apresentar os resultados obtidos pelo estudo bem como suas considerações finais. As etapas utilizadas foram:

a) Escolha da família de produtos: o produto escolhido para o estudo trata-se de um redutor de dupla redução denominado "Modelo 1". Sua escolha justifica-se pela significativa demanda de mercado e a frequência com que é produzido para atendêla, sendo considerado pela empresa um produto relevante;

b) Desenho do estado atual: sua construção está embasada em informações coletadas através de relatório fornecidos pelo PCP com os tempos de produção de cada processo produtivo do componente eixo sem fim, com consentimento dos dirigentes da empresa, o que possibilitou um contexto favorável a execução do estudo, visualizado na Figura 2;

c) Desenho do estado futuro: construído com o objetivo de reduzir desperdícios de tempo no fluxo dos processos. Suas considerações serão apresentadas na seção 4 - Aplicação da ferramenta MFV;

d) Plano de trabalho: consiste na apresentação do mapa futuro aos dirigentes da empresa como sugestão de melhoria, sem, contudo, implementá-lo de fato.

\section{APLICAÇÃO DA FERRAMENTA MFV \\ 4.1 APRESENTAÇÃO DO MAPA ATUAL}

Para aplicação da ferramenta MFV no sistema produtivo como um todo, foi feito um desmembramento do setor de usinagem para melhor visualização do mesmo, que é considerado um gargalo no processo de fabricação do redutor "Modelo 1". A usinagem utiliza uma grande variedade de itens semiacabados, adquiridos de fornecedores, para serem transformados em itens acabados, a fim de utilizá-los na montagem final do equipamento.

Dos itens que compõem o equipamento "Modelo 1" foi escolhida a usinagem do eixo sem fim. A usinagem é o setor produtivo com maior quantidade de processos, sendo: corte, faceamento, desbaste, rosca, desbaste, acabamento e chaveta externa, visualizado na Figura 2. O eixo sem fim escolhido é apenas um componente do redutor "Modelo 1", porém o mesmo eixo pode ser utilizado em mais de um modelo de redutor, aumentando, portanto, a demanda para esse componente.

Para a construção do MFV atual foram coletadas informações através do setor de Planejamento e Controle da Produção (PCP), dos tempos e sequências de todos os processos de fabricação do equipamento. Após foi feito uma análise da situação atual, obtendo informações no nível do fluxo "porta a porta", identificando os fluxos reais de materiais e de informações. Dessa forma foi possível visualizar, de acordo com a Figura 2, o tempo de ciclo, tempo de setup, o lead time e o tempo total do processo.

Tempo de ciclo (T/C) é o tempo de execução do processo; Tempo de setup (TR) é o tempo de preparação da máquina para execução do processo; Lead time é a quantidade de dias que leva para finalizar o lote de produto, conforme cronograma de fabricação fornecido pela empresa, utilizando estoque entre cada processo, e; Tempo total do processo é soma dos tempos de ciclo de cada processo.

Com a construção do mapa do estado atual (Figura 2), é possível visualizar o processo iniciando pela ação do cliente efetuando o pedido, com a informação de saída do produto final da expedição chegando ao setor de planejamento e controle da produção, as outras informações necessárias para fabricação de um novo produto são disparadas aos fornecedores com solicitação 
de novos insumos, à usinagem e montagem mostrando a necessidade de um novo produto. À partir da montagem, o novo produto segue para teste e logo depois para a expedição novamente, até que um novo processo se inicie.

Figura 2: Desenho do estado atual.

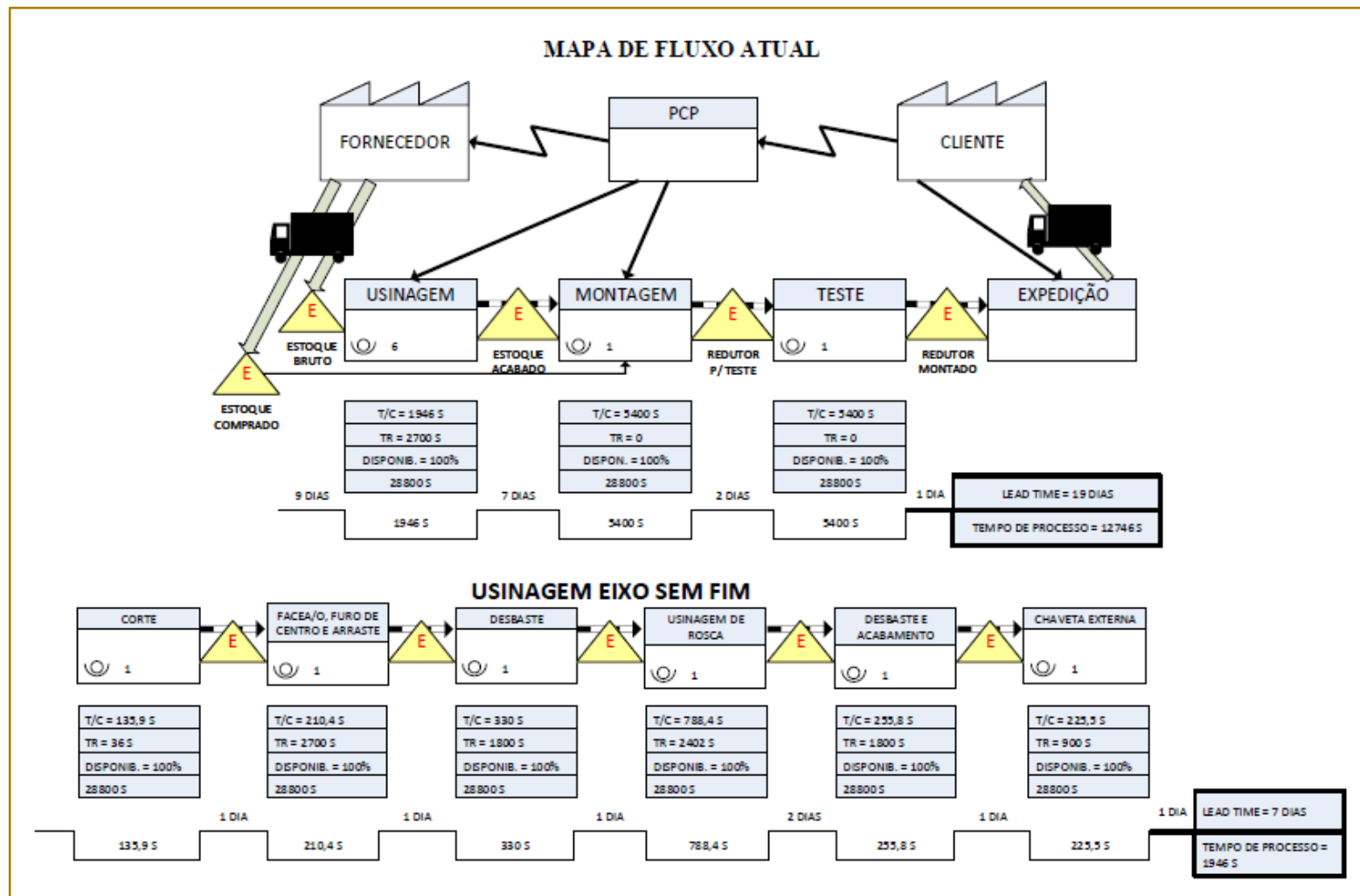

Fonte: Desenvolvido pelos autores (2018).

\subsection{CONSIDERAÇÕES E SUGESTÕES DE MELHORIA}

Após a construção do MFV atual foram identificadas melhorias, em caráter de sugestão,

levando a construção do MFV futuro. Neste processo foi avaliada a possibilidade de diminuir em 6 dias o tempo total do lead time de produção do redutor "Modelo 1" (de 19 para 13 dias). Adotando a forma de produção puxada, o item somente será produzido se o processo posterior (montagem) o solicitar. Isto ocorre através do consumo de estoque controlado, o chamado supermercado, que fica localizado entre os processos de produção. Caso o processo seguinte não tenha consumido o item não será produzido, mesmo que isso vá contra a previsão de vendas.

Devido ao pedido dos redutores não seguirem uma quantidade definida, o que ocorre por demanda de mercado, não é possível estabelecer um fluxo contínuo de produção para evitar acúmulo excessivo de estoque. Os processos produtivos do setor usinagem foram então nivelados para melhor aproveitamento do tempo ocioso identificado no processo corte, que possui tempo de ciclo (T/C) 135,9 segundos. Primeiramente o nivelamento consiste em unir

os processos "faceamento" e "desbaste" e posteriormente unir os processos "desbaste acabamento" e "chaveta". Com isso o operador do processo "corte" deverá utilizar $30 \%$ da disponibilidade no corte, $10 \%$ no novo processo faceamento e desbaste e os outros $60 \%$ no processo rosca. O processo rosca possui o maior $\mathrm{T} / \mathrm{C}$ dos processos, com 788,4 segundos.

O nivelamento sugerido na Tabela 2 proporcionará, além de preencher o tempo ocioso do setor corte, aumentar a quantidade de peças produzidas, aumentar a produtividade do setor usinagem e reduzir dois operadores nos processos produtivos. 
Tabela 1: Processos do setor usinagem eixo sem fim redutor Modelo 1.

PROCESSOS DO SETOR DE USINAGEM

\begin{tabular}{|c|c|c|c|c|c|c|c|}
\hline Processos (atuais) & Corte & $\begin{array}{c}\text { Faceamento, } \\
\text { Furo de } \\
\text { Centro e } \\
\text { Arraste }\end{array}$ & Desbaste & $\begin{array}{c}\text { Usinagem de } \\
\text { Rosca }\end{array}$ & $\begin{array}{c}\text { Desbaste } \\
\text { Acabamento }\end{array}$ & Chaveta & Total \\
\hline $\mathrm{T} / \mathrm{C}$ (segundos) & 135,90 & 210,40 & 330,00 & 788,40 & 255,80 & 225,50 & \\
\hline Operador & 1,0 & 1,0 & 1,0 & 1,0 & 1,0 & 1,0 & 6,0 \\
\hline Disponibilidade (segundos) & 28.800 & 28.800 & 28.800 & 28.800 & 28.800 & 28.800 & 172.800 \\
\hline Prođução (peças/dia) & 211,92 & 136,88 & 87,27 & $\mathbf{3 6 , 5 3}$ & 112,59 & 127,72 & \\
\hline
\end{tabular}

Fonte: Desenvolvido pelos autores (2018).

Tabela 2: Nivelamento dos processos do setor usinagem eixo sem fim redutor Modelo 1.

NIVELAMENTO DOS PROCESSOS DO SETOR DE USINAGEM

\begin{tabular}{|l|r|r|r|r|r|}
\hline Processos (nivelados) & Corte & $\begin{array}{c}\text { Faceamento, } \\
\text { Furo de } \\
\text { Centro e } \\
\text { Arraste }+ \\
\text { Desbaste }\end{array}$ & $\begin{array}{c}\text { Desbaste } \\
\text { Acabamento }\end{array}$ & $\begin{array}{c}\text { Desbaste } \\
\text { Acabamento }+ \\
\text { Chaveta }\end{array}$ & Total \\
\hline T/C (segundos) & 135,90 & 540,40 & 788,40 & 481,30 & 4,0 \\
\hline Operador & 0,3 & 1,1 & 1,6 & 1,0 & 115.200 \\
\hline TR (segundos) & 36 & 4.500 & 2.402 & 2.700 & \\
\hline Disponibilidade (segundos) & 8,640 & 31.680 & 46.080 & 28.800 & 59,84 \\
\hline Produção (peças/dia) & 63,58 & 58,62 & $\mathbf{5 8 , 4 5}$ & 59 & \\
\hline
\end{tabular}

Fonte: Desenvolvido pelos autores (2018).

Será necessário introduzir sistemas puxados com supermercados no setor da expedição, montagem e usinagem. Com a aplicação na usinagem o lead time será reduzido em 4 dias e na montagem a redução também será de 2 dias. O sistema FIFO (first in, first out) será aplicado da montagem para o setor de teste, ou seja, os testes serão realizados na mesma sequência que os redutores forem enviados pela montagem. O setor de teste por sua vez alimentará o supermercado para retirada da expedição.

A programação da produção será transmitida para a expedição através dos pedidos recebidos dos clientes. A expedição puxará todo o processo produtivo através do consumo no supermercado alimentado pelo setor de teste, por meio dos cartões Kanban.

A introdução dos supermercados nas áreas de usinagem, montagem e expedição, permite que o processo de produção do eixo sem fim torne-se puxado, devido a necessidade da produção do mesmo para a fabricação do redutor "Modelo 1" e dos demais redutores produzidos pela empresa.

A principal melhoria necessária é a diminuição do tempo de produção do eixo sem fim com implantação de um supermercado no setor de usinagem, melhoria esta acompanhada pela implantação dos cartões Kanban nos processos de montagem e teste; e a substituição do estoque identificado pelo método FIFO.

A avaliação considera a redução de 2 dias no tempo de emissão de requisições para os setores responsáveis através da utilização de um supermercado para retirada de itens pelo setor de usinagem, mais 2 dias de redução no tempo com a utilização de outro supermercado para retirada dos itens pelo setor de montagem. A utilização de supermercados requer que a retirada seja feita com cartões.

Após o setor de montagem, como sugestão de melhoria no mapa futuro, o redutor "Modelo 1" deverá ser enviado para o setor 
de teste utilizando o método FIFO no lugar do estoque identificado no mapa atual.
As sugestões de melhorias podem ser identificadas na Figura 3 através dos balões em amarelo.

Figura 3: Desenho do estado atual com sugestões de melhorias.

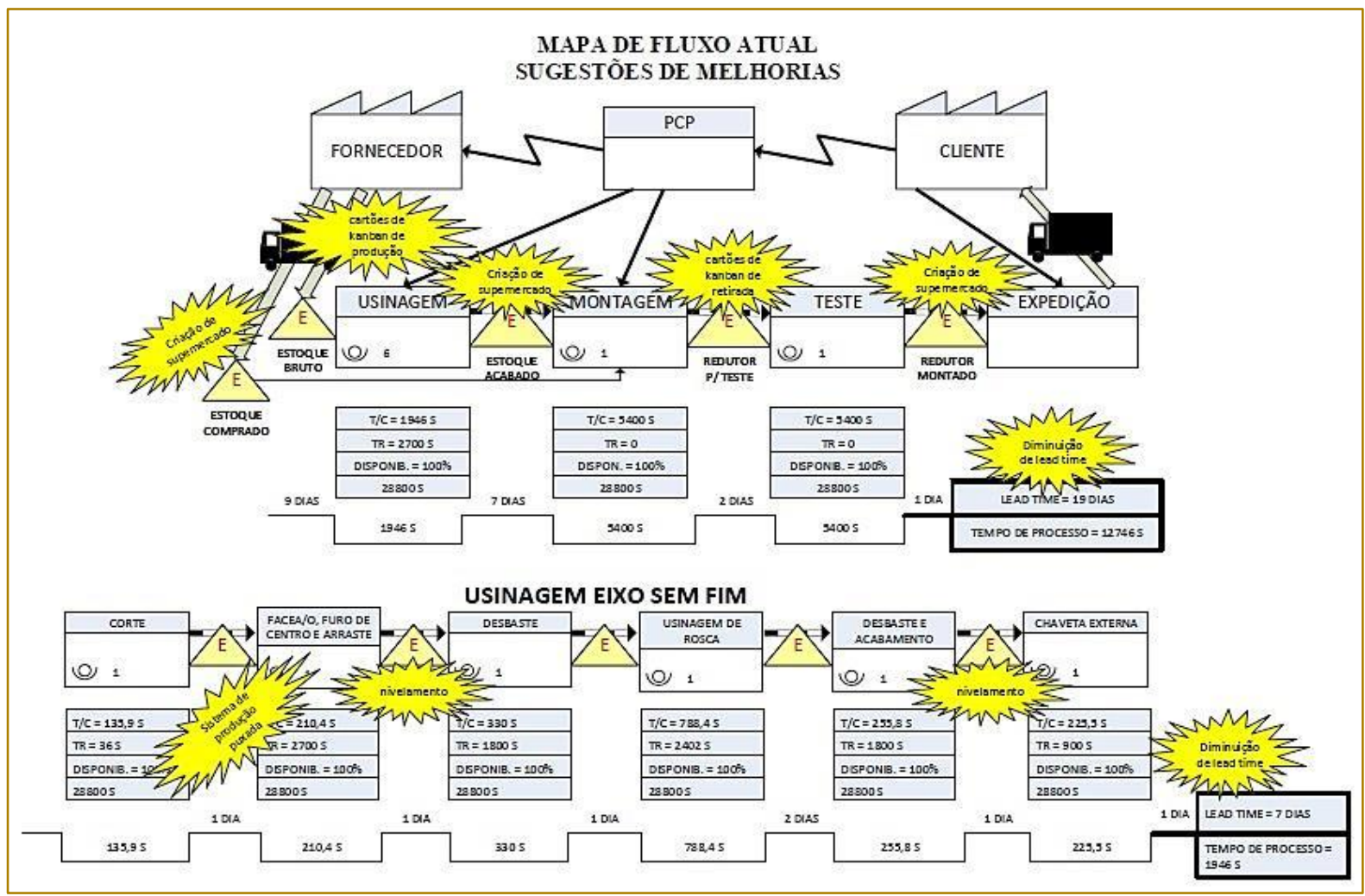

Fonte: Desenvolvido pelos autores (2018).

No mapa futuro o fluxo de material no setor produtivo usinagem passou a ser puxado com utilização de supermercado e nivelamento de produção, conforme apresentado na Tabela 2. No mapa atual o processo produtivo usinagem era empurrado, dividido em 6 processos diferentes com utilização de estoque e desnivelados com lead time de 7 dias. Essa alteração permitiu a redução do lead time de 7 para 3 dias sem alterar 0 tempo de processo, permanecendo em 1.946 segundos. A aplicação do nivelamento permitiu reduzir de 6 para 4 operadores, e aumentar a quantidade de peças produzidas de 36 para 58 por dia. 
Figura 4: Desenho do estado futuro.

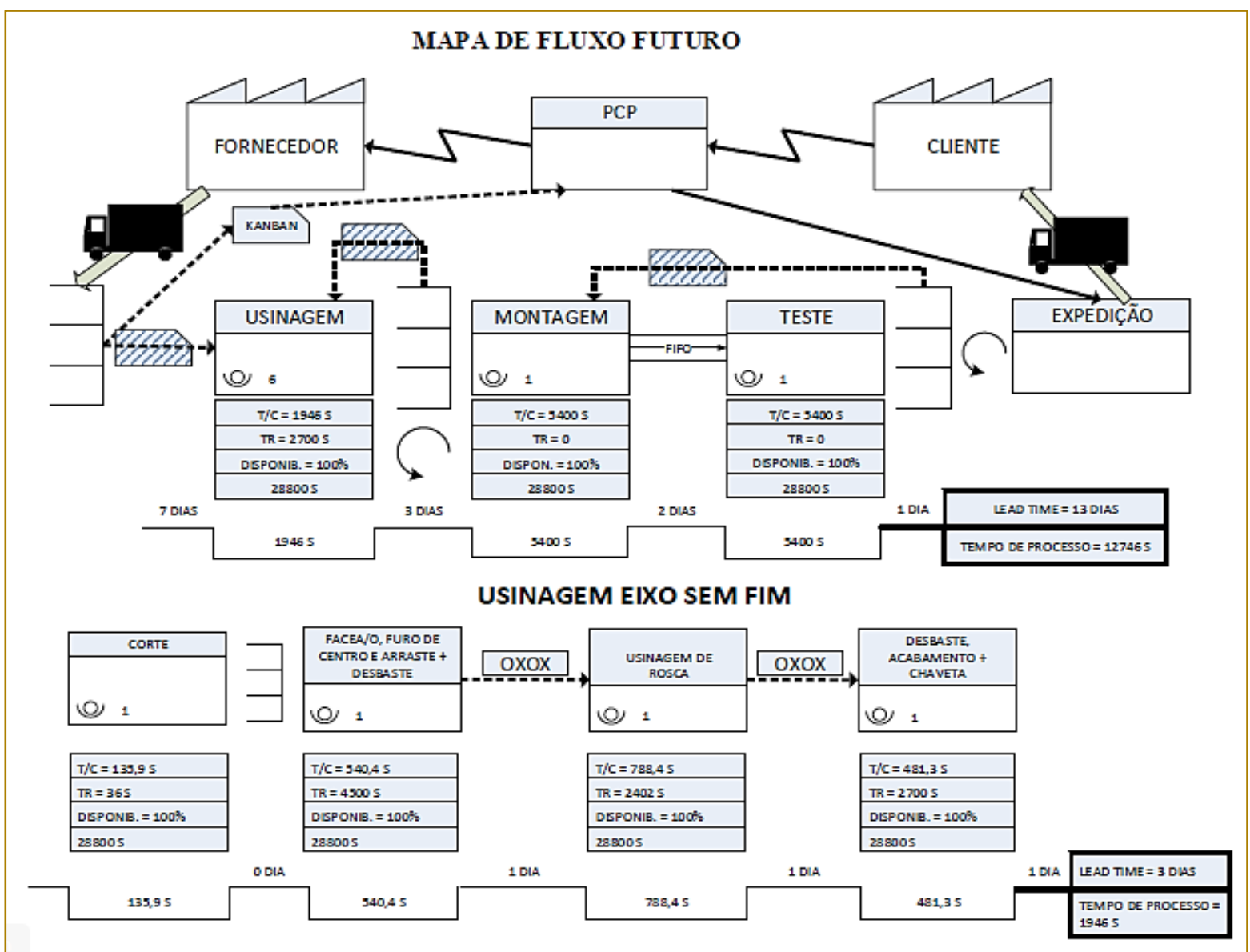

Fonte: Desenvolvido pelos autores (2018).

\section{CONCLUSÃO}

$\mathrm{Na}$ etapa de mapeamento do processo de fabricação do redutor "Modelo 1" foi identificada a dificuldade de atender rapidamente a solicitação de um novo produto, caso seja solicitado, devido ao elevado lead time de 7 dias do processo produtivo na usinagem do eixo sem fim. Por esse motivo se expandiu esta etapa, no MFV foram analisados os processos de produção apenas do eixo sem fim, mas todas as peças usinadas devem receber atenção individualmente em seus processos para se verificar quais melhorias poderão ser feitas em cada uma delas.

O mapeamento do processo permitiu observar o processo de fabricação de redutores e identificar o gargalo encontrado no processo de usinagem. Foram descritas as etapas do processo, desde a solicitação de um novo produto pelos clientes até a fabricação e entrega do redutor "Modelo 1".
$\mathrm{Na}$ usinagem o tempo de resposta é muito elevado, desta forma a sugestão é nivelar os processos de usinagem para redução de ociosidade, e de implantar um supermercado para o setor de montagem, onde conforme os pedidos de compra de redutores são recebidos, pode-se fazer a reposição do supermercado que atende a expedição.

O mapa futuro do processo produtivo de redutores, visualizado na Figura 4, foi confeccionado e sugerido à empresa com o objetivo de reduzir desperdícios. Faz-se necessário que a empresa, após a utilização e implantação dos processos do novo mapa, efetue a coleta de dados continuamente, visando sua constante melhoria. O mapa futuro de hoje deverá ser o mapa atual de amanhã.

Visualizar e compreender as etapas do processo é de extrema importância, pois são diversas atividades e informações que estão em sequência e várias delas podem ser eliminadas. Portanto, através das descrições contidas nessa seção, o objetivo do artigo de 
analisar a aplicação da ferramenta MFV na detecção de desperdícios em uma empresa

\section{REFERÊNCIAS}

[1] GOULART, B. C.; BOND, D. Estudo da Aplicação do Mapeamento do Fluxo de Valor no Processo de Itens de Suprimentos Importados. In: ENCONTRO NACIONAL DE ENGENHARIA DE PRODUÇÃO, 36, 2016, João Pessoa (PB). Anais... Florianópolis: UDESC, 2016.

[2] LEAN INSTITUTE BRASIL. Definição o que é lean, 2017. Disponível em: <https://www.lean.org.br/o-que-e- lean.aspx>. Acesso em: 16 dez. 2017.

[3] LUZ, A. A. C.; BUIAR, D. R. Mapeamento de Fluxo de Valor - Uma Ferramenta do Sistema de Produção Enxuta. In: ENCONTRO NACIONAL DE ENGENHARIA DE PRODUÇÃO, 24, 2004, Florianópolis (SC).

[4] Anais... Curitiba: CEFET/PR, 2004.

[5] ROTHER, M.; SHOOK, J. Aprendendo a enxergar: mapeamento de fluxo de valor para agregar valor e eliminar o desperdício. São Paulo: Lean Institute Brasil, 1999.

[6] SILVA, R. C. O Mercado Globalizado, 28 set. 2004 Disponível em: fabricante de redutores e motorredutores foi atingido.

<http://www.administradores.com.br/artigos/marketi ng/o-mercado-lobalizado/10180/>. Acesso em: 09 dez. 2017

[7] SILVA, M. H. P.; OliVEIRA, M. C. Avaliação de um Sistema de Produção por Meio da Aplicação do Mapeamento do Fluxo de Valor. In: ENCONTRO NACIONAL DE ENGENHARIA DE PRODUÇÃO, 36, 2016, João Pessoa (PB). Anais... Piracicaba: UNIMEP, 2016.

[8] VASCONCELOS, V. M. M.; NOBREGA, M. M. Proposta de Implantação do Lean Manufacturing em uma Empresa do Ramo Plástico Através do Mapeamento do Fluxo de Valor. In: ENCONTRO NACIONAL DE ENGENHARIA DE PRODUÇÃO, 36, 2016, João Pessoa (PB). Anais... João Pessoa: UFPB, 2016.

[9] WOMACK, J.; JONES, D. A mentalidade enxuta nas empresas. Rio de Janeiro: Editora Campus, 1998. WOMACK, J.; JONES, D.; ROOS, D. A máquina que mudou o mundo. Rio de Janeiro: Editora Campus, 2004 


\section{Bapítulo 6}

\section{INDÚSTRIA 4.0: UMA ANÁLISE DA INDÚSTRIA BRASILEIRA PERANTE O MUNDO}

\section{Anderson Senhoreli}

Camila Aparecida Soares de Oliveira

Viviane Yukari Yamada

Resumo: O presente artigo trata da Industria 4.0 e uma análise da indústria brasileira perante o mundo. O objetivo dessa análise foi descrever o cenário atual do Brasil para elencar alternativas de investimento com o intuito de que a Industria 4.0 fosse concretizada no país. O conceito da fábrica avançada incide sobre o conjunto de tecnologias da informação e da engenharia intitulada Pilares da Indústria 4.0. Os pilares são tecnologias inovadoras a serem implementadas nas fábricas para tornarem inteligentes. Essa implementação permite automatizar os processos, reduzindo os custos e aumentando a produtividade. Dessa forma, foram realizadas comparações do Brasil com a Alemanha (país que já possui smart factories). Por fim, foram extraídas considerações finais para o Brasil, de modo a enfatizar que independente do patamar em que o país se encontra, esse cenário deve ser visto como uma oportunidade de crescimento. Para isso, foi salientado que o estudo e o planejamento a longo prazo devem ser realizados, levando em consideração suas particularidades e metas de crescimento. Foi abordado a importância das políticas públicas no desenvolvimento do país, gerando lucro para as empresas, alavancando as vendas e impulsionando o crescimento do Brasil.

Palavras chave: Indústria 4.0. Brasil. Smart factories. 


\section{INTRODUÇÃO}

Ao longo dos anos, a indústria tem passado por transformações que a história intitula de Revolução Industrial. Na segunda década do século XXI, o mundo se prepara para viver a Indústria 4.0, caracterizada pelos avanços tecnológicos (BANZATO, 2015, p. 40). Avanços esses que afetam diretamente os processos, os produtos e o comportamento do consumidor final.

A incorporação da digitalização à atividade industrial resultou no conceito de Indústria 4.0, em referência ao que seria a $4^{a}$ revolução industrial, caracterizada pela integração e controle da produção a partir de sensores e equipamentos conectados em rede e da fusão do mundo real com o virtual, criando os chamados sistemas ciberfísicos e viabilizando - emprego da inteligência artificial (CONFEDERAÇÃO NACIONAL DA INDÚSTRIA, 2016).

Ao que concerne indústria brasileira, o setor carece de muitos avanços tecnológicos e estruturais para acompanhar essa nova revolução. Assim, se faz necessário um levantamento da situação contemporânea, de como o Brasil está perante o mundo e como deveria ser realizado o investimento para que a Indústria 4.0 fosse concretizado no país.

Segundo a Federação das Indústrias do Estado do Rio de Janeiro (2016, p. 4) é preciso:

entender e identificar os impactos que influenciarão os diversos setores industriais, quais serão beneficiados, quais necessitarão de ajustes ou se algum poderá desaparecer; ou como ficará a mão de obra e os custos de produção.

Logo, o tema abordado justifica-se devido à grande importância das transformações necessárias que o setor industrial irá enfrentar ao longo dos anos e pela sua representatividade na economia brasileira. A pesquisa reportará a situação vivenciada na segunda década do século XXI, suas oportunidades e estratégias.

\section{INDUSTRIA 4.0}

O conceito de Indústria 4.0 surgiu pela primeira vez em 2011, na Alemanha, em um evento de tecnologia industrial (Hannover Fair), em que foi apresentado uma nova tendência: as smart factories (TADEU; SANTOS, 2016, p. 2).

As fábricas inteligentes incidem diretamente nos conceitos atuais de automação industrial, entretanto, com todos os processos (máquinas, pessoas e sistemas) conectados por intermédio da internet ao longo de toda a cadeia produtiva.

Segundo Lydon (2015), o objetivo da Indústria 4.0 "é melhorar os processos de fabricação em uma série de dimensões, incluindo eficiência, capacidade de resposta e a capacidade de satisfazer as necessidades individuais dos clientes em tempo hábil".

A aplicação do conceito da Indústria 4.0 fará com que as fábricas sejam inteligentes o suficiente para ter a capacidade e a autonomia para programar manutenções, antecipar falhas e adaptar aos requisitos e mudanças não planejadas no processo produtivo.

A propagação dessa manufatura avançada consiste no conjunto de tecnologias da informação e da engenharia. São os chamados Pilares da Indústria 4.0, que podem ser compreendidos no Quadro 1. 
Quadro 1 - Pilares da Indústria 4.0

PILARES DA INDÚSTRIA 4.0

\begin{tabular}{|c|c|}
\hline \multicolumn{2}{|r|}{ PILARES DA INDÚSTRIA 4.0} \\
\hline Big data & $\begin{array}{l}\text { A coleta e a análise de grandes volumes de dados, por softwares avançados, são } \\
\text { uma das principais fontes da indústria 4.0. Com o Big Data, as decisões podem } \\
\text { ser tomadas com base em dados reais, analisados em tempo real. }\end{array}$ \\
\hline Internet das coisas & $\begin{array}{l}\text { A internet das coisas está chegando a todo o tipo de produto. No contexto da } \\
\text { indústria 4.0, ela é conhecida como internet das coisas industriais (IloT) e chega } \\
\text { também às máquinas. Assim, equipamentos e dispositivos estão conectados à } \\
\text { rede mundial de computadores, abrindo um novo mundo de possibilidades como } \\
\text { operação remota, comunicação entre máquinas e assim por diante. }\end{array}$ \\
\hline Robótica & $\begin{array}{l}\text { Os robôs, já presentes nas fábricas, ganham novas funcionalidades e novas } \\
\text { tecnologias. A expectativa é que eles se tornem cada vez mais autônomos e } \\
\text { realizem as tarefas consideradas de alto risco ou desconfortáveis para o ser } \\
\text { humano. Eles também são usados para minimizar as falhas e aumentar a } \\
\text { produtividade. }\end{array}$ \\
\hline Simulação & $\begin{array}{l}\text { A simulação computacional e as ferramentas de CAE (Computer Aided } \\
\text { Engineering) chegam aos mais diversos setores da indústria. Processos de } \\
\text { fabricação, performance de produtos, comportamento térmico, estático, de fluidos, } \\
\text { acústico, entre outros, são analisados no ambiente virtual antes de se } \\
\text { transformarem em realidade. Com isso, é possível otimizar o uso de recursos, } \\
\text { diminuir o desperdício, desenvolver processos de fabricação mais eficientes, } \\
\text { reduzir custos e criar produtos mais atrativos. }\end{array}$ \\
\hline $\begin{array}{l}\text { Integração de } \\
\text { sistemas }\end{array}$ & $\begin{array}{l}\text { A maioria dos gestores já sofreu com a falta de comunicação entre equipes e } \\
\text { sistemas da empresa ou, até mesmo, com clientes e fornecedores. Por isso, na } \\
\text { indústria 4.0, os sistemas são integrados e as informações ficam mais acessiveis. }\end{array}$ \\
\hline $\begin{array}{l}\text { Segurança da } \\
\text { informação }\end{array}$ & $\begin{array}{l}\text { Com tudo conectado e integrado, a segurança da informação se torna ainda mais } \\
\text { importante nessa nova indústria. Soluções de segurança cibernética precisam } \\
\text { trabalhar para manter os sistemas confiáveis e protegidos. }\end{array}$ \\
\hline $\begin{array}{c}\text { Computação em } \\
\text { nuvem }\end{array}$ & $\begin{array}{l}\text { Na indústria 4.0, a maioria dos dados e das informações compartilhadas pela } \\
\text { internet é armazenada em nuvem. Assim, eles se tornam acessiveis de qualquer } \\
\text { lugar, além de serem independentes da capacidade individual de computadores } \\
\text { ou dispositivos. Com os sistemas de segurança corretos, o uso da nuvem garante } \\
\text { a proteção dos dados. }\end{array}$ \\
\hline Realidade aumentada & $\begin{array}{l}\text { A indústria } 4.0 \text { também se caracteriza pela fusão entre os ambientes online e } \\
\text { offline. Para isso, a realidade aumentada tem um papel importante. Apesar de seu } \\
\text { desenvolvimento ainda dar os primeiros passos, a tendência é que ela seja } \\
\text { aplicada a funções como manuais de montagem, operação e manutenção de } \\
\text { máquinas. }\end{array}$ \\
\hline Manufatura aditiva & $\begin{array}{l}\text { A manufatura aditiva, também conhecida como impressão 3D, já é uma realidade } \\
\text { em muitas indústrias e deve ganhar ainda mais espaço. Ela é usada, por exemplo, } \\
\text { para facilitar a construção de protótipos, agilizar a realização de modificações e } \\
\text { permitir a criação de produtos personalizados. }\end{array}$ \\
\hline
\end{tabular}

Fonte: Adaptado de Engprocess (2017).

Entretanto, para a implementação desses pilares, Hermann, Pentek e Otto (2015, p. 1113) descrevem seis requisitos que definem os sistemas de produção inteligentes, apresentados no Quadro 2. 
Quadro 2 - Requisitos que definem os sistemas de produção inteligentes pilares da Indústria 4.0

\begin{tabular}{|c|l|}
\hline $\begin{array}{c}\text { Interoperabilidade } \\
\text { (Interoperability) }\end{array}$ & $\begin{array}{l}\text { O Sistema Ciber-Físico (Cyber Physical Systems - CPS) e as pessoas estarão } \\
\text { conectados à Internet das Coisas (Internet of Things - iot) e à Internet dos Serviços } \\
\text { (Internet of Services - ios), permitindo a comunicação entre a CPS de vários } \\
\text { fabricantes. }\end{array}$ \\
\hline $\begin{array}{c}\text { Virtualização } \\
\text { (Virtualization) }\end{array}$ & $\begin{array}{l}\text { Os CPS serão capazes de monitorar e simular processos físicos por meio de } \\
\text { sensores que estarão interligados a modelos de plantas virtuais. }\end{array}$ \\
\hline $\begin{array}{c}\text { Descentralização } \\
\text { (Decentralization) }\end{array}$ & $\begin{array}{l}\text { Os computadores conectados aos CPS serão aptos a tomar decisões de modo } \\
\text { autônomo, com o intuito de descentralizar e aprimorar os processos produtivos. }\end{array}$ \\
\hline $\begin{array}{c}\text { Adaptação da } \\
\text { produção em tempo } \\
\text { real }\end{array}$ & $\begin{array}{l}\text { Os dados serão coletados e analisados do modo instantâneo, possibilitando que a } \\
\text { produção seja redirecionada para outra máquina caso haja uma falha. }\end{array}$ \\
$\begin{array}{c}\text { (Real-Time Capability) } \\
\text { Orientação a serviços } \\
\text { (Service Orientation) }\end{array}$ & $\begin{array}{l}\text { Os dados e os serviços estarão disponíveis na ios, tornando-a ainda mais robusta e } \\
\text { permitindo a customização de processos de produção e operação de acordo com as } \\
\text { especificações dos clientes. }\end{array}$ \\
\hline $\begin{array}{c}\text { Modularidade } \\
\text { (Modularity) }\end{array}$ & $\begin{array}{l}\text { Poderão ser facilmente ajustados em caso de flutuações sazonais ou alteração nas } \\
\text { características dos produtos, uma vez que serão capazes de adaptar-se de forma } \\
\text { flexível a essas mudanças. }\end{array}$ \\
\hline
\end{tabular}

Fonte: Adaptado de Hermann, Pentek e Otto (2015).

Mediante as definições que envolvem a Indústria 4.0 e seus preceitos, interessa-se por conhecer o panorama das fábricas inteligentes perante a realidade brasileira.

\section{O BRASIL E A INDÚSTRIA 4.0}

As indústrias brasileiras encontram-se atualmente, no patamar da Indústria 2.0. Ao compararmos os índices de exportação do
Brasil com relação a Alemanha (país em que as indústrias já estão se adequando ao patamar da Indústria 4.0), é notório a diferença.

O Gráfico 1 apresenta as perspectivas de diversificação de mercado para todos os produtos exportados pela Alemanha. O Trade Map apontou os 20 primeiros países exportadores da Alemanha.

Gráfico 1 - Perspectivas de diversificação de mercado para todos os produtos exportado pela Alemanha em 2017

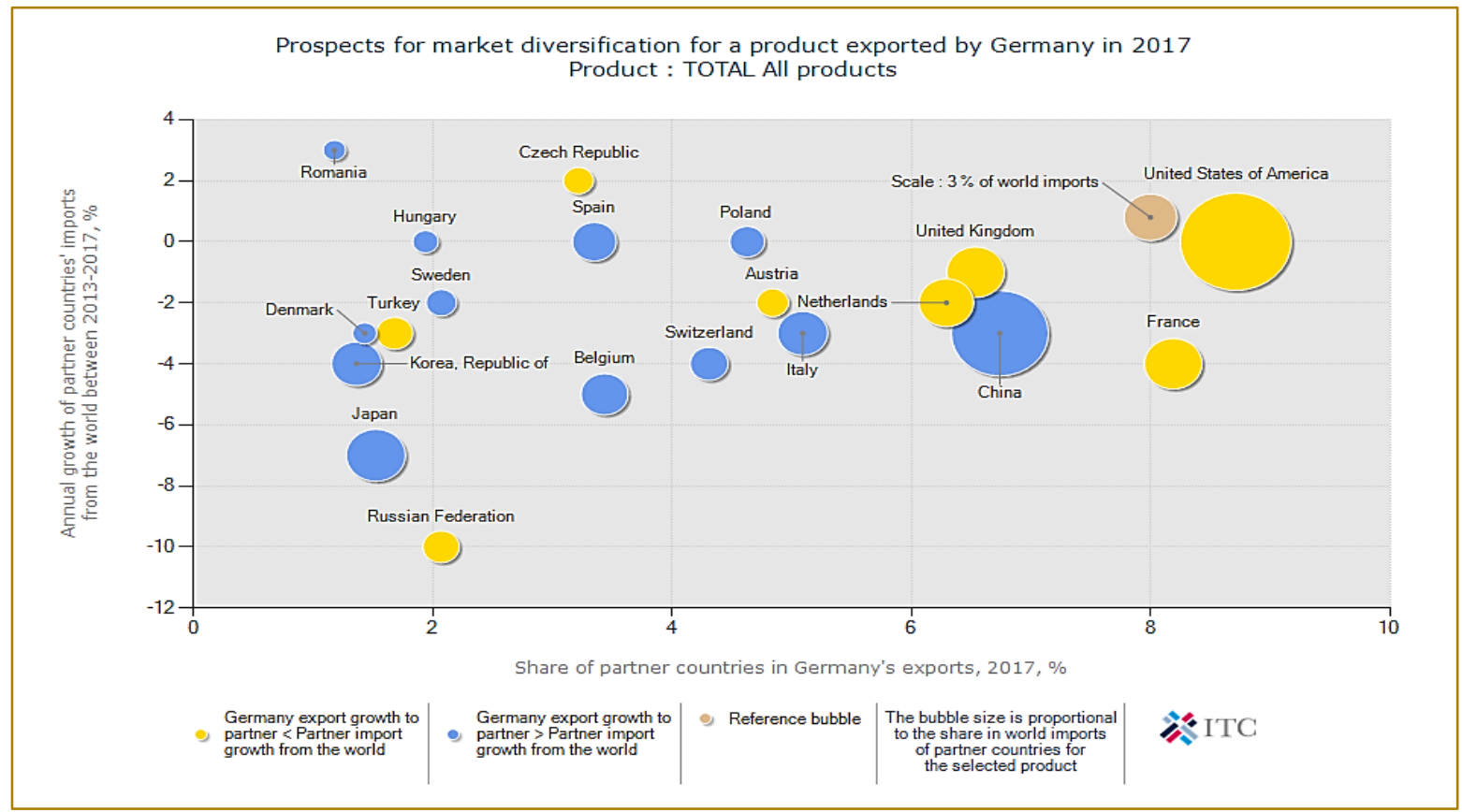

Fonte: Trade Map (2018). 
Os destaques em amarelo indicam que $\mathrm{o}$ crescimento das exportações da Alemanha para o parceiro é menor que o crescimento das importações de parceiros do mundo.

Os destaques em azul indicam que o crescimento das exportações da Alemanha para parceiro é maior que o crescimento das importações de parceiros do mundo.

Isto é, o Gráfico 1 relata que as exportações da Alemanha, representam, $8,2 \%$ das exportações mundiais para todos os produtos. Segundo o Trade Map, a Alemanha ocupa a posição 3 no ranking das exportações mundiais referente a todos os produtos.

O Gráfico 2 apresenta as perspectivas de diversificação de mercado para todos os produtos exportados pelo Brasil. O Trade Map apontou os 20 primeiros países exportadores do Brasil.

Gráfico 2 - Perspectivas de diversificação de mercado para todos os produtos exportado pelo Brasil em 2017

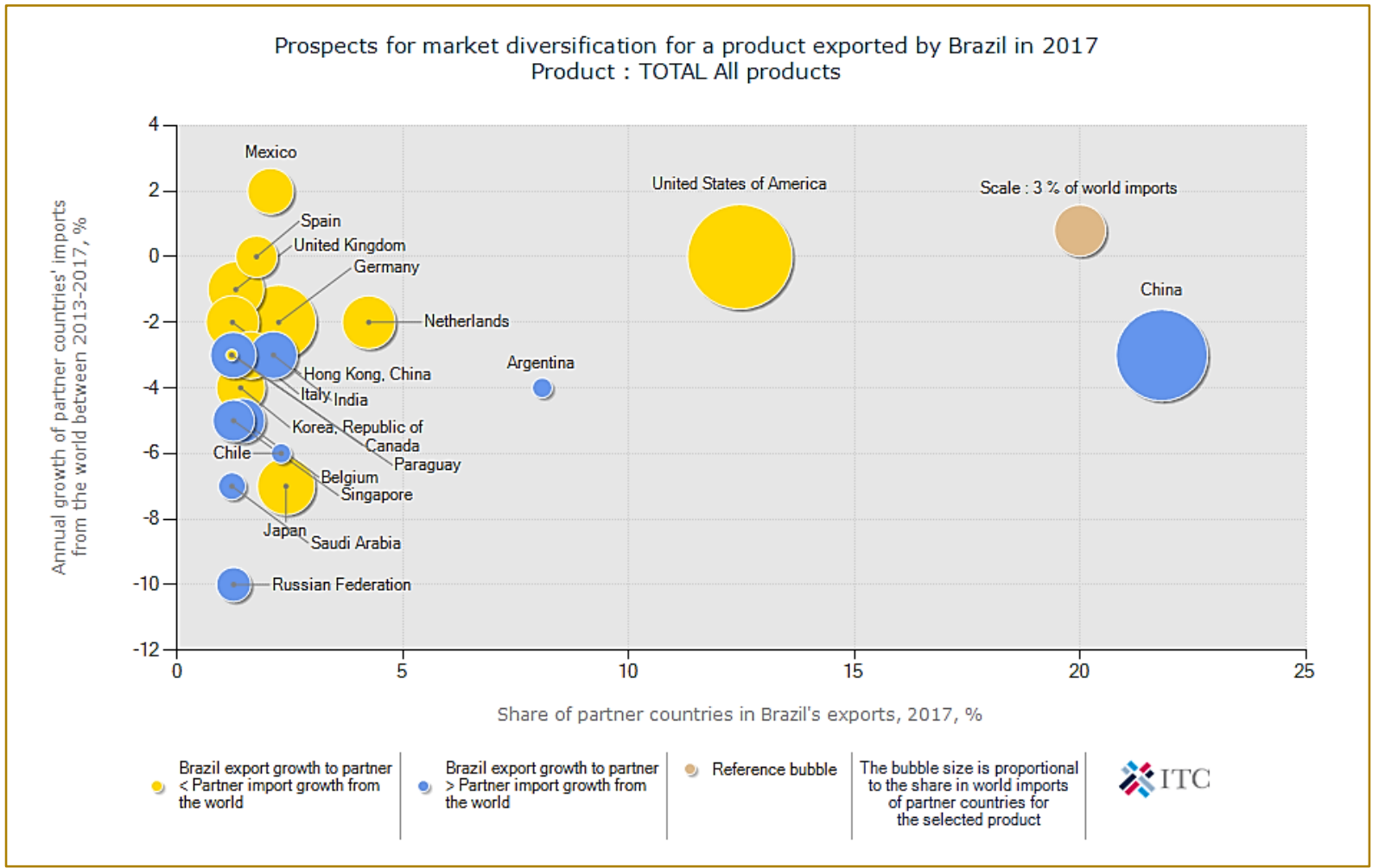

Fonte: Trade Map (2018)

Os destaques em amarelo indicam que o crescimento das exportações do Brasil para o parceiro é menor que o crescimento das importações de parceiros do mundo.

Os destaques em azul indicam que o crescimento das exportações do Brasil para parceiro é maior que o crescimento das importações de parceiros do mundo.

Isto é, o Gráfico 2 relata que as exportações do Brasil, representam, 1,2\% das exportações mundiais para todos os produtos. Segundo o Trade Map, o Brasil ocupa a posição 25 no ranking das exportações mundiais referente a todos os produtos.

Já ao compararmos os índices de importação do Brasil com relação a Alemanha, é possível notar o atraso da indústria brasileira perante a indústria alemã.

O Gráfico 3 apresenta as perspectivas de diversificação $\urcorner$ de fornecedores para todos os produtos que foram importados pela Alemanha. O Trade Map apontou os 20 primeiros países fornecedores da Alemanha. 
Gráfico 3 - Perspectivas de diversificação de fornecedores para todos os produtos importados pela Alemanha em 2017

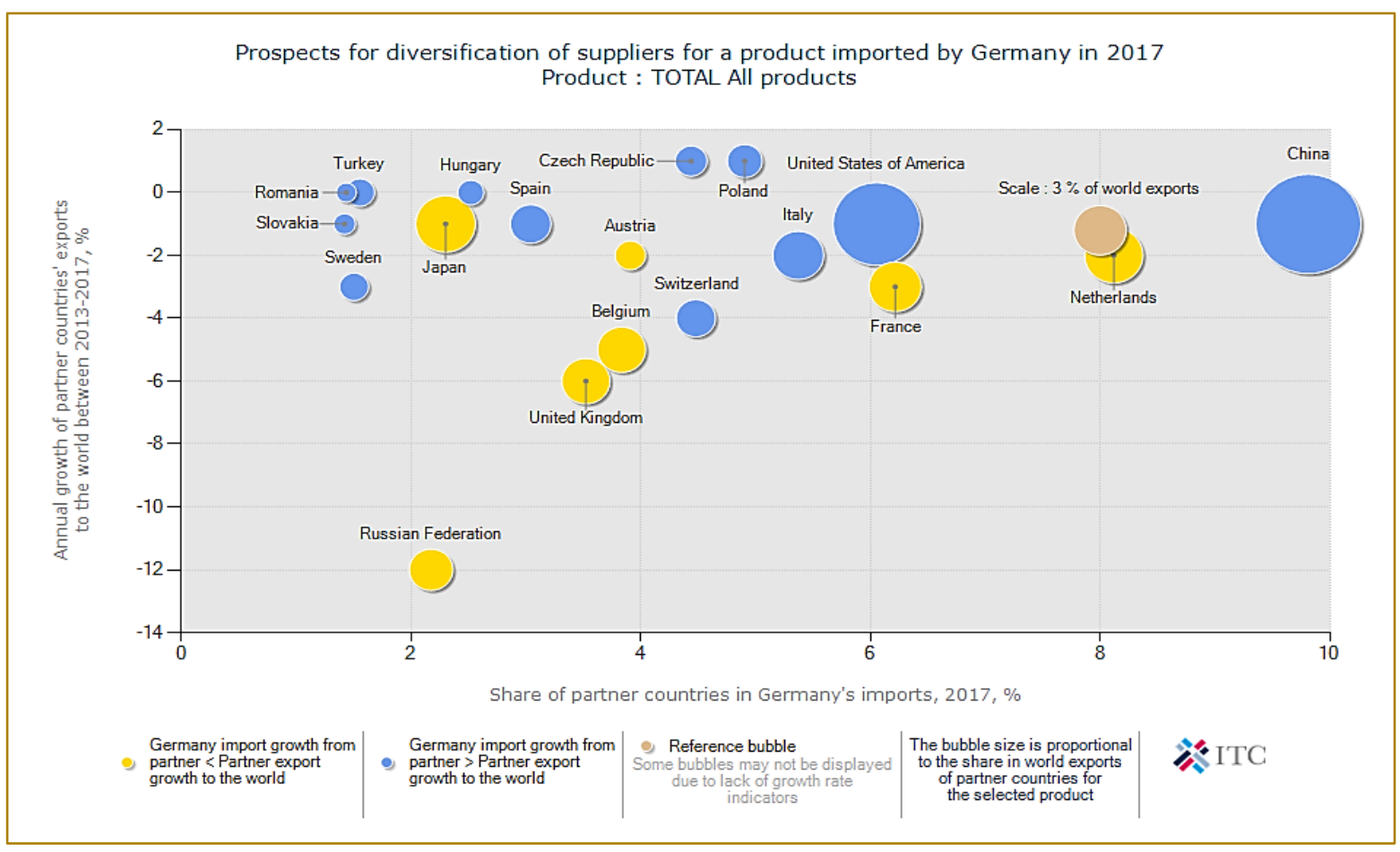

Fonte: Trade Map (2018).

Os destaques em amarelo indicam que 0 crescimento das importações da Alemanha para o parceiro é menor que o crescimento das exportações de parceiros do mundo.

Os destaques em azul indicam que 0 crescimento das importações da Alemanha para parceiro é maior que o crescimento das exportações de parceiros do mundo.

Ou seja, o Gráfico 3 relata que as importações da Alemanha, representam, 6,6\% das importações mundiais para todos os produtos. Segundo o Trade Map, a Alemanha ocupa a posição 3 no ranking das importações mundiais referente a todos os produtos.

O Gráfico 4 apresenta as perspectivas de diversificação de fornecedores para todos os produtos que foram importados pelo Brasil. $\mathrm{O}$
Trade Map apontou os 20 primeiros países fornecedores do Brasil.

Os destaques em amarelo indicam que o crescimento das importações do Brasil para o parceiro é menor que o crescimento das exportações de parceiros do mundo.

Os destaques em azul indicam que 0 crescimento das importações do Brasil para parceiro é maior que o crescimento das exportações de parceiros do mundo.

Ou seja, o Gráfico 4 relata que as importações do Brasil, representam, 0,8\% das exportações mundiais para todos os produtos. Segundo o Trade Map, o Brasil ocupa a posição 31 no ranking das importações mundiais referente a todos os produtos. 
Gráfico 4 - Perspectivas de diversificação de fornecedores para todos os produtos importado pelo Brasil em 2017

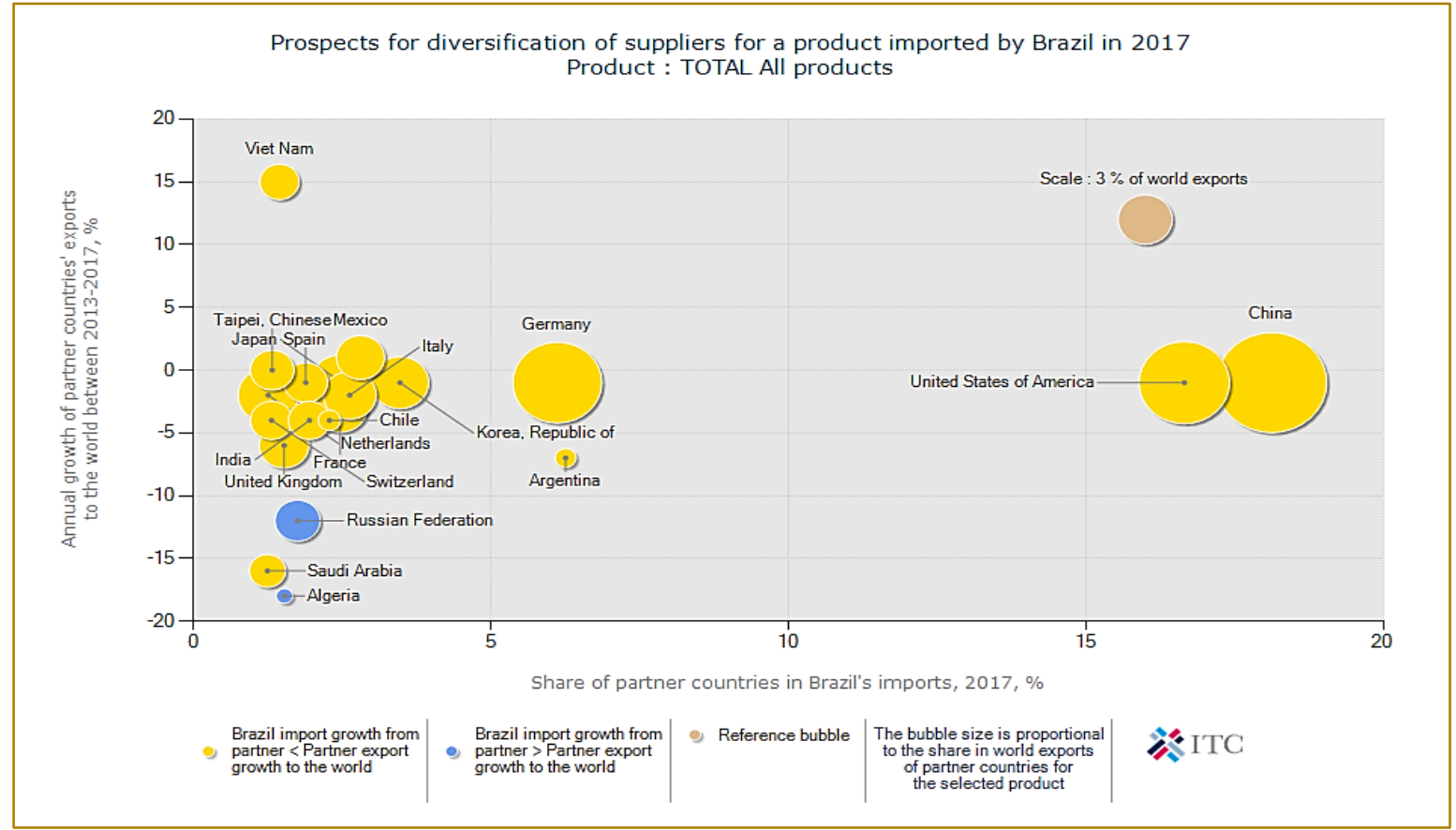

Fonte: Trade Map (2018).

Segundo a Confederação Nacional das Indústrias (2016), a participação do setor de transformação industrial no PIB de 1985 a
2016 sofreu uma queda, em valores, percentuais, como pode ser observado no Gráfico 5.

Gráfico 5 - Participação do setor de transformação industrial no PIB (\%) 1985 - 2016

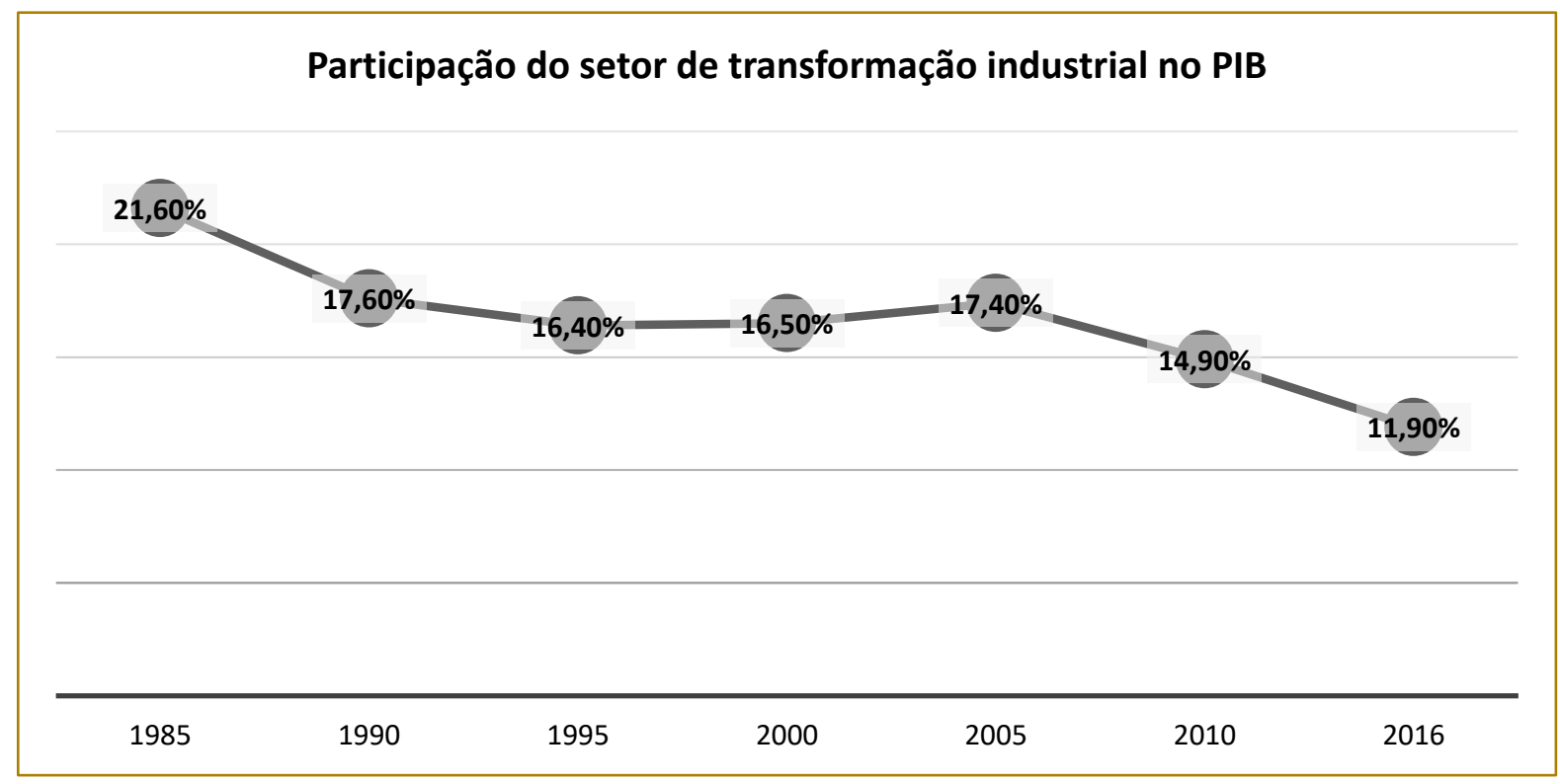

Fonte: Adaptado de Confederação Nacional da Indústria (2016). 
A atuação da indústria de transformação no PIB, que em 1985 chegou a atingir mais de $20 \%$, em 2016 sofreu uma queda para quase $12 \%$, consequência das mudanças na estrutura produtiva do país e dos novos modelos de negócios.

O índice global de inovação aponta o ranking de eficiência da inovação de cada país. A avaliação é realizada pelos critérios de performance nos temas relacionados a inovação, crescimento da produtividade, investimento em pesquisa e desenvolvimento, educação, exportação de produtos de alta tecnologia, entre outros. Na Tabela 1, é possível verificar a posição do Brasil.

Tabela 1 - Ranking de eficiência da inovação

\begin{tabular}{|c|c|c|}
\hline Posição & País & Pontos \\
\hline $1^{0}$ - & SUIÇA & 67,6 pontos \\
\hline $2^{\circ}$ & SUÉCIA & 63,8 pontos \\
\hline $3^{\circ}$ & PAISES BAIXOS & 63,3 pontos \\
\hline $4^{\circ}$ & EUA & 61,4 pontos \\
\hline $5^{\circ}$ & REINO UNIDO & 60,8 pontos \\
\hline $6^{\circ}$ & DINAMARCA & 58,7 pontos \\
\hline $7^{\circ}$ 은 & CINGAPURA & 58,6 pontos \\
\hline $8^{\circ}$ & FINLÂNDIA & 58,4 pontos \\
\hline $69^{\circ}$ & BRASIL & 33,1 pontos \\
\hline
\end{tabular}

Este ranking brasileiro necessita prosperar. E os conceitos da Indústria 4.0 podem influenciar nesse objetivo. De acordo com a Confederação Nacional da Indústria (2016), entre os anos de 2006 a 2016, a produtividade industrial brasileira caiu mais de 7 pontos. No índice Global de Competitividade da Manufatura, o Brasil que em 2010 ocupava a 5a posição, em 2016 passou a ocupar a $26^{\underline{a}}$ posição.

Diante dessas comparações, o Brasil necessita analisar a viabilidade e os impactos que cada tecnologia terá nas fábricas para que os seus índices e o seu patamar avancem em comum acordo com os pilares da Industria 4.0. A transição é uma oportunidade de melhorar processos, otimizar os recursos e inovar.

\section{ESTRATÉGIAS E OPORTUNIDADES}

A inclusão de novas tecnologias como estratégia para 0 desenvolvimento das indústrias brasileiras será primordial para garantir a competitividade e aumentar a participação do Brasil no mercado mundial. Entretanto, as indústrias brasileiras encontram-se no patamar da Indústria 2.0, o que não impede em avançar pois:

Em relação ao Brasil, dado o nosso atraso tecnológico, temos a oportunidade de pular algumas etapas e migrarmos direto para a indústria 4.0. Contudo, os riscos são enormes. Primeiramente, precisamos capacitar a nossa mão de obra e habilitá-la a atender às demandas dessa nova indústria. Ademais, necessitamos criar novos mecanismos regulatórios para que essa indústria possa se desenvolver. No entanto, dado o novo arranjo econômico em que "winner takes all (o vencedor leva tudo)", corremos um sério risco de termos a nossa indústria ainda mais deteriorada, uma vez que empresas estrangeiras inseridas nessa cadeia global de suprimentos serão mais competitivas e terão maior possibilidade de conquistar mercados hoje protegidos por governos locais (FERREIRA, 2017).

Com o conceito e a implantação da Indústria 4.0 no Brasil, será possível competir com as grandes potências mundiais, devido a esse conjunto de tecnologias e suas vantagens. Entretanto, para que isso venha a ocorrer, os maiores desafios estão concentrados em fatores como: 
obter políticas estratégicas inteligentes, incentivos e fomentos por parte do governo; reunir empresários e gestores da indústria com visão, arrojo e postura proativa; dispor de desenvolvimento tecnológico e formação de profissionais altamente qualificados por parte das instituições acadêmicas e de pesquisa, preferencialmente em grande proximidade com a indústria (FEDERAÇÃO DAS INDÚSTRIAS DO ESTADO DO RIO DE JANEIRO, 2016, p. 17-18).
De acordo com o IEL - Instituto Euvaldo Lodi (2018), é necessário a construção de prioridades e estratégias nacionais, centradas nas decisões das autoridades executivas de cada país, conciliando o público com o privado e a sua devida realocação dos recursos, sejam substantivas e/ou previsíveis. Para isso, metas são criadas para direcionar os países rumo as conquistas, como pode ser observado no Quadro 3.

Quadro 3 - Metas dos principais países da Indústria 4.0

\begin{tabular}{|c|c|}
\hline Estratégias Digitais & Meta \\
\hline Alemanha & META: ser a maior referência em fábricas inteligentes, com manufatura integrada. \\
\hline China & $\begin{array}{l}\text { META: alcançar o investimento americano até } 2025 \text { e tornar-se uma superpotência } \\
\text { até } 2049 \text {. }\end{array}$ \\
\hline Estados Unidos & $\begin{array}{l}\text { META: manter a liderança em inovação e recuperar a ponta em manufatura } \\
\text { avançada. }\end{array}$ \\
\hline Japão & META: desenvolver robôs para substituir a força de trabalho humana. \\
\hline Brasil & $\begin{array}{l}\text { DESAFIO SUGERIDO PELA CNI: elevar a fatia de indústrias acima da terceira } \\
\text { geração de } 24 \% \text { a } 61 \% \text { do total até } 2017\end{array}$ \\
\hline
\end{tabular}

Fonte: Adaptado de IEL (2018).

As estratégias de cada país apresentado no Quadro 3 está diretamente relacionada com o investimento em inovação que cada país pretende desembolsar. É necessário compreender que o avanço para alcançar as metas propostas depende da atuação de cada empresa/país, bem como a situação econômica, financeira e tecnológica.

A ABDI - Agência Brasileira de Desenvolvimento Industrial, o Ministério da Indústria, Comércio e Serviços e o Governo Federal, com o apoio da FGV - Fundação Getúlio Vargas na área de projetos, criaram uma plataforma nomeada "Agenda brasileira para a Indústria 4.0 - O Brasil preparado para os desafios do futuro", que pode ser acessado no link industria40.gov.br. Nela, é possível conhecer o conceito da Industria 4.0, bem como os desafios, as expectativas, os impactos, a retomada do crescimento econômico em 2018, o grupo de trabalho da Industria 4.0, a estrutura de governo, as premissas e as medidas rumo a indústria 4.0.

A edição especial da Revista Exame, criou um guia simples, mas prático do passo a passo de como inserir a empresa na Indústria 4.0.

ENXUGUE: antes de digitalizar os processos, avalie a situação da empresa para adotar práticas gerenciais como eficiência energética, lean manufacturing e medidas para reduzir desperdícios.

QUALIFIQUE: as tecnologias da Industria 4.0 demandam profissionais especializados, com conhecimento de robótica e análise de dados. É válido estimular a criatividade e o empreendedorismo.

SIMPLIFIQUE: inicialmente, adote medidas simples e de baixo custo, como sensoriamento, internet das coisas, computação em nuvem e big data, para ter ganhos rápidos e se preparar para os próximos passos.

INOVE: invista em pesquisa e desenvolvimento com o objetivo de implantar fábricas inteligentes, flexíveis e ágeis, com capacidade de customização da produção em massa. (REVISTA EXAME, 2018).

Dessa forma, é possível avançar, aos poucos, na busca das boas práticas, fazer mais com menos, preservando a produção, reduzindo os custos e aumentando a segurança das informações. Ademais, é preciso estar atentos as oportunidades para que as fábricas e os processos não se tornem obsoletos. 
Investir é preciso, porém, é necessário um bom estudo e um planejamento adequado para cada fábrica, identificando as suas deficiências e buscando as melhorias para reduzir custos, aumentar a produtividade e alcançar o patamar da Industria 4.0.

\section{CONSIDERAÇÕES FINAIS}

A posição das indústrias brasileiras no âmbito mundial da tecnologia, inovação, automatização de processos e qualidade nos serviços ainda está muito aquém do esperado para alcançar o patamar da Indústria 4.0. Novas premissas e ideais ainda necessitam ser apresentadas e entendidas para obter uma boa produtividade, com baixo custo.

A realidade do Brasil perante os demais países foi vista como uma oportunidade de crescimento, não somente na economia, mas social. É possível descobrir novas formas de trabalho, gerando qualidade de vida para a população, diminuindo $\mathrm{o}$ desperdício e

\section{REFERÊNCIAS}

[1] BANZATO, Eduardo. Indústria 4.0: Com a IoT ("Internet of Things") se consolida mais uma nova revolução industrial, que demanda tecnologia e mudança no modelo de negócio. Revista Logística, São Paulo, n. 229, p.40-44, set. 2015. Disponível em: <https://www.imam.com.br/logistica/artigos/serietecnologia-da-informacao/2278-industry-4-0> Acesso em: 08 jun. 2018

[2] COMO CONSTRUIR O BRASIL 4.0. Revista Exame, São Paulo: Abril, 2018. Edição especial.

[3] CONFEDERAÇÃO NACIONAL DA INDÚSTRIA (Brasília). Desafios para a indústria 4.0 no Brasil. Brasília: CNI, 2016. 37 p. Disponível em: <http://www.portaldaindustria.com.br/publicacoes/ 2016/8/desafios-para-industria-40-no-brasil/>. Acesso em: 09 jun. 2018.

[4] ENGPROCESS. Indústria 4.0 - como seus pilares podem afetar sua empresa? out. 2017. Disponível

em: <http://engprocess.com.br/industria-4-0/>. Acesso em: 09 jun. 2018.

[5] FEDERAÇÃO DAS INDÚSTRIAS DO ESTADO DO RIO DE JANEIRO (Rio de Janeiro). Indústria 4.0. Rio de Janeiro: FIRJAN, 2016. 20 p. Disponível em: <http://www.firjan.com.br/publicacoes/publicacoesde-inovacao/industria-4-0.htm>. Acesso em: 12 jun. 2018 . produzindo com mais qualidade. Ademais, os empreendedores devem olhar esse cenário atual como uma alavanca para os seus negócios.

A busca por melhorias gera lucro, aumenta as vendas e impulsiona o desenvolvimento do país. Assim, é necessário que políticas públicas e iniciativas privadas trabalhem em conjunto em busca desse desenvolvimento nacional.

Investir em pesquisa e desenvolvimento é o caminho para alcançar o patamar da Indústria 4.0. Os investimentos são necessários, porém, é preciso um estudo, um planejamento a longo prazo, com metas reais e ações incisivas sobre os problemas e oportunidades de melhorias.

Assim, com o uso da tecnologia e aplicação dos pilares da indústria 4.0, é possível promover uma mudança nos negócios, com redução de custos, flexibilidade de produção e personalização de produtos em todos os setores.

[6] FERREIRA, Pedro Guilherme. A oportunidade da Indústria 4.0 para o Brasil. Blog do IBRE - Fundação Getúlio Vargas, 2017. Disponível <http://blogdoibre.fgv.br/posts/oportunidade-daindustria-40-para-o-brasil>. Acesso em: 19 jun. 2018.

[7] HERMANN, Mario; PENTEK, Tobias; OTTO, Boris. Design Principles for Industrie 4.0 Scenarios: A Literature Review. 2015. Disponível em: $\quad<\quad$ http://www.snom.mb.tudortmund.de/cms/de/forschung/Arbeitsberichte/De sign-Principles-for-Industrie-4_0-Scenarios.pdf> . Acesso em: 09 jun. 2018.

[8] INSTITUTO EUVALDO LODI. Núcleo Central. Síntese dos resultados/Instituto Euvaldo Lodi, Luciano Coutinho, João Carlos Ferraz, David Kupfer, Mariano Laplane, Caetano Penna, Luiz Antonio Elias, Fernanda Ultremare, Giovanna Gielfi, Carolina Dias, Jorge Nogueira de Paiva Britti, Julia Ferreira Torracca - Brasília: IEL/NC, 2018. 193 p. il. (Indústria 2027: riscos e oportunidades para o Brasil diante de inovações disruptivas). Disponível em: < https://bucket-gw-cni-static-cmssi.s3.amazonaws.com/media/filer_public/d0/53/d05 3291b-3fof-4c54-add9-

5c2a2dc2dcd2/nota_tecnica_-_sintese.pdf >. Acesso em: 02 set. 2018.

[9] LYDON, Bill. Industry 4.0: Should you bet on it? Automation.com, 2015. Disponível em: <https://www.automation.com/automation- 
news/article/industry-40-should-you-bet-on-it> Acesso em: 10 jul. 2018.

[10] TADEU, Hugo Ferreira Braga; SANTOS, Eduardo Stock dos. O que seria a Indústria 4.0? Fundação Dom Cabral. Alphaville, p. 4. 2016. Disponível em: $<$ https://www.fdc.org.br/professoresepesquisa/nucl eos/Documents/inovacao/digitalizacao/boletim_digi talizacao_fevereiro2016.pdf>. Acesso em: 10 jul. 2018.

[11] TRADE MAP. Trade statistics for international business development. Monthly, quarterly and yearly trade data. Import \& export values, volumes, growth rates, market shares, etc. Disponível em:

https://www.trademap.org/Index.aspx>. Acesso em: 15 ago. 2018.

[12] UNIVERSIDADE CORNELL, INSEAD E WIPO (2017): Índice Global de Inovação de 2017 : A Inovação Nutrindo o Mundo, Ithaca, Fontainebleau e Genebra. Disponível em: $<$ https://www.globalinnovationindex.org/userfiles/fil e/reportpdf/GII\%202017\%20Portuguese\%20transla titr_WEB.pdf>. Acesso em 21 ago. 2018. 


\section{Gapítulo 7}

\section{IMPULSO DAS TECNOLOGIAS 4.0 NA INDÚSTRIA TEXTIL}

\section{Gabriela Maestri}

Fernando Ribeiro Oliveira

\section{Fernanda Steffens}

Resumo: A tecnologia é uma ferramenta fundamental na definição de padrões de competitividade global. Atualmente, vive-se a era digital, conhecida como Indústria 4.0, que faz uso de tecnologias conectadas, como por exemplo a robótica e internet das coisas. Historicamente, o setor têxtil sempre utilizou a tecnologia como fator estratégico para acompanhar as mudanças em desenvolvimento. Esta indústria é também responsável por uma cadeia complexa, com diversas ramificações e possibilidades de criar os mais diferentes produtos. Além disso, destaca-se na geração de empregos nos mais diversos segmentos do setor. No entanto, alguns pesquisadores acreditam que a Indústria 4.0 encontra barreiras na sua disseminação devido a questões relativas a geração de desemprego. Desta forma, este trabalho visa encontrar oportunidades de inserção de tecnologias digitais nos setores de fiação, confecção e estamparia. Ainda, um estudo acerca de empregos ao longo dos anos é apresentado, com o objetivo de esclarecer conceitos sóciotécnicos pertinentes a quarta revolução industrial. O trabalho apresentou possibilidades inovadoras para alguns setores da indústria têxtil, justificando suas escolhas.

Palavras-chave: Indústria 4.0. Indústria têxtil. Tecnologias digitais. 


\section{INTRODUÇÃO}

A transferência de tecnologia é um processo antigo e é utilizada no desenvolvimento de novos produtos ou processos, entre organizações.. O seu objetivo é a geração de impacto econômico. Em um mercado competitivo e veloz nas mudanças de produtos e serviços, a transferência de tecnologia se tornou parte das estratégias organizacionais das empresas. Os principais tipos de transferência de tecnologia são: Spinoff Technology - a tecnologia é desenvolvida por uma organização federal e transferida ao setor privado (FUSTER et al., 2018); Spin-on Technology - as tecnologias são desenvolvidas por organizações privadas, mas com potencial de transferência para setores públicos; Dual-Use Technology - o desenvolvimento das tecnologias ocorre no setor público e privado, onde os custos são divididos e ambos os setores são beneficiados (JR; PIO; ANTUNES, 2009; LU et al., 2016).
A tecnologia é uma ferramenta fundamental na definição de padrões de competitividade global, onde o elemento primordial é a inovação por meio de processos e métodos (LUIZ et al., 2008).

Assim, ao longo dos anos, diversas tecnologias importantes foram desenvolvidas e aprimoradas. Atualmente, vivemos em uma era digital - também conhecida como Indústria 4.0 - onde as tecnologias estão conectadas entre si a fim de promover principalmente a rapidez na disseminação de conteúdo, rompendo barreiras físicas, auxiliando organizações e indivíduos, de acordo com a necessidade.

Muitas destas tecnologias são conhecidas também como "pilares da Indústria 4.0", termo usado para designar a atual quarta revolução industrial.. A figura 1 apresenta de forma resumida as principais evoluções tecnológicas desenvolvidas ao longo do tempo.

Figura 1 - Cronologia das principais evoluções tecnológicas

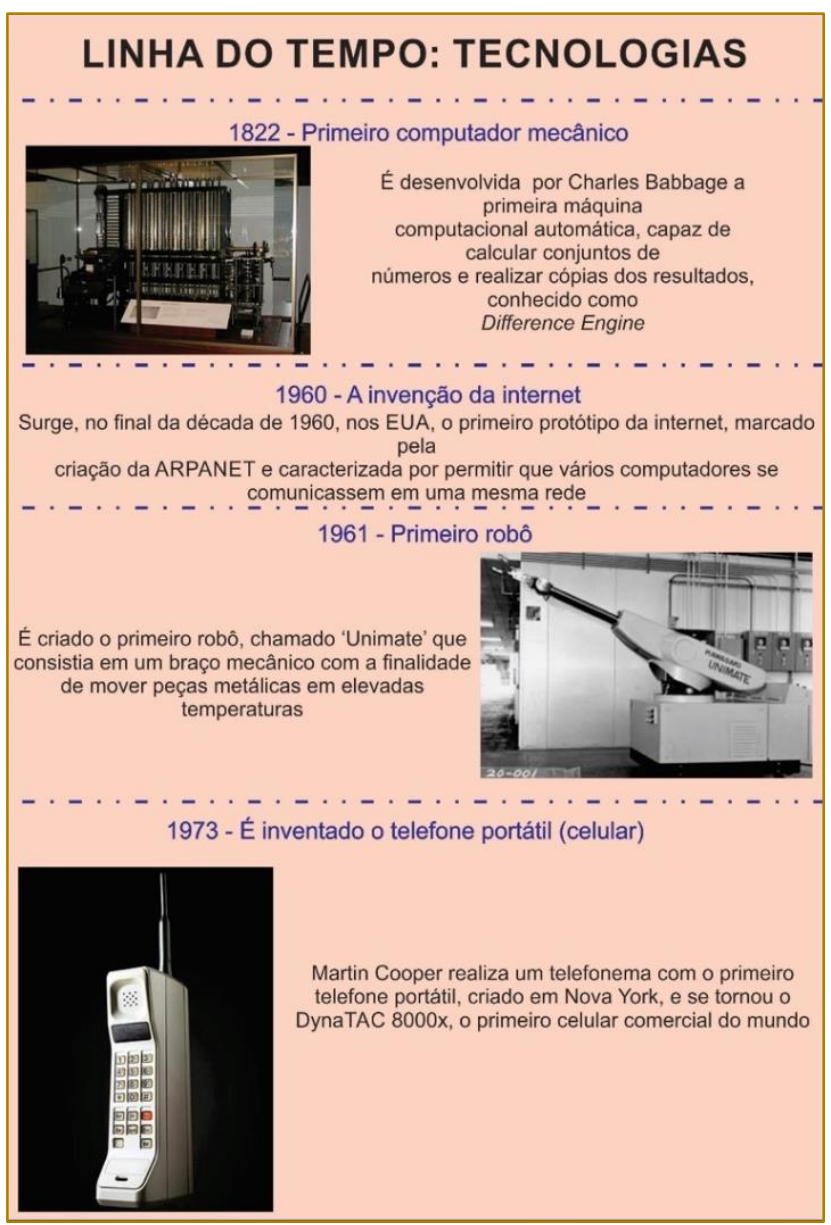




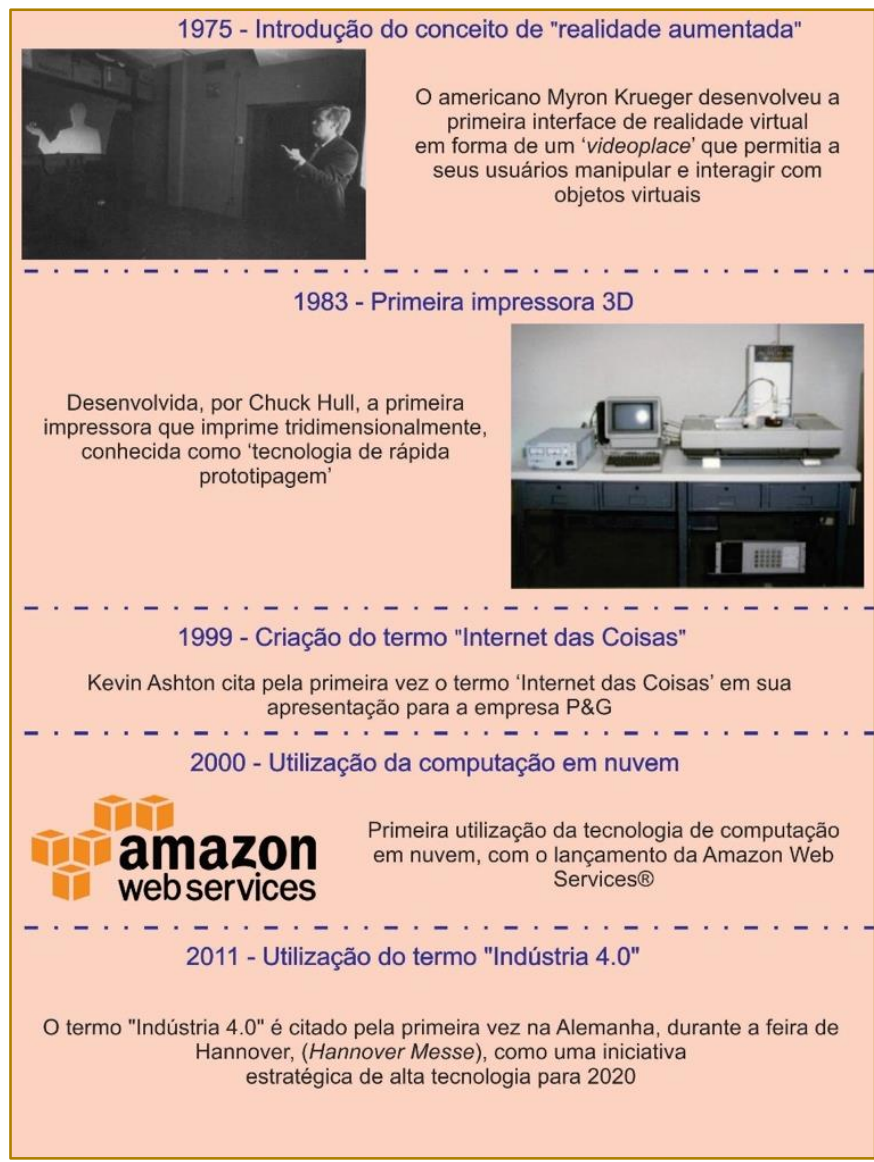

Fonte: Adaptado de (ASHTON, 2010; DIFTLER et al., 2011;

GILCHRIST, 2016; KAMBLE; GUNASEKARAN; SHARMA, 2018; KRUEGER, 1985; ZHANG; CHENG; BOUTABA, 2010).

Dentre as tecnologias de maior relevância quando no desenvolvimento da Indústria 4.0, destacam-se: robótica, realidade aumentada, manufatura aditiva, internet das coisas (IoT) e computação em nuvem. Estas podem ser melhor compreendidas observando a figura 2.

Figura 2 - Tecnologias relacionadas à Indústria 4.0

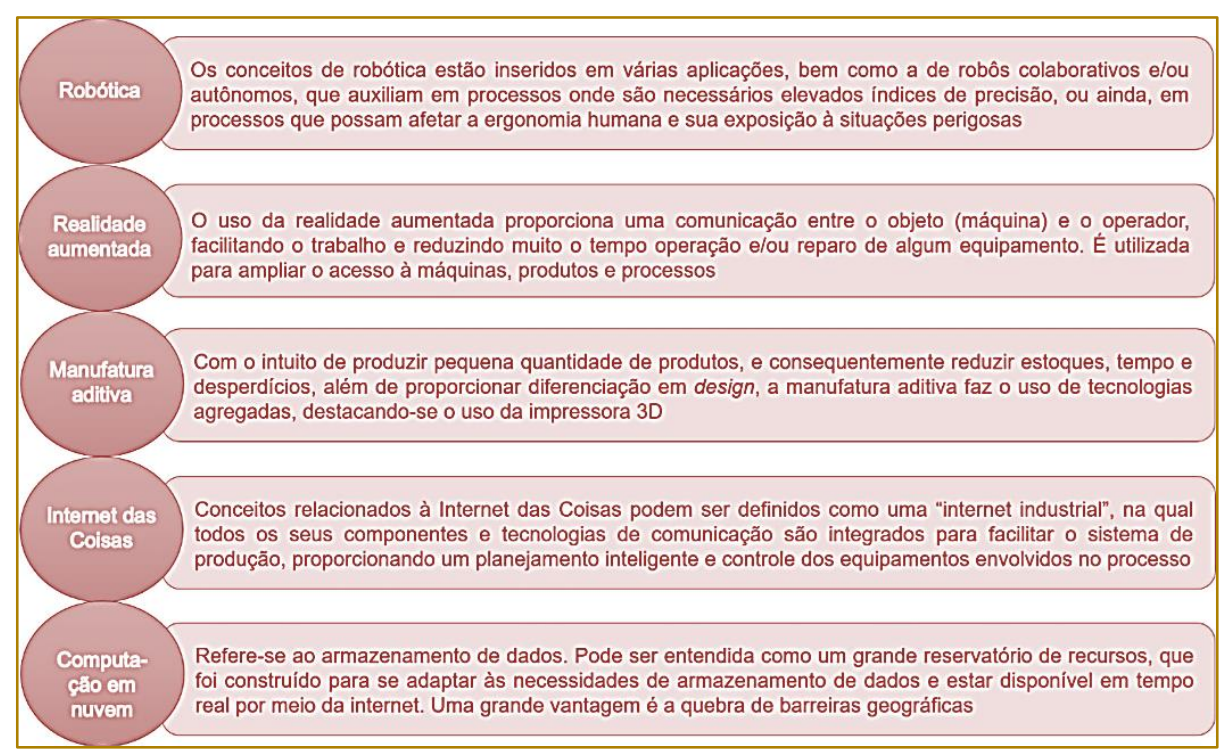

Fonte: Adaptado de (GILCHRIST, [s.d.]; MOKTADIR et al., 2018; VAIDYA; AMBAD; BHOSLE, 2018). 
Historicamente, o setor têxtil brasileiro sempre utilizou a tecnologia como fator estratégico para acompanhar as mudanças em curso. A indústria têxtil está presente em praticamente todos os lugares pela necessidade primordial de vestir-se, e também de usos variados como, por exemplo, têxteis decorativos (homewear), têxteis hospitalares (gazes, suturas, ataduras), têxteis militares, entre outros. Sendo assim, possui elevada importância em termos sociais, culturais, econômicos e políticos de maneira a influenciar costumes e tendências (MAYUMI; FUJITA, 2015).

Esta indústria é também responsável por uma estrutura composta por diferentes áreas. O quadro 1 apresenta as ramificações da indústria têxtil e uma breve descrição dos processos envolvidos.

\section{Quadro 1 - Cadeia têxtil e seus processos}

\begin{tabular}{|c|c|c|c|}
\hline \multicolumn{2}{|c|}{ Principais processos } & Descrição & Produtos obtidos \\
\hline \multirow{3}{*}{ Fiação } & $\begin{array}{l}\text { Fibras naturais } \\
\text { ou misturas }\end{array}$ & $\begin{array}{l}\text { Processo que transforma substratos naturais, ou } \\
\text { possíveis misturas em fios, sendo classificados de } \\
\text { acordo com sua origem. Características importantes } \\
\text { são: teor de impurezas, cor, comprimento de fibra, } \\
\text { micronaire e torção }\end{array}$ & $\begin{array}{l}\text { O fio natural mais comum é } \\
\text { proveniente do algodão, mas } \\
\text { também se destacam o linho, a lã } \\
\text { e a seda. Uma mistura muito } \\
\text { comum corresponde a } \\
\text { Poliéster+Algodão }\end{array}$ \\
\hline & Fibras artificiais & $\begin{array}{l}\text { Transforma celulose em fios, e são classificados de } \\
\text { acordo com o tipo de processo empregado e } \\
\text { solventes utilizados }\end{array}$ & $\begin{array}{l}\text { Destacam-se os fios de viscose e } \\
\text { acetato }\end{array}$ \\
\hline & Fibras sintéticas & $\begin{array}{l}\text { Processo a partir da polimerização de monômeros, } \\
\text { originando uma massa viscosa que passa por fieiras }\end{array}$ & $\begin{array}{l}\text { Também conhecidos por } \\
\text { filamentos, os fios sintéticos mais } \\
\text { comuns são: poliéster, poliamida, } \\
\text { elastano e acrílico }\end{array}$ \\
\hline \multicolumn{2}{|c|}{ Tecelagem plana } & $\begin{array}{l}\text { Os fios são engomados e enrolados em rolo de } \\
\text { urdume. Em seguida, por meio de entrelaçamento, os } \\
\text { teares transformam fios em tecidos planos }\end{array}$ & $\begin{array}{l}\text { Tecidos planos diversos como } \\
\text { sarja, tafetá, cetim e suas } \\
\text { derivações. }\end{array}$ \\
\hline \multirow{2}{*}{ Malharia } & Por trama & $\begin{array}{l}\text { Processo de tricotagem onde as laçadas são } \\
\text { formadas no sentido horizontal. Teares circulares e } \\
\text { retilíneos (monofrontura e duplafrontura) }\end{array}$ & $\begin{array}{l}\text { Tecidos de malha diversos como } \\
\text { rib, jersey e piquet }\end{array}$ \\
\hline & Por urdume & $\begin{array}{l}\text { Processo de tricotagem onde as laçadas são } \\
\text { formadas no sentido vertical. Teares retilíneos } \\
\text { (Raschel e Ketten) }\end{array}$ & $\begin{array}{l}\text { Obtêm-se as rendas, estruturas } \\
\text { spacerentre outras }\end{array}$ \\
\hline \multicolumn{2}{|c|}{ Tingimento } & $\begin{array}{l}\text { Podem-se tingir fibras, fios, tecidos/malhas ou até } \\
\text { mesmo peças prontas. Necessita da preparação do } \\
\text { substrato e da água a ser utilizada. Cada tipo de fibra } \\
\text { exige uma classe específica de corantes e auxiliares }\end{array}$ & $\begin{array}{l}\text { Obtenção de cores uniformes e } \\
\text { reprodutíveis ao substrato têxtil }\end{array}$ \\
\hline \multirow[b]{2}{*}{ Acabamentos } & Físicos & $\begin{array}{l}\text { Conferem modificações nos materiais por meio de } \\
\text { processos físicos, como escovagem, navalhagem, } \\
\text { chamuscagem, entre outros }\end{array}$ & $\begin{array}{l}\text { Obtenção da peça peluciada } \\
\text { e/ou aveludada }\end{array}$ \\
\hline & Químicos & $\begin{array}{l}\text { Por meio da utilização de agentes químicos, } \\
\text { modifica-se o substrato }\end{array}$ & $\begin{array}{l}\text { Exemplos: Anti-UV, } \\
\text { antimicrobianos, antichama, anti- } \\
\text { inseto, modificações hidrofílicas e } \\
\text { hidrofóbicas, entre outros }\end{array}$ \\
\hline \multicolumn{2}{|c|}{ Confecção } & $\begin{array}{l}\text { O enfesto é o processo que otimiza e organiza em } \\
\text { camadas o substrato, de acordo com a quantidade } \\
\text { de peças a serem produzidas. Em seguida estas } \\
\text { camadas serão cortadas (manual ou } \\
\text { automaticamente). A costura é o processo que une } \\
\text { as partes a fim de confeccionar a peça desejada, } \\
\text { sendo as máquinas mais comuns: reta, cobertura e } \\
\text { overloque }\end{array}$ & $\begin{array}{l}\text { Podem ser confeccionados } \\
\text { infinitos produtos, desde } \\
\text { vestuário convencional, como } \\
\text { vestidos, calças e camisetas, até } \\
\text { têxteis técnicos de elevado } \\
\text { desempenho, como pára- } \\
\text { quedas, airbags, coletes } \\
\text { balísticos e geotêxteis }\end{array}$ \\
\hline \multicolumn{2}{|c|}{ Estamparia } & $\begin{array}{l}\text { Processo pela qual a cor é aplicada a uma superfície } \\
\text { têxtil, a partir de um design específico. Exemplos são: } \\
\text { estamparia digital, por quadros, por cilindros } \\
\text { rotativos, transfer e sublimação }\end{array}$ & $\begin{array}{l}\text { Obtenção de um desenho } \\
\text { localizado na peça }\end{array}$ \\
\hline \multicolumn{2}{|c|}{ Tratamento de água e efluentes } & $\begin{array}{l}\text { Processo responsável por tratar a água a ser utilizada } \\
\text { em processos têxteis e também os efluentes gerados, } \\
\text { removendo cor, cheiro, substâncias tóxicas e outros } \\
\text { aspectos indesejados. Dentre as técnicas aplicadas } \\
\text { estão: decantação, filtração, floculação, lodo ativado, } \\
\text { filtração por membrana, oxidação química, dentre } \\
\text { outras. }\end{array}$ & $\begin{array}{l}\text { Água limpa e devidamente } \\
\text { tratada }\end{array}$ \\
\hline
\end{tabular}

Fonte: Do autor, 2018. 
Devido às grandes ramificações do setor têxtil, este também é responsável pela geração de muitos empregos, sendo classificado no Brasil como o segundo maior empregador da indústria de transformação, ficando atrás apenas para a indústria de alimentos e bebidas juntas. Atualmente, 0 setor têxtil possui 1,5 milhão de empregados diretos e 8 milhões de indiretos, dos quais $75 \%$ são de mão-de-obra feminina, e é ainda o setor classificado como o $2^{\circ}$ maior gerador do primeiro emprego, representando 16,7\% dos empregos de toda a indústria da transformação (ABIT, 2018). No entanto, alguns pesquisadores afirmam que uma das barreiras/desafios da Indústria 4.0 está intimamente relacionada a aspectos sociais, neste caso tratando-se da questão do desemprego (SUNG, 2018).

O objetivo deste estudo é propor sugestões automatizadas e tecnológicas para o setor têxtil brasileiro, nas áreas de fiação, confecção e estamparia, a fim de acompanhar a quarta revolução industrial, e ainda, realizar um levantamento na literatura das transformações nos empregos ao longo dos anos, esclarecendo ainda aspectos sociais históricos e perspectivas futuras, a fim de comprovar os inúmeros benefícios de investimentos em tecnologias industriais que a Indústria 4.0 pode proporcionar.

\section{METODOLOGIA}

O trabalho foi desenvolvido após estudo das tecnologias industriais, em especial da Indústria 4.0 no setor têxtil, para a identificação de oportunidades e a apresentação de propostas.

\subsection{PROPOSTAS DE TECNOLOGIAS INOVADORAS PARA O SETOR TÊXTIL}

A partir da identificação de oportunidades de inserção de tecnologias a fim de promover benefícios ao setor têxtil, foram desenvolvidas sugestões para as áreas de fiação, confecção e estamparia.

\subsection{O FATOR HUMANO}

Foi realizada uma pesquisa em bases de dados, relacionando fatores históricos, políticos e econômicos, com o intuito de gerar esclarecimentos relativos a conceitos sóciotécnicos.

\section{RESULTADOS E DISCUSSÃO}

\subsection{SUGESTÕES TECNOLÓGICAS PARA O SETOR TÊXTIL}

As sugestões desenvolvidas no decorrer deste estudo são apresentadas nos itens 3.1.1, 3.1.2 e 3.1.3, para os setores de fiação, confecção e estamparia, respectivamente.

\subsubsection{SETOR DE FIAÇÃO}

Apesar do rápido desenvolvimento de tecnologias, muitas fiações brasileiras, ainda realizam cálculos de mistura de fibra (cor, teor de impurezas, comprimento, resistência, entre outros), de forma manual. Além disso, muitas vezes, o colaborador posiciona os fardos sequencialmente na entrada da sala de abertura (abridor alimentador), de maneira manual. Dessa forma, identifica-se neste caso uma atividade que não possui um controle específico, uma vez que os cálculos - quando realizados manualmente - podem ocasionar erros. É sabido que a correta mistura de fardos de algodão é essencial para a obtenção de um fio de qualidade, garantindo um bom controle de propriedades como uniformidade/regularidade. A sugestão tecnológica é ilustrada na figura 3 . 
Figura 3 - Oportunidades encontradas no setor de fiação

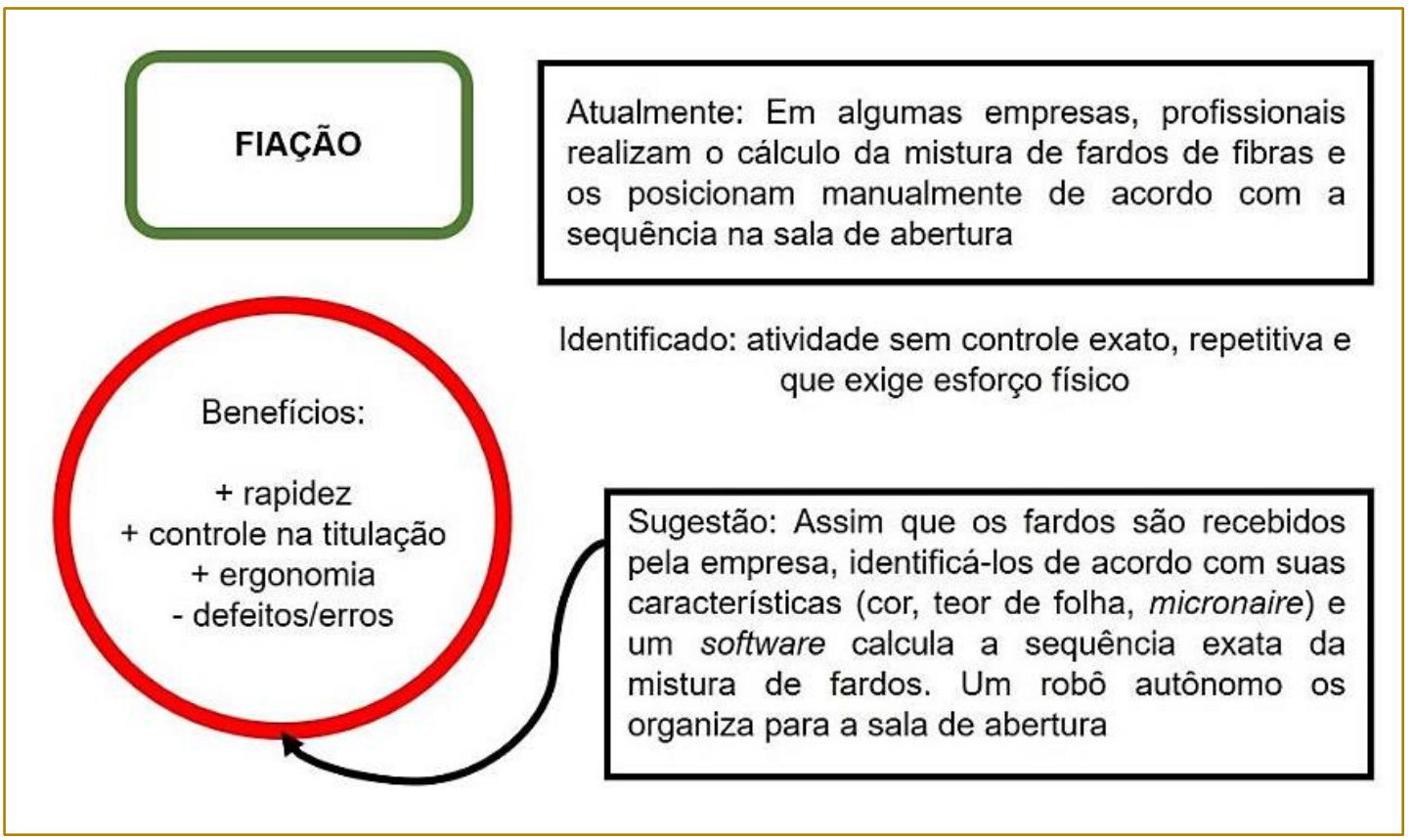

Fonte: Do autor, 2018.

Neste âmbito, a sugestão é que assim que os fardos são recebidos pela empresa, estes são classificados de acordo com suas características, e esta identificação pode ainda ser realizada por meio de QR CODE. Neste QR CODE podem ainda ser inseridos informações dos fardos (tipo, origem, safra, logística e outras propriedades importantes). Um software específico deve fazer a leitura destes dados e o cálculo das misturas de fardos, conectado com um robô autônomo. O software envia as informações para o robô a fim de este posicionar os fardos de acordo com os cálculos obtidos automaticamente.

A geração e análise de dados/informações são importantes, principalmente na segura tomada de decisão a chão de fábrica.

Neste caso, obtêm-se melhor gestão da qualidade dos fios e suas propriedades, rapidez e maior controle do ciclo de produção, facilitando ainda em aspectos ergonômicos para os colaboradores.

\subsubsection{SETOR DE CONFECÇÃO}

Com o rápido crescimento dos produtos confeccionados e da demanda pelo vestuário atual (tendências de moda), muitas indústrias optaram por confeccionar seus produtos por meio de facções independentes (terceirização), pagando apenas pelo serviço prestado (costura e/ou revisão), sem se responsabilizar pelos equipamentos, manutenções, e outras questões relacionadas a produção.

No entanto, nestes casos, o que ocorre é que o motorista da empresa transporta os lotes de peças até a facção designada e então, aguarda que a facção entre em contato com a empresa, quando as peças estiverem finalizadas. Durante este processo, diversas situações indesejadas ocorrem, como por exemplo:

- A facção faz o contato com a empresa no momento em que termina o lote, entretanto, devido a falta de tempo hábil, a empresa não consegue se programar para as próximas etapas de produção. Consequentemente o lote fica parado até ser inserido na linha de produção seguinte, que pode ser: estamparia, revisão, embalagem, aplicações diversas como bordados e/ou pedrarias, entre outros;

- A facção faz o contato com a empresa muito antes de finalizar a costura, estimando uma data para o término. Neste sentido, muitas vezes o motorista chega até a facção para buscar o lote de peças, e este ainda não está finalizado, por diversos motivos relacionados ao processo produtivo. Isto pode resultar em desperdício de tempo do motorista e também em desperdício financeiro para a empresa, considerando os custos do carro da empresa, o custo do colaborador, etc. Além disso, se a empresa já havia 
programado os próximos setores (acabamento) para este lote, este planejamento fica comprometido e precisa ser refeito.
Desta forma, a figura 4 esquematiza as oportunidades e sugestões para a confecção, a partir do caso mencionado.

Figura 4 - Oportunidades encontradas no setor de confecção

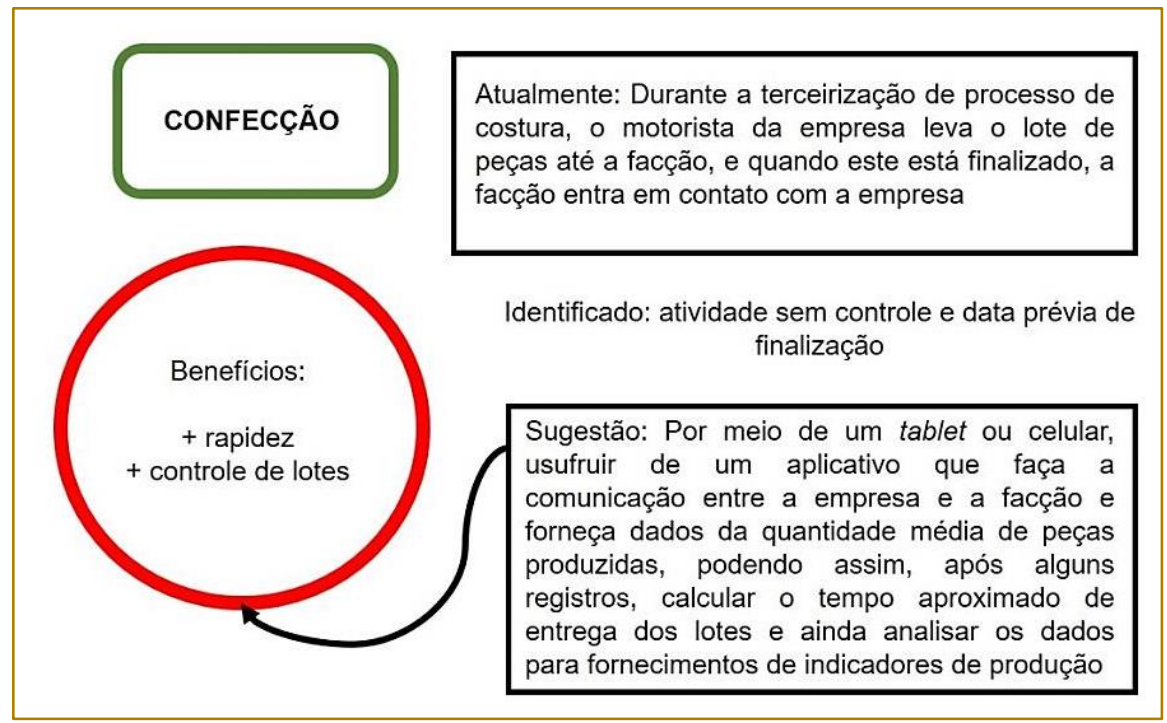

Fonte: Do autor, 2018.

Tendo em vista as oportunidades encontradas, a sugestão é que tanto o motorista, a empresa e a facção estejam conectados por meio de um aplicativo que faça a interação em tempo real de finalização dos lotes, a fim de evitar as situações indesejáveis mencionadas.

\subsubsection{SETOR DE ESTAMPARIA}

É visto que o setor de estamparia obteve um elevado crescimento tecnológico nos últimos anos, considerando o desenvolvimento principalmente da estamparia digital, e da automatização da máquina de estamparia por quadros circular. Contudo, esta última ainda possui uma atividade manual demasiada repetitiva, que é a colocação e retirada da peça na chapa metálica da máquina.

Com isso, sugere-se a inserção de um robô na linha de produção a fim de realizar esta operação, como esquematizado na figura 5.

Figura 5 - Oportunidades encontradas no setor de estamparia

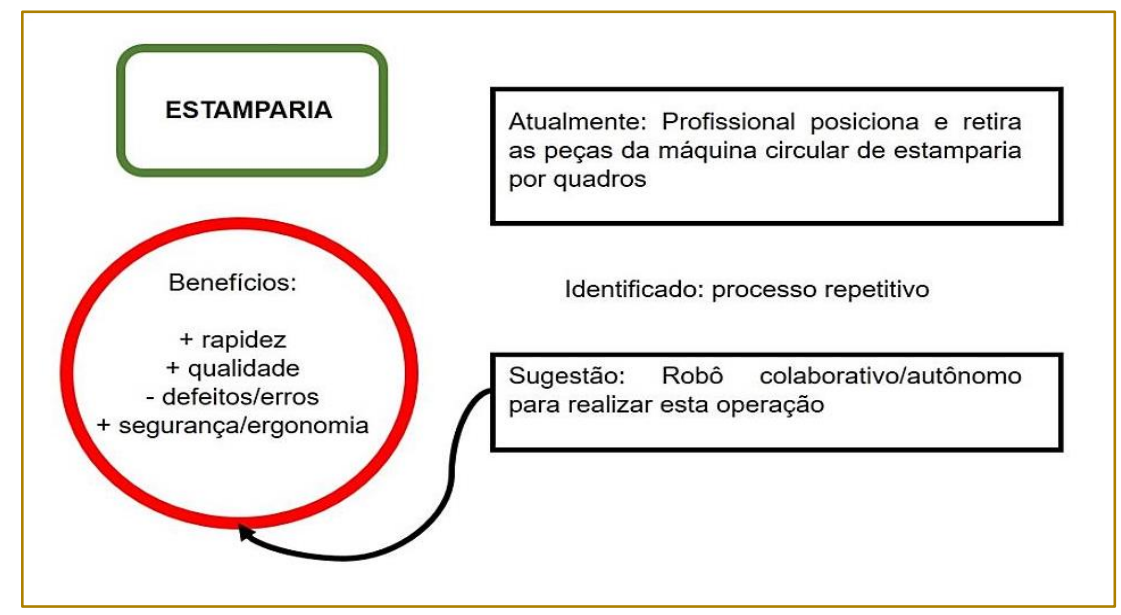

Fonte: Do autor, 2018. 
Neste caso, um robô pode proporcionar diversos benefícios, bem como mais rapidez e precisão do processo. Além disso, diminui muito ou totalmente o esforço físico humano durante a colocação das peças, proporcionando maior segurança para o colaborador, podendo ainda reduzir a quantidade de defeitos.

Além dos setores supracitados, outros relacionados a indústria têxtil também podem aderir a novas tecnologias da era digital, modernizando-se e mantendo-se competitivos ao mercado no qual estão inseridos. A identificação destas oportunidades pode ser realizada por meio de pesquisas na literatura, estudos de casos, ou observação empírica das situações cotidianas das organizações.

É importante destacar a relevância de se realizar um planejamento financeiro e estratégico na organização, a fim de prever a relação custo e benefício de determinadas tecnologias relacionadas com o porte da empresa, expectativa de crescimento da mesma, entre outros fatores.

\subsection{O FATOR HUMANO}

Em todas as revoluções ocorreram transformações no trabalho dos profissionais. No início, os produtos eram fabricados muitas vezes manualmente, e conforme as tecnologias foram se desenvolvendo, surgiram máquinas, computadores, e outros equipamentos, e a partir destes, deu-se início ao surgimento dos operadores de máquinas, os técnicos de informática, e outras profissões oriundas da necessidade da operabilidade de novas tecnologias (RIBEIRO, 2017).

Com o surgimento da era digital, ou Indústria 4.0, percebeu-se que muitas atividades podem ser transformadas ou alteradas, como por exemplo, atividades repetitivas sendo executadas por robôs e atividades de locomoção de itens sendo alteradas por esteiras automáticas. Este fato desencadeia muitas discussões a respeito de uma possível geração de "desemprego" nos próximos anos, resultantes das tecnologias desenvolvidas (EDWARDS et al., 2016; ZANAKI, 2018).

Segundo Susskind, esta mudança pode ser percebida, pois há 300 anos, predominantemente a população trabalhava em atividades relacionadas ao cultivo da terra. Há 150 anos, a maior parte das pessoas trabalhava em fábricas. Atualmente, grande parte trabalha em escritórios (SUSSKIND, 2018).

O ponto crucial é que recentemente caminhase para uma era de mudanças tecnológicas irreversíveis, e neste sentido, alguns pesquisadores afirmam que alguns empregos irão desaparecer ao mesmo tempo que novos empregos irão surgir.

No entanto, as tecnologias podem também auxiliar os profissionais. Um exemplo a ser citado refere-se à utilização do software Audaces $\AA$, que tem como objetivo auxiliar o modelista; ou o software AutoCAD®, que facilita o trabalho do projetista. A utilização destes softwares não gera desemprego, pelo contrário, promove rapidez, segurança e confiabilidade ao processo. Destaca-se neste momento o fato de que a digitalização reduz o esforço físico, diminuindo o espaço necessário para arquivar protótipos, possibilitando o engrandecer do pensamento humano (RIBEIRO, 2017).

As mudanças na nova configuração empregatícia podem ser relacionadas com o aumento da complexidade dos processos de manufatura, tornando as produções mais flexíveis e diversificadas, reduzindo lotes e proporcionando tempo de entrega mais rápidos. A implementação de sistemas digitais também provoca mudanças, uma vez que exige um maior nível de qualificação do operador (RIBEIRO, 2017).

É importante ressaltar que dificilmente o ser humano vence as máquinas em velocidade e volume, mas pode vencê-las em "situações inovadoras". As máquinas, ainda, têm pouca capacidade de inventar novas coisas, e o processo de criatividade, seja em pequenas ocorrências, acontece com os indivíduos milhões de vezes ao dia (GOLDBLOOM, 2016).

Para que este cenário ocorra futuramente em condições ótimas, entende-se que existem quatro principais fatores que influenciam quanto ao bom andamento destas mudanças, que são:

- Incentivos oriundos das organizações privadas;

- Motivação do próprio indivíduo, ou seja, a pessoa deve buscar informações acerca do tema e procurar se qualificar para o futuro digital;

- Incentivo público/governamental: o governo, investindo em educação, 
melhorando a economia e qualidade de vida da população, por meio do incentivo ao estudo e entendimento dos benefícios que envolvem as tecnologias 4.0;

- Incentivo proveniente das instituições de ensino: entende-se que as universidades devem promover aulas, palestras, cursos e congressos relacionados ao tema, a fim de incentivar os estudantes a se qualificarem quanto a este, e também a outros temas inovadores e tecnológicos.

Vale salientar que já existem discussões a respeito da "Revolução 5.0", que integra a inteligência humana junto da inteligência artificial, afirmando que esta nova conjuntura ocorrerá quando profissionais estiverem aptos a lidarem com esta situação (ALVARENGA, 2018).

\section{REFERÊNCIAS}

[1] ABIT. Associação Brasileira das Indústrias Têxteis. Disponível em: < http://www.abit.org.br/cont/perfil-do-setor> acessado em dezembro de 2018.

[2] ALVARENGA, B. Colaboração no chão de fábrica. Revista VEJA, 2018.

[3] ASHTON, K. That "Internet of Things" Thing. That "Internet of Things" Thing-RFID Journal, p. 4986, 2010.

[4] DIFTLER, M. A. et al. Robonaut 2 - The first humanoid robot in space. Proceedings - IEEE International Conference on Robotics and Automation, v. 1, p. 2178-2183, 2011.

[5] EDWARDS, $A$. et al. Robots in the classroom: Differences in students' perceptions of credibility and learning between "teacher as robot" and "robot as teacher". Computers in Human Behavior, v. 65, p. 627-634, 2016.

[6] FUSTER, E. et al. Technological Forecasting \& Social Change The emerging role of university spin-o ff companies in developing regional entrepreneurial university ecosystems: The case of Andalusia. Technological Forecasting \& Social Change, n. October, p. 0-1, 2018.

[7] GILCHRIST, A. Industry 4.0. 2016.

[8] JR, E. B.; PIO, M.; ANTUNES, A. O Processo de Transferência de Tecnologia na Indústria Têxtil. v. 4, n. 1, 2009.

[9] KAMBLE, S. S.; GUNASEKARAN, A.; SHARMA, R. Analysis of the driving and dependence power of barriers to adopt industry 4.0 in Indian manufacturing industry. Computers in Industry, v. 101, n. May, p. 107-119, 2018.

[10] KRUEGER, M. W. "VIDEOPLACE": A Report from the ARTIFICIAL REALITY Laboratory. Leonardo, v. 18, n. 3, p. 145-151, 1985.

\section{CONCLUSÃO}

Este estudo evidenciou as principais tecnologias da Indústria 4.0, e apresentou a complexidade da cadeia têxtil, suas ramificações e produtos obtidos.

Com base nas tecnologias envolvidas na Indústria 4.0, o presente trabalho forneceu também propostas de inovação para os setores de fiação, confecção e estamparia.

Após estudo de fatos históricos, sociais e econômicos, este capítulo apresentou discussões acerca de variáveis empregatícias para a quarta revolução industrial, confirmando os benefícios que as tecnologias industriais podem vir a oferecer à população como um todo.

[11] LU, W. et al. Evaluating the ef fi ciency of dual-use technology development programs from the $R$ \& $D$ and socio-economic perspectives $\$$. Omega, v. 62, p. 82-92, 2016.

[12] LUIZ, F. et al. A INDÚSTRIA TÊXTIL NA REGIÃO NORDESTE : GARGALOS

POTENCIALIDADES E DESAFIOS TEXTILE INDUSTRY IN THE NORTHEAST REGION : RESTRAINTS ,. v. VIII, n. 85, 2008.

[13] MAYUMI, R.; FUJITA, L. A Indústria Têxtil no Brasil : uma perspectiva histórica e cultural The Brazilian Textile Industry: a cultural and historical perspective. p. 153-174, [s.d.].

[14] MOKTADIR, M. A. et al. Assessing challenges for implementing Industry 4.0: Implications for process safety and environmental protection. Process Safety and Environmental Protection, v. 117, p. 730-741, 2018.

[15] RIBEIRO, J. M. O conceito da indústria 4.0 na confeção: análise e implementação. 2017.

[16] SUSSKIND, D. TED: 3 Mitos sobre o futuro do trabalho (e porque não são verdade). Disponível em:

https://www.youtube.com/watch?v=2j00U6IUC-

$c \& t=2 s>$ acesso em dezembro de 2018.

[17] SUNG, T. K. Industry 4.0: A Korea perspective. Technological Forecasting and Social Change, v. 132, n. November 2017, p. 40-45, 2018.

[18] VAIDYA, S.; AMBAD, P.; BHOSLE, S. Industry 4.0 - A Glimpse. Procedia Manufacturing, v. 20, p. 233-238, 2018.

[19] ZHANG, Q.; CHENG, L.; BOUTABA, R. Cloud computing: State-of-the-art and research challenges. Journal of Internet Services and Applications, v. 1, n. 1, p. 7-18, 2010. 


\section{Bapítulo 8}

\section{DESIGN E SIMULACÃO DOS MOVIMENTOS DE UM BRAÇO ROBOTICO DE 4 GRAUS DE LIBERDADE}

\section{Matheus Adriano Godoy Ramos}

Resumo: O desenvolvimento tecnológico vem sendo cada vez mais um ponto de grande importância, não apenas por inovar, mas por facilitar a vida humana e propor recursos viáveis em diversas áreas de concentração. O presente trabalho visa relacionar a robótica industrial com a tecnologia de simulação a partir da simulação de movimentos de um braço robótico de 4 graus de liberdade criado no software Autodesk Inventor. O estudo apresenta um manipulador de pequeno porte, para fins didáticos e com uma estrutura que o possibilita não apenas ser simulado, mas também ser impresso em impressora 3D para posterior programação dos movimentos das juntas, com a utilização de servo motores. Além disso, o conteúdo abordado permite ao leitor compreender como se comportam o deslocamento angular, a velocidade angular e a aceleração angular ao programar um braço robótico para executar movimentos específicos.

Palavras-chave: Braço robótico; Simulação; Inovar. 


\section{INTRODUÇÃO}

A robótica pode ser definida como o estudo, planejamento e uso de sistemas robóticos para fabricação. Os robôs usualmente são utilizados para realizar tarefas inseguras, arriscadas, repetitivas e desconfortantes, como por exemplo: manuseamento de materiais, montagem, alguns tipos de soldagem, carga de ferramentas de máquinas e funções de descarga, pintura, pulverização, entre outros (KATO, 2015).

Nesse âmbito, de acordo com Graig (2017) há sobretudo dois tipos de robôs: um robô de serviço e um robô industrial. O robô de serviço é um robô que atua de forma parcial ou totalmente autônoma para executar serviços pertinentes para o bem-estar das pessoas e dos equipamentos, excluindo as operações de manufatura. O robô industrial, em contrapartida, é oficialmente definido pela ISO como um manipulador multifuncional controlado automaticamente e programável em três ou mais eixos.

Os robôs industriais que atualmente são muito utilizados em indústrias são criados e projetados para mover materiais, peças, ferramentas ou dispositivos especializados através de movimentos preestabelecidos, programados para operar diferentes tarefas. Um sistema de robôs industriais contém não apenas robôs industriais, mas também dispositivos e/ou sensores essenciais para o robô realizar suas tarefas, bem como sequenciar ou monitorar interfaces de comunicação (CABRAL, 2013).

A partir desse grande avanço tecnológico, para acompanhar as grandes exigências, principalmente relacionadas à precisão $e$ velocidade na execução de tarefas, fez-se necessário o desenvolvimento de técnicas de controle capazes de identificar a trajetória do manipulador a fim de obter êxito no posicionamento do órgão terminal. A técnica mais utilizada é a cinemática inversa que é um processo pelo qual os ângulos das juntas de um atuador são calculados a partir da posição em que se deseja colocar o órgão terminal. O cálculo desses ângulos possibilita a construção de sistemas de controle tendo no seu desenvolvimento as matrizes jacobianas, em conjunto com as pseudoinversas (PINHEIRO, 2013).

Contudo, não somente a cinemática inversa é importante nos projetos relacionados aos robôs, mas também o estudo do comportamento das variáveis deslocamento, velocidade e aceleração durante o movimento automatizado das juntas, o qual será analisado no decorrer desse trabalho.

\section{METODOLOGIA}

A metodologia consistiu em duas etapas, apresentadas a seguir.

\subsection{CONSTRUÇÃO DAS PEÇAS}

A primeira etapa foi a construção das peças no software Autodesk Inventor. Essa etapa consistiu em criar o design do manipulador robótico, levando em consideração que o mesmo será futuramente impresso em impressora 3D para sua programação.

Pensou-se em um braço leve com no máximo $1,5 \mathrm{~kg}$ (uma vez que o intuito é a construção de um braço robótico de baixo custo para fins didáticos), com 4 graus de liberdade, além de possuir um suporte e um órgão terminal que possa ser trocado conforme a aplicação. Com base nessas considerações, suas medidas são de um braço de pequeno porte, a base possui um diâmetro externo de $150 \mathrm{~mm}$; o elo 2 (conectado diretamente com a base) possui um comprimento de $85 \mathrm{~mm}$; os elos 3 e 4 possuem ambos um comprimento de $120 \mathrm{~mm}$; e o elo 5 (elo conectado ao órgão terminal) possui um comprimento de $34 \mathrm{~mm}$. Vale ressaltar que os elos 3 e 4 são compostos pela união de duas peças como mostra a Figura 
Figura 1 - Braço Robótico projetado no software Inventor

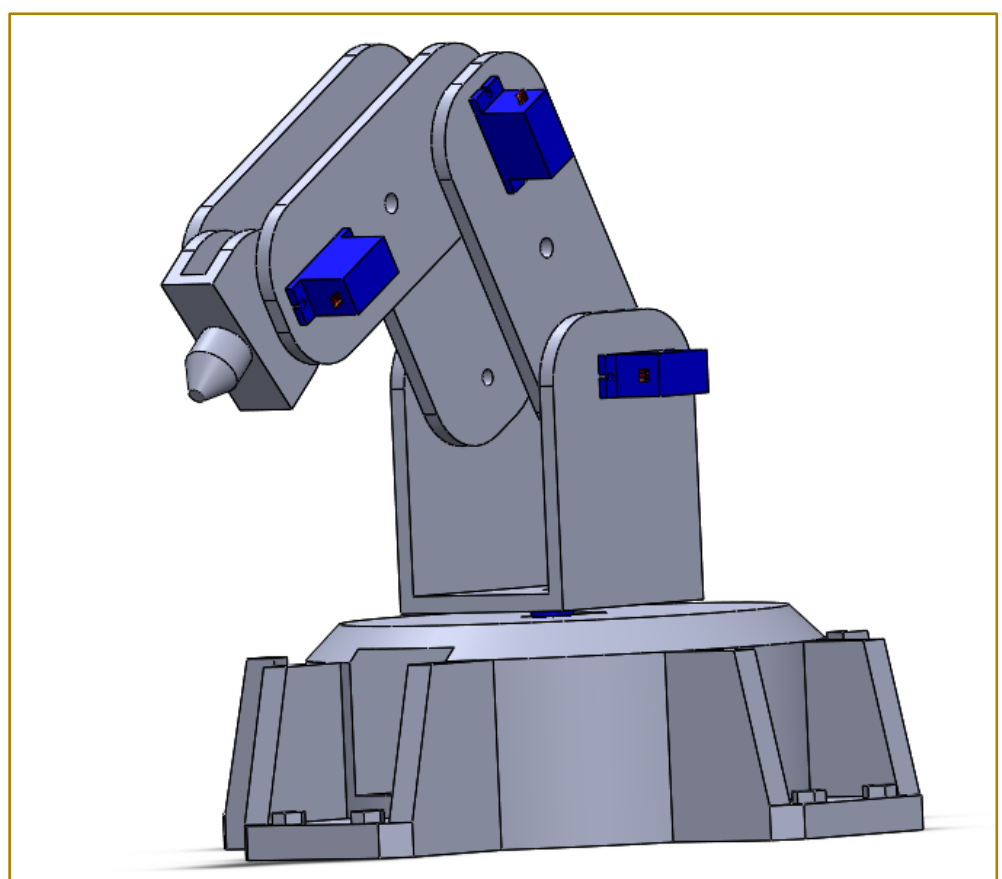

Fonte: Autor, 2018.

Essa estrutura com 5 elos possibilita que o braço execute um movimento rotacional em 4 juntas, sendo, portanto, um braço de 4 graus de liberdade.

\subsection{SIMULAÇÃO}

A segunda etapa baseou-se na simulação. $O$ intuito principal desse manipulador robótico é ser utilizado para movimentar objetos após sua impressão, porém, primeiramente desejou-se simular seus movimentos no software Autodesk Inventor para analisar como suas juntas se comportam, isto é, a partir de um movimento específico qual será o deslocamento, a velocidade e a aceleração angular em função do tempo.

Primeiramente, tomou-se como base o braço estático com as seguintes condições iniciais:
- Elo 2 - Posicionado a 90ํe em relação ao elo 1; ao elo 2;

- Elo 4 - Posicionado a 90ํe em relação ao elo 3;

Elo 3 - Posicionado a $150^{\circ}$ em relação

- Elo 5 - Desconsiderado a angulação deste para a simulação em questão.

Uma vez que o braço esteja posicionado a próxima etapa resumiu-se em inserir "motores ocultos" nas juntas especificando os deslocamentos angulares desejados, para que as mesmas possam efetuar os movimentos, essa condição é possível a partir da ferramenta "Estudo de movimento". A Tabela 1 apresenta os deslocamentos que cada junta irá realizar durante uma trajetória de 5 segundos.

- Elo 1 (base) - Posicionado a 0 o em relação ao eixo horizontal;

Tabela 1 - Deslocamentos angulares das juntas em função do tempo

\begin{tabular}{|c|c|c|c|c|}
\hline Tempo (s) & Junta 1 & Junta 2 & Junta 3 & Junta 4 \\
\hline 0 & 0 & 0 & 0 & 0 \\
\hline 1 & 9,3 & 20 & 10 & 0 \\
\hline 2 & 31,5 & 10 & -10 & 0 \\
\hline 3 & 58,5 & 0 & -30 & 0 \\
\hline 4 & 80,6 & -10 & -10 & 0 \\
\hline 5 & 90 & -20 & 10 & 0 \\
\hline
\end{tabular}

Fonte: Autor, 2018. 
Vale ressaltar que os deslocamentos angulares apresentados na Tabela 1 partem todos da sua própria origem ( $\left.0^{\circ}\right)$, logo, percebe-se que não foi atribuído movimentos para a junta 4, a mesma não varia sua angulação do começo ao fim da simulação. Outra observação é que para as juntas 2 e 3 foram estabelecidos 5 movimentos diferentes partindo da inércia até o instante de 5 segundos (cada um com duração de 1 segundo), diferentemente da junta 1, para a qual estabeleceu-se apenas um movimento partindo desde o repouso até o instante de 5 segundos. Essas considerações justificam o porquê de os valores da junta 1 apresentarem um comportamento diferente das demais.

\section{ANÁLISE DOS RESULTADOS}

Após a simulação dos movimentos das juntas obteve-se os dados disponibilizados pelo software. Como mencionado anteriormente, a junta 1 percorre uma trajetória angular sem alterar o sentido, uma vez que especificou-se apenas um comando de movimento, de $0^{\circ}$ até 90․ Caso fossem especificados 5 movimentos para a junta 1 a partir de $0^{\circ}$ até 90으. o deslocamento não seria contínuo, ou seja, a junta estacionaria por alguns milissegundos para iniciar o próximo movimento, causando dessa forma, uma aceleração e desaceleração a cada novo movimento.

\subsection{ANÁLISE DO COMPORTAMENTO DA JUNTA 1}

As Figuras 3, 4 e 5 apresentam os gráficos de deslocamento, velocidade e aceleração em função do tempo para a junta 1, obtidos a partir da simulação.

Figura 3 - Deslocamento angular da junta 1

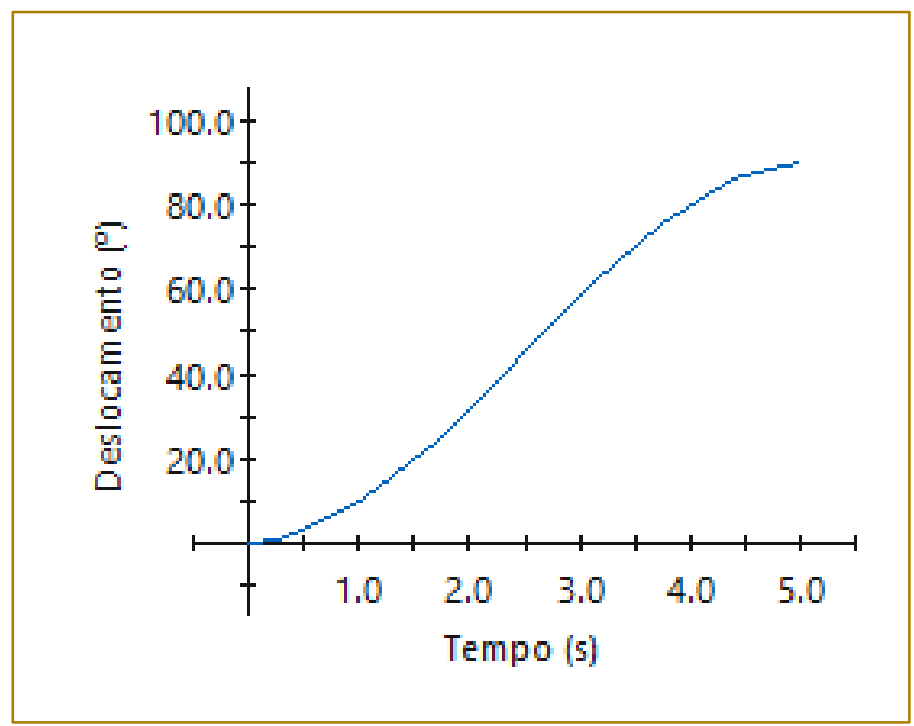

Fonte: Autodesk Inventor, 2018.

Percebe-se pela Figura 3 que 0 comportamento da junta é equivalente a um movimento real, visto que ao partir da inércia a velocidade varia de acordo com o tempo, gerando uma curva não linear de deslocamento. 
Figura 4 - Velocidade angular da junta 1

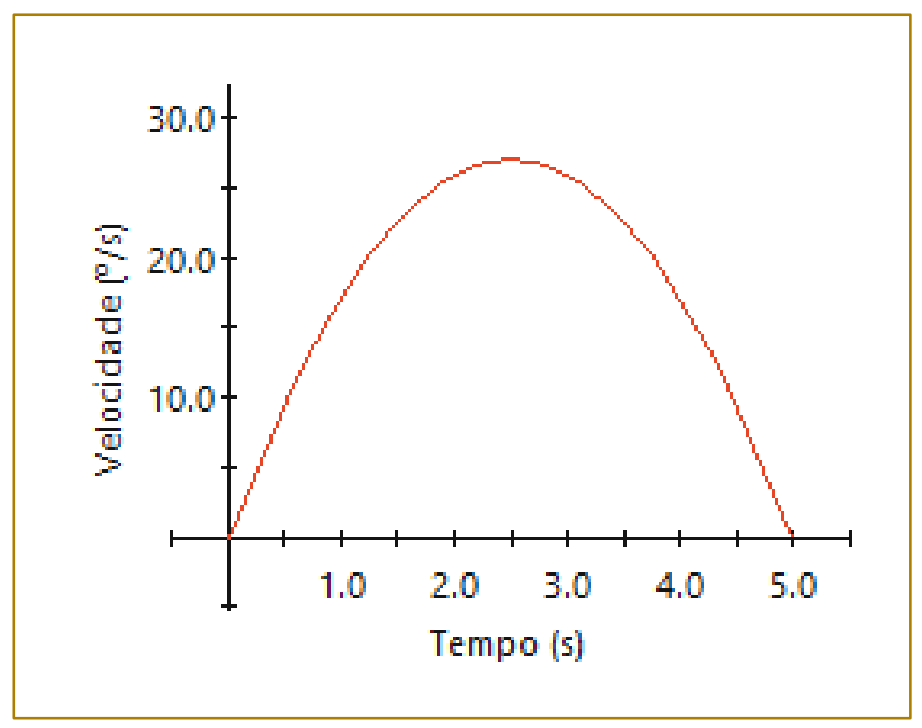

Fonte: Autodesk Inventor, 2018.

Pela Figura 4 verifica-se que a maior velocidade é atingida no meio do trajeto, isso ocorre devido ao movimento ser realizado em um curto espaço de tempo e, portanto, a junta tende a acelerar até atingir o tempo médio e após isso desacelerar até completar $\mathrm{O}$ movimento estabelecido.

Figura 5 - Aceleração angular da junta 1

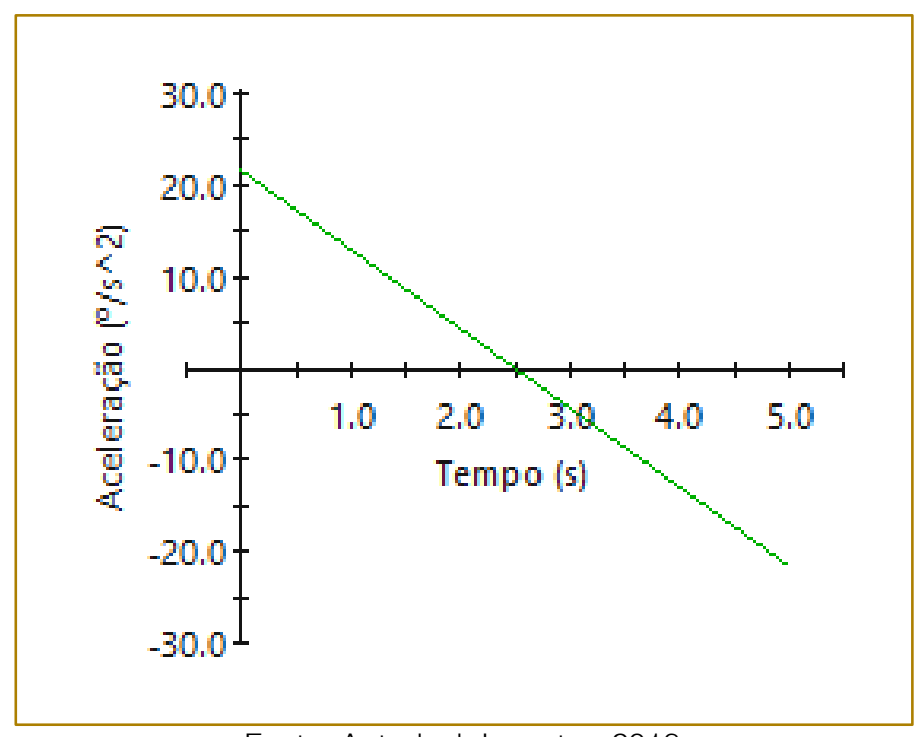

Fonte: Autodesk Inventor, 2018.

Com base na Figura 5 fica inteligível o que foi mencionado anteriormente. A junta tem sua aceleração máxima no início e final da trajetória, mudando o sentido logo que é atingido a velocidade máxima.
A seguir a Tabela 2 apresenta os valores de deslocamento, velocidade e aceleração obtidos a partir dos gráficos das Figuras 3, 4 e

5. 
Tabela 2 - Deslocamento, velocidade e aceleração para a junta 1

\begin{tabular}{|c|c|c|c|}
\hline Tempo $(\mathrm{s})$ & Deslocamento $(\stackrel{\circ}{ })$ & Velocidade $(\% / \mathrm{s})$ & Aceleração $(\% / \mathrm{s} \wedge 2)$ \\
\hline 0 & 0 & 0 & 21,55 \\
\hline 1 & 9,30 & 17,27 & 12,95 \\
\hline 2 & 31,45 & 25,93 & $-4,30$ \\
\hline 3 & 58,50 & 25,93 & $-12,95$ \\
\hline 4 & 80,60 & 17,27 & $-21,55$ \\
\hline 5 & 90 & 0 & \\
\hline
\end{tabular}

Fonte: Autor, 2018.

\subsection{ANÁLISE DO COMPORTAMENTO DA JUNTA 2 \\ função do tempo para a junta 2, obtidos a partir da simulação.}

As Figuras 6, 7 e 8 apresentam os gráficos de deslocamento, velocidade e aceleração em

Figura 6 - Deslocamento angular da junta 2

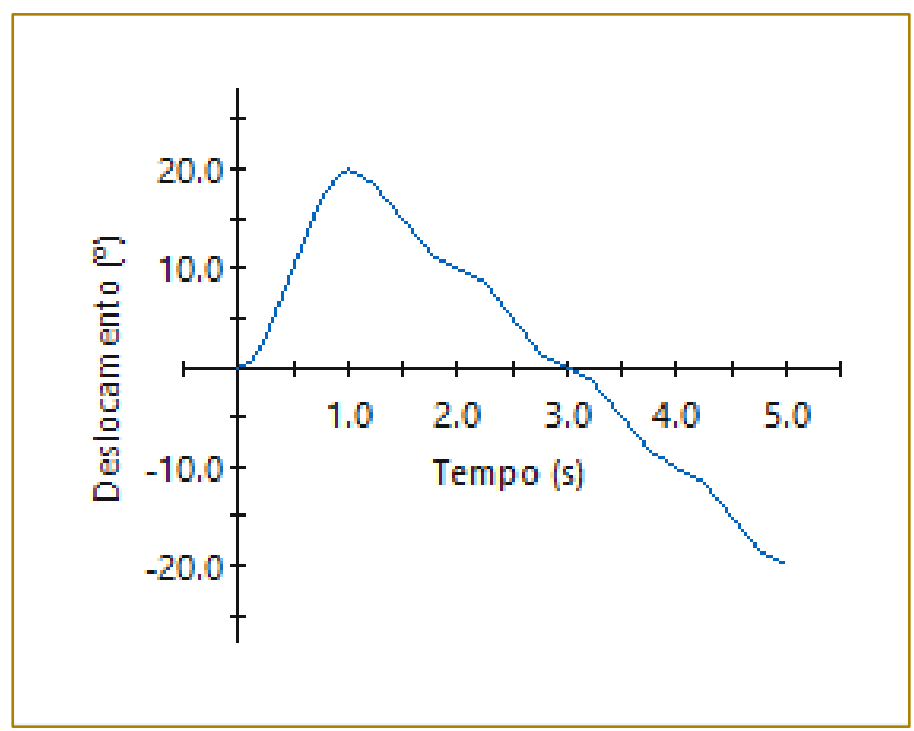

Fonte: Autodesk Inventor, 2018

Percebe-se pela Figura 6 que o fato de definir 5 movimentos diferentes durante o trajeto da junta fez com que a mesma não se deslocasse linearmente, mesmo quando o movimento seguinte mantém o mesmo sentido, como é o caso dos movimentos que vão desde o instante 1 até o instante 5 . Esse fato acontece porque a cada início e fim de movimento há uma aceleração e desaceleração, respectivamente. 
Figura 7 - Velocidade angular da junta 2

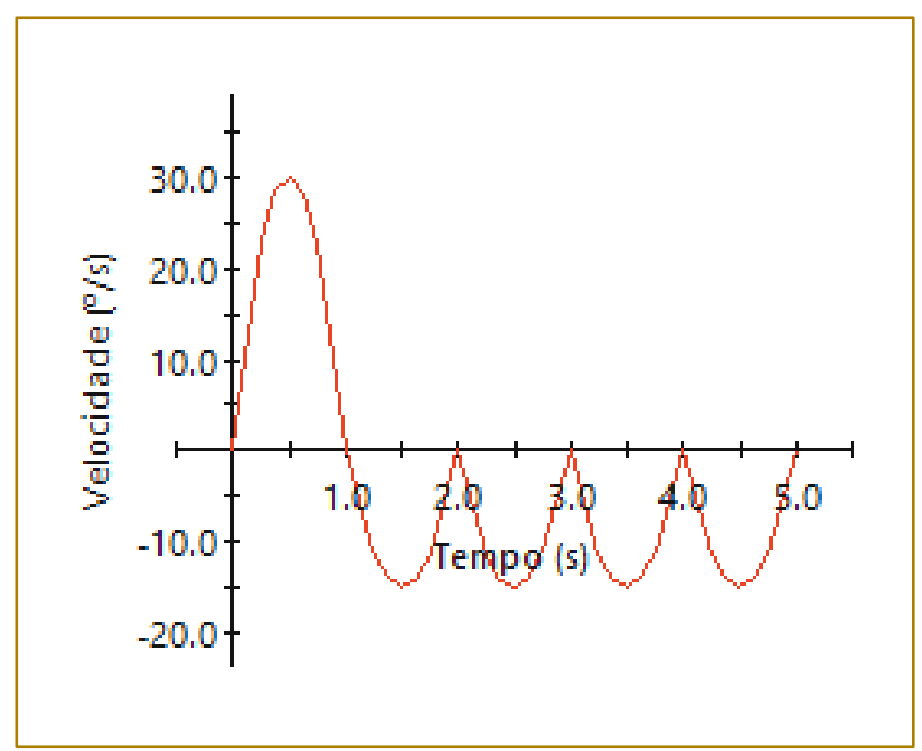

Fonte: Autodesk Inventor, 2018.

Pela Figura 7 verifica-se que há picos de velocidade durante a trajetória dessa junta em consequência da realização de um movimento por vez, gerando dessa forma, uma ligeira parada entre os movimentos. Nota-se também que a maior velocidade é atingida no intervalo de tempo onde o deslocamento requerido é maior, exigindo, dessa forma, uma velocidade maior durante esse período.

Figura 8 - Aceleração angular da junta 2

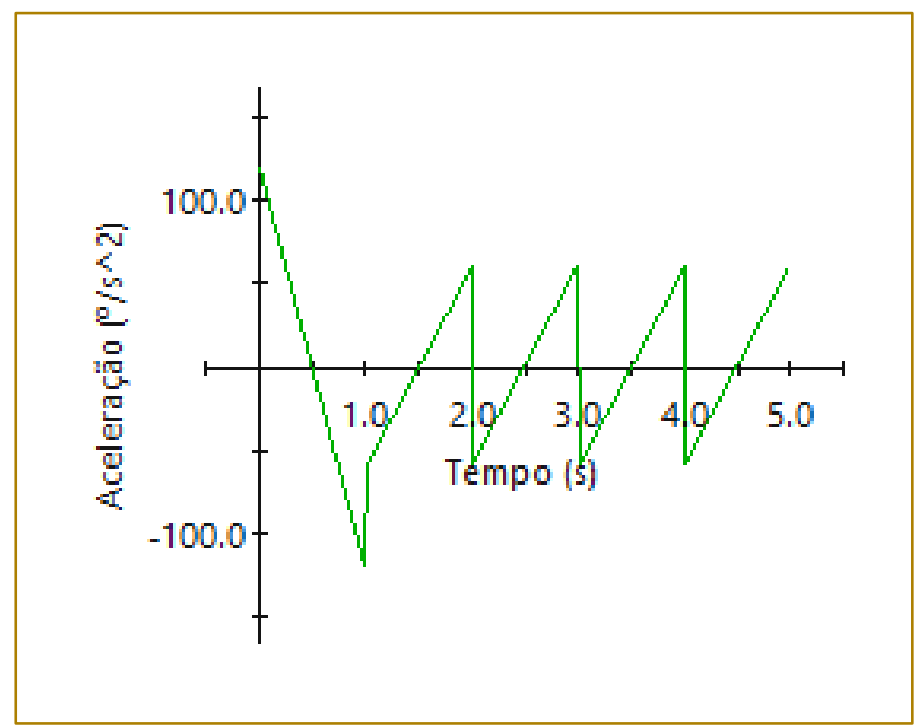

Fonte: Autodesk Inventor, 2018.

Com base na Figura 8 observa-se que nos instantes em que velocidade atinge o valor máximo para cada movimento a aceleração é nula. Matematicamente descobre-se o instante em que há a velocidade máxima derivando a equação da mesma e igualando a 0 , uma vez que a derivada da velocidade é equivalente a aceleração compreende-se que os valores apresentados estão coerentes com a realidade.

A seguir a Tabela 3 apresenta os valores de deslocamento, velocidade e aceleração no início e fim de cada movimento, obtidos a 
partir dos gráficos das Figuras 6, 7 e 8 . Notase que a velocidade é nula em todos pontos, devido a ligeira parada da junta para executar o próximo movimento.

Tabela 3 - Deslocamento, velocidade e aceleração para a junta 2

\begin{tabular}{|c|c|c|c|}
\hline Tempo (s) & Deslocamento $(\stackrel{\circ}{)}$ & Velocidade (\%/s) & Aceleração $\left(\% / s^{\wedge} 2\right)$ \\
\hline 0 & 0 & 0 & 120 \\
\hline 1 & 20 & 0 & -120 \\
\hline 2 & 10 & 0 & 60 \\
\hline 3 & 0 & 0 & 60 \\
\hline 4 & -10 & 0 & 60 \\
\hline 5 & -20 & 0 & 60 \\
\hline
\end{tabular}

Fonte: Autor, 2018

\subsection{ANÁLISE DO COMPORTAMENTO DA JUNTA 3}

As Figuras 9, 10 e 11 apresentam os gráficos de deslocamento, velocidade e aceleração em função do tempo para a junta 3, obtidos a partir da simulação.

Figura 9 - Deslocamento angular da junta 3

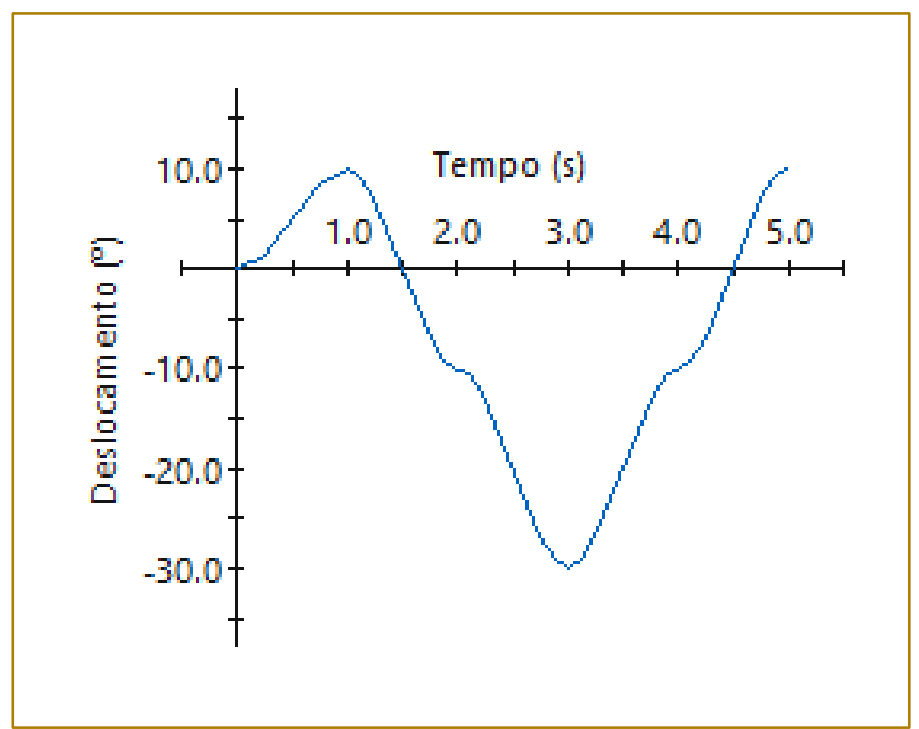

Fonte: Autodesk Inventor, 2018.

Constata-se pelo gráfico da Figura 9 que, os deslocamentos seguem a mesma fundamentação dos realizados pela junta 2, isto é, a cada segundo foi solicitado um novo movimento, fazendo com que a curva apresente oscilações durante $\mathrm{O}$ trajeto. A diferença é o fato de, nesse caso, a junta inverter o sentido duas vezes. 
Figura 10 - Velocidade angular da junta 3

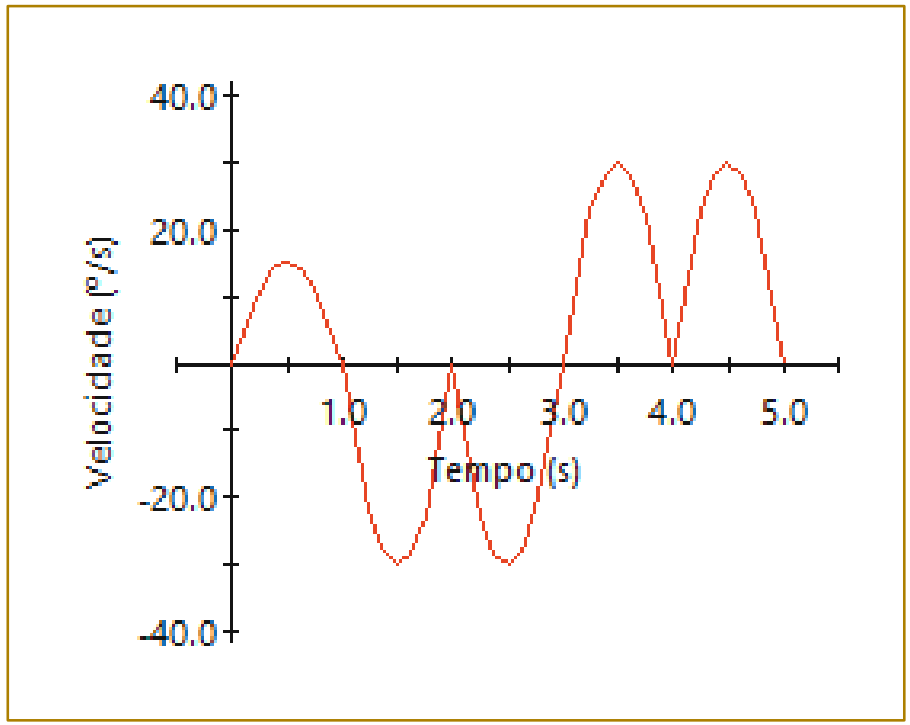

Fonte: Autodesk Inventor, 2018.

Da mesma forma, no gráfico da Figura 10 a velocidade segue o padrão apresentado no tópico anterior, onde a velocidade máxima de cada movimento é atingida no meio do trajeto. Para a junta 3, entretanto, a velocidade máxima do percurso como um todo ocorre em 4 situações, onde há um deslocamento angular de 20 graus durante 1 segundo.

Figura 11 - Aceleração da junta 3

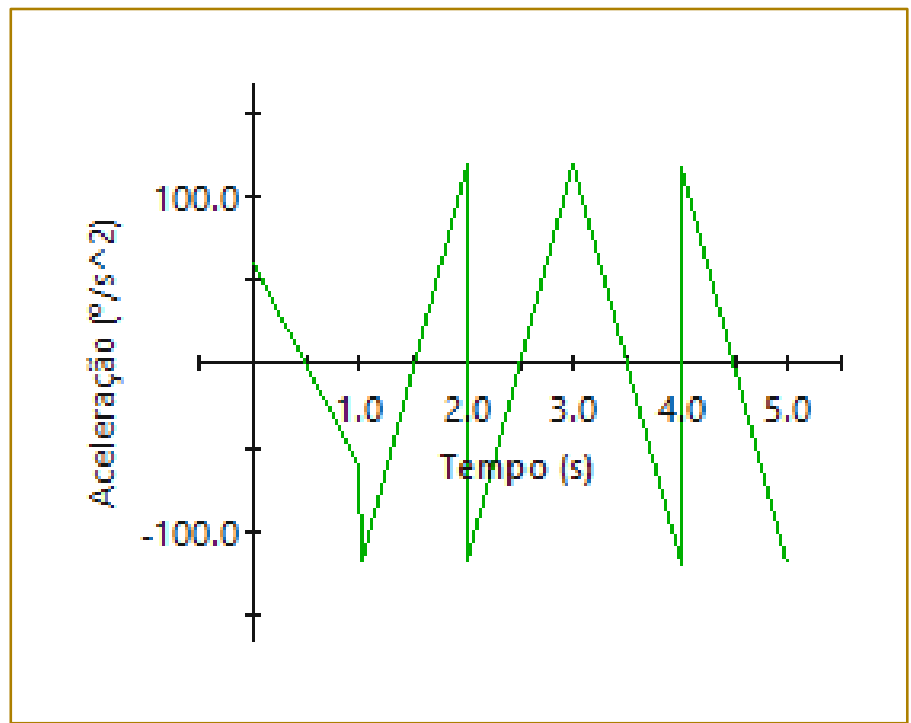

Fonte: Autodesk Inventor, 2018.

Em relação à aceleração durante os movimentos da junta 3 pela Figura 11 verificase que no instante de 1 segundo, logo após efetuar o primeiro movimento, a aceleração é comutada com dois valores distintos, apresentando uma aceleração negativa de 60 \%/s e 120 \%s. Tal fenômeno justifica-se pelo fato de a junta estar realizando um movimento que varia seu deslocamento em $10^{\circ}$ entre os instantes 0 e 1 e em seguida partir para um novo movimento que realiza um deslocamento de $20^{\circ}$ entre os instantes 1 e 2 .

A Tabela 4 apresenta os valores de deslocamento, velocidade e aceleração no 
início e fim de cada movimento, obtidos a partir dos gráficos das Figuras 9, 10 e 11.

Tabela 4 - Deslocamento, velocidade e aceleração para a junta 3

\begin{tabular}{|c|c|c|c|}
\hline Tempo $(\mathrm{s})$ & Deslocamento $(\stackrel{\circ}{*})$ & Velocidade $(\% / \mathrm{s})$ & Aceleração $(\% / \mathrm{s} \wedge 2)$ \\
\hline 0 & 0 & 0 & -60 \\
\hline 1 & 10 & 0 & 120 \\
\hline 2 & -10 & 0 & 120 \\
\hline 3 & -30 & 0 & 120 \\
\hline 4 & -10 & 0 & 120 \\
\hline 5 & 10 & 0 & \\
\hline
\end{tabular}

Fonte: Autor, 2018.

A partir das informações iniciais de simulação e dos dados obtidos após a mesma percebese que cada uma das juntas comportou-se de maneira diferente.

A junta 1 teve um deslocamento contínuo e apenas um pico de velocidade, pois foi atribuído só um movimento para esta junta; A junta dois por sua vez não apresentou uma trajetória contínua, isso se deve ao fato da atribuição de mais de um movimento dentro do intervalo especificado de 5 segundos. Além disso, a junta 2 apresentou uma maior velocidade durante o primeiro deslocamento pois variou $20^{\circ}, 10^{\circ}$ a mais do que nos demais intervalos de tempo; E por fim, a junta 3 apresentou um comportamento semelhante ao da junta 2, entretanto, nesse caso a velocidade no primeiro intervalo de tempo foi menor do que nos outros 4 , nos quais os picos de velocidade obtiveram o mesmo valor em função da igualdade de deslocamento angular entre esses 4 movimentos.

A Tabela 5 apresenta o deslocamento máximo, a velocidade máxima e a aceleração máxima para cada uma das juntas ao finalizar os movimentos estabelecidos.

Tabela 5 - Valores máximos para deslocamento angular, velocidade angular e aceleração angular de cada junta

\begin{tabular}{|c|c|c|c|}
\hline \multicolumn{1}{|c|}{ Junta } & Deslocamento $(\stackrel{\circ}{*})$ & Velocidade $(\% / \mathrm{s})$ & Aceleração $(\% / \mathrm{s} \wedge 2)$ \\
\hline Junta 1 & 90 & 27 & 21,6 \\
\hline Junta 2 & 20 & 30 & 120 \\
\hline Junta 3 & 20 & 30 & 120 \\
\hline Junta 4 & 0 & 0 & 0 \\
\hline
\end{tabular}

Fonte: Autor, 2018.

\section{CONCLUSÃO}

Os resultados obtidos através da simulação foram muito satisfatórios e coerentes com a realidade, demonstrando dessa forma, que a montagem do braço está bem estruturada. A partir da análise dos dados de deslocamento, velocidade e aceleração percebe-se que os gráficos apresentam uma visão real do que, de fato, ocorre com um braço industrial. Isto é perceptível ao verificar os instantes em que os deslocamentos das juntas 2 e 3 invertem o sentido, pois há uma leve inclinação nos gráficos de velocidade $x$ tempo $e$ deslocamento $\mathrm{x}$ tempo. 
Além disso, pelos dados obtidos verificou-se que os mesmos condizem realmente com os conceitos matemáticos e, portanto, demonstra a eficiência do software Autodesk Inventor nesse âmbito.

Como os dados foram satisfatórios e as juntas perfeitamente movimentadas o braço está

\section{REFERENCIAS}

[1] CABRAL, E.L.L. "Análise de Robôs", ch.5. Disponível em: <www.poli.usp.br/p/eduardo.cabral/Cinemática Direta.pdf>. Acesso em 28 de Agosto de 2018.

[2] CARRARA, V. Apostila de Robótica. Disponivel em <http://www. dem.inpe.br/val/homepage/cursos/rb_apostila.pdf> . Acesso em 20 de Setembro de 2018.

[3] CRAIG, J. J. Introduction to Robotics: Mechanics and Control, Vol.3, Pearson Prentice Hall, New York. pp. 62-164, 2005.

[4] GRAIG, J. Introduction to Robotics: Mechanics and Control (4th Edition). Pearson, 2017.

[5] KATO, L. Projeto de um braço robótico para fins didáticos. Universidade Federal de Santa pronto para ser impresso, montado e programado com um micro controlador, a fim de executar movimentos de deslocamento de peças, substituindo, é claro, o órgão terminal apresentado nesse trabalho por uma garra.

Catarina. Relatório submetido à Universidade Federal de Santa Catarina como requisito para a aprovação na disciplina. Florianópolis, 2015.

[6] PINHEIRO, T., PANTOJA, B. Cinemática Inversa de um Manipulado Robótico de quatro Graus de liberdade utilizando método numérico iterativo da jacobiana pseudo-inversa. Instituto de Estudos Superiores da Amazônia, Belém-PA, 2013.

[7] TOLIS, C. An experimental mechatronic design and control of a 5 DOF Robotic arm for identification and sorting of different sized objects. Laboratory of Robotics and Applied Control Systems Dept. Of Electrical Engineering Western Macedonia Univ. of Applied Sciences ,Kozani, Hellas. November 13, 2017. 


\section{Capítulo 9}

\section{IMPLEMENTAÇÃO DE ROBÔS COLABORATIVOS EM UMA INDÚSTRIA DO SETOR AUTOMOTIVO}

\section{Marcela Monique Donadelli \\ Telma Tamires Barbosa Vieira \\ Rafael Rodrigues Benelli \\ Alexandre Carvalho Dantas \\ Ivan Correr}

Resumo: As novas tecnologias estão substituindo a maneira de realizar funções mecânicas, assim, a mão de obra humana tende a deslocar-se para trabalhos que demandem um índice de complexidade e análise maior. Neste contexto surge o conceito de robôs colaborativos, que abrangem as mais recentes inovações tecnológicas nos campos da automação em conjunto com a manufatura flexível. Os robôs colaborativos possibilitam a integração da mão de obra humana compartilhada com a mão de obra robótica, visando o trabalho mútuo por meio de comunicação e cooperação em tempo real com humanos, máquinas e processos. Nesse contexto, o presente artigo tem como objetivo apresentar uma pesquisaação relacionando a aplicação de robôs colaborativos no chão de fábrica, visando identificar as principais abrangências, resultados obtidos, vantagens e a interação homem-robô. Para a elaboração dos resultados foram extraídos dados como: takt time, balanceamento do tempo de trabalho, investimento e payback. Com os resultados obtidos, relacionados a retorno financeiro pode-se concluir que o tema abordado tem crescido consideravelmente e tornado-se de grande relevância para o desenvolvimento de novas tecnologias relacionadas ao uso de robôs colaborativos em sistemas de manufatura.

Palavras chaves: Robôs colaborativos; indústria; payback 


\section{INTRODUÇÃO}

A necessidade de modernização das indústrias para se adequar ao atual desenvolvimento tecnológico e assim garantir a competitividade, gerou uma demanda alta no que se refere à adaptação e dinamismo das organizações e suas maneiras de produção. Os novos métodos de trabalho vieram para coadjuvar e expandir a capacidade de produção das indústrias. Esta adaptação é necessária para se alcançar o conceito de indústria 4.0, que nos agrega vantagens de maneira a reduzir custos de produção e tempos de ciclo, com velocidade e qualidades avançadas (BLOEM et al., 2014).

Um dos objetivos da Indústria 4.0 é viabilizar tecnicamente e economicamente a introdução de novas tecnologias que auxiliem os operadores do chão de fábrica a produzirem de forma mais eficiente e ergonômica (KRUGER, 2009).

Dentro do contexto de modernização, a interação entre robô-homem é altamente necessária e traz o aumento da eficiência sistemática dentro das indústrias. A adaptação de novos tipos de sistemas robóticos é fundamental, assim, a criação do robô colaborativo surgiu para auxiliar as células de produção a possuírem um nível de integração maior entre homem-máquina. Dessa forma, o operador consegue trabalhar ao lado do robô sem sofrer riscos que possa afetar a sua segurança (KRUGER, 2009).

Através do cenário exposto, o presente artigo tem como objetivo aplicar conceitos de robôs colaborativos em uma linha de produção, visando identificar as principais abrangências, resultados obtidos, vantagens e a interação homem-robô no chão de fábrica.

\section{REFERENCIAL TEÓRICO}

\subsection{EVOLUÇÃO DA MANUFATURA - REVOLUÇÃO INDUSTRIAL E INDÚSTRIA 4.0}

Até hoje, foram três marcos classificados pelas revoluções industriais. A primeira revolução industrial teve seu início no século XVIII e foi até meados do século XIX, a qual foi definida pelo aprimoramento das máquinas a vapor e do tear mecânico. A segunda revolução industrial, iniciada no final do século XIX e terminada no início do século XX, teve como marco a utilização em grande escala do aço, a energia elétrica, os motores elétricos e a utilização de combustíveis originados do petróleo. A terceira e última revolução industrial ocorreu no século $X X$, a qual englobou toda a categoria de sistemas computadorizados, avanço tecnológico e robótico para a área manufatureira (KAGERMANN et al., 2013).

Após a terceira revolução industrial (na qual ocorreu o maior uso de tecnologia e equipamentos eletrônicos em fábricas), a Indústria 4.0 chegou para revolucionar os paradigmas estabelecidos pelas outras revoluções. O uso de novas tecnologias, a interconexão de equipamentos de fábricas, por meio da correlação dessas tecnologias, alicerçando margens existentes atualmente de forma a realizar a ligação entre seres humanos e máquinas, tornou-se fator predominante para a evolução manufatureira (SCHWAB, 2016).

O conceito de indústria 4.0, teve seu início sendo apresentado como um projeto de alta tecnologia do governo alemão, na qual o objetivo principal era que as tecnologias fossem interligadas e integradas nos processos produtivos. Nesses processos as máquinas, ferramentas e o próprio produto estariam ativos e por meio de inteligência artificial iriam se comunicar e definir automaticamente como $\mathrm{o}$ produto seria fabricado, dessa maneira, os robôs colaborativos, foram definidos como um dos pilares da indústria 4.0 (KAGERMANN et al., 2013).

\subsection{ROBÔS COLABORATIVOS}

Em um dado momento, o ser humano sentiu a necessidade de buscar a melhoria da qualidade do padrão de qualidade de serviços através da possibilidade de substituição do operário em trabalhos executados em ambientes insalubres ou trabalhos braçais que demandassem força mecânica excessiva, além de buscar o aumento da produtividade e à redução de custos nas indústrias (LAFRATTA, 1990).

A utilização de robôs nas indústrias não é um conceito novo no mercado, porém, a integração do trabalho entre homem e robô é uma novidade que surgiu através dos robôs colaborativos, que são máquinas que agem com autonomia e operam em um ambiente real sem qualquer tipo de controle externo, dividindo o espaço com seres humanos. Podem ser definidos também como máquinas 
autossuficientes capazes de operar em ambientes de forma rápida e eficiente, executando tarefas complexas, com autonomia, flexibilidade e cooperatividade (BEKEY, 2005).

De acordo com a International Federation of Robotics (2016), os robôs colaborativos estão revolucionando as indústrias ao redor do mundo. Até 2019, é estimado um aumento na produção de robôs, podendo chegar a mais de 1,4 milhão de novas máquinas industriais ao redor mundo. Dessa maneira, o desafio enfrentado por todas as indústrias de atender a demandas cada vez mais exigentes de mercado será aliviada com a utilização em nova escala dos robôs colaborativos. Indústrias consagradas como a automotiva já estão realizando as mudanças necessárias para adequar as linhas de produção a utilização total de maquinários especiais como robôs, dando espaço para o trabalho humano em áreas que necessitem de trabalhos racionais, substituindo os braçais pelas máquinas.

Para classificar um robô como colaborativo, ele deve estar de acordo com as normas ISO 10218 (Robots and robotic devices -- Safety requirements) parte 1 e 2 , que definem suas quatro características. A parada monitorada de segurança, talvez a característica primordial de um robô colaborativo, é definida como a total liberdade de um operador trabalhar simultaneamente com este sem colocar em risco sua segurança. Outra característica é "Ensinando manualmente", que é utilizada para guiar o robô ou ensinar o caminho que este deverá percorrer. A terceira característica é "Monitoramento de velocidade e separação", a qual define o ambiente do robô e o robô passa a ser monitorado por um sistema de visão que rastreia a posição dos funcionários. Por fim, a "Limitação de potência e força", a qual define que os robôs colaborativos podem trabalhar ao lado de seres humanos sem dispositivos adicionais (ISO 10218-1, 2011).

\section{TAKT TIME}

O Takt Time pode ser definido como o compasso do tempo (ao pé da letra), origem de palavra alemã. Anos mais tarde, o termo takt time foi repaginado, adequando-se à indústria de maneira a condizer com o ritmo de produção e denominado como sendo a velocidade ou então o tempo estipulado para percorrer os processos produtivos. Ou seja, takt time é o tempo em que deve-se produzir uma peça, ou um produto, baseado na demanda estipulada pelos clientes (COSTA JUNIOR, 2012).

\section{BALANCEAMENTO DE TEMPO DE TRABALHO}

Balanceamento de linha pode ser definido como a forma de dividir de maneira igual todos os trabalhos para uma célula, linha, estágio, para cada operador (SLACK et al., 2002)

Existem alguns passos para balancear uma linha, e faz-se necessário obter informações sobre estudos de tempo, associado ao trabalho, de maneira a alcançar o takt time. O primeiro passo é identificar as somas de tempos poderão ser maior ou menor que o takt time, devido a individualidade de cada padrão estipulado (ORTIZ, 2010).

O segundo passo é identificar no trabalho de estudo de tempo o que pode ser modificado em uma estação de trabalho sem que afete a qualidade do produto e serviço fornecido (ORTIZ et al., 2010).

\section{INVESTIMENTO}

O investimento pode ser definido como o valor estipulado gasto de dinheiro, ou outros recursos financeiros, feitos visando colher benefícios, ou retornos maiores no futuro (CAMARGO, 2007).

O investimento deve ser analisado de acordo com fatos iniciais, que unificados possibilitam classificar vantagens e desvantagens econômicas implementando investimentos em produção de bens ou serviços (REBELLATO, 2004)

Para uma decisão de investimentos bem estruturada, necessita-se uma preparação antecedente, avaliação e escolha das melhores propostas e análise de recursos, objetivando adquirir o retorno estimado a longo ou médio prazo (ASSAF, 2009).

Newman e Lavelle (2000), mostram que inicialmente para que seja viável é imprescindível avaliar e explorar os investimentos para aprovar sua efetividade econômica.

O investimento visado deve ser aquele capaz de pagar o capital que foi aplicado (ASSAF, 2009). 


\section{PAYBACK}

De acordo com Gitman (2010), payback pode ser definido como um meio para determinar quanto tempo a organização levará para recuperar o capital investido no projeto, através de análises de fluxo de caixa, como entrada e lucro obtido em cada período.

O tempo de payback pode ser definido com base em investimentos antecedentes, o quanto refere-se à rentabilidade pretendida, entre outros fatores.

A ferramenta payback é definida como o tempo esperado pelo fornecedor para a recuperação do capital investido. (SEBRAE, 2004).

Pode ser calculado através da fórmula:

Payback = Investimento Total /Lucro Líquido (por ano)

\section{METODOLOGIA DO DESENVOLVIMENTO DA PESQUISA}

Este presente artigo foi realizado em uma empresa multinacional do setor automobilístico, que produz sistemas de exaustão, localizada na região de Campinas interior do estado de São Paulo, com o objetivo de aumentar a produtividade de uma célula para atender a crescente demanda do cliente e reduzir os esforços braçais dos trabalhadores utilizando tecnologias da indústria 4.0. Os dados foram levantados na empresa, contando com o time de desenvolvimento do projeto para implementação do robô colaborativo.

Este artigo trata-se de uma pesquisa-ação e teve como base uma metodologia empírica, realizada em associação a um projeto prático, visando a resolução direta de problemas encontrado dentro de uma organização, na qual ocorre a interação entre pesquisadores do tema, e trabalhadores diretos nas ações tomadas posteriormente (THIOLLENT, 1996).

O início do projeto se deu devido ao interesse de empresa em modernizar sua planta rumo à indústria 4.0, que têm como objetivo aumentar a produtividade, reduzir custos e o esforço braçal do homem. Com este objetivo foi analisado a proposta de se utilizar um robô colaborativo em suas instalações, conforme a figura abaixo.

Figura 1 - Imagem do robô colaborativo.

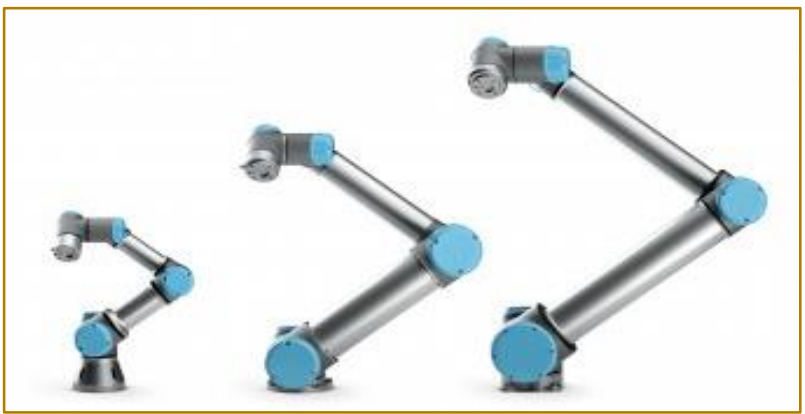

Fonte: Universal Robots (2018).

A partir desta ideia foi analisado em qual célula produtiva ele poderia ser melhor aproveitado e quanto tempo levaria para se obter o payback. Neste estudo a célula encontrada foi a responsável por produzir tubos para o produto de maior volume da fábrica que teve um aumento de demanda de aproximadamente $25 \%$ nos últimos meses. 
Figura 2 - Desenho do produto.

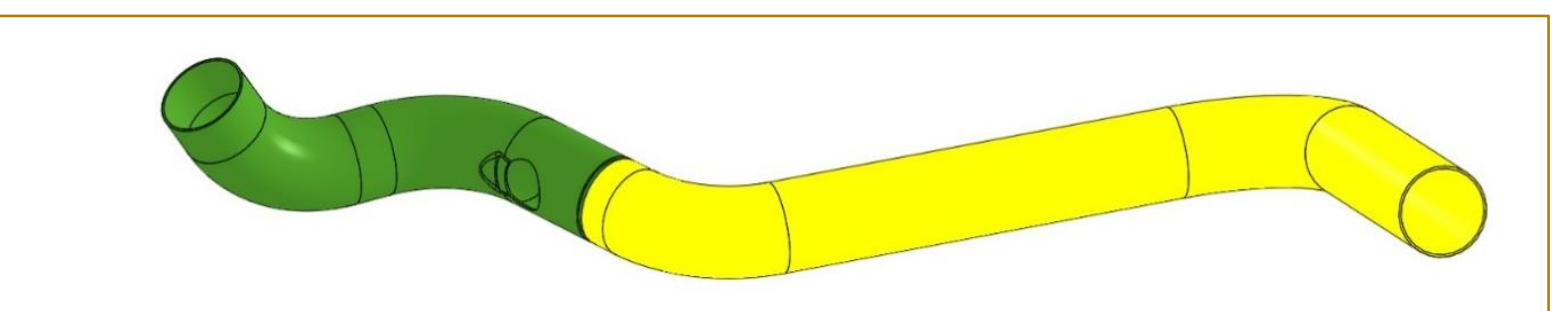

Fonte: Autores (2018).

O processo de fabricação deste tubo é composto pela operação de curvamento CNC (Comando numérico computadorizado), recorte, calibração, furação e acomodação na embalagem, conforme a figura acima. A célula funcionava em 3 turnos trabalhando com 1 operador por turno, conforme mostrado no layout da figura 03, e apresentava os dados de produção abaixo:

Figura 3 - Layout antigo da célula com 01 operador.

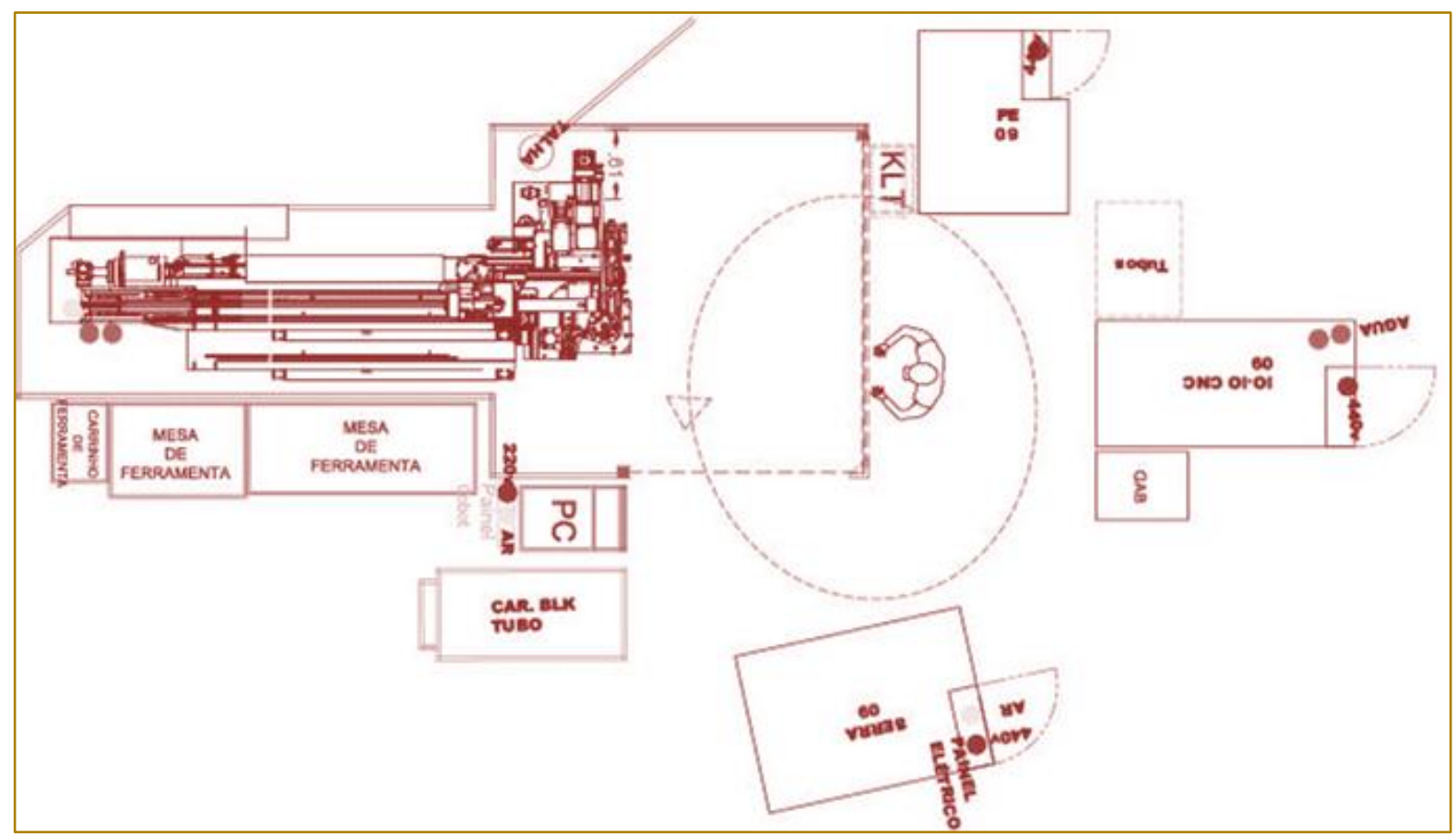

Fonte: Autores (2018).

Dados de produção:

- Demanda diária: 1.380 Peças/dia

- Tempo produtivo disponível: 55.800 segundos/dia
- Tempo de Ciclo: 40 segundos/peça

- Taxa de produção horária: 90 Peças/hora 
Gráfico 01 - Balanceamento antigo da célula com 01 operador.

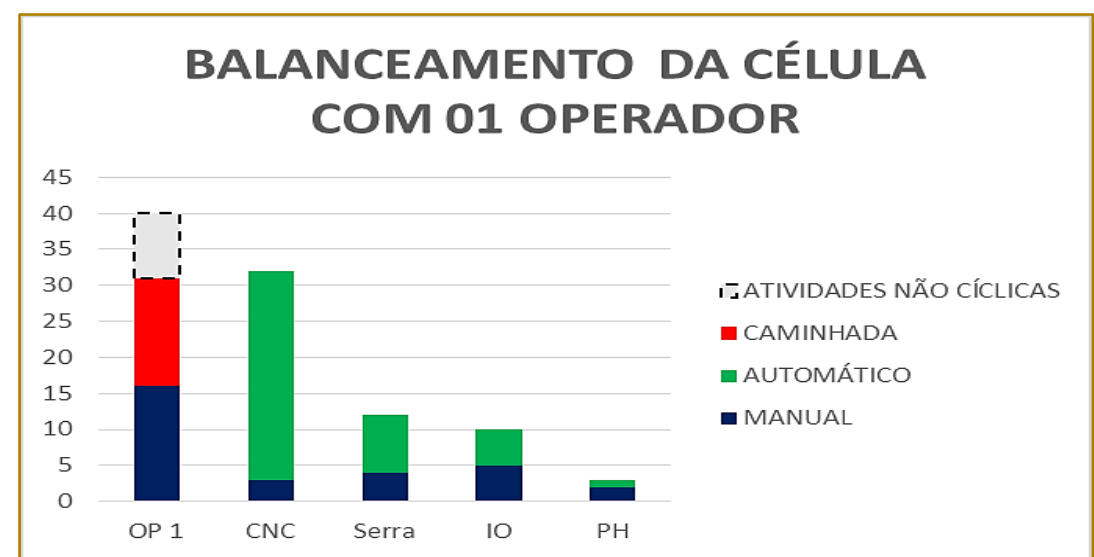

\begin{tabular}{|l|c|c|c|c|c|}
\hline & MANUAL & AUTOMÁTICO & CAMINHADA & ATIVIDADES NÃO CÍCLICAS & TOTAL \\
\hline OP 1 & 16 & $\mathrm{X}$ & 15 & 9 & 40 \\
\hline CNC & 3 & 29 & $\mathrm{X}$ & $\mathrm{X}$ & 32 \\
\hline Serra & 4 & 8 & $\mathrm{X}$ & $\mathrm{X}$ & 12 \\
\hline IO & 5 & 5 & $\mathrm{X}$ & $\mathrm{X}$ & 10 \\
\hline PH & 2 & 1 & $\mathrm{X}$ & $\mathrm{X}$ & 3 \\
\hline
\end{tabular}

Fonte: Autores (2018).

Conforme o gráfico "Balanceamento antigo da célula com 01 operador" acima, foi possível identificar que o operador era o responsável pelo número de peças produzidas, ou seja, ela era o gargalo da célula, e precisava de mais um operador para suportar o aumento de demanda do cliente. Então foi necessário distribuir as atividades entre os dois operadores para melhorar o nível de produtividade da célula. Com esse novo operador os dados da célula foram alterados e ficaram conforme apresentados abaixo:

Dados de produção:

Demanda diária: 1700 Peças/dia

Tempo produtivo disponível: 55800 segundos/dia

Tempo de Ciclo: 32 segundos/peça

Taxa de produção horária:

Figura 4 - Layout antigo da célula com 02 operadores.

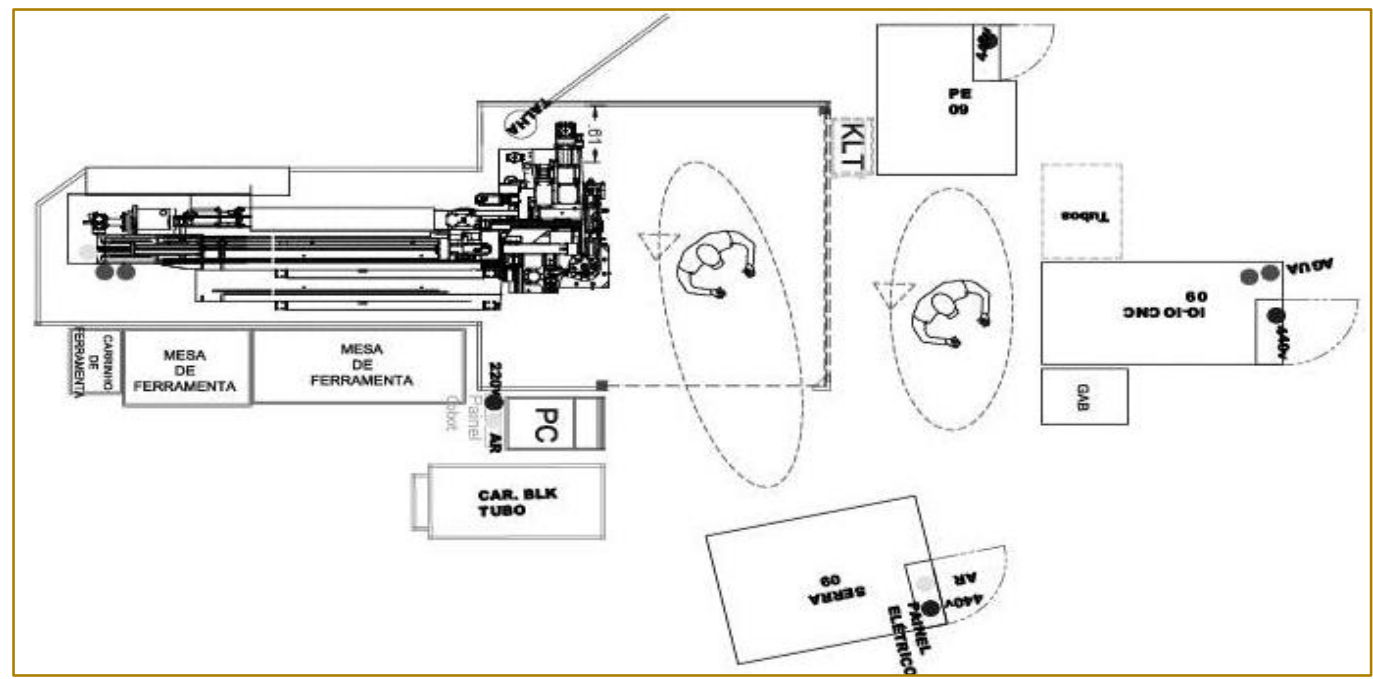

Fonte: Autores (2018) 
Gráfico 02 - Balanceamento antigo da célula com 02 operadores.

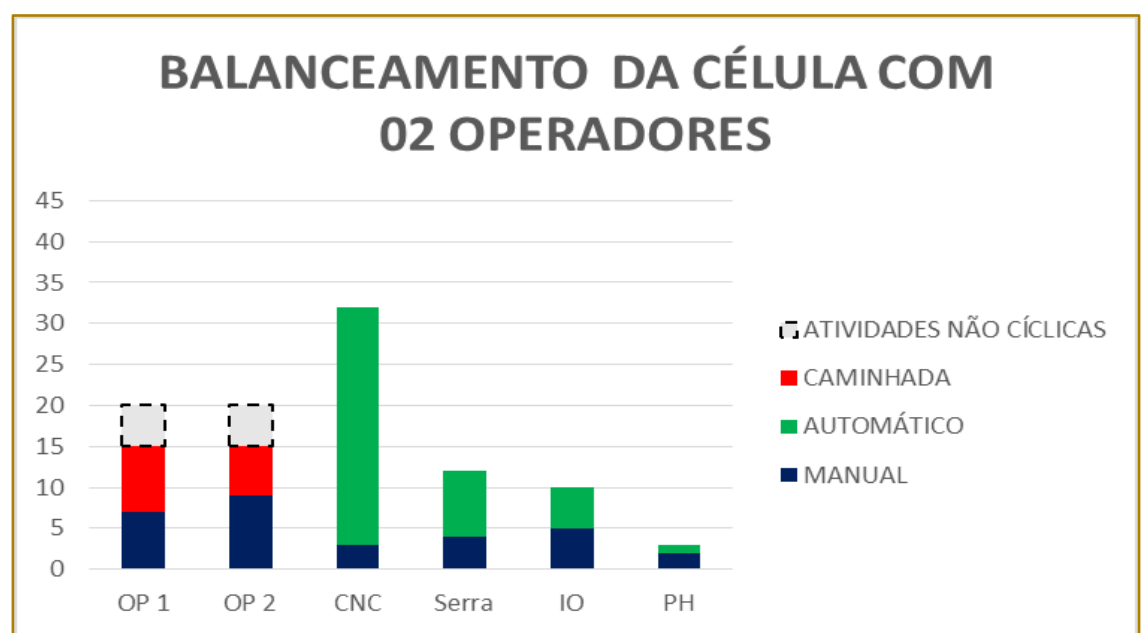

\begin{tabular}{|l|c|c|c|c|c|}
\hline & MANUAL & AUTOMÁTICO & CAMINHADA & ATIVIDADES NÃO CÍCLICAS & TOTAL \\
\hline OP 1 & 7 & $\mathrm{X}$ & 8 & 5 & 20 \\
\hline OP 2 & 9 & $\mathrm{X}$ & 6 & 5 & 20 \\
\hline CNC & 3 & 29 & $\mathrm{X}$ & $\mathrm{X}$ & 32 \\
\hline Serra & 4 & 8 & $\mathrm{X}$ & $\mathrm{X}$ & 12 \\
\hline $\mathrm{IO}$ & 5 & 5 & $\mathrm{X}$ & $\mathrm{X}$ & 10 \\
\hline $\mathrm{PH}$ & 2 & 1 & $\mathrm{X}$ & $\mathrm{X}$ & 3 \\
\hline
\end{tabular}

Fonte: Autores (2018)

Devido ao aumento de demanda geral do setor automotivo nos últimos tempos a empresa precisava contratar mais operadores, além dos 3 recém contratados para operar na célula de tubos, para outras células produtivas. Foi então que se identificou a oportunidade de se utilizar o robô colaborativo, pois a célula em estudo poderia liberar 3 operadores para outras células da fábrica.

Analisando a célula com os dois operadores o gargalo passou a ser a curvadora CNC, ou seja, ela determinava o volume de produção agora. Após essa análise iniciou-se o estudo de onde seria possível instalar o robô colaborativo na célula para manter o nível de produtividade de 02 operadores, mas agora com 01 operador e um robô colaborativo. Novamente através do estudo de tempos foi elaborada uma proposta de divisão de tempos das operações entre o operador e o robô colaborativo conforme apresentado no gráfico abaixo:

Gráfico 03 - Balanceamento da célula com 01 operador e CoBot.

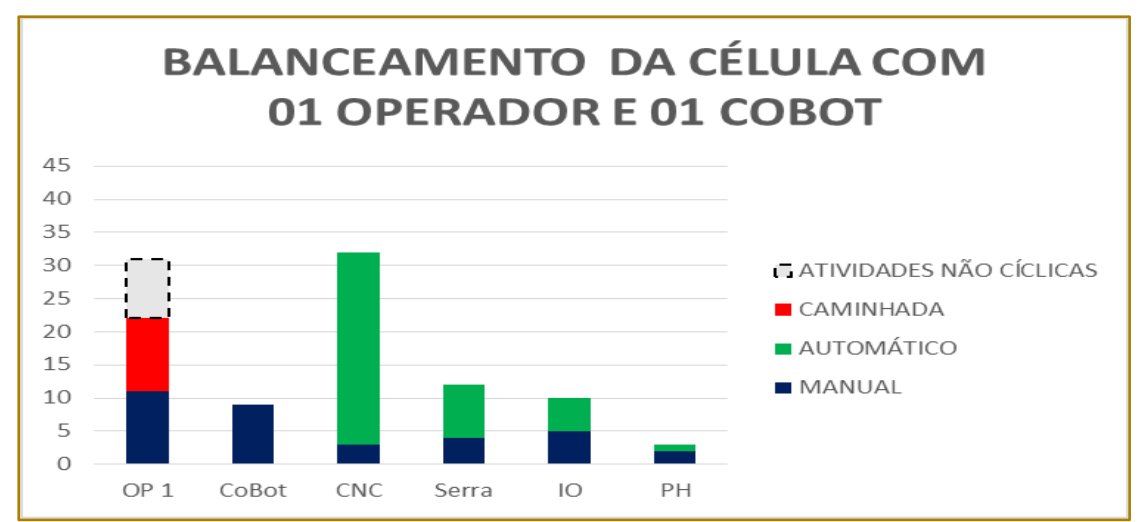




\begin{tabular}{|l|c|c|c|c|c|}
\hline & MANUAL & AUTOMÁTICO & CAMINHADA & ATIVIDADES NÃO CÍCLICAS & TOTAL \\
\hline OP 1 & 11 & $\mathrm{X}$ & 11 & 9 & 31 \\
\hline CoBot & 9 & $\mathrm{X}$ & $\mathrm{X}$ & $\mathrm{X}$ & 9 \\
\hline CNC & 3 & 29 & $\mathrm{X}$ & $\mathrm{X}$ & 32 \\
\hline Serra & 4 & 8 & $\mathrm{X}$ & $\mathrm{X}$ & 12 \\
\hline IO & 5 & 5 & $\mathrm{X}$ & $\mathrm{X}$ & 10 \\
\hline PH & 2 & 1 & $\mathrm{X}$ & $\mathrm{X}$ & 3 \\
\hline
\end{tabular}

Fonte: Autores (2018).

Após a análise de a proposta ser aprovada pelos especialistas e engenheiros deu-se início ao estudo de viabilidade econômica para justificar o investimento necessário e verificar quanto tempo seria necessário para se obter o retorno do valor aplicado. A proposta de viabilidade econômica se dá através da relação entre o valor investido e o ganho com a redução de necessidade de mão de obra na célula. Para identificar os valores necessários para o investimento foi elaborado uma lista com os custos dos equipamentos que está apresentada abaixo:

Tabela 1 - Custos de investimento

\begin{tabular}{|l|r|}
\hline Robô colaborativo & $\mathrm{R} \$ 106.500,00$ \\
\hline Rampa de abastecimento & $\mathrm{R} \$ 12.178,15$ \\
\hline Sistema de lubrificação & $\mathrm{R} \$ 14.880,00$ \\
\hline Scanner & $\mathrm{R} \$ \mathbf{6 . 1 5 9 , 0 0}$ \\
\hline Garra & $\mathrm{R} \$ 22.480,00$ \\
\hline Gradil + Rampa de saída & $\mathrm{R} \$ 5.130,00$ \\
\hline TOTAL & $\mathbf{R} \$ \mathbf{1 6 7 . 3 2 7 , 1 5}$ \\
\hline
\end{tabular}

Fonte: Autores (2018)

Após o levantamento de custos foi analisado quanto tempo, em meses, seria necessário para se obter o payback dado pela função: payback = Valor de Investimento / Saving
Mensal. O saving mensal apresentado consiste no valor gasto pela empresa para manter os 3 operadores mensalmente que é de $R \$ 15.820,00$ por mês.

\section{CÁLCULO DO PAYBACK}

$$
\text { Payback }=\frac{167 \cdot 327,15}{15 \cdot 820,00}=10,58 \text { meses }
$$

Com o payback aprovado pela companhia se deu início a implementação do robô colaborativo na célula. Após a instalação dos recursos a célula apresentou os seguintes dados produtivos:

Dados de produção:
- $\quad$ Tempo produtivo disponível: 55800 segundos/dia

- Tempo de Ciclo: 32 segundos/peça

- Taxa de produção horária: 112 Peças/hora

- Demanda diária: 1700 Peças/dia 
Figura 5 - Layout atual da célula com 01 operador e o cobot.

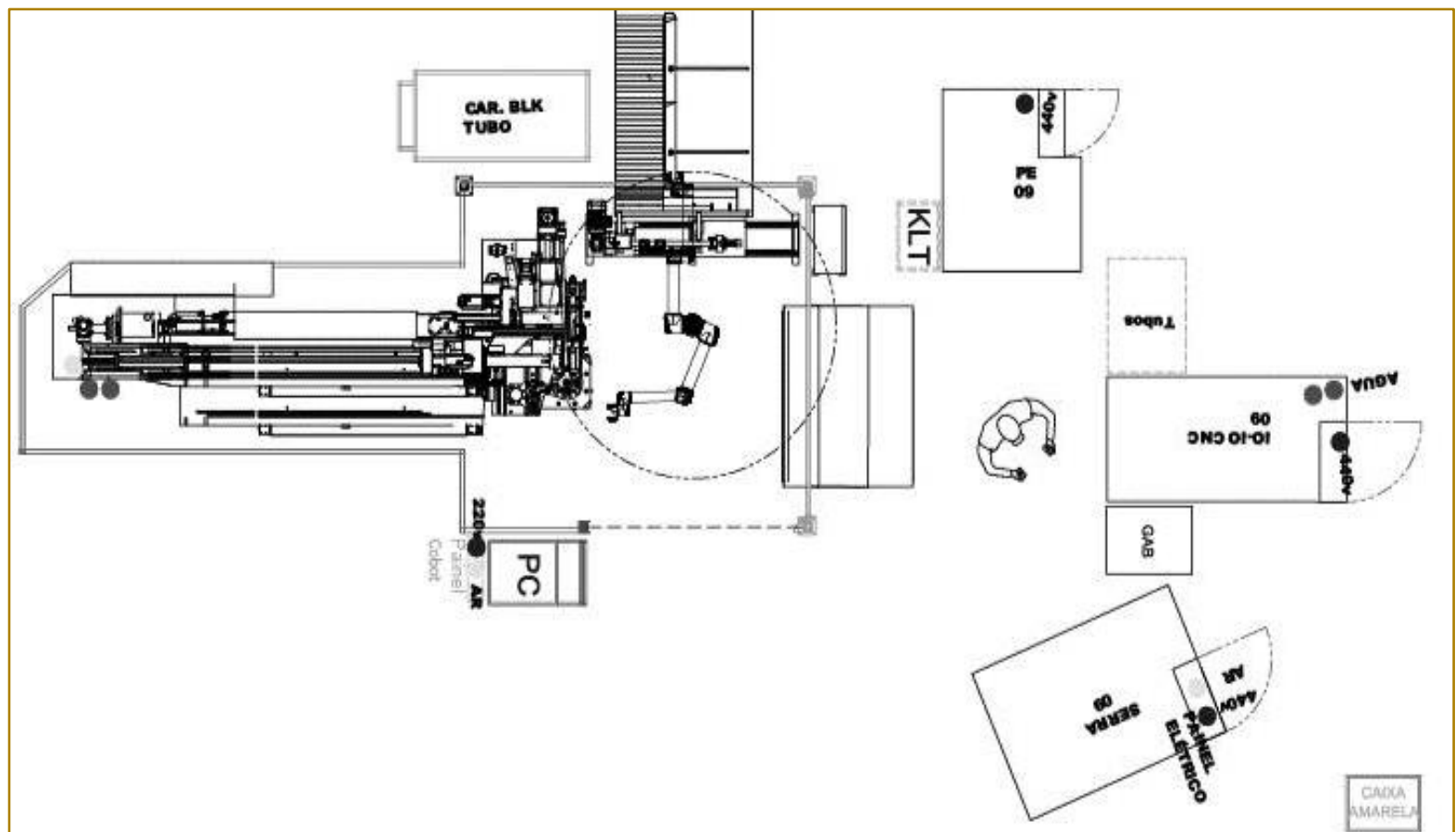

Fonte: Autores (2018).

Com a análise dos dados da célula após a instalação do robô colaborativo podemos confirmar sua viabilidade, pois a célula mantém o mesmo nível de produção de quando possuía 02 operadores.

\section{CONSIDERAÇÕES FINAIS}

O presente artigo atingiu o objetivo de apresentar a introdução dos robôs colaborativos em uma linha de produção, auxiliando a empresa a melhorar seus resultados produtivos, além disso, foi apresentado as vantagens e como acontece a interação homem-robô. Para a elaboração dos resultados foram extraídos dados como: takt time, balanceamento do tempo de trabalho, investimento e payback.

\section{REFERÊNCIAS}

[1] ASSAF, A. N. Finanças Corporativas e Valor . 4. ed. São Paulo: Atlas, 2009.

[2] BEKEY, G. A. Autonomous Robots. Massachusetts Institute of Technology Press. 2005.

[3] BLOEM, J.; VAN DOORN, M.; DUIVESTEIN, S.; EXCOFFIER, D.; MAAS, R.; e VAN OMMEREN, E. The fourth industrial revolution things to tighten the link between IT and OT. 2014.
Os resultados obtidos mostram uma grande relevância no que se refere ao aumento de produtividade, redução de custos e redução de força mecânica exercida pelo homem, (houve maior comodidade no que se refere à ergonomia do operador), e ao término dos estudos, pôde-se concluir que a instalação do robô colaborativo foi altamente vantajosa e o retorno pôde ser mensurado em apenas 11 meses de implementação. É notável a velocidade com que estamos evoluindo no que se refere às novas tecnologias. Esse projeto serve como base para a introdução de uma metodologia nova aplicada ao chão de fábrica, que de maneira gradativa tem como objetivo final a expansão para o aumento da ergonomia e retornos financeiros futuros nas fábricas em um contexto geral.

[4] CAMARGO, C. Análise de investimentos e demonstrativos financeiros . Curitiba : Ibpex, 2007.

[5] COSTA JUNIOR, EUDES LUIZ. Gestão em Processos Produtivos; Ibpex,Curitiba v.20 ,p. 1226,2008

[6] GITMAN, L. J. Princípios de administração financeira. 12. ed. São Paulo: Pearson, 2010. 
[7] INTERNATIONAL FEDERATION OF ROBOTICS. Disponível em: < https://ifr.org/robothistory> Acesso em: 15 de abr. 2018.

[8] INTERNATIONAL ORGANIZATION FOR STANDARDIZATION ROBOTS AND ROBOTIC DEVICES. Safety requirements for industrial robots. ISO 10218-1:2011, 2011.

[9] KRÜGER, J.; TERJE. K L.; E VERL A. Cooperation of human and machines in assembly lines, 2009.

[10] KAGERMANN, H.; WAHLSTER, W.; AND HELBIG, J. Recommendations for implementing the strategic, 2013.

[11] LAFRATTA, F. H., "Metodologia e instrumentação para qualificação de robôs industriais - Ensaio de repetibilidade", Dissertação de Mestrado, Universidade Federal de Santa Catarina, Brasil Florianópolis, 1990.

[12] NEWMAN, D.; LAVELLE, J. Fundamentos de Engenharia Econômica. 1. ed. Rio de Janeiro: LTC, 2000. $359 \mathrm{p}$.
[13] ORTIZ, CRIZ A. Kaizen e implementação de eventos Kaizen; Bookman, São Paulo, 1eedição,p. 121 -122, 2010.

[14] REBELLATO, D. Projeto de investimento. Barueri : Manole Itda, 2004.

[15] SCHWAB, KLAUS. A Quarta revolução industrial. Editora Edipro. 1ํㅡㄹ ed. Brasil. 2016.

[16] SEBRAE. Como elaborar um plano de negócios. Minas Gerais, 2004.

[17] SLACK, N.; CHAMBER, S e JOHNSTON, R. Administração da produção. Atlas, São Paulo, 2. ed.p.89-95,2002.

[18] THIOLLENT, M. Metodologia da pesquisaação. 7. ed. São Paulo: Cortez, 1996

[19] Universal Robots. Disponível em: $<$ https://www.universal-robots.com/pt/produtos/> Acesso em: 13 de jun. 2018. 


\section{Gapítulo 10}

\section{MODELO DE UTILIZACÃO DE SISTEMAS CIBER-FÍSICOS NA IMPLEMENTAÇÃO DA METODOLOGIA WCM}

\section{Guilherme Louro Brezinski}

André Luiz Alcântara Castilho Venâncio

\section{Eduardo de Freitas Rocha Loures}

\section{Fernando Deschamps}

Resumo: Com a utilização mais frequente de sistemas digitalmente integrados na manufatura, surge a necessidade de adequação de metodologias que já são utilizadas, e inclusive, consideradas referência em boa gestão e efetividade, a essas novas tecnologias cada vez mais presentes e consolidadas. A indústria 4.0 traz consigo a digitalização dos ativos e de toda a informação gerada no ambiente fabril, e isso impacta em todo o fluxo de trabalho, aumentando a transparência, produtividade e comunicação. Estes são, inclusive, os três principais objetivos da Manufatura de Classe Mundial (WCM), uma metodologia criada nos anos 80 visando a excelência industrial e largamente utilizada nos dias de hoje. Este trabalho visa, primeiramente, analisar o contexto em que o WCM está inserido e, após isso, prever uma inserção rápida e segura da principal tecnologia da indústria 4.0, os Sistemas Ciber-Físicos (CPS) em uma manufatura estrategicamente alinhada com a metodologia WCM e os impactos desta inserção, tanto na manufatura quanto na metodologia. Isso será desenvolvido em duas partes: 1) análise das definições pertinentes e 2) criação de um modelo de cooperação entre CPS e WCM.

Palavras chave: Sistemas Ciber-Físicos, Manufatura de classe mundial, Industria 4.0 . 


\section{INTRODUÇÃO}

Desde que surgiu, o conceito de Industria 4.0 tem se difundido em âmbito industrial como a maior tendência tecnológica das últimas décadas. A digitalização total dos processos fabris e das informações geradas no chão de fábrica traz consigo um poder de controle operacional sem precedentes na história da manufatura.

Ser parte desta transformação digital, ao contrário do que pode se pensar, é inevitável. É esperado que a transformação seja de longo alcance, mas o ritmo da mudança seja mais lento do que na ruptura digital da Internet, por exemplo. Devido aos seus longos ciclos de investimento, as empresas tendem a ser conservadoras em suas decisões quando se trata de uma ruptura fundamental. Tecnologias disruptivas que, em muitos casos, não estão vinculadas a grandes atualizações de maquinário, permitirão ganhos de produtividade e novos modelos de negócios e alterarão fundamentalmente 0 cenário competitivo (MCKINSEY, 2015).

Uma questão bastante recorrente nos meios industriais diz respeito a implementação destas novas tecnologias atreladas a indústria 4.0 em ambientes fabris que já possuem uma filosofia de planejamento e de produção bastante embasada. Se, por exemplo, uma empresa trabalha com a filosofia de Manufatura Enxuta (Lean Manufacturing) ou com a metodologia Manufatura de Classe Mundial (World Class Manufacturing ou WCM) estará apta a receber estas novas tecnologias disruptivas sem necessitar passar por mudanças mais profundas em sua estrutura organizacional? Se estas mudanças alterarão todo o cenário competitivo, não é necessário alterar também as metodologias de execução?

Para responder estas questões, este trabalho busca, primeiramente no próximo capítulo, contextualizar o universo de trabalho. Para isso, trabalhamos com os conceitos fundamentais da indústria 4.0, com uma atenção especial para os Sistemas Ciberfísicos (Cyber-Physical Systems ou CPS) devido a sua singularidade de aplicação e seu potencial disruptivo (voltamos a falar sobre eles na seção 2.1). Outro ponto considerado também são as filosofias e metodologias mais praticadas atualmente nas empresas, como, por exemplo, o WCM. Neste artigo, abordamos melhor a perspectiva CPS + WCM, pois ambos possuem objetivos muito parecidos: Transparência, Produtividade e Comunicação. Após isso, no capítulo 3, é realizada uma discussão sobre a implementação do CPS em empresas que utilizam a metodologia WCM, com o impacto desta decisão e seus desafios. No capítulo 4, a partir das descobertas do capítulo 3, é desenvolvido um modelo de fácil implementação CPS que possa abranger toda a metodologia WCM. Por fim, no capítulo 5, são discutidos os resultados do trabalho, e propostas novas abordagens sobre o tema para estudos futuros.

\section{CONTEXTO}

As tecnologias disruptivas da indústria 4.0 prometem fábricas inteligentes altamente eficientes e cada vez mais integradas, com uma troca de informação cada vez maior. A informação, aliás, é o ativo principal da quarta revolução industrial. A análise desta grande quantidade de dados gerada nestes equipamentos integrados possibilita uma mudança de patamar na criação de valor de toda a empresa. Um ponto forte da quarta revolução industrial é que, diferentemente da terceira revolução, esta terá um alto impacto, apesar da limitada substituição de equipamentos.

No entanto, segundo Batalha e Parli (2017), para liberar o potencial da Indústria 4.0, as empresas precisam entender as novas tecnologias e seus desafios e oportunidades. Portanto é vital que vários sistemas sejam totalmente integrados uns aos outros, caso contrário, apenas $40-60 \%$ do valor potencial será capturado.

Toda a atitude tradicional das empresas deverá ser modificada, introduzindo inclusive mudanças radicais (não apenas incrementais) já que, segundo Malavasi (2017) a Indústria 4.0 visa transferir os princípios da internet para o mundo industrial: a fábrica digital é construída sobre o alicerce dos sistemas ciber-físicos e será obtida pela introdução de disruptivas inovações.

\subsection{CPS}

O termo sistemas ciber-físicos (CPS) foi definido como os sistemas em que aplicações naturais e idealizadas para o mundo físico estão intimamente integradas com sistemas computacionais, de comunicação e de controle (mundo digital ou cibernético) 
(BAGHERI et al., 2015). A evolução dos CPS é resultado da interação entre os avanços destas tecnologias e seus potenciais econômicos e sociais.

Os sistemas ciber-físicos são o produto do desenvolvimento contínuo e da utilização integrada de dois principais campos de inovação: sistemas de software embarcado e redes de dados globais como a internet, com sistemas de aplicativos distribuídos e interativos. Estes são capacitados por uma poderosa infraestrutura composta por sensores, atuadores e redes de comunicação que são empregados por empresas que atuam e cooperam em nível global (ACATECH, 2015).

Considerando avanços recentes e a ampla implementação de sensores, sistemas de aquisição de dados, redes de computadores e computação em nuvem tem preparado a infraestrutura para desenvolvimento e implementação de sistemas ciber-físicos. Por outro lado, a vasta utilização destes sensores e sistemas de controle na indústria gera uma quantidade imensa de dados. O gerenciamento de um volume tão grande de dados, que é chamado de Big Data, requer consideração específica (LEE et al., 2013). Neste ambiente, é importante ter uma forma sistemática de adquirir, gerenciar e administrar os dados para se obter as informações desejadas. Os CPS podem ser utilizados para solucionar este problema nas indústrias atuais trazendo controle autônomo e capabilidades de autogerenciamento a máquinas industriais (NATIONAL INSTITUTE OF S. \& TECHNOLOGY, 2013). Na Figura 1, um mapa do universo de aplicação dos sistemas

Figura 1 - Sistemas Ciber-físicos.

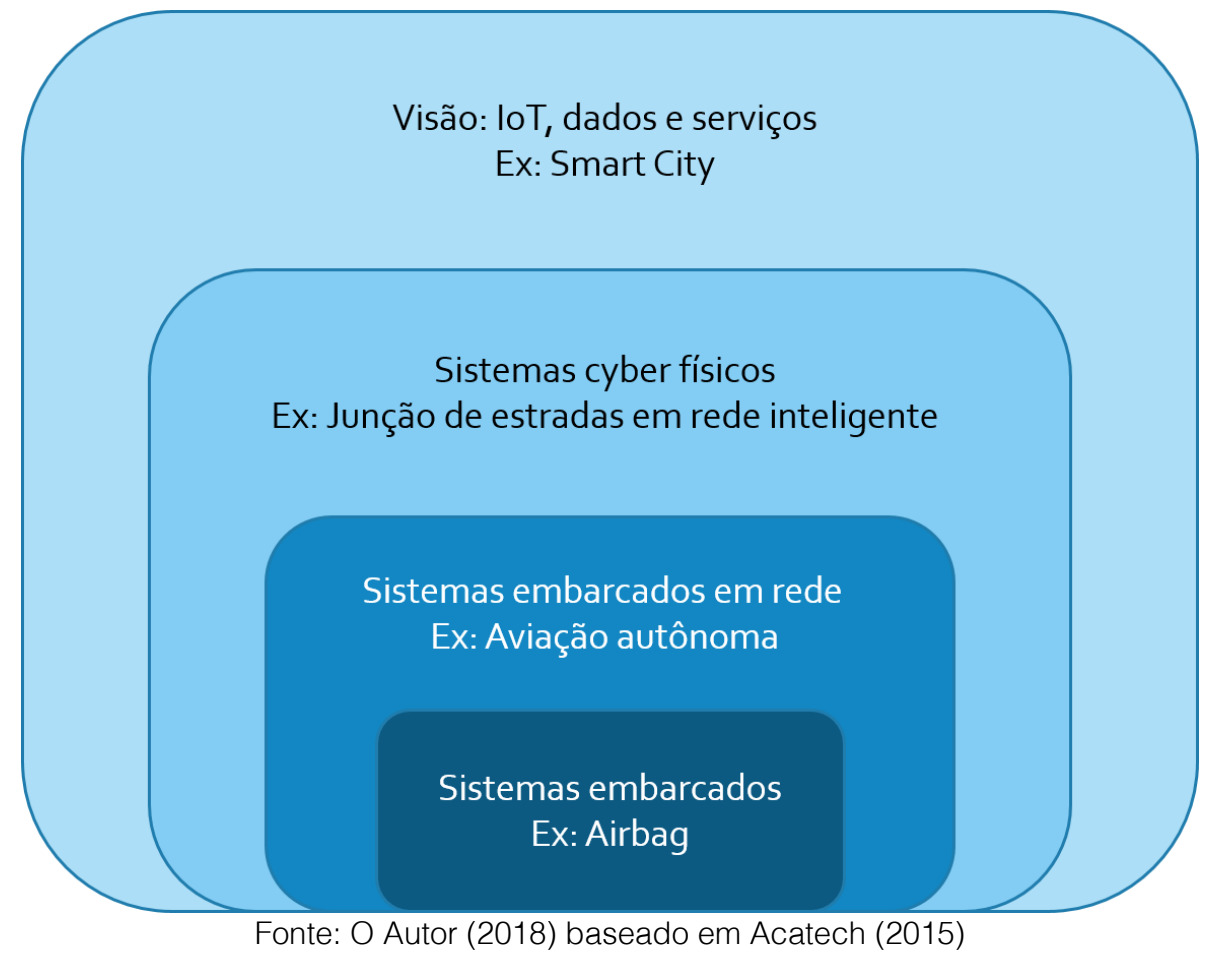

Segundo Acatech (2015), estas são as tecnologias e tendências que atuam como principais impulsionadores dos sistemas ciber-físicos:

a) $O$ uso de poderosos sistemas embarcados inteligentes, serviços móveis e computação onipresente; b) O uso da Internet como uma rede de negócios, ou seja, como uma plataforma de cooperação econômica.

c) O uso dos processos semânticos Web e Web 2.0 e o design interativo de serviços integrados (neste caso, não particularmente interessante para a aplicação de CPS em ambientes industriais, em um primeiro momento, sendo seu uso reservado a aplicações sociais e econômicas). 
São algumas das principais características dos sistemas ciber-físicos:

- Utilizam sensores para capturar diretamente dados físicos e atuadores que afetam os processos físicos;

- Interpretam e armazenam dados que são utilizados como base para interações ativas ou reativas com os mundos físico e digital;

- $\quad$ Estão ligados uns aos outros através de redes digitais que pode ser sem fio ou com fio e local ou global;

- Utilizam dados e serviços disponíveis globalmente;

- Possuem uma gama de interfaces multimodais homem-máquina, oferecendo uma variedade de opções diferenciadas e dedicadas para comunicação e controle, por exemplo, usando comandos de voz e gestos.

\subsection{WCM}

O termo "manufatura de classe mundial" (ou World Class Manufacturing- WCM) foi utilizado pela primeira vez por Hayes e Wheelwright (1985) para descrever organizações que alcançaram uma vantagem competitiva global através do uso de suas capacidades de fabricação como arma estratégica. Eles citam uma série de práticas, incluindo o desenvolvimento da força de trabalho, desenvolvendo um grupo de gestão tecnicamente competente, competindo com qualidade, estimulando a participação dos trabalhadores e investindo em equipamentos e instalações de última geração (Flynn et al., 1997).

Figura 2 - Pilares WCM

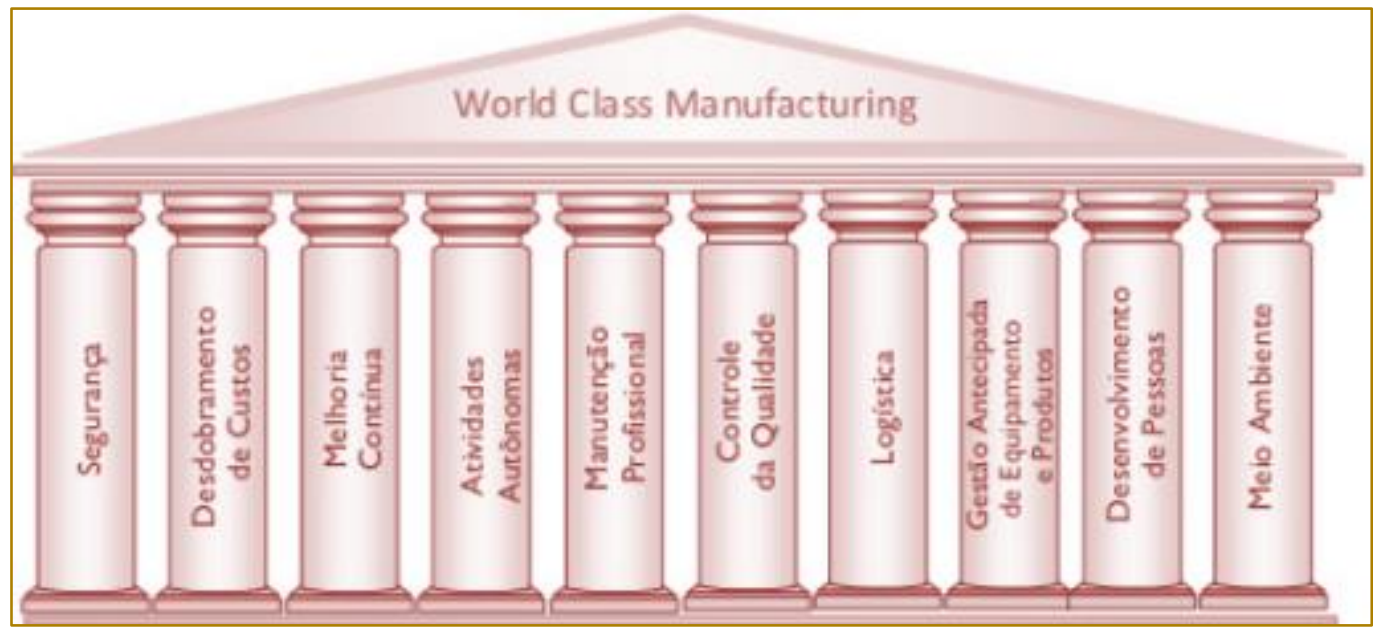

Fonte: Da Silva (2016)

\subsubsection{PILARES WCM}

Como mencionado por Palucha (2012), o modelo WCM é baseado em 10 pilares técnicos interligados (relacionados ao processo de fabricação) conforme ilustrado na Figura 2. Abaixo, uma breve descrição de cada pilar individualmente.

a) Segurança: Evitar acidentes, incorporando comportamento seguro e sua cultura na empresa;

b) Desdobramento de Custos: Reduz o impacto dos problemas de uma perspectiva de desperdício e perda; c) Melhoria contínua: Melhora a qualidade e produtividade, e reduz custos usando métodos apropriados e corretos;

d) Atividades Autônomas: Aumenta a competência dos funcionários do chão de fábrica pelo local de trabalho; layout organizacional em áreas de trabalho intensivo e manutenção autônoma em áreas de capital intensivo:

e) Manutenção Profissional: Zero avarias e minimização dos custos de manutenção;

f) Controle da Qualidade: Zero defeitos, zero desperdício; 
g) Logística: $100 \%$ de satisfação do cliente, eliminando estoque e maximizando o manuseio de material;

h) Gestão Antecipada de Equipamento e Produtos: Lançamento de novos equipamentos ou produtos para ajudar na competitividade e minimizar os custos e o tempo do projeto;

i) Desenvolvimento Pessoal: Educação e treinamento dos funcionários para tornar a WCM responsabilidade de todos;

j) Meio Ambiente: Controle e redução de todo o impacto ambiental das operações.

\section{DISCUSSÃO}

Com o advento da indústria 4.0, é inerente que a manufatura passará por grandes mudanças. Invariavelmente, empresas que adotaram o WCM, que é tido como uma das mais eficientes metodologias de produção que existe, sendo amplamente utilizado ao redor do planeta, precisarão também passar por estas mudanças. Sendo relativamente novo e de aplicação um tanto quanto complexa, simplesmente abandonar toda a metodologia assim que as tecnologias CPS começarem a ser implementadas não é o caminho mais prático, nem mais barato. É preciso fazer com que as novas definições e tecnologias atreladas aos sistemas ciberfísicos trabalhem em conjunto com os pilares já implementados da manufatura de classe mundial. De início, isso pode parecer um trabalho extenso e pouco embasado. Porém partindo da ideia de que ambos conceitos possuem objetivos parecidos, ou que se completam em busca de um ambiente fabril mais transparente, produtivo e comunicativo, é possível mapear mudanças que não apenas serão capazes de habilitar CPS para funcionamento conjunto com as metodologias WCM, como também potencializar as vantagens de utilização dos dois.

No tópico a seguir, discutimos a implementação de CPS em cada pilar técnico da manufatura classe mundial separadamente e suas consequências respondendo duas perguntas:

1) É possível realizar o "encaixe" entre o pilar e a tecnologia?

2) Este encaixe potencializa os conceitos?

As definições encontradas nesta discussão servirão de base para a modelagem no capítulo 4. Serão discutidos também os pilares que, por alguma razão, não se encaixam nas novas tecnologias. No tópico 3.2 é realizada também uma análise de atuação dos sistemas legados nesta implementação.

\subsection{INSERÇÃO DAS TECNOLOGIAS CPS NO CONTEXTO WCM}

1) Segurança

É o pilar que envolve a redução dos fatores geradores de acidentes e ocorrências perigosas. Palucha (2012) diz que este pilar requer ações preventivas mais intensas e habilidades necessárias para eliminar eventos perigosos. Os sistemas ciber-físicos trabalham muito bem com ações preventivas, pois possuem a capacidade de analisar os dados gerados e tomar decisões (geralmente envolvendo cognição e inteligência artificial) em prol de ações mais seguras. Portanto, este pilar não apenas encaixa-se com os conceitos de CPS, como também os potencializa.

\section{2) Desdobramento de Custos}

Neste pilar, o fabricante deve apresentar um plano eficaz de redução de resíduos (desperdício). Segundo Palucha (2012), são realizadas atividades para identificar estes resíduos, determinar local de produção, identificar métodos de eliminação e etc. Assim como o pilar anterior, as tecnologias CPS podem auxiliar este processo por meio da análise quantitativa de dados, potencializando a tomada de decisão para eliminação dos desperdícios.

3) Melhoria Contínua

O principal objetivo aqui é eliminar os resíduos identificados no pilar de desdobramento de custos. Novamente, por meio da análise dos dados gerados no CPS é possível analisar o sucesso na redução de resíduos e eliminar atividades que não geram valor agregado, porém a curto prazo sem uma potencialização nas atividades do pilar.

\section{4) Atividades Autônomas}

Este é, sem dúvidas, o pilar mais afetado pela introdução dos sistemas ciber-físicos no ambiente fabril. As atividades autônomas são o centro da transformação ciber-física. A capacidade de se auto reparar e o envolvimento em um sistema de cooperação autônomo que capacita os sistemas a auto regulação e tomada de decisão são os fatores 
que tornam os CPS tão atraentes. Aqui não apenas o pilar é potencializado, como também é elevado ao posto de "estado da arte" possível da manufatura de classe mundial.

\section{5) Manutenção Profissional}

Segundo Palucha (2012) o escopo das atividades associadas a este pilar é resultado do número de falhas que ocorrem em muitos sistemas, falta de medidas preventivas sistemáticas e falta de cooperação entre os operadores das máquinas e a equipe de manutenção. Este pilar também é potencializado com a utilização de CPS na criação de medidas preventivas, já que torna a comunicação e transparência quanto ao status das máquinas muito mais acessíveis e claros.

\section{6) Controle da Qualidade}

Este pilar é geralmente projetado para fornecer aos clientes produtos de alta qualidade a um custo mínimo, para desenvolver condições adequadas de operação para sistemas de produção e para aumentar as habilidades de resolução de problemas de qualidade dos funcionários. O pilar também será afetado pela utilização de CPS, porém, não deve ter mudanças a curto prazo no modo de operação.

\section{7) Logística}

O objetivo aqui é criar condições favoráveis para o fluxo de materiais dentro da empresa e entre os fornecedores e a fábrica e reduzir o nível de estoque. Os CPS influenciam diretamente nestes objetivos, auxiliando a tomada de decisão quanto aos níveis de estoque e a utilização de matéria prima. Porém, sem total interoperabilidade entre o setor de produção e demais setores envolvidos na logística, este pilar é apenas afetado pela introdução de CPS.

8) Gestão Antecipada de Equipamento e Produtos

Outro pilar que, além de potencializado pela tecnologia CPS, acaba alcançando um nível de excelência operacional com a introdução destas tecnologias. A implementação eficiente de um novo equipamento permite a otimização de custos e a eliminação de perdas resultantes do período de inatividade, e isso é também um dos principais objetivos de possuir um sistema disponível em meios físicos e virtuais.

\section{9) Desenvolvimento Pessoal}

Segundo Palucha (2012), as atividades dentro deste pilar são garantir, por meio de um sistema estruturado de treinamento, habilidades e qualificações apropriadas para cada cargo. Em curto e médio prazo, as implementações CPS não possuem efeito visível neste pilar.

\section{0) Meio Ambiente}

O décimo pilar é utilizado para atender aos requisitos e padrões da gestão ambiental. A longo prazo, os sistemas ciber-físicos atenderão também estes requisitos. Mas por não ser objetivo principal da implementação, aqui consideraremos que em um primeiro momento este pilar também não é afetado.

\subsection{SISTEMAS LEGADOS}

É importante frisar também que na transição para sistemas ciber-físicos proporcionada pela Indústria 4.0 alguns sistemas naturalmente não possuirão as características necessárias para adequação. A esses sistemas, damos o nome de sistemas legados. São características dos sistemas legados: (i) possuem extrema relevância para a organização em matéria de negócios (valor de negócio); e (ii) suas características são obsoletas em relação as exigências técnicas dos demais sistemas da organização Uma estratégia bem aceita no âmbito acadêmico é a adesão de uma camada sensorial a esses sistemas, para que seja possível a interação deles com o resto dos sistemas inteligentes na manufatura.

\section{MODELAGEM}

Depois de analisado cada caso de implementação das tecnologias ciber-físicas nos moldes estruturados pelos pilares da manufatura de classe mundial, é possível observar que a transformação tecnológica que trará os conceitos de digitalização e horizontalização dos meios de produção pode sim se desenvolver em um ambiente já ocupado por metodologias como o WCM. De fato, alguns pilares WCM parecem não apenas encaixar (juntar ou unir) corretamente com os conceitos dos sistemas ciber-físicos, como também ter seus objetivos e meios de realização potencializados (tornado mais eficaz, ativo, ou ter seus efeitos reforçados) por estes conceitos. No capítulo 3, foram definidos os papéis de cada um dos pilares e 
as consequências da evolução CPS. Além disso, foram respondidas as questões: "É possível realizar o "encaixe" (ou junção, união) entre o pilar e a tecnologia?" E "Este encaixe potencializa os conceitos?". $\mathrm{Na}$ Tabela 1 é possível observar um compilado das respostas.

Tabela 1 - Resultado da aplicação de CPS em cada pilar WCM

\begin{tabular}{|l|l|}
\multicolumn{1}{c}{ Pilar WCM } & \multicolumn{1}{c|}{ Aplicação CPS } \\
\hline Segurança & Potencializado \\
\hline Desdobramento de Custos & Potencializado \\
\hline Melhoria Contínua & Afetado \\
\hline Atividades Autônomas & Potencializado \\
\hline Manutenção Profissional & Potencializado \\
\hline Controle da Qualidade & Afetado \\
\hline Logística & Afetado \\
\hline Gestão Antecipada & Potencializado \\
\hline Desenvolvimento Pessoal & Não afetado \\
\hline Meio Ambiente & Não afetado \\
\hline
\end{tabular}

Com uma visão mais estratégica de como cada pilar WCM é afetado pela inserção das tecnologias CPS a curto prazo, é possível distinguir pontos de atenção e reformulação da metodologia. Alguns pilares parecem potencializar seus objetivos com a chegada desta digitalização, enquanto outros, em um primeiro momento, parecem não ser tão afetados. Isso gera um novo paradigma no acompanhamento do desenvolvimento do WCM dentro das empresas pois, com o CPS, alguns dos pilares acabarão se tornando autossustentáveis, enquanto outros continuarão seguindo um caminho pouco digital.

Figura 3 - Rearranjo dos pilares WCM com inserção de CPS a curto prazo

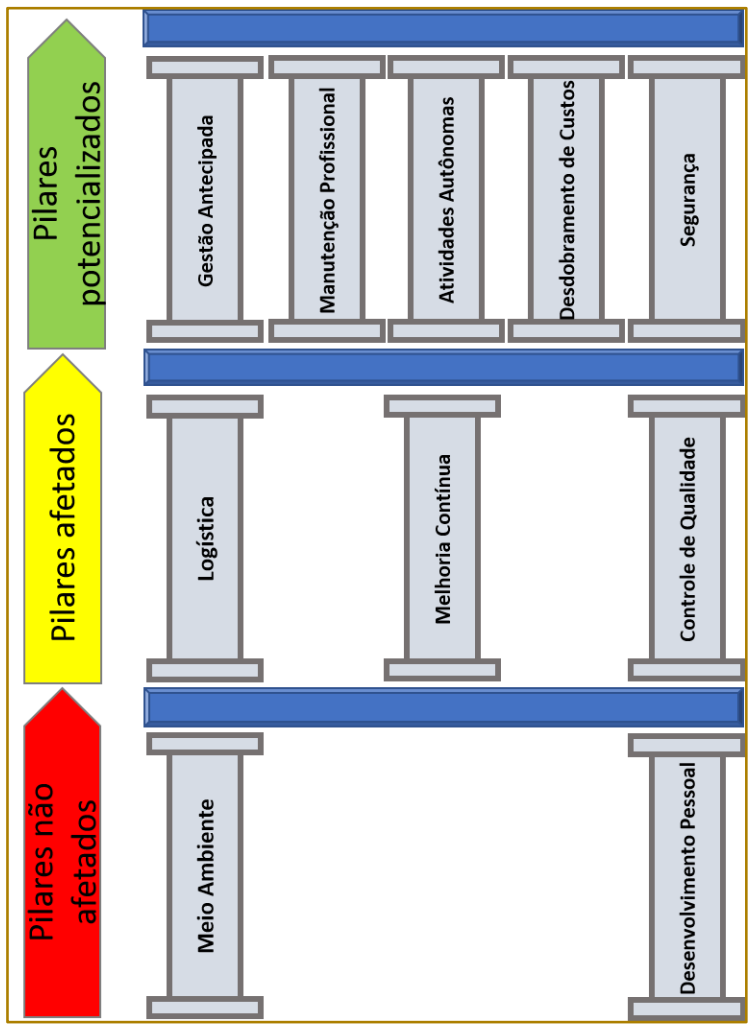


É importante salientar novamente que as análises foram realizadas idealizando um cenário a curto prazo. Cenários a médio e longo prazo tendem a ter diferentes resultados em cada análise, porém, este seria um caminho ainda muito nebuloso, tendo em vista que os próprios sistemas ciber-físicos encontram se ainda em fase inicial de implementação e, portanto, ainda não é possível definir com certeza quais serão os caminhos do desenvolvimento destas tecnologias. Na Figura 3, foi realizada a modelagem de um novo padrão da estrutura WCM pelo nível de sensibilização que a implementação CPS trará ao ambiente em que a metodologia está inserida a curto prazo, tendo em vista que os pilares foram divididos em três grupos: Os pilares que serão potencializados pela transformação digital, os que serão apenas afetados e os que não sofrerão nenhum impacto.

\section{CONSIDERAÇÕES FINAIS}

Considerando que, à medida que a indústria 4.0 avança em implementação e robustez de seus conceitos, se faz necessária uma visão estratégica da consistência que os padrões

\section{REFERÊNCIAS}

[1] ACATECH. Integrated research agenda Cyber-Physical Systems (agenda CPS). München, 2015.

[2] BATALHA, A. V.; PARLI, A. L. Industry 4.0 with a Lean perspective: Investigating IIoT platforms possible influences on data driven Lean. 2017. Dissertação de mestrado- Uppsala University. Sweden, 2017.

[3] DA SILVA, E. M. WCM - World Class Manufacturing (Produção de Classe Mundial). 2016.

[4] DUBEY, R. et al. The impact of big data on world-class sustainable manufacturing. The International Journal Of Advanced Manufacturing Technology, [s.I.], v. 84, n. 1-4, p.631-645, 30 ago. $2015 . \quad$ Springer Nature. http://dx.doi.org/10.1007/s00170-015-7674-1.

[5] FLYNN, B.; SCHROEDER, R.; FLYNN, J.; SAKAKIBARA, S.; BATES, K. World Class Manufacturing Project: Overview and Results. International Journal of Operations \& Production Management, Vol. 17 No. 7 , p. 671-685, 1997.

[6] KOLBERG, D.; ZÜHLKE, D. Lean Automation enabled by Industry 4.0 Technologies. Ifac-papersonline, [s.I.], v. 48, n. 3, p.1870-1875, 2015. Elsevier BV. http://dx.doi.org/10.1016/j.ifacol.2015.06.359. atuais terão em um futuro cada vez mais inteligente e conectado. Este estudo traz significativas contribuições para esta visão.

Primeiramente, foi possível alinhar as estratégias atuais de desenvolvimento com previsões de evolução. Isso é importante porque nem sempre as novas tecnologias trazem consigo um plano de redefinição de conceitos já existentes. A metodologia WCM é complexa e, ao contrário de outras definições que acabaram sumindo com a evolução natural da tecnologia, merece evoluir para que seja possível acompanhar a indústria 4.0.

Além disso, é interessante constatar que algumas definições desta revolução tecnológica concebida em 2011 podem se encaixar tão bem a definições metodológicas criadas nos anos 80 e, em alguns casos, até mesmo potencializar pontos que serão de extrema importância nas fábricas do futuro.

Para pesquisas futuras, é possível ir mais a fundo no entendimento das mudanças causadas pelas novas tecnologias em metodologias já existentes, assim como traçar estratégias de desenvolvimento de um modelo WCM + CPS mais robusto a médio e longo prazo.

[7] LEE, J. Recent advances and trends in predictive manufacturing systems in big data environment. Manufacturing Letters, 1, p.38-41, 2013.

[8] MALAVASI, M. Lean Manufacturing and Industry 4.0: an empirical analysis between Sustaining and Disruptive Change. 2017. Dissertação de mestrado. Politecnico di Milano. Italia, 2017.

[9] MCKINSEY Digital. Industry 4.0: How to navigate digitization of the manufacturing sector. 2015.

[10] NATIONAL INSTITUTE OF S. AND TECHNOLOGY. Foundations for Innovation in Cyber-Physical Systems. 2013.

[11] PALUCHA, K. World Class Manufacturing Model in Production Management. Archives of Materials Science and Engineering, v. 58, n. 2, p. 227-234, Dezembro 2016.

[12] SANDERS, A.; ELANGESWARAN, C.; WULFSBERG, J. Industry 4.0 implies lean manufacturing: Research activities in industry 4.0 function as enablers for lean manufacturing. Journal Of Industrial Engineering And Management, [s.I.], v. 9, n. 3, p.811-833, 21 set. 2016. Omnia Publisher SL. 


\section{Capítulo 11}

\section{USO DA BLACKBOARD E SWAY NO DESENVOLVIMENTO DO LIVRO DIGITAL NO COLÉGIO MARISTA DE CRICIÚMA}

\section{Tiago Cesconeto Roque}

\section{Lucimara Cardoso Nicolau}

Resumo: Este trabalho tem como objetivo geral avaliar a diversidade entre o livro impresso e o livro digital, detalhando as características de utilizar o livro digital em uma era onde a informação está nas palmas das mãos, inclusive das crianças. Os estudantes de hoje aprendem com muita facilidade e rapidez, mas se cansam facilmente das práticas repetitivas do ensino cotidiano. Eles anseiam sempre por novidades! E é por isso que o uso da tecnologia em sala de aula desperta o interesse dos alunos. Com isso foi proposto duas ferramentas do TIC para auxiliar na produção do livro Crianças como eu, a Plataforma Blackboard para reunir todas as informações necessárias dos alunos e o Sway para o desenvolvimento propriamente dito do livro digital para um dos problemas gerados em um dos projetos do Ensino Fundamental-Anos Iniciais, $5^{\circ}$ s anos, do colégio Marista de Criciúma.

Palavras chave: Inovação, Digital, Sway, Microsoft, Blackboard. 


\section{INTRODUÇÃO}

A evolução das tecnologias digitais de informação e comunicação tem transformado profundamente a sociedade em todas as suas dimensões, inclusive a educação, sendo por meio de um ambiente virtual, entretenimentos em sala de aula ou até publicação e organização de conteúdo. As metodologias ativas, que colocam o aluno no centro do aprendizado, transformando-o em protagonista de sua evolução acadêmica, encontram na tecnologia suporte para que o aluno absorva o conteúdo.

A partir de uma experiência onde os estudantes podem aprender na prática, utilizando-se de aplicativos ou de softwares, que proporcionem 0 aprendizado. Um exemplo dessa possibilidade de aprendizado se dá através do uso de aplicativos que ajudam na organização das atividades desejadas, como a Blackboard, que é uma plataforma como Moodle utilizado por outras instituições como pela UFSC, nela conseguimos concentrar todo $\mathrm{O}$ material necessário para os alunos, podendo também realizar atividades e que essas atividades já saem com resultados após o termino do processo.

Para fins de conhecimento os trabalhos acadêmicos de pós-graduação são desenvolvidos e aplicados em forma de publicação científica, isso para que outras pessoas possam dar continuidades em pesquisas ou até mesmo conseguir saber como foi tal estudo em determinado lugar, portanto mostrando a diferença ou similaridades de uma mesma pesquisa aplicada em áreas diferentes.

Com isso após publicação em repositórios ou base de dados reconhecidas, podemos afirmar que essas pesquisas são pertinentes e possam servir de conteúdos válidos, norteando novas pesquisas, para uma busca constante para o desenvolvimento da ciência.

Com isso vimos a necessidade por objetivo geral de desenvolver um livro digital para os quintos anos do Ensino Fundamental anos iniciais, pensando na sustentabilidade, na praticidade e claro, trazer o aluno que é o protagonista do livro essa interação total. Esse desenvolvimento foi realizado como experimento no colégio Marista de Criciúma, de uma forma que o aluno passa ser visto como o protagonista, já o docente e o Analista de TE darão suporte para o aluno.
Com isso sabemos que precisamos organizar a pesquisa e buscar as informações nas bases de dados para levantar informações sobre o conteúdo desejado.

Para Setenareski (2013. p.13) "As instituições de pesquisa e as universidades, produtoras de conteúdo científico, logo perceberam os benefícios da utilização dos repositórios digitais para alcançar a visibilidade mundial deste conteúdo".

Setenareski (2013) afirma que com a dificuldade de publicação em editoras privadas, as pesquisas acabam sendo publicadas em repositórios digitais abertos. Falando em repositório digital aberto houve um aumento após o Google disponibilizar os serviços de pesquisa para os usuários, predominando na área de buscas pela internet.

Como vamos utilizar um dos softwares no auxílio do livro digital e não poderíamos deixar de falar da Blackboard conforme Rodrigues et al (2015), o AVA são ambientes utilizados por professores e alunos em cursos presenciais, mas é de extrema importância para uso na modalidade de ensino a distância, como apoio no processo de aprendizagem.

\section{PROCEDIMENTOS METODOLÓGICOS}

Para a pesquisa, foram levantados alguns temas na forma de identificar as referências teóricos, estudá-los, avaliá-los e consequentemente coletar as melhores informações de cada pesquisa que foi avaliada, feito isso para uma melhor elaboração e conhecimento científico do assunto que será abordado.

Garrutti (2007), afirma que para cada pesquisa científica existe um procedimento metodológico específico, portanto o procedimento vai variar conforme o problema a ser pesquisado, a mostra envolvida e principalmente pelos objetivos geral e específicos da pesquisa.

Utilizaremos a técnica de entrevista que permite ao pesquisador extrair uma quantidade significativa de dados e informações que possibilitam saber a satisfação dos professores, consequentemente dos educandos ao desenvolverem o livro digital contanto sua história de vida.

Ribeiro (2008 p.141) trata a entrevista como: 
A técnica mais pertinente quando o pesquisador quer obter informações a respeito do seu objeto, que permitam conhecer sobre atitudes, sentimentos e valores subjacentes ao comportamento [...] incorporando novas fontes [...].

Para uma elaboração bem concreta do presente artigo, sete etapas que devem ser desenvolvidas segundo Jackson et al (2004 apud TOSTA et al, 2012). Essas etapas direcionam para: Formulação da pergunta; Localização e seleção dos estudos; Avaliação crítica dos estudos; Coleta de dados; Análise e apresentação de dados; Interpretação de dados e Aprimoramento e atualização da revisão.

Inicialmente apresentamos as perguntas: Como era o processo anterior da ferramenta na criação do livro digital? Como foi o processo? As vantagens do processo adotado? As dificuldades encontradas? Oportunidades de melhorias?

Já na segunda etapa no processo de localização e seleção de estudos, a divisão foi feita a fim de identificar quais as bases de dados seriam realizadas, buscas para desenvolvimento teórico do processo de documentação, sendo essas bases de dados à da Scielo, Periódicos da Capes e Repositório Institucional da UFSC (RI), que foi a principal utilizada no desenvolvimento e também utilizado o para o complemento da pesquisa.

Após a escolha das bases de dados, a definição das palavras chaves para responder à pergunta foram as palavras chaves: Tecnologia Educacional, Livro, Blackboard e Sway, porém não foi possível encontrar nada utilizando esses parâmetros, com isso realizamos uma busca em par e com isso na base da Scielo utilizando "Tecnologia educacional e livro" foram encontrados 3 arquivos, na base do periódicos da Capes foram encontrados 92 onde a pesquisa foi feita com os termos "Tecnologia educacional e livro digital" para tentar diminuir o campo de pesquisa, pois com os termos "Tecnologia educacional e livro" foram encontrados 337 e no repositório da UFSC com a mesma pesquisa do periódicos da Capes foram encontrados 99 publicações.

Com os termos "Tecnologia educacional e Blackboard" na base da Scielo foi encontrado 1 publicação, já nos periódicos da Capes foram 7 publicações e o no repositório da UFSC não foi encontrado nenhum. Para os outros termos não foi possível encontrar em pares, com isso começamos com as buscas acima tentar eliminar o máximo de publicações que não nos interessam.

A partir deste momento, com os resultados da coleta, análise (leitura), realizado a interpretação nos resultados obtidos dos documentos científicos e com isso seguido a diante do trabalho proposto.

\section{BASE CONCEITUAL PRÉVIA}

Por meio deste capítulo, apresentaremos alguns dos conceitos básicos do projeto principal que é a tecnologia educacional, livro digital, Blackboard e o Sway.

Franke (2014) tecnologia educacional é um meio que está disponível de obter o conhecimento. Nele temos fluxos de informação, normalmente com a facilidade de acesso devido as inovações tecnológicas que nos põem sempre a frente e que carregam a atribuição de facilitar e colaborar com as diversas formas de comunicação que estão disponíveis para a sociedade com o apoio das tecnologias digitais.

Uliano (2016) aponta a tecnologia educacional no auxílio seja ele diretamente ou indiretamente, promovendo ações desenvolvidas, onde essas ações podem ser interativas entre as pessoas e uma grande possibilidade do desenvolvimento coletivo.

Neste tipo de tecnologia ou de mídias digitais é possível uma interação muito maior que possam facilitar a aprendizagem do aluno, visto que podemos utilizar textos, sons, gráficos, imagens entre outros tipos de mídias, Uliano (2016).

Uliano (2016) apresenta a importância de que a tecnologia digital traz, permitindo que os alunos desenvolvam seu raciocínio e a maneira de interagir com os demais, até porque devido os softwares ou aplicações direcionais para educação recebem constantes atualizações, claro que se esses ambientes forem de certa forma pagos, os suportes para softwares livres ainda são um pouco escassos.

Nos dias atuais se discutem, de que forma da Tecnologia da Informação e Comunicação podem ser inseridas na área educacional, até porque sabem do potencial educativo da Tecnologia Educacional, com isso para poder tirar o melhor proveito dessa ferramenta, por meio de Plataformas Digitais que auxiliam 
nessa caminhada da Tecnologia Educacional (MARTINI; BUENO 2014).

E falando em Plataforma Digital utilizaremos é a Blackboard, essa ferramenta é uma AVA, pago e que permite utilização de diversos recursos dentro desse ambiente, que é de fácil configuração e simplicidade de acesso, com isso o ambiente criado para a disciplina é bem interativo para o uso do aluno que
(Avelino et al, 2017), irá disponibilizar seus arquivos para montagem de sua história de vida por essa Plataforma Digital. Por sua vez essa ferramenta Educacional que nos auxiliará indiretamente no desenvolvimento do livro digital.

Podemos acessar a plataforma pelo link marista.blackbord.com e teremos a página inicial como é demonstrado na figura abaixo:

Figura 1 - Tela de acesso a Blackboard

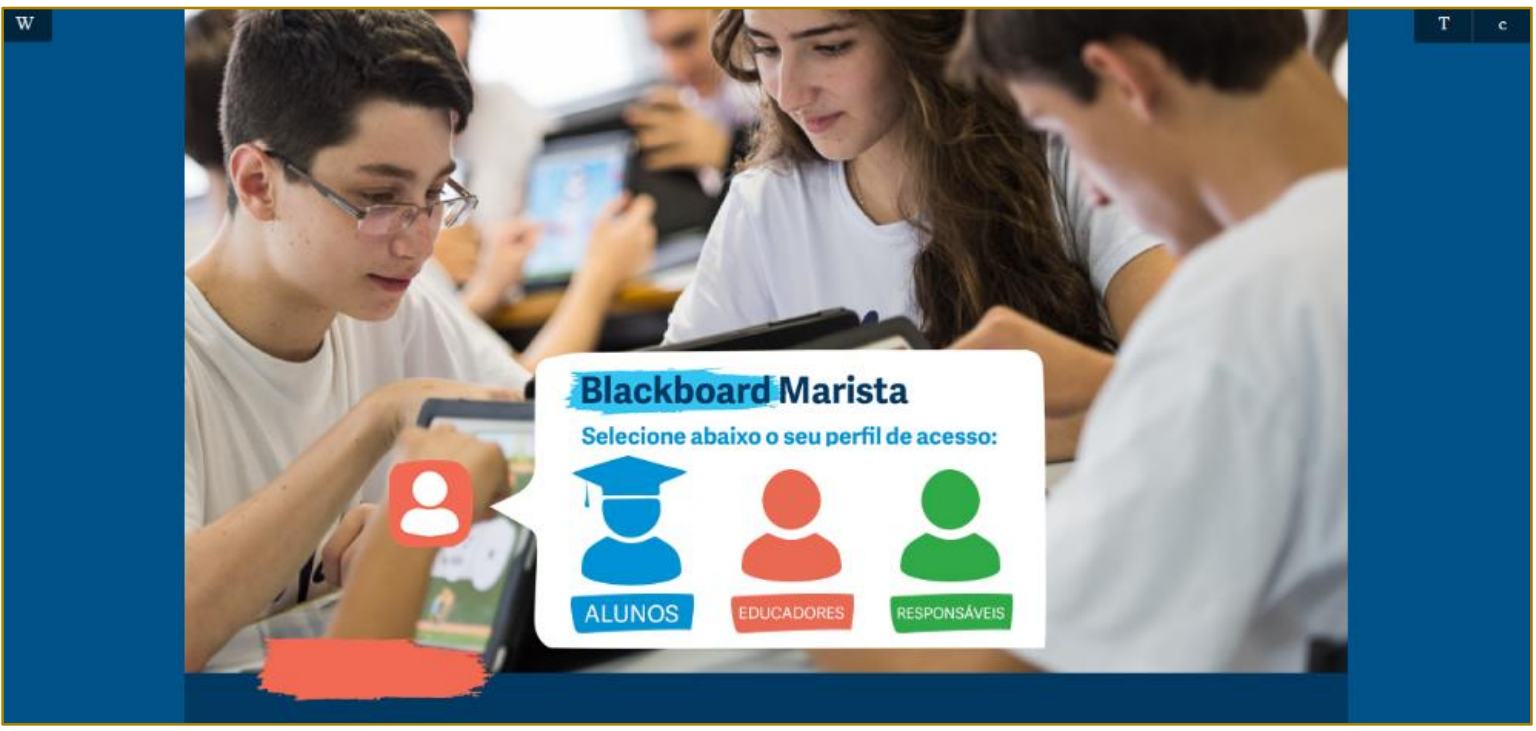

$\mathrm{Na}$ entrada do século $X X$ e com o movimento de toda as TIC's e a ascensão da internet, elevou as formas de se distribuírem, a criação e também as leituras dos livros, alterando a forma tradicional das editoras onde utilizam apenas os livros impressos, sendo possível criar além desses mesmos livros impressos, livros interativos ou versões digitais mesmo para serem utilizados em computadores, tablets e celulares. (DA SILVA, 2014).

Esse tipo de escolha se faz necessário conforme Carvalho et al (2016), "pesquisadores têm se debruçado sobre a investigação de novas práticas e estratégias, baseadas em teorias, capazes de propiciar a superação das dificuldades".

Quando falamos de livros digitais vimos um certo entendimento do pessoal da comunidade escolar e acadêmica e também dos profissionais do mercado editorial, que dizem que os livros digitais ainda não têm uma interação e ou é tão atrativo quanto uma plataforma digital. (Artuso, 2016).

Artuso (2016, p. 172). "Começam a surgir, contudo, iniciativas nacionais e internacionais que estão substituindo o formato inicial de livro digital - um modelo de "PDF linkado", onde livro impresso e objetos digitais são claramente dissociados".

Balensiefer (2016. p.32) "deve-se compreender o potencial das tecnologias no processo de formação que acontece no universo escolar. Crianças e adolescentes convivem dentro desse universo e é imprescindível o uso das mesmas.".

Pensando no livro que será desenvolvido, analisando os softwares disponíveis, acabamos optando pelo Sway que é um novo aplicativo do Microsoft Office que facilita a criação e o compartilhamento interativos de apresentações, histórias pessoais, entre outros.

A escolha do Sway foi simples, não é preciso gastar muito tempo com a formatação. O mecanismo de design interno garante que sua criação tenha a melhor aparência possível. Se o design inicial não corresponder exatamente ao seu humor ou gosto, você poderá aplicar outro com facilidade ou personalizar totalmente o layout como preferir. 
Abaixo segue a figura da tela inicial do software escolhido.

Figura 2 - Tela do Sway

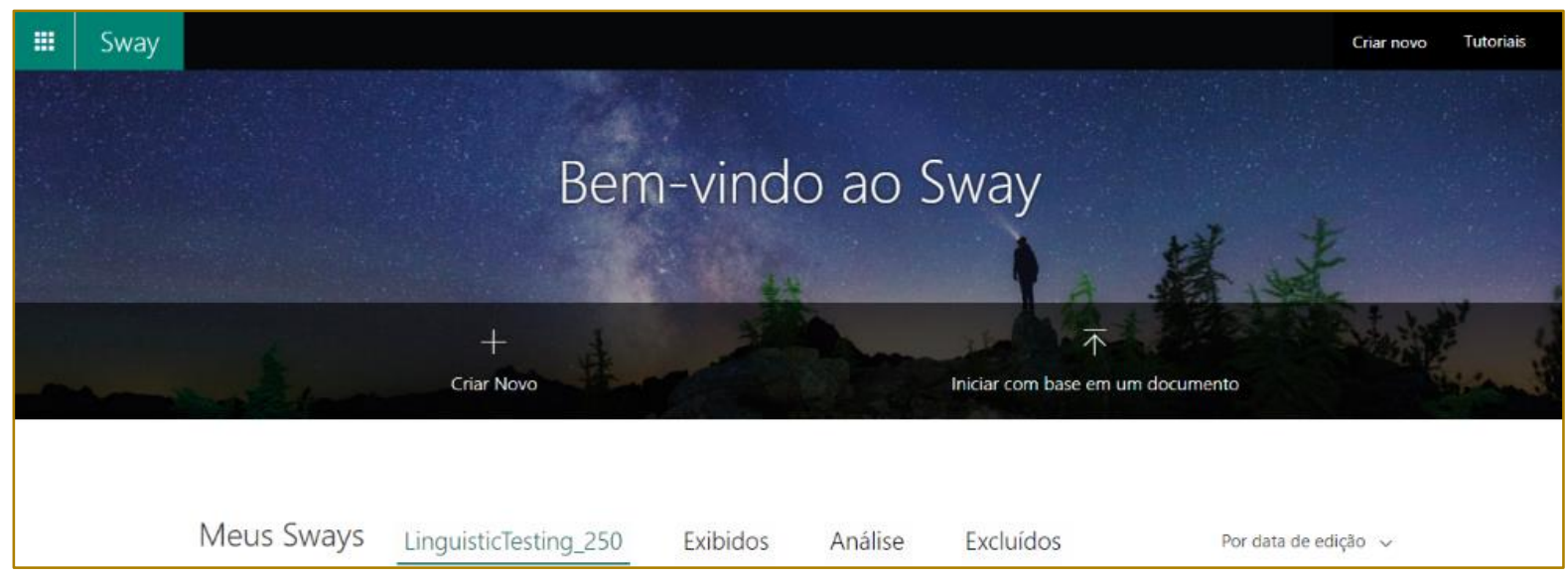

Portanto para o uso dessas ferramentas tecnológicas, precisamos de conhecimento para utilização das mesmas, isso inclui uma formação para o Analista de TE e para o docente com replicação para os alunos que serão os protagonistas desse livro digital, como cita o Carvalho et al (2016), o valor de uma formação apropriada para o entendimento e determinado suporte das tecnologias educacionais.

Sabemos também que hoje as crianças vivem em um mundo onde tudo é via toque do dedo, já se dispersando do teclado e mouse, como víamos em épocas anteriores não tão distante.

Com esses detalhes desses autores é possível ver o quão é importante o andar paralelo da tecnologia com a educação.

\section{RESULTADOS ENCONTRADOS}

Com a análise das pesquisas onde grande maioria é um estudo de um determinado caso e ou uma pesquisa do funcionamento do produto final. A entrevista pode desempenhar um papel vital para um trabalho científico se combinada com outros métodos de coleta de dados, visões e percepções procedente dela, podem melhorar a qualidade de um levantamento e de sua interpretação. A entrevista é uma das técnicas mais utilizadas por pesquisadores para a coleta de dados, tendo em vista que se pode classificá-las conforme o seu grau de diretividade assim consequentemente a profundidade do material verbal recolhido.

Utilizamos o tipo de entrevista por pautas apresentando certo grau de estruturação, já que se guia por uma relação de pontos de interesse que o entrevistador vai explorando ao longo de seu curso. As pautas foram guiadas a fim de englobar certa relação entre si. O entrevistador faz poucas perguntas diretas e deixa o entrevistado falar espontaneamente, à medida que reporta às pautas assinaladas.

Obtivemos respostas de seis entrevistados e serão chamados de E1 até E6. Agora com base na análise de conteúdo conforme Bardin, (2011), das entrevistas chegamos as conclusões

como: 
Tabela 1 - Pesquisa dos docentes envolvidos

\begin{tabular}{|c|c|c|}
\hline \multicolumn{2}{|r|}{ Análise de conteúdo } & \multirow{2}{*}{$\begin{array}{r}\text { Freq } \\
5\end{array}$} \\
\hline \multirow{13}{*}{ 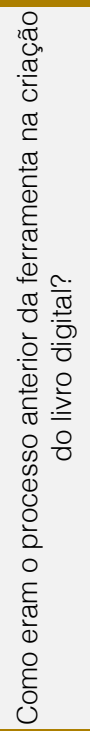 } & E1 - Responsabilidade do professor realizar o processo de formatação & \\
\hline & E3 - Dificuldades em formatar os textos & \\
\hline & E4 - Preparação pelas professoras & \\
\hline & E5 - Trabalho maior por parte das professoras & \\
\hline & E6 - Executavamos boa parte das tarefas & \\
\hline & E1 - Digitavam o texto reescrito. & 4 \\
\hline & E3 - Utilizavam o Word para digitação & \\
\hline & E4 - Digitavam na sala de informática & \\
\hline & E5 - Eram produzidos em um programa de texto & \\
\hline & E1 - Traziam fotos em Pen Drive & 4 \\
\hline & E3 - Organizar as pastas de imagens individuais dos alunos & \\
\hline & E4 - Escanear fotos & \\
\hline & E6 - Escaneamento de fotos & \\
\hline & E2 - Processo inovador & 5 \\
\hline & E3 - Facilitou bastante a produção & \\
\hline O. & E4 - Foi muito rápido e prático & \\
\hline $\begin{array}{l}\infty \\
0\end{array}$ & E5 - Rapidez e estimulante para o aluno & \\
\hline$\frac{1}{0}$ & E6 - Mais produtivo, objetivo e atrativo & \\
\hline$\underbrace{\overline{0}}$ & E1 - Postagem dos textos e fotos na Blackboard & 4 \\
\hline हू & E2 - Os alunos fizeram e postaram na plataforma & \\
\hline & E4 - Escrita e postagem na Blackboard & \\
\hline & E6 - Tecnologia auxiliou o processo de produção & \\
\hline & E1 - Aproveitamento de tempo & 9 \\
\hline & E1 - Processo de construção mais participativo & \\
\hline & E2 - Foi muito mais interessante & \\
\hline & E2 - Visualizar o conteúdo tornou a aprendizagem mais gratificante & \\
\hline & E3 - Não precisamos de investimentos com muitas pessoas envolvidas & \\
\hline & E4 - Participou de todo o processo de produção do livro. & \\
\hline $\mathscr{\infty}$ & E5 - Criança é realmente a autora do material & \\
\hline$\underset{\mathbb{D}}{\mathbb{D}}$ & E5 - Bela produção & \\
\hline 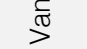 & E6 - O recurso tecnológico ajudou no processo de educação & \\
\hline & E1 - Autonomia e responsabilidade do aluno & 6 \\
\hline & E2 - Foi estimulante para o aluno & \\
\hline & E3 - Os alunos foram os grandes protagonistas & \\
\hline & E4 - Proporcionou um protagonismo maior do aluno & \\
\hline & E5 - Os alunos como protagonismo principal & \\
\hline & E6 - As crianças tiveram mais acesso a toda a elaboração & \\
\hline
\end{tabular}


Tabela 1 - Pesquisa dos docentes envolvidos

(continuação...)

\begin{tabular}{|c|c|c|}
\hline Assunto & Análise de conteúdo & Freq. \\
\hline \multirow{6}{*}{$\begin{array}{l}0 \\
0 \\
0 \\
0 \\
\frac{0}{0} \\
\frac{0}{3} \\
0 \\
.0 \\
0 \\
0\end{array}$} & E1 - Não encontrei dificuldades & 6 \\
\hline & E2 - Dificuldades no início, mas depois foram superadas & \\
\hline & E4 - Alunos perderam o prazo & \\
\hline & E4 - Achei que os pais sentiriam falta do livro físico & \\
\hline & $\begin{array}{l}\text { E5 - Dificuldades de algumas pessoas em compreender como podem acessar o } \\
\text { livro }\end{array}$ & \\
\hline & $\begin{array}{l}\text { E6 - Recurso novo tem seus contratempos e dificuldades, porém tivemos um } \\
\text { ótimo suporte }\end{array}$ & \\
\hline \multirow{5}{*}{ 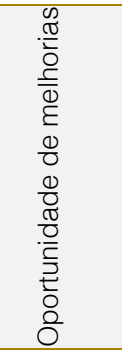 } & $\begin{array}{l}\text { E1 - Alunos terem seus e-mails individuais e postarem diretamente texto e fotos } \\
\text { no Sway }\end{array}$ & 5 \\
\hline & E2 - Que continue as inovações na aprendizagem & \\
\hline & E4 - Sway ter mais layouts & \\
\hline & $\begin{array}{l}\text { E5 - Oportunizar os alunos em sala o acesso ao livro, para orientar melhor seus } \\
\text { familiares }\end{array}$ & \\
\hline & E6 - Utilizar a tecnologia não somente no livro, em outras atividades também. & \\
\hline
\end{tabular}

Com base na observação da tabela 1 , é notório que os objetos de aprendizagens utilizados que são o Sway e Blackboard apresentaram melhorias tanto para o corpo docente e quanto ao discente, pois o mesmo gerou facilidade de recolhimento de dados e desenvolvimento do livro digital.

Levando em conta que a metodologia utilizada na construção do projeto é do cotidiano dos alunos, fez com que os mesmos demonstrassem mais interesse pelo processo construção, já que se tratava de uma ferramenta tecnológica que faz parte do dia a dia do aluno. $E$ isso gerou um grande um impacto diretamente na relação do professor e aluno, diferentemente dos anos anteriores, que por sua vez o professor se via na obrigação de finalizar, se não desenvolver o livro devido ao tempo.

A aplicabilidade das ferramentas tecnológicas, para um projeto do porte que foi realizado, sempre irá facilitar o desenvolvimento, visto que a organização de todo o livro foi de fácil acesso para o aluno que é o protagonista principal, para as famílias que deram suporte auxiliando quando necessário, quanto o professor que precisa realizar as correções dos textos e suas respectivas maneiras de aprendizagem.

Podemos dizer também que a obra por ser uma experiência nova para os envolvidos, chegou ao fim de uma forma esperada, sem muitas complicações e com o desenrolar do projeto bem definido.

Por fim percebesse que os professores conseguiram tirar proveito dos benefícios que a tecnologia pode trazer para o processo de ensino aprendizagem do livro Crianças como você, atuando de maneira mais atraente inovadora junto aos seus alunos. É importante ressaltar que a tecnologia quando usada de modo contextualizado é capaz de aproximar para sala de aula aquilo que o aluno já está adaptado em sua vida particular.

\section{CONSIDERAÇÕES FINAIS}

Com a finalidade de buscar e analisar as pesquisas científicas de tecnologia educacional e Livro Digital, além de outros temas que contribuem como objetos de aprendizagem e tecnologia na educação para uma organização dos temas e uma melhor apresentação desses temas no corpo do trabalho.

As tecnologias digitais da informação tornaram-se uma grande aliada do professor em sala de aula e deve ser vista como um instrumento que consolida o aprendizado do aluno. As aulas ficam ainda mais fascinantes, a relação entre professor e aluno fica enriquecida, os alunos mais motivados e receptivos ao aprendizado e o ensino mais ativo. Dessa forma, uma educação inovadora, 
participativa poderá ser estabelecida, a partir do compromisso dos envolvidos no processo de aprendizagem e a tecnologia ao ser acrescentada será uma grande aliada na construção da educação na formação do cidadão.

O educador, psicólogo, escritor e palestrante Marcos Meier aconselha os professores a promoverem a interação do aluno com a tecnologia para desenvolver a criatividade. "Pense sempre no desenvolvimento da autonomia e da criatividade de seus alunos. Faça com que eles interajam com essas tecnologias para aumentar o nível de aprendizado e de conhecimento".

\section{REFERÊNCIAS}

[1] ARTUSO, A. R. Livro Didático Digital o Presente, as Tendências e as Possibilidades Do Mercado Editorial No Contexto Brasileiro e Internacional. 2016. 29p. Disponível em: <http://www.redalyc.org/pdf/567/56745576010.pdf >. Acesso em: 22 out. 2017

[2] AVELINO, C. C; V.; DA COSTA, L. C. S.; BUCHHORN, S. M.M.; NOGUEIRA, D. A.; GOYATÁ, S. L. T. Avaliação do ensino-aprendizagem sobre a CIPE® utilizando o Ambiente Virtual de Aprendizagem. 2017. 8p. Disponível em: <http://www.scielo.br/pdf/reben/v70n3/pt_00347167-reben-70-03-0602.pdf> Acesso em: 23 out. 2017.

[3] BARDIN, L. Análise de Conteúdo. 2011. 281p. Disponível em: < https://pt.scribd.com/doc/217069465/Analise-deConteudo> Acesso em 23 nov. 2017.

[4] CARVALHO, R. L.; FILHO, J. A de C.; MAIA, D. L.; PINHEIRO, J. L. Contribuições do campo conceitual multiplicativo para a formação inicial de professores com suporte das tecnologias digitais. 2016. 25p. Disponível em: <https://revistas. pucsp.br/index.php/emp/article/vie wFile/25004/pdf>Acesso em: 01 nov. 2017.

[5] DA SILVA, T. R. Sobre O Impresso e o Digital: Analisando os Livros, As Leituras e os Impactos Sociais Das Novas Técnicas e Tecnologias. 2014. 83p. Disponível em: < https://repositorio.ufsc.br/bitstream/handle/1234567 89/126441/Tiago\%20R.\%20da\%20Silva.pdf>Acess o em: 01 nov. 2017.

[6] FRANKE, S. M. P. Experiência de Integração do Moodle no Ensino de Física no Ensino Médio - Percepção dos Alunos. 2014. 165 p. Disponível em: < https://repositorio.ufsc.br/xmlui/bitstream/handle/12 3456789/129134/329070.pdf> Acesso em: 22 out. 2017.
Por fim, atende-se o objetivo geral na usabilidade da plataforma digital após sua implantação, de forma que mostram as qualidades e seus respectivos benefícios.

Com a prática do uso da tecnologia em sala de aula podemos perceber que se torna mais significativo o aprendizado, inovando e desenvolvendo o conhecimento que está sendo colocado ao alcance dos educandos. Sendo assim, o uso da tecnologia não é visto apenas como uma ferramenta e sim parte integrante do currículo escolar. Contudo fica nítido ver o quão é importante o andar paralelo da tecnologia na educação.

[7] GARRUTI, E. A. Procedimentos De Pesquisa $\mathrm{Na}$ Produção Científica Discente Do PPGEES/UFSCAR. 2007. 189p. Disponível em: $<$ https://repositorio.ufscar.br/bitstream/handle/ufsc ar/2969/DissEAG.pdf>. Acesso em 16 out. 2017.

[8] MARTINI, C. M.; BUENO, J. L. P. O desafio das tecnologias de informação e comunicação na formação inicial dos professores de matemática. 2014. 22p. Disponível em: < https://revistas.pucsp.br/index.php/emp/article/view /16952/pdf> Acesso em 02 nov. 2017.

[9] RODRIGUES, C.; PERASSI, R.; DE NARDI, B. Z.; FIALHO, F. A. P. E-books Didáticos Nos Ambientes De Aprendizagem Em Rede. 2015. 17p. Disponível em: $<$ http://seer.ufrgs.br/index.php/EmQuestao/article/vi ewFile/50744/33753>. Acesso em 02 nov. 2017.

[10] SETENARESKI, L. E, Repositórios Digitais Abertos: Um Movimento Do Livre Acesso Alternativo À Estrutura Oligopolizada Das Editoras Científicas. 2013. 115p. Disponível em:< http://politicaspublicas.weebly.com/uploads/5/3/9/6 /5396788/repositrios_digitais_abertos_-

_um_movimento_do_livre_acesso_alternativo_estr utura_oligopolizada_das_editoras_cientficas.pdf $>$. Acesso em 02 nov. 2017.

[11] TOSTA, K. C. B. T.; SPANHOL, F. J.; TOSTA, H. T.; TECCHIO, E. L. As Relações Entre Competências Essenciais E Aprendizagem Organizacional: Uma Revisão Sistemática. 2012. 13 p. Disponível em: <http://www.inovarse.org/sites/default/files/T12_056 8_2992.pdf> Acesso em 22 out. 2017.

[12] ULIANO, K. C. M. L. Tecnologia Digital De Informação E Comunicação (Tdic) Na Educação: Aplicativos E O Mundo Tecnológico No Contexto Escolar. 2016. 50 p. Disponível em: < https://repositorio.ufsc.br/bitstream/handle/1234567 89/169814/TCC_Uliano.pdf> Acesso em 02 nov. 2017. 


\section{Gapítulo 12}

\section{A PRÁTICA NAS ENGENHARIAS: A IMPORTÂNCIA DO CONTATO COM UM MAKERSPACE PARA ENGENHEIROS EM FORMAÇÃO}

\section{Lucas Davis Ribeiro de Paula}

Danielle Saranh Galdino Duarte Garcia

Raquel Ferreira de Souza

Resumo: A prática em todas as áreas da Educação se mostra um desafio para as escolas de ensino superior. Com a engenharia não é diferente. Muito se fala em engenheiros diplomados que não sabem executar atividades básicas que fazem parte da sua grade curricular, sendo esse o resultado da falta de aulas práticas nos cursos de engenharia do Brasil. Lentamente, as escolas de engenharia brasileiras têm aderido à ideia dos espaços do fazer, chamados Makerspaces, mas ainda são poucas perto do número de cursos de engenharia existentes. Este estudo tem como objetivo principal analisar a importância desses espaços para o engenheiro em formação.

Palavras-chave: Educação em Engenharia. Makerspace. Prática. 


\section{INTRODUÇÃO}

Com a dinâmica do mundo atual, a necessidade de obter cada vez mais conhecimento, o tempo escasso para tantas disciplinas importantes dentro de um curso de engenharia, além dos novos cursos EAD para algumas engenharias específicas, como a Engenharia de Produção, as Instituições de Ensino Superior (IES) têm priorizado formar engenheiros com grande embasamento teórico, o que de fato é importante, pois esse é fundamental para a execução correta, porém, pouca atenção recebe o conhecimento prático, o que é preocupante para a educação e para o mercado, afinal, trata-se de uma profissão cuja prática é vital ao seu exercício.

Nesse contexto de necessidade, surgem os makerspaces como uma opção para os estudantes de engenharia e demais profissionais. Trata-se de um laboratório comunitário, para que os alunos "desvirtualizem" e ampliem seus conhecimentos práticos. Esses laboratórios possuem diversos nomes, que os distinguem em algumas características, como FabLabs, hackerspaces, makerspaces, makerplaces são os mais conhecidos, contudo, sempre voltados para a mentalidade do "fazer".

Tais espaços podem ser alugados por períodos, para equipes ou individualmente ou particulares, como dentro de uma IES. Em geral, possuem aparatos tecnológicos, como computadores impressoras 3D, CNCs e outras ferramentas comuns às necessidades de uma oficina.

Para um estudante de engenharia, o acesso a um desses espaços do "fazer" pode se mostrar um grande diferencial em sua formação, uma vez que ele sairá preparado para trabalhar, de modo que não perderá um tempo precioso em sua carreira tentando concretizar na prática aquilo que conheceu apenas na teoria.

Assim, o objetivo principal deste artigo é demonstrar a importância e a positividade da implantação dos makerspaces ou similares como elementos de formação nos currículos das engenharias, a partir de pesquisas bibliográficas sobre esses espaços e do levantamento de experiências em instituições de ensino superior nacionais e estrangeiras que já implantaram tal prática.

\section{O QUE É UM ESPAÇO DO FAZER?}

O makerspace é um espaço comunitário semelhante a uma oficina ou garagem, equipado com ferramentas como impressora 3D, cortadora a laser e demais ferramentas de uma oficina, além do acréscimo tecnológico, como computadores, arduínos e periféricos para suporte na fabricação, criação ou manutenção de projetos, protótipos, objetos, peças e equipamentos.

Esses espaços são criados por indivíduos para possibilitar o uso do espaço por empresas, escolas, universidades, bibliotecas, dando acesso aos equipamentos, ao espaço e à sua infraestrutura (MENA, 2015).

\section{A PRÁTICA NA FORMAÇÃO DO ENGENHEIRO}

A prática se faz fundamental na formação do engenheiro, que cada vez mais é cobrado para sair "pronto" dos cursos de graduação. Nesse intento, depois de graduado, a exigência do mercado de trabalho não dá a esse profissional tempo para "praticar até conseguir fazer". Além disso, a prática fortalece seu aprendizado, sendo uma forte ferramenta didática, que faz daquele que a possui diferenciado frente aos concorrentes.

Como parte da formação, o makerspace possibilita ir além da teoria, aguçando a criatividade, possibilitando descobertas e aumentando o interesse do estudante pela disciplina cursada. Outro ponto que vale ressaltar é a segurança que o profissional terá depois de formado para reproduzir uma prática já executada durante a formação e não somente uma construção baseada em elementos teóricos. Em grande parte das IES do Brasil, o contato dos estudantes de engenharia ocorre pelas as aulas experimentais ministradas em laboratórios, que geralmente formam o cenário prático mais comum às atividades profissionais do cotidiano. Entretanto, só as práticas laboratoriais não se mostram mais suficientes para a formação completa e qualificada exigida pelo mercado de trabalho atual. Nesse sentido, as escolas de Engenharia deverão aparelhar seus espaços e pessoas que saibam avaliar a tecnologia e suas implicações, fornecendo-as condições para que possam entendê-las além da teoria (PEREIRA, et al.,2002), simulando 
experiências, imitando uma operação de um processo ou sistema da realidade, para descrever, analisar e resolver os problemas de seus comportamentos (BANKS, 1998).

De acordo com as Diretrizes Curriculares para os cursos de Engenharia (PARECER CNE/CES 1.362/2001), a formação de um engenheiro deve possibilitá-lo desenvolver as seguintes competências e habilidades:

a) aplicar conhecimentos matemáticos, científicos, tecnológicos e instrumentais à engenharia;

b) projetar e conduzir experimentos e interpretar resultados;

c) conceber, projetar e analisar sistemas, produtos e processos;

d) planejar, supervisionar, elaborar e coordenar projetos e serviços de engenharia;

e) identificar, formular e resolver problemas de engenharia;

f) desenvolver e/ou utilizar novas ferramentas e técnicas;

g) supervisionar a operação e a manutenção de sistemas;

h) avaliar criticamente a operação e a manutenção de sistemas;

i) comunicar-se eficientemente nas formas escrita, oral e gráfica;

j) atuar em equipes multidisciplinares;

k) compreender e aplicar a ética e responsabilidade profissionais;

I) avaliar o impacto das atividades da engenharia no contexto social e ambiental;

m) avaliar a viabilidade econômica de projetos de engenharia;

n) assumir a postura de permanente busca de atualização profissional. (grifos nossos)
Como se percebe a maioria dos parâmetros a serem observados pelas grades curriculares dos cursos de engenharia remetem ao desenvolvimento de habilidades práticas e sociais, de forma conjunta.

Importa ressaltar que nessa mudança de cultura de ensino-aprendizagem das engenharias, o papel do professor é fundamental, pois ele é o condutor do processo e, por isso, também deve estar alinhado com a necessidade de inserir prática no aprendizado. Dessa forma, o trabalho do professor exige meios específicos para direcionar as atividades aos alunos, criando relações com pessoas e fontes, inserindo novidades para o estudante em meio à sua bagagem de conhecimento. Por isso, é preciso afirmar que não há transmissão de saberes, nem como adiantar o processo de aprendizagem, pois, aprender exige dentre muitas coisas, observação, reflexão, prática, leitura e experimentação (VYGOTSKY, 1987).

\section{AS EXPERIÊNCIAS COM ESPAÇOS DO FAZER NACIONAIS E ESTRANGEIRAS}

A experiência do makerspace iniciou em uma disciplina do MIT - Masssachusetts Institute of Technology chamada "How to make (almost) anything", ou seja: "Como fazer (quase) qualquer coisa". A Instituição criou o primeiro laboratório em 2006, que deu origem aos demais.

Com o sucesso do espaço e a crescente utilização no ensino e desenvolvimento de estudantes, outras instituições de ensino passaram a adotar o modelo, que vem sendo cada vez mais utilizado e aprimorado. Hoje, existem FabLabs por todo o mundo (QUINTELLA et al., 2017). 
Figura 1 - Neil Gershenfeld no MIT

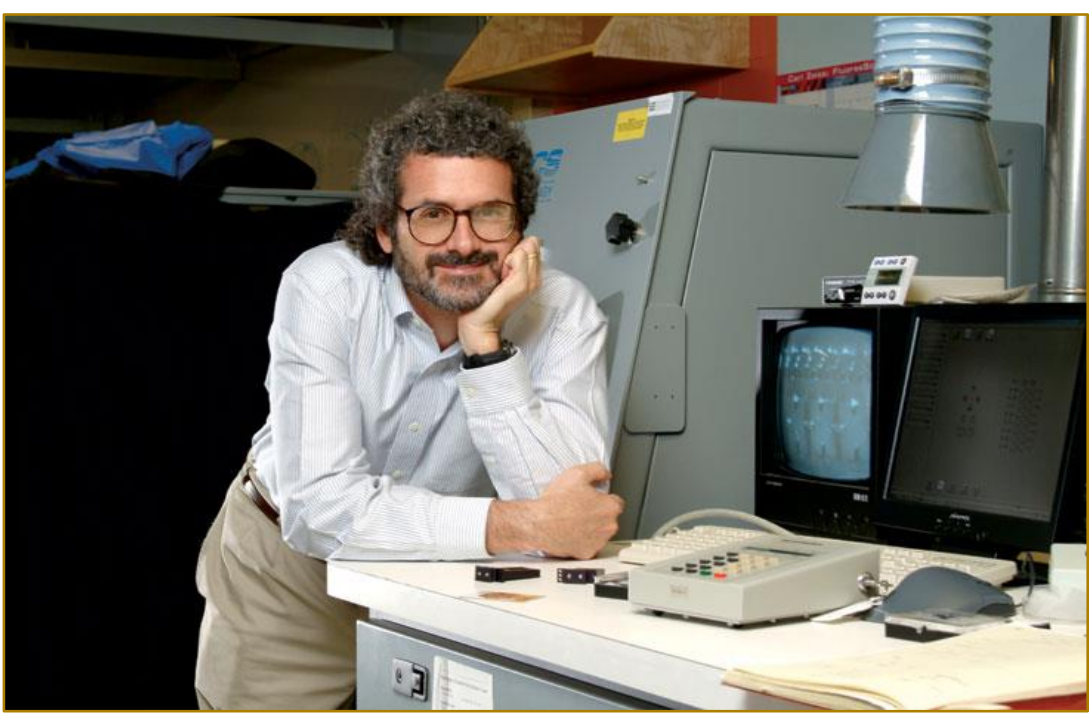

Fonte: Revista Espectro do MIT

Sendo uma novidade em alguns cursos de ensino médio e de graduação, alguns estudos que possuem os makerspaces como ferramenta de auxílio didático foram feitos para avaliar sua eficácia.

Um deles foi realizado pleo LITE - Laboratório de Inovação e Tecnologia na Educação - em que alguns alunos do ensino médio participaram de um trabalho, cujo objetivo era o desenvolvimento de um projeto para uma feira de ciências. Ao final da pesquisa, o resultado encontrado foi satisfatório, pois os estudantes se dedicaram, a maioria colaborou mutuamente em seus projetos, desenvolveram novos conhecimentos e colocaram em prática o que aprenderam em sala de aula (RAABE et al.,2016).

Ressalta-se que por meio dessa ferramenta prática de ensino-aprendizagem várias competências e habilidades científicas e sociais foram desenvolvidas no grupo de estudantes pesquisado.

Figura 2 - LITE - Laboratório de Inovação Tecnológica na Educação - Univali

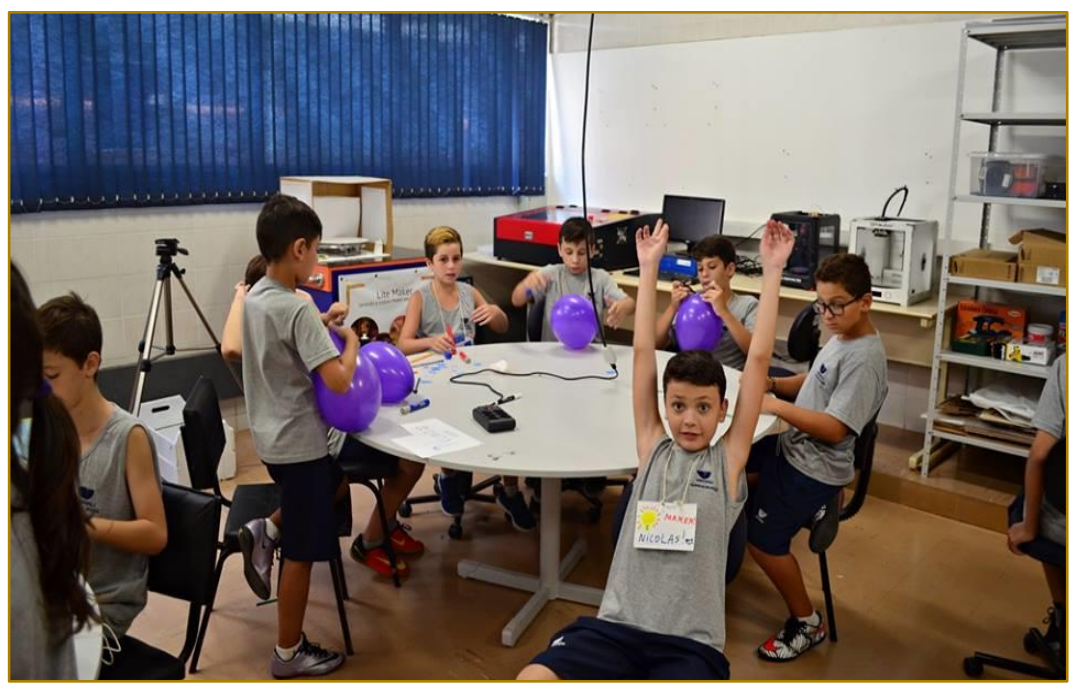

Fonte: Página do LITE no Facebook

Outra experiência satisfatória que merece atenção foi realizada no POALab, que é o laboratório da IFRS - Instituto Federal do Rio Grande do Sul, em Porto Alegre.
A IES desenvolveu um projeto para a disciplina de "Tópicos Avançados", do curso Superior de Tecnologias em Sistemas Para Internet. Para tanto, foram selecionados alguns alunos do último período do curso, 
com o objetivo de avaliar como o grupo utilizava o conceito de pensamento computacional no desenvolvimento de um produto voltado para a área da saúde, além de investigar como as atividades poderiam promover o uso do pensamento formal.
Os resultados da pesquisa comprovaram a relação do pensamento computacional e da atividade maker, bem como a relação desse tipo de pensamento com o raciocínio formal, mais evidente no uso do raciocínio lógico, a abstração e a generalização (BORGES et al.,2016).

Figura 3 - POA Lab - IFRS

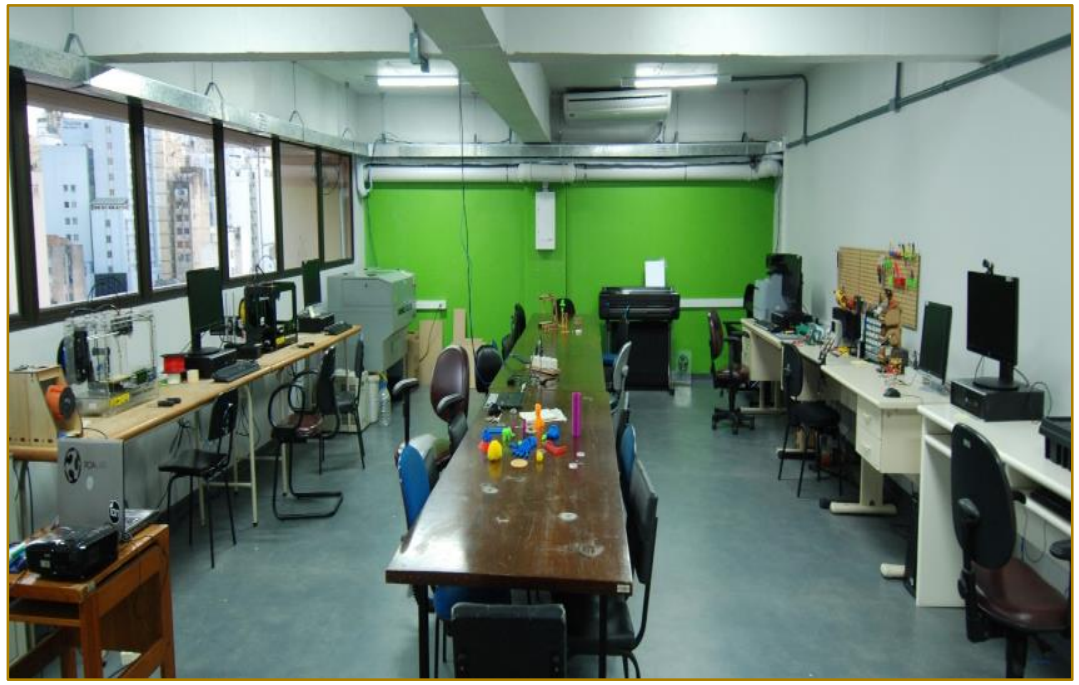

Fonte: Página inicial do POALab

$\mathrm{Na}$ cidade de Belo Horizonte/MG, o primeiro espaço do fazer foi criado pelo Unicentro Newton Paiva, utilizado em seus cursos de engenharia. Trata-se de um FabLab de caráter acadêmico, que buscou seguir o padrão do primeiro do mundo, criando pelo MIT.
O laboratório conta com regulamento próprio e a marcação de aulas práticas se dá por meio do preenchimento pelo docente, de formulário de solicitação de uso.

Figura 4 - FabLab Newton Paiva

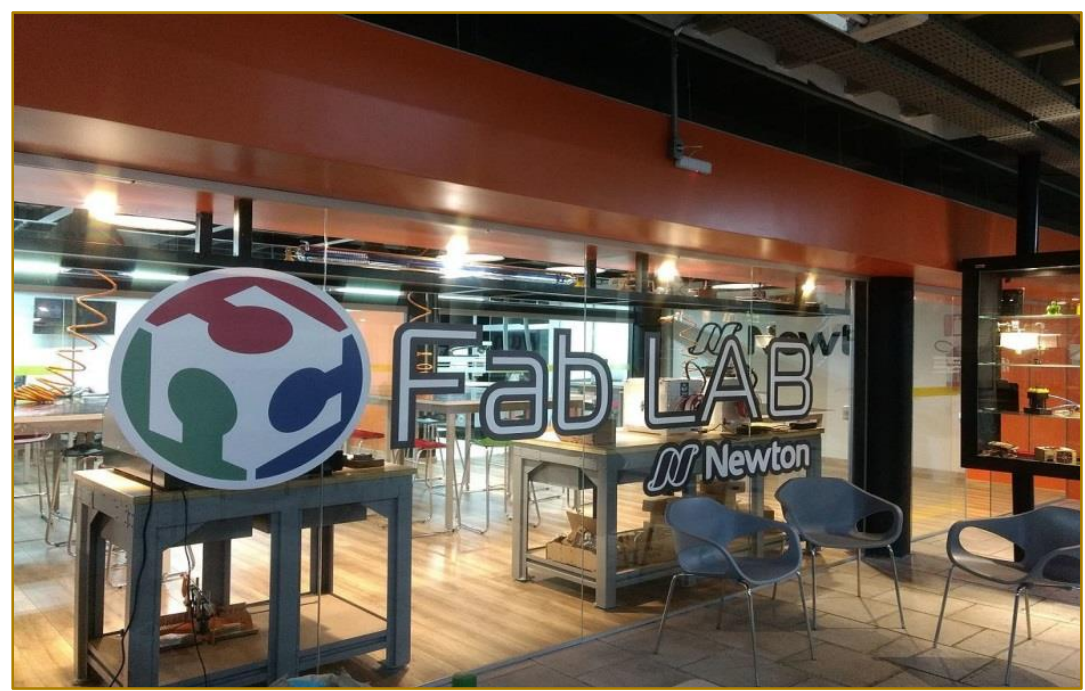

Fonte: Site Newton Paiva (2018) 
Figura 5- FabLab Newton Paiva

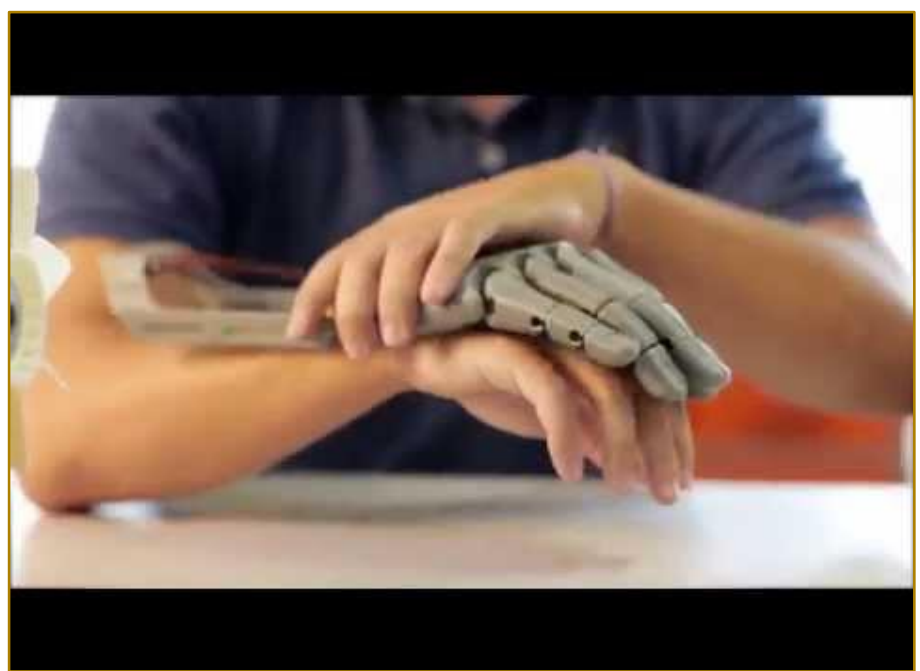

Fonte: Site Newton Paiva (2018)

No Brasil, percebe-se certa resistência por parte das IES, em face do valor para se montar um espaço do fazer (cerca de $\mathrm{R} \$ 100.000,00)$, de modo que, mesmo tendo plena consciência de que tendo um laboratório prático como este, a Instituição apresentará ao mercado um enormne diferencial, ainda sim são poucas que possuem o mesmo.

A título de ilustração, na capital mineira, Belo Horizonte/MG, há atualmente 23 cursos de
Engenharia Civil e de Engenharia de Produção privados e 2 em universidades públicas em funcionamento, de acordo com o RUF (2018). Da soma dessas duas engenharias, dos 50 cursos em funcionamento, apenas duas IES possuem laboratórios de prática semelhantes a um Makerspace ou Fab Lab (IBMEC e NEWTON PAIVA), sendo cobertos por essa oportunidade prática apenas 4 cursos, 2 de cada instituição, como se verifica a seguir.

\begin{tabular}{|c|} 
NOME DA INSTITUIÇÃO - PRIVADAS \\
Centro Universitário de Belo Horizonte (UNI-BH) \\
\hline Centro Universitário Estácio de Belo Horizonte (ESTÁCIO BH) \\
Centro Universitário Metodista Izabela Hendrix (CEUNIH) \\
\hline Centro Universitário Newton Paiva (NEWTON PAIVA) \\
\hline Centro Universitário Una (UNA) \\
\hline Escola Bahiana de Medicina e Saúde Pública (EBMSP) \\
\hline Faculdade Pitágoras \\
\hline Faculdade Antônio Meneghetti (AMF) \\
\hline Faculdade Cenecista de Capivari (FACECAP) \\
\hline Faculdade de Engenharia de Minas Gerais (FEAMIG) \\
\hline Faculdade de Ensino Superior do Interior Paulista (FAIP) \\
\hline Ciências Contábeis e Administrativas de Cachoeiro do Itapemirim (FACCACI) \\
\hline
\end{tabular}


(continuação...)

\begin{tabular}{|c|} 
NOME DA INSTITUIÇÃO - PRIVADAS \\
Faculdade de Tecnologia Senac Df (FAC SENAC DF) \\
\hline Faculdade Ibmec (IBMEC) \\
\hline Faculdade Ibs (IBS) \\
\hline Faculdade Kennedy de Belo Horizonte (FKBH) \\
\hline Faculdade Novos Horizontes (NOVOS HORIZONTES) \\
\hline Faculdade Pitágoras de Belo Horizonte (FPAS) \\
\hline Instituto Superior de Ciências Aplicadas (ISCA) \\
\hline Pontifícia Universidade Católica de Minas Gerais (PUC MINAS) \\
\hline Universidade Fumec (FUMEC) \\
\hline Universidade Vila Velha (UVV) \\
\hline
\end{tabular}

Ou seja, trata-se de quantidade diminuta, frente às possibilidades educacionais oferecidas por esses espaços.

Os makerspaces, nos Estados Unidos da América, são bem comuns. Esse impulso ocorreu em parte, graças a uma declaração do Presidente americano Barack Obama, que dizia querer que todos pensassem em formas criativas para os jovens desenvolverem ciências e engenharias, seja em festivais de ciências, competições de robótica, feiras que os incentivassem a construir e não somente a serem extremamente consumidores. Tal declaração foi importante, pois, além de incentivar a redução do consumismo, motivou a geração de empreendedores, criadores e não somente jovens "procuradores de empregos" (PEPPLER et al., 2013).

Para demonstrar o quão forte é essa tendência nos Estados Unidos, em Cambridge, no estado de Massachusetts, em 2016, foi organizado o 1o Simpósio Internacional de Espaços Acadêmicos. O evento contou com mais de 300 participantes de 115 universidades, 20 empresas e 6 continentes. Ocorreram workshops, sessões de trabalho e pessoas, inclusive estudantes e docentes do Brasil (WILCZYNSKI et al., 2017).

Como se vê, a criação e estímulo do uso desses espaços do fazer é uma tendência crescente nacionalmente e internacionalmente, motivada pela necessidade da interação entre teoria e prática, presente nos cursos de engenharia.
5 O USO DE INOVAÇÃO E DAS NOVAS TECNOLOGIAS NA FORMAÇÃO DO ENGENHEIRO

Atualmente, a capacidade de produzir inovação tecnológica e transformá-la em produto é um dos principais atrativos econômicos, por isso é importante entender a melhor forma de preparar o estudante de engenharia para tal cenário.

Nos Estados Unidos, após alguma transformação da sociedade, é costumeiro fazer uma revisão do ensino de engenharias, unindo o ambiente acadêmico ao empresarial. Os resultados dessa prática demonstram que os processos produtivos mudam o andamento da história e que esses definem a função do engenheiro e não o contrário, ao longo do tempo (SILVEIRA, 2005). Essa também deveria ser uma prática do Brasil, país tão carente de engenheiros com formação adequada.

As inovações tecnológicas têm sido as propulsoras dos padrões de vida dos países desenvolvidos, desde a Revolução Industrial (KUZNETS, 1966), ou seja, o desenvolvimento tecnológico após a Primeira Revolução Industrial, com a chamada "industrialização", possibilitou o crescimento econômico dos países desenvolvidos também chamados "industrializados".

Nesse contexto, o engenheiro é o responsável pelo processo de industrialização e tomada de crescimento econômico das empresas, o que reflete positivamente no país. Nessa perspectiva, o conhecimento das tecnologias 
por este profissional éimprescindível, uma vez que possibilita a criação de novas opções ou o melhoramento do seu trabalho, desde o planejamento até a execução.

Assim, para além do conhecimento teórico, conviver com tecnologias se mostra fundamental para a formação do profissional de engenharia, uma vez que não só cria possibilidades avançadas de trabalho, como também faz com que esse profissional acompanhe os desenvolvimento e inovações em sua área de trabalho.

\section{INTERLOCUÇÃO ENTRE TEORIA E PRÁTICA NA EDUCAÇÃO EM ENGENHARIA}

Atualmente, a teoria e a prática separadas já se mostram insuficientes em qualquer conceito de produção/fabricação ou execução de uma atividade, "Teoria sem prática é paralítica e prática sem teoria é cega." Esse pensamento popular é válido para o ensino superior da engenharia em que o casamento da teoria com a prática gera o melhor resultado para o discente e futuro profissional.

A prática, dentro do ensino superior, é a concretização e fixação dos conceitos teóricos, materializando-os na vida do estudante. É clara a dificuldade dos alunos em aplicar os conceitos teóricos na prática e relacionar o conteúdo aprendido em uma disciplina com a outra, no entanto, quando se cria a cultura do "praticar", o estudante percebe que tais conhecimentos devem caminhar juntos e se compelmentarem (BUONICONTRO, 2003).

Assim, o ensino deve gerar consciência crítica no aluno, o que só ocorre quando o mesmo é capacitado a pensar, questionar, criar, formular hipóteses, por em prática e obter respostas. Para isso ocorrer, é necessário que

\section{REFERÊNCIAS}

[1] BORGES, Karen S.; MENEZES, Crediné S.; FAGUNDES, Léa C. Projetos Maker como Forma de Estimular o Raciocínio Formal através do Pensamento Computacional. In: V Congresso Brasileiro De Informática Na Educação, 2016 Uberlândia. Anais do XXII Workshop de Informática na Escola. p. 515-524.

[2] BUONICONTRO, Célia M. S.; Interação Teoria e Prática no Ensino da Engenharia: Uma Experiência Pedagógica no Curso de Engenharia sejam ministradas aulas práticas (LUZ et al., 1989).

\section{CONSIDERAÇÕES FINAIS}

A eficiência do uso de makerspace como local para praticar engenharia que atenda às necessidades do aluno é indiscutível, pois dá ao mesmo a possibilidade de materializar e praticar aquilo que aprendeu em sala de aula, trabalhando de modo associado conceitos teóricos e práticos.

A utilização desses espaços possibilita aos estudantes de engenharia um ambiente inspirador, com suporte necessário para desenvolver seus próprios projetos, praticarem mais os conteúdos ministrados, trocarem conhecimentos, experiências, colocando em prática suas ideias e gerando novas colaborações entre os frequentadores, a fim de complementarem o seu aprendizado, possibilitando um potencial criativo/empreendedor nos estudantes.

Os espaços do fazer, além de se mostrarem bastante didáticos, fortalecem o desenvolvimento de soluções de problemas, o trabalho em grupo, a cooperação e a multidisciplinaridade do profissional engenheiro como solucionador de problemas, seja com projetos e/ou de fato executando. Ou seja, não só desenvolve habilidades e competências científicas e técnicas, mas também sociais e de cooperação.

A pesquisa em questão cumpriu seus objetivos, ao apresentar instituições que já fazem uso desses espaços como elemento formador dos seus engenheiros, que têm obtido resultados positivos, bem como apontou os caminhos para os quais as instituições de ensino podem caminhar em busca de aprofundamento do aprendizado e desenvolvimento dos seus engenheiros em formação.

Mecatrônica da PUC Minas. In: COBENGE Congresso Brasileiro de Ensino de Engenharia, 2003, Rio de Janeiro.

[3] CARLETTO, Marcia R., Avaliação de Impacto Tecnológico: Alternativas e Desafios para a Educação Crítica em Engenharia. Programa de Pós-Graduação em Educação Científica e Tecnológica Universidade Federal de Santa Catarina, 2009. 
[4] CESAR, Danilo R.; BONILLA, Maria H. S. Robótica Livre: Implementação de um Ambiente Dinâmico de Robótica Pedagógica com Soluções Tecnológicas Livres no Cet CEFET em Itabirito Minas Gerais - Brasil. In: XIII Workshop sobre Informática na Escola, Anais do XXVII Congresso do SBC, Rio de Janeiro, 2007.

[5] CONCEIÇÃO, Pedro; HEITOR, Manuel. Engenharia e mudança tecnológica: as dinâmicas do conhecimento e o desafio da inovação. Brito, 2002

[6] FOLHA. Rankink Universitário da Folha. Disponível em: <http://ruf.folha.uol.com.br/2018/lista/?extra[tab]=c ursos\&extra[course]=14\&extra[uf]=mg\&extra[city]= 78>. Acesso em: 12 de dezembro de 2018.

[7] IFRS. Foto POALAB. Disponível em: $<$ http://www.poalab.net.br/>. Acesso em: 28 de setembro de 2018.

[8] MINISTÉRIO DA EDUCAÇÃO. Parecer CNE/CES 1.362/2001. Parâmetros curriculares para os cursos de engenharia. Disponível em: http://portal.mec.gov.br/cne/arquivos/pdf/CES1362. pdf. Acesso em: 29 de setembro de 2018.

[9] NEWTON PAIVA. Guia do Professor FabLab. 2017. Disponível em: <https://www.newtonpaiva.br/system/file_centers/ar chives/000/000/331/original/FABLAB_GUIA_DO_PR OFESSOR.pdf?1495194441>. Acesso em: 28 de setembro de 2018

[10] PEKELMAN, Helio; MELLO JR, Antônio G. A Importância dos Laboratórios no Ensino de Engenharia Mecânica. In: COBENGE - Congresso Brasileiro de Ensino de Engenharia, Brasília, 2004.

[11] PEPPLER, Kylie; MALTESE, Adam; KEUNE, Anna; CHANG, Stephanie; REGALLA, Lisa. Maker Education Initiative - Survey of Makerspaces, Part II In: Open Portfolios.

[12] PEREIRA, Carlos R. P.; LIMA, Milena C. A Importância da Relação Teoria e Prática Sob o Olhar dos Estudantes de Administração: Um Estudo de Caso na Universidade do Estado da
Bahia. In: ADM - Congresso Internacional de Administração, Natal ,2016.

[13] PINTO, Danilo P.; OLIVEIRA, Vanderlí F. Reflexões sobre a Prática do Engenheiro-Professor. In: COBENGE XL - Congresso Brasileiro de Educação em Engenharia, Belém, 2012.

[14] PROJETO DRAFT: O que é Makerspace. Disponível em: <https://projetodraft.com/verbetedraft-o-que-e-makerspace/>. Acesso em 22 de julho de 2018.

[15] QUINTELLA, Ivvy P. C. P.; FLORÊNCIO, Eduardo Q.; SANTOS, Luciana G.; SILVEIRA, Eduardo S. S.; SANTOS, Luciano B. Fab Labs: A Expansão da Rede Brasileira e Sua Inserção no Contexto Acadêmico e no Ensino de Engenharia. In: Primeira Conferência FabLearn. Brasil, São Paulo, 2016.

[16] RAABE, André L. A.; SANTANA, André L. M.; SANTANA, Luís F. M.; VIEIRA, Marli F. V.; METZGER, Julia P.;GOMES, Eduardo B. Atividades Maker no Processo de Criação de Projetos por Estudantes do Ensino Básico para uma Feira de Ciências. In: V Congresso Brasileiro De Informática $\mathrm{Na}$ Educação, Anais do XXII Workshop de Informática na Escola. Uberlândia, 2016, p.181190.

[17] SILVEIRA, Marcos A. A formação do engenheiro inovador: uma visão internacional. Rio de Janeiro: PUC-Rio, 2005.

[18] SPECTRUM. Foto FabLab. Disponível me: <http://spectrum.mit.edu/spring-2006/fab-lab/> Acesso em 28 de setembro de 2018.

[19] UNIVALI. Foto LITE. Disponível me: <https://www.facebook.com/univalilite/photos/a.210 980375910356.1073741828.196779033997157/416 $743792000679 /$ ?type $=3 \&$ theater $>$. Acesso em 28 de setembro de 2018.

[20] WILCZYNSKI, Vincent; COOKE, Malcom N. Identifying and Sharing Best Pratices in International Higher Education Makerspaces. In: ASEE - American Society For Engineering Education, ASEE International Forum. Columbus, 2017. 


\section{Capítulo 13}

\section{IMPLEMENTACÃO DE INTERFACE COMPUTACIONAL PARA DETERMINACÃO DO COEFICIENTE DE DIFUSIVIDADE MÁSSICA DE CORANTES EM TECIDOS TEXXTEIS}

\section{Gylles Ricardo Ströher}

Fernando dos Santos Freitas

\section{Gisely Luzia Ströher}

Resumo: $O$ presente trabalho teve como objetivo implementar uma interface computacional, denominada de FiberTex, que realiza a determinação do coeficiente de difusão, Dab, de corantes em fibras têxteis cilíndricas. A solução do modelo matemático para a difusão não permanente foi obtida por meio de uma metodologia analítica e a determinação do Dab por meio do método de mínimos quadrados utilizando o algoritmo Simplex de otimização. A partir de dados experimentais de ensaios de tingimento disponíveis na literatura os resultados obtidos indicaram que a interface é capaz de prover o Dab corretamente. A interface também provê ao usuário a distribuição de concentração do corante na fibra, a comparação gráfica entre os dados experimentais e do modelo matemático e também o coeficiente de correlação, $R$.

Palavras chave: Tingimento, Coeficiente de Difusão Mássica, Otimização 


\section{INTRODUÇÃO}

O tingimento é um dos métodos mais eficazes e populares para colorir tecidos e outros materiais, sendo uma técnica muito antiga, o que permitiu uma disponibilidade enorme de corantes têxteis comerciais. A tecnologia de tingimento, independente do grau de automatização, pode ser composta de várias etapas que são determinadas segundo a natureza da fibra têxtil, disponibilidade do corante para aplicação, considerações financeiras entre outras.

Como descreve GUARATINI e ZANNI (2000) até a metade do século XIX, todos os corantes eram derivados de folhas, ramos, raízes, frutos ou flores de várias plantas e de substâncias extraídas de animais. Embora a indústria de corantes têxteis tenha se originado na Europa desde o século XVI, o primeiro corante sintético foi descoberto apenas em 1856 na Inglaterra. Hoje a indústria de corantes dos Estados Unidos é a maior fonte exportadora destes produtos, colocando no mercado aproximadamente 2.000 tipos diferentes de corantes sintéticos.

Em geral, o objetivo do tingimento é produzir uma coloração uniforme de um substrato geralmente para combinar com uma cor préselecionada. A cor deve ser uniforme em todo o substrato, sem desnivelamento ou alteração. Há muitos fatores que influenciam na aparência da tonalidade final, incluindo: textura do substrato, constituição do substrato (físico e químico), pré-tratamentos aplicados ao substrato antes do tingimento e póstratamentos aplicados após o processo de tingimento (CLARK,2011).

O desenvolvimento de novos corantes e fibras têxteis, bem como a necessidade de maior competitividade das indústrias têxteis, vem forçando de forma significativa a geração de novos métodos de tingimento e influenciando de maneira fundamental a geração de novas tecnologias de tingimento. O objetivo principal destes avanços tecnológicos é propiciar melhores condições termodinâmicas e cinéticas ao tingimento (GUARATINI; ZANONI, 2000).

Quando todo o material fibroso é imerso numa solução de um corante as partículas de corantes se adsorvem na superfície externa do material, difundindo pelos canais capilares formados pelos espaçamentos das fibras. $O$ processo de adsorção continua até 0 momento em que um equilíbrio entre o corante em solução e aquele na fibra se estabelece. Este momento de equilíbrio caracteriza a completa penetração do corante dentro do material fibroso (TWARDOKUS, 2004)

Cada corante é utilizado para tingir determinados tipos de fibras, dependendo da interação fibra-corante que é, por sua vez condicionada às propriedades físicas e químicas dos corantes e das fibras (TROTMAN, 1984).

Esta atração corante/fibra promove a transferência do corante desde o banho de tingimento até as fibras. A intensidade desta atração depende da interação do par corante/fibra, que determina as características de solidez do produto têxtil final (ROBLEDO, 1985)

De um modo geral, a retenção das partículas do corante pelas fibras do tecido envolve várias forças atrativas como interação iônica, forças de Van der Waals e pontes de Hidrogênio e no caso dos corantes reativos às ligações covalentes (MORAES, 2010).

As indústrias têxteis consomem grandes volumes de água e substâncias químicas para fixar os corantes às fibras (ROBINSON et all, 2001). Estima-se que são consumidos de 30 a 60 litros de água por quilograma de tecido tinto (SIVARAJ et. all, 2001)

Para prevenir os desperdícios de água e minimizar a quantidade de resíduos provenientes dos processos de tingimento que hoje é a maior preocupação das indústrias têxteis, pois agride 0 meio ambiente, os corantes devem ter certa afinidade com as fibras a serem tingidas, na qual, se fixem e não desbote em sucessivas lavagens, garantindo desta forma, um tingimento equalizado e duradouro. Portanto, para minimizar a quantidade de resíduo industrial e a porcentagem de corante presente no banho de tingimento, faz-se necessário a otimização do processo de fixação do corante nas fibras através de estudos que determinam as condições ideais de processo (MORAES, 2010).

O ensaio experimental em que é realizada a imersão da fibra têxtil no banho de tingimento está representada na Figura 1. Comumente, o corante é diluído em um banho de solução em que a concentração é monitorada ao longo do tempo de tingimento, informações detalhadas deste tipo de ensaio podem ser obtidas em MORAES, 2010 e VIDART, 2013. 
Figura 1 - Fibra Têxtil durante o banho de tingimento

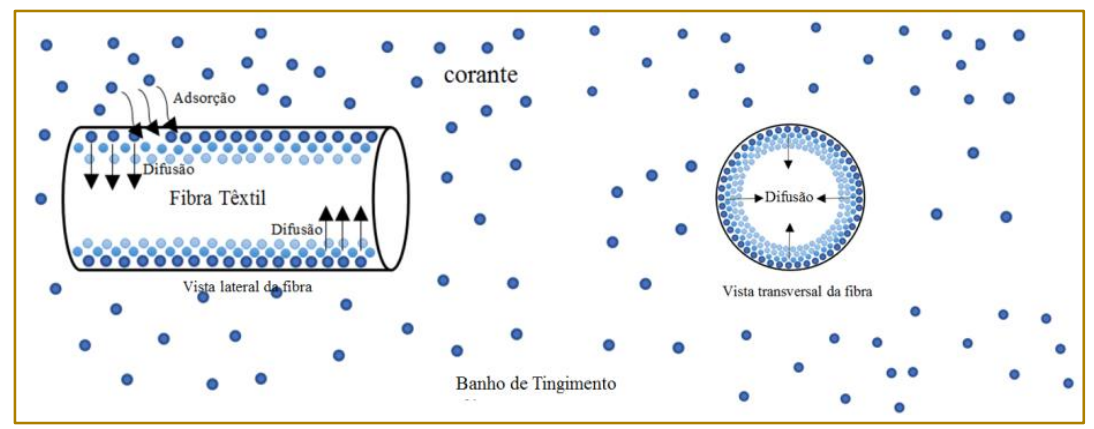

Neste contexto, o presente estudo teve como objetivo propor uma metodologia para determinar os coeficientes de difusão de corantes por meio de dados de ensaios experimentais do tempo e concentração de corante na solução de tingimento com a finalidade de reduzir efluentes gerados e maximizar o rendimento no processo de tingimento e prover uma interface computacional intuitiva, a FiberTex, para o setor da área têxtil que trabalha com tingimento.

\section{MÉTODOS}

\subsection{MODELAGEM MATEMÁTICA DA DIFUSÃO DE CORANTE}

Assumindo uma estrutura cilíndrica para as fibras, a equação de difusão para a variação de concentração do corante na fibra pode ser descrita como:

$$
\frac{\partial C^{f}}{\partial t}=D_{a b}\left[\frac{\partial^{2} C^{f}}{\partial r^{2}}+\frac{1}{r} \frac{\partial C^{f}}{\partial r}\right]
$$

onde $C^{f}$ é a concentração de corante na fibra, $D_{a b}$ a constante de difusão, $r$ é a coordenada espacial e $t$ é o tempo.
A condição de contorno da Equação (1) é dada pela Equação (2), considerando a simetria da concentração com o raio e o centro das fibras:

$$
\frac{\partial C^{f}}{\partial r}=0, \quad \text { para } r=0
$$

O banho de tingimento é um sistema fechado, desta forma, a taxa de redução da concentração de corante na solução é igual a taxa de difusão do corante na superfície da fibra. Partindo deste princípio e assumindo uma agitação eficiente, a condição de contorno da superfície da fibra é dada pelas Equações (3) e (4).

$$
\begin{gathered}
L \frac{\partial C^{S}}{\partial t}=D_{a b} \cdot S \cdot N_{c} \cdot \frac{\partial C^{f}}{\partial r}, \quad \text { para } r=a \\
C_{f}(t)=K C_{0}^{S}, \quad \text { para } r=a
\end{gathered}
$$


onde $a$ é o raio da fibra, $L$ é a relação de banho, $C^{s}$ a concentração de corante na solução, $C^{f}$ a concentração de corante nas fibras, $N_{c}$ o número de cilindros, $D_{a b}$ o coeficiente de difusão, $S$ a área superficial das fibras e $K$ o coeficiente de distribuição.

\subsection{SOLUÇÃO ANALÍTICA}

Supondo que, o cilindro ocupa um espaço $r<$ a, durante a seção transversal em que 0 banho da solução está imerso em $S$ (excluindo o espaço ocupado pelo cilindro). A concentração do soluto na solução é sempre uniforme e inicialmente CO. O cilindro é inicialmente livre de soluto. A quantidade total de soluto $M_{t}$, no cilindro no instante de tempo t é expresso pela fração correspondendo à quantidade de $M_{\infty}$, quantidade de corante na fibra após um tempo infinito, conforme Equação (5) (CRANK, 1979).

$$
\frac{M_{t}}{M_{\infty}}=1-\sum_{n=1}^{\infty} \frac{4 \alpha(1+\alpha)}{4+4 \alpha+\alpha^{2} q_{n}^{2}} \cdot e^{\frac{-D q_{n}^{2} \cdot t}{a^{2}}}
$$

em que $\alpha$ é a razão dos volumes da solução e das fibras cilíndricas, obtido pela Equação
(6), e $\square_{\square}$ raízes positivas e diferentes de zero, obtidas pela Equação (7).

$$
\begin{gathered}
\alpha=\frac{\text { volume }_{\text {solução }}}{\text { volume }_{\text {cilindro }}}=\frac{V_{\text {total }}}{\pi r^{2} h N_{\text {cilindros }}} \\
\alpha q_{n} J_{O}\left(q_{n}\right)+2 \cdot J_{1}\left(q_{n}\right)=0
\end{gathered}
$$

onde $J_{O}$ é a função Bessel de ordem zero e $J_{1}$ função Bessel de primeira ordem.

\subsection{DETERMINAÇÃO DO $D_{a b}$}

A interface proposta FiberTex, Difusão em Fibra Têxtil, determina computacionalmente o coeficiente de difusão, $D_{a b}$, em fibras de tecido têxtil. Para execução de tal tarefa definiu-se uma função objetivo $(F O)$ baseada no método de mínimos quadrados, podendo ser dada pela Equação

$$
F O\left(D_{a b}\right)=\sum_{n=1}^{\infty}\left(C_{\text {Teórico }}-C_{\text {Experimental }}\right)^{2}
$$

O valor de Dab que proverá o menor valor da FO $\left(D_{a b}\right)$ fornecerá o melhor ajuste do perfil de concentração teórica com relação à experimental.

Subsequentemente, é realizado o cálculo do coeficiente de correlação de Pearson, $R$, entre os valores teóricos $(\mathrm{T})$ e os experimentais $(\mathrm{E})$, Equação (9). O coeficiente $R$ varia entre -1 e 1, o sinal indica a direção, se a correlação é positiva ou negativa, e o valor indica a força da correlação, valores acima de 0.9 indicam uma correlação muito forte entre os dados teóricos e experimentais (MUKAKA, 2012)

$$
R=\frac{\sum\left(C_{E}-\bar{C}_{E}\right)\left(C_{T}-\bar{C}_{T}\right)}{\sqrt{\left[\sum\left(C_{E}-\bar{C}_{E}\right)^{2}\right]\left[\sum\left(C_{T}-\bar{C}_{T}\right)^{2}\right]}}
$$




\subsection{MÉTODO DE OTIMIZAÇÃO}

Para determinação do mínimo absoluto da FO $\left(D_{a b}\right)$, foi utilizado o Método Simplex proposto por Nelder e Mead (MATHEWS, 2004). O algoritmo Simplex pertence a uma classe mais geral de algoritmos de pesquisa direta e que não faz uso de derivadas, portanto trata-se uma técnica de otimização não linear, baseada no método de otimização livre de derivada, Derivative-Free Optimization (DFO). O Simplex busca, a partir de uma primeira solução básica viável, percorrer de forma iterativa os vértices de um polígono até alcançar uma solução considerada ótima para o problema. Constitui-se de um método que minimiza uma função de $M$ variáveis que, por sua vez, depende da comparação da função nos seus $(M+1)$ vértices de um simplex geral seguido pela recolocação do vértice com o valor mais alto por outro ponto de menor valor na função objetivo. O próprio simplex adaptase à paisagem local e contrai-se a um mínimo local final. De um ponto de vista computacional, esse método mostra-se ser compacto e efetivo (GOMES, 2017).

\subsection{INTERFACE COMPUTACIONAL}

A interface do aplicativo, Figura 2, foi proposta com o intuito de facilitar e agilizar o dia-a-dia de uma rotina de trabalho, pensouse também, sobretudo, em uma interface intuitiva, para que além de atender as necessidades do usuário seja de fácil utilização em que o grau de conhecimento requerido do usuário que utilize o programa seja mínimo. Outro fator importante à implementação da interface é a carência de indústrias em obter licença de programas computacionais técnicos.

\section{RESULTADOS E DISCUSSÃO}

Para a realização da simulação computacional baseada na segunda lei da difusão de Fick, implementou-se uma interface computacional mostrada na Figura 2, com uma reposta direta de inserção de dados e obtenção do respectivo valor de difusividade mássica do corante em análise. $\mathrm{Na}$ interface outras informações também são exibidas, como: perfil de concentração no banho de tingimento, distribuição de concentração na fibra e coeficiente de correlação entre os dados teóricos e experimentais.

Figura 2 - Interface do Programa

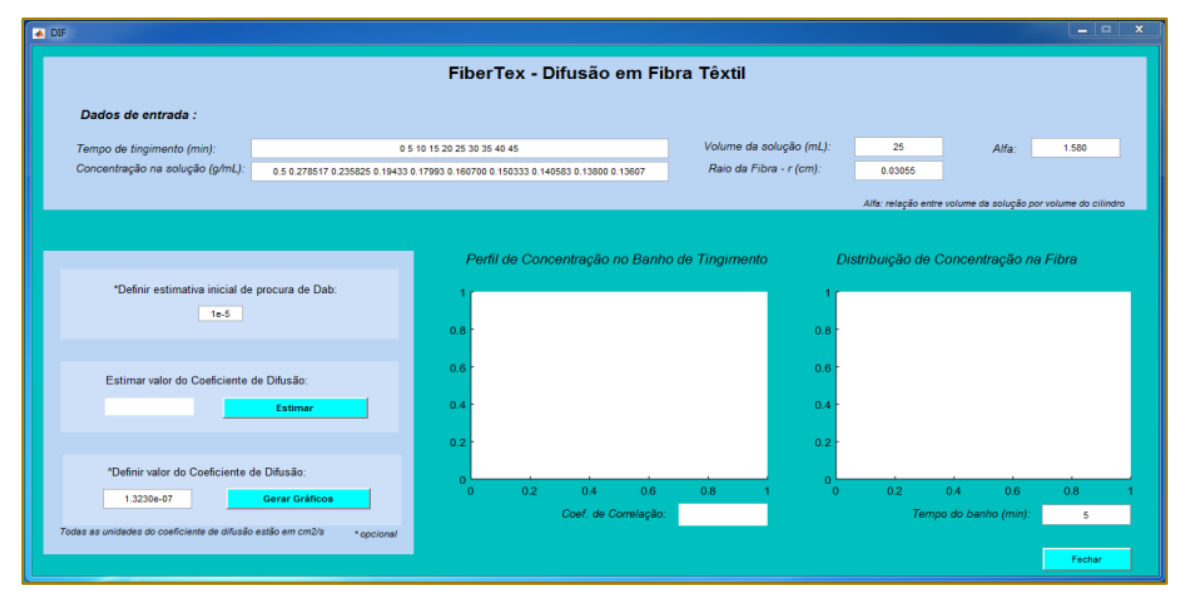

A partir de dados de ensaios experimentais de tempo e concentração de corante no banho de tingimento, existentes na indústria têxtil obtidos pela literatura, MORAES e
VIDART, foi possível realizar a simulação e determinar os valores dos coeficientes de difusão, Dab, e gerar o perfil de concentração pelo tempo de tingimento, Figura 3. 
Figura 3 - Perfis de Concentração de Corante pelo Tempo de Tingimento

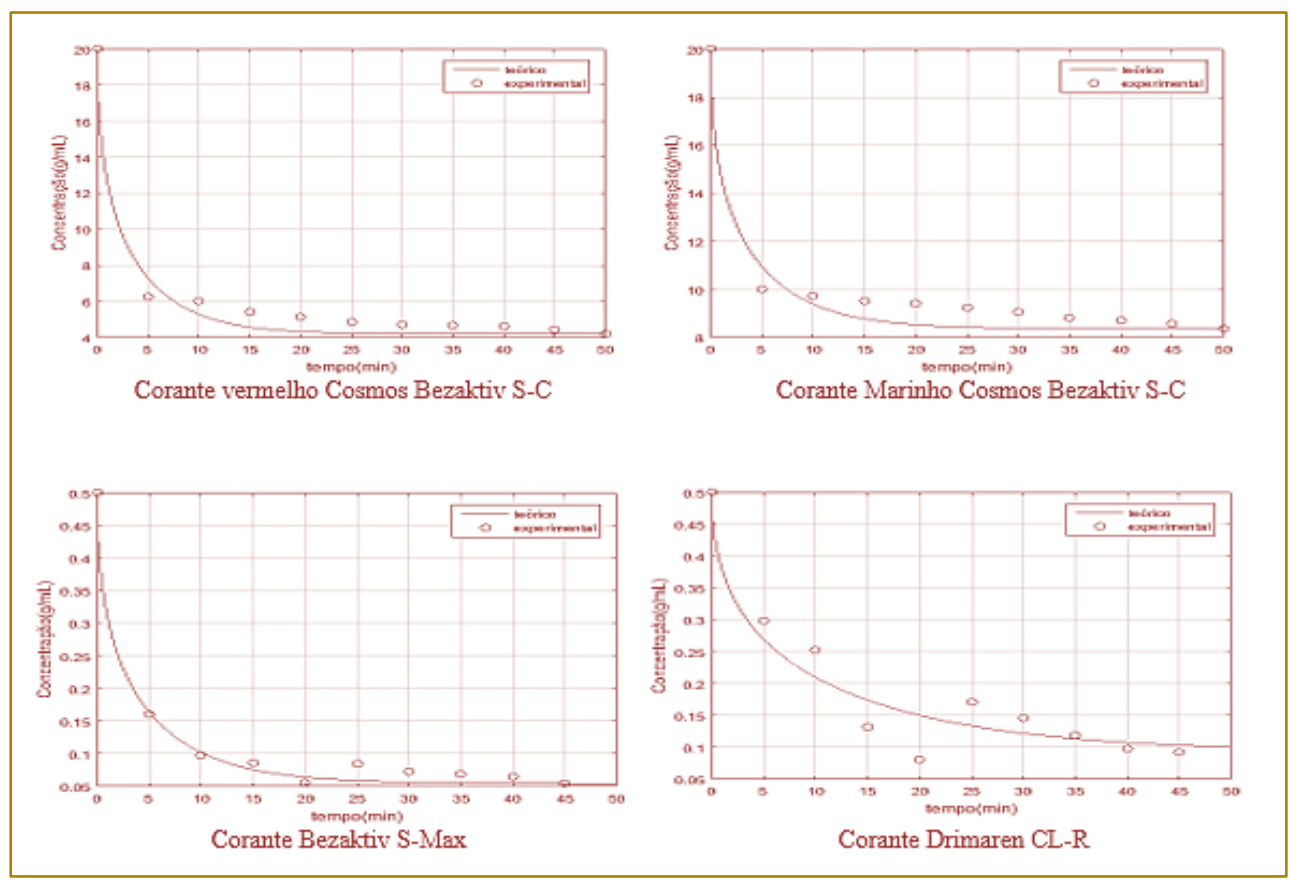

Observou-se um decaimento da concentração de corante no banho de tingimento ao longo do tempo, Figura 3, onde os valores simulados concordam satisfatoriamente com os dados experimentais.

apresentados na Tabela 1, os testes foram realizados para quatro tipos diferentes de corantes a fim de comparar os resultados obtidos com os já existentes.

Os dados, requeridos pela interface, para gerar os perfis de concentração foram

Tabela 1 - Valores para gerar arquivo de dados

\begin{tabular}{|l|c|c|c|}
\multicolumn{1}{|c|}{ Corante } & Vsolução $-(\mathrm{mL})$ & Raio $-r(\mathrm{~cm})$ \\
\hline Vermelho Cosmos Bezaktiv S-C & 50 & 0,0145 & 6,75 \\
\hline Marinho Cosmos Bezaktiv S-C & 25 & 0,03055 & 1,58 \\
\hline Bezaktiv S-Max & & & \\
\hline Drimaren CL-R & & & \\
\hline
\end{tabular}

Fonte: Autora Própria (2018)

Com valores de Dab disponível na literatura e os obtidos pela interface computacional realizou-se os devidos cálculo já mencionados para obter os respectivos valores da função objetivo a ser minimizada, $F O\left(D_{a b}\right)$. Os resultados são apresentados na Tabela 2. 
Tabela 2 - Resultados Obtidos da Literatura e pela Interface Computacional

\begin{tabular}{|c|c|c|c|c|c|c|}
\hline Corante & $\begin{array}{c}\text { Dab } \\
(\mathrm{cm} 2 \mathrm{~s}- \\
\text { 1) } \times 107\end{array}$ & Literatu & $\mathrm{R}$ & $\begin{array}{c}\text { Dab } \\
(\mathrm{cm} 2 \mathrm{~s}- \\
1) \\
\times 107\end{array}$ & tterface & $\mathrm{R}$ \\
\hline $\begin{array}{l}\text { Vermelho Cosmos } \\
\text { Bezaktiv S-C. }\end{array}$ & 138 & 11,49 & 0,990 & 1,29 & 4,92 & 0,993 \\
\hline $\begin{array}{l}\text { Marinho Cosmos } \\
\text { Bezaktiv S-C. }\end{array}$ & 125 & 8,63 & 0,988 & 1,16 & 4,31 & 0,988 \\
\hline Bezaktiv S-Max. & 0,95 & 0,019 & 0,948 & 3,25 & 0,0014 & 0,997 \\
\hline Drimaren CL-R. & 0,66 & 0,038 & 0,957 & 1,34 & 0,011 & 0,962 \\
\hline
\end{tabular}

Fonte: Autora Própria (2018)

Observou-se para todos os casos que a função objetivo $F O\left(D_{a b}\right)$, Equação (8), foi melhor minimizada com os valores de coeficiente de difusão obtidos da interface computacional. Os resultados de Dab provenientes da interface estiveram na mesma ordem de grandeza para os dois últimos corantes utilizados em MORAES e cem vezes menor em comparativo com os dois primeiros de VIDART.

Utilizando um microcomputador com a configuração Windows 7 Ultimate, processador Intel $®$ CoreTM i3-2310M CPU @ 2.10 GHz, memória (RAM) de $4 \mathrm{~GB}$, sistema operacional de 64 Bits, o tempo de processamento para a convergência do valor de Dab foi em média 30 a 60 segundos, contudo deve ficar claro que esse tempo depende fortemente da capacidade de processamento do computador utilizado, assim variações em relação ao tempo de processamento podem ocorrem.

Após a inserção dos dados de entrada a interface realiza os cálculos já mencionados para determinar o coeficiente de difusão, e por fim, exibe na tela, além do Dab e o R, o perfil de concentração no banho de tingimento e o perfil de concentração na fibra, mostrados na Figura 4.

Figura 4. Interface do programa após finalizar os cálculos

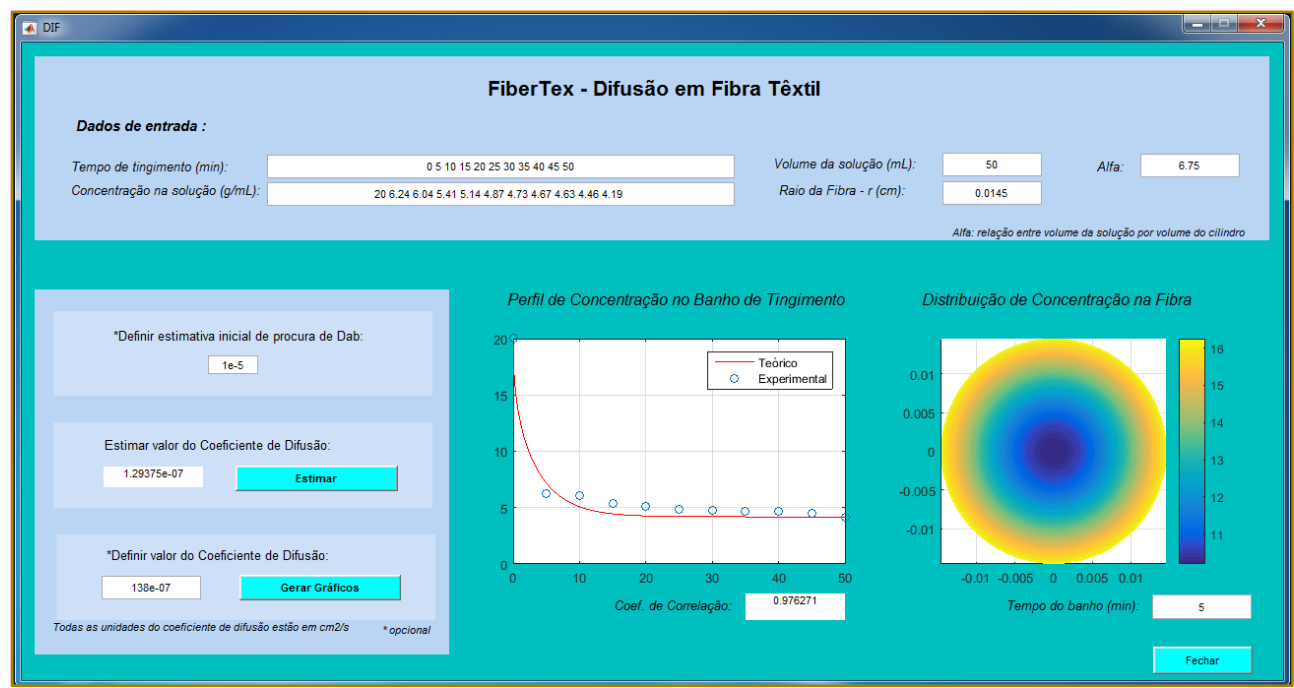


Também foi possível comparar a distribuição de concentração na fibra têxtil para os corantes testados, em que pôde-se verificar, para um tempo de 5 minutos, que a concentração de corante é maior na superfície da fibra, diminuindo gradativamente até o centro da mesma, que está isenta de corante. Ao se comparar a distribuição de concentração na fibra com valores de Dab obtidos da interface com os da literatura, mostrado na Figura 5, observou-se que, para o tempo especificado, os dois primeiros corantes, com o Dab da literatura, a fibra estaria praticamente isenta de corante, e para os dois últimos, a concentração de corante na fibra é menor com os Dab obtidos da interface.

Figura 5 - Perfis de Concentração de Corante na Fibra

(1) Dab obtido da interface, (2) Dab obtido da literatura

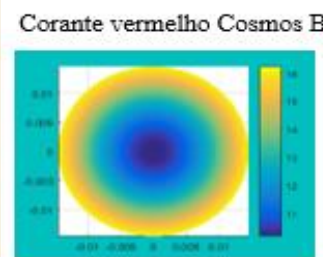

(1)

Corante Bezaktiv S-Max

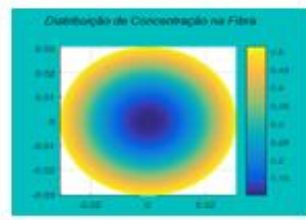

(1)

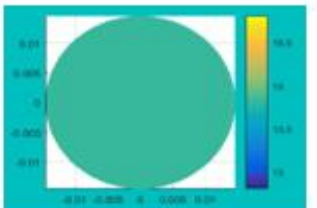

(2)

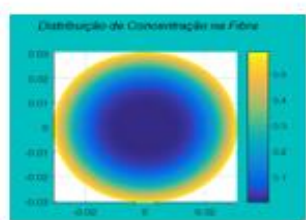

(2)

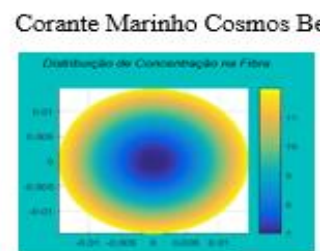

(1)

Corante Drimaren CL-R

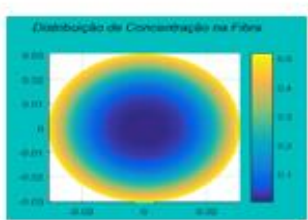

(1)

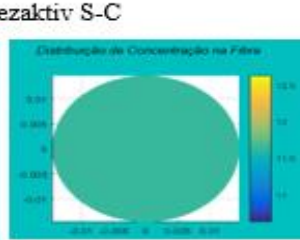

(2)

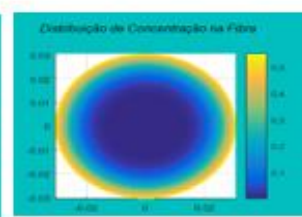

(2)
É opcional que o usuário forneça uma estimativa inicial para o coeficiente de difusão mássica Dab, uma vez que a interface já disponibiliza um valor default baseado na faixa do valor numérico para o Dab. Caso o usuário opte por trocar o valor default a interface realiza um aprimoramento desta estimativa inicial antes do valor ser redirecionado para o algoritmo Simplex. Nesse aprimoramento, gera-se uma faixa de valores, com base em uma estimativa de referência fixada pelo algoritmo, em que, com o auxílio de uma função de mínimos, seleciona o Dab no qual têm-se o menor valor para a função objetivo, tendo então uma nova estimativa inicial melhorada. Este aprimoramento acarreta em um leve aumento de tempo de processamento computacional, porém provê uma melhora substancial na convergência do algoritmo Simplex.

\section{CONCLUSÃO}

No presente trabalho foi obtida a solução matemática para um problema baseado na segunda lei de Fick da difusão por meio da solução analítica do modelo e com o método de mínimos quadrados associado ao algoritmo Simplex. A solução implementada foi verificada com a solução de outros autores e os resultados indicaram concordância entre os valores de Dab obtidos. O método Simplex mostrou-se eficiente para os dados experimentais testados convergindo para um valor mínimo satisfatório da função objetivo. Os resultados obtidos apresentaram boa concordância com os dados experimentais em que foi possível obter coeficientes de correlação, R, maior que 0.9 para os testes realizados. Adicionalmente a interface se mostrou de fácil utilização e certamente contribuirá para setores de tingimento da indústria têxtil assim como para pesquisas no meio acadêmico.

\section{AGRADECIMENTOS}

Os autores agradecem a Fundação Araucária pelo incentivo e apoio financeiro ao projeto. 


\section{REFERÊNCIAS}

[1] CLARK, M. Handbook of Textile and Industrial Dyeing, Volume 1 - Principles, Processes and Types of Dyes, Woodhead Publishing,Philadelphia, 2011.

[2] GOMES, F. I. F. N. et al. Estratégia Híbrida de Otimização sem Derivadas para a Inversão Completa da Forma da Onda. holos, v. 33, n. 2, p. 2-34, 2017.

[3] GUARATINI, C. C. I.; Zanoni, M.V. B. Corantes têxteis, Química Nova, p. 71-78, 2000.

[4] MATHEWS, John $H$. et al. Numerical methods using MATLAB. Upper Saddle River, NJ: Pearson Prentice Hall, 2004.

[5] MORAES, C.M. Estudo da difusão de corantes reativos em tecido de algodão. Dissertação, Faculdade de Engenharia Química, UNICAMP, 2010.

[6] MUKAKA, Mavuto M. A guide to appropriate use of correlation coefficient in medical research. Malawi Medical Journal, v. 24, n. 3, p. 6971, 2012.

[7] NILSSON, Ralph et al. Asthma, rhinitis, and dermatitis in workers exposed to reactive dyes. Occupational and Environmental Medicine, v. 50, n. 1, p. 65-70, 1993.
[8] ROBINSON, Tim et al. Remediation of dyes in textile effluent: a critical review on current treatment technologies with a proposed alternative. Bioresource technology, v. 77, n. 3, p. 247-255, 2001.

[9] ROBLEDO, J. C. Principios de la Tintura a la continua II, Colombia Textil, v. 32, n. 117, p. 3742, 1995.

[10] SIVARAJ, Rajeshwari; NAMASIVAYAM, C.; KADIRVELU, K. Orange peel as an adsorbent in the removal of acid violet 17 (acid dye) from aqueous solutions. Waste management, v. 21, n. 1, p. 105110, 2001

[11] TROTMAN, E. R. Dyeing and Chemical Technology of Textile Fibres, 6a ed, Editora Charles Griffin \& Company Limited, England, 1984.

[12] TWARDOKUS R. G. Reuso de Água no Processo de Tingimento da Indústria Têxtil. Dissertação, Engenharia Química do Centro Tecnológico da Universidade Federal de Santa Catarina, Florianópolis SC, 2004.

[13] VIDART, Jacyara Moreira Martins et al. Simulação da difusão de corantes reativos em fibras de algodão. 2013. 


\section{Gapítulo 14}

\section{OS BENEFICIOS DA APLICAÇ̃̃O DA CRONOANÁLISE NO PROCESSO PRODUTIVO: UMA PESQUISA-AÇÃO EM EMPRESA DO RAMO DE PUERICULTURA PESADA.}

Lucas Eduardo Barbieri

Eduardo Ezequiel Zaniboni

Vanessa Moraes Rocha de Munno

Bianco Gallazzi da Silva Leite

Ivan Correr

Resumo: Em um mercado consumidor extremamente competitivo, empresas buscam os melhores recursos relacionados aos ganhos produtivos, pois estão diretamente ligados em sua permanência no mercado. Muitas empresas investem no estudo de tempos e movimentos, por meio da cronoanálise, visando racionalizar a produção de forma planejada, contribuindo para se determinar o tempo padrão de um produto bem como auxiliar na compreensão dos métodos de trabalho de um processo, a fim de reduzir o tempo de fabricação, aumentando-se consequentemente a produtividade. Em uma empresa do ramo de puericultura pesada, objeto da pesquisa, foram identificados pontos críticos do processo que estavam impossibilitando o cumprimento das metas diárias estabelecidas, fazendo com que houvessem oscilações na produção e desequilíbrios nos volumes produtivos. A partir desta problemática, o presente trabalho teve como objetivo aplicar o método de cronoanálise em uma linha de fabricação de conjuntos de componentes costurados para acoplamento em dispositivos de retenção para autos, visando gerar melhorias na produtividade, eficiência e balanceamento do processo produtivo, permitindo estabelecer uma capacidade produtiva adequada para o atingimento de metas e expectativas da empresa. A metodologia utilizada para o desenvolvimento do estudo foi baseada em uma pesquisa-ação. Os resultados obtidos na presente pesquisa foram: o balanceamento adequado do processo e melhoria nas condições de trabalho dos funcionários; o aumento da capacidade produtiva de 308 conjuntos/dia para 352 conjuntos/dia com a manutenção do número de funcionários; a estabilidade no cumprimento da meta diária estabelecida; e o aumento da eficiência da produção de 94,06\% para $99,46 \%$.

Palavras-chave: cronoanálise, Estudo de Tempos e Movimentos, Tempo Padrão, puericultura 


\section{INTRODUÇÃO}

$\mathrm{Na}$ atualidade, em um mercado globalizado, os consumidores exigem produtos com baixos custos e de extrema qualidade, fazendo com que as empresas busquem recursos relacionados ao aumento da produtividade em seus processos (PEINADO; GRAEML, 2007).

O Estudo de Tempos e Movimentos está diretamente relacionado ao aumento de produtividade, pois geram melhores condições de execução da determinada operação, obtendo-se redução de fadigas e redução no tempo de execução, aumentandose consequentemente a produtividade do processo (NASCIMENTO et al., 2014).

O Estudo de Tempos e Movimentos tem como objetivo medir e avaliar o desempenho das operações de um produto estabelecendo o melhor método de trabalho para realização da operação, auxiliando na determinação da capacidade produtiva da organização, no balanceamento de processos, na determinação do valor da mão de obra direta no custo do produto vendido, além de proporcionar estimativas referentes à determinação do custo de um novo produto em sua fase de projeto de criação (PEINADO; GRAEML, 2007).

A Cronoanálise surgiu através do Estudo de Tempos e Movimentos como uma ferramenta adotada para racionalizar a produção de forma planejada, contribuindo para se determinar o tempo padrão de um produto bem como auxiliar na compreensão dos métodos de trabalho de um processo (TOLEDO, 2004).

Portanto o presente trabalho tem como objetivo aplicar o método de cronoanálise em uma linha de fabricação de conjuntos de componentes costurados para acoplamento em dispositivos de retenção para autos, visando gerar melhorias na produtividade, eficiência e balanceamento do processo produtivo, permitindo estabelecer uma capacidade produtiva adequada para o atingimento de metas e expectativas da empresa.

\section{REFERENCIAL TEÓRICO}

\subsection{ESTUDOS DE TEMPOS E MOVIMENTOS}

Através de técnicas precisas se obtêm análises específicas para todas as operações que compõe o processo, objetivando estabelecer os mais precisos e corretos métodos de trabalhos, excluindo-se também operações e métodos desnecessários para a realização da operação (PEINADO; GRAEML, 2007).

Desta forma, o Estudo de Tempos e Movimentos permite obter dados confiáveis para os indicadores de uma organização. Essas informações reais proporcionam uma modificação na forma de analisar os dados produtivos e qualitativos em um processo produtivo (TAKASHINA; FLORES, 1999).

Para Venâncio et al. (2015), os estudos referentes aos tempos e movimentos em uma organização permitem se terem uma visão mais abrangente da capacidade produtiva do processo, gerando através deste conhecimento, melhorias nos processos de fabricação. Desta forma, o estudo relacionado aos tempos é extremamente eficiente na aplicação dos recursos em prol de um melhor desempenho de trabalho, auxiliando na detecção de problemas, no acompanhamento e otimização do sistema produtivo.

\subsection{CRONOANÁLISE}

Segundo Toledo (2004), a cronoanálise permite estabelecer parâmetros de inúmeras formas, fazendo com que haja um melhor planejamento e racionalização industrial, ou seja, esses parâmetros de forma coordenada permitem uma melhor compreensão dos processos produtivos.

Também é vista como uma ferramenta para determinar o tempo padrão de execução da operação e contribui para um desenvolvimento produtivo e contínuo da organização (FELLIPE et al., 2012).

Segundo Dorigon (2011), a cronoanálise é de fundamental importância no controle e planejamento da produção, pois objetiva analisar os tempos de processos e permite com isso se ter um balanceamento preciso das operações, e todas as etapas que são necessárias para um fluxo produtivo positivo. Dessas etapas, podem-se destacar: melhor controle da capacidade produtividade, elaboração de um layout preciso, melhorar a produtividade e a sequência das operações do produto. A cronoanálise é uma ferramenta que possibilita a identificação dos gargalos e desperdícios que ocorrem em uma linha produtiva. 
Para a obtenção de uma cronoanálise denominada correta, existem etapas que devem ser aplicadas na prática: Obtenção e registro das operações e do operador; divisão das operações em elementos; observação e registro do tempo gasto da operação; determinação do número de ciclos; avaliação do ritmo do operador; determinação do tempo normal; determinação das tolerâncias; determinação do tempo padrão (PESSOTTI et al., 2015).

\subsubsection{OBTENÇÃO E REGISTRO DAS OPERAÇÕES E DO OPERADOR}

Para se obter informações das operações e do operador, de acordo com Silva e Coimbra (1980), primeiramente o observador deve analisar e verificar as operações/movimentos anteriores e posteriores do operador e definir pontos de início e término da operação. Para complementar, Costa Júnior (2008) afirma que está etapa permite entender o processo de fabricação do produto, bem como elaborar um sequenciamento das operações, facilitando as medições.

\subsubsection{DIVISÃO DAS OPERAÇÕES EM ELEMENTOS}

Segundo Pena et al. (2016), a observação do método de trabalho permite que a divisão do método em elementos se torne consistente, permitindo sequenciar e padronizar as atividades, dividindo-se em elementos e facilitando o registro dos dados.

Para determinar o tempo de execução da operação, é preciso identificar os movimentos desnecessários e os problemas durante o processo, bem como dividir os conjuntos de movimentos da operação em subgrupos (COSTA JÚNIOR, 2008).

\subsubsection{OBSERVAÇÃO E REGISTRO DO TEMPO GASTO DA OPERAÇÃO}

De acordo com Barnes (1977), o tempo real da operação é o tempo medido com o uso do cronômetro e existem dois métodos para a leitura dos dados, que são a leitura repetitiva, no qual se objetiva retornar o cronômetro ao zero no final de cada elemento e também, a leitura contínua, cujo objetivo é realizar a leitura durante todo o período da análise a partir do primeiro elemento.

\subsubsection{DETERMINAÇÃO DO NÚMERO DE CICLOS}

Para determinar o número de ciclos que se deve cronometrar por elemento, Peinado e Graeml (2007) concluem que é necessária a realização de medições de tempo para ter uma média aritmética entre os tempos medidos (Equação 1).

$$
N=\left(\frac{Z \times R}{\operatorname{Er} \times D_{2} \times \bar{X}}\right)
$$

Com relação a esse método estatístico, Z representa um coeficiente de distribuição normal de uma probabilidade estabelecida, $\mathrm{R}$ amplitude da amostra, Er erro relativo da medição, D2 coeficiente em função do número de cronometragens efetuadas previamente e X valor médio das medições.

Para Peinado e Graeml (2007) o grau de confiabilidade da medição utilizada gira em torno de $90 \%$ e $95 \%$ com um erro relativo aceitável com variação entre 5\% e 10\%. Com esses dados, a partir de $95 \%$ de probabilidade, a média dos valores registrados não diferenciará mais que 5\% do valor considerado verdadeiro para a duração do elemento medido.

\subsubsection{AVALIAÇÃO DO RITMO DO OPERADOR}

Com relação à análise do ritmo em que o operador executa as operações, Barnes (1977) estabelece sistemas utilizados, que são:

- Habilidade e esforço: Considera as habilidades e esforços do operador e o uso de uma tabela padronizada de tolerâncias a fadigas;

- Sistema westinghouse: São estabelecidos quatros fatores de análise: habilidade, esforço, condições e consistência;

- $\quad$ Avaliação sintética do ritmo: consiste na comparação da velocidade do operador ao executar a operação com valores definidos em uma tabela de tempos sintéticos; 
- $\quad$ Avaliação objetiva do ritmo: consiste em priorizar apenas a velocidade do movimento e o grau da atividade, desconsiderando a tarefa em questão;

- Desempenho relacionado ao ritmo: esse método considera apenas ao fator ritmo, tempo ou velocidade do operador.

\subsubsection{DETERMINAÇÃO DO TEMPO NORMAL}

Pode-se definir tempo normal como sendo um processo capaz de analisar a velocidade com que o operador executa suas operações com desempenho padrão (PEINADO E GRAEML, 2004). Slack, Chambers e Johnston (2009) afirmam que o tempo normal é estabelecido através da análise da velocidade de trabalho do operador a uma velocidade que corresponde a um desempenho padrão.

\subsubsection{DETERMINAÇÃO DAS TOLERÂNCIAS}

Para Barnes (1977), durante o processo, há interrupções, necessidades pessoais que são caracterizadas como tolerância para fadiga (esforço do operador e sua energia consumida), tolerância para questões pessoais ou tolerância relacionada a esperas, no qual se pode denominar como evitáveis (modo intencional - não devem ser consideradas para cálculos) e inevitáveis (quebras, ajustes técnicos, etc).

\subsubsection{DETERMINAÇÃO DO TEMPO PADRÃO}

Para se determinar o tempo padrão da operação, é necessário agregar as tolerâncias definidas no tempo normalizado. O tempo padrão é de fundamental importância para análises da capacidade produtiva dentro de um processo, dando ênfases aos aspectos impactantes no tempo considerado necessário para a fabricação do produto. $O$ tempo padrão visa obter produtividade através da racionalização do trabalho (CRUZ, 2008).

É necessário também que uma análise seja feita em uma condição normal de trabalho. $O$ tempo padrão também é utilizado para padronizar e tornar como referência em treinamento para novos funcionários, estabelecendo métodos adequados, uma condição favorável. Para que isso seja feito, é necessário que o operador seja apto a executar as operações, tendo como características habilidades e esforços médios durante a rotina de trabalho (CRUZ, 2008).

\section{METODOLOGIA E DESENVOLVIMENTO DA PESQUISA}

O modelo de pesquisa utilizado neste presente estudo é a pesquisa-ação. De acordo com Gil (2002), a pesquisa-ação visa determinar o campo da investigação, as expectativas dos envolvidos e o auxílio dos envolvidos no processo de pesquisa.

A pesquisa-ação não tem uma ordem estabelecida de suas fases, no qual se caracteriza pela dinâmica dos pesquisados com relação a situação da pesquisa e também com suas ações dentro do processo de pesquisa.

Com isso, segundo Gil (2002) pode-se delinear conjuntos de ações que podem ser consideradas etapas do processo de pesquisa-ação e que foram utilizadas nesta pesquisa, são estas:

- Fase exploratória;

- Formulação o problema;

- Construção das hipóteses;

- Formação da equipe / elaboração das diretrizes da pesquisa-ação;

- Seleção as amostras dos elementos em análise;

- Coleta de dados;

- Analise e interpretação dos dados;

- Elaboração de planos de ação;

- Divulgação dos resultados.

\subsection{CARACTERIZAÇÃO DA EMPRESA E DOS PROCESSOS}

A empresa estudada é do ramo de puericultura pesada, fabricante de produtos para bebês, tais como: carrinhos berços, carrinhos passeios, cadeiras de refeição, dispositivos de retenção para autos, banheiras, cercados, entre outros.

Em seu escopo, a empresa possui setores produtivos para todos os componentes dos produtos, tais como: Injeção Termoplástica (peças plásticas), Estamparia (estruturas metálicas), Tapeçaria (conjuntos de 
componentes costurados), Corte (tecidos cortados utilizados pela Tapeçaria). Há também em seu escopo os setores de apoio, controle e desenvolvimento tais como: Engenharia de Manufatura e Processos, Qualidade e Desenvolvimento de Produtos.

O setor de Tapeçaria, setor responsável pela transformação de tecidos cortados em componentes costurados, para que assim sejam acoplados na estrutura do produto, foi o setor no qual a pesquisa foi desenvolvida. A implantação da cronoanálise se deu em um conjunto de componentes costurados para acoplamento em um dispositivo de retenção para autos. Os processos de costura são executados em etapas conforme a Figura 1.

Figura 1 - Processo de costura

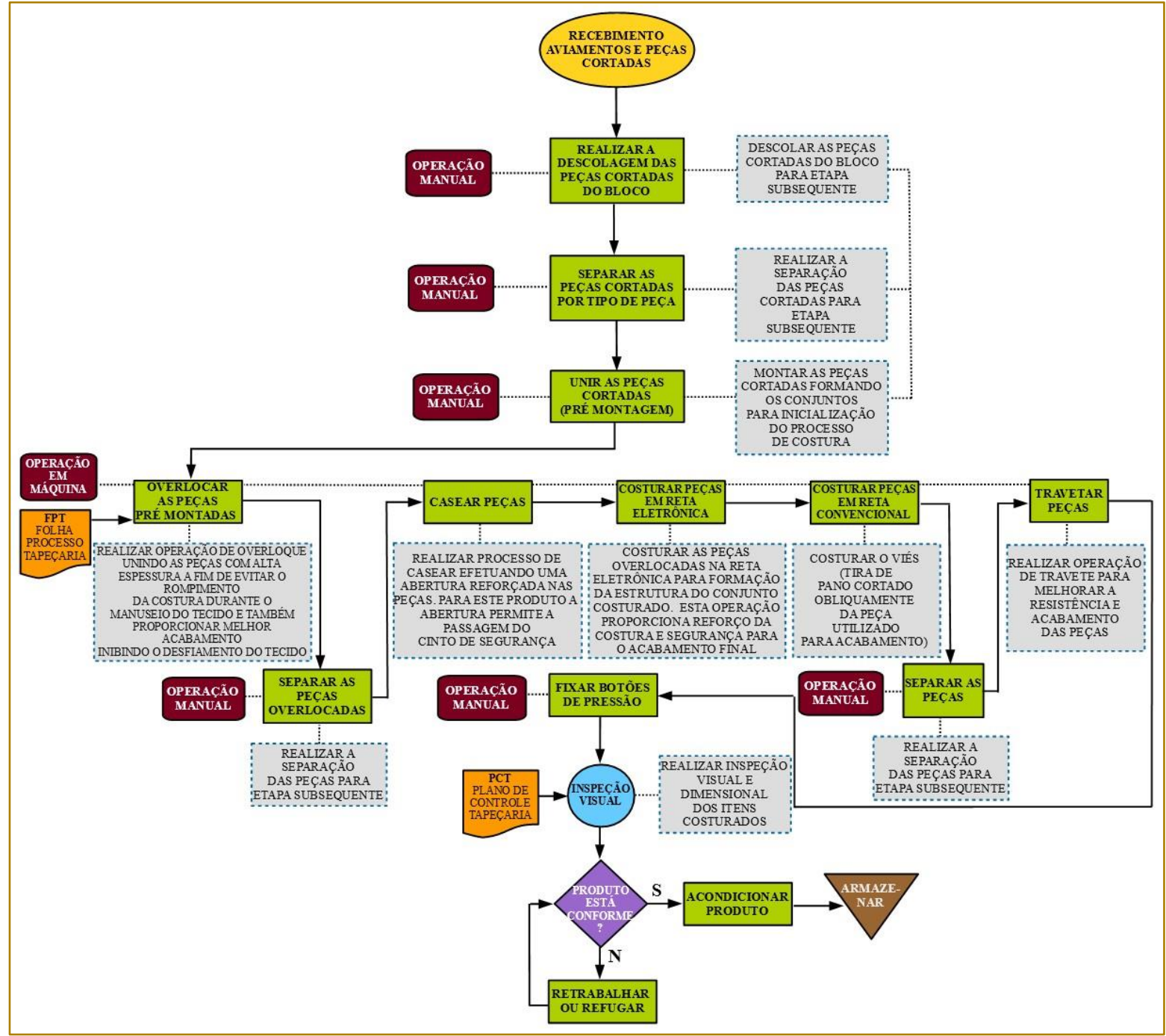

Fonte: Os autores.

\subsection{ESTUDO, DESENVOLVIMENTO E APLICAÇÃO DA CRONOANÁLISE}

$\mathrm{Na}$ fase exploratória, foi observado alguns pontos críticos no processo de costura que não estavam possibilitando o cumprimento da meta diária estabelecida. Os pontos críticos foram listados para se definir as diretrizes da pesquisa-ação.
Foi identificado que o tempo padrão para os componentes costurados eram estimados de acordo com o número de costureiras e operadoras de processos disponíveis no setor, ou seja, não havia uma cronoanálise definida para os elementos que compõe o produto.

Pode-se identificar então, que o processo analisado não estava balanceado corretamente, a meta diária de produção não 
era exata e as oscilações identificadas no processo eram oriundas do não balanceamento das máquinas e das operações manuais, gerando desequilibrios da quantidade de peças costuradas e sobrecargas na capacidade horária das máquinas.

A Tabela 1 apresenta o tempo padrão definido pela empresa e a Figura 2 apresenta os dados de produção referente ao mês de julho de 2017 com base no tempo padrão definido.

Como pode ser observado na Figura 2, apenas nos dias 05, 14 e 20 a meta estabelecida foi atingida e no restante dos dias, se têm uma nítida oscilação na produção, obtendo-se uma média de eficiência mensal de 94,06\%.

Tabela 1 - Tempo padrão definido pela empresa

\begin{tabular}{|cc|}
\hline Descrição & Quantidade \\
\hline Costureiras & 12 \\
Operadoras de processos & 6 \\
Total de funcionárias & 18 \\
Meta diária (conjuntos) & 308 \\
Tempo estimado & 0.430000 horas \\
Eficiência (\%)/ Ref. Julho/2017 & $94,06 \%$ \\
\hline
\end{tabular}

Fonte: Os autores

Figura 2 - Registro de produção e eficiência (Julho/2017)

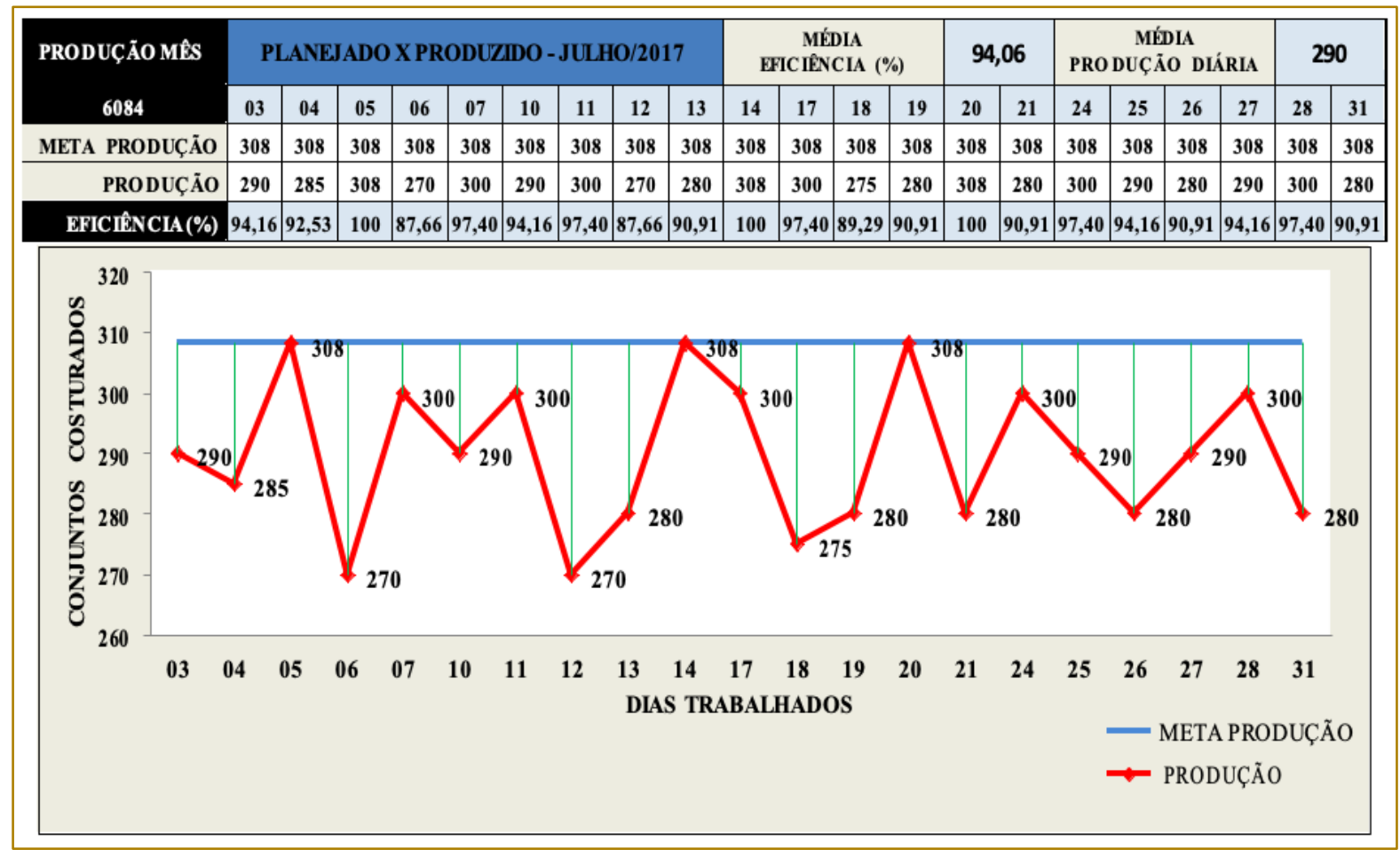

Fonte: Os autores

Com os dados coletados, foi definido cronoanalisar os componentes para gerar melhorias quanto à produtividade e eficiência do processo e permitir um balaceamento adequado para o layout produtivo.

As etapas da cronoanálise foram iniciadas checando as folhas de processos estabelecidas para os componentes com relação aos processos realizados na prática. Pode-se verificar com esta etapa, que os dados das folhas de processos estavam coerentes com os processos desempenhados pelas funcionárias.

Após as observações das operações efetuadas no processo foi definido os pontos de ínicio e término para cada operação 
(Tabela 2) e foi decidido padronizar os pontos dos processos: operações das máquinas de costura, operações manuais (descolagem, montagem e separação) e operações de revisão dos componentes (visual e dimensional)

Tabela 2 - Pontos de início e término para cada operação

\begin{tabular}{|cll}
\hline $\begin{array}{c}\text { Descrição do } \\
\text { Processo }\end{array}$ & \multicolumn{1}{c}{ Início } & \multicolumn{1}{c}{ Término } \\
\hline Máquinas & Pegar a peça A na bancada. & Pegar a peça B na bancada. \\
\hdashline Manuais & $\begin{array}{l}\text { Pegar a peça A para } \\
\text { Descolagem, Montageme } \\
\text { Separação. }\end{array}$ & $\begin{array}{l}\text { Pegar a peça B para Descolagem, } \\
\text { Montageme Separação. }\end{array}$ \\
\hline \multirow{2}{*}{ Revisão } & $\begin{array}{l}\text { Pegar o componente A para } \\
\text { revisão. }\end{array}$ & $\begin{array}{l}\text { Pegar o componente B para } \\
\text { revisão. }\end{array}$ \\
\hline
\end{tabular}

Fonte: Os autores

Com base na checagem das operações com as folhas de processos existentes e a padronização dos pontos de início e término de cada elemento, as operações foram distribuidas pelos elementos nos componentes (Tabela 3).
O produto estudado é composto de 8 componentes e um total de 66 elementos distribuídos em operações de máquinas de costura, operações manuais e operações de revisão. Esses componentes constituirão o tempo padrão do produto.

Tabela 3 - Distribuição dos elementos nos componentes

\begin{tabular}{|c|c|c|c|c|}
\hline Componentes & $\begin{array}{c}\text { Operações } \\
\text { de MÁquinas }\end{array}$ & $\begin{array}{c}\text { Operações } \\
\text { Manuais }\end{array}$ & $\begin{array}{c}\text { Operações de } \\
\text { Revisão }\end{array}$ & $\begin{array}{c}\text { Total de } \\
\text { Elementos }\end{array}$ \\
\hline Assento & 12 & 12 & 1 & 25 \\
\hline Capota & 7 & 6 & 1 & 14 \\
\hline Embalagem & 0 & 4 & 0 & 4 \\
\hline Protetor de Barriga & 3 & 1 & 1 & 5 \\
\hline Protetores de Ombro & 2 & 1 & 1 & 4 \\
\hline Redutor de Assento & 5 & 1 & 1 & 7 \\
\hline Redutor de Encosto & 4 & 1 & 1 & 6 \\
\hline Kit de Manuais & 0 & 1 & 0 & 1 \\
\hline
\end{tabular}

Fonte: Os autores

Para iniciar o processo de cronometragem, foi definido padronizar as medições com base na leitura repetiva, ou seja, o cronômetro foi retornado ao zero no final de cada elemento utilizando a opção de leitura do próprio cronômetro.

A leitura dos dados de forma contínua foram definidas para utlização em dois tipos de processo: em alguns processos de revisão e embalagem, no qual as operadoras realizam as operações de forma conjunta, ou seja, separam uma determinada quantidade para efetuar a operação e também no processo de descolagem, no qual as operadoras separam blocos de peças (45 peças/bloco) cortadas e realizam a descolagem do bloco. Nesses processos foi concluído como sendo o melhor método empregado para operações rápidas e também como ganho produtivo (no caso do processo de revisão e embalagem) cujo objetivo foi proporcionar maior confiabilidade de medição.

Para se determinar o número de ciclos à serem cronometrados para cada elemento, foi definida uma quantidade padrão de 10 cronometragens por elemento e após isso, foram comparados com o método estatístico adotado por Peinado e Graeml (2007), visando um coeficente de distribuição normal de probabilidade de 95\%, ou seja Z: 1,96 (Tabela 4) e um coeficiente em função do 10 de cronometragens efetuadas, ou seja D2: 3,078 (Tabela 5). A comparação foi realizada em todos os elementos constituintes do produto. 
Tabela 4 - Coeficiente de distribuição normal da probabilidade

\begin{tabular}{|ccccccccccc|}
\hline Probabilidade & $\mathbf{9 0} \%$ & $\mathbf{9 1} \%$ & $\mathbf{9 2} \%$ & $\mathbf{9 3} \%$ & $\mathbf{9 4} \%$ & $\mathbf{9 5} \%$ & $\mathbf{9 6} \%$ & $\mathbf{9 7 \%}$ & $\mathbf{9 8} \%$ & $\mathbf{9 9} \%$ \\
\hline Z & 1,65 & 1,7 & 1,75 & 1,81 & 1,88 & 1,96 & 2,05 & 2,17 & 2,33 & 2,58 \\
\hline
\end{tabular}

Fonte: Adaptado de Peinado e Graeml (2007)

Tabela 5 - Coeficiente em função do número de cronometragens efetuadas

\begin{tabular}{|cccccccccc|}
\hline $\mathbf{N}$ & $\mathbf{2}$ & $\mathbf{3}$ & $\mathbf{4}$ & $\mathbf{5}$ & $\mathbf{6}$ & $\mathbf{7}$ & $\mathbf{8}$ & $\mathbf{9}$ & $\mathbf{1 0}$ \\
\hline D2 & 1,1 & 1,69 & 2,06 & 2,33 & 2,53 & 2,7 & 2,85 & 2,97 & 3,08 \\
\hline \multicolumn{7}{c}{ Fonte: Adaptado de Peinado e Graeml (2007) }
\end{tabular}

A partir da definição dos coeficientes, foi calculado e determinado o número de ciclos do componete capota (Tabela 6).

Tabela 6 - Determinação do número de ciclos do componente "capota"

\begin{tabular}{|c|c|c|c|c|c|c|c|c|c|c|c|c|c|c|}
\hline Ciclos & $\begin{array}{c}\text { OP. } \\
10\end{array}$ & $\begin{array}{c}\text { OP. } \\
20\end{array}$ & $\begin{array}{c}\text { OP. } \\
30\end{array}$ & $\begin{array}{c}\text { OP. } \\
40\end{array}$ & $\begin{array}{c}\text { OP. } \\
\mathbf{5 0}\end{array}$ & $\begin{array}{c}\text { OP. } \\
60\end{array}$ & $\begin{array}{c}\text { OP. } \\
70\end{array}$ & $\begin{array}{c}\text { OP. } \\
80\end{array}$ & $\begin{array}{c}\text { OP. } \\
90\end{array}$ & $\begin{array}{l}\text { OP. } \\
100\end{array}$ & $\begin{array}{l}\text { OP. } \\
110\end{array}$ & $\begin{array}{l}\text { OP. } \\
120\end{array}$ & $\begin{array}{l}\text { OP. } \\
130\end{array}$ & $\begin{array}{l}\text { OP. } \\
140\end{array}$ \\
\hline 1 & 8 & 14 & 2 & 9 & 3 & 7 & 3 & 9 & 35 & 11 & 21 & 3 & 57 & 10 \\
\hline 2 & 6 & 19 & 3 & 13 & 3 & 10 & 3 & 9 & 36 & 9 & 21 & 2 & 69 & 8 \\
\hline 3 & 6 & 16 & 3 & 12 & 3 & 10 & 3 & 8 & 33 & 10 & 23 & 3 & 60 & 8 \\
\hline 4 & 8 & 19 & 3 & 9 & 3 & 9 & 3 & 8 & 34 & 10 & 23 & 3 & 70 & 8 \\
\hline 5 & 7 & 16 & 3 & 9 & 3 & 8 & 3 & 8 & 38 & 10 & 22 & 2 & 69 & 10 \\
\hline 6 & 7 & 16 & 3 & 12 & 3 & 8 & 2 & 8 & 39 & 10 & 23 & 3 & 64 & 7 \\
\hline 7 & 6 & 17 & 3 & 11 & 3 & 9 & 2 & 7 & 37 & 9 & 29 & 3 & 64 & 7 \\
\hline 8 & 7 & 15 & 3 & 10 & 2 & 8 & 2 & 10 & 31 & 10 & 23 & 3 & 59 & 7 \\
\hline 9 & 8 & 17 & 3 & 10 & 2 & 9 & 3 & 9 & 31 & 10 & 24 & 3 & 63 & 10 \\
\hline 10 & 6 & 16 & 3 & 10 & 2 & 9 & 3 & 9 & 31 & 10 & 29 & 3 & 66 & 8 \\
\hline $\mathbf{R}$ & 2 & 5 & 1 & 4 & 1 & 3 & 1 & 3 & 8 & 2 & 8 & 1 & 12 & 3 \\
\hline $\mathbf{X}$ & 6,9 & 16,5 & 2,9 & 10,5 & 2,7 & 8,7 & 2,7 & 8,5 & 34,5 & 9,9 & 23,8 & 2,8 & 64,1 & 8,3 \\
\hline $\mathbf{Z}$ & \multicolumn{14}{|c|}{1,96} \\
\hline $\mathbf{E r}$ & \multicolumn{14}{|c|}{0,05} \\
\hline D2 & \multicolumn{14}{|c|}{3,078} \\
\hline $\mathbf{N}$ & 7,38 & 7,72 & 8,78 & 9,7 & 9,43 & 8,78 & 9,43 & 8,99 & 5,9 & 5,15 & 8,56 & 9,1 & 4,77 & 9,2 \\
\hline
\end{tabular}

Fonte: Os autores

Por meio dos cálculos obtidos, foi possivel definir que a determinação padrão de 10 ciclos por elemento foi confiável para darmos continuidade as etapas, considerando que todas as medições registradas das operaçoões se submiteram ao método estátisco e obtiveram número de ciclos necessários abaixo do padrão de ciclos adotado.

A etapa da determinação do número de ciclos é de fundamental importância na implantação da crononálise pois, é possível visualizar previamente as oscilações do elemento e com isso conseguir de forma eficaz determinar um número de ciclos adequado e confiável para registrar os tempos de processos.

Durante o processo de cronometragem, todos os elementos foram estudados a fim de se obter dados com relação à habilidade das operadoras quanto à operação e os esforços pertinentes à cada uma delas, analisando os esforços aplicados, a área de concentração durante a operação, posição em que as operações eram realizadas, as condições do ambiente e monotomia quanto às operações. Foi utilizada uma tabela padronizada de 
Barnes (1977) para estabelecer tolerâncias para compensação de fadigas causadas durante as operações efetuadas (Figura 3).

Figura 3 - Tolerâncias para compensação de fadiga

\begin{tabular}{|c|c|c|c|c|}
\hline \multicolumn{5}{|c|}{ COMPENSAÇÃO DE FADIGA } \\
\hline ESFORÇO & $\%$ & \multicolumn{2}{|c|}{ ATENÇÃO: ÁREA DE CONCENTRAÇÃO } & $\%$ \\
\hline Usando dedos, pulsos e mãos. & 1 & \multicolumn{2}{|c|}{ Até 2,5cm. } & 7 \\
\hline Usando mãos e braços. & 2 & \multicolumn{2}{|c|}{$2,5-10 \mathrm{~cm}$} & 5 \\
\hline Usando tronca, braços e mãos. & 3 & \multicolumn{2}{|c|}{$10-40 \mathrm{~cm}$. } & 4 \\
\hline Andando sem carga no nível. & 5 & \multicolumn{2}{|c|}{$4090 \mathrm{~cm}$. } & 3 \\
\hline Andando com carga para cima. & 30 & \multicolumn{2}{|c|}{$90 \mathrm{~cm}$ para cima. } & 1 \\
\hline Andando com carga para baixo. & 10 & \multirow{2}{*}{\multicolumn{2}{|c|}{ ESFORÇO APLICADO }} & \\
\hline POSIÇÃO & $\%$ & & & $\%$ \\
\hline Sentado confortavelmente. & 0 & PESO / KG & Homens & $\begin{array}{l}\text { Mulhere } \\
\text { s }\end{array}$ \\
\hline Sentado em posição difícil. & 2 & 2 & 1 & 2 \\
\hline De pé, normal. & 2 & 3 & 1,5 & 3 \\
\hline De pé, corpo meio inclinado. & 4 & 4 & 2 & 4 \\
\hline De pé, corpo completamente inclinado. & 6 & 5 & 3,5 & 7 \\
\hline Ajoelhado. & 4 & 6 & 6 & 12 \\
\hline Abaixar e levantar contínuo. & 7 & 7 & 8 & 16 \\
\hline \multirow[t]{6}{*}{ Agachado. } & \multirow[t]{6}{*}{10} & 8 & 10 & 20 \\
\hline & & 9 & 12 & 24 \\
\hline & & 10 & 14 & 28 \\
\hline & & 12 & 18 & 36 \\
\hline & & 15 & 25 & 50 \\
\hline & & \multicolumn{3}{|c|}{$\begin{array}{l}\text { Observação: Para cada quilo acima de } 15 \mathrm{~kg} \text {, } \\
\text { aumentar } 2 \% \text { para homens e } 4 \% \text { para mulheres. }\end{array}$} \\
\hline \multicolumn{2}{|l|}{ CONDIÇOES } & \multicolumn{2}{|c|}{ MONOTOMIA } & $\%$ \\
\hline $37^{\circ} \mathrm{C}$ ou mais. & 15 & \multicolumn{2}{|c|}{ De 5 à 10 segundos. } & 2 a 3 \\
\hline $35^{\circ} \mathrm{C}$ à $37^{\circ} \mathrm{C}$ & 12 & \multicolumn{2}{|c|}{ Menos de 5 segundos. } & 4 a 5 \\
\hline $32^{\circ} \mathrm{C}$ à $35^{\circ} \mathrm{C}$ ou $0^{\circ} \mathrm{C}$ a $4^{\circ} \mathrm{C}$ & 8 & & & \\
\hline $29^{\circ} \mathrm{C}$ à $32^{\circ} \mathrm{C}$ ou $-4^{\circ} \mathrm{C}$ à $6^{\circ} \mathrm{C}$ & 5 & \multicolumn{2}{|c|}{ NECESSIDADES PESSOAIS } & $\%$ \\
\hline $26^{\circ} \mathrm{C}$ à $29^{\circ} \mathrm{C}$ ou $-6^{\circ} \mathrm{C}$ à $-10^{\circ} \mathrm{C}$. & 2 & & & 5 \\
\hline $10^{\circ} \mathrm{C}$ à $26^{\circ} \mathrm{C}$. & 0 & & & \\
\hline
\end{tabular}

Fonte: Adaptado de Barnes (1977) 
Com isso, foram estabelecidas as tolerâncias para as operações dos componentes costurados, conforme Tabela 7, demonstrando o desenvolvimento de um padrão para cada tipo de operação.

Tabela 7 - Determinação das tolerâncias do processo

\begin{tabular}{|ccccc|}
\hline Tipo de Compensação & $\begin{array}{c}\text { Operações } \\
\text { de Máquinas }\end{array}$ & $\begin{array}{c}\text { Operações } \\
\text { Manuais }\end{array}$ & $\begin{array}{c}\text { Operação } \\
\text { de Revisão }\end{array}$ & $\begin{array}{c}\text { Operação de } \\
\text { Embalagem }\end{array}$ \\
\hline Esforço & $3 \%$ & $3 \%$ & $3 \%$ & $3 \%$ \\
Área de Concentração & $3 \%$ & $3 \%$ & $3 \%$ & $3 \%$ \\
Posição & $0 \%$ & $2 \%$ & $2 \%$ & $2 \%$ \\
Esforço Aplicado & $0 \%$ & $0 \%$ & $0 \%$ & $0 \%$ \\
Condições & $5 \%$ & $5 \%$ & $5 \%$ & $5 \%$ \\
Necessidades Pessoais & $5 \%$ & $5 \%$ & $5 \%$ & $5 \%$ \\
Monotomia (0 à 5 segundos) & $4 \%$ & $4 \%$ & $4 \%$ & $4 \%$ \\
Monotomia (5 à 10 segundos) & $2 \%$ & $2 \%$ & $2 \%$ & $2 \%$ \\
\hline
\end{tabular}

Fonte: Os autores

Durante o estudo, observou-se que para as executar as operações de máquinas, as costureiras utilizam o tronco, os braços e as mãos com uma área de concentração que varia entre $40 \mathrm{~cm}$ à $90 \mathrm{~cm}$. Quanto à posição, considerou-se a posição sentada confortavelmente, no qual conforme Tabela 7 , não foi estabelecida tolerância.

Com relação às operações manuais, de revisão e de embalagem, verificou-se que para executar as operações, as operadoras também utilizam o tronco, os braços e as mãoes com uma área de concentração variando de $40 \mathrm{~cm}$ à $90 \mathrm{~cm}$. Em análise da posição, foi definida a tolerância para execução da operação em pé em modo normal de trabalho.

Para a compensação relacionada à condição do ambiente foi definida a tolerância de 5\% para temperaturas que variam de $29^{\circ} \mathrm{C}$ à $32^{\circ} \mathrm{C}$. Esses dados foram coletados através das análises efetuadas periodicamente pela empresa.
No caso dos esforços aplicados, não foram estabelecidas tolerâncias devido às peças não pesarem acima de $0,800 \mathrm{~kg}$ e serem consideradas leves.

Concluíndo o processo, foi aplicada para as operações com menos de 5 segundos, $4 \%$ de tolerância à fadigas e para operações entre 5 e 10 segundos, 2\%. Em todos os elementos, foram concedidos $5 \%$ de tolerância à fadigas para necessidades pessoais.

Para a normalização do tempo de processo cronometrado, a empresa definiu como padrão a variação de $85 \%$ a $115 \%$, ou seja, com base no valor médio do tempo das cronometragens, foram utilizadas para dar continuidade na formação do tempo padrão, apenas os tempos que se enquadraram nos requisitos adotados.

Com todos os dados coletados, iniciou-se a formação do tempo padrão dos componentes. A Tabela 8 apresenta a determinação do tempo padrão para o componente "capota", e a Tabela 9 a descrição das operações do componente "capota". 
Tabela 8 - Determinação do tempo padrão para o componente "capota"

\begin{tabular}{|c|c|c|c|c|c|c|c|c|c|c|c|c|c|c|}
\hline \multicolumn{15}{|c|}{ CÁLCULO DO TEMPO PADRÃO / COMPONENTE: CAPOTA } \\
\hline \multirow{2}{*}{$\begin{array}{c}\text { QTDE } \\
\text { CICLOS }\end{array}$} & \multicolumn{14}{|c|}{ OPERAÇÕES } \\
\hline & 10 & 20 & 30 & 40 & 50 & 60 & 70 & 80 & 90 & 100 & 110 & 120 & 130 & 140 \\
\hline 1 & 8 & 14 & 2 & 9 & 3 & 7 & 3 & 9 & 35 & 11 & 21 & 3 & 57 & 10 \\
\hline 2 & 6 & 19 & 3 & 13 & 3 & 10 & 3 & 9 & 36 & 9 & 21 & 2 & 69 & 8 \\
\hline 3 & 6 & 16 & 3 & 12 & 3 & 10 & 3 & 8 & 33 & 10 & 23 & 3 & 60 & 8 \\
\hline 4 & 8 & 19 & 3 & 9 & 3 & 9 & 3 & 8 & 34 & 10 & 23 & 3 & 70 & 8 \\
\hline 5 & 7 & 16 & 3 & 9 & 3 & 8 & 3 & 8 & 38 & 10 & 22 & 2 & 69 & 10 \\
\hline 6 & 7 & 16 & 3 & 12 & 3 & 8 & 2 & 8 & 39 & 10 & 23 & 3 & 64 & 7 \\
\hline 7 & 6 & 17 & 3 & 11 & 3 & 9 & 2 & 7 & 37 & 9 & 29 & 3 & 64 & 7 \\
\hline 8 & 7 & 15 & 3 & 10 & 2 & 8 & 2 & 10 & 31 & 10 & 23 & 3 & 59 & 7 \\
\hline 9 & 8 & 17 & 3 & 10 & 2 & 9 & 3 & 9 & 31 & 10 & 24 & 3 & 63 & 10 \\
\hline 10 & 6 & 16 & 3 & 10 & 2 & 9 & 3 & 9 & 31 & 10 & 29 & 3 & 66 & 8 \\
\hline Total & 69 & 165 & 29 & 105 & 27 & 87 & 27 & 85 & 345 & 99 & 238 & 28 & 641 & 83 \\
\hline Média Inicial & 6,9 & 16,5 & 2,9 & 10,5 & 2,7 & 8,7 & 2,7 & 8,5 & 34,5 & 9,9 & 23,8 & 2,8 & 64,1 & 8,3 \\
\hline Tolerância T.N (15\%) & 1,04 & 2,48 & 0,44 & 1,58 & 0,41 & 1,31 & 0,41 & 1,28 & 5,18 & 1,49 & 3,57 & 0,42 & 9,62 & 1,25 \\
\hline Tempo Normalizado & 45 & 113 & 27 & 92 & 21 & 80 & 21 & 68 & 345 & 99 & 180 & 24 & 641 & 32 \\
\hline $\mathbf{N}^{\circ}$ Itens & 7 & 7 & 9 & 9 & 7 & 9 & 7 & 8 & 10 & 10 & 8 & 8 & 10 & 4 \\
\hline Média Final & 6,43 & 16,14 & 3 & 10,22 & 3 & 8,89 & 3 & 8,5 & 34,5 & 9,9 & 22,5 & 3 & 64,1 & 8 \\
\hline Tolerância (\%) & 20 & 16 & 22 & 16 & 22 & 18 & 22 & 20 & 16 & 18 & 16 & 22 & 16 & 20 \\
\hline Tempo Eemento & 7,71 & 18,73 & 3,66 & 11,86 & 3,66 & 10,49 & 3,66 & 10,2 & 40,02 & 11,68 & 26,1 & 3,66 & 74,36 & 9,6 \\
\hline Ritmo Funcionário (\%) & 100 & 100 & 100 & 100 & 100 & 100 & 100 & 100 & 100 & 100 & 100 & 100 & 100 & 100 \\
\hline Tempo Operação Final & 7,71 & 18,73 & 3,66 & 11,86 & 3,66 & 10,49 & 3,66 & 10,2 & 40,02 & 11,68 & 26,1 & 3,66 & 74,36 & 9,6 \\
\hline
\end{tabular}

Fonte: Os autores

Tabela 9 - Descrição das operação do componente Capota

\begin{tabular}{|c|c|}
\hline \multicolumn{2}{|r|}{ DESCRIÇÃO DAS OPERACXÕES } \\
\hline 10 & Montar Capota Trás - Operação Manual. \\
\hline 20 & $\begin{array}{l}\text { Overlocar a parte reta da Capota Trás inserindo o Viés de } 35 \mathrm{~mm} \text { entre as partes externa e interna - Operação } \\
\text { de Máquina (Overloque). }\end{array}$ \\
\hline 30 & Separar peças - Operação Manual. \\
\hline 40 & Overlocar a parte curvada da Capota Trás - Operação de Máquina (Overloque). \\
\hline 50 & Separar peças - Operação Manual. \\
\hline 70 & Separar peças - Operação Manual. \\
\hline 80 & $\begin{array}{l}\text { Montar a Capota Frente s/ furo (tecido) + Capota Frente s/ furo (espuma) + Capota Frente c/ furo (tecido) - } \\
\text { Operação Manual. }\end{array}$ \\
\hline 90 & Overlocar Capota Frente - Operação de Máquina (Overloque). \\
\hline 100 & Casear Capota Frente nas laterais - Operação de Máquina (Caseadeira). \\
\hline 140 & Revisar Capota - Operação de Revisão. \\
\hline
\end{tabular}

Fonte: Os autores

Para se determinar o tempo padrão dos componentes costurados, foi elaborado um documento para registro das informações da cronoanálise e descrições dos elementos (operações) conforme Tabelas 8 e 9. Os cálculos do tempo padrão dos componentes costurados, foram estabelecidos através das seguintes etapas:

- Cálculo da média inicial dos elementos em segundos;
- Cálculo para normalização do tempo dos elementos, eliminando as operações que não estavam no intervalo de $85 \%$ à 115\%;

- Cálculo dos elementos normalizados e obtenção da média final;

- Média final multiplicada pela tolerância à fadiga estabelecida em porcentagem;

- Cálculo do tempo da operação final em segundos acrescentando o ritmo do 
funcionário analisado durantre às medições;

- Conversão do tempo de processo de segundos para horas com 6 casas decimais conforme procedimento adotado pela empresa e abastecimento do sistema.
Foram obtidos através dos cálculos descritos, os tempos padrão dos componentes do produto (Tabela 10).

Tabela 10 - Tempo padrão dos componentes

\begin{tabular}{|cc|}
\hline Componentes & $\begin{array}{c}\text { Tempo padrão } \\
\text { (horas) }\end{array}$ \\
\hline Assento & 0,18499 \\
Capota & 0,065385 \\
Embalagem & 0,007146 \\
Protetor de Barriga & 0,010192 \\
Protetores de Ombro & 0,019875 \\
Redutor de Assento & 0,035299 \\
Redutor de Encosto & 0,032775 \\
Kit de Manuais & 0,00413 \\
\hline
\end{tabular}

Fonte: Os autores

Após o cálculo do tempo padrão dos componentes, foi obtido um tempo total de 0,359792 horas. O tempo padrão estabelecido para o conjunto de componentes costurados se deu através da somatória dos tempos-padrão expressados na Tabela 10 após a cronoanálise efetuada.

Com o tempo padrão do produto estabelecido o layout produtivo foi revisto, no qual foi permitido realizar um balancemaneto adequado e eficaz do processo, gerando equilibrío da carga horária das operadoras e permitindo com isso, uma maior eficiência e aumento no número de conjuntos costurados por dia.

\section{RESULTADOS E DISCUSSÕES}

A Figura 4 e a Tabela 11, apresentam os resultados obtidos após a elaboração, desenvolvimento e aplicação das técnicas da cronoanálise e o antes e o depois dos tempos e quantidades padrões definidas pela empresa.

Figura 4 - Registro de produção e eficiência após implantação

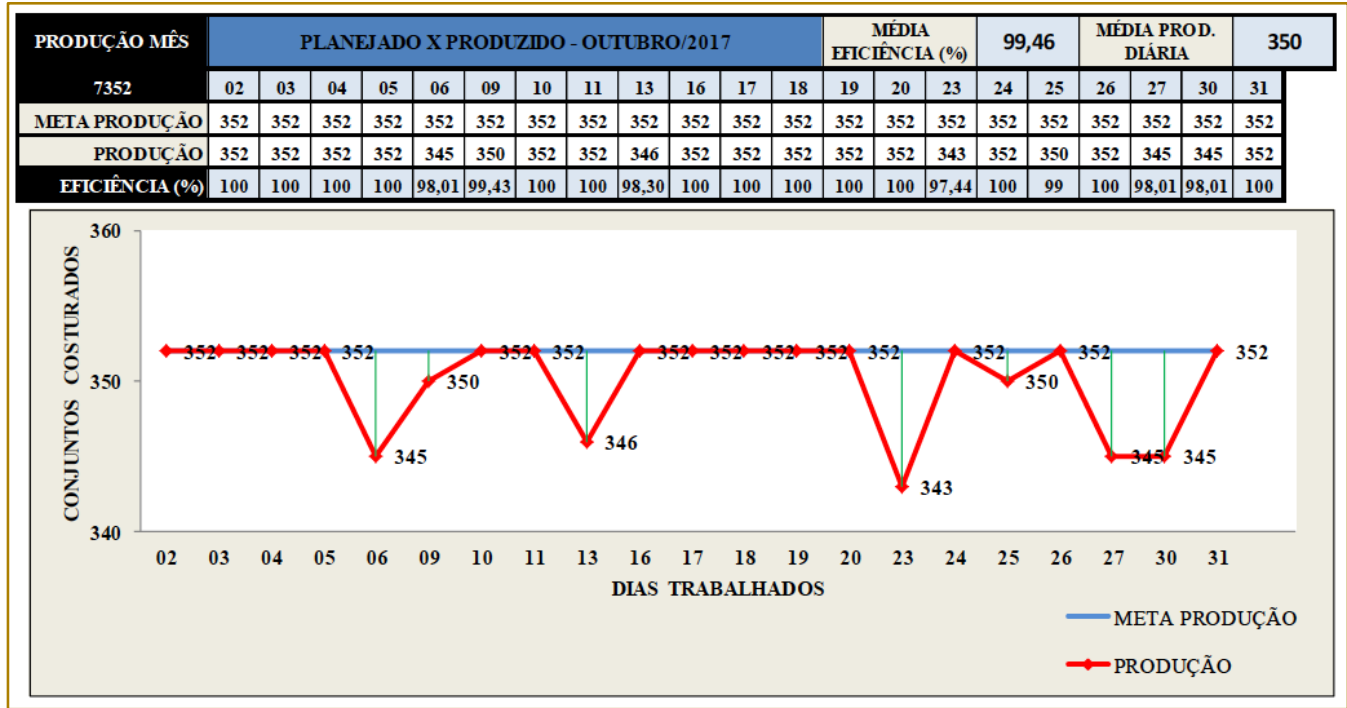

Fonte: Os autores 
Tabela 11 - Cenário anterior x Cenário após implantação

\begin{tabular}{|ccc|}
\hline & Cenário Anterior & Cenário após implantação \\
\hline Costureiras & 12 & 12 \\
Operadoras de processos & 6 & 6 \\
Meta diária (conjuntos) & 308 & 352 \\
Tempo do processo (horas) & 0,43 & 0,359792 \\
Eficiência (\%) & 94,06 & 99,46 \\
\hline
\end{tabular}

Fonte: Os autores.

A aplicação das técnicas de cronoanálise no conjunto de componentes costurados possibilitou benefícios em prol do aumento da produtividade e eficiência do processo, no qual podemos destacar:

- Balanceamento adequado do processo e melhoria nas condições de trabalho das funcionárias;

- Aumento da capacidade produtiva de 308 conjuntos/dia para 352 conjuntos/dia com a manutenção do número de funcionárias;

- Estabilidade no cumprimento da meta diária estabelecida;

- Eficiência da produção de 94,06\% para $99,46 \%$.

Os dados obtidos refletem as indicações de Fellipe et al. (2012) e possibilitam melhorar o desempenho das operadoras através da alocação adequada dos processos, padronizar as operações e métodos estimulando as operadoras para o cumprimento de metas e também desenvolver indicadores eficazes de qualidade e produtividade.

Júnior et al. (2015), utilizaram as técnicas de cronoanálise em uma confecção que contém processos similares ao abordado, e pôde-se comprovar que o uso adequado das técnicas de cronoanálise proporcionam estabelecer o

\section{REFERÊNCIAS}

[1] BARNES, Ralph Mosser. Estudo de movimentos e de tempos: projeto e medida do trabalho. 6.ed. São Paulo: Edgar Blücher, 1977.

[2] COSTA JÚNIOR, Eudes Luiz. Gestão em processos produtivos. Curitiba: Ibpex, 2008.

[3] CRUZ, Juliana Martins. Melhoria no tempo padrão de produção em uma indústria de montagem de equipamentos eletrônicos. Monografia (Graduação em Engenharia de tempo real e identificar as ineficiências do processo produtivo.

\section{CONSIDERAÇÕES FINAIS}

A elaboração, desenvolvimento e aplicação das técnicas de cronoanálise em um processo de costura, possibilitou atingir os objetivos propostos satisfatoriamente, tomando-se como base a aplicação correta de todas as etapas coordenadas para se estabelecer um tempo-padrão.

Os resultados obtidos na presente pesquisa foram: o balanceamento adequado do processo e melhoria nas condições de trabalho das funcionárias; o aumento da capacidade produtiva de 308 conjuntos/dia para 352 conjuntos/dia com a manutenção do número de funcionárias; a estabilidade no cumprimento da meta diária estabelecida; e o aumento da eficiência da produção de 94,06\% para 99,46\%.

Após a aplicação das etapas da cronoanálise, pôde-se constatar que a compreensão do processo se tornou mais eficaz, permtindo analisar os métodos de trabalho e elaborar um layout produtivo eficiente e adequadamente balanceado, contribuindo assim para aumentar a capacidade produtiva do processo, estabilizar a quantidade produzida diariamente e aumentar consideravelmente a eficiência da produção.

Produção) - Universidade Federal de Juiz de Fora, Juiz de Fora, Minas Gerais, 2008.

[4] DORIGON, Vanderlei Carlos. Cronometragem na costura. Revista: O Confeccionista, Ano I n.1, Fevereiro/Março, 2011.

[5] FELLIPE, Adélia Denísia; CUSTODIO, Maycon Roger; DOLZAN, Neseli; TEIXEIRA, Edson Sidnei Maciel. Análise descritiva do estudo de tempos e métodos: uma aplicação no setor de 
embaladeira de uma indústria têxtil. Simpósio de Excelência em Gestão e Tecnologia - SEGeT, IX., 2012, Resende, Rio de Janeiro, SEGET, 2012.

[6] GIL, Antônio Carlos. Como elaborar projetos de pesquisa, 4 ed. São Paulo: Atlas, 2002.

[7] JÚNIOR, Jesus Ribeiro Viana; BONFIM, Willame Balbino; DUARTE, José Alfredo da Silva. Os benefícios da implantação da cronoanálise. Encontro Nacional de Engenharia de Produção ENEGEP, XXXV., Fortaleza., 2015.

[8] NASCIMENTO, Lenuzia Santos; NASCIMENTO, Paula Flaviane Pinheiro; PEREIRA, Karoline Isabelle de Almeida; SOUZA, Mariane Cristina Lima. Estudo de tempos e movimentos no processo produtivo de uma organização do ramo alimentício. Revista Latino-Americana de Inovação e Engenharia de Produção v. 2, n. 3. Jul./Dez. 2014.

[9] PEINADO, Jurandir; GRAEML, Alexandre Reis. Administração da produção: operações industriais e de serviços. Curitiba: UnicenP, 2007.

[10] PENA, Débora Corrêa; SILVA, Daniela Regina; RIGO, Paola Mantoani; CALVENTO, Maria Fernanda; LIMA, Rafael Henrique Palma. Estudo de tempos e métodos no setor de envase de uma indústria de produtos para higiene oral. Revista Produção Industrial e Serviços. Universidade Estadual de Maringá - UEM - Campus SEDE, Paraná. v. 03, n.2, p. 26-37, 2016.
[11] PESSOTTI, Rafaella Queiroz; CHAGAS, Thayse da Silva; MORTE, Jhonatan Almeida Boa. Aplicação da cronoanálise e de ferramentas da qualidade como meio para o aumento da produtividade em uma empresa do ramo moveleiro. Encontro Nacional de Engenharia de Produção - ENEGEP, XXXV, Fortaleza., 2015.

[12] SILVA, Argens Valente; COIMBRA, Rubens Ricardo de Castro. Manual de tempos e métodos. São Paulo: Hemus, 1980.

[13] SLACK, Nigel; CHAMBERS, Stuart; JOHNSTON, Robert. Administração da produção, 3.ed. São Paulo: Atlas, 2009.

[14] TAKASHINA, Newton Tadashi; FLORES, Mário César Xavier. Indicadores da qualidade e do desempenho: como estabelecer metas e medir resultados. Rio de Janeiro. Editora Quaitymark, 1999.

[15] TOLEDO, Itys Fides Bueno. Tempos \& Métodos. 8.ed. São Paulo. Edição. Assessoria Escola Editora, 2004. VENÂNCIO, Alan de Matos; PONTES, Heraclito Lopes Jaguaribe; CORDEIRO, Rodrigo Anjos; CARNEIRO,

[16] Rebeca Farias; RIBEIRO, Pedro Davi Matos. Estudo de layout e tempos e métodos no processo de produção

[17] de uma indústria e fabricação de carrocerias. Encontro Nacional de Engenharia de Produção - ENEGEP, XXXV., Fortaleza., 2015. 


\section{Capítulo 15}

\section{ANÁLISE DOS MODELOS MATEMÁTICOS PARA O TRANSPORTE DE AJUDA HUMANITÁRIA EM SITUAÇÕES DE DESASTRES}

\section{Lorena Hernández Mastrapa}

Daniel René Tasé Velázquez.

\section{Everton Dias de Oliveira}

\section{Caroline Kuhl Gennaro}

\section{Maria Julia Xavier Belém}

Resumo: Este trabalho apresenta uma revisão de artigos científicos que propõem uma modelagem matemática para atuação na logística humanitária na atividade de transporte, na roteirização e desenho de rotas em situações de desastre. A partir desta revisão, foram analisadas as funções objetivo e os tipos de modelos de programação na pesquisa operacional mais utilizado. Também foram estudadas como se faz a previsão e o tratamento da demanda. Desta forma, foi possível perceber as dificuldades de utilização de modelos de transporte em situações de desastre. Além, permite reconhecer os aspectos associados às características que impedem um melhor desenvolvimento e funcionalidade nos modelos, as fraquezas que ainda existem neste contexto e as potencialidades de pesquisa nesta área com o intuito de criar ou adaptar modelos matemáticos de transporte nas reais condições operacionais na ação humanitária.

Palavras chave: modelos matemáticos, otimização das redes de transporte, situações de desastre, situações de pôs-desastre, situações pre-desastre. 


\section{INTRODUÇÃO}

Desastre é definido como o evento súbito e calamitoso que interrompe as atividades de uma sociedade ou comunidade, causando perdas humanas, materiais, econômicas ou ambientais que excedem a capacidade de recuperação da sociedade atingida usando apenas seus próprios recursos (Natarajarathinam et al., 2009). De acordo com Van Wassenhove, 2006 os desastres são classificados por: (i) a velocidade de início (súbito ou lento) e (ii) se são "provocados pelo homem" ou "naturais". A classificação é necessária para definir as medidas de: mitigação, preparação, de resposta e de recuperação que permitam a orientação dos especialistas e órgãos envolvidos em determinado desastre.

É importante destacar que os desastres naturais geralmente obtém maior atenção da mídia, o que, muitas vezes, leva a um maior financiamento. Entretanto, tais desastres apresentam, cada vez mais, impactos maiores sobre comunidades e nações por todo o mundo e previsões confirmam que esta tendência deve continuar (Guha-Sapir, 2013). Nas últimas três décadas, a ocorrência de desastres naturais aumentou de 50 para 400 por ano (Kovács e Spens, 2007). Para os próximos 50 anos, esperasse que esta taxa se torne cinco vezes maior (Thomas e Kopczack, 2005). Além de que os provocados pelo homem tem uma taxa de aumento, percebível nos últimos anos.

O cenário instável e aleatório imposto por um desastre natural gera uma tarefa de difícil solução no contexto de alívio humanitário, exigindo a presença de uma gestão adequada para a melhoria do planejamento da resposta. Castro (1999) e Van Wassenhove (2006) consideram o gerenciamento de desastres em quatro fases: Prevenção, Preparação, Resposta e Reconstrução.

Sistemas de infraestruturas críticas - incluindo transporte - desempenham um papel essencial na mitigação de desastres, resposta e recuperação, em toda a comunidade e, portanto, alvos de alta prioridade para aprimoramento de resiliência (Tierney e Bruneau, 2007). Nestas ações, atrasos na entrega de suprimentos ou na prestação de ajuda podem custar vidas e a atividade de transportação tem um papel muito importante nelas.

A eficiência do transporte na logística é um aspecto crítico para o sucesso de uma ação humanitária deste tipo por garantir o fluxo de bens e serviços em uma cadeia de suprimentos complexa. Neste contexto, tornase essencial a busca, por meio da Logística Humanitária, de um procedimento para a transportação eficiente, com o objetivo de contribuir na cadeia de suprimentos para a ajuda humanitária, no planejamento, implantação e controle dos suprimentos, além de acompanhar o fluxo de informações, desde a origem até o consumo, com o propósito de atender aos requisitos do beneficiário final (Thomas e Mizushima, 2005; Thomas e Kopczak, 2005).

No entanto, na logística humanitária, as decisões costumam ser tomadas com urgência e com base na experiência e na intuição dos profissionais envolvidos. O processo decisório durante este tipo de operação é complexo, uma vez que atributos importantes do problema são incertos. As necessidades mudam rapidamente, além do pouco tempo disponível e dificuldade em obter informações necessárias para a tomada de decisão (Beamon e Balcik, 2005).

O presente artigo se foca nas operações de transportação nas situações de desastres e tem o objetivo de contribuir na melhora do desempenho da atividade de transporte na ajuda humanitária em desastres; a partir de uma revisão e análise de artigos científicos que propõem modelos matemáticos para a roteirização e desenho de rotas em situações de desastres, e sua comparação com os modelos gerais de transporte.

O trabalho está composto por três tópicos, onde no primeiro se fez uma introdução do tema, abordando os conceitos fundamentais e o objetivo da pesquisa. No segundo se realiza uma seleção a partir da pesquisa em diferentes bases de dados e uma análise da literatura encontrada como relevante nela. Logo, no terceiro tópico os artigos selecionados foram analisados de acordo a seus objetivos, a abordagem logística, técnicas e tipos de modelos de programação na pesquisa operacional, além da forma de análise da demanda. Além disso, é apresentada uma análise comparativa dos modelos de transporte gerais e os modelos de transporte para situações de desastres, avaliando as condições em que possam contribuir para que as operações logísticas atinjam melhores resultados. Finalmente, foram expostas as conclusões obtidas a partir da análise da literatura, e as futuras 
possibilidades de pesquisas neste campo da logística humanitária.

\section{ANÁLISE E SELEÇÃO DA LITERATURA}

Para a busca da literatura relacionada com o tema de estudo foi feita uma pesquisa nas bases de dados da Science Direct, Web of Science, Scopus, Proquest e Google Academic. Com o intuito de obter a bibliografia mais atualizada e relacionada com o objeto de estudo foi feita uma combinação das palavras chaves: "Modelos de transporte" e "Modelos de otimização de redes de transporte" com "situações de desastre", "situações de pôs-desastre" e "situações predesastre". Nas bases de dados, foi realizado um filtro selecionando os campos "Pesquisa Operacional e Ciências Gerenciais" e "Transportes" como áreas de pesquisa, onde se obtiveram um total de 65 artigos relevantes com o tema da pesquisa. Após a coleta inicial dos artigos, se fez uma classificação segundo os que propõem modelos matemáticos para as atividades de distribuição na rede e os que propõem modelos de roteirização e desenho de rede de transporte. Assim, dos artigos inicialmente selecionados, 40 são a base da revisão apresentada neste trabalho.

A análise dos objetivos propostos pelos autores permitiu uma melhor compreensão da abordagem de cada modelo na busca de melhoras no desempenho da atividade logística objeto de estudo.

\subsection{ANÁLISE DA LITERATURA SELECIONADA}

Thomas (2003) propõe um modelo composto por sete etapas onde se representam os processos logísticos da cadeia de suprimentos humanitária. Onde um dos elos é o transporte e a distribuição, o qual atua em situações extremas para levar a ajuda onde seja preciso no menor tempo possível e nas melhores condições.

Dependendo em grande medida da preparação da sociedade onde aconteça o desastre, a demanda pode ser melhor prevista, e os reportes do efeito na infraestrutura e outras informações podem ser melhor fornecida em um tempo mais curto, podendo tomar decisões mais acertadas, e começar a brindar a ajuda em um menor tempo. É por isso que a logística humanitária tem que ter ferramentas praticas que the permitam atuar em qualquer cenário ao longo da cadeia de suprimentos de ajuda.

O plano de transporte na logística humanitária envolve prazos de recolhida e de entrega ótimos para os veículos dentro do horizonte de tempo planejado, tanto como as quantidades ideais e tipos de cargas apanhadas e entregas ótimas sejam definidas nestas rotas. Esses planos são regenerados, enquanto aos novos pedidos de demanda ocorrer ou enquanto novos fornecedores e os modos de transporte se tornam disponíveis durante o horizonte de tempo de planejamento (Argollo et al., 2014).

Um dos problemas que mais se destacam ao longo das etapas do desastre, antes definidas, com respeito a atividade de transporte é a roteirização e o desenho de rede de transporte. Os modelos, propostos pelos artigos estudados, voltados para o problema de roteirização no contexto humanitário tratam, de forma geral, das questões referentes ao tempo e ao atendimento da demanda, de maneira similar a aplicação para o contexto comercial. Mas existem adequações para cenários próprios da logística humanitária.

Têm sido propostos grande número de abordagens baseadas na optimização determinística para a concepção e a distribuição da produção nas redes, ao longo da cadeia (Vidal e Goetschalckx, 1997). Há também um grande esforço de investigação na componente de localização de instalações de desenho de rede da cadeia de abastecimento sobre a incerteza (Owen e Daskin, 1998).

Segundo Han, et al., (2010) incertezas de demanda são a natureza inerente do fornecimento de material de emergência devido à rápida mudança do ambiente e as exigências na região do desastre. Mesmo assim, na Logística humanitária se tem poucos estudos onde se analisa a incerteza da demanda ao longo da cadeia de suprimento de ajuda (Argollo et al., 2014).

Pesquisas em modelos mais complexos, localização multi-escalão sobre a incerteza única propõem uma estrutura de otimização robusta para desenho de rede sobre a incerteza. Outros consideram um modelo de programação estocástica de dois estágios para um multi-produto, multi-escalão na cadeia de abastecimento baseada em cenários de incerteza da demanda, mas 
maioritariamente voltada sobre a logística comercial.

Embora alguns dos modelos publicados sobre o problema no planejamento na logística de emergência têm algumas características em comum com eles, pois em muitos dos modelos construídos para a análise da rede de abastecimento na logística comercial tem analisado além da incerteza na demanda o análise de riscos, podendo ser aplicados prevenção e preparação e determinar os pontos mais vulneráveis na cadeia. Mas eles não podem ser adotados para condições específicas de desastres por duas razões: os pontos de demanda de resgate em um desastre ocorrem aleatoriamente, e a distribuição de recursos de resgate exige uma assistência mútua entre multi-grupo, multi-escalão, e multi-níveis de fornecedores.

\section{ANÁLISE DOS MODELOS DE TRANSPORTE PARA SITUAÇÕES DE DESASTRES ENCONTRADOS NA LITERATURA}

Com base nas observações feitas durante 0 trabalho de pesquisa, se identificaram algumas características relevantes em formulações matemáticas nos modelos de transporte. A Tabela 1 resume as características que se quiseram ressaltar dos modelos avaliados.

Em termos de funções objetivo, é predominante a minimização do atraso do percurso para o fornecimento da ajuda, seguido por minimização de custos operacionais (logísticos) e sociais. Levando em conta que a dependência exclusiva dos custos logísticos é apropriada para atividades da logística comercial, mas não é para modelos de operações nas situações extremas de pôs-desastre na logística humanitária. Enquanto a demandas não atendidas também tem um número importante de pesquisas que se preocupam por minimiza-la nos seus modelos de transporte, assim como a maximização da demanda e da fiabilidade da rota.

Alguns dos modelos onde minimizam demandas não atendidas, ou maximizam a carga entregue, não levam em conta o tempo que uma população ficou sem suprimentos e/ ou a urgência com que os fornecimentos poderão ser necessários em diferentes locais, aspectos de especial importância nestes cenários.
No estudo dos artigos, identificou-se que as principais técnicas de Pesquisa Operacional adotadas nos modelos propostos são: programação inteira (PI), Programação Linear Inteira Mista (PLIM), Programação Estocástica Linear Inteira Mista (PELIM). Alguns autores oferecem aplicações integradas de técnicas, como Yi e Özdamar (2007), para a localização prévia de instalações integrando os problemas de roteirização e de localização; ou Özdamar et al. (2004) que propõem um modelo híbrido dos problemas de fluxo de rede multiproduto $(P L)$ e de roteirização de veículos $(\mathrm{PI})$ para a coordenação do processo de distribuição.

A programação estocástica de dois estágios é preferencialmente utilizada em modelos que propõem decisões pré-desastre, com reavaliação após sua ocorrência, atualizando as condições das áreas atingidas e, em determinados trabalhos, com a indisponibilidade de alguns componentes da infraestrutura inicial. Por exemplo, a proposta Mete e Zabinsky (2010), integra um problema de roteirização de veículos com capacidade reduzida utilizando programação estocástica.

A programação inteira tem aplicação também na roteirização de entregas, na localização de instalações e no problema de alocação de pessoal, apresentados, respectivamente, no desenvolvimento multi-objetivo de Lin et al. (2009 e 2011) com solução por heurística de decomposição e atribuição onde estabelecem prioridades baseadas na urgência da entrega dos itens críticos, em que a janela de tempo limita o prazo de envio a partir do qual o não cumprimento gera uma penalização. Ainda no campo da PI, a proposta de Perez et al. (2010) desenvolve o problema de roteirização de veículos onde avaliam a minimização dos custos compostos por uma parcela operacional, incluindo componentes sociais de aspecto humanitário, porém o modelo é de solução complexa e para aplicação em pequenos eventos.

Para tratar de aproximar o melhor possível dois tipos de métodos na situação de emergência na resposta do desastre com incertezas, são muitas vezes aplicados: programação estocástica e teoria difusa. Teoria fuzzy utiliza conjuntos fuzzy para incorporar imprecisa informação de um modo não probabilística com base na experiência e julgamento subjetivo gerencial. Wei e Ozdamar (2007) formulam um modelo de roteamento e transporte com os parâmetros 
fuzzy para representar incerteza relacionada com a oferta.

$\mathrm{Na}$ análise da demanda dos modelos, foi observado que muitos têm definidos as demandas como parâmetros. Geralmente todos eles estão sujeitos a criação de cenários para sua previsão através de uma estimação, baseados no nível de informação que possa obter nas situações, tendo em conta que elas poderão ser ainda mais exatas na medida de quanto forte e bem estruturada esteja a cadeia de informação e sua tecnologia, além das experiências obtidas em outros desastres similares, tanto em situações de pre ou pôs-desastre. A demanda nas situações de desastre é um aspecto critico na criação de modelos matemáticos de roteirização e desenho de rotas de transporte, pois seu comportamento varia dependendo do início e da magnitude do desastre, das características da zona afetada, entre outros aspectos que influenciam no nível de demanda.

De maneira geral os modelos anteriormente analisados evidenciam rasgos acentuados herdados da logística comercial. Mas, podemse diferenciar, de acordo ao objetivo do sistema, nas dimensões onde eles se desenvolvem, as características da rede de transporte, os planos de programação, e o trade-off entre o algoritmo de optimização e/ou eficiência.

Além da análise feita entre os modelos para situações de desastres, se fez uma análise comparativa entre estes modelos e os de transporte gerais, que não tem analisado situações de desastre, o que se pode observar na Tabela 2.

Os modelos de transporte gerais operam em redes regulares, os de desastres tem que atuam em redes temporárias. Além de que as decisões para os modelos de transporte para situações de desastre se tomam maioritariamente com urgência, não assim para os modelos de transporte gerais que tem um plano de programação mais organizado que permite tomar decisões a longos, medianos e curtos prazos. Os modelos de transporte gerais tem sua maior preocupação na otimização de recursos, ou seja, na criação de condições mais favoráveis para o desenvolvimento da atividade em questão. Entretanto, os modelos criados para situações de desastres estão enfocados na obtenção de um melhor rendimento da atividade de transporte e dos recursos, com o mínimo de erros e dispêndios com o intuito de alcançar a maior quantidade de afetados no menor tempo possível para aliviar o sofrimento humano.

\section{CONCLUSÕES}

O problema de roteirização de veículos de emergência é maioritariamente enfocado a minimizar a soma dos tempos de chegada. Outro dos maiores desafios é responder a demanda com o mínimo custo de operação além dos custos sociais, pois na logística humanitária o objetivo fundamental é oferecer o maior nível de serviço no menor tempo possível, o que muitas vezes requer de custos de operações e sociais muito altos.

Mesmo assim, as operações logísticas humanitárias tentam minimizar os custos sociais dos impactos de um desastre, dentro de um contexto de grave escassez. Isso requer a tomada de decisões sobre quem vai e quem não vai receber ajuda, em um dado momento.

A maioria dos artigos pesquisados fazem o análise da distribuição de bens ou serviços e alguns tem ligado um modelo de roteirização do transporte para integrar sua análise, além de facilitar o planejamento e otimizar a atuação ao aplicar os modelos. Mas são poucos os que só se dedicam ao analise de transporte ao respeito da roteirização e/ou otimização de rede. O desenho de rotas tem um papel fundamental na distribuição das equipes que vão a prestar a ajuda ou as que vão realizar sua evacuação, ou simplesmente pessoas que tem que transportar-se para atingir alguma necessidade nas situações de desastre. 
Tabela 1: Características dos modelos de roteirização e desenho de rota para situações de desastre

\begin{tabular}{|c|c|c|c|c|c|c|c|c|c|}
\hline \multirow[b]{2}{*}{ Autores } & \multicolumn{5}{|c|}{ Função objetivo } & \multirow[b]{2}{*}{$\begin{array}{l}\text { Técnicas } \\
\text { de } \\
\text { pesquisa } \\
\text { operaciona } \\
\text { l adotadas }\end{array}$} & \multirow[b]{2}{*}{ Abordagem do analise da demanda } & \multicolumn{2}{|c|}{$\begin{array}{l}\text { Momento do } \\
\text { desastre }\end{array}$} \\
\hline & $\begin{array}{l}\text { Min } \\
\text { demanda } \\
\text { insatisfeita }\end{array}$ & $\begin{array}{l}\text { Min } \\
\text { atraso do } \\
\text { percurso }\end{array}$ & $\begin{array}{c}\text { Min } \\
\text { custos } \\
\text { de } \\
\text { operação } \\
\text { e sociais }\end{array}$ & $\begin{array}{c}\text { Max } \\
\text { satisfação } \\
\text { da } \\
\text { demanda }\end{array}$ & $\begin{array}{l}\text { Max } \\
\text { fiabilidade } \\
\text { da rota }\end{array}$ & & & Pre & Pôs \\
\hline Ozdamar. L. et al.(2004) & $\checkmark$ & & & & & PLIM & $\begin{array}{l}\text { Declaram variáveis para a demanda e demanda } \\
\text { insatisfeita de suprimentos de ajuda em cada no. }\end{array}$ & $\checkmark$ & \\
\hline Yi, W. e Kumar A. (2007) & & $\checkmark$ & & & & PLIM & $\begin{array}{l}\text { Declaram uma variável para a insatisfação da } \\
\text { demanda de cada commodity. }\end{array}$ & & $\checkmark$ \\
\hline Yi, W. e Qzdamar. L. (2007) & $\checkmark$ & & & & & PLIM & $\begin{array}{l}\text { Declaram variáveis para a demanda insatisfeita } \\
\text { de cada commodity e pessoas não atendidas. }\end{array}$ & & $\checkmark$ \\
\hline $\begin{array}{l}\text { Chang , M., Tseng, L. , Chen, } \\
\text { J. (2007) }\end{array}$ & & $\checkmark$ & & & & PELIM & $\begin{array}{l}\text { A demanda é prevista segundo os cenários } \\
\text { declarados (parâmetro). }\end{array}$ & $\checkmark$ & \\
\hline $\begin{array}{l}\text { Tzeng, G. Cheng, H., Huang. } \\
\text { T. D. (2007) }\end{array}$ & & $\checkmark$ & $\checkmark$ & $\checkmark$ & & PI & $\begin{array}{l}\text { Declaram-se parâmetros para a estimação ou } \\
\text { previsão da demanda. }\end{array}$ & & $\checkmark$ \\
\hline $\begin{array}{l}\text { De Angelis, V., Mecoli, M., } \\
\text { Nikoj, C., Storchi, G. (2007) }\end{array}$ & & & & $\checkmark$ & & $\mathrm{PI}$ & $\begin{array}{l}\text { Declaram-se parâmetros para a estimação ou } \\
\text { previsão da demanda. }\end{array}$ & & $\checkmark$ \\
\hline Lin et al. (2009) & $\checkmark$ & & $\checkmark$ & & & $\mathrm{PI}$ & Definição de variável para a demanda insatisfeita. & & $\sqrt{ }$ \\
\hline $\begin{array}{l}\text { Qnur Mete, H. e Zabinsky, Z. } \\
(2010)\end{array}$ & & $\checkmark$ & & & & PELIM & Definição de variável para a demanda insatisfeita. & $\checkmark$ & \\
\hline Nolz, P et al. (2010) & & $\checkmark$ & & & & $\mathrm{PI}$ & $\begin{array}{l}\text { Declaram-se parâmetros para a estimação ou } \\
\text { previsão da demanda. }\end{array}$ & $\checkmark$ & \\
\hline Perez, N. et al (2010) & & & $\checkmark$ & & & PLIM & $\begin{array}{l}\text { Declaram-se parâmetros para a estimação ou } \\
\text { previsão da demanda. }\end{array}$ & & $\checkmark$ \\
\hline $\begin{array}{l}\text { Han, Y., Guan, X., Shi, L. } \\
(2010)\end{array}$ & & $\checkmark$ & & & $\checkmark$ & PLIM & $\begin{array}{c}\text { Definição de variável para a quantidade enviada } \\
\text { ao longo do arco. }\end{array}$ & & $\checkmark$ \\
\hline $\begin{array}{l}\text { Raws, C. G. e Turnquist, M. A. } \\
\text { (2010) }\end{array}$ & & & $\checkmark$ & & & PELIM & $\begin{array}{l}\text { A demanda segundo os cenários declarados é } \\
\text { analisada por o comportamento das variáveis. }\end{array}$ & $\checkmark$ & \\
\hline Hu, Z. (2011) & & & $\checkmark$ & & & $\mathrm{PI}(0-1)$ & $\begin{array}{l}\text { Declaram-se parâmetros para a estimação ou } \\
\text { previsão da demanda. }\end{array}$ & & $\checkmark$ \\
\hline Lin et al.(2011) & $\checkmark$ & & & & & PLIM & $\begin{array}{l}\text { Se fez uma previsão da demanda (parâmetro), } \\
\text { definição de variável para a quantidade enviada } \\
\text { ao longo do arco. }\end{array}$ & & $\checkmark$ \\
\hline $\begin{array}{l}\text { Wang, H., Du, L., Ma, S. } \\
\text { (2014) }\end{array}$ & & $\checkmark$ & $\checkmark$ & & $\checkmark$ & PLIM & $\begin{array}{c}\text { Definição de variável para a quantidade enviada } \\
\text { aos nós. }\end{array}$ & & 1 \\
\hline
\end{tabular}

Tabela 2: Comparação ente modelos gerais de transporte e modelos de transporte para situações de desastre

\begin{tabular}{|c|c|c|}
\hline $\begin{array}{c}\text { Itens de } \\
\text { comparação }\end{array}$ & Modelo geral de transporte & Modelo de transporte para situações de desastre \\
\hline $\begin{array}{l}\text { Objetivos dos } \\
\text { modelos }\end{array}$ & $\begin{array}{l}\text { Minimizar o tempo da viagem, o custo de } \\
\text { usuário e de operador, o tamanho da frota. } \\
\text { (Cipriani et al., 2012), (Medina et al., 2013), } \\
\text { (Amiripour et al., 2014), (Nikolic' e } \\
\text { Teodorovic', 2014). }\end{array}$ & $\begin{array}{l}\text { Minimizar o tempo de entrega dos suprimentos } \\
\text { prioritários, o tempo de espera das pessoas feridas } \\
\text { ou necessitadas o custo de transporte. } \\
\text { Maximizar a eficiência. } \\
\text { (Yi, W. e Kumar, A.,2007),( Lin et al., 2009), (Onur } \\
\text { Mete, H. e Zabinsky, Z.,2010), ( Perez, N. et } \\
\text { al ,2010) }\end{array}$ \\
\hline Dimensões do rol & $\begin{array}{l}\text { Pontos de origem ou destino (fabrica, } \\
\text { rodoviária, parada de ônibus, armazém, } \\
\text { etc.) } \\
\text { Pontos de transferência } \\
\text { Clientes } \\
\text { Redes de transporte } \\
\text { (Fan and Machemehl, 2011), (Bagloee and } \\
\text { Ceder, 2011), (Yu et al. ,2012), (Amiripour } \\
\text { et al., 2014) }\end{array}$ & $\begin{array}{l}\text { Pontos de coleta de commodities ou pessoas } \\
\text { Depósitos de transferência de commodities ou de } \\
\text { evacuação de pessoas } \\
\text { Pontos de demanda das commodities } \\
\text { Redes de transporte } \\
\text { (De Angelis, V., et al., 2007) (Yi, W. e Ozdamar, L., } \\
\text { 2007),( Lin et al. (2009), (Lin et al.,2011), }\end{array}$ \\
\hline $\begin{array}{l}\text { Características da } \\
\text { rede }\end{array}$ & $\begin{array}{l}\text { Rede regular } \\
\text { (Szeto and Jiang, 2012),(Yu et al. ,2012), } \\
\text { (Medina et al., 2013) }\end{array}$ & $\begin{array}{l}\text { Rede temporária } \\
\text { (Raws, C. G. e Turnquist, M. A.,2010), (Lin et al., } \\
\text { 2009), (Onur Mete, H. e Zabinsky, Z.,2010), ( Perez, } \\
\text { N. et al. ,2010) }\end{array}$ \\
\hline $\begin{array}{l}\text { Plano de } \\
\text { programação }\end{array}$ & $\begin{array}{l}\text { Longo prazo: Localização (Ceder, 2003), } \\
\text { (Hu et al., 2005) } \\
\text { Mediano prazo: Tamanho da frota (Szeto } \\
\text { and Wu, 2011),( Zhao and Zeng,2007) } \\
\text { Corto prazo: Programação (Fusco et al., } \\
\text { 2002), (Wan and Lo ,2003) }\end{array}$ & $\begin{array}{l}\text { Decisões urgentes baseadas nas informações } \\
\text { disponíveis } \\
\text { (Tzeng, G. Cheng, H., Huang, T. D.,2007),( De } \\
\text { Angelis, V., et al. ,2007), (Lin et al., 2009) }\end{array}$ \\
\hline $\begin{array}{l}\text { Trade-off entre } \\
\text { algoritmo-eficiência } \\
\text { e otimização }\end{array}$ & $\begin{array}{l}\text { Maior atenção na otimização de recursos } \\
\text { (Cipriani et al., 2012), (Szeto and Jiang, } \\
\text { 2012), (Medina et al., 2013), (Amiripour et } \\
\text { al., 2014), }\end{array}$ & $\begin{array}{l}\text { Maior atenção na eficiência do atendimento } \\
\text { (Özdamar, L. et al.,2004), (Yi, W. e Ozdamar, } \\
\text { L. ,2007), (De Angelis, V. et al., 2007),(Lin et } \\
\text { al.,2011) }\end{array}$ \\
\hline
\end{tabular}

É por isso que nestas situações, a roteirização e o desenho de redes de veículos joga um papel importante, pois pode ser um aspecto sensível e vulnerável em situações de desastre; o que representa uma atividade da 
logística humanitária a potenciar em para futuras pesquisas.

O estudo dos modelos matemáticos apresentados mostra que ainda há uma lacuna entre o que é modelado e o que realmente ocorre no campo em operações de desastres (no ambiente dos desastres). Existem importantes avanços na área, como a inclusão de aspectos humanitários por meio de variáveis de decisão na formulação destes modelos, mas ainda a abordagem está fortemente relacionado com a logística comercial. Contudo, não se verifica a possibilidade de uma utilização direta dos modelos propostos no processo de desastres, com a expectativa de que algum dos problemas identificados seja efetivamente solucionado ou tenha a perspectiva de solução.

\section{REFERÊNCIAS}

[1] AMIRIPOUR, S., CEDER, A., MOHAYMANY, A. Designing large scale bus network with seasonal variations of demand. Transportation Research Part C 48, 322-338, 2014.

[2] ARGOLLO DA COSTA, S. DE MELLO BANDEIRA, R. A., GOUVÊA CAMPOS, V. B., DE PAULA BANDEIRA, A. F. Revisão sobre modelagem matemática na logística humanitária. Transportes. Vol 22.No.2, 2014, pp. 70-84, 2014.

[3] BAGLOEE, S., CEDER, A. Transit network design methodology for actual-size road networks. Transportation Research Part B 45, 1787-1804, 2011.

[4] BEAMON, B. M. e BALCIK, B. Distribution Network Design for Humanitarian Relief Chains. IE Graduate Seminar, November 8, 2005

[5] BOZORGI-AMIRI, A, JABALAMELI, M. S., MIRZAPOUR AL-E-HASHEM, S. M. J. A multiobjective robust stochastic programming model for disaster relief logistics under uncertainty. OR Spectrum, Vol.35, Pages: 905-933, 2013.

[6] CASTRO, A. L. Manual de planejamento em defesa civil. Vol.1. Brasília: Imprensa Nacional. 1999.

[7] CHANG, M., TSENG, Y., CHEN, J. A scenario planning approach for the flood emergency logistics preparation problem under uncertainty. Transportation Research Part E: Logistics and Transportation Review 43, 737-754, 2007.

[8] CIPRIANI, E., GORI, S., PETRELLI, M. A bus network design procedure with elastic demand for large urban areas. Public Transport 4, 57-76, 2012.
Apesar do papel importante da infraestrutura do transporte em recuperação, a literatura existente, raramente relata modalidades de transporte de pós-catástrofe, especialmente durante os estágios de recuperação (Hitomi Nakanishi et al.,2014).

A análise feita também permitiu captar que o sofrimento humano não é adequadamente abordado pelos modelos tratados. O que sem dúvida, tomando em conta o tratado por Holguín Veras et al. (2013), reflete raízes logísticas comerciais dos modelos, e de fato que a modelagem tanto no pre e o pôs desastre ainda está em estágios iniciais de desenvolvimento. O que representa um dos principais pontos que precisam ser melhorados para motivar os gestores das operações de ajuda a usar modelos matemáticos propostos.

[9] DE ANGELIS, V., MECOLI, M., NIKOI, C., STORCHI, G. Multiperiod integrated routing and scheduling of World Food Program cargo planes in Angola. Computers \& Operations Research,Vol. 34, pp.1601-1615, 2007.

[10] FAN, W., MACHEMEHL, R. Bi-level optimization model for public transportation network redesign problem. Transportation Research Record 2263, 151-162, 2011.

[11] GUHA-SAPIR, D., HOYOIS, P., BELOW, R. Annual Disaster Statistical Review 2012: The numbers and trends. Centre for Research on the Epidemiology of Disasters. Brussels: CRED; 2013.

[12] HAN, Y., GUAN, X., SHI, L. Optimal supply location selection and routing for emergency material delivery. International Conference on Information, Networking and Automation (ICINA). 2010.

[13] HOLGuÍN-VERAS, J., PÉREZ, N., JALLER, M., VAN WASSENHOVE, L., AROS-VERA, F. On the appropriate objective function for post-disaster humanitarian logistics models. Journal of Operations Management 31 (2013) 262-280.

[14] HU, Z. A container multimodal transportation scheduling approach based on immune affinity model for emergency relief. International Journal Expert Systems with Applications. Vol. 38, pp. 2632-2639, 2011.

[15] KOVACS, G. e SPENS, K. Humanitarian logistics in disaster relief operations. International Journal of Physical Distribution \& Logistics Management, v. 37, n. 2, p. 99-114, 2007.

[16] LIN, Y. H. BATTA, R. ROGERSON, P. A. BLATT, A. FLAN-IGAN, M. Application of a 
Humanitarian Relief Logistics Model to an Earthquake Disaster. Transportation Research Record. 2009.

[17] LIN, Y.H., BATTA, R., ROGERSON, P.A., BLATT, A., FLANIGAN, M., LEE, K. A Logistics Model for Emergency Supply of Critical Items in the Aftermath of a Disaster. Socio-Economic Planning Sciences Volume 45, Issue 4, December 2011, Pages 132-145

[18] MEDINA, M., GIESEN, R., MUÑOZ, J. Model for the optimal location of bus stops and its application to a public transport corridor in Santiago, Chile. Transportation Research Record 2352, 84-93, 2013.

[19] NATARAJARATHINAM, M.; CAPAR, I. E NARAYANAN, A. Managing supply chains in times of crisis: a review of literature and insights. International Journal of Physical Distribution and Logistics Management. Vol. 39, No.7, pp.535-573, 2009 .

[20] NIKOLIC', M., TEODOROVIC', D. A simultaneous transit network design and frequency setting: computing with bees. Expert Systems with Applications 41, 7200-7209, 2014.

[21] NOLZ, P. et al. A Bi-objective Metaheuristic for Disaster Relief Operation Planning. Advances in Multi-Objective Nature Inspired Computing Studies in Computational Intelligence. Vol. 272, pp. 167-187, 2010.

[22] ONUR METE, H. e ZABINSKY, Z. Stochastic Optimization of Medical Supply Location and Distribution in Disaster Management. International Journal of Production Economics, pp 76-84, 2009.

[23] ÖZDAMAR, L., EKINCI, E., KÜC, ÜKYAZICI, B. Emergency logistics planning in natural disasters. Annals of Operations Research 129 (1), 217-245, 2004.

[24] PEREZ, N. et al. Integrated Vehicle Routing Problem With Explicit Consideration Of Social Costs In Humanitarian Logistics. Politecnic Institute, 2010.
[25] RAWLS, C.G., TURNQUIST, M.A. Prepositioning of emergency supplies for disaster response. Transportation Research Part B: Methodological 44 (4), 521-534, 2010.

[26] SZETO, W., JIANG, Y. Hybrid artificial bee colony algorithm for transit network design. Transportation Research Record 2284, 47-56, 2012

[27] THOMAS, A.S. Humanitarian Logistics: Enabling Disaster Response. Fritz Institute. 2003.

[28] THOMAS, A. MIZUSHIMA, M. Logistics training: Necessity or luxury Forced Mitigation Review. Vol.22, pp. 60-61, 2005.

[29] TIERNEY, K., BRUNEAU, M. Conceptualizing and Measuring Resilience: A Key to Disaster Loss Reduction. Journal of the Transportation Research Board.Vol.257, pp.14-17, 2007.

[30] TZENG, G., CHENG, H., HUANG, T.D. Multi-objective optimal planning for designing relief delivery systems. Transportation Research Part E: Logistics and Transportation Review 43, 673-686, 2007

[31] VAN WASSENHOVE, L. Humanitarian aid logistics: supply chain management in high gear. Journal of the Operational Research Society. Vol.57, pp.475-498, 2006.

[32] WANG, H., DU, L., MA, S. Multi-objective open location-routing model with split delivery for optimized relief distribution in post-earthquake. Transportation Research Part E 69 (2014) 160-179.

[33] $\mathrm{Yl}, \mathrm{W}$. e KUMAR, A. Ant colony optimization for disaster relief operations. Transportation Research Part E: Logistics and Transportation Review. Volume 43, No. 6, pp. 660 672, 2007

[34] YI, W., ÖZDAMAR, L. A dynamic logistics coordination model for evacuation and support in disaster response activities. European Journal of Operational Research 179 (3), 1177-1193, 2007. 


\section{Bapítulo 16}

\section{PREVISÃO DE CARGA ELÉTRICA EM CURTO PRAZO UTILIZANDO MODELOS DE BOX \& JENKINS ESPECIFICADOS VIA OTIMIZAÇÃO POR ENXAME DE PARTICULAS}

\section{Guilherme Guilhermino Neto}

\section{Henrique Steinherz Hippert}

Resumo: para a gestão eficiente das operações, um sistema de energia elétrica necessita estimar, com antecedência, a carga demandada pelo consumidor. Em particular, as previsões em curto prazo, feitas um dia antes e em base horária, têm importância vital no contexto do atual mercado. Várias técnicas têm sido empregadas a fim de elaborar previsões com menor erro. Dentre elas, os modelos estatísticos de Box \& Jenkins, que procuram extrapolar o comportamento de dados históricos de carga, se destacam pela facilidade de interpretação e a flexibilidade para especificar uma forma funcional. No entanto, métodos tradicionais de estimação dos parâmetros dependem de procedimentos numéricos que podem convergir para resultados pouco confiáveis. Neste trabalho, utilizamos a metaheurística de Otimização por Enxame de Partículas (PSO) para buscar pelos parâmetros de um modelo de Box \& Jenkins que minimizem o erro médio quadrático das previsões. Para uma base de dados com cargas da cidade do Rio de Janeiro, conduzimos simulações computacionais a fim de verificar o desempenho do método. O erro médio obtido é baixo, assim como a variabilidade dos resultados, o que nos leva a crer que o uso da PSO no contexto seja promissor. 


\section{INTRODUÇÃO}

Um Sistema de Energia Elétrica (SEE) é o conjunto de empresas responsáveis pela geração, transmissão e distribuição de energia elétrica. Para administrar esse tipo de sistema de forma eficiente, é necessário estimar, com antecedência, a quantidade de carga demandada pelos consumidores. Como não é possível armazenar grandes volumes de energia elétrica para consumo posterior, a previsão de demanda é crucial para um SEE.

Em nível de horizonte de planejamento, as previsões de carga são feitas para longo, médio ou curto prazo (Hong e Fan, 2016). Ações de planejamento estratégico, como a construção de uma nova usina ou desativação de uma já existente, requerem previsões de longo prazo, feitas com antecedência de, no mínimo, três anos. Já ações táticas, como compra de equipamentos ou de combustível, são baseadas em previsões de médio prazo, com antecedência de duas semanas a três anos. Por sua vez, previsões de curto prazo, que são feitas com antecedência de um dia a duas semanas, em base horária, são utilizadas na operação cotidiana dos SEE para otimizar a distribuição da carga entre os subsistemas. Devido a sua crescente importância para o mercado de energia, as previsões de curto prazo são o foco deste trabalho.

Uma das principais características do atual mercado de transmissão e distribuição de energia é o fato de que a energia elétrica pode ser comprada e vendida, no mercado de commodities (com preços definidos de hora em hora), entre subsistemas interligados. Bunn (2000) explica que, caso a demanda supere a oferta, uma empresa pode comprar a carga faltante de outra que esteja disposta a vender. Ocorre que, comprada de última hora, a energia tem custo elevado devido à urgência da transação. Alternativamente, quando a oferta supera a demanda, a empresa pode pôr o excedente à venda; no entanto, não há garantia de haver comprador e, portanto, há o risco de desperdício da produção ou de danos ao sistema por sobrecarga, comprometendo a sustentabilidade e a qualidade da operação. Vale destacar que a sustentabilidade, qualidade e transparência não tem sido apenas objetivos internos das empresas, mas exigências comuns entre os participantes do mercado de energia, que tem firmado acordos nesse sentido. Como exemplo, podemos mencionar o acordo da Comissão Reguladora 543/2013 da União Europeia (EU, 2013) e, no Brasil, o Plano Nacional de Dados Abertos da Agência Nacional de Energia Elétrica (ANEEL, 2017).

Ao longo dos anos, muitas técnicas foram testadas para resolver o problema da previsão de carga elétrica em curto prazo. Dentre elas, os modelos estatísticos baseados em séries temporais, como os modelos de Box \& Jenkins, se destacam devido à facilidade de interpretação e flexibilidade. Apesar disso, um dos problemas destes métodos está na dificuldade em estimar os valores dos parâmetros, já que métodos tradicionais dependem de procedimentos numéricos complexos, que podem ter dificuldades para convergência.

Neste trabalho, propomos um modelo Box \& Jenkins para previsão de carga elétrica em curto prazo e empregamos a Otimização por Enxame de Partículas (particle swarm optimization, PSO), uma meta-heurística de inspiração biológica. Utilizando a PSO, que se baseia em um algoritmo relativamente simples, porém, eficiente para o que se propõe, fazemos a busca pelos parâmetros do modelo. Simulações são feitas para diferentes amostras de uma base de dados reais, com cargas de um subsistema da cidade do Rio de Janeiro, e os resultados são discutidos.

\section{MATERIAL E MÉTODOS}

\subsection{DADOS DE CARGA}

Os dados que utilizamos para simulações computacionais correspondem às cargas elétricas horárias (em MW) em um subsistema que atende a uma região residencial e comercial da cidade do Rio de Janeiro. Estes dados foram mensurados pela distribuidora local para o período de 12/08/1996 a 31/12/1997, constituindo uma série histórica de 12.096 observações.

Na Figura 1, podemos observar as cargas de uma típica quinzena de verão e outra de inverno, escolhidas por conveniência: 
FIGURA 1 - Cargas típicas de uma semana de verão e outra de inverno para os dados da cidade do Rio de Janeiro.

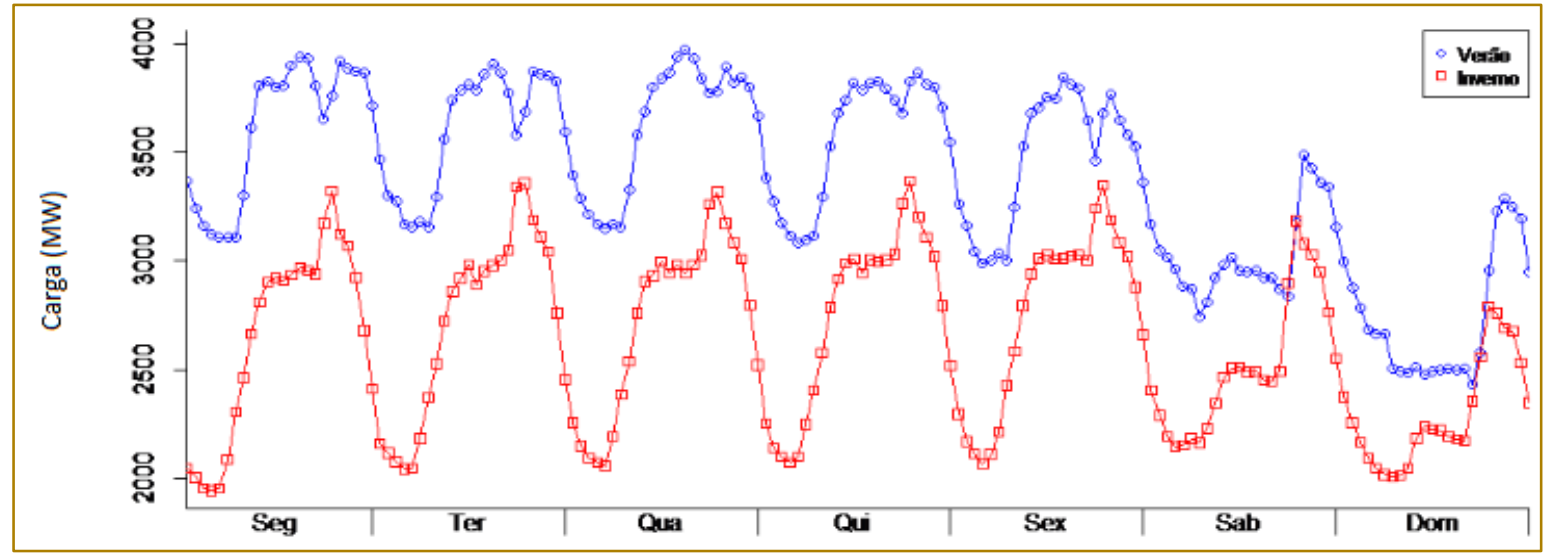

A principal característica dos dados de carga elétrica é a existência de várias sazonalidades sobrepostas. A Figura 1 sugere a existência de uma sazonalidade diária (cargas sempre mais baixas durante as madrugadas), uma sazonalidade semanal (cargas sempre mais baixas aos finais de semana) e outra sazonalidade anual (cargas sempre mais baixas nos meses de verão). Enquanto as sazonalidades diária e semanal podem ser explicadas pelas diferenças entre o consumo de energia em horário comercial e nãocomercial, a sazonalidade anual parece diretamente ligada aos efeitos da temperatura ambiente, devido à qual, nos meses mais quentes, o uso de aparelhos de ar- condicionado aumenta, impactando a carga demandada.

À parte dos dias típicos, o comportamento das cargas elétricas nos feriados costuma ser diferente devido a efeitos de ordem social. Como estes dias são normalmente modelados à parte, com métodos que fogem do escopo deste trabalho, substituímos os dados pelas médias das cargas observadas no mesmo horário, nas semanas anterior e seguinte.

Para verificar se o modelo proposto funciona de maneira adequada em conjuntos de dados distintos, dividimos a base de dados do Rio de Janeiro em cinco seções, como na Tabela 1 :

TABELA 1 - Subdivisões dos dados de carga do Rio de Janeiro

\begin{tabular}{|c|c|c|}
\hline \multicolumn{2}{|c|}{$\begin{array}{c}\text { Estimação de } \\
\text { parâmetros (semanas) }\end{array}$} & {$[23,32]$} \\
\hline A & {$[01,22]$} & {$[33,42]$} \\
\hline B & {$[13,32]$} & {$[43,52]$} \\
\hline C & {$[23,42]$} & {$[53,62]$} \\
\hline D & {$[33,52]$} & {$[63,72]$} \\
\hline E & {$[43,62]$} & Teste (semanas) \\
\hline
\end{tabular}

As seções para estimação de parâmetros correspondem aos dados que utilizamos para que o algoritmo da PSO faça a busca pelos parâmetros do modelo. Já as seções de teste, servem para verificar o desempenho do algoritmo fora dos dados para os quais o modelo foi ajustado, como se fossem novas observações.

\subsection{MÉTODOS DE PREVISÃO DE CARGA}

A literatura recente mostra que muitos autores têm optado por resolver o problema da previsão de carga utilizando métodos de Inteligência Computacional, como Redes Neurais Artificiais (Hippert et al., 2001), Regressão de Vetor Suporte (Xiong et al., 2014) ou Gradient Boosting (Mayrink, 2016). 
Estes métodos costumam produzir resultados acurados e de baixo erro, e são particularmente interessantes quando queremos modelar a relação não-linear entre carga e variáveis meteorológicas, como a temperatura ambiente. Entretanto, como o usuário não estabelece a forma funcional da carga elétrica a priori, os algoritmos podem encontrar relações muito complexas, tornando-se difícil interpretá-las.

Apesar da recente profusão de métodos de Inteligência Computacional na literatura, os modelos estatísticos de Box \& Jenkins (Box et al. 2008) continuam sendo usados por muitos profissionais do mercado (Weron, 2006). Além disso, em estudo recente de Makridakis et al. (2018), modelos ARIMA tiveram melhor desempenho que métodos diversos de Inteligência Computacional para vários conjuntos de dados. Os modelos de Box \&

$$
\hat{L}_{t}=\phi_{1} L_{t-1}+\phi_{2} L_{t-2}+\ldots+\phi_{p} L_{t-p}+\beta
$$

Nesta equação, $\phi_{1}, \ldots, \phi_{p}$ são coeficientes que atribuem pesos às cargas passadas e $\beta$ é uma constante.

Podemos representar a sazonalidade dos dados acrescentando termos periódicos, pela composição de um modelo chamado $\operatorname{SAR}(p) \times(P)_{s}$, auto-regressivo sazonal, onde $\mathrm{p}$ é a quantidade de cargas
Jenkins trazem a vantagem de maior facilidade de interpretação e flexibilidade, permitindo que o usuário defina a priori a forma funcional que considere pertinente aos dados. Além disso, os modelos não dependem de dados de variáveis exógenas, como as meteorológicas.

Os modelos de Box \& Jenkins descrevem a carga em determinada hora de um dia como função das cargas passadas na série histórica (alternativamente, podemos dizer que a carga futura é uma extrapolação de seu comportamento no passado).

O modelo mais simples é o chamado $A R(p)$ ou auto-regressivo de ordem $p$, em que a carga prevista no instante $t, \hat{L}_{t}$, é descrita como combinação linear das $p$ cargas mais recentes no histórico, isto é:

imediatamente anteriores levadas em conta, $\mathrm{P}$ é a quantidade de cargas de ciclos anteriores levadas em conta e s é o tamanho do intervalo entre um ciclo e outro. Por exemplo, para incluir a sazonalidade diária de nossos dados, o intervalo seria $s=24$ horas, e a carga prevista em um instante $t$ ficaria da seguinte forma:

$$
\hat{L}_{t}=\phi_{1} L_{t-1}+\phi_{2} L_{t-2}+\ldots+\Phi_{1} L_{t-24}+\Phi_{2} L_{t-48}+\ldots+\Phi_{p} L_{t-P_{1} \times 24}+\Psi_{1} L_{t-168}+\Psi_{2} L_{t-336}+\ldots+\Psi_{p} L_{t-P_{2} \times 168}+\beta
$$

No modelo acima, $\Phi_{1}, \ldots, \Phi_{P}$ são coeficientes das $P$ cargas de períodos sazonais passados.

Como as séries de carga tem mais de uma sazonalidade, Taylor (2010) sugere incorporar mais termos periódicos. Um modelo autoregressivo de dupla sazonalidade é chamado $\operatorname{SAR}(p) \times\left(P_{1}\right)_{s 1} \times\left(P_{2}\right)_{s_{2}}$, onde p é o número de cargas imediatamente passadas e $P_{1}$ e
$P_{2}$ são o número de cargas dos ciclos anteriores levadas em conta, e ${ }^{s_{1}}$ e $^{s_{2}}$ são os tamanhos dos intervalos dos ciclos. Para considerar as sazonalidades diária e semanal, podemos fazer, respectivamente, $s_{1}=24$ $s_{2}=168$ horas, e então temos o seguinte polinômio:

$$
\hat{L}_{t}=\phi_{1} L_{t-1}+\phi_{2} L_{t-2}+\ldots+\Phi_{1} L_{t-24}+\Phi_{2} L_{t-48}+\ldots+\Phi_{p} L_{t-P_{1} \times 24}+\Psi_{1} L_{t-168}+\Psi_{2} L_{t-336}+\ldots+\Psi_{p} L_{t-P_{2} \times 16}
$$


Com inspiração nos modelos discutidos, e com base no comportamento dos dados, discutido na seção 2.2, propomos o seguinte modelo para as cargas do Rio de Janeiro:

$\hat{L}_{t+k}=\phi L_{t-1}+\Phi L_{t+k-24}+\Psi L_{t+k-168}+\beta$

$\hat{L}_{t+k}$ instante $t$. Este que este modelo tem a flexibilidade de fazer previsões $k$ passos à frente de um instante, atributo importante para fazer previsões de perfis diários (i.e. das 24 horas do dia seguinte no final de um dia), o que, de acordo com Bunn (2000), é particularmente importante para o mercado de energia.

As componentes que escolhemos para descrever a carga, e suas justificativas, são:

(i) $L_{t-1}$ : última atualização de carga disponível. Este termo pode ajudar a indicar a tendência mais recente nos dados (ou seja, se a carga parece vir crescendo ou decrescendo).

(ii) $L_{t+k-24}$ : última atualização da carga disponível para a hora que está sendo prevista; medida no dia anterior. Por exemplo, se quisermos prever a carga à $1 \mathrm{~h}$ a.m. de amanhã, usaremos a carga à 1h a.m. de hoje. Este termo incorpora ao modelo a sazonalidade diária.

(iii) $L_{t+k-168}$ : última atualização da carga disponível para a hora que está sendo prevista; no mesmo dia da semana anterior. Por exemplo, se hoje for segunda-feira e quisermos prever a carga à $1 \mathrm{~h}$ a.m. de amanhã, usaremos a carga à $1 \mathrm{~h}$ a.m. da segunda-feira passada. Este termo incorpora ao modelo a sazonalidade semanal.

Destacamos que fizemos a opção pela formulação aditiva do modelo de Box \&
Jenkins por simplicidade, já que o foco do trabalho é o uso da PSO. Alternativamente, poder-se-ia empregar um modelo multiplicativo.

Apesar da facilidade de interpretação (o modelo é apenas função da soma ponderada de cargas passadas em períodos definidos, acrescida de uma constante), a estimação dos parâmetros $\phi, \Phi, \Psi, \beta$ não é trivial: os métodos tradicionais são fundamentados em procedimentos numéricos para resolução de um problema de mínimos quadrados lineares, os quais, a depender do condicionamento dos dados, podem levar a erros de arredondamento e soluções pouco confiáveis (Heath, 2002). Isto justifica a pesquisa por métodos alternativos para buscar os parâmetros do modelo proposto.

\subsection{OTIMIZAÇÃO POR ENXAME DE PARTÍCULAS (PSO)}

O algoritmo de otimização por enxame de partículas (particle swarm optimization, PSO), proposto por Kennedy e Eberhart (1995) e aprimorado por outros autores, é um algoritmo inspirado no comportamento de populações que, na natureza, vivem em enxames, como revoadas de pássaros. Quando um pássaro de uma revoada, por exemplo, fica mais próximo de encontrar comida, ele pode se comunicar com os demais, que modificam sua trajetória com base na informação recebida, até que toda a revoada comece a convergir para o local onde está a comida.

Em analogia, o algoritmo PSO funciona da seguinte forma: uma população de $N$ soluções iniciais para um problema (o que seriam as partículas do enxame) é gerada em um espaço de busca D-dimensional. Cada partícula tem posição $\mathbf{x}$ e velocidade $\mathbf{v}$. A cada iteração do algoritmo, a velocidade e a posição são atualizadas de acordo com as equações: 
$\mathbf{v}_{i, G+1}=\omega \mathbf{v}_{i, G}+c_{1} \mathbf{r}_{i}\left(\right.$ pbest $\left._{i, G}-\mathbf{x}_{i, G}\right)+c_{2} \mathbf{r}_{i}\left(\right.$ gbest $\left._{G}-\mathbf{x}_{i, G}\right)$

$\mathbf{x}_{i, G+1}=\mathbf{x}_{i, G}+\mathbf{v}_{i, G+1}$

$\mathbf{v}_{i, G}=\left(v_{i, G}^{1}, v_{i, G}^{2}, \ldots, v_{i, G}^{D}\right)$ é a velocidade da i-ésima partícula na iteração $\mathrm{G}, \quad \mathbf{x}_{i, G}=\left(x_{i, G}^{1}, x_{i, G}^{2}, \ldots, x_{i, G}^{D}\right)$

é a posição da i-ésima partícula na iteração $G, c_{1}, c_{2}$ são coeficientes de aceleração, $r_{i, G}=\left(r_{i, G}^{1}, r_{i, G}^{2}, \ldots, r_{i, G}^{D}\right)$ são números aleatórios dentro do intervalo $[0,1], \omega$ é um coeficiente de inércia, pbest $_{i, G}$ é a melhor posição já visitada pela i-ésima partícula na G-ésima iteração e gbest $_{G}$ é a melhor posição conhecida por todo o enxame na G-ésima iteração.

As equações de atualização significam que, a cada iteração, a velocidade da partícula é atualizada de acordo com informações provenientes do "conhecimento" da própria partícula (componente cognitiva; primeira parcela da soma) e do "conhecimento" global do enxame (componente social; segunda parcela da soma). Ao fim do cálculo da nova posição, é verificado se há melhora nos resultados atuais, de modo que se deva atualizar a melhor posição da partícula e/ou do enxame. A comparação do desempenho das partículas é feita por meio da comparação dos valores de uma função de custo que se queira minimizar, avaliada no ponto correspondente à posição da partícula. Este procedimento é repetido até que algum critério de parada seja atendido, por exemplo, um número fixado de iterações.

Neste trabalho, utilizamos a PSO para determinar os parâmetros do modelo de Box \& Jenkins que propusemos da seguinte forma: cada partícula corresponde aos valores $\phi, \Phi, \Psi, \beta$ que queremos encontrar no espaço de busca. A função de custo escolhida é o erro médio quadrático das previsões (mean squared error, MSE), o qual procuramos minimizar. O MSE é dado pela equação seguinte:

$$
M S E=\frac{1}{n} \sum_{t=1}^{n}\left(\hat{L}_{t}-L_{t}\right)^{2}
$$

onde $\mathrm{n}$ é o número de observações no conjunto de dados.

Sobre a inicialização do algoritmo que implementamos:

(i) Inicializamos as posições das partículas como valores aleatórios no intervalo [-1,1];

(ii) Inicializamos as velocidades das partículas como valores aleatórios da distribuição normal com média 0 e desvio-padrão 1;

(iii) Inicializamos os coeficientes de aceleração como $c_{1}=c_{2}=1,49$ (padrão no PSO original de 1995);

(iv) O critério de parada foi o alcance de 100 iterações do algoritmo (percebemos que, para os dados, um ponto de mínimo sempre é atingido com menos que 100 iterações);

(v) O tamanho do enxame escolhido foi de 100 partículas (usar mais partículas não trouxe melhoras consideráveis);

(vi) Para evitar convergência prematura do algoritmo, escolhemos inicializar o fator de inércia como sugerido no estudo de Clerc e Keneddy (2002):

$$
\omega=2 \times \frac{\kappa}{\left|2-\phi-\sqrt{\phi^{2}-4 \times \phi}\right|} ; \kappa=1, \phi=2,05
$$


A implementação do algoritmo foi feita em linguagem $\mathrm{R}$, em um computador Intel (R) Core (TM) i5-7200U CPU @ 2,50 GHz, 2712 Mhz, 2 Núcleos, 4 Processadores Lógicos, 8,00 GB de memória RAM.

\subsection{MÉTODOS PARA BENCHMARK}

Hyndman e Athanasopoulos (2018) sugerem que, ao desenvolver um método de previsão, primeiramente, comparemos seus resultados com os de previsores ingênuos, que são métodos de benchmark simples. Estes métodos assumem que a previsão de carga em determinada hora seja igual à última atualização disponível. Caso o método proposto tenha desempenho pior que 0 destes, há indícios de que a nova abordagem não traga contribuições significativas e que deva ser aprimorada ou descartada.

Utilizaremos os dois tipos de previsor ingênuo descritos a seguir.

\subsubsection{NAIVE24}

Para este previsor, a carga em determinada hora é dada pela carga na mesma hora do dia anterior:

$$
\hat{L}_{t+k}=L_{t+k-24}
$$

\subsubsection{NAIVE168}

Neste caso, a carga em determinada hora é dada pela carga na mesma hora do mesmo dia na semana anterior:

$$
\hat{L}_{t+k}=L_{t+k-168}
$$

\subsection{ROTEIRO DAS SIMULAÇÕES}

Para cada amostra da base de dados, o PSO foi executado 100 vezes. Isso foi feito porque, como o algoritmo depende de componentes aleatórias, pode haver alguma variação nos resultados de uma execução para outra. Vale mencionar que mais de 100 execuções não trouxeram resultados razoavelmente diferentes.

Em cada execução, a PSO busca, na fração da amostra reservada para esta finalidade, os valores de parâmetros do modelo de Box \& Jenkins que minimizam o MSE. Depois, os valores encontrados são utilizados para fazer previsões na amostra de teste. Para estas previsões, calculamos uma métrica de erro para comparar o desempenho do modelo com o dos previsores ingênuos. A métrica escolhida foi o erro percentual absoluto médio (mean absolute percentage error, MAPE). Escolhemos esta métrica por ser de fácil interpretação e pelo vasto uso na literatura de previsão de carga. Seu cálculo é dado pela equação:

$$
M A P E=100 \times \frac{1}{n} \sum_{t=1}^{n} \frac{\left|\hat{L}_{t}-L_{t}\right|}{L_{t}}
$$

As previsões são feitas em perfis, ou seja, à última hora de um dia são feitas as previsões das cargas de todas as $24 \mathrm{~h}$ do dia seguinte. Este é um padrão comum na literatura de previsão de carga elétrica. Como já mencionado, o mercado costuma fazer previsões vários passos à frente.

\section{RESULTADOS E DISCUSSÃO}

Na Figura 2, podemos observar a distribuição dos MAPEs para as 100 execuções do PSO, além dos MAPEs dos previsores ingênuos, nas amostras de teste $A, B, C, D$ e E: 
FIGURA 2 - Distribuição dos MAPEs para os três métodos de previsão, com 100 execuções da PSO, por amostra (dados de teste).

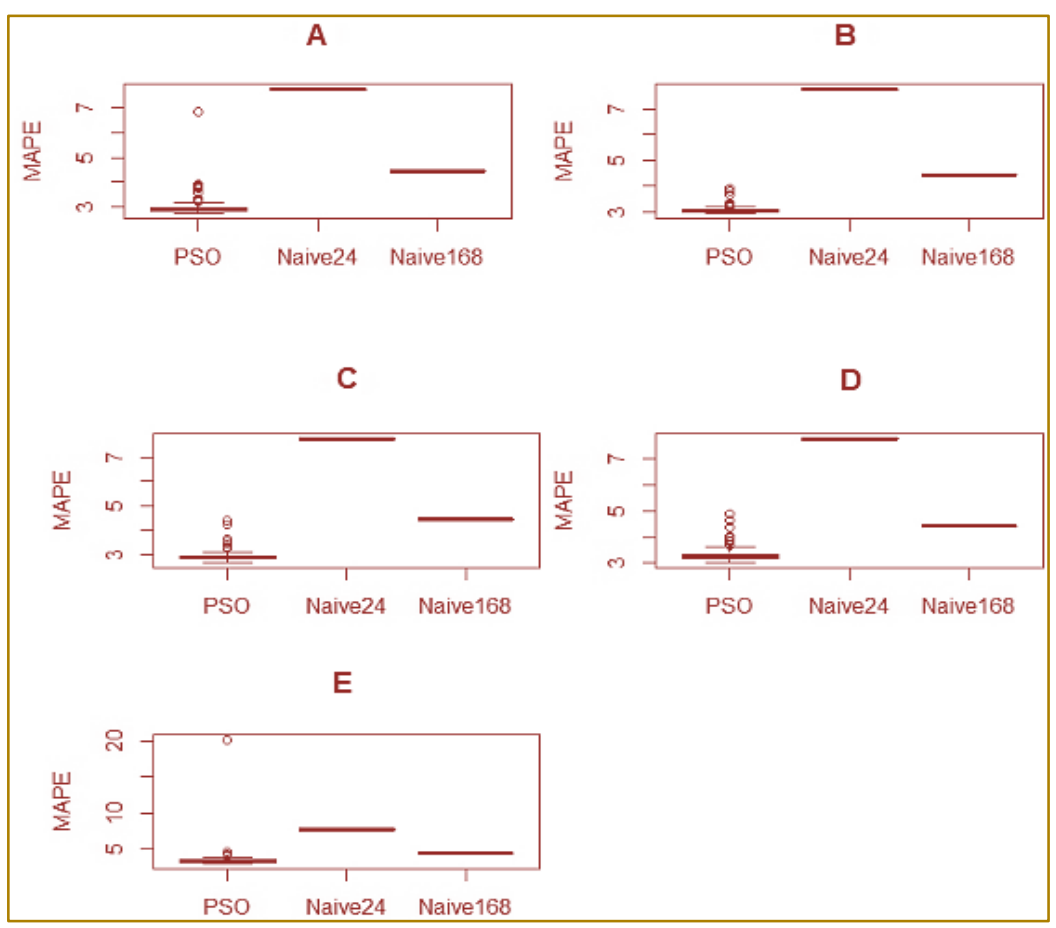

A PSO teve, considerando o MAPE, melhor desempenho do que os previsores ingênuos na maioria das execuções. Notamos que existem alguns valores discrepantes nas execuções do PSO, o que provavelmente decorre de convergência prematura do algoritmo (mesmo com a limitação do fator de inércia).

As Estatísticas da Tabela 2 fundamentam uma análise mais detalhada:

TABELA 2 - Estatísticas para os MAPEs das simulações por método e amostra (dados de teste)

\begin{tabular}{|c|c|c|c|c|c|c|}
\hline \multirow[b]{2}{*}{ Método } & \multirow[b]{2}{*}{ Estatística } & \multicolumn{5}{|c|}{ Amostra } \\
\hline & & A & B & C & D & $\mathrm{E}$ \\
\hline \multirow{4}{*}{ PSO } & MAPE médio (\%) & 3,00 & 3,09 & 2,92 & 3,32 & 3,50 \\
\hline & MAPE mínimo (\%) & 2,75 & 2,95 & 2,66 & 3,03 & 2,96 \\
\hline & MAPE máximo (\%) & 6,85 & 3,92 & 4,38 & 4,89 & 20,21 \\
\hline & $\begin{array}{l}\text { Coeficiente de variação do } \\
\text { MAPE (\%) }\end{array}$ & 14,96 & 4,96 & 9,44 & 9,37 & 48,93 \\
\hline Naive24 & MAPE (\%) & 7,77 & 7,68 & 6,54 & 7,11 & 7,63 \\
\hline Naive168 & MAPE (\%) & 4,44 & 4,66 & 3,84 & 5,63 & 6,60 \\
\hline
\end{tabular}

Para as amostras B, C e D, o coeficiente de variação (quociente entre o desvio padrão e a média) dos MAPEs da PSO é menor que 10\%, nível que traz alguma segurança à operação do método, já que podemos esperar com boa certeza que seus resultados estejam próximos de um dado intervalo. Já para as amostras $A$ e E, o valor desta estatística é mais alto (no caso da amostra 3, muito mais alto). Acreditamos que isso ocorra por causa dos valores discrepantes que foram mencionados: em algumas poucas execuções, o erro foi muito maior que nas demais, o que, reforçamos, deva ser fruto de convergência prematura do algoritmo, que pode ter ficado "preso" em um ponto de mínimo local. Outra explicação possível está nos dados: a amostra 3 contém muitos dados de dias de final de ano, onde o comportamento da carga elétrica costuma ser diferente devido a fatores sociais (época de Natal, férias etc.).

Apesar de alguma variabilidade ser sempre esperada devido à natureza estocástica do algoritmo, a média dos resultados supera o desempenho dos previsores ingênuos. 


\section{CONSIDERAÇÕES FINAIS}

Os métodos de previsão baseados em modelos de Box \& Jenkins são convenientes para previsão de carga elétrica em curto prazo devido à facilidade de interpretação e à flexibilidade. No entanto, a estimação dos parâmetros é tradicionalmente uma tarefa complexa do ponto de vista computacional, o que motivou a busca por um método alternativo de otimização.

Para dados de uma zona comercial e residencial da cidade do Rio de Janeiro, analisamos o comportamento histórico da carga e, com base nas sazonalidades, propusemos um modelo de Box \& Jenkins. Para cinco subdivisões dos dados, procuramos pelos parâmetros do modelo proposto utilizando a meta-heurística da

\section{REFERÊNCIAS}

[1] AGÊNCIA NACIONAL DE ENERGIA ELÉTRICA - ANEEL Aprova o Plano de Dados Abertos da Agência Nacional de Energia Elétrica ANEEL para o biênio 2018-2019. Portaria n. 4170, de 19 de dezembro de 2017

[2] BOX, G. E. P., JENKINS, G. M., e REINSEL, G. C.. Time series analysis: forecasting and control. 4 ed. New York: Wiley, 2008

[3] BUNN, D.. Forecasting Loads and Prices in Competitive Power Markets, Proceedings of the IEEE, v. 88, n. 2, pp. 163-169, 2000

[4] CLERC, M. e KENNEDY, J. The Particle Swarm-Explosion, Stability, and Convergence in a Multidimensional Complex Space. IEEE Transactions on Evolutionary Computation, v. 6, n. 1, pp. 58-73, 2002

[5] EUROPEAN UNION - EU. Regulations: Comission Regulation (EU) No 543/2013 of 14 June 2013 on submission and publication of data in electricity markets and amending Annex I to Regulation (EC) No 714/2009 of the European Parliament and of the Council. Official Journal of the European Union. 15 Jun. 2013, pp $163 / 5-163 / 12$

[6] HYNDMAN, R.J. e ATHANASOPOULOS, G.. Forecasting: principles and practice. Melbourne: Otexts. Disponível em <http://otexts.org/fpp/>. Acesso em 15 jul. 2018

[7] KENNEDY, J. e EBERHART, R. Particle Swarm Optimization. Proceedings of the IEEE International Conference on Neural Networks, v. 4, pp. 1942-1948, 1995 otimização por enxame de partículas (PSO). Foram feitos testes para previsões de perfil e os resultados, em média, superaram os obtidos por previsores ingênuos, apesar da presença de erros discrepantes em algumas poucas execuções.

Como os resultados indicam que o método seja promissor, sugerimos que seja mais explorado em trabalhos futuros. Podem ser testadas diferentes topologias para a comunicação das partículas (topologia de anel, por exemplo), outros modelos de Box \& Jenkins (como as formulações multiplicativas) e a inclusão de variáveis exógenas, como a temperatura ambiente (modelos SARMAX). Também sugerimos comparar os resultados com os de benchmarks mais sofisticados, como o de Redes Neurais Artificiais, e testar o método em outras bases de dados, inclusive oriundas de operações diferentes.

[8] HEATH, M.T. Scientific Computing. 2 ed. New York: McGraw-Hill, 2002.

[9] HIPPERT, H. S., PEDREIRA, C. E., e SOUZA, R. C. Neural networks for short-term load forecasting: A review and evaluation. IEEE Transactions on Power Systems, v. 16, n. 1, 44-55., 2001

[10] HONG, T. e FAN, S.. Probabilistic electric load forecasting: A tutorial review, International Journal of Forecasting, v. 32, n. 3, pp. 914-938, 2016

[11] MAKRIDAKIS, S.; SPILIOTIS; E. e ASSIMAKOPOULOS, V. Statistical and Machine Learning forecasting methods: Concerns and ways forward. PLoS One, v. 13, n. 3, 2018.

[12] MAYRINK, V. T. M.; HIPPERT, H. S. Aprimoramento do desempenho de previsão a curto prazo de carga elétrica utilizando o algoritmo gradient boosting. Anais do XXIII Simpep, Bauru: UNESP, 2016

[13] TAYLOR, J.W.. Triple Seasonal Methods for Short-term Load Forecasting. European Journal of Operational Research, v. 204, n. 1, 139-152., 2010.

[14] WERON, R. Modelling and forecasting electriciy loads and prices: an Statistical Approach. New York: Wiley, 2006.

[15] XIONG, T., BAO, Y. e HU, Z.. Interval forecasting of electricity demand: A novel bivariate EMD-based support vector regression modeling framework. International Journal of Electrical Power \& Energy Systems, v. 63, n. 1, 353-362., 2014. 


\section{Bapítulo 17}

\section{MODELAGEM DA PRODUÇÃO INDUSTRIAL ALIMENTÍCIA BRASILEIRA (2002-2017) A PARTIR DA COMBINACָAOO DOS MODELOS SARIMA HOLT-WINTERS}

\section{Karina Sayuri Ueda}

Silvia Maria Martelli

Ícaro Agostino

Renan Mitsuo Ueda

Adriano Mendonça Souza

Resumo: As indústrias alimentícias brasileiras compreendem diversas variedades de produtos, estando diretamente ligadas à pecuária e agricultura, movimentando a economia do país. Sendo assim, o presente estudo teve como objetivo a utilização de modelos de previsões para a produção industrial de alimentos no Brasil através dos modelos SARIMA, Holt- Winters e a combinação entre ambos. As séries temporais foram utilizadas para fazer previsões estatísticas, a fim de realizarem uma aproximação real dos acontecimentos futuros referentes aos dados mensais da produção da indústria de alimentos brasileira compreendendo o período de janeiro de 2002 e dezembro de 2017, um total de 192 observações (mensais). Para a combinação das previsões foram adotadas três abordagens: média aritmética (MS), método Least Squares Weights (LS), e método Inverse Mean Squared (IMS). Pelo fato do método IMS utilizar pesos diferentes para cada horizonte de previsão, o mesmo foi considerado a abordagem mais precisa entre as previsões individuais e combinadas, sendo comprovado por meio da medida de acurácia Root Mean Squared Error (RMSE) e o coeficiente U-Theil. Sendo assim, baseado no presente estudo, a combinação de métodos reduziu os erros da previsão, aumentando a sua acurácia.

Palavras chave: Indústria de Alimentos, Box-Jenkins, ARIMA, Combinação de Previsão. 


\section{INTRODUÇÃO}

A industrialização no Brasil ocorreu de maneira tardia se comparado com países europeus que já haviam substituído produtos artesanais por manufaturados. A industrialização trouxe muitos benefícios econômicos para o país, além de transformações políticas, sociais e educacionais (ALMEIDA; SUHR, 2012). Nesse contexto, segundo Suzigan (2000), a indústria de alimentos teve uma parcela de responsabilidade na industrialização do Brasil. Esse processo iniciou-se no século XIX, a partir da economia de expansão e exportação, os setores que disseminaram estavam ligados ao aumento da demanda por matérias primas industriais. A partir do século XX houve o processo de urbanização no Brasil, estando relacionado diretamente com o esvaziamento rural e a industrialização.

No final da década de 1980 e início da década de 1990, começa a ocorrer a abertura comercial, consequentemente há um aumento da competitividade de mercado. Durante esse período houve uma elevação da importação de insumos das indústrias alimentícias, incentivando as empresas a desenvolverem novos processos e técnicas com intuito de aumentar a produtividade e maximizar os lucros. Atualmente, a agropecuária fornece os insumos para as indústrias, ocasionando o processo de sazonalidade da produção e da oferta, assim como outros fatores que influenciam como por exemplo: embalagens, transporte, canais de distribuições, máquinas, entre outros (BENTO; TELES, 2013).

Considerando a importância do tema estudado, este artigo tem como objetivo a utilização de previsões de demanda da produção industrial de alimentos no Brasil através dos modelos ARIMA, Holt- Winters e a combinação entre ambos, a fim de realizar uma aproximação real dos acontecimentos futuros referentes aos dados mensais de produção da indústria. Em inúmeros casos a combinação das previsões individuais se torna eficaz para minimizar as incertezas que envolvem as realizações de previsões. As previsões confiáveis geralmente utilizam mais de uma técnica, pois se torna capaz de captar um número maior de informações (MARTINS e WERNER, 2014).

\section{REVISÃO DE LITERATURA}

A seguir apresenta-se a contextualização teórica, abordando os temas da indústria brasileira de alimentos, modelos de previsão e combinação de previsão.

\subsection{INDUSTRIA BRASILEIRA DE ALIMENTOS}

Nos últimos anos a indústria alimentos têm crescido constantemente devido ao aumento da demanda. Dentro deste contexto, a nanotecnologia surge para transformar e desenvolver o setor agroalimentar por meio do avanço tecnológico, com o potencial de aumentar a produção global de alimentos, qualidade, valor nutricional e segurança alimentar (HANDFORD et al., 2014, PETERS et al., 2016, SEKHON, 2014).

Com o avanço de diversas tecnologias em indústrias alimentícias, surge a necessidade de novas estratégias de mercado. A inovação é um dos principais métodos através dos quais as empresas de processamento de alimentos podem ser inseridas no mercado competitivo (DRIVAS; GIANNAKAS, 2010; KARANTININIS; SAUER; FURTAN, 2010; ALARCON; SANCHEZ, 2013).

A diferenciação de produtos também representa uma grande estratégia de mercado, onde líderes precisam tomar decisões com elevados níveis de incertezas. Essa diferenciação possibilita a comercialização de produtos com maior valor agregado, proporcionando benefícios econômicos, além de melhorar o produto produzido e consequentemente garantir a satisfação dos consumidores. Davcik (2013) relata que o valor agregado dos alimentos recém desenvolvidos é um fator e pode ser aprimorado através do uso de uma estratégia de marca.

Dessa forma, os métodos de previsões de demanda são de extrema importância para as tomadas de decisões, sendo úteis para o planejamento da organização. Segundo Ismai et al (2016), a previsão de demanda é um processo iterativo que avalia a quantidade de serviço ou produto que um cliente comprará ou consumirá, além de ser empregado também em tomadas de decisões sobre preços. Ou seja, é um processo que estima as possíveis vendas futuras levando em considerações diversas condições, baseadas em métodos estatísticos, matemáticos e séries temporais. 


\subsection{MODELOS DE PREVISÃO}

Um modelo de previsão de demanda utilizado amplamente em diversas áreas do conhecimento é conhecido como método de suavização exponencial, popularizado por Holt (1957) e Winters (1960), que objetiva o ajuste de uma curva adequada dos dados histórico ao longo do tempo (GUJARATI E
PORTER, 2011; MONTGOMERY; JENNINGS; $\mathrm{KULAHCl}, 2007)$. Este método denominado de Holt-Winters tem duas abordagens: multiplicativa e aditiva. Conforme Makridakis, Steven e Hyndman (1998), na abordagem multiplicativa, a amplitude da série aumenta a cada ciclo, enquanto que na aditiva, a mesma permanece constante em relação ao tempo. A Tabela 1 a seguir apresenta a equação das duas abordagens:

Tabela 1 - Equação do Método de Holt-Winters

\begin{tabular}{|c|c|c|}
\hline Abordagem & & uações \\
\hline Aditiva & $Z_{t+m}=\left(L_{t}+b_{t} m\right)+S_{t-s+m}$ & $\begin{array}{c}L_{t}=\alpha\left(Z_{t}-S_{t-s}\right)+(1-\alpha)\left(L_{t-1}+b_{t-1}\right) \\
b_{t}=\beta\left(L_{t}-L_{t-1}\right)+(1-\beta) b_{t-1} \\
S_{t}=\gamma\left(Z_{t}-L_{t}\right)+(1-\gamma) S_{t-s}\end{array}$ \\
\hline Multiplicativa & $Z_{t+m}=\left(L_{t}+b_{t} m\right) S_{t-s+m}$ & $\begin{array}{c}L_{t}=\alpha\left(Z_{t} / S_{t-s}\right)+(1-\alpha)\left(L_{t-1}+b_{t-1}\right) \\
b_{t}=\beta\left(L_{t}-L_{t-1}\right)+(1-\beta) b_{t-1} \\
S_{t}=\gamma\left(Z_{t} / L_{t}\right)+(1-\gamma) S_{t-s}\end{array}$ \\
\hline
\end{tabular}

$L_{t}$ representa o valor estimado do nível; $b_{t}$ representa a estimativa de tendência; $\alpha, \beta$ e $\gamma$ são as constantes de suavização no intervalo de 0 a $1 ; Z_{t+m}$ corresponde a previsão no período "t+m", em que "m" representa quantos passos à frente se deseja prever; $S_{t}$ o índice sazonal da série temporal.

Fonte: Elaborado pelos autores

Um outro método para a modelagem de séries temporais desenvolvido por Box e Jenkins (1970) é o modelo autorregressivo integrado de médias móveis (ARIMA). Segundo Montgomery, Jennings e Kulahci (2007), por meio dos modelos ARIMA é possível captar a correlação existente entre os valores da série temporal, permitindo a realização de futuras previsões. Para Gujarati e Porte (2011), as quatro etapas a serem seguidas para o uso deste modelo são: (i) Identificar o modelo que mais que melhor explica o comportamento da série original, a partir da análise das funções de autocorrelação (FAC) e autocorrelação parcial (FACP); (ii) Estimar os parâmetros autorregressivos e de médias móveis; (iii) Validar a adequação do modelo ajustado por meio dos resíduos do modelo; e (iv) Prever o comportamento futuro da série.

A equação do modelo ARIMA ( $p, d, q)$ é comumente representado da seguinte forma:

$$
\phi(B) \Delta^{d} Z_{t}=\theta(B) \varepsilon_{t}
$$

Onde: $Z_{t}$ corresponde a série temporal analisada, B o operador retroativo, d representa a ordem de integração, $\phi$ corresponde ao termo do parâmetro autoregressivo de ordem $p, \theta$ o parâmetro de médias móveis de ordem q e $\varepsilon_{t}$ a sequência de erros. Onde o erro é denominado de ruído branco caso a variância seja constante e a média dos erros igual a zero (BUENO, 2008; SOUZA, 2016).

Se a série temporal analisada apresentar sazonalidade (repetição de um fenômeno a cada período de tempo idêntico) é utilizado modelos conhecidos como SARIMA. De acordo com Werner e Ribeiro (2003) A descrição genérica deste modelo é SARIMA $(p, d, q)(P, D, Q) s$, pois apresenta os parâmetros iguais aos dos modelos ARIMA ( $p$, $d, q)$, porém com uma parte sazonal $(P, D$, Q)s, onde "s" representa a ordem da sazonalidade.

A fim de garantir que os parâmetros estimados ao longo do tempo apresentem significância, a metodologia de Box e Jenkins pressupõe que a série temporal estudada seja estacionária. A verificação da estacionariedåđø da série pode ser realizada por meio de análise gráfica ou testes de raízes unitárias. No presente estudo, os testes de raízes unitárias adotados serão: Phillips e Perron (1988) e Kwiatkowski, Phillips, Schmidt e Shin - KPSS (KWIATKOWSKI et al., 1992). 
Cabe ressaltar que segundo Souza (2016), a fim de que a análise do grau de estacionariedade da série se torne mais acurada, é aconselhável que os testes de raízes unitárias sejam utilizados de forma conjunta. Caso a série apresente um comportamento não estacionário, aplica-se diferenças na mesma (MARTIN et al., 2016).

Já para a seleção do melhor modelo ajustado levando em consideração dos modelos concorrentes, são utilizados os critérios penalizadores - considera a variância dos erros gerados (MORETTIN, 2008). Os dois critérios penalizadores são: Akaike Information Criteria - AIC (AKAIKE, 1973) e Bayesian Information Criteria - BIC (SCHWARZ, 1978). O modelo que apresentar o menor valor nos critérios penalizadores AIC e BIC será considerado o mais ajustado, portanto, o melhor. As equações para os cálculos dos valores dos critérios AIC e BIC são apresentados a seguir:

$$
\begin{aligned}
& A I C(p, q)=\ln {\sigma_{p . q}}^{2}+\frac{2(p+q)}{n} \\
& B I C(p, q)=\ln {\sigma_{p . q}}^{2}+(p+q) \frac{\ln N}{N}(5)
\end{aligned}
$$

Onde: $p$ e q representam os parâmetros conhecidos, $\mathrm{n}$ corresponde ao tamanho da amostra, In é o logaritmo neperiano e $\sigma^{2}$ a variância estimada dos erros.

Para a avaliação da acurácia do modelo previsto, compara-se os dados da série original com os estimados (TUBINO, 2009). As medidas de acurácia utilizadas neste estudo foram: Root Mean Squared Error (RMSE) e o coeficiente U-Theil. As equações para o cálculo de RMSE e U-Theil são apresentados a seguir:

$$
\begin{gathered}
\text { RMSE }=\frac{\sqrt{\sum_{t=1}^{n}\left(\varepsilon_{t}\right)^{2}}}{n}(6) \\
U-\text { Theil }=\frac{\sqrt{\sum_{t=1}^{n}\left(E_{t}\right)^{2}}}{\sqrt{\sum_{t=1}^{n}\left(z_{t}-Z_{t-1}\right)^{2}}}(7)
\end{gathered}
$$

Onde $E_{t}$ representa o erro de previsão no instante $\mathrm{t} ; \mathrm{n}$ corresponde ao número de observações; $Z_{t}$ é o valor real no tempo t e $\mathrm{t}=$ $1,2, \ldots, n$. No coeficiente $U$-Theil a medida de acurácia é realizada por meio da comparação dos dados do modelo previsto e a previsão ingênua. Se o valor de U-Theil for maior ou igual a 1, então pode-se dizer que o erro médio do modelo ajustado é maior ou igual a previsão ingênua, por outro lado se U-Theil for menor que 1, o erro médio do modelo ajustado é menor que uma previsão ingênua.

\subsection{COMBINAÇÃO DE PREVISÃO}

Objetivando o aumento da precisão nas previsões, pesquisadores tem se esforçado para desenvolverem modelos cada vez mais acurado em diversas áreas do conhecimento, ou seja, com menor erro de previsão (FIRMINO; MATTOS NETO; FERREIRA, 2014). Neste sentido, a combinação entre os melhores modelos previstos se torna uma abordagem interessante, uma vez que ao invés de simplesmente selecionar apenas o melhor modelo para a série analisada, investiga-se quais os modelos que conjuntamente podem aumentar a acurácia da previsão (MARTINS; WERNER, 2014). Portanto, ao utilizar a técnica de combinação de previsões, obtêm-se modelos com maior precisão (SOUZA et al., 2011).

Segundo Martins e Werner (2014) ury)dos métodos mais utilizados para a realização da combinação de previsões é a média aritmética simples (MS), que consiste em uma combinação linear das previsões individuais, considerando os pesos fixos, de acordo com a equação a seguir:

$$
F_{c}=\left(F_{1}+F_{2}+\cdots+F_{n}\right) / n(8)
$$

$\mathrm{Na}$ equação anterior $F_{c}$ representa a previsão combinada e $F_{1}, F_{2}, \ldots, F_{n}$ corresponde as previsões individuais; $n$ é entendido como o número de previsões individuais utilizadas na combinação.

Outra abordagem para a combinação de previsões é a Least Squares Wights (LS) estimado a partir do uso de Mínimos Quadrados em relação a série original, no caso em que há mais de dois preditores individuais. Neste tipo de abordagem a combinação é a linear utilizando modelos de regressão sem restrição em relação aos pesos (GRANGER; RAMANATHAN, 1984). A equação para a combinação de previsão por meio da LS é dada a seguir: 


$$
F_{c}=w_{0}+w_{1} F_{1}+w_{2} F_{2}+\cdots+w_{n} F_{n}(9)
$$

Onde $F_{c}$ representa a previsão combinada; $w_{0}$ corresponde ao intercepto da regressão; $w_{1}, w_{2}, \ldots, w_{n}$ são os pesos estimados para cada previsão individual; $F_{1}, F_{2}, \ldots, F_{n}$ são as previsões individuais; $e n$ representa 0 número de previsões individuais utilizadas para a realização da combinação.

A terceira abordagem de previsão combinada elaborada por Stock e Watson (2004) e utilizada no presente estudo é o Inverse Mean Squared (IMS). Tal método tem como base o inverso do erro quadrático médio de cada uma das previsões, utilizando pesos diferentes para cada horizonte predito. Neste sentido, o cálculo destes pesos é apresentado a seguir na equação (10):

$w_{i}=\frac{1 / M S E_{i}^{k}}{\sum_{j=1}^{n} 1 / M S E_{j}^{k}}$

O peso dado para cada previsão "i" é representado por $w_{i}$; MSE corresponde ao erro quadrático médio cometido por cada previsão individual; $k$ pode ser entendido como o horizonte da previsão; $e n$ representa o número de previsões individuais utilizadas para a realização da combinação das previsões.

\section{METODOLOGIA}

De acordo com Prodanov e Freitas (2013) e Gil (2010), o estudo classifica-se como sendo aplicado, pois tem como foco a aplicação de conceitos teóricos em casos pr(t)icos objetivando a resolução de problemas específicos. Quanto a sua abordagem é classificada como quantitativa, uma vez que são utilizadas ferramentas matemáticas e apresentado resultados quantitativos. Em relação ao objetivo, o estudo é de caráter exploratório, visto que procura a explicação e a geração de hipótese sobre o problema em questão. A pesquisa em termos de procedimentos técnicos representa um estudo de caso, pois busca o detalhamento e o conhecimento amplo sobre um caso particular.

Os dados utilizados neste estudo foram coletados do site do Instituto de Pesquisa Econômica Aplicada (http://www.ipeadata.gov.br/) e corresponde a série temporal do índice de producão industrial alimentício brasileiro (PIM-PF), compreendendo o período de janeiro de 2002 e dezembro de 2017, um total de 192 observações (mensais).

As três etapas seguidas para o desenvolvimento deste estudo são: (1) Ajuste dos modelos concorrentes pelo método de Holt-Winters e de Box-Jenkins; (2) Combinação dos modelos individuais ajustados; e (3) Seleção do melhor modelo por meio da comparação das medidas de acurácia. Na Figura 1 é apresentado as etapas da execução desta pesquisa:

Figura 1 - Etapas para modelagem e combinação das previsões

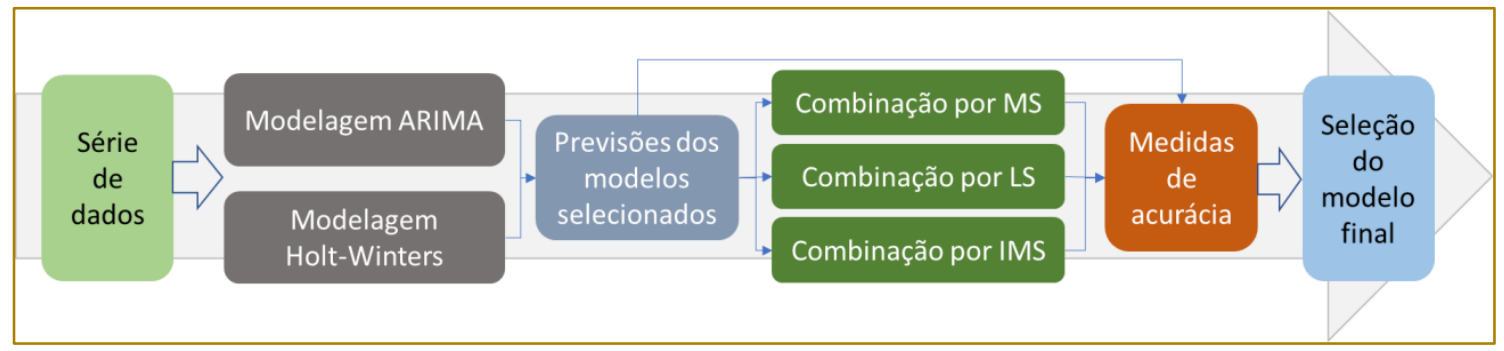

Fonte: Elaborado pelos autores

Para a modelagem pelo método ARIMA, seguiu-se as etapas propostas por BoxJenkins (1970), ou seja, primeiramente analisou-se o comportamento da série original em relação a sua estacionariedade e autocorrelação. Utilizando as funções de autocorrelação (FAC), autocorrelação parcial (FACP) e suas defasagens, determinou-se os filtros a serem adotados, e em posteriormente, por meio do Método da Máxima Verossimilhança foi estimado os parâmetros dos modelos concorrentes.

No caso da modelagem pelo método de HoltWinters, verificou-se a priori se a série original apresentava tendência e sazonalidade para a identificação do tipo de modelo a ser adotado (Suavização simples, linear de Holt, Holt- 
Winters). Os parâmetros foram estimados e posteriormente realizou-se a previsão, determinando o valor para as medidas de acurácia do modelo.

As três abordagens para a combinação das previsões foram: combinação por média aritmética (MS), método Least Squares Weights (LS), e método Inverse Mean Squared (IMS). Sendo o melhor modelo de previsão, tanto individual quanto combinado, determinado por meio das medidas de acurácia RMSE e U-Theil.
O software utilizado para tratamento e modelagem dos dados foi o Eviews 9 S.V.

\section{CLASSIFICAÇÃO DOS ARTIGOS}

A Figura 2 exibe o comportamento temporal do índice de produção industrial alimentício (IPIA) brasileiro, a partir da inspeção visual percebesse um acentuado comportamento sazonal na variável, com ciclos anuais e um crescimento moderado ao longo do tempo de período do estudo.

Figura 2 - Índice de Produção Industrial Alimentício Brasileiro (2002 - 2017)

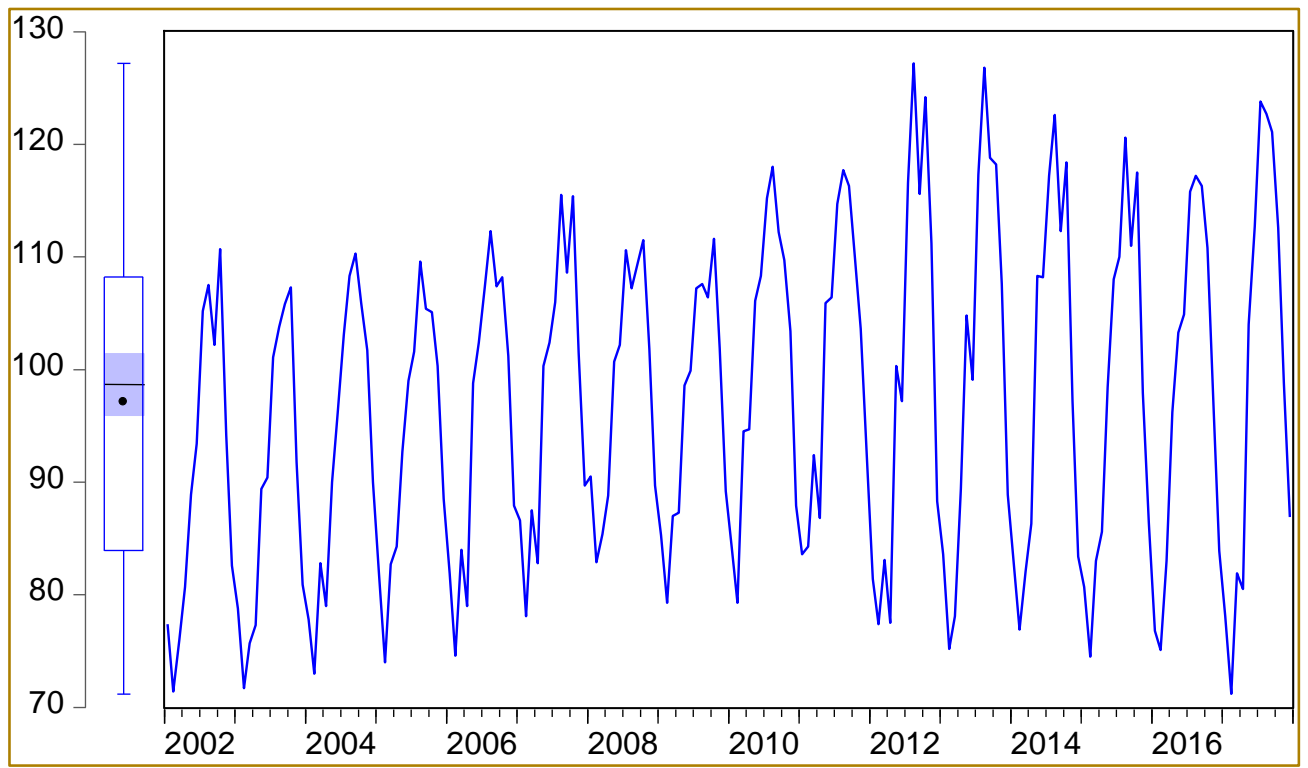

Fonte: Elaborado pelos autores

Para investigar o comportamento sazonal da variável foi construído o gráfico de médias sazonais, conforme proposto por Hyndman e Athanasopoulos (2018). A partir da Figura 3 percebe-se que existe uma tendência de crescimento da produção iniciando em marco e se prolongando até o mês de agosto, e após esse movimento segue-se um decaimento da produção de setembro a fevereiro, tal característica é comum devido a variação da frequência da demanda pelos alimentos. Essa variação é causada pelas datas comemorativas, alterações climáticas, além de outros fatores, conforme discutido por Queiroz e Cavalheiro (2003). 
Figura 3 - Gráfico sazonal do IPIA (2002 - 2017)

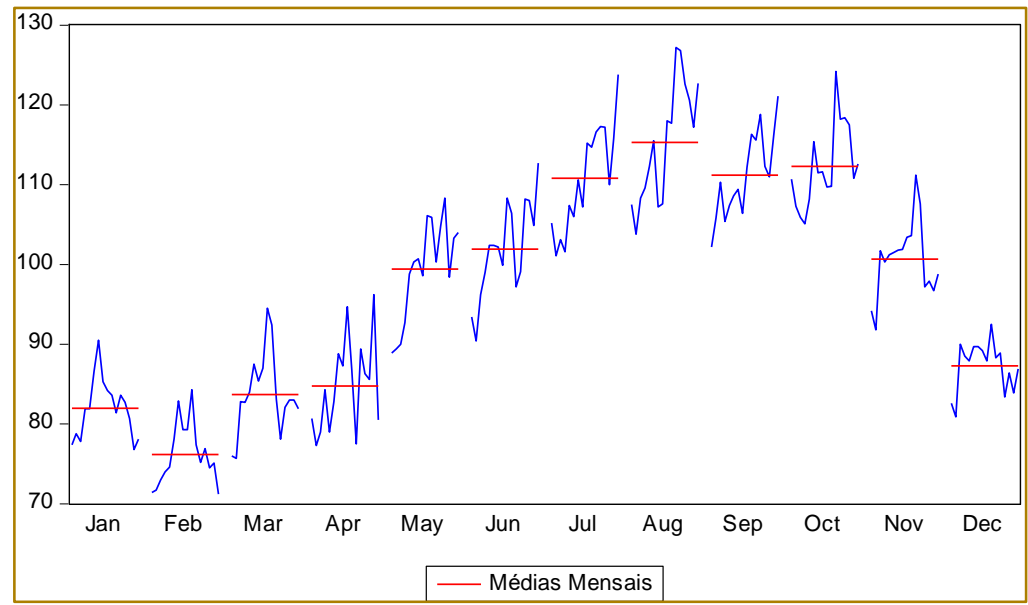

Fonte: Elaborado pelos autores

A verificação da estacionariedade da série foi realizada a partir da aplicação dos testes PP e KPSS, os resultados dos testes são exibidos na Tabela 2. A série foi considerada estacionaria em nível, em que os dois testes convergiram em seus resultados.

Tabela 2 - Resultado dos Testes de Raízes Unitárias

\begin{tabular}{|c|c|c|}
\hline \multicolumn{2}{|c|}{ PPa } & KPSSb \\
\hline Série em nível & $-5,6453(p=0,00) c$ & $0,4506 d$ \\
\hline
\end{tabular}

a H0: a série possui uma raiz unitária; $\alpha=0,05 ; b$ HO: a série é estacionária; $\alpha=0,05$

c Valor crítico para o teste PP: -2,8780; d Valor crítico para o teste KPSS: 0,4630

Fonte: Elaborado pelos autores

Posteriormente foi investigado as funções de autocorrelação (FAC) e autocorrelação parcial (FACP), a Figura 4 exibe o comportamento das funções. É possível observar o comportamento sazonal com autocorrelação significativa até o terceiro período, voltando a crescer a cada ciclo de 12 meses.

Figura 4 - Função de autocorrelação e autocorrelação parcial

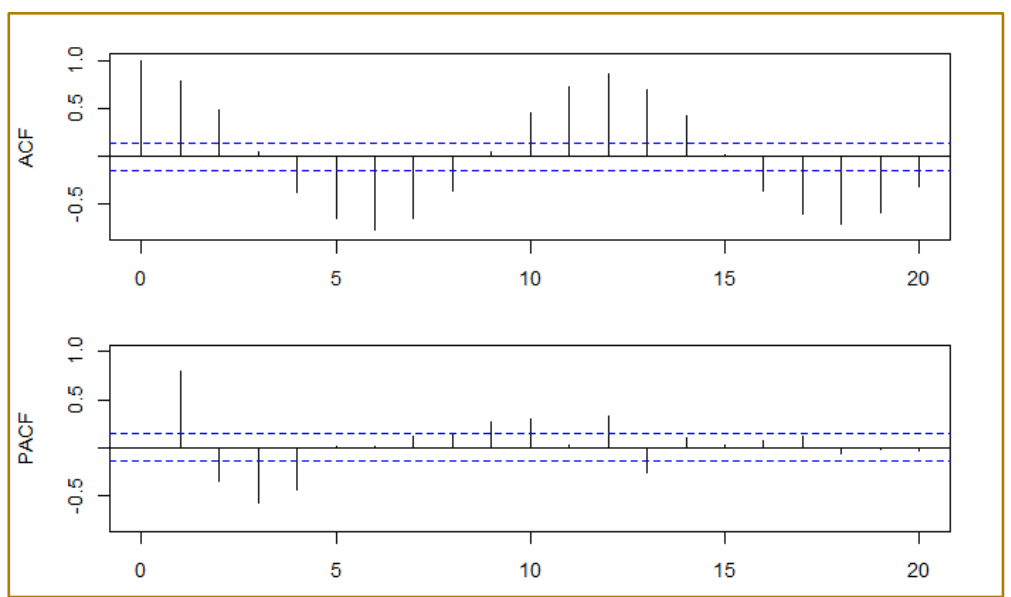

Fonte: Elaborado pelos autores 
Foram estimados os modelos concorrentes ARIMA para representar a série, na Tabela 3 estão descritos os componentes dos modelos ajustados, os parâmetros, o nível de significância e os valores para os critérios de AIC e BIC.

Tabela 3 - Modelos concorrentes ARIMA ajustados

\begin{tabular}{|c|c|c|c|c|c|c|}
\hline Modelo & $\operatorname{AR}(p)$ & p-valor & $\mathrm{MA}(\mathrm{q})$ & p-valor & $\mathrm{AIC}$ & $\mathrm{BIC}$ \\
\hline ARIMA $(3,0,0)$ & $\begin{array}{l}\phi 1=1,131 \\
\phi 2=0,180 \\
\phi 3=-0,320\end{array}$ & $\begin{array}{l}<0,001 \\
0,085 \\
<0,001\end{array}$ & - & - & 7,146 & 7,217 \\
\hline ARIMA $(0,0,3)$ & - & - & $\begin{array}{l}\theta 1=1,594 \\
\theta 2=1,543 \\
\theta 3=0,781\end{array}$ & $\begin{array}{l}<0,001 \\
<0,001 \\
<0,001\end{array}$ & 9,181 & 9,252 \\
\hline ARIMA $(3,0,3)$ & $\begin{aligned} \phi 1 & =2,729 \\
\phi 2 & =-2,728 \\
\phi 3 & =0,998\end{aligned}$ & $\begin{array}{l}<0,001 \\
<0,001 \\
<0,001\end{array}$ & $\begin{array}{l}\theta 1=-2,496 \\
\theta 2=2,295 \\
\theta 3=-0,771\end{array}$ & $\begin{array}{l}<0,001 \\
<0,001 \\
<0,001\end{array}$ & 6,058 & 6,613 \\
\hline $\begin{array}{c}\text { SARIMA } \\
(3,0,0)(1,0,0) 12\end{array}$ & $\begin{aligned} \phi 1 & =0,398 \\
\phi 2 & =0,297 \\
\phi 3 & =0,225 \\
\Phi 12 & =0,953\end{aligned}$ & $\begin{array}{l}<0,001 \\
<0,001 \\
0,002 \\
<0,001\end{array}$ & - & - & 5,979 & 6,068 \\
\hline
\end{tabular}

Fonte: Elaborado pelos autores

O modelos selecionado foi 0 $\operatorname{SARIMA}(3,0,0)(1,0,0) 12$, pois apresentou todos os parâmetros significativos $(p<0,05)$, assim como menores valores de AIC e BIC. O modelo apresentou três parâmetros autorregressivos, confirmando a autocorrelação verificada anteriormente, assim como um parâmetro sazonal autorregressivo, confirmando a forte presença de movimentos sazonais na série.
Posteriormente foi ajustado o modelo de HoltWinters, na Tabela 4 é apresentado os modelos ajustados pelo método multiplicativo e aditivo, assim como os erros cometidos por cada modelo e os valores dos critérios de AIC e BIC. O modelo de Holt-Winters pelo método multiplicativo apresentou menores erros, assim como menores valores para os critérios de seleção.

Tabela 4 - Modelos concorrentes ARIMA ajustados

\begin{tabular}{|l|c|c|c|}
\hline \multicolumn{1}{|c}{ Modelos } & RMSE & AIC & BIC \\
\hline Modelo de Holt-Winters (Método Multiplicativo) & 0,03908 & 1438,59 & 1483,30 \\
\hline Modelo de Holt-Winters (Método Aditivo) & 0,03964 & 1443,82 & 1488,52 \\
\hline
\end{tabular}

Fonte: Elaborado pelos autores

A etapa seguinte consistiu na realização da combinação das previsões pelas três abordagens definidas a partir dos modelos individuais ajustados. A combinação pelos métodos da aritmética simples (MS), Least
Squares Weights (LS), assim como pelo método Inverse Mean Squared (IMS), obtendo cinco previsões diferentes. Os resultados da medida de acurácia RMSE e U-Theil para os modelos são apresentados na Tabela 5. 
Tabela 5 - Medidas de acurácia dos modelos de previsão analisados

\begin{tabular}{|l|c|c|}
\multicolumn{1}{|c|}{ Modelos } & RMSE & U-Theil \\
\hline Holt-Winters (Multiplicativo) & 8.620923 & 0.043909 \\
\hline SARIMA $(3,0,0)(1,0,0) 12$ & 7.902275 & 0.040056 \\
\hline Previsão combinada (média aritmética) & 7.955516 & 0.040428 \\
\hline Previsão combinada (regressão) & 7.902275 & 0.040056 \\
\hline Previsão combinada (IMS) & 7.866196 & 0.039941 \\
\hline
\end{tabular}

Fonte: Elaborado pelos autores

O modelo mais acurado para representar a série foi oriundo da combinação dos modelos SARIMA e Holt-Winters a partir do método IMS. O modelo final ajustado apresentou valores de acurácia de 7.8661 para a medida RMSE, sendo $8.75 \%$ mais preciso que o modelo de Holt-Winter individualmente, assim como $0.46 \%$ mais acurado que o modelo
SARIMA. Para a medida de U-Theil o modelo apresentou o valor aproximado de 0.0399, indicando como um bom previsor em relação a um modelo ingênuo. A Figura 5 ilustra o ajuste do modelo em relação a série original, evidenciando a convergência dos valores estimados em relação aos reais.

Figura 5 - Função de autocorrelação e autocorrelação parcial

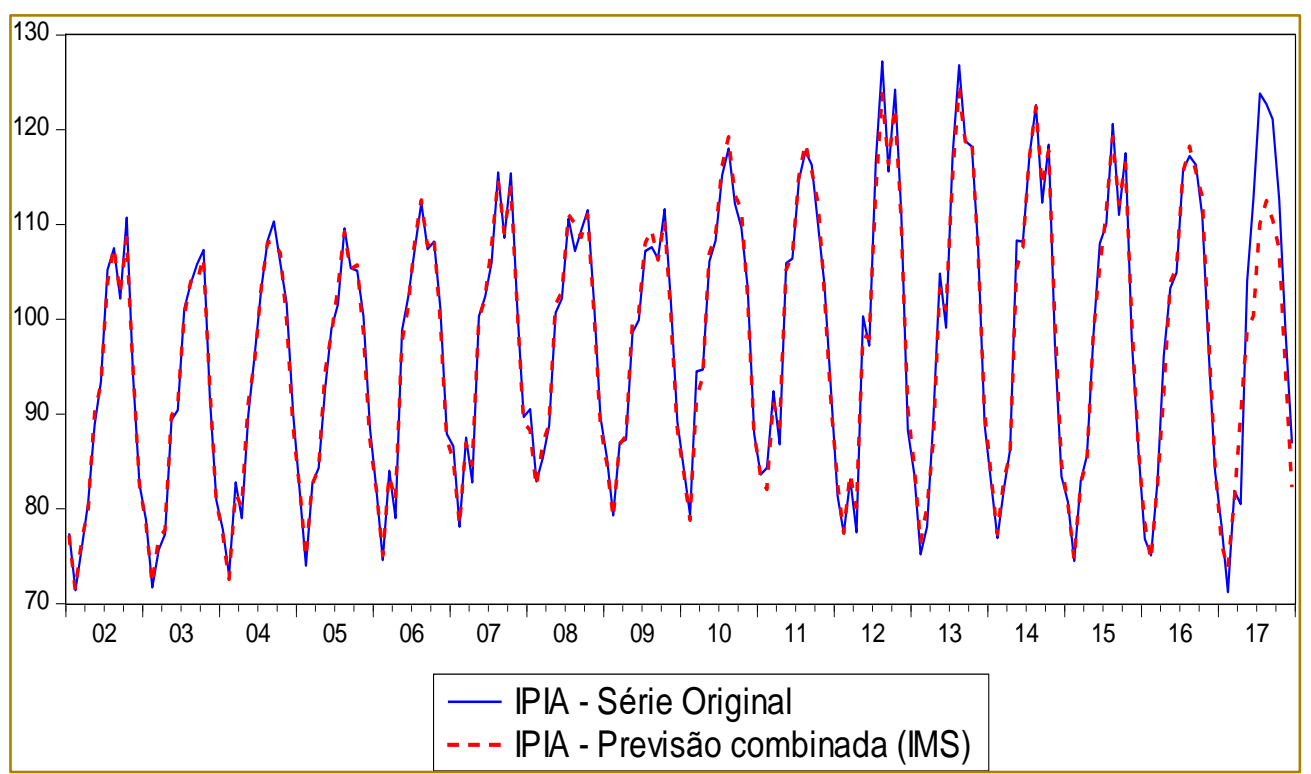

Fonte: Elaborado pelos autores

A validação do modelo se deu pela análise dos resíduos, conforme é possível evidenciar na Figura 6 o modelo produziu resíduos independentes, com características de ruído branco, sendo, portanto, adequado para realização de previsões. 
Figura 6 - Função de autocorrelação e autocorrelação parcial

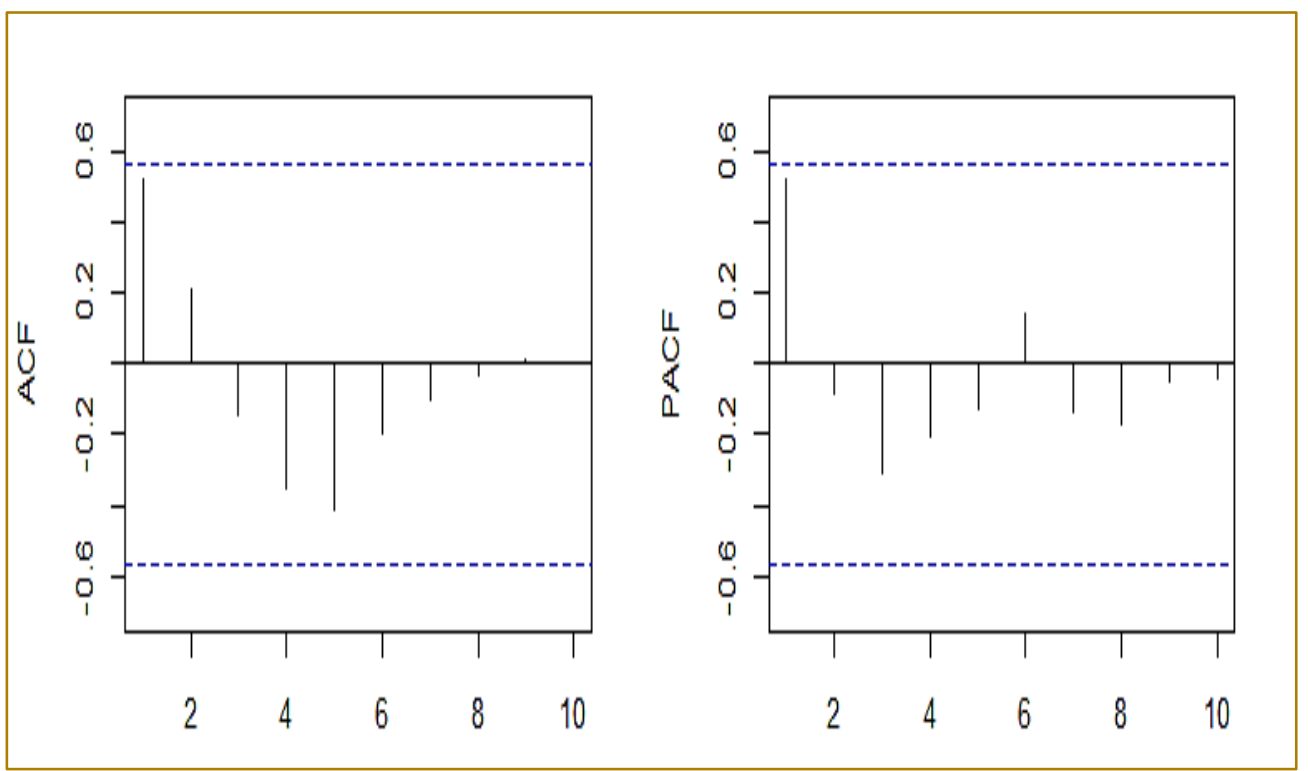

Fonte: Elaborado pelos autores

Tais resultados vão de encontro com a literatura, pois a combinação das previsões possibilitou um aumento da precisão dos resultados, gerando previsões estatisticamente superiores comparadas às previsões individuais, pois comumente no processo de realização de previsões, em que são ajustados 2 ou 3 modelos, utiliza-se alguma medida de acurácia para selecionar o melhor e os demais são descartados, muitas vezes perdendo alguma informação capturada pelos modelos não selecionados.

Dessa forma, foi possível evidenciar que os modelos não selecionados como ótimos no processo de ajustes de modelos correntes podem contribuir positivamente na previsão final quando utilizado algum procedimento de combinação capaz de reduzir a perda de informação dos modelos individuais.

Entre os métodos adotados, o método Inverse Mean Squared utiliza pesos diferentes para cada horizonte de previsão, o que permitiu uma abordagem mais acurada devido a variabilidade da série temporal em estudo, em que os modelo de combinação com pesos fixos utilizados não foram eficazes em reduzir os erros gerados pelos modelos individuais.

\section{CONSIDERAÇÕES FINAIS}

Os métodos de previsões de demanda são importantes pois auxiliam empresas nas tomadas de decisões a médio e longo prazo. Esses métodos também têm sido desenvolvidos a fim de analisar previamente o comportamento das variáveis que podem influir no planejamento estratégico das empresas, garantindo o atendimento eficaz dos clientes e maximização dos lucros.

Neste trabalho foram comparadas previsões individuais por meio dos modelos ARIMA e Holt-Winters, e três métodos de combinações (média aritmética simples, Least Squares Wights, e Inverse Mean Squared), objetivando investigar qual o melhor método para a série estudada. O modelo que se ajustou melhor ao histórico da demanda de produção industrial alimentícia brasileira foi o obtido pela combinação dos modelos a partir da abordagem Inverse Mean Squared.

Sendo assim, os resultados corroboraram com a literatura, podendo o modelo apresentado ser utilizado por empresas do setor alimentício que possuem sazonalidade, com o objetivo de realizar o planejamento de suas futuras produções. 


\section{REFERÊNCIAS}

[1] AKAIKE, $H$. Information theory and an extension of the maximum likelihood principle. 2nd International Symposium on Information Theory, Tsahkadsor, Armenia, USSR, 1973.

[2] ALARCON, S.S, ANCHEZ, M. External and internal R\&D, capital investment and business performance in the Spanish agri-food industry. Journal of Agricultural Economics. v.64, p. 654675,2013

[3] ALMEIDA, A.C.; SUHR, I.R.F. Educação profissional no Brasil: a construção de uma proposta educativa dual. Revista Intersaberes, v.7, n.8, p. 81-110, 2012.

[4] BENTO, D.G.C; TELES, F.L. A sazonalidade da produção agrícola e seus impactos na comercialização de insumos. Rio Verde: Revista Científica do Centro Superior Almeida Rodrigues. v.1, n.1, p. 15-19, 2013.

[5] BOX, G.; JENKINS, G. Time Series Analysis, forecast and control. San Francisco: Holden- Day, 1970.

[6] BUENO, R. L. S. Econometria de séries temporais. São Paulo: Cengage Learning, 2008.

[7] DAVCIK, N. An empirical investigation of brand equity: drivers and their consequences. British Food Journal v.115. n.9, p. 1342-1360, 2013.

[8] DRIVAS, K. GIANNAKAS, K. The effect of cooperatives on quality-enhancing innovation. Journal of Agricultural Economics. v.61, p. 295317,2010

[9] FIRMINO, P. R. A.; MATTOS NETO, P. S. G.; FERREIRA, T. A. E. Correcting and combining time series forecasters. Neural Networks, v. 50, p. 1-11, 2014.

[10] GIL, A. C. Como elaborar projetos de pesquisa. São Paulo: Atlas, v. 5, 2010.

[11] GRANGER, C. W. J.; RAMANATHAN, R. Improved Methods of Combining Forecasts. Journal of Forecasting, v. 3, p. 197-204, 1984.

[12] GUJARATI, D. N.; PORTER, D. C. Econometria Básica. 5. ed. Porto Alegre: AMGH, 2011.

[13] HANDFORD, $M$. et al. Implications of nanotechnology for the agri-food industry: Opportunities, benefits and risks. Trends in Food Science \& Technology. v.40, n.2, p. 226-241, 2014.

[14] HOLT, C. C. Forecasting seasonals and trends by exponentially weighted moving averages. ONR Memorandum, 1957.

[15] HYNDMAN, R.; ATHANASOPOULOS, G. Forecasting: principles and practice. OTexts, 2018.

[16] ISMAI. Z.; ABU. N.; SUFAHANI. S. New product forecasting with limited or no data. AIP Conference Proceedings, 2016.
[17] KARANTININIS, K.; SAUER, J.: FURTAN, W.H. Innovation and integration in the agri-food industry. Food Policy. v.35, p. 112-120, 2010.

[18] KWIATKOWSKI, D. et al. Testing the null hypothesis of stationarity against the alternative of a unit root. Journal of Econometrics, v. 54, 159-178. North-Holland, 1992.

[19] MAKRIDAKIS, S.; WHEELWRIGHT, S.; HYNDMAN, R. Forecasting Methods and Applications. 3. ed. New York: John Wiley \& Sons, 1998.

[20] MARTIN, A. C. et al. Análise de séries temporais para previsão da evolução do número de automóveis no Município de Joinville. Revista Espacios, v. 37, n. 06, 2016.

[21] MARTINS, V. L. M.; WERNER, L. Comparação de previsões individuais e suas combinações: um estudo com séries industriais. Production, v. v. 24, n. 3, p. 618-627, 2014.

[22] MONTGOMERY, D. C.; JENNINGS, C. L.; $\mathrm{KULAHCl}, \mathrm{M}$. Introduction to Time Series Analysis and Forecasting. New Jersey: John Wiley \& Sons, 2007

[23] MORETTIN, P.A. Econometria Financeira: Um curso em séries temporais financeiras. São Paulo: Blucher, 2008

[24] PETERS. R.J. et al. Nanomaterials for products and application in agriculture, feed and food. Trends in Food Science \& Technology, v. 54, p. 155-164, 2016.

[25] PHILLIPS, P.; PERRON, P. Testing for a unit root in time series regression. Biometrika, v. 75, n. 2, p. 335-346, 1988.

[26] PRODANOV, C. C.; FREITAS, E. C. Metodologia do trabalho científico: métodos e técnicas da pesquisa e do trabalho acadêmico. 2 . ed. Novo Hamburgo: Universidade Feevale, 2013.

[27] QUEIROZ, A.; CAVALHEIRO, D. Método de previsão de demanda e detecção de sazonalidade para o planejamento da produção de indústrias de alimentos. Anais do Encontro Nacional de Engenharia de Produção, v. 23, 2003.

[28] SCHWARZ, G. E. Estimating the dimension of a model. Annals of Statistics, v. 6, p. 461-464, 1978.

[29] SEKHON. B.S. Nanotechnology in agrifood production: An overview. Nanotechnology, Science and Applications, v.7, p. 31-53, 2014.

[30] SOUZA, A. M. et al. Eletrical energy supply for Rio Grande do Sul, Brazil, using forecast combination of weighted eigenvalues. GEPROS: Gestão da Produção, Operações e Sistemas, v. 6, p. 23, 2011. 
[31] SOUZA, F. M. Modelos de Previsão: aplicações à energia elétrica - ARIMA - ARCH - AI e ACP. Curitiba: Appris, 2016.

[32] STOCK, J. W.; WATSON, M. W. Combination Forecasts of Output Growth in a Seven-Country Data Set. Journal of Forecasting, v. 23, p. 405-430, 2004.

[33] SUZIGAN, W. Indústria Brasileira: origens e desenvolvimento. São Paulo: Hucitec, 2000.
[34] TUBINO, D. F. Planejamento e controle da produção: teoria e prática. 2. ed. São Paulo: Atlas, 2009.

[35] WERNER, L.; RIBEIRO, J. L. D. Previsão de demanda: uma aplicação dos modelos BoxJenkins na área de assistência técnica de computadores pessoais. Gestão \& Produção, v. 10, p. 47-67, 2003.

[36] WINTERS, P. R. Forecasting Sales by Exponentially Weighted Moving Averages. Management Science, p. 324-342, 1960. 


\section{Gapítulo 18}

\section{APLICACÃO DA PROGRAMACÃO LINEAR INTEIRA NO PLANEJAMENTO DOS PEDIDOS DE FRALDAS DESCARTÁVEIS DO MUNICÍPIO DE OURO PRETO - MG}

\section{Luis Guilherme Esteves Leocadio}

Resumo: O presente artigo tratou do planejamento de pedidos de fraldas descartáveis do município de Ouro Preto-MG, realizado por sua Secretaria Municipal de Saúde. Para tanto, o problema clássico de programação linear de dimensionamento de lotes (monoestágio) foi adaptado com o objetivo de determinar as quantidades ótimas de fraldas descartáveis por tamanho (XG, G, M e P) a serem pedidas em um horizonte de planejamento de 12 meses, minimizando o custo total dos pedidos e de estocagem. Foram consideradas as seguintes restrições: conservação do estoque, capacidade do caminhão do fornecedor e quantidades totais de fraldas da "Ata de Registro de Preços". Os resultados obtidos após resolução do modelo permitiram concluir que seria necessário uma política de entregas diferente da atual para garantir a minimização do custo total dos pedidos e da estocagem de fraldas descartáveis.

Palavras chave: Planejamento, Programação Linear, Fraldas Descartáveis. 


\section{INTRODUÇÃO}

Em 2009, o então Ministério do Planejamento lançou um conjunto de iniciativas para melhorar a gestão pública nas esferas federal, estadual e municipal. Entre essas iniciativas, destacou-se o a elaboração do "Guia referencial para a medição do desempenho da gestão e controle para o gerenciamento dos indicadores de eficiência, eficácia e de resultados do programa nacional de gestão pública e desburocratização". O Guia abrange seis dimensões da gestão pública: efetividade, eficácia, eficiência, excelência, execução e economicidade. Essa última, por exemplo, possui indicadores de gastos do governo, entre outros aspectos (BRASIL, 2009).

Nos últimos 40 anos, o fator custo (economicidade) tem ganhado relevância na gestão pública, ou seja, o conceito da eficiência (alcançar certo objetivo com o menor custo) vem ser tornando cada vez mais importante. Isso é corroborado pelo Princípio Constitucional da Eficiência (PCE), instituído pela Emenda Constitucional de 1998, que impôs a adoção do PCE nas práticas de planejamento, execução e fiscalização orçamentário-financeira da despesa públicas realizadas pelos Agentes Administrativos (SILVA, 2008).

As licitações públicas buscam a seleção da proposta mais vantajosa, isto é, a mais econômica. A partir dessa ideia, é necessário determinar quantos e quando serão realizados os pedidos parciais diante dos quantitativos totais estabelecidos na proposta mais vantajosa, que possui um prazo de validade.

O objetivo do presente artigo foi determinar quais seriam as quantidades parciais solicitadas de fraldas descartáveis pela Secretária Municipal de Saúde (SMS) da Prefeitura Municipal de Ouro Preto (PMOP) ao fornecedor vencedor da proposta mais vantajosa. Para tanto, foi desenvolvido um modelo de planejamento do pedido de fraldas descartáveis baseado no problema de dimensionamento de lotes (monoestágio), que poderá ser empregado pelas organizações que necessitam adquirir fraldas descartáveis.

O presente trabalho é composto de cinco seções, além da introdução e das referências, sendo que as duas próximas seções referencial teórico e metodologia - tratam da abordagem teórica e metodológica do problema descrito na seção 3. Na seção 4, apresentou-se os resultados obtidos a partir da resolução do modelo adaptado. Encontram-se, na seção 5, as considerações finais sobre o trabalho, destacando-se a comparação da política de entrega atual com a proposta elaborada após a resolução do modelo adaptado.

\section{REFERENCIAL TEÓRICO}

\subsection{LEGISLAÇÃO DAS FRALDAS DESCARTÁVEIS}

A Lei no 10.741/03 dispõe sobre o Estatuto do Idosos, cujo objetivo principal é regulamentar e assegurar os direitos das pessoas com idade igual ou superior a 60 anos. O artigo 15 dessa lei institui a obrigatoriedade do Poder Público de fornecer aos idosos, gratuitamente, medicamentos, especialmente os de uso continuado, assim como próteses, órteses e outros recursos relativos ao tratamento de doenças, habilitação ou reabilitação (BRASIL, 2003)

Do mesmo modo, o artigo 18 da Lei $n^{\circ}$ 13.146/15 (Lei Brasileira de Inclusão da Pessoa com Deficiência - Estatuto da Pessoa com Deficiência) assegura aos deficientes os mesmos recursos do artigo 15 da lei citada, além de meios auxiliares para locomoção, insumos e fórmulas nutricionais. Em dezembro de 2017, a Comissão de Defesa dos Direitos da Pessoa Idosa propôs uma alteração na Lei no 328/11, substituindo-se o trecho "pessoas com necessidades especiais" por "pessoas com deficiência". Além disso, foi instituída a obrigatoriedade do fornecimento de fraldas na seção relativa ao direito à saúde dessa Lei. Atualmente, a proposta está em tramitação na Câmara dos Deputados (HAJE, 2017).

Com o objetivo de adequar-se a legislação vigente sobre uma eventual obrigatoriedade do poder público em fornecer fraldas descartáveis, a PMOP, por meio da SMS, realiza licitação para a aquisição de fraldas descartáveis.

\subsection{LICITAÇÕES}

A licitação é o procedimento por meio do qual a administração pública adquire bens e serviços de forma mais vantajosa a partir do estabelecimento de critérios objetivos atendidos pelos fornecedores interessados (FILHO, 2008). 
O artigo 22 da Lei no 8.666/93 define as seguintes modalidades de licitações: concorrência, tomada de preços, convite, concurso e leilão. Além dessas, há ainda o pregão, regido pela Lei nำ10.520/02.

Segundo Motta (2008), os pregões podem ocorrer de duas formas: presencial - a vivavoz - ou por meio eletrônico - pregão eletrônico. O pregão eletrônico constitui "um instrumento de comparação e seleção de propostas de fornecedores de bens e serviços para o setor público, em que as ofertas são apregoadas em uma reunião com a presença de todos" (MOTTA, 2008, p. 787).

Os custos de transporte compõem uma parcela dos custos do fornecedor e podem impactar os preços do processo licitatório, sobretudo na situação em estudo, na qual os preços unitários das fraldas descartáveis são baixos mas, em contrapartida, as quantidades de fraldas a serem transportadas são elevadas.

\subsection{CUSTO DE TRANSPORTE}

Os custos de transporte são classificados em variáveis (mão de obra, combustível, manutenção, entre outros), fixos (veículos e infraestrutura de apoio), associados (custo do retorno) e comuns (despesas de terminal) (BOWERSOX, 2014).

A utilização máxima da capacidade de caminhões leva à redução dos custos unitários de transporte. Em contrapartida, a redução dos custos de transporte pode reduzir as frequências de entrega, o que ocasiona uma elevação no nível do estoque e, consequentemente, um aumento do custo total do estoque.

\subsection{CUSTO DE ESTOQUE}

Os custos de manutenção de estoque decorrem da manutenção do armazenamento de itens físicos, sendo compostos pelos seguintes custos: espaço para armazenagem (aluguel, mão de obra, energia e outros), capital (custo do dinheiro empatado), serviço (seguro), risco (obsolescência do material), falta de estoque (perdas de produção, por exemplo) (BERTAGLIA, 2016).

O somatório dos custos citados compreende o custo total de estoque, que pode ser representado como um percentual do item estocado, cujos valores são os coeficientes de uma parcela da função objetivo apresentada na próxima seção.

\subsection{PROGRAMAÇÃO LINEAR INTEIRA (PLI)}

De acordo com Hillier e Lieberman (2013, p. 442), "o modelo matemático para a programação inteira é o modelo de programação linear com uma restrição adicional de que as variáveis devem ser valores inteiros".

Goldbarg, Goldbarg e Luna (2016, p. 18), apresentam a formulação geral de um PLI como:

$$
\text { Otimizar (Min ou Max) } f\left(x_{1}, \ldots, x_{n}\right)
$$

Sujeito a:

$$
\begin{aligned}
& g_{j}\left(x_{1}, \ldots x_{n}\right)\left\{\begin{array}{l}
\leq \\
= \\
\geq
\end{array}\right\} b_{j} \\
& x_{i} \in Z \text { para todo } i
\end{aligned}
$$

em (1) e (2), $f \varepsilon g_{j}, j=1, \ldots, m$ são funções lineares em $x$ e $b$ é o vetor de termos independentes do modelo.

O problema de dimensionamento de lotes (monoestágio) pertence à classe dos problemas de planejamento da produção, que por sua vez, podem ser modelados como uma PLI, cuja simbologia e modelo completo foram apresentados por Arenales et al. (2011, p. 29) na Tabela 1. 
Tabela 1 - Itens, parâmetros e variáveis do problema de dimensionamento de lotes

\begin{tabular}{|c|c|c|}
\hline & Simbologia & Descrição \\
\hline \multirow{2}{*}{ Índices } & $i=1, \ldots, n$ & Item \\
\hline & $\mathrm{t}=1, \ldots, \mathrm{T}$ & Período \\
\hline \multirow{5}{*}{ Parâmetros } & $d_{i t}$ & Demanda do item i no período $t$ \\
\hline & $R_{t}$ & Disponibilidade de recursos (renováveis) no período $t$ \\
\hline & $r_{i}$ & $\begin{array}{l}\text { Quantidade de recursos necessários para a produção de } \\
\qquad \text { uma unidade do item } i\end{array}$ \\
\hline & $c_{i t}$ & Custo de produzir uma unidade do item $i$ no período $t$ \\
\hline & $h_{i t}$ & Custo de estocar uma unidade do item $i$ no período $t$ \\
\hline \multirow{2}{*}{ Variáveis } & $x_{i t}$ & O número de itens do tipo $i$ produzidos no período $t$ \\
\hline & $I_{i t}$ & O número de itens do tipo $i$ em estoque no final do período $t$ \\
\hline
\end{tabular}

Fonte: Adaptado de Arenales et al. (2011)

$$
\begin{aligned}
& \text { Minimizar } f\left(x_{11}, l_{11}, x_{12}, l_{12}, \ldots\right)=\sum_{i=1}^{n} \sum_{t=1}^{T} c_{i t} x_{i t}+\sum_{i=1}^{n} \sum_{t=1}^{T} h_{i t} l_{i t} \\
& x_{i t}+l_{i, t-1}-l_{i t}=d_{i t} \\
& r_{1} x_{1 t}+r_{2} x_{2 t}+\cdots+r_{n} x_{n t} \leq R_{t} \\
& x_{i t}, l_{i t} \geq 0
\end{aligned}
$$

A função objetivo em (4) busca a minimização dos custos totais de produção e de estoque dos produtos. A restrição (5) garante a conservação do estoque, enquanto a (6) delimita a quantidade produzida em função da capacidade de produção da fábrica. A restrição (7) é a garantia de atendimento às demandas.

\section{METODOLOGIA}

O presente trabalho é um estudo de caso, modalidade de estudo definida por Yin (2010) como uma investigação empírica que investiga um fenômeno contemporâneo, usando-se do planejamento, coleta e análise dos dados.

Como o objetivo desse trabalho foi buscar uma solução para um modelo matemático, cujos parâmetros são subsidiados por dados, empregou-se uma metodologia quantitativa, que fornece uma descrição numérica dos acontecimentos a fim de se quantificar suas possíveis relações ou, simplesmente, de se narrar objetivamente os fatos (CRESWELL, 2007).

O modelo para o planejamento de pedidos de fraldas descartáveis foi implementado e resolvido com o uso da ferramenta Solver do software Excel, versão 2013.

\section{DESCRIÇÃO DO PROBLEMA}

A PMOP, por meio de sua Secretaria de Saúde, realiza a aquisição de fraldas descartáveis com o objetivo de atender aos pacientes que usam fraldas dos seguintes tamanhos: extra grande $(X G)$, grande $(G)$, média $(M)$ e pequena $(P)$. Para tanto, uma dotação orçamentaria é realizada para um horizonte de 12 meses, que constitui o fundo a ser usado para efetuar a compra.

A partir do pregão eletrônico de preços ocorrido no mês de maio de 2018, foi gerada uma "Ata de Registro de Preços", cujos quantitativos e valores unitários para aquisição das fraldas descartáveis devem vigorar pelo período um ano (Tabela 2). 
Tabela 2 - Quantitativos e custos das fraldas descartáveis da Ata de Registro de Preços (Pregão Eletrônico de maio/2018)

\begin{tabular}{|c|c|c|c|} 
Tamanho & \multicolumn{1}{c}{$\begin{array}{c}\text { Preço } \\
(\mathrm{R} \$)\end{array}$} & $\begin{array}{c}\text { Quantidade } \\
\text { (un.) }\end{array}$ & Custo total (R\$) \\
\hline XG & 1,07 & 100.000 & $107.000,00$ \\
\hline G & 1,04 & 225.000 & $234.000,00$ \\
\hline M & 1,05 & 150.000 & $157.000,00$ \\
\hline P & 1,05 & 35.000 & $36.750,00$ \\
\hline
\end{tabular}

Fonte: PMOP (2018)

Pedidos parciais são emitidos mensalmente para atender à demanda por fralda dos pacientes, cujos valores estimados encontram-se na Tabela 3. Conforme pode ser observado nessa tabela, considerou-se uma demanda constante para um período de um ano, pois o histórico de consumo começou a ser registrado em maio de 2018.

Tabela 3 - Demandas de fraldas por tipo estimadas entre os meses de julho/18 à junho19

\begin{tabular}{|c|c|c|c|c|}
\hline \multirow{2}{*}{ Mês } & \multicolumn{4}{|c|}{ Tamanho } \\
\hline & XG (un.) & G (un.) & M (un.) & $\mathrm{P}$ (un.) \\
\hline Jul./18 & 7.007 & 16.288 & 7.168 & 1.056 \\
\hline Ago./18 & 7.007 & 16.288 & 7.168 & 1.056 \\
\hline Mai./19 & 7.007 & 16.288 & 7.168 & 1.056 \\
\hline Jun./19 & 7.007 & 16.288 & 7.168 & 1.056 \\
\hline
\end{tabular}

Fonte: PMOP (2018)

O fornecedor atual de fraldas descartáveis está instalado em Cajamar-SP, e possui um veículo com capacidade para transportar um total de 26.000 unidades das fraldas dos 4 tipos, tendo disponibilidade para realizar mais de uma viagem por mês.

Mensalmente, incorre-se no problema de determinar o quantitativo de fraldas por tipo que maximize a utilização da capacidade do caminhão do fornecedor, objetivando-se reduzir o seu custo unitário de transporte. Por outro lado, existe a necessidade de se solicitar quantidades que garantam $\mathrm{o}$ atendimento da demanda sem gerar quantidades excessivas de fraldas descartáveis no estoque, pois o custo de estocagem eleva-se com o aumento de itens estocados. Adotou-se, assim, um custo unitário de estoque correspondente a $20 \%$ dos preços das fraldas, como está apresentado na Tabela 4.

Tabela 4 - Custo de estocagem de fraldas descartáveis por tipo

\begin{tabular}{|c|c|}
\hline Tamanho & $\begin{array}{c}\text { Custo unitário de } \\
\text { estocagem }(R \$)\end{array}$ \\
\hline XG & 0,214 \\
\hline G & 0,208 \\
\hline M & 0,210 \\
\hline P & 0,210 \\
\hline
\end{tabular}

Fonte: PMOP (2018) 
As quantidades de itens em estoque no mês de julho de 2018 constam na Tabela 5. Esses valores são usados na restrição de conservação de estoque do modelo adaptado a seguir.

Tabela 5 - Quantidades de fraldas descartáveis no mês de julho/2018

\begin{tabular}{|c|c|}
\hline Tamanho & Quantidade \\
\hline XG & 5.933 \\
\hline $\mathrm{G}$ & 8.652 \\
\hline $\mathrm{M}$ & 5.092 \\
\hline $\mathrm{P}$ & 1.766 \\
\hline \multicolumn{2}{|c|}{ Fonte: PMOP (2018) } \\
\hline
\end{tabular}

\subsection{MODELO ADAPTADO}

O modelo adaptado para a obtenção do menor custo do planejamento de pedidos de fraldas descartáveis baseou-se no problema de dimensionamento de lotes (monoestágio) com as seguintes adequações:

a) Exclusão da restrição de capacidade da fábrica; b) Inclusão de restrição da capacidade do caminhão;

c) Inclusão de restrição dos quantitativos totais na "Ata de Registro de Preços".

Os itens, parâmetros e variáveis do modelo adaptado encontram-se na Tabela 6. Em seguida, há a formulação matemática do modelo.

Tabela 6 - Itens, parâmetros e variáveis do problema de planejamento de pedidos de fraldas descartáveis

\begin{tabular}{|c|c|c|}
\hline & Simbologia & Descrição \\
\hline \multirow{2}{*}{ Índices } & $\mathrm{i}=1, \ldots, 4$ & Item \\
\hline & $\mathrm{t}=1, \ldots, 12$ & Período \\
\hline \multirow{4}{*}{ Parâmetros } & $p_{i}$ & Preço da fralda do tipo i \\
\hline & $h_{i t}$ & Custo de estocar uma unidade da fralda do tipo $i$ no período $t$ \\
\hline & $d_{i t}$ & Demanda das fraldas do tipo $i$ no período $t$ \\
\hline & $V_{i}$ & $\begin{array}{l}\text { Quantidades totais a serem pedidas de fraldas do tipo } i \text { em um } \\
\text { ano }\end{array}$ \\
\hline \multirow{2}{*}{ Variáveis } & $x_{i t}$ & O número de fraldas do tipo $i$ pedidos no período $t$ \\
\hline & $I_{i t}$ & O número de fraldas do tipo $i$ em estoque no final do período $t$ \\
\hline
\end{tabular}

Fonte: O autor (2018)

$$
\begin{aligned}
& \text { Minimizar } f\left(x_{11}, l_{11}, x_{12}, l_{12}, \ldots\right)=\sum_{i=1}^{4} \sum_{t=1}^{12} c_{i t} x_{i t}+\sum_{i=1}^{4} \sum_{t=1}^{12} h_{i t} l_{i t} \\
& x_{i t}+l_{i, t-1}-l_{i t}=d_{i t} \\
& \sum_{i=1}^{4} x_{i t} \leq 52.000 \\
& \sum_{i=1}^{4} x_{i t} \geq 41.600 \\
& \sum_{t=1}^{12} x_{i t}=V_{i} \\
& x_{i t}, l_{i t} \geq 0 \\
& x_{i t}, I_{i t} \in Z
\end{aligned}
$$


A função objetivo em (8) busca a minimização dos custos totais incorridos nos pedidos e estocagem de fraldas descartáveis. A restrição (9) garante a conservação do estoque. A restrição (10) impõe a condição de que seja realizada no máximo 2 entregas de fraldas pelo fornecedor em um mesmo mês, enquanto a restrição (11) determina que pelo menos $80 \%$ da capacidade do caminhão seja utilizada, em média, em cada uma das 2 viagens. A restrição (12) determina que seja usado todo o valor reservado para a aquisição presente na "Ata de Registro de Preços". Por último, há as restrições (13) e (14), que correspondem a garantia de atendimento às demandas e a restrição que caracteriza uma PLI.

\section{ANÁLISES E RESULTADOS}

Após a análise dos dados sobre as quantidades de fraldas descartáveis por tipo necessárias para o atendimento da demanda em um período de 12 meses, obteve-se um custo total de pedidos e estocagem de $\mathrm{R} \$ 755.284,01$.

Na Tabela 7 encontram-se as quantidades de fraldas por tipo que precisariam ser pedidas e estocadas em um horizonte de 12 meses.

Tabela 7 - Quantidades de fraldas pedidas em um período de planejamento de 12 meses

\begin{tabular}{|c|c|c|c|c|c|c|c|c|}
\multirow{2}{*}{ Mês } & \multicolumn{7}{c}{ Quantidade Pedida (un.) } \\
\cline { 2 - 10 } & XG & G & \multicolumn{7}{c|}{ M } & P & XG & G & M & P \\
\hline Jul./18 & 1.074 & 38.450 & 2.076 & 0 & 0 & 30.814 & 0 & 710 \\
\hline Ago./18 & 7.007 & 27.079 & 7.168 & 346 & 0 & 41.605 & 0 & 0 \\
\hline Set./18 & 7.007 & 26.639 & 7.168 & 1.056 & 0 & 51.686 & 0 & 0 \\
\hline Out./18 & 7.007 & 26.639 & 7.168 & 1.056 & 0 & 61.767 & 0 & 0 \\
\hline Nov./18 & 7.007 & 26.639 & 7.168 & 1.056 & 0 & 71.848 & 0 & 0 \\
\hline Dez./18 & 7.007 & 26.639 & 7.168 & 1.056 & 0 & 81.929 & 0 & 0 \\
\hline Jan./19 & 7.007 & 26.639 & 7.168 & 1.056 & 0 & 92.010 & 0 & 0 \\
\hline Fev./19 & 7.007 & 26.639 & 7.168 & 1.056 & 0 & 102.091 & 0 & 0 \\
\hline Mar./19 & 7.007 & 1.257 & 7.168 & 26.168 & 0 & 87.060 & 0 & 25.112 \\
\hline Abr./19 & 7.007 & 0 & 32.433 & 2.150 & 0 & 70.722 & 25.275 & 26.206 \\
\hline Mai./19 & 7.007 & 0 & 34.933 & 0 & 0 & 54.484 & 53.100 & 25.150 \\
\hline Jun./19 & 28.856 & 0 & 23.144 & 0 & 21.849 & 38.196 & 69.076 & 24.094 \\
\hline & & & Fonte: 0 autor (2018) & & & \\
\hline
\end{tabular}

Na Figura 1 constam os valores da "Margem de Atraso" do "Relatório de Respostas" obtido após a resolução do modelo matemático. A partir dessa figura foi possível observar a necessidade do fornecimento mensal de 41.600 unidades (52.000 un. - 10.400 un.) de fraldas entre os meses de jul./18 à abr./18, 42.000 unidades (52.000 un. - 10.000 un.) em mai./19 e 52.000 unidades (52.000 un. - 0) em jun./19. Os valores da "Margem de Atraso" para as restrições (11) do modelo adaptado apresentaram valores iguais a 400 e 10.400 nos meses de mai./19 e jun./19, o que indica, respectivamente, uma ociosidade do veículo nesses meses de 19\% e uma ociosidade nula. Para as demais restrições, os valores da "Margem de Atraso" foram nulos, o que demonstram um ajuste adequado do modelo aos dados considerados.

O uso dos resultados obtidos com o modelo levarão a uma capacidade ociosa do veículo na maior parte das viagens ao mesmo tempo que o custo de estocagem da PMOP será minimizado. Isso é um trade-off logístico clássico: a redução do custo de estoque implica na elevação do custo de transporte (representado neste trabalho em termos da ociosidade do veículo, dada a dificuldade de se obter os custos de transporte do fornecedor). O modelo adaptado busca a redução dessas duas parcelas do custo total, mesmo que de forma indireta para o custo de transporte. 


\section{CONCLUSÃO}

O presente artigo tratou do planejamento de pedidos de fraldas descartáveis da Secretaria de Saúde do município de Ouro Preto-MG. Para tanto, foi proposto um modelo matemático adaptado de PLI para determinar as quantidades de fraldas por tipos a serem adquiridas, considerando-se os preços dessas fraldas, o seus custos de estocagem, a capacidade do caminhão do fornecedor e as quantidades totais que devem ser pedidas em um horizonte de planejamento de 12 meses (valores presentes na "Ata de Registro de Preços"). Esse modelo baseou-se no modelo de dimensionamento de lotes (monoestágio).

A partir da resolução do modelo matemático por meio do uso da ferramenta Solver do software Excel, obteve-se resultados que mostram a necessidade da realização de 2 viagens pelo caminhão entre os meses de jul./18 a abr./19 com uma utilização de $80 \%$ da sua capacidade, isto é, há uma capacidade ociosa do veículo em cada viagem de 5.200 unidades (10.400 nas duas viagens). Dessa forma, seriam necessárias 2 viagens do caminhão nos meses de mai./18 e jun./19 com utilização, respectivamente, de $81 \%$ e $100 \%$ do caminhão.

A fim de se obter a utilização máxima da capacidade dos caminhão do fornecedor, propõe-se o uso de um caminhão com capacidade aproximada de 42.000 unidades para a realização das entregas nos 11 primeiros meses do horizonte de planejamento, mantendo-se o caminhão com capacidade de 26.000 unidades, que faria 2 viagens no $12^{\circ}$ mês.

Sendo assim, seria necessário uma política de entregas diferente da atual para se garantir a minimização dos custos envolvidos no pedido e estocagem das fraldas descartáveis em um horizonte de planejamento de 12 meses.

Figura 1 - Relatório de resposta do modelo adaptado

Restrições

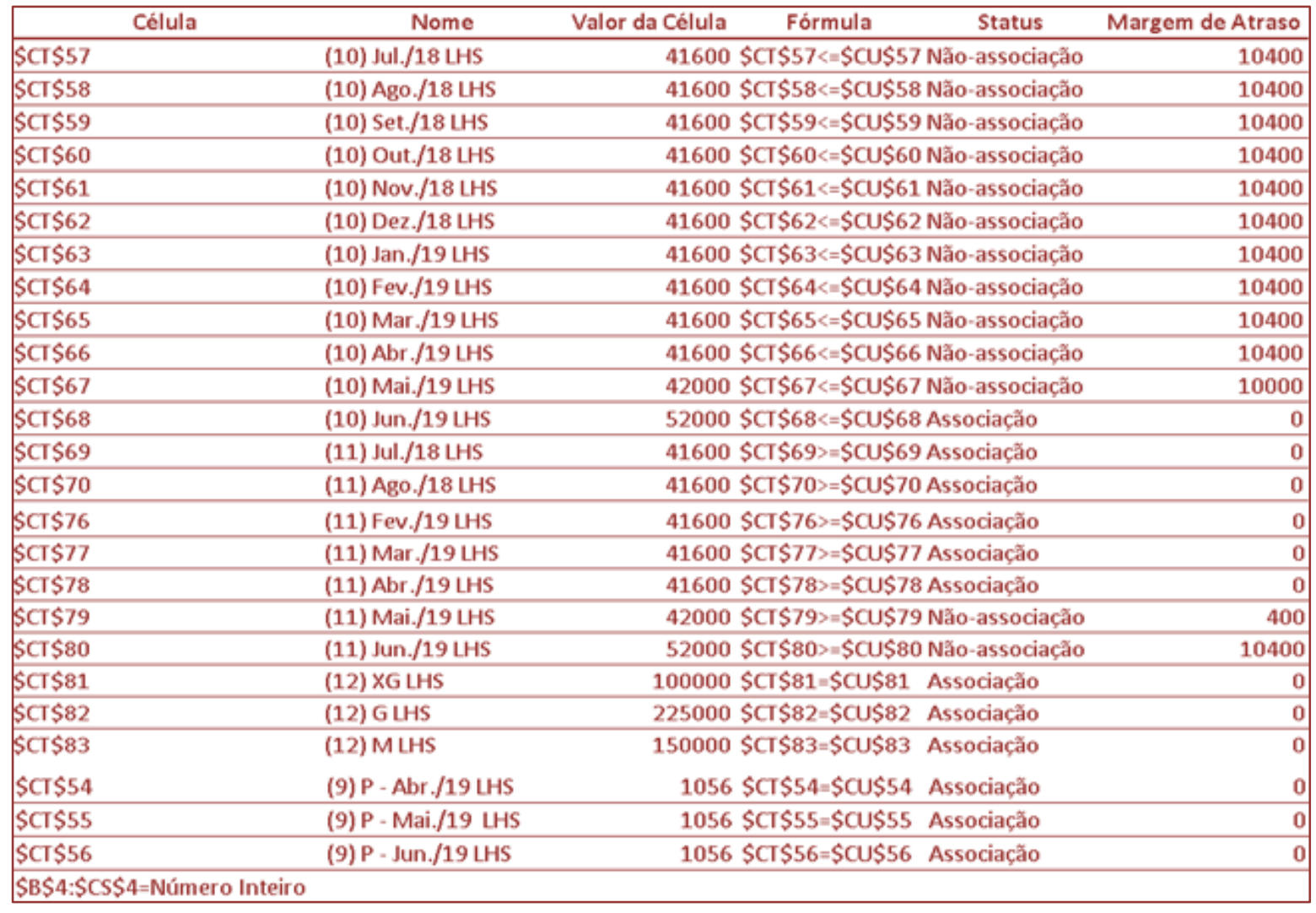




\section{REFERÊNCIAS}

[1] ARENALES, M. et. al. Pesquisa operacional. Rio de Janeiro: Elsevier, 2011.

[2] BERTAGLIA, P. R. Logística e gerenciamento da cadeia de abastecimento. São Paulo: Saraiva, 2016.

[3] BOWERSOX, J. C. et. al. Gestão logística da cadeia de suprimentos. Porto Alegre: AMGH, 2014.

[4] BRASIL. Lei $n$ ํ 13.146, de 06 de julho de 2015. Institui a Lei Brasileira de Inclusão da Pessoa com Deficiência. Diário Oficial da União, Brasília, 07 jul. 2015. Disponível em: <http://www2.camara.leg.br/>. Acesso em: 20 ago. 2018.

[5] BRASIL. Lei no 10.741 , de $1^{\circ}$ de outubro de 2003. Dispõe sobre o Estatuto do Idosos e dá outras providências. Diário Oficial da União, Brasília, 03 out. 2003. Disponível em: < http://www.planalto.gov.br/>. Acesso em: 20 ago. 2018.

[6] BRASIL. Lei no 10.520, de 17 de julho de 2002. Institui modalidade de licitação denominada pregão, para aquisição de bens e serviços comuns, e dá outras providencias. Diário Oficial da União, Brasília, 18 jul. 2002. Disponível em: < http://www.planalto.gov.br/>. Acesso em: 31 ago. 2018

[7] BRASIL. Lei no 8.666, de 21 de junho de 1993. Institui normas para licitações e contratos da Administração Pública e dá outras providencias. Diário Oficial da União, Brasília, 22 jun. 1993. Disponível em: < http://www.planalto.gov.br/>. Acesso em: 31 ago. 2018.

[8] BRASIL. Ministério do Planejamento. Melhoria da gestão pública por meio da definição de um guia referencial para a medição do desempenho da gestão e controle para o gerenciamento dos indicadores de eficiência, eficácia e de resultados do programa nacional de gestão pública e desburocratização. Produtos 1 e 4. Brasília: Ministério do Planejamento. 2009. Disponível em: < http://www.planalto.gov.br/>. Acesso em: 17 jul. 2018

[9] BRASIL. Portaria de consolidação $\mathrm{n}^{\circ}$ 2, de 28 de setembro de 2017. Consolidação das normas sobre as políticas nacionais de saúde do Sistema Único de Saúde. Ministério da Saúde, Brasília, 03 out. 2017. Disponível em: <http://bvsms.saude.gov.br/ >. Acesso em: 21 ago. 2018.

[10] CRESWELL, J. W. Projeto de pesquisa: métodos qualitativo, quantitativo e misto. 2 ed. Porto Alegre: Artmed, 2007

[11] FILHO, M. J. Comentários à lei de licitações e contratos administrativos. São Paulo: Dialética, 2008

[12] GOlDBARG, M. C.; GOLDBARG, M. C.; LUNA, H. P. L. Otimização combinatória e metaheurísticas: algoritmos e aplicações. Rio de Janeiro: Elsevier, 2016.

[13] HILLIER, F. S.; LIEBERMAN, G. J. Introdução à pesquisa operacional. 9. ed. Porto Alegre: AMGH, 2013.

[14] MOTTA, C. P. C. Eficácia nas licitações e contratos. Belo Horizonte: Del Rey, 2008.

[15] SILVA, M. A. O conceito de eficiência aplicado as licitações públicas: uma análise teórica à luz da economicidade. Revista do TCU, n. 113, set./dez. , 2008. Disponível em: < revista.tcu.gov.br> Acesso em: 03 ago. 2018.

[16] YIN, R. K. Estudo de caso: planejamento e métodos. 4. ed. Porto Alegre: Bookman, 2010. 


\section{Gapítulo 19}

\section{MODELO DE PROGAMAÇÃO INTEIRA PARA PROBLEMA DE MIX DE PRODUÇÃO NO BENEFIAMENTO DO GRANITO COM MATRIZES DE PRODUÇÃO}

\section{Marcos Wagner Jesus Servare Junior}

Resumo: Um mix de produção é uma importante informação na gestão da produção, devido a questões relativas a atendimento da demanda, disponibilidade de recursos, capacidades e outros fatores. O seu objetivo primordial é realizar o planejamento de produção de acordo com a sua capacidade, quantidade vendida e especificação do produto e, ainda, da maneira mais rápida possível. Para empresas que utilizam padrões de produção, ou matrizes de produção, para recorte de seus produtos, esta combinação se torna ainda mais complexa, uma vez que o corte de uma matriz determina diferente produtos. Na otimização deste sistema como este é observado diversos possíveis objetivos desse problema como, por exemplo, maximizar a receita da programação, o atendimento da demanda, aproveitamento da capacidade da planta, por exemplo. Esses fatores apontam uma variedade de abordagens sobre o problema e este artigo tem como objetivo apresentar um modelo matemático utilizado para planejar a produção considerando a demanda de cada produto. O resultado obtido foi satisfatório e aponta o ganho otimizado possível com a utilização das informações disponíveis com um modelo de programação inteira.

Palavras chave: Problema de Mix de Produção, Programação Inteira, Matrizes de Produção. 


\section{INTRODUÇÃO}

Um dos grandes desafios para as empresas são as tomadas de decisões estratégicas relacionadas ao sistema de produção, entre elas está a definição do mix de produção e tamanho do lote de cada item e, entre outras, (RODADO et al., 2017) e estas decisões são relevantes tanto para a eficiência da empresa relacionada aos custos envolvidos na produção, bem como o atendimento da demanda dos clientes.

A organização de uma empresa no ponto de vista estratégico deve se comunicar entre os diversos setores das empresas, para que a venda possa indicar a quantidade demandada pelo mercado que o setor produtivo seja capaz de produzir e os diversos setores da empresa possam alimentá-los quanto a abastecimento de matérias-primas, informações e outras características que sejam indispensáveis para o planejamento empresarial.

Dentre as características desejáveis, uma organização deverá ser capaz de oferecer aos seus gestores informações relacionadas ao custo de produção e o portfólio de produtos para que sejam adotados métodos e ferramentas de gestão eficientes para a realidade e visão da empresa (DAL MAGRO et al., 2015). Para tanto, os gestores deverão ser capazes de determinar em suas escolhas estratégicas a combinação de produtos capazes de otimizar os resultados organizacionais, com intuito de aproveitar a capacidade instalada, os recursos disponíveis e maximizar as receitas da organização (CASSEL et al., 2006).

Um problema de mix de produção consiste na determinação da quantidade que cada um dos produtos escolhidos deverá ser fabricado com a maximização do ganho total, levando em consideração alguns fatores (SOBREIRO; NEGANO, 2013). Essa combinação de produtos deverá estar sujeita a alguns fatores limitantes, tais como matéria-prima, recursos compartilhados e demanda do produto, entre outros.

Linhares (2009) caracteriza o problema de definir o mix de produtos como um problema do tipo NP-Completo (do inglês, NP-Hard), no qual o aumento do número de produtos leva a um crescimento exponencial no número de soluções possíveis. Na literatura podem ser encontradas diversas abordagens para 0 problema.
E ainda, de acordo com Badri et al. (2014) muitos pesquisadores propuseram métodos heurísticos para resolver este tipo de problema e, dentre elas, uma abordagem relacionada a Teoria das Restrições (do inglês, Theory of Constraints - TOC) é uma das abordagens mais eficazes.

Uma abordagem de otimização do problema de mix de produtos foi utilizada por Aparicio et al (2017) utilizando a analise envoltória de dados (do inglês, Data Envelopment Analysis - DEA) para otimizar a eficiência de produção do portfólio. Por sua vez, Hadidi e Moawad (2017) utilizaram a programação linear para em um estudo de caso na indústria do aço para o problema de mix de produtos para um estudo com múltiplas linhas de produção com estágios em sequência.

Outro aspecto citado na literatura e amplamente estudado é a modelagem do mix de produção considerando aspectos ambientais, na literatura essa ramificação é conhecida como Green Product Mix Solution, conforme descrito por Wellington et al. (2014) que indica que o modelo em suas restrições devará ser capaz de limitar, dentre outros aspectos, a emissão dos gases poluentes.

Além das referências já citadas e suas ramificações, o problema se torna cada vez mais complexo a medida que o portfólio de produtos passa a ser variado e a matériaprima passa a ser compartilhada, como na industria de benefiação de chapas de granito, onde de uma mesma chapa poderá ser extraído diversos produtos diferentes, tais como, pisos, tampos, soleiras, pias, lavabos, entre outros. A combinação entre eles e o maior aproveitamento das chapas vai indicar quanto a sua venda irá contribuir para formação do lucro da empresa.

A programação linear inteira (PLI) é a técnica frequentemente usada para otimizar o mix de produtos, e requer um alto nível de expertise para formulação e, também, para resolvê-lo (TANHAEI; NAVAHANDI, 2013). Embora haja esse requisito quanto a expertise, um modelo matemático quando resolvido aponta a solução ótima para o problema, ou seja, se o modelo for capaz de ser resolvido, sua solução será a melhor combinação de produtos possível no universo de soluções.

Assim, o presente artigo tem como objetivo propor e implementar um modelo matemático de programação linear inteira capaz de solucionar o problema de mix de produção 
nessa situação especifica relacionada ao melhor aproveitamento da chapa, através da determinação da quantidade de cada matriz de produção que será utilizada para atendimento da demanda. Este trabalho foi publicado nos anais do Congresso Brasileiro de Engenharia de Produção (CONBREPRO) de 2018.

Na Seção 2 será apresentado o contexto em que o modelo será implementado, bem como a descrição das matrizes de produção propostas. Por sua vez, na Seção 3 o modelo matemático será apresentado. Na Seção 4 os resultados computacionais do modelo matemático de otimização proposto serão apresentados a partir da utilização do software de otimização LINDO para sua resolução e, por fim, na Seção 5 serão realizadas as considerações finais e sugestões de trabalhos futuros.

\section{REVISÃO DE LITERATURA}

A empresa objeto de estudos está localizada na cidade de Nova Venécia, no norte do Espírito Santo, e produz pias beneficiadas a partir de chapas de granitos. A empresa comercializa pias nos tamanhos $1,20 \mathrm{~m}$, $1,40 \mathrm{~m}, 1,50 \mathrm{~m}, 1,60 \mathrm{~m}, 1,80 \mathrm{~m}$ e 2,00m, todas essas com $0,55 \mathrm{~m}$ de largura. Para as pias de $1,80 \mathrm{~m}$ e 2,00m ainda existe uma opção de pia que tenha dois bojos.

A organização, na tentativa de aproveitar ao máximo a chapa, corta em formato de pisos, de dimensões $29,5 \mathrm{~cm} \times 29,5 \mathrm{~cm}$, a parte retirada para o encaixe dos bojos. A tabela 1 mostra a demanda mensal e o preço de venda do piso e de cada tipo de pia produzido pela empresa.

Tabela 1 - Preço e demanda dos produtos

\begin{tabular}{|c|c|c|c|c|c|c|c|c|c|c|}
\hline Produto & $\begin{array}{c}\text { Piso } \\
\left(\mathrm{m}^{2}\right)\end{array}$ & $\begin{array}{c}\text { Pia } \\
1,20 \mathrm{~m}\end{array}$ & $\begin{array}{c}\text { Pia } \\
1,40 \mathrm{~m}\end{array}$ & $\begin{array}{c}\text { Pia } \\
1,50 \mathrm{~m}\end{array}$ & $\begin{array}{c}\text { Pia } \\
1,60 \mathrm{~m}\end{array}$ & $\begin{array}{c}\text { Pia } \\
1,80 \mathrm{~m}\end{array}$ & $\begin{array}{c}\text { Pia } \\
2,00 \mathrm{~m}\end{array}$ & $\begin{array}{c}\text { Pia 1,80m } \\
\text { (Dois } \\
\text { bojos) }\end{array}$ & $\begin{array}{c}\text { Pia 2,00m } \\
\text { (Dois } \\
\text { bojos) }\end{array}$ \\
\hline Preço (R\$) & 35 & 140 & 150 & 160 & 180 & 200 & 230 & 250 & 280 \\
\hline Demanda & 230 & 700 & 575 & 350 & 275 & 300 & 250 & 25 & 25 \\
\hline Produto & $\begin{array}{c}\text { Piso } \\
\left(\mathrm{m}^{2}\right)\end{array}$ & $\begin{array}{c}\text { Pia } \\
1,20 \mathrm{~m}\end{array}$ & $\begin{array}{c}\text { Pia } \\
1,40 \mathrm{~m}\end{array}$ & $\begin{array}{c}\text { Pia } \\
1,50 \mathrm{~m}\end{array}$ & $\begin{array}{c}\text { Pia } \\
1,60 \mathrm{~m}\end{array}$ & $\begin{array}{c}\text { Pia } \\
1,80 \mathrm{~m}\end{array}$ & $\begin{array}{c}\text { Pia } \\
2,00 \mathrm{~m}\end{array}$ & $\begin{array}{c}\text { Pia 1,80m } \\
\text { (Dois } \\
\text { bojos) }\end{array}$ & $\begin{array}{c}\text { Pia 2,00m } \\
\text { (Dois } \\
\text { bojos) }\end{array}$ \\
\hline Preço (R\$) & 35 & 140 & 150 & 160 & 180 & 200 & 230 & 250 & 280 \\
\hline Demanda & 230 & 700 & 575 & 350 & 275 & 300 & 250 & 25 & 25 \\
\hline
\end{tabular}

Para que a empresa possa produzir pia de diversos tamanhos em um mesmo lote a chapa possui algumas alternativas para 0 recorte. Para a criação das matrizes de corte foi utilizado critérios que atendam aos limites gerados pelas dimensões da chapa tomada como padrão. As chapas de tamanho padrão possuem 2 metros de altura por 3 metros de largura, dessa região é aproveitado 1,90m na vertical e $2,90 \mathrm{~m}$ na horizontal, essa retirada de parte da chapa é necessário devido as chapas não possuírem bordas com formas regulares, o que impossibilita a utilização destas partes da chapa.

A partir das exigências foram propostos 8 modelos de matrizes para o corte da chapa em pias, em que neles existem diversas combinações de encaixe de formato de pias na chapa. Na figura 1 é apresentado os modelos e as pias cortadas a partir deles. 
Figura 1 - Matrizes de Produção

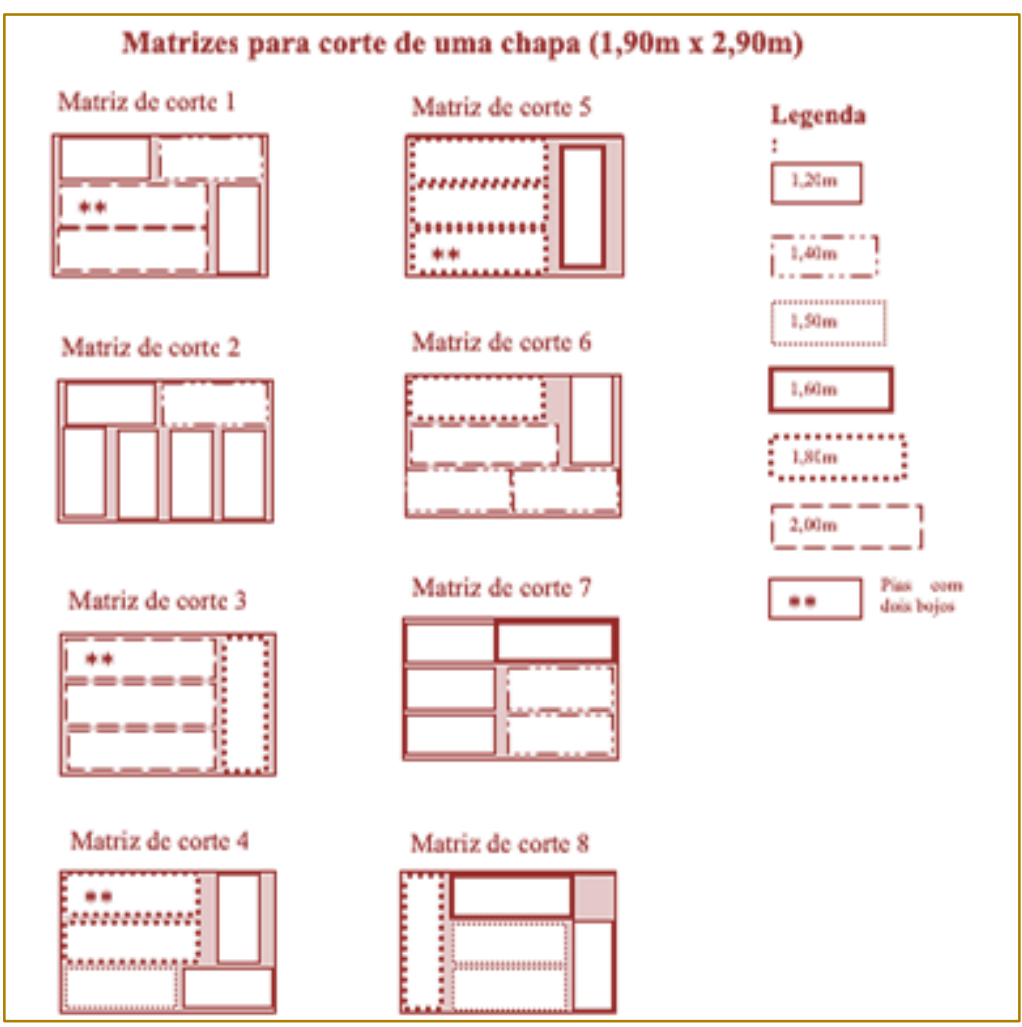

É desejado encontrar o melhor mix de utilização das matrizes de forma que seja máxima a receita com a venda dos produtos. $\mathrm{Na}$ tabela 2 vê-se a quantidade de cada produto por matriz e a receita obtida com a venda total dos produtos oriundos de chapas feitas por cada molde proposto.

Tabela 2 - Quantidade de produto e receita por matriz de produção

\begin{tabular}{|c|c|c|c|c|c|c|c|c|c|c|}
\hline Produto & $\begin{array}{l}\text { Piso } \\
\left(m^{2}\right)\end{array}$ & $\begin{array}{c}\text { Pia } \\
1,20 \\
m\end{array}$ & $\begin{array}{c}\mathrm{Pia} \\
1,40 \\
\mathrm{~m}\end{array}$ & $\begin{array}{l}\text { Pia } \\
1,50 \\
m\end{array}$ & $\begin{array}{c}\text { Pia } \\
1,60 \\
m\end{array}$ & $\begin{array}{c}\text { Pia } \\
1,80 \\
m\end{array}$ & $\begin{array}{l}\text { Pia } \\
2,00 \\
m\end{array}$ & $\begin{array}{c}\text { Pia 1,80m } \\
\text { (Dois } \\
\text { bojos) }\end{array}$ & $\begin{array}{c}\text { Pia } \\
2,00 \mathrm{~m} \\
\text { (Dois } \\
\text { bojos) }\end{array}$ & $\begin{array}{c}\text { Receita } \\
(\mathrm{R} \$)\end{array}$ \\
\hline Matriz 1 & 0,5222 & 2 & 1 & 0 & 0 & 0 & 1 & 0 & 1 & 958,28 \\
\hline Matriz 2 & 0,5222 & 5 & 1 & 0 & 0 & 0 & 0 & 0 & 0 & 868,28 \\
\hline Matriz 3 & 0,4351 & 0 & 0 & 0 & 0 & 1 & 2 & 0 & 1 & 955,23 \\
\hline Matriz 4 & 0,5222 & 2 & 0 & 1 & 0 & 1 & 0 & 1 & 0 & 908,28 \\
\hline Matriz 5 & 0,4351 & 0 & 0 & 0 & 1 & 2 & 0 & 1 & 0 & 845,23 \\
\hline Matriz 6 & 0,4351 & 1 & 2 & 0 & 0 & 1 & 1 & 0 & 0 & 885,23 \\
\hline Matriz 7 & 0,5222 & 3 & 2 & 1 & 0 & 0 & 0 & 0 & 0 & 898,28 \\
\hline Matriz 8 & 0,5222 & 1 & 0 & 2 & 1 & 0 & 0 & 1 & 0 & 908,28 \\
\hline
\end{tabular}

\section{MODELO MATEMÁTICO}

A seguir será detalhado o modelo matemático para a resolução do problema em questão. Este modelo será usado no software de otimização LINDO, que retornará a melhor combinação de matrizes.
1) Seja xi a quantidade de vezes que a matriz i será utilizada para o corte das chapas, onde $i \in\{1,2,3, \ldots, 7,8\}$. 
2) Função objetivo:

\section{Maximizar}

$Z=958,28^{*} \times 1+868,28^{*} \times 2+955,23^{*} \times 3+$ $908,28^{*} \times 4+845,23^{*} \times 5+885,23^{*} \times 6+$ $898,28^{*} \times 7+908,28^{*} \times 8$

3) Restrições:

$2^{*} x 1+5^{*} x 2+2^{*} x 4+1^{*} x 6+3^{*} x 7+1^{*} x 8 \leq$ 700 (Pias de 1,20m) - (2)

$1^{*} x 1+1^{*} x 2+2^{*} x 6+2^{*} x 7 \leq 575$ (Pias de $1,40 \mathrm{~m})-(3)$

$1^{\star} x 4+1^{\star} x 7+2^{*} x 8 \leq 350$ (Pias de 1,50m) (4)

$1^{*} \times 5+1^{*} x 8 \leq 275$ (Pias de $\left.1,60 \mathrm{~m}\right)-(5)$

$1^{*} x 3+1^{*} x 4+2^{*} x 5+1^{*} x 6 \leq 300$ (Pias de $1,80 \mathrm{~m})-(6)$

$1^{*} x 1+2^{*} x 3+1^{*} x 6 \leq 250$ (Pias de 2,00m) (7)

$1^{*} x 4+1^{*} x 5+1^{*} x 8 \leq 25$ (Pias de $1,80 \mathrm{~m}$ e dois bojos) $-(8)$

$1^{*} \times 1+1^{*} \times 3 \leq 25$ (Pias de $2,00 m$ e dois bojos) $-(9)$

$0,52^{*} \times 1+0,52^{*} \times 2+0,44^{*} \times 3+0,52^{*} \times 4+$ $0,44^{\star} x 5+0,44^{\star} x 6+0,52^{*} x 7+0,52^{*} x 8 \leq 230$ (Pisos) - (10) $x i \geq 0 \forall i \in\{1,2,3, \ldots, 7,8\}(11)$

$x i \in$ inteiros $\forall i \in\{1,2,3, \ldots, 7,8\} \quad(12)$

função objetivo (1) determina a quantidade de receita obtida com a produção e venda dos itens de cada matriz de produção, as restrições de (2) - (9) limitam a quantidade produzida a demanda de cada produto, para Pias de 1,20m, Pias de 1,40m, Pias de 1,50m, Pias de 1,60m, Pias de 1,80m, Pias de 2,00m, Pias de $1,80 \mathrm{~m}$ e dois bojos, Pias de 2,00m e dois bojos e Pisos, respectivamente.

Por fim, o conjunto de restrições representado em (11) indicam que os valores deverão ser iguais ou superiores a zero e as restrições (12) são restrições referentes a natureza das variáveis de decisão.

\section{EXPERIMENTOS COMPUTACIONAIS E DISCUSSÃO}

O modelo matemático proposto na seção anterior foi aplicado no software de otimização LINDO, como é apresentado na figura 2.

Figura 2 - Modelo aplicado no LINDO

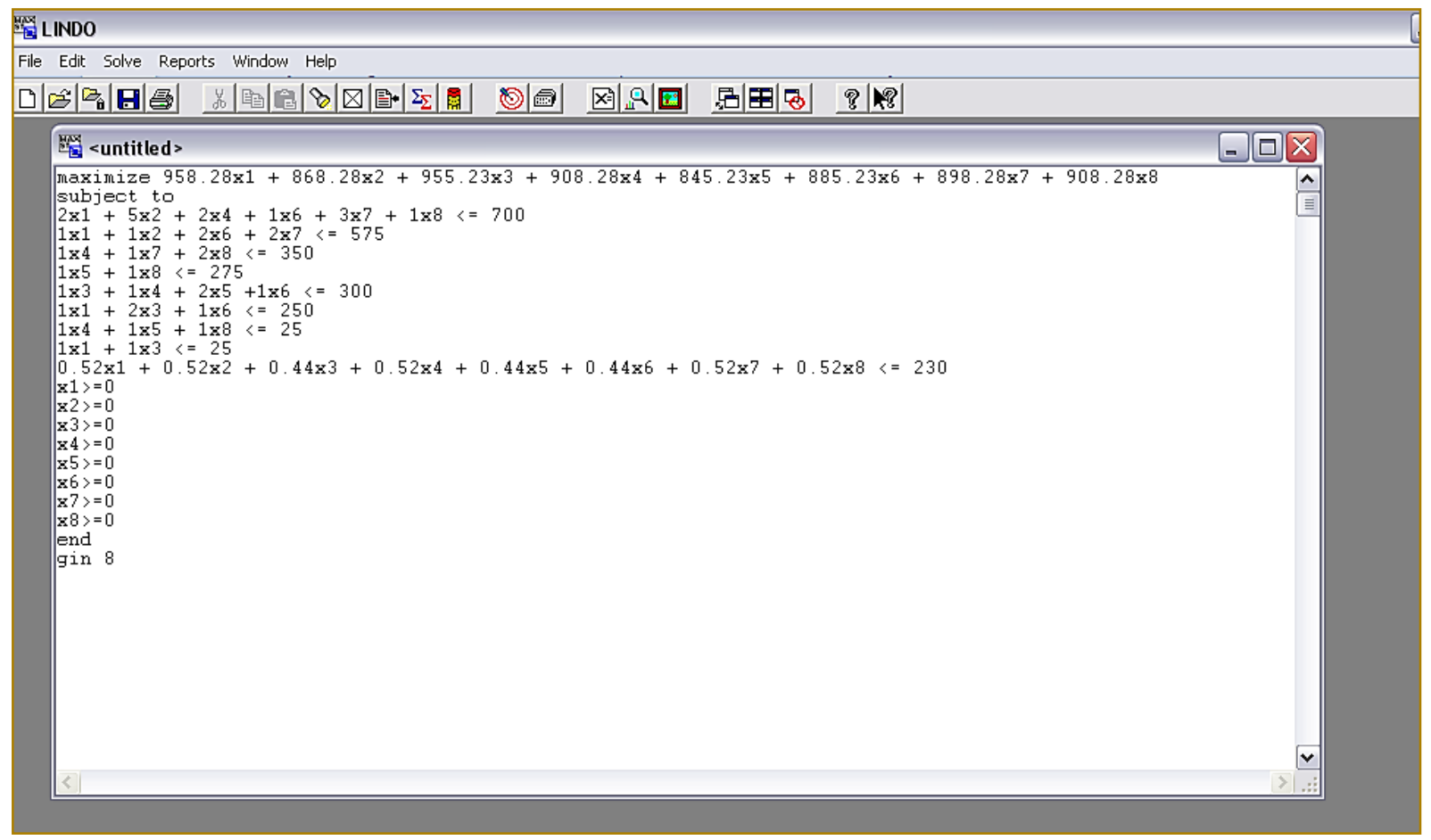


Após a resolução do modelo matemático proposto é obtido os valores de $\times 1=0, \times 2=$ $67, x 3=25, x 4=0, x 5=22, x 6=200, x 7=54 \mathrm{e}$ $x 8=3$, visto na coluna "VALUE", mostrada na figura 3 .

Figura 3 - Solução

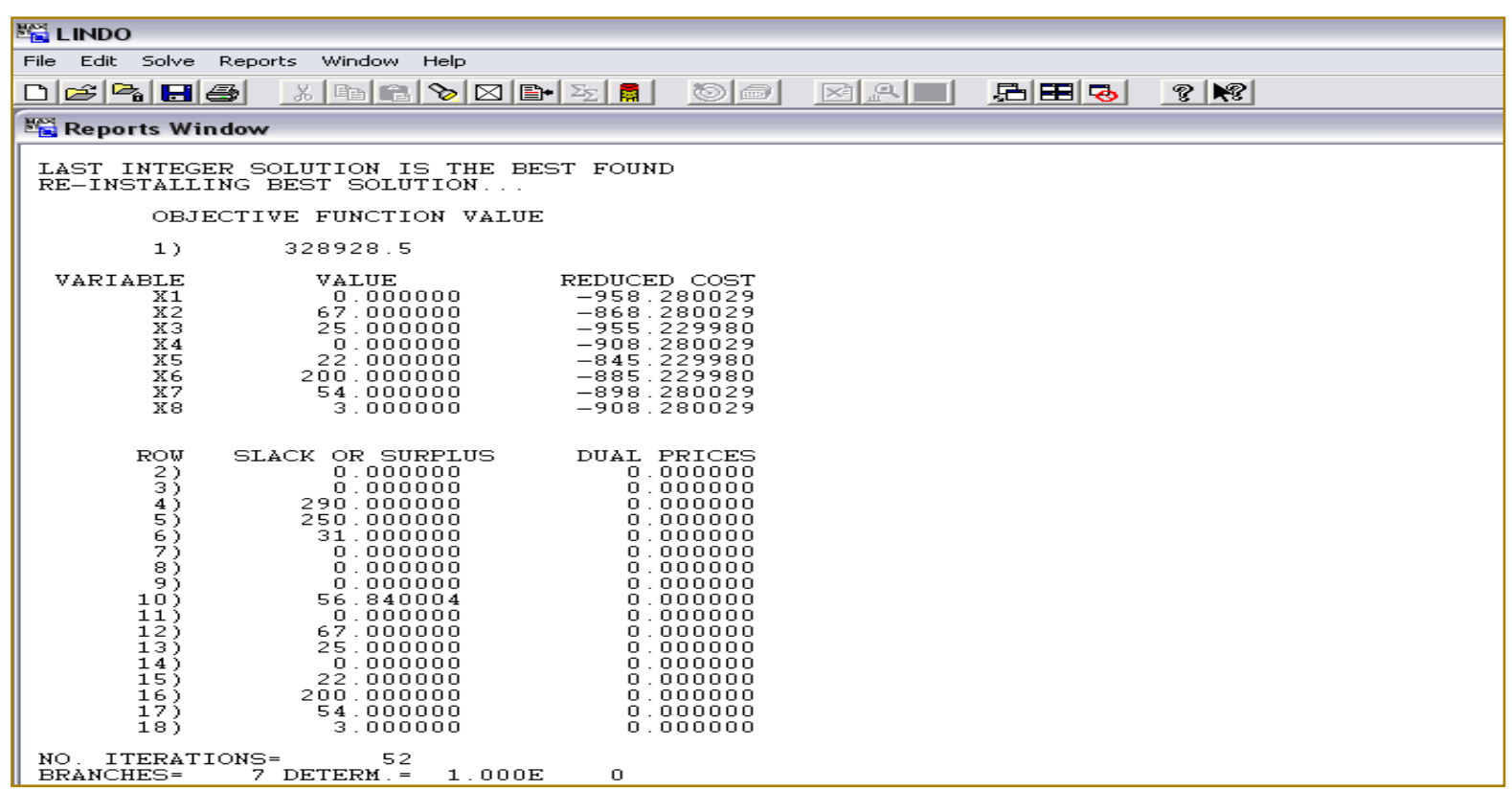

$\mathrm{Na}$ coluna "SLACK OR SURPLUS" é apresentado os valores das variáveis de folga, ou seja, a produção da demanda máxima de alguns tamanhos de pias não precisa ser cumprida para que se tenha a maior receita, dada a combinação das matrizes de produção.

Na figura 3 também se pode observar o valor ótimo da função objetivo em "OBJECTIVE FUNCTION VALUE", que será a receita de $\mathrm{R} \$ 328928,50$.

Para a análise de sensibilidade será solucionado novos modelos matemáticos, em que será adicionada em cada restrição uma unidade, para que se descubra uma nova combinação com um novo valor de receita máxima. A diferença entre a receita encontrada nessa alteração no modelo e a receita ótima original será o preço dual para aquela restrição.

No caso da pia de $1,20 \mathrm{~m}$ que possui demanda de 700 pias, o aumento para 701 acarretará numa nova receita ótima de $\mathrm{R} \$ 328991,60$. Com diferença de $\mathrm{R} \$ 63,10$, sendo este o preço dual para as pias de $1,20 \mathrm{~m}$. A figura 4 mostra os novos valores de solução do novo modelo, além do novo valor ótimo da função objetivo. 
Figura 4 - Solução do novo modelo para demanda de 701 pias de 1,20m

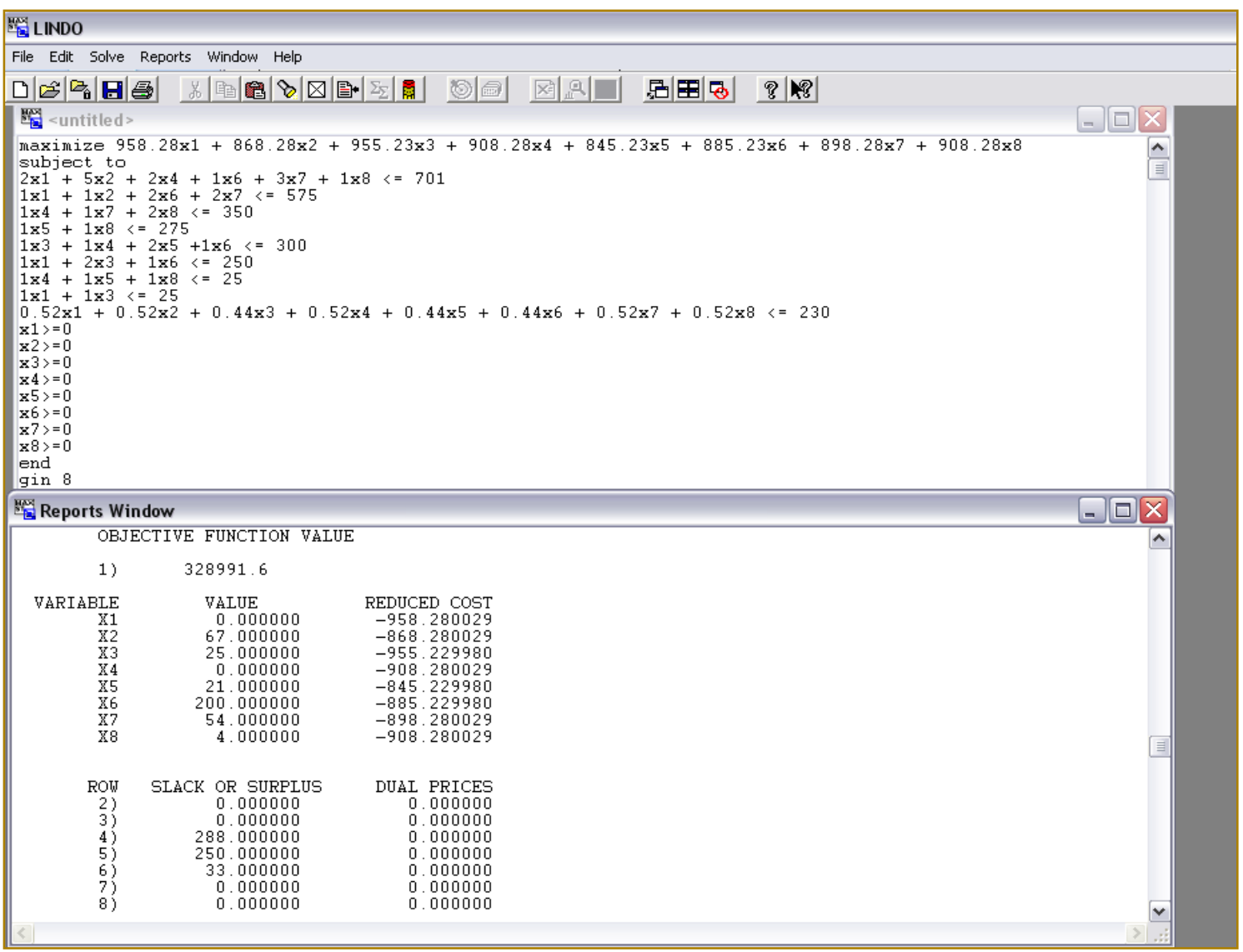

Após a repetição do procedimento para as restrições relacionadas aos outros produtos, foi organizada em forma de tabela, a tabela 3, a exposição dos valores de preço dual encontrado.
A partir da tabela 3, é visto que o acréscimo de uma unidade na demanda de pias de $1,80 \mathrm{~m}$ será a mais interessante visto que é a que promove o maior preço dual, com esse aumento.

Tabela 3 - Preço dual

\begin{tabular}{|c|c|c|c|c|c|c|c|c|c|}
\hline Produto & Piso $\left(m^{2}\right)$ & Pia 1,20m & Pia $1,40 m$ & Pia 1,50m & Pia 1,60m & Pia $1,80 \mathrm{~m}$ & Pia 2,00m & $\begin{array}{c}\text { Pia } 1,80 \mathrm{~m} \\
\text { (Dois } \\
\text { bojos) }\end{array}$ & $\begin{array}{c}\text { Pia } 2,00 \mathrm{~m} \\
\text { (Dois } \\
\text { bojos) }\end{array}$ \\
\hline Demanda & 231 & 701 & 576 & 351 & 276 & 301 & 251 & 26 & 26 \\
\hline $\begin{array}{l}\text { Receita } \\
\quad(\mathrm{R} \$)\end{array}$ & 328928,50 & 328991,60 & 329084,60 & 328928,50 & 328928,50 & 328928,50 & 329041,60 & 329773,80 & 329260,70 \\
\hline $\begin{array}{l}\text { Preço dual } \\
\text { (R\$) }\end{array}$ & 0 & 63,10 & 156,10 & 0 & 0 & 0 & 113,10 & 845,30 & 332,20 \\
\hline
\end{tabular}

Na sequência da análise de sensibilidade é feito um acréscimo de $R \$ 1,00$ em cada pia para verificar. Na figura 5 é possível ver essa alteração feita no valor dos pisos, agora de $R \$ 36,00$, que é percebido no valor dos coeficientes da função objetivo, também é notável a mudança nos valores ótimos da receita. No caso em questão não houve alteração do mix de utilização das matrizes de produção, ou seja, as variáveis. 
Figura 5 - Solução do modelo para um novo preço de piso ajustado para $\mathrm{R} \$ 36,00$

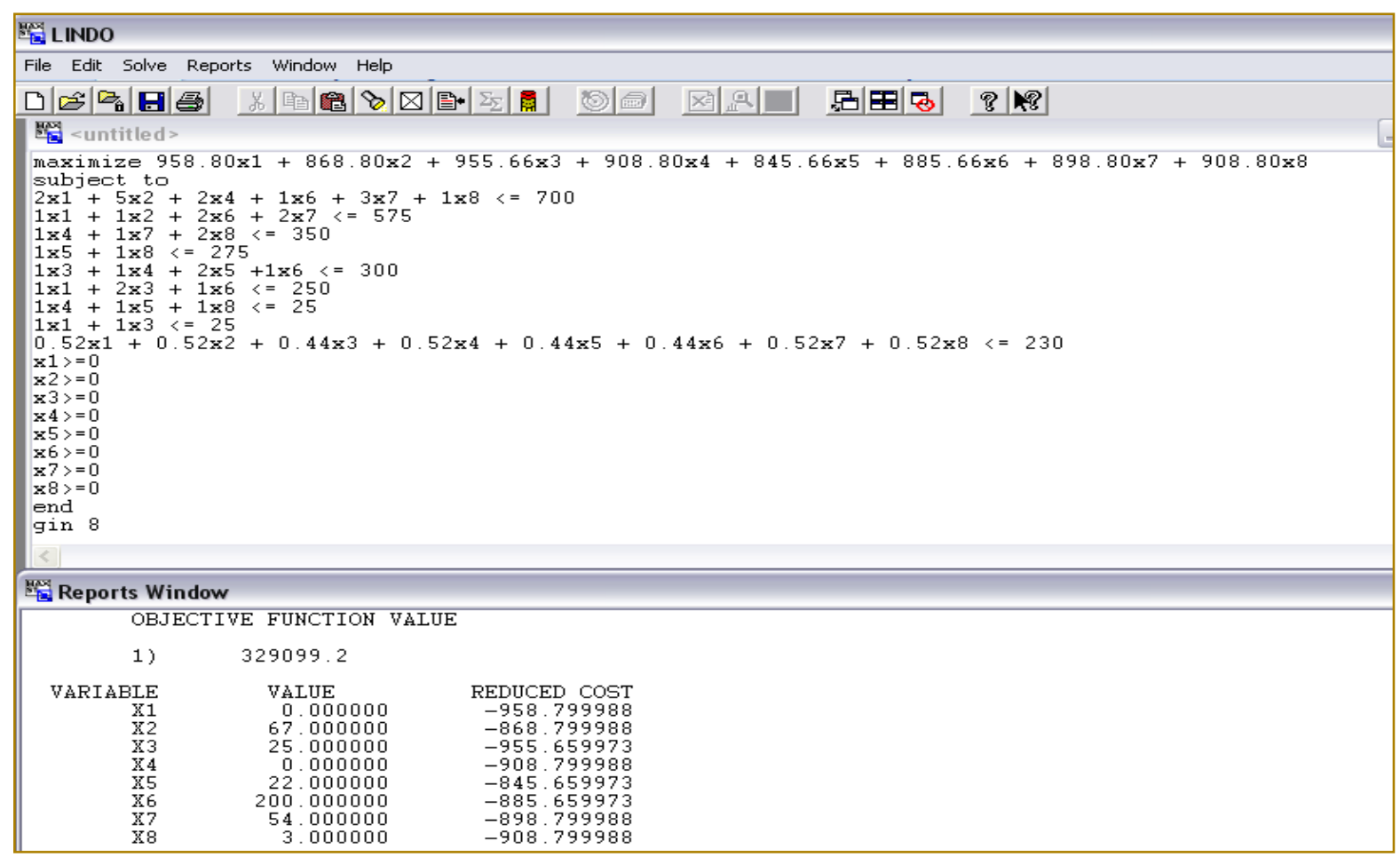

Como observado na tabela 4, o produto que melhor justifica este acréscimo em seu preço será a pia de $1,20 \mathrm{~m}$, pois apresenta um maior aumento na receita. O que é de lógico, pois é o produto com maior demanda, e a variação será igual a quantidade produzida. Para todos os produtos, o incremento de $\mathrm{R} \$ 1,00$ não alterou o mix de utilização das chapas.

Tabela 4 - Variação na receita com a alteração de $R \$ 1,00$ nos produtos

\begin{tabular}{|c|c|c|c|c|c|c|c|c|c|}
\hline Produto & Piso $\left(m^{2}\right)$ & Pia 1,20m & Pia 1,40m & Pia 1,50m & Pia 1,60m & Pia 1,80m & Pia 2,00m & $\begin{array}{c}\text { Pia } 1,80 \mathrm{~m} \\
\text { (Dois } \\
\text { bojos) }\end{array}$ & $\begin{array}{c}\text { Pia } 2,00 m \\
\text { (Dois } \\
\text { bojos) }\end{array}$ \\
\hline Preço (R\$) & 36 & 141 & 151 & 161 & 181 & 201 & 231 & 251 & 281 \\
\hline Receita (R\$) & 329099,20 & 329628,50 & 329503,50 & 328988,50 & 328953,50 & 329197,50 & 329178,50 & 328953,50 & 328953,50 \\
\hline Diferença $(\mathrm{R} \$)$ & 170,7 & 700 & 575 & 60 & 25 & 269 & 250 & 25 & 25 \\
\hline
\end{tabular}

\section{CONSIDERAÇÕES FINAIS}

Como observado, este trabalho é resultado de um estudo de caso, que exigiu no decorrer do mesmo uma análise e reflexão das respostas encontradas. O modelo matemático foi capaz de descrever o problema, e propor soluções e uma releitura do mix de produção na empresa, com informações reais e direcionadas a melhoria do processo produtivo e atendimento do mercado.
Deste estudo se pôde tirar algumas conclusões a respeito da utilização das matrizes, conclusões estas a respeito da quantidade de vezes que cada uma será utilizada, um possível reajuste no preço em um produto e o produto que deve receber investimentos para aumento da demanda que acarretará em um aumento na receita.

Uma observação importante é de que com essas matrizes de produção não será possível 
um atendimento total da demanda sem que seja produzida uma quantidade de pias que não foram vendidas. Uma forma que possa melhorar este aspecto é que sejam disponibilizadas mais matrizes de produção, que possam incluir outras combinações de pias em uma chapa e assim aproximar a produção da demanda.

\section{REFERÊNCIAS}

[1] APARICIO, J. et al. Evaluating productive performance: A new approach based on the product-mix problem consistent with Data Envelopment Analysis. Omega, v. 67, p. 134-144, 2017.

[2] BADRI, S et al.. An integrated model for product mix problem and scheduling considering overlapped operations. Decision Science Letters, v. 3, n. 4, p. 523-534, 2014.

[3] CASSEL, R. A. et al. Maximização da lucratividade em produção conjunta: um caso na indústria frigorífica. Produção, v. 16, n. 2, p. 244257, 2006

[4] DAL MAGRO, C. B. et al. Análise do mix de produção para maximização da lucratividade em produção conjunta: um caso na indústria de lácteos. In: Anais do Congresso Brasileiro de Custos-ABC. 2015

[5] HADIDI, L. A.; MOAWAD, O. A. The product-mix problem for multiple production lines in sequenced stages: a case study in the steel industry. The International Journal of Advanced Manufacturing Technology, v. 88, n. 5- 8, p. 14951504, 2017.
Outras abordagens e trabalhos futuros poderão ser realizados com a inclusão de novas restrições relativas ao atendimento da demanda, inclusão de políticas de estoques, modelos capacitados, interação entre os stakeholders e seus fluxos, novos objetivos e técnicas de solução, como heurísticas e metaheurísticas.

[6] LINHARES, A. Theory of constraints and the combinatorial complexity of the product-mix decision. International Journal of Production Economics, v. 121, n. 1, p. 121-129, 2009.

[7] RODADO N. D. et al. A mathematical model for the product mixing and lot-sizing problem by considering stochastic demand. International Journal of Industrial Engineering Computations, v. 8, p. 237-250, 2017.

[8] SOBREIRO, V. A.; NAGANO, M. S. Proposta de uma heurística construtiva baseada na TOC para definição de mix de produção. Produção, v. 23, n. 3, p. 468-477, 2013.

[9] TANHAEI, F.; NAHAVANDI, N. Algorithm for solving product mix problem in two-constraint resources environment. The International Journal of Advanced Manufacturing Technology, v. 64, n. 5-8, p. 1161-1167, 2013

[10] WELLINGTON, J. F.et al. Interior analysis of the green product mix solution. European Journal of Operational Research, v. 237, n. 3, p. 966-974, 2014. 


\section{Bapítulo 20}

\section{MODELAGEM MATEMÁTICA PARA O PROBLEMA DE ALOCAÇÃO DE PILHAS EM UM PÁTIO DE ESTOCAGEM E PORTO}

\section{Marcos Wagner Jesus Servare Junior}

Álvaro Daniel Oliveira Lopes

José Leandro Felix Salles

Helder Roberto de Oliveira Rocha

Resumo: Pátios de estocagem em áreas portuárias são importantes na gestão da cadeia de suprimentos, devido a agregação de custos logísticos. O seu objetivo primordial é realizar o carregamento dos navios de acordo com a sua capacidade, quantidade vendida e especificação do produto e, ainda, da maneira mais rápida possível. Para granéis sólidos, nos pátios de estocagem ocorrem a alocação das pilhas de produtos ao longo de sua extensão, juntamente ao sistema de recebimento e movimentação, além de misturas e recuperação de pilhas para abastecimento de navios. Na otimização deste sistema é observado um trade-off entre possíveis objetivos desse problema como, por exemplo, maximizar a precisão da programação, a taxa de transferência entre os estágios e minimizar o custo. Esses fatores apontam uma variedade de fluxos, aumentando a complexidade do sistema. Sendo assim, este artigo tem como objetivo apresentar um novo modelo matemático considerando instalações e equipamentos utilizados nessa movimentação e analisar a eficiência desde em um conjunto de cenários. 


\section{INTRODUÇÃO}

Os pátios de estocagem são elos importantes da cadeia logística a que pertencem, influenciando de forma significativa no seu desempenho. Especificamente no caso de granéis sólidos, como o carvão e o minério de ferro, o planejamento de alocação das pilhas e sequenciamento da utilização dos recursos ao longo da extensão destes pátios, impactam de maneira direta no desempenho dos processos portuários e, de acordo com a gravidade da situação, pode até interromper o processo de fornecimento por um período. Um navio que venha a ter sua partida atrasada pela ineficiência no processo pode incidir uma multa contratual oriunda do proprietário da embarcação.

Em oposição, se a alocação for feita de forma eficiente irá proporcionar maiores capacidades, menores custos e melhor resultado global desta cadeia de abastecimento. No entanto, devido a complexidade do sistema de produção e a flexibilidade exigida, é muito difícil garantir uma produção lucrativa sem qualquer suporte à otimização.

Uma boa solução de otimização pode resultar em economias significativas por meio de melhor utilização da capacidade. Além dos benefícios econômicos, a otimização também pode contribuir para reduzir os impactos ambientais, os gastos com energia, violações de várias regulamentações e auxiliar na maneira mais eficiente de lidar com as incertezas, tanto na produção quanto nos pedidos dos clientes.

Uma série de artigos de revisão sobre planejamento a curto prazo foram apresentados recentemente na literatura científicas, por exemplo, Floudas e Lin (2004), Méndez et al. (2006), Li e lerapetritou (2008a, 2008b), Ribas et al. (2010), Phanden et al. (2011), e Maravelias (2012). Devido à ampla gama de problemas de programação de produção, várias abordagens foram desenvolvidas. Algumas incluem programação manual suportada por computador (por exemplo, gráficos de Gantt interativos), sistemas especialistas, programação matemática (Programação Linear - LP, Programação Linear Inteira Mista - MILP - e Programação Não-Linear Inteira Mista - MINLP), várias heurísticas, algoritmos evolutivos e diferentes métodos de inteligência artificial (IA).
O planejamento de pilhas no pátio deve otimizar o processo de empilhamento e recuperação, de tal forma que o espaço disponível no pátio seja capaz de acomodar os lotes de minério que chegam dos trens e permita mudanças de planos alternativos em caso de falhas do equipamento e refazendo assim o planejamento. Existem poucos problemas discutidos na literatura semelhantes ao problema de planejamento de um pátio estudado neste artigo.

No estudo feito pelos autores Abdekhodaee et al.(2004), considera-se uma cadeia de carvão na Austrália, focando mais na programação dos trens do que no planejamento do pátio em si. Esses autores decomporam os dois problemas em vários módulos resolvendo cada um deles através de uma heurística gulosa. Atualmente, a geração de colunas (CG) é um dos métodos mais frequentemente aplicados para resolver problemas de larga escala com um grande número de variáveis, e este método foi aplicado no trabalho de Menezes et al. (2017)

Em Boland et al. (2012), desenvolveram um algoritmo de planejamento de pátios de carvão com intuito de aumentar o fluxo de matérias primas e diminuir o tempo médio dos navios no berço. O algoritmo proposto por estes autores combina uma técnica construção gulosa, que depois foi melhorada utilizando uma otimização com programação inteira.

Além de todos os trabalhos já citados, cabe destacar que em situações reais novas considerações, equipamentos ou participantes devem ser considerados, tais como, o fluxo entre os equipamentos, quantidade de carga carregada nos navios e quantidade de navios atendidos, aumentando a complexidade.

Assim, o presente artigo tem por objetivo apresentar um modelo matemático para um sistema de armazenamento de minério, sua movimentação dentro do sistema e abastecimento dos navios, que busca maximizar a quantidade de carga que será enviada aos clientes ou maximizar a quantidade de navios que tenha sua demanda atendida em um horizonte de planejamento, se aproximando assim da realidade observada nas empresas. Este trabalho foi publicado nos anais do Congresso Brasileiro de Engenharia de Produção (CONBREPRO) de 2018. 
A Seção 2 apresenta uma revisão bibliográfica de trabalhos relativos ao tema deste artigo. A Seção 3 apresenta o modelo matemático proposto destacando as possibilidades de função objetivo, fluxos e relações entre os participantes. Na Seção 4 são apresentados alguns experimentos computacionais com o CPLEX 12.5 (IBM, 2012) para mostrar a aplicabilidade do modelo matemático, e por último, na Seção 5 são apresentadas as conclusões finais.

\section{REVISÃO DE LITERATURA}

De acordo com Menezes et al (2017), os planejamentos de médio e curto prazos são decisões que a Pesquisa Operacional estuda como problema de Planejamento e Sequenciamento, considerando as quantidades a serem produzidas, preços e contratação, além da forma de alcançar as metas definidas pelos níveis superiores.

A solução do problema planejamento de alocação de pilhas e sequenciamento não é trivial, exigindo uma pesquisa detalhada para identificar as alternativas existentes, de tal forma a propor e construir as de maior efetividade e potencial de utilização. Dado o grau de complexidade verificado, este problema pode ser classificado como NPhard, ou seja, os que requerem tempo exponencial para obtenção de solução ótima global (Voudouris, 1997). Assim, além da busca pela solução ótima, é importante que se busque alternativas com soluções locais de boa qualidade que possam ser utilizadas pelos operadores e gestores do pátio no processo de tomada de decisão.

Pimentel (2011) aborda otimização da cadeia logística do minério como um todo, sendo que as análises efetuadas na gestão de pátios das minas são feitas de maneira simplificada, sem considerar os aspectos de rotas e manutenções de equipamentos. A solução adotada por Almeida e Pimentel (2010) utilizou um modelo de programação inteira mista para resolver o problema de programação de curto prazo de produção, processamento e expedição de minério. Em conjunto com o modelo utilizado, foi adotada a abordagem de Programação por Metas (Ignizio, 1978) para lidar com o aspecto de conflito de objetivos de cada etapa ou parte do processo (Pimentel, 2011).

Nóbrega (1996) também trata o problema do ponto de vista da cadeia, sendo que na etapa de pátios de estocagem aborda somente que existem pilhas que são formadas e recuperadas sem haver preocupação de localização ou dimensões e geometria das mesmas. Neste caso, utiliza métodos clássicos de programação inteira e programação linear. Bittencourt e Matede (2009) fazem uma análise de pátios de estocagem de bobinas de aço de uma forma simplificada, considerando somente as movimentações internas de bobinas e formatos resultantes dos empilhamentos destes produtos. Neste caso é usado algoritmo de evolução diferencial para solução do problema.

Em Amorim Júnior (2006) analisa a estocagem de bobinas de aço com objetivo de acelerar o processo de despachos realizado em um período de planejamento pré-estabelecido. Mais recentemente, a integração entre o planejamento e sequenciamento tem sido um campo investigado por diversos autores, tais como Ago et al (2007), Mateus et al (2010), Kis e Kovacs (2012), Meyr e Mann (2013) e Menezes et al (2017), por exemplo. Nos trabalhos destes autores tratam do processo integrado e planejamento e sequenciamento considerando fatores que podem contemplar até a definição de rotas nas correias transportadores e diversas técnicas de solução.

Em linhas gerais, pelas suas características, este problema deverá exigir utilização conjunta de uma ou mais técnicas de otimização, podendo incluir heurística ou meta heurística. A solução final deverá avaliar, também, aspectos de aleatoriedade, risco e tomada de decisão que são inerentes a este processo.

\section{MODELO MATEMÁTICO}

O caso simulado partirá da quantidade de equipamentos que uma empresa do setor de mineração possui, para que seja trabalhado em relação a este caso real. A início do sistema de pátios ocorre em quatro terminais de descarga onde os minérios oriundos das minas entram no sistema através de linhas férreas. A partir da chegada de um lote de minério nos terminais de descarga, estes são transportados para as empilhadeiras através de esteiras transportadoras e em seguida são empilhadas no pátio de estocagem pelas empilhadeiras. 
Os pátios de estocagem são divididos em sessenta e quatro posições para a alocação de pilhas para estocagem, conforme apresenta a Figura 1. A construção de todas as pilhas para atender a um único navio pode demorar diversos dias. Uma pilha do pátio é recuperada usando uma recuperadora de roda de balde sendo a carga imediatamente direcionada aos navios.

Figura 1: Layout do Pátio simulado

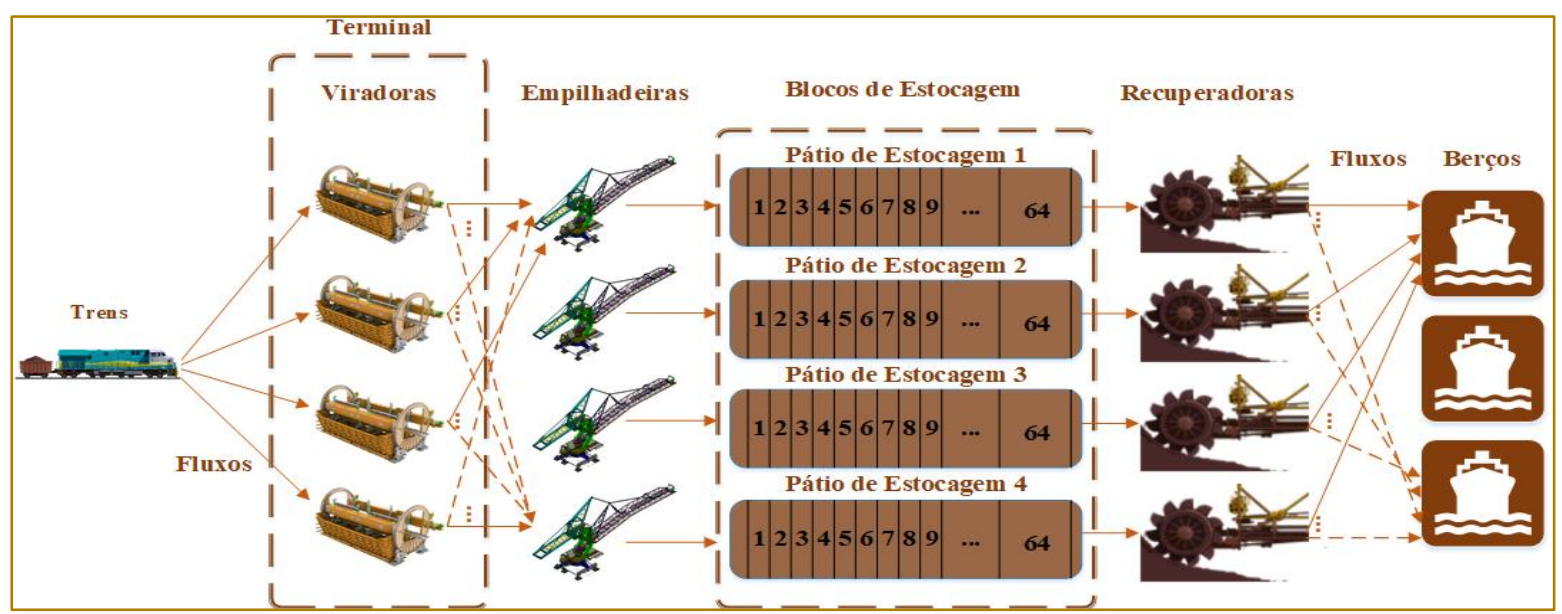

No pátio encontram-se quatro terminais de descarga (estações de despejo), quatro pátios de estocagem, quatro empilhadeiras, quatro recuperadoras e três berços para os navios. As empilhadeiras estão totalmente disponíveis para os terminais e os pátios de estocagem e as recuperadoras só para os pátios de estocagem. As empilhadeiras e as recuperadoras movem-se livremente para atender às posições e as pilhas nos pátios de estocagem. Para um bom funcionamento das empilhadeiras e das recuperadoras, estes devem permanecer a uma certa distância para evitar colisões.

Para efeitos de aplicação considera-se que ao longo de todo o processo existe apenas um tipo de minério, desconsiderando as suas variações quanto a qualidade do produto. Com um pedido realizado, são calculados os movimentos do minério e os trens enviados carregados com os lotes ou vagões de minério para os terminais descarga. Após a chegada dos lotes nos terminais, estes são transferidas para as empilhadeiras que serão empilhadas nos pátios de estocagem, onde permanecerão em repouso até que o navio chegue no berço.

Para um dado conjunto de navios que chegam ao porto, deve-se atribuir os primeiros navios nos berços. Um navio não pode chegar no berço antes da sua hora previamente estimada. Após o navio chegar no berço, inicia-se a recuperação das pilhas no pátio. O tempo de carregamento do navio é diretamente proporcional a quantidade de pilhas recuperadas.

Assim, com base na apresentação do problema, e com as relações indicadas na Figura 1, são descritos os conjuntos, parâmetros e varáveis do modelo proposto; 
Conjuntos

\begin{tabular}{|l|l|}
\hline $\boldsymbol{A}$ & Conjunto de minas \\
\hline $\boldsymbol{B}$ & Conjunto de Viradoras \\
\hline $\boldsymbol{C}$ & Conjunto de Empilhadeiras, Pátios e Recuperadoras \\
\hline $\boldsymbol{D}$ & Conjunto de Pilhas \\
\hline $\boldsymbol{F}$ & Conjunto de Berços \\
\hline $\boldsymbol{N}$ & Conjunto de Navios \\
\hline
\end{tabular}

Parâmetros

\begin{tabular}{|l|l|}
\hline $\boldsymbol{D}_{\boldsymbol{n}}$ & Demanda do navio $n$ \\
\hline $\boldsymbol{P r o d}_{\boldsymbol{a}}$ & Capacidade de produção da mina $a$ \\
\hline $\boldsymbol{C a p v}_{\boldsymbol{b}}$ & Capacidade do viradora $b$ \\
\hline $\boldsymbol{C a p e}_{\boldsymbol{c}}$ & Capacidade da empilhadeira $c$ \\
\hline $\boldsymbol{C a p p}_{\boldsymbol{c d}}$ & Capacidade da pilha $d$ localizada no pátio $c$ \\
\hline $\boldsymbol{C a p r}_{\boldsymbol{c}}$ & Capacidade da recuperadora $c$ \\
\hline $\boldsymbol{C a p b}_{\boldsymbol{f}}$ & Capacidade do berço $f$ \\
\hline
\end{tabular}

Variáveis

\begin{tabular}{|l|l|}
\hline $\boldsymbol{X}_{\boldsymbol{f}}^{n}$ & $X_{f}^{n}=1$ caso o navio $n$ seja atendido no berço $f$, ou 0 caso contrário \\
\hline $\boldsymbol{P}_{\boldsymbol{a b}}$ & Quantidade de minério transportado da mina $a$ para o viradora $b$ \\
\hline $\boldsymbol{Q}_{\boldsymbol{b c}}$ & Quantidade de minério transportado do viradora $b$ para a empilhadeira/pátio $c$ \\
\hline $\boldsymbol{R}_{\boldsymbol{c d}}$ & Quantidade de minério transportado da empilhadeira/pátio $c$ para a pilha $d$ \\
\hline $\boldsymbol{S}_{\boldsymbol{d} \boldsymbol{c}}$ & Quantidade de minério transportado da pilha $d$ para a recuperadora do pátio $c$ \\
\hline $\boldsymbol{T}_{\boldsymbol{c} \boldsymbol{f}}$ & Quantidade de minério transportado da recuperadora do pátio $c$ para o berço $f$ \\
\hline
\end{tabular}

De acordo com a notação definida, o modelo matemático proposto é apresentado pelas equações (1) $-(16)$.

Função objetivo

$$
\begin{aligned}
& \text { Maximizar } Z_{1}=\sum_{n \in N} \sum_{f \in F} X_{f}^{n} \\
& \text { Maximizar } Z_{2}=\sum_{n \in N} \sum_{f \in F} D_{n} X_{f}^{n}
\end{aligned}
$$

Sujeito a:

$$
\begin{aligned}
& \sum_{b \in B} P_{a b} \leq \operatorname{Prod}_{a} \quad \forall a \in A \\
& \sum_{c \in C} Q_{b c} \leq \operatorname{Capv}_{b} \quad \forall \quad b \in B
\end{aligned}
$$




$$
\begin{gathered}
\sum_{d \in D} R_{c d} \leq \operatorname{Cape}_{c} \quad \forall \quad c \in C \\
\sum_{d \in D} S_{d c} \leq \operatorname{Capr}_{c} \quad \forall \quad c \in C \\
\sum_{f \in F} T_{c f} \leq \operatorname{Caph}_{f} \quad \forall \quad f \in F \\
R_{c d} \leq \operatorname{Capp}_{c d} \quad \forall \quad c \in C, \quad \forall \quad d \in D \\
\sum_{a \in A} P_{a b}=\sum_{c \in C} Q_{b c} \quad \forall \quad b \in B \\
\sum_{b \in B} Q_{b c}=\sum_{d \in D} R_{c d} \quad \forall \quad c \in C \\
R_{c d} \leq S_{d c} \quad \forall \quad c \in C, \quad \forall \quad d \in D \\
\sum_{d \in D} S_{d c}=\sum_{f \in F} T_{c f} \quad \forall \quad c \in C \\
\sum_{c \in C} T_{c f}=\sum_{n \in N} D_{n} X_{f}^{n} \quad \forall \quad f \in F \\
\sum_{f \in F} X_{f}^{n} \leq 1 \quad \forall \quad n \in N \\
X_{f}^{n} \in\{0,1\} \quad \forall \quad n \in N, \quad \forall \quad f \in F
\end{gathered}
$$

A função objetivo (1) maximiza a quantidade de navios que o sistema consegue atender dentro do horizonte de planejamento do estudo. Por sua vez, a função objetivo (2) maximiza a quantidade de carga transportada pelos navios. A diferença entre as funções objetivos ao ser implementado o modelo será a escolha de número de clientes atendidos ou a quantidade de carga vendida, sendo essa decisão direcionada a partir de qual função objetivo será usada.

O conjunto de restrições (3) garante que tudo que é enviado de uma mina ao sistema seja menor que a capacidade produtiva desta mina. Já a restrição (4) define que toda a carga transportada dos viradora para uma empilhadeira não ultrapasse a capacidade de processamento suportada pelos viradora, de maneira semelhante, as restrições (5)-(8) impedem que sejam transportados além das capacidades da empilhadeira, recuperadora, berços e pilhas de cada pátio, respectivamente.
O conjunto de restrições (9)-(12) garante que todo o fluxo que chega a um equipamento seja igual ao que sai dele, para viradora, empilhadeira, pilha de cada pátio e recuperadora, respectivamente. A restrições (13) assegura que o material transportado seja para abastecer cada navio que tem sua demanda atendida em cada berço.

A restrição (14) garante que um navio só pode ser atendido por no máximo um berço. Por fim, as restrições (15) e (16) estão relacionadas ao domínio e natureza das variáveis de decisão do modelo matemático proposto.

\section{EXPERIMENTOS COMPUTACIONAIS E DISCUSSÃO}

Para verificação e validação do modelo proposto, foram realizados experimentos computacionais com o auxílio do solver comercial CPLEX (IBM, 2012). Sem que pudessem ser disponibilizados valores reais para que os cenários fossem simulados, 
utilizou-se os valores aleatórios para definir a demanda de cada navio.

O computador utilizado nos experimentos computacionais foi um Intel Core i5 com 4Gb de memória RAM. Como o modelo matemático proposto apresenta duas funções objetivos, optou-se por resolver o modelo considerando cada uma delas como única função objetivo do problema. Na Tabela 1 encontram-se as informações relativas aos conjuntos de cada instância que foi criada para efeito de comparação entre elas.

Tabela 1: Instâncias produzidas para a validação do modelo matemático

\begin{tabular}{|c|c|c|c|c|c|c|}
\hline Instância & A & B & C & $\mathrm{D}$ & $\mathrm{F}$ & $\mathrm{N}$ \\
\hline 1 & 1 & 4 & 4 & 64 & 2 & 10 \\
\hline 2 & 2 & 4 & 4 & 64 & 2 & 10 \\
\hline 3 & 2 & 4 & 4 & 64 & 3 & 10 \\
\hline 4 & 2 & 4 & 4 & 64 & 5 & 10 \\
\hline 5 & 2 & 4 & 4 & 64 & 6 & 10 \\
\hline 6 & 2 & 4 & 4 & 64 & 7 & 10 \\
\hline
\end{tabular}

A evolução das instâncias foi com o objetivo de estudar a variação para que toda a demanda fosse atendida, na primeira delas considerou-se a existência de uma mina e foi duplicada essa quantidade para que fosse observado se era a produção da demanda que fosse o gargalo do sistema.

A partir da terceira instância variação ocorreu na quantidade de berços para que todos os navios fossem atendidos no horizonte de planejamento estudado. A partir dessa análise considerando apenas a Função objetivo (1), na Tabela 2 encontram-se os resultados computacionais da implementação das instâncias, com o esforço computacional medido em segundos (ou fração de segundos) para que o solver CPLEX (IBM, 2012) indicasse a solução ótima para a instância em questão.

Tabela 2: Implementação da modelagem matemática com a Função Objetivo (1)

\begin{tabular}{|c|c|c|}
\hline \multirow{2}{*}{ Instância } & $\begin{array}{c}\text { Função objetivo } \\
\text { (no navios atendidos) }\end{array}$ & $\begin{array}{c}\text { Tempo } \\
(\mathrm{seg})\end{array}$ \\
\hline 1 & 4 & 0,11 \\
\hline 2 & 4 & 0,17 \\
\hline 3 & 6 & 0,2 \\
\hline 4 & 8 & 0,14 \\
\hline 5 & 9 & 0,12 \\
\hline 6 & 10 & 0,18 \\
\hline
\end{tabular}

De maneira semelhante, na Tabela 3 é apresentada os resultados da implementação do modelo matemático considerando a Função objetivo 2. 
Tabela 3: Implementação da modelagem matemática com a Função Objetivo (2)

\begin{tabular}{|c|c|c|}
\hline Instância & $\begin{array}{c}\text { Função objetivo } \\
\left(\text { carga transportada }{ }^{*}\right)\end{array}$ & $\begin{array}{c}\text { Tempo } \\
(\text { seg })\end{array}$ \\
\hline 1 & 4 & 0,12 \\
\hline 2 & 4 & 0,21 \\
\hline 3 & 6 & 0,18 \\
\hline 4 & 9 & 0,18 \\
\hline 5 & 11,5 & 0,17 \\
\hline 6 & 12,5 & 0,12 \\
\hline *Valores simulados para milhões de toneladas \\
\hline
\end{tabular}

Considerando um horizonte de planejamento restrito, em um tempo pequeno, com uma quantidade de 10 navios a serem atendidos pelo porto o modelo foi suficiente para resolver o problema de maneira ótima pelo CPLEX 12.5 (IBM, 2012), embora casos reais apresentem maior horizonte de planejamento e a quantidade de navios, o modelo matemático poderá ser empregado para esse tipo de programação.

Está análise considera a possibilidade de a empresa realizar planejamentos e replanejamentos em um horizonte de tempo reduzido para que se tenha uma solução ótima a todo momento mediante a consideração de eventuais mudanças que possam ocorrer durante um período de planejamento mais extenso.

\section{CONSIDERAÇÕES FINAIS}

Este trabalho apresentou um modelo matemático bi-objetivo para projetos de otimização na alocação pilhas em um pátio de estocagem de portos e carregamento de navios, com atores e uma abordagem voltada a fluxo que até então não haviam sido considerados por obras de outros autores.

Para os testes computacionais, considerou-se uma única função objetivo por análise. Os resultados obtidos foram satisfatórios, que foram suficientes para validar o modelo e, ainda, processados e tempo computacional baixo, conforme mostrado nas Tabelas 2 e 3 . Em todos os casos, solver comercial, como o CPLEX (IBM, 2012), foi capaz de resolver o problema em um tempo computacional aceitável.

Entretanto, para análise de problemas de grande porte, verifica-se a necessidade de implementação em instâncias maiores, que superem em quantidade de variáveis as previstas nesse trabalho, para tanto poderá ser realizado junto a implementação de heurísticas ou metaheurísticas específicas.

Outra abordagem que poderá ser adotada em trabalhos futuros é considerar este tipo de problema para situações distintas devido a seu e dinamismo e complexidade, em que o acompanhamento pode ser feito de forma contínua ou, ainda, considerar eventuais problemas de abastecimento, intempéries ou manutenção de equipamento ao realizar a programação. Para isso deverão ser consideradas as técnicas de resolução usando a programação dinâmica ou programação estocástica.

Ainda com relação aos métodos de solução, e considerando a importância da abordagem multi-objetivo do problema aqui apresentado, verifica-se a existência da necessidade de desenvolver algoritmos específicos multiobjetivos. Acredita-se que estas técnicas permitirão obter soluções de compromisso ainda mais adequadas ao problema considerando as duas abordagens

\section{AGRADECIMENTOS}

Os autores agradecem à FAPES/Vale pelo financiamento desta pesquisa no projeto no 529/2016 do edital 1/2015. 


\section{REFERÊNCIAS}

[1] Abdekhodaee A. et al. (2004) Integration of stockyard and rail network: a scheduling case study. In: Proceedings 5th Asia-Pacific industrial engineering and management systems conference, Gold Coast, Australia, December 12-15, pp 1-16

[2] Ago, M. et al. (2007) Simultaneous Optimization of Storage Allocation and Routing Problems for Belt-conveyor Transportation. Journal of Advanced Mechanical Design, Systems, and Manufacturing, 1(2), pp.250-261.

[3] Almeida, F. A. e B. S. Pimentel (2010) Um modelo matemático para o problema de programação integrada de curto prazo em minas. Anais do XLII Simpósio Brasileiro de Pesquisa Operacional, SBPO, Bento Gonçalves.

[4] Bittencourt, S.V. e W. C. Matede (2009) Uma abordagem acerca dos problemas de otimização referentes ao sistema de alocação em pátios de estocagem e às movimentações de bobinas de aço laminadas. Simpósio Projeto e Análise de Algoritmos, UFES, Vitória.

[5] Boland, N. et al. (2012) A stockyard planning problem. EURO Journal on Transportation and Logistics, 1(3), pp.197-236.

[6] Floudas, C. A. e X. Lin (2004). Continuoustime versus discrete-time approaches for scheduling of chemical processes: a review. Computers \& Chemical Engineering, 28(11), 21092129.

[7] IBM (2012) IBM ILOG CPLEX v12.5: User's manual for CPLEX, 2012

[8] Ignizio, J. P. (1978) A review of Goal Programming: a tool for multiobjective analysis. Journal of the Operational Research Society, v. 29, n. 11, p. 1109-1119.

[9] Kis, T. e A. Kovács (2012) A cutting plane approach for integrated planning and scheduling. Computers \& Operations Research, v. 39, n. 2, p. 320-327.

[10] Li, Z. e M. G. Ierapetritou (2008a). Process scheduling under uncertainty: Review and challenges. Computers \& Chemical Engineering, 32(4-5), 715-727.,

[11] Li, Z. e M. G. lerapetritou (2008b). Robust optimization for process scheduling under uncertainty. Industrial \& Engineering Chemistry Research, 47(12), 4148-4157.

[12] Maravelias, C. T. (2012). General framework and modeling approach classification for chemical production scheduling. AIChE Journal, 58(6), 1812-1828.)

[13] Méndez, C. A. et al. (2006). State-of-the-art review of optimization methods for short-term scheduling of batch processes. Computers \& Chemical Engineering, 30(6-7), 913-946.

[14] Menezes, G. C. et al. (2017) A branch and price algorithm to solve the integrated production planning and scheduling in bulk ports. European Journal of Operational Research, v. 258, n. 3, p. 926-937.

[15] Meyr, H. e Mann, M. (2013) A decomposition approach for the general lotsizing and scheduling problem for parallel production lines. European Journal of Operational Research, v. 229, n. 3, p. 718-731.

[16] Nóbrega, M. A. (1996) Modelagem matemática de um sistema de produção e transporte de minério de ferro (dissertação de mestrado). Campinas: Universidade estadual de Campinas.

[17] Phanden, R. K. et al. (2011). Integration of process planning and scheduling: a state-of-the-art review. International Journal of Computer Integrated Manufacturing, 24(6), 517-534.

[18] Pimentel, B. S. (2011) Modelos e Algoritmos para Planejamento Integrado da Indústria da Mineração (Tese de Doutorado). Belo Horizonte (MG-Brasil): Universidade Federal de Minas Gerais.

[19] Ribas, I., R. et al. (2010) Review and classification of hybrid flow shop scheduling problems from a production system and a solutions procedure perspective. Computers \& Operations Research, 37(8), 1439-1454.

[20] Voudoris, C. (1997) Guided local search for combinatorial optimisation problems (Tese PhD). Colchester (UK): Department of Computer Science, University of Essex. 


\section{Gapítulo 21}

\section{PROJETO MODELAGEM BIFOCAL: BUSCANDO MELHORIAS NO PROCESSO DE SOLDAGEM UTILIZANDO ARAME TUBULAR}

\section{Maria Verônica Macedo de Lima Galm}

Peter Jonas Ribeiro Hachmann

\section{Victor de Souza Ribeiro}

Simone Cavenati

Resumo: A região das cidades de Itajaí e Navegantes, Santa Catarina (SC), destaca-se no segmento da construção naval, sendo referência no cenário nacional. Ao longo das últimas décadas, vários estaleiros e empresas especializadas na construção de navios de apoio às atividades off shore instalaram-se nos municípios, produzindo embarcações que demandam de uma grande quantidade de processos de fusão, sendo responsável pela união de peças metálicas, conforme estudos realizados por Santiago (2012) cerca de $4 \%$ do peso de um navio é oriundo de material depositado por vários tipos de processo de soldagem. Mundialmente um dos maiores processos utilizados pela grande deposição de material é a soldagem a Arco com Eletrodo Tubular (Gas Metal Arc Welding - GMAW). Dessa forma, quem trabalha no processo de soldagem tem conhecimento do quanto é importante ter uma boa solda para garantir um bom funcionamento técnico e econômico do produto. O objetivo da pesquisa é criar um modelo computacional que consiga avaliar o processo de soldagem, na deposição do arame tubular em chapas de aço, através do programa NetLogo. De modo a desenvolver este trabalho foi realizada uma revisão bibliográfica de natureza qualitativa com o objetivo exploratório e descritivo, tendo dados coletados em um estaleiro de Itajaí (corpo de prova). A partir dos dados obtidos com o programa NetLogo gerou-se um resultado que foi então comparado aos resultados obtidos no estaleiro, de modo que essa análise se mostrou compatível com o modelo real, apresentando ao usuário as alterações encontradas na soldagem com variações na tensão do equipamento de solda.

Palavras chave: Soldagem, GMAW, NetLogo, Modelagem. 


\section{INTRODUÇÃO}

A simulação consiste em efetuar uma projeção de um modelo real, podendo realizar estudos virtuais com o intuito de melhorar a qualidade e eficiência do sistema real (PEGDEN,1979). Os integrantes que participam do estudo obtêm uma vasta experiência em cada simulação realizada, podendo utilizar informações de um modelo computacional em outro.

Sendo utilizada como uma técnica ou ferramenta, a simulação opera com a criação de modelos computacionais a partir de um modelo real, que tem como objetivo obter conhecimento do problema abordado, realizando analises do caso estudado e buscando resultados para a melhoria do projeto.

Hodiernamente a simulação computacional é essencial para qualquer empresa que tem como intuito a minimização de falhas, tanto na área operacional, que envolve os processos de um produto ou serviço, quanto na parte orçamentária, que visa obter uma alta receita mensal para a empresa e a economia de custos.

Aragão (2011) cita que para alguns autores importantes na área de modelagem computacional, Saliby (1989), Banks et al.(1996), Banks (2000), Pegden et al.(1979), Law \& Kelton (2000), este tipo de técnica possui algumas vantagens e desvantagens, sendo algumas delas:

Vantagens:

- Modelos mais realistas;

- Facilidade de comunicação;

- Soluções rápidas;

- Grande flexibilidade.

Desvantagens:

- Treinamento especial;

- Dificuldade na interpretação de alguns resultados;

- Pode ser oneroso financeiramente e em relação a tempo.
A fim de garantir uma maior competitividade, buscando uma solução para a deposição de impurezas da atmosfera no processo de soldagem, e consequentemente, reduzir seus custos, as empresas viram a necessidade de criar um método de soldagem, chamado de arame tubular, parecido com o MIG/MAG, mas com a diferença que o arame utilizado possui no seu interior um fluxo, dando características que o diferem dos outros processos.

Esse fluxo acompanhado de uma proteção gasosa externa produz soldas com uma qualidade que não se encontra facilmente. $\mathrm{O}$ processo de soldagem com arame tubular possibilita a deposição de material na junção de peças metálicas, por aquecimento com o arco elétrico, entre o arame e a peça trabalhada.

Deste modo, a simulação computacional se mostra eficiente para demonstrar o funcionamento do sistema antes de ser implementado, podendo assim o usuário fazer ajustes, buscando a melhoria do processo estudado. Por outro lado, a simulação precisa ser o mais real possível para se tornar viável, caso isso não ocorra, pode trazer prejuízos financeiros e de recursos.

Diante dessa proposta, o presente artigo tem por objetivo criar um projeto de modelagem bifocal utilizando o software de programação NetLogo, com o propósito de descrever o processo de soldagem com arco elétrico mostrando a sua deposição em uma chapa de metal, mudando a cor da solda de acordo com a tensão que passa pelo sistema, para representar se a tensão está baixa, acima ou dentro do padrão estabelecido.

\section{MATERIAIS E MÉTODOS}

A pesquisa realizada nesse presente trabalho fundamenta-se em análises de artigos e TCC's publicados em anais de Engenharia de Produção, como mostrado abaixo. Palavras chaves foram usadas a fim de buscar trabalhos mais relevantes de pesquisa, como por exemplo, Modelagem de sistema, Simulação computacional, Processo de soldagem e Programação NetLogo: 


\begin{tabular}{|c|}
\hline SIMPEP \\
\hline AEBEPRO \\
\hline SCIENCEDIRECT \\
\hline IEEE XPLORE \\
\hline ACM DIGITAL LIBRARY \\
\hline GOOGLE ACADEMICO \\
\hline
\end{tabular}

A partir da pesquisa realizada, a simulação do modelo no NetLogo resultou ao usuário em uma experiência interessante, principalmente para os que trabalham na área, e de acordo com a tensão que passa pelo sistema, a solda se apresenta com cores diferentes, e para isso foi apresentado ao sistema três faixas de tensão.

As cores determinadas são: amarelo, quando a tensão está abaixo do padrão estabelecido pela empresa; preto, quando a tensão varia pelo padrão estabelecido; e alaranjado, quando a tensão está acima do permitido pela empresa.

Após avaliações na qualidade das soldas com arco elétrico, em um estaleiro localizado em Itajaí, verificou-se que o funcionamento do modelo real se dá a partir do momento em que o operador liga a máquina em uma fonte de energia capaz de gerar uma grande intensidade de corrente elétrica.
A corrente gerada passará por um controlador de tensão que levará a corrente até um controle de alimentação (cabeçote: regulando a bobina de arame e a saída de gás de proteção), que é conectado a um controle de pistola, e por fim saindo na pistola (FBTS, 2012). Devido a importância desse processo para o setor, notou-se a necessidade de elaboração da pesquisa para ajudar a trazer uma maior qualidade de solda, desligando a máquina se a corrente de tensão estiver fora dos padrões exigidos.

Para validar o projeto, foi criado um modelo computacional que representasse o mais próximo a soldagem real. Para que a simulação fosse realizada de acordo com o esperado, foram utilizados alguns parâmetros do mundo real para a execução de um aperfeiçoamento no processo de soldagem, diminuindo o retrabalho, e melhorando a qualidade das peças para que não possam se tornar problemas no futuro.

Figura 1 - Metodologia para a criação do modelo

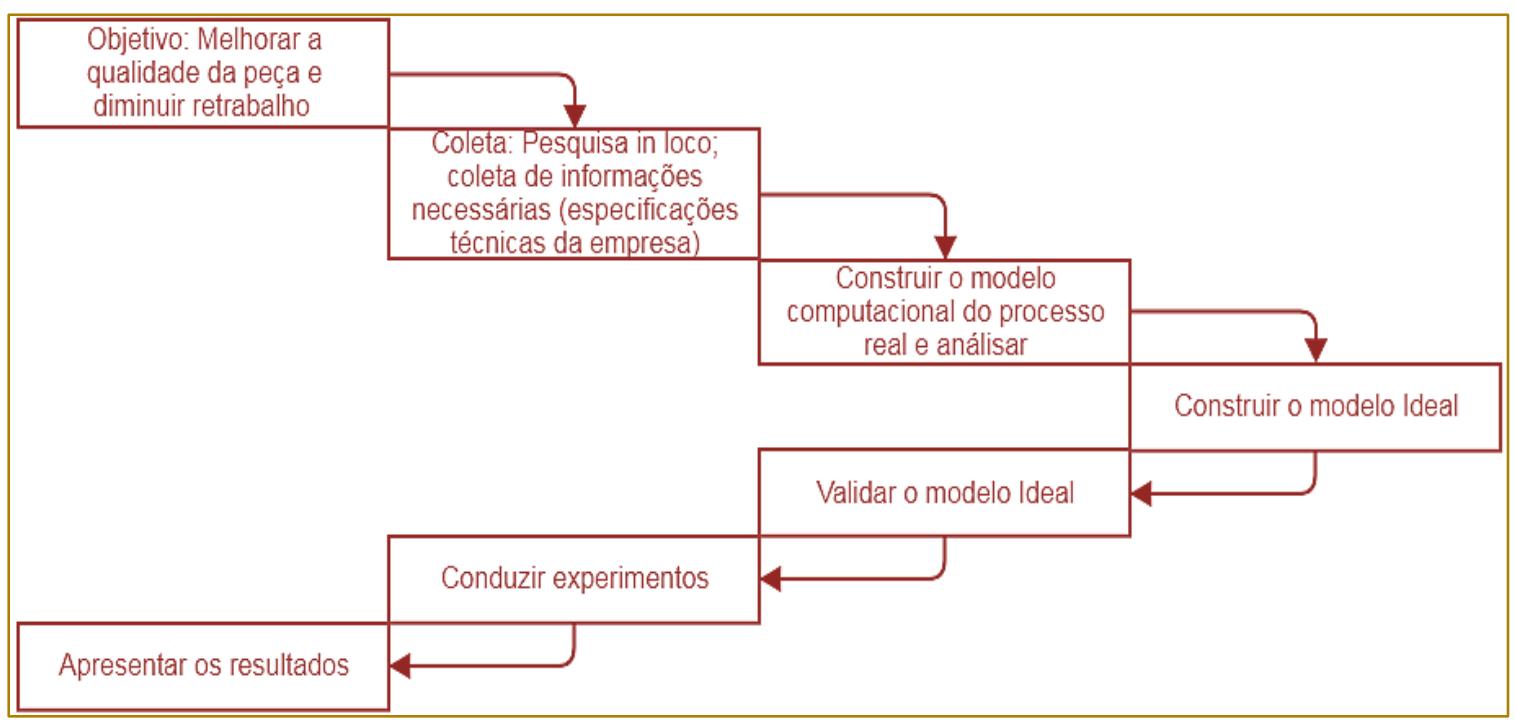


A Figura 1 ilustra as etapas do projeto realizado, sendo que cada uma delas foi analisada com $\mathrm{O}$ intuito de realizar um processo de melhoria da soldagem com arco elétrico, visando à diminuição do retrabalho por peças soldadas errada e o aumento da qualidade da peça.

\section{RESULTADOS OBTIDOS}

Analisando os resultados obtidos com a simulação do sistema no programa NetLogo, no laboratório, e comparando com os resultados obtidos no modelo real no estaleiro estudado na região do Vale do Itajaí, é possível observar que o modelo simulado permite representar o comportamento de processos de soldagem, que usualmente são aplicados na indústria do segmento metalúrgico.

Atualmente, as máquinas utilizadas no processo de soldagem com arco elétrico não possuem um dispositivo capaz de desligar automaticamente o equipamento, ao detectar variação na tensão, acima ou abaixo, dos limites especificados pela empresa.

Durante $\mathrm{o}$ processo da modelagem computacional, foi desenvolvido, como primeira etapa, um procedimento real de soldagem por arco elétrico, onde durante a execução pode ocorrer falhas na peça devido à alteração da tensão, conforme descrito na Figura 2, onde as cores amarelo, preto e alaranjado significam, respectivamente: abaixo da tensão padrão; tensão dentro do padrão; acima da tensão padrão.

Os padrões definidos para o valor da tensão seguem as normas técnicas da ASTM (American Society for Testing and Materials, 2017), em que no projeto simulado, a tensão permitida varia entre 31 e 50 volts.

Conforme descrito já anteriormente, as cores simuladas no projeto representam se a tensão está abaixo (menor que 30 volts), no padrão (entre 31 e 50 volts), ou acima (maior que 51 volts) do valor estabelecido pela empresa. A Figura 2 representa essa mudança de cores durante a simulação.

Figura 2 - Exemplo de simulação com o modelo criado e soldagem real

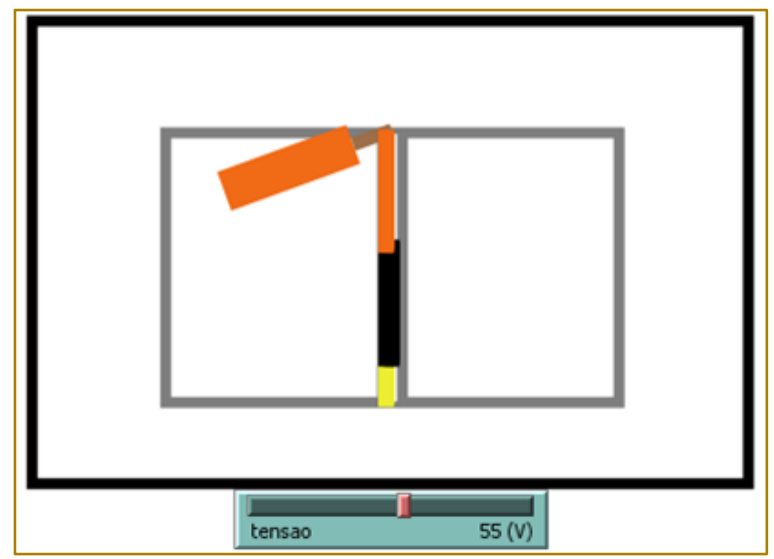

Para a melhoria do processo de soldagem, foi desenvolvido uma simulação anti falhas, onde o soldador não precisará ficar prestando atenção no equipamento que realiza a passagem de energia para a tocha de soldagem. O anti falhas é programado com os parâmetros adequados nas normas técnicas específicas para cada processo de soldagem, e assim, se a tensão variar fora dos padrões, o equipamento irá parar de funcionar.

A Figura 3 ilustra o processo de soldagem ideal, onde caso a tensão varie fora das especificações da ASTM, o equipamento para de funcionar e a peça não danifique, mantendo a qualidade e integridade da mesma sem precisar do retrabalho. 
Figura 3 - Simulação do sistema ideal de soldagem, apresentando o processo de parada da máquina com a tensão irregular.

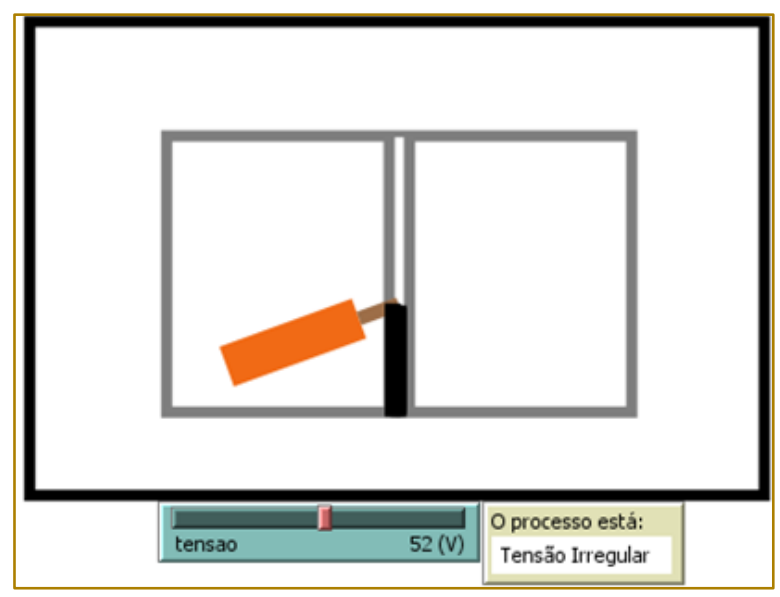

Conforme ilustrado no desenho acima, este simula uma tensão de 52(v), onde o processo está com a tensão irregular, em união de duas chapas de aço.

\section{ANÁLISE DOS RESULTADOS}

A partir dos resultados obtidos nos dois modelos, o real e computacional, observa-se que no modelo real existe uma dificuldade em se obter uma solda de qualidade, visto que ao ocorrer troca de tensão na corrente que passa pela máquina, a mesma continuará funcionando da mesma maneira.

Deste modo, caso a máquina continue com seu processo normal, o material que será depositado na chapa sofrerá alterações.

Com tudo, ao analisar os resultados obtidos através do modelo computacional NetLogo, nota-se que ao passar uma corrente elétrica diferente da estipulada pelo operador da máquina, o equipamento então irá se desligar para que haja uma correção da tensão.

Este procedimento de desligar a máquina automaticamente melhora consideravelmente a qualidade da peça trabalhada, evitando assim o retrabalho com peças defeituosas, e consequentemente, aumentando a produtividade do setor. Dessa forma, mesmo que ocorram alterações na rede externa de energia da empresa, não afetará diretamente a produção (AWS, 1997).

O soldador que for utilizar o equipamento, ao ligar, já irá atribuir as informações da norma técnica da empresa para iniciar o processo de soldagem, sem se preocupar com os parâmetros da máquina, já que a mesma possui um bloqueio no sistema interno, caso ocorra queda de tensão na rede, e o equipamento será automaticamente desligado.

Os profissionais têm outros equipamentos para analisarem antes de começar o processo de soldagem, como ilustra a Figura 4.

O processo de soldagem requer não só habilidade e agilidade do soldador, mas também requer conhecimento dos equipamentos básicos, conforme a Fundação Brasileira de Tecnologia da soldagem (FBTS, 2012):

Os equipamentos básicos do processo conforme FBTS (2012):

- Fonte de energia elétrica;

- Sistema de alimentação do eletrodo em forma de bobina de arame;

- Tocha de soldagem;

- Arame para a abertura do arco;

- Fonte de gás protetor;

- Cabeçote (internamente roldanas).

Devido ao fato do arame tubular ser mais flexível do que o arame sólido, é aconselhável uma menor pressão no mecanismo de tracionamento, sendo então necessária a utilização das roldanas recartilhadas para uma alimentação precisa de arame, que conduz corrente elétrica, ocasionando desta maneira aumento da taxa de fusão por efeito joule, para uma mesma corrente de soldagem (ESAB, 2017). 
Figura 3 - Equipamentos analisados antes do processo de soldagem

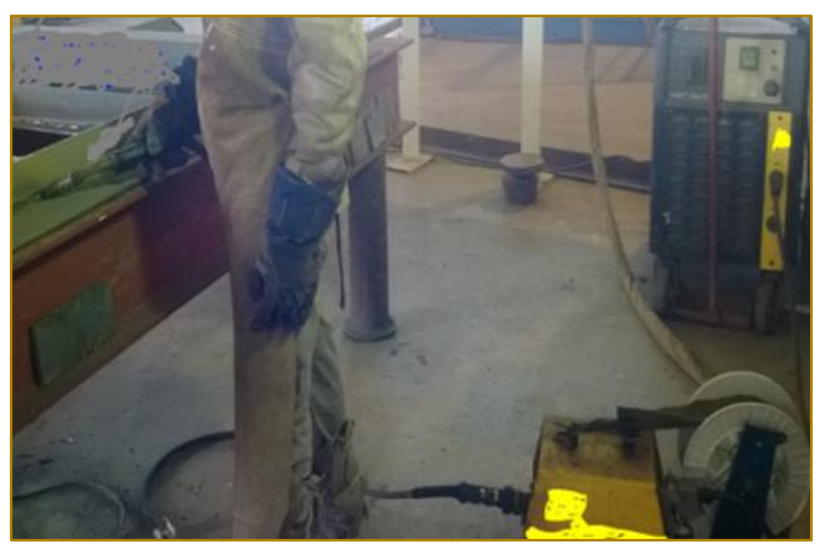

\section{CONCLUSÃO}

A partir do estudo realizado, e da análise dos resultados obtidos, percebe-se a relevância de um estudo mais aprofundado e o desenvolvimento de um equipamento, que seja capaz de realizar no mundo real, o que o modelo computacional produziu.

Constata-se então que o modelo computacional desenvolvido atende as expectativas de trazer o comportamento do processo de soldagem a Arco Elétrico para uma linguagem computacional, buscando encontrar melhorias.

Após o estudo realizado, verificou-se que o programa NetLogo gerado para o processo de soldagem, poderá ser implantado em empresas de produção, e com isto:

- Reduzirá o retrabalho nas peças produzidas;

\section{REFERÊNCIAS}

[1] AMERICAN WELDING SOCIETY. Welding Handbook. Vol.5,7.ed., Miami, 1997.

[2] ASTM - American Society for Testing and Materials. ASTM International - Standards Worldwide. Disponível em: < http:// www.astm.org>. Acesso em: 07 dez. 2017.

[3] ARAGÃO, A. P. Modelagem e Simulação Computacional de Processos Produtivos: o caso da cerâmica vermelha de Campos dos Goytacazes, R.J. Campo dos Goytacazes, Rio de Janeiro. $143 \mathrm{f}$. Mestrado em Engenharia de Produção, Universidade Estadual do Norte Fluminense, 2011.

[4] BANKS, J.; Carson, J.S.II \& NELSON, B.L. Discret-Event System Simulation. 2. ed., Prentice Hall, Upper Saddle Rive, 1996.
- Diminuirá o desperdício da matéria prima jogada para reciclagem, trocando custo por lucro para empresa;

- Evitará danos diretos ao profissional, pois terá uma maior segurança ao realizar o trabalho.

Sugere-se a criação dos processos por setor, para maior aproveitamento dos mesmos, e que seja realizado um estudo da quantidade de peças sem retrabalho por motivo de tensão.

Por meio de medidas diárias de conscientização de todos os envolvidos, o volume de peças sem retrabalho pode ser maior. O negócio, assim como o forte conhecimento técnico, a busca por aprimoramento de tecnologia, e a melhoria contínua refletem as exigências do mercado onde hoje não existe máquina que faça esse processo de desligamento automático, conforme pesquisa desse estudo.

[5] BANKS, J.; Carson, J.S. Discret-Event System Simulation. 3. ed., Prentice Hall, 2000.

[6] ESAB - PROCESSOS DE SOLDAGEM: ARAMES TUBULARES. Disponível em: < http://www.esab.com.br/br/pt/education/blog/proce sso_soldagem_arames_tubulares.cfm >. Acesso em: 07 dez. 2017.

[7] FBTS - FUNDAÇÃO BRASILEIRA DE TECNOLOGIA DA SOLDAGEM (Org.). Curso de Inspetor de Soldagem. Vol. 1, 417 p., Rio de Janeiro: Publit Soluções, 2012.

[8] LAW, A. M. \& KELTON, W. D. Simulation modeling and analysis. 3. ed. Boston: McGraw-Hill, 2000. 
[9] PEDGEN, C.D.; PRITSKER, A. A. B. Simulation Language for Alternatives Modeling. Simulation. Vol. 33, n. 5, 1979.

[10] SALIBY, R. Repensando a simulação: a amostragem descritiva. Rio de Janeiro: Atlas, 1989.
[11] SANTIAGO, P. M. de C. Automação da Colocaçãode Reforços numa Linha de Produção de Soldura. 87 f. Dissertação (Mestrado) - Curso de Engenharia Mecânica, Universidade Técnica de Lisboa, Lisboa, 2012. Disponível em <https://fenix.tecnico.ulisboa.pt/downloadFile/3951 44227003/Tese.pdf>. Acesso em: 04/12/17. 
APÊNDICE

Soldagem a Arco com Eletrodo Tubular, GMAW (ESAB, 2017).

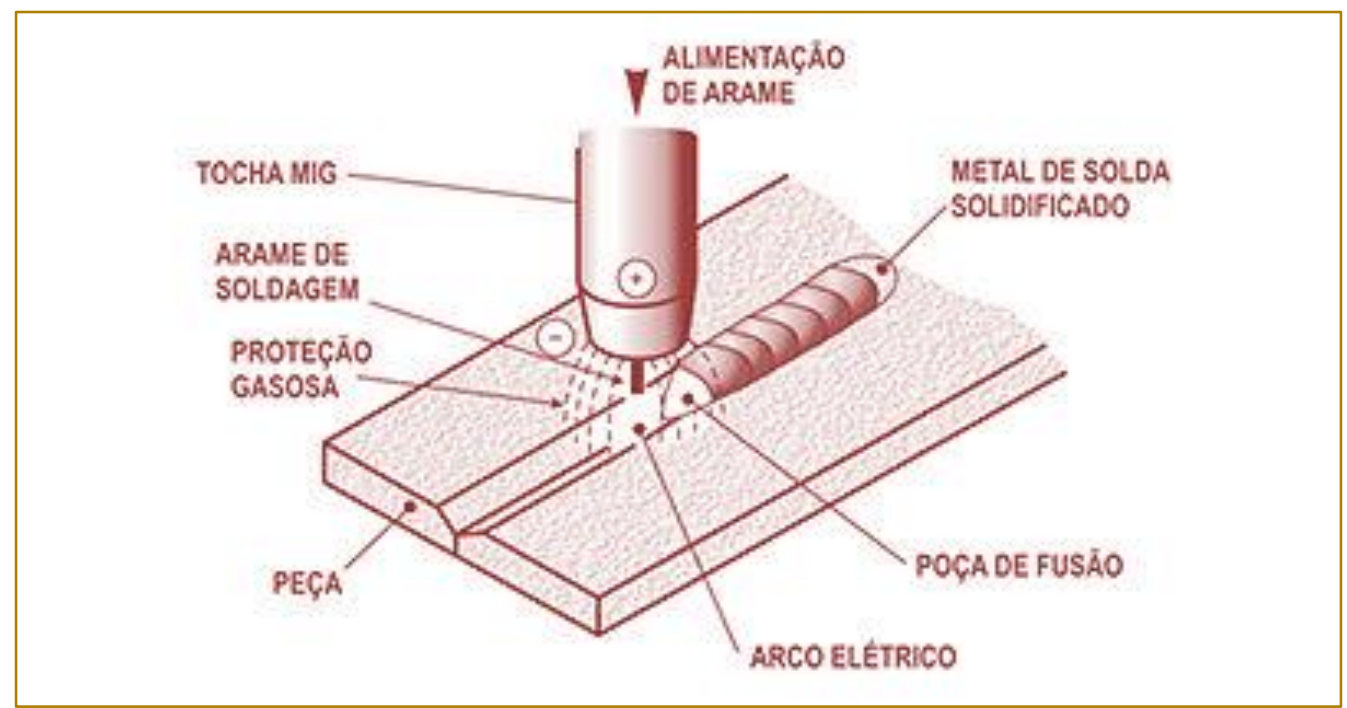




\section{Capítulo 22}

\section{APLICACÃO DA PROGRAMACÃO LINEAR NA MAXIMIZAÇÃO DOS LUCROS DE UMA PANIFICADORA}

\section{Lara Cristine Pereira dos Santos}

Natália Cibele de Sousa Santos

Jarbas Ancelmo da Silva Júnior

Resumo: O nível de concorrência enfrentado pelo meio empresarial está cada vez mais acirrado, sendo importante que as empresas busquem estratégias para atingir o melhor desempenho para sua empresa. Neste contexto, a Pesquisa Operacional se apresenta como uma ferramenta que auxilia o processo decisório, sendo a Programação Linear (PL) um de seus métodos. Dessa forma, a proposta deste trabalho é modelar um problema de maximização de lucros de uma empresa do setor de panificação a partir da PL. Para isso foi empregado o procedimento de pesquisa experimental devido ao uso do software $L I N D O \circledR$, o qual foi a ferramenta utilizada para a resolução do problema proposto. Através dos resultados, foi possível a análise de quais produtos possuem mais saídas e quais são menos vendidos e assim direcionar a tomada de decisão sobre o que deverá ser feito para que a empresa maximize seus lucros.

Palavras-chave: Pesquisa Operacional, Programação Linear, Maximização de Lucros. 


\section{INTRODUÇÃO}

É crescente o nível de concorrência enfrentado pelo meio empresarial, e se torna de extrema importância que estas não se estagnem ou retardem frente a seus concorrentes. Em consonância com o abordado, se torna interessante que as empresas busquem estratégias, ferramentas e métodos de distintas áreas, associando-as, com o intuito de atingir o melhor desempenho para sua empresa.

Neste contexto, é essencial, a adoção de ferramentas e métodos que auxilie as empresas e proporcione fundamento consistente para a tomada dessas relevantes decisões. E, nesta conjuntura que a Pesquisa Operacional (PO) se apresenta, como é defendido por Jesus, Toralles e Behrens (2015) onde a definem como sendo uma ferramenta com características matemáticas de auxílio ao processo decisório. Um dos métodos apresentados pela $\mathrm{PO}$, é a Programação Linear $(\mathrm{PL})$ que para Silva et al (2010), se trata de um modelo usado como um auxiliador de decisões, de cunho estratégico, no que tange uma maior eficiência, dentro das possibilidades, dos recursos disponíveis em cada um dos sistemas produtivos a fim de atingir os objetivos cobiçados pela empresa.

Hellier e Liebernman (2010, p.25), ainda acrescentam que "a programação linear envolve o planejamento de atividades para obter um resultado ótimo, isto é, um resultado que atinja o melhor objetivo especificado (de acordo com o modelo matemático) entre todas as alternativas viáveis".

Diante do apresentado, será utilizado no presente trabalho a PL, como uma auxiliadora de decisões, para o caso apresentado de uma panificadora, que atua no mercado em aproximadamente três anos. As informações coletadas são de dados semanais e as quitandas são comercializadas por quilograma.

Contudo, o objetivo geral do trabalho é modelar um problema de maximização de lucros a partir da Programação Linear. Com os resultados obtidos, será possível analisar quais os produtos que tem melhor saída, quais os de menor saída; a partir disso, tomar decisões sobre as atitudes que deverão ser tomadas pela empresa a fim de maximizar lucros.
Para cumprir o objetivo, o presente trabalho foi estruturado da seguinte forma: na seção 2 há o referencial teórico; a seção 3 apresenta a metodologia; na seção 4 apresenta um breve histórico da empresa; a seção 5 expõe os resultados obtidos; e, por fim, na seção 6 há as considerações finais.

\section{REFERENCIAL TEÓRICO}

\subsection{PROGRAMAÇÃO LINEAR}

A Pesquisa Operacional (PO) é um campo da ciência que dedica-se na criação de metodologias específicas para favorecer o gerenciamento de decisões. A PO teve sua origem nos primórdios da Segunda Guerra Mundial, no momento em que pesquisadores buscavam desenvolver métodos para resolução de problemas associados a operações militares (ANDRADE, 2009).

Em PO não existe apenas uma técnica para resolver todos os modelos matemáticos que surgem na prática. De acordo com Taha (2008), a complexidade do modelo matemático é que define a natureza do método de solução. A técnica mais empregada em $\mathrm{PO}$, principalmente tratando de problemas de otimização é a programação linear, a qual é aplicada a modelos, onde as restrições e a função objetivo são lineares.

Segundo Hillier e Lieberman (2010), a programação linear tem como principal objetivo alocar da melhor forma possível recursos escassos a atividades que competem entre si.

Ainda, segundo Andrade (2009) os problemas que envolvem alocação de recursos, buscam encontrar a melhor distribuição admissível dos recursos, de modo a atingir um valor ótimo do objetivo determinado. De modo geral, os problemas de $\mathrm{PL}$ pretendem alocar eficientemente os recursos limitados para atender um objetivo já definido, seja ele, maximizar os lucros ou minimizar os custos de uma organização. Tal objetivo é apresentado por meio de uma função linear, nomeada de função objetivo.

Para construir um modelo matemático para a resolução de problemas de $\mathrm{PL}$, deve-se seguir alguns passos a saber: definir o objetivo do problema, definir as variáveis de decisão, que são as incógnitas a serem determinadas na solução do modelo, como também elaborar a função objetivo, a qual é uma função linear com variáveis de decisão, 
em que seu valor deve ser otimizado (maximizado ou minimizado), deve-se ainda elaborar as restrições tecnológicas dos recursos e as restrições de não negatividade, por fim através de todas essas informações, elaborar o modelo que será otimizado e escolher o método matemático de solução (ANDRADE, 2009).

Existem vários métodos que podem ser utilizados na resolução de problemas de PL, um deles é o método simplex, realiza-se também resoluções manuais. Porém segundo Taha (2008), algumas resoluções manuais são particularmente tediosas, repetitivas e maçantes. Como também, encontrar soluções de PL em ambientes empresariais através de resoluções manuais, pode ser inviável, devido a maior quantidade de restrições e variáveis. Nesse sentido, alguns softwares foram criados para auxiliar na resolução e análise dos modelos, alguns deles são: AMPL, Excel Solver e o LINDOß.

O software LINDOR. (Linear, Interactive, and Discrete, Optimizer), foi desenvolvido para resolução de modelos de programação linear, quadrática ou inteira, sendo considerada uma importante ferramenta para resolução destes problemas, principalmente para resolução de problemas de programação linear, indicado por Prado (1999) e Caixeta Filho (2004). O mesmo tem sido utilizado em várias instituições de ensino superior. Através do software é possível encontrar a solução ótima para o problema, realizar interpretações econômicas, como custo reduzido, preço sombra, faixas de viabilidades para coeficientes da função objetivo e RHS.

Já o solver, complemento do Microsoft Excel, é uma ferramenta integrada ao conjunto de programas de análise hipotética, isto é, uma ferramenta que propicia encontrar um valor otimizado (ideal) para uma equação predeterminada. Para a resolução de problemas lineares, o Solver aplica o algoritmo Simplex com limites acerca das variáveis. Através desta ferramenta, assim como no LINDOR, é possível realizar a análise de sensibilidade, ou seja, as interpretações econômicas, bem como: custo reduzido, preço sombra, faixa de valores para RHS e coeficientes da função objetivo.

Em suma, a PL é considerada uma técnica poderosa para resolver problemas de alocação de recursos limitados. Todas as organizações preocupam-se com a alocação de recursos em alguma situação, portanto a
PL se tornou uma ferramenta de grande importância para várias organizações comerciais e industriais, por essa razão é perceptível a crescente aplicabilidade dessa técnica nos dias atuais.

\subsection{APLICAÇÕES INTERDISCIPLINARES DA PROGRAMAÇÃO LINEAR}

Os processos produtivos, antes restritos a unidades fabris, estão cada vez mais sendo vistos e analisados seguindo um contexto muito mais dinâmico e amplo das cadeias de suprimentos, sendo confrontado os métodos da administração vigentes (CAYRES et al., 2005). Exigindo das organizações que busquem e relacionem ferramentas de diversas áreas da engenharia de produção a fim de amplificarem seus rendimentos.

Segundo Jantsch e Bianchetti (1999) a interdisciplinaridade se caracteriza através da associação dentre um conjunto de disciplinas, em que uma destas ocupa um nível hierárquico superior se comparada com a outra. De acordo com Nicolescu (2005) um de seus objetivos consiste no uso de um método utilizado em uma disciplina aplicando-a em uma outra área.

Ferreira e Bachega (2011) afirmam que pesquisa operacional apresenta um campo de aplicação ampla em diversos segmentos, como finanças, saúde, transporte, indústria, serviços públicos, telecomunicações e operações militares. Prado (2010) destaca, ainda, que a PL (programação linear) se caracteriza como sendo uma ferramenta de planejamento apropriada na produção de resultados em diversas áreas das atividades humanas. Mesquista e Santoro (2004) destacam que, tradicionalmente, as áreas de logística e de planejamento e controle da produção são os campos que proporcionam uma maior emprego de modelos de otimização. $O$ presente trabalho se apresentará através da relação entre a PL e o PCP.

O planejamento e controle da produção tem como funcionalidade administrativa a determinação, de forma antecipada, de quais os objetivos almejados, assim como, o que, o quanto e como fazer, a fim de garantir que a finalidade proposta seja atingida (NICOLESCU, 2005).

O presente trabalho tem como finalidade realizar uma modelagem matemática a fim de encontrar a solução de produção e venda 
ótima, garantindo de forma mais eficiente a alocação de recursos para a produção em uma panificadora, assegurando uma maximização do lucro da mesma. Será feita uma associação com o PCP, utilizando os dados encontrados na modelagem, com o objetivo de antecipar e realizar um planejamento mais adequado para a realidade da empresa.

Com as informações adquiridas através da programação é possível realizar uma previsão de demanda, ferramenta do PCP, que segundo Corrêa (2009) é de extrema valia que a empresa saiba usar todas as ferramentas acessíveis com a finalidade de antecipar as futuras demandas com precisão.

Foi possível determinar o quanto deve-se produzir de cada produto comercializado pela empresa, utilizando os recursos disponíveis. Tendo esta informação encontrada, é possível fazer um planejamento mais eficaz e antecipado dos recursos a serem adquiridos e a quantidade a ser produzida pela panificadora.

\section{METODOLOGIA}

O procedimento de pesquisa utilizado neste trabalho é a pesquisa experimental, pois de acordo com Trivinos (1987) a pesquisa experimental demanda um planejamento rigoroso que parte da formulação do problema e das hipóteses que restringem as variáveis que atuam sobre o fenômeno estudado, o que torna esse método bastante útil para o seguinte trabalho.

No que se refere à abordagem a pesquisa pode ser qualitativa ou quantitativa (BRYMAN, 1989) exposto isso, podemos classificar a natureza desse estudo como quantitativa. A pesquisa foi realizada na padaria Nascer do Sol, localizada na cidade de Catalão - GO, a coleta de dados se restringiu ao período de uma semana.

No objetivo de conhecer a fundo o dia a dia da padaria empregou-se primeiramente a visita in loco e a entrevista estruturada como fontes de evidência, sendo possível coletar informações do histórico da empresa e suas principais atividades, bem como as características do processo de produção das quitandas como: limitação de matéria- prima, capacidade produtiva, horário de funcionamento, demanda etc.
De acordo com Arenales et al. (2007, p. 3) "o modelo matemático é uma representação simplificada(abstração) do problema real" dessa forma, após a coleta dos dados definiuse as principais variáveis de decisão que maximizam o lucro da padaria, e as restrições tecnológicas, dentre as quais destacam- se: limitações de mercado e disponibilidade de matérias-primas.

Segundo Cervo e Bervian (1983) a pesquisa experimental tem como característica a manipulação direta das variáveis que estão relacionadas com o objeto de estudo, tendo como resultado a relação entre causa e efeito de um fenômeno em questão, para tanto, temos as seguintes fases que proporcionam a resolução de um problema de pesquisa operacional (TAHA, 2008):

- Definição do problema: são determinadas as variáveis de decisão, os objetivos almejados, bem como as limitações operacionais;

- Construção do modelo: formula-se matematicamente o problema em questão;

- Solução do modelo: com o auxílio de softwares, é possível realizar análises de sensibilidade e de cenários, verificar a consistência das soluções, e a adequação do modelo computacional;

- Validação do modelo: verifica-se a representação do modelo com relação ao problema, ou seja, se o modelo descreve apropriadamente 0 respectivo sistema estudado de acordo com as hipóteses definidas;

- Implementação da solução: etapa onde os resultados obtidos são traduzidos em conclusões, e repassados para o corpo administrativo da empresa.

A técnica de otimização utilizada na resolução do modelo matemático, foi a Programação Linear Não Inteira com a participação do software LINDO® v.6.1 trial version, cujo método de solução aplicado foi o LP Simplex, devido o caráter linear do problema.

\section{BREVE HISTÓRICO DA EMPRESA}

A Panificadora Nascer do Sol é uma microempresa que está no mercado há dois anos e dez meses e está localizada no Setor Universitário em Catalão - GO. 
A proprietária trabalha no ramo de panificação há nove anos. A oportunidade de abrir o próprio negócio surgiu nas redes sociais, quando, em um anúncio, o antigo proprietário estava vendendo a panificadora. A atual proprietária se interessou pelo ponto e depois de algumas negociações comprou a panificadora.

A empresa é de caráter familiar e trabalham cinco pessoas nos horários:

- Segunda à sexta - 6:00 às 18:00

- Sábado - 6:00 às 15:00

- Domingo - 7:00 às 12:00

A panificadora é a empresa de estudo deste trabalho, cujo objetivo é maximizar seus lucros através de suas quitandas. Vários são os produtos oferecidos pela panificadora, porém, neste trabalho, optou-se pelos que mais têm saída.

Dentre os instrumentos de coleta de dados, optou-se por entrevista por pauta, que tem por característica o agendamento pelo entrevistador de vários pontos a serem explorados com o entrevistado, como por exemplo, os produtos comercializados, matérias primas utilizadas, quantidades de venda.

\section{RESULTADOS E DISCUSSÕES}

\subsection{DEFINIÇÃO DO PROBLEMA}

Para a modelagem matemática do problema, o objetivo escolhido é a maximização do lucro. As informações coletadas através da entrevista realizada referem-se às quantidades produzidas e vendidas em uma semana.

As variáveis foram selecionadas de acordo com seu grau de relevância. Foram escolhidas cinco tipos de quitandas que possuem maior saída, sendo, portanto, as responsáveis pela maior parte do lucro obtido. São elas: pão de queijo; biscoito de queijo; biscoito de goma; broa de fubá de sal; broa de fubá de doce.

O lucro e a quantidade utilizada de polvilho são referentes a um quilo do produto final. A limitação de venda se refere à quantidade máxima vendida em uma semana. Todos esses dados estão explicitados na tabela 1.

TABELA 1 - Informações coletadas dos produtos da panificadora

\begin{tabular}{|l|c|c|c|}
\multicolumn{1}{c|}{ Quitanda } & Lucro $/ \mathrm{Kg}$ & $\begin{array}{c}\text { Limitação de venda - } \\
\mathrm{Kg}\end{array}$ & $\begin{array}{c}\text { Utilização de polvilho / } \\
\mathrm{Kg}\end{array}$ \\
\hline Pão de queijo & $\mathrm{R} \$ 15,50$ & 180 & 0,6 \\
\hline Biscoito de queijo & $\mathrm{R} \$ 21,50$ & 20 & 0,48 \\
\hline Biscoito de goma & $\mathrm{R} \$ 13,50$ & 7,5 & 0,48 \\
\hline Broa de fubá de sal & $\mathrm{R} \$ 12,75$ & 11 & 0,12 \\
\hline Broa de fubá de doce & $\mathrm{R} \$ 18,00$ & 12 & 0,16 \\
\hline
\end{tabular}

Fonte: Elaborada pelos autores

O polvilho foi a matéria prima escolhida por ser a única com restrições, sendo $120 \mathrm{~kg}$ por semana. Outras matérias primas, como ovo, queijo, leite, óleo, entre outros, são de fácil obtenção, pois os fornecedores desses itens conseguem entregá-los no mesmo momento do pedido e os que não podem ser adquiridos dessa forma, são comprados em um supermercado que fica a 200 metros da panificadora. Tal decisão pode levar à custos maiores, pois no supermercado o preço é maior que dos fornecedores.

\subsection{CONSTRUÇÃO DO MODELO}

Em posse de todos os dados que foram apresentados, se torna possível a construção do modelo.

- Passo 1 - Definir as variáveis de decisão

Quantidade a ser produzida em uma semana de:

- X1 - pão de queijo;

- X2 - biscoito de queijo;

- X3 - biscoito de goma;

- X4 - broa de fubá de sal; 
- X5 - broa de fubá de doce.

- Passo 2 - Elaborar a função objetivo

$\operatorname{MAX} Z=15,5 X 1+21,5 X 2+13,50 X 3+$ $12,75 \times 4+18 \times 5$

- Passo 3 - Formular as restrições tecnológicas e de não negatividade

- $\mathrm{X} 1 \leq 180$

- $\quad x 2 \leq 20$

- $\mathrm{X} 3 \leq 7,5$

- $\mathrm{X} 4 \leq 11$

- $\mathrm{X} 5 \leq 12$

- $0,6 \times 1+0,48 \times 2+0,48 \times 3+0,12 \times 4+$

$0,16 \times 5 \leq 120$

- $\quad X i \geq 0, i=1,2, \ldots, 5$

Das restrições, temos: de 1 à 5 referente a quantidade máxima vendida das respectivas quitandas em uma semana; (6) quantidade máxima de polvilho disponível em uma semana; (7) restrição de não negatividade.
- Passo 4 - Elaborar o modelo

Portanto, o modelo matemático deste problema é:

MAX $Z=15,5 X 1+21,5 X 2+13,50 X 3+$ $12,75 \times 4+18 \times 5$

s.a.

$\mathrm{X} 1 \leq 180$

$\mathrm{X} 2 \leq 20$

$\mathrm{X} 3 \leq 7,5$

$\mathrm{X} 4 \leq 11$

$\mathrm{X} 5 \leq 12$

$0,6 \times 1+0,48 \times 2+0,48 \times 3+0,12 \times 4+0,16 \times 5 \leq$ 120

$X i \geq 0, i=1,2, . ., 5$

\subsection{ANÁLISE DOS RESULTADOS}

Após a construção do modelo matemático de maximização, utilizou-se o software LINDO® para obter a solução do problema.

$\mathrm{Na}$ figura a seguir, temos os relatórios gerados pelo software que nos permite analisar os resultados obtidos:

FIGURA 1 - Relatório gerado pelo LINDO®

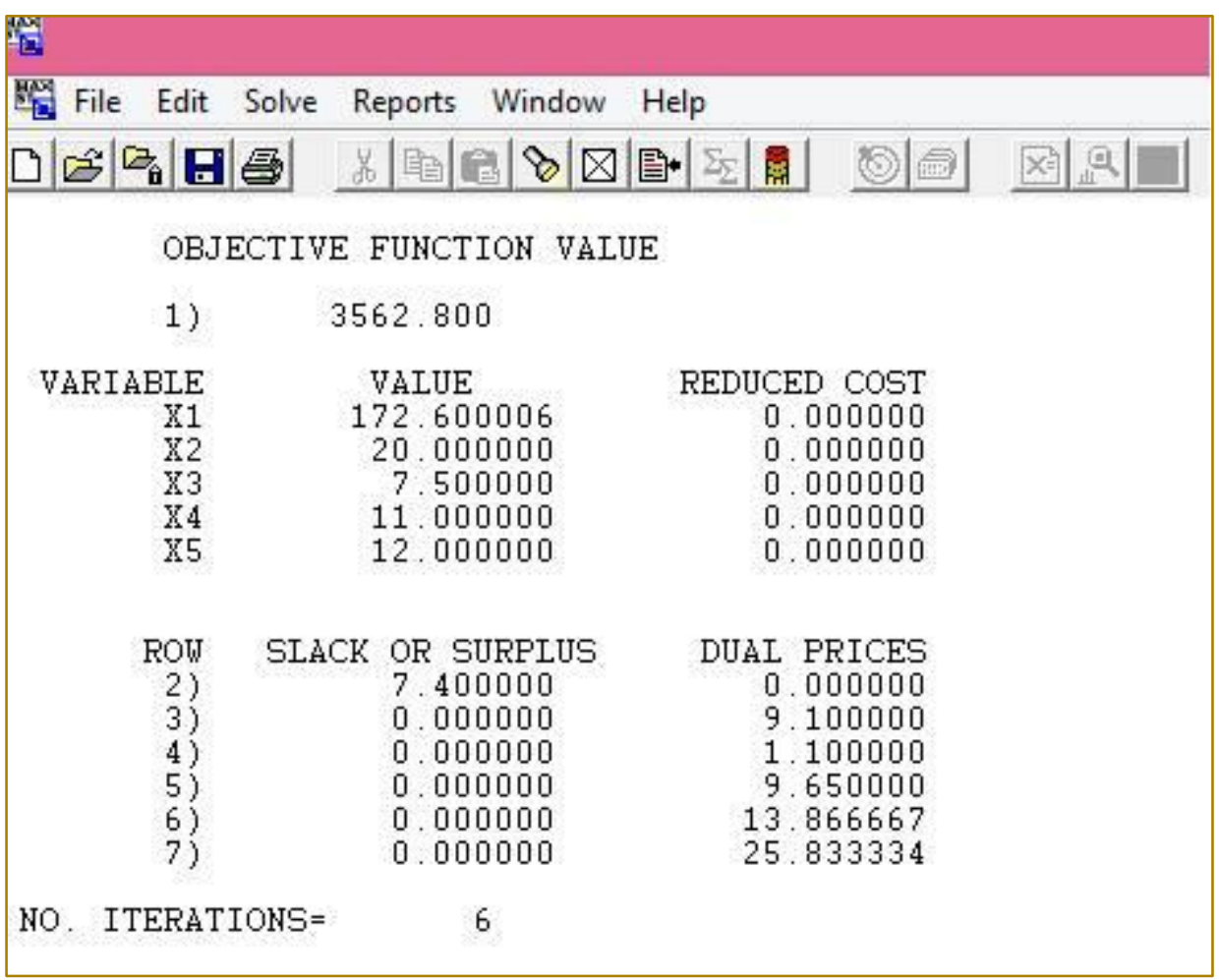

Fonte: Adaptado do LINDO®. 
Como pode ser observado na figura 1 , depois de serem feitas seis iterações, tem-se que 0 lucro máximo alcançado é de $R \$ 3562,80$ quando realiza-se a venda de quitandas nas seguintes quantidades: $172,6 \mathrm{Kg}$ de pão de queijo; $20 \mathrm{Kg}$ de biscoito de queijo; 7,5 $\mathrm{Kg}$ de biscoito de goma; $11 \mathrm{Kg}$ de broa de fubá de sal; $12 \mathrm{Kg}$ de broa de fubá de doce.

O custo reduzido aparece quando uma variável não entra na solução ótima do problema. Caso a variável apresente custo reduzido, haverá uma penalidade a pagar para que a mesma possa entrar na solução ou esse valor deverá ser incrementado no coeficiente da variável, na função objetivo, para que a variável participe da solução. $\mathrm{Na}$ coluna Reduced Cost, que pode ser observada na figura 1, tem-se que nenhuma variável apresentou custo reduzido, ou seja, todas as variáveis entraram para a solução do problema.

O preço sombra indica que se for possível aumentar o RHS da restrição, haverá um aumento na função objetivo. Na coluna Dual Prices ou Shadow Prices, todas as restrições tiveram preço sombra, exceto pela restrição (1), referente a limitação de venda do pão de queijo.

- Para a restrição (2), referente ao biscoito de queijo, tem-se o preço sombra de $\mathrm{R} \$$ 9,10;
- Para a restrição (3), referente ao biscoito de goma, tem-se o preço sombra de $\mathrm{R} \$ 1,10$;

- $\quad$ Para a restrição (4), referente à broa de fubá de sal, tem-se o preço sombra de $\mathrm{R} \$$ 9,65;

- $\quad$ Para a restrição (5), referente à broa de fubá de doce, tem-se o preço sombra de $R \$ 13,87$

Ou seja, para cada uma dessas restrições apresentadas, se aumentar $1 \mathrm{Kg}$ da venda de suas respectivas quitandas, aumentará o lucro em seus respectivos preços sombra.

- Para a restrição (6), referente ao polvilho, tem-se o preço sombra de $R \$ 25,83$; ou seja, a cada $\mathrm{Kg}$ a mais disponível de polvilho aumentará o lucro em $\mathrm{R} \$$ 9,10.

Folga ou excesso indica que a disponibilidade total não foi usada completamente, gerando folga, ou foi preciso usar mais que a disponibilidade, gerando excesso. Na coluna Slack or Surplus, como pode ser observado na figura $x$, tem-se folga de $7,4 \mathrm{Kg}$ apenas para a restrição (1). Havia uma disponibilidade de até $180 \mathrm{Kg}$ por semana para a venda do pão de queijo, porém, houve uma sobra de 7,4 Kg, vendendo apenas 172,6 Kg por semana. Dessa forma, não foi preciso vender toda a disponibilidade de pão de queijo para alcançar o lucro máximo.

FIGURA 2 - Relatório de faixas de viabilidade gerado pelo LINDO®

\begin{tabular}{|c|c|c|c|}
\hline \multicolumn{2}{|c|}{ RANGES IN WHICH THE BASIS } & \multicolumn{2}{|l|}{ IS UNCHANGED: } \\
\hline $\begin{array}{l}\mathrm{X} 1 \\
\mathrm{X} 2 \\
\mathrm{X} 3 \\
\mathrm{X} 4 \\
\mathrm{X} 5\end{array}$ & $\begin{array}{l}\text { CURRENT } \\
\text { COEF } \\
15.500000 \\
21.500000 \\
13.500000 \\
12.750000 \\
18.000000\end{array}$ & $\begin{array}{l}\text { OBJ COEFFICIENT RANGES } \\
\text { ALIOWABIE } \\
\text { INCREASE } \\
1.375000 \\
\text { INFINITY } \\
\text { INFINITY } \\
\text { INFINITY } \\
\text { INFINITY }\end{array}$ & $\begin{array}{l}\text { ALIOWABIE } \\
\text { DECREASE } \\
15.500001 \\
9.100000 \\
1.100000 \\
9.650000 \\
13.866667\end{array}$ \\
\hline $\begin{array}{l}2 \\
3 \\
4 \\
5 \\
6 \\
7\end{array}$ & $\begin{array}{r}\text { CURRENT } \\
\text { RHS } \\
180.000000 \\
20.000000 \\
7.500000 \\
11.000000 \\
12.000000 \\
120.000000\end{array}$ & $\begin{array}{c}\text { RIGHTHAND SIDE RANGES } \\
\text { ALIOWABLE } \\
\text { INCREASE } \\
\text { INFINITY } \\
215.750000 \\
215.750000 \\
863.000000 \\
647.250000 \\
4.440000\end{array}$ & $\begin{array}{r}\text { ALLOWABLE } \\
\text { DECREASE } \\
7.400000 \\
9.250000 \\
7.500000 \\
11.000000 \\
12.000000 \\
103.560005\end{array}$ \\
\hline
\end{tabular}

Fonte: Adaptado do LINDO®. Elaborado pelos autores

A tabela 3 apresenta as faixas de valores mínimos e máximos, nos quais, poderão ser acrescentados ou diminuídos ao coeficiente da Função Objetivo da variável em questão, sem que haja alteração na solução ótima do problema. Pode-se chegar aos valores descritos abaixo, através do relatório gerado pelo LINDOR, em Obj Coeficient Ranges, apresentado na figura 2. 
TABELA 2 - Faixas de valores as quais a solução ótima permanece a mesma

\begin{tabular}{|c|c|c|c|}
\hline Quitandas & Mínimo & Atual & Máximo \\
\hline Pão de Queijo (X1) & 0 & 15,5 & 16,875 \\
\hline Biscoito de Queijo (X2) & 12,4 & 21,5 & Infinito \\
\hline Biscoito de Goma (X3) & 12,4 & 13,5 & Infinito \\
\hline Broa de fubá de sal (X4) & 3,1 & 12,75 & Infinito \\
\hline Broa de fubá de doce (X5) & 4,13 & 18 & Infinito \\
\hline
\end{tabular}

Fonte: Elaborado pelos autores

De acordo com o relatório gerado pelo LINDO®, em Righthand side ranges temos as faixas de viabilidade nas quais o preço sombra permanece o mesmo. Ao alterarmos o RHS, o preço sombra permanecerá válido para essas faixas de valores descritas abaixo. Variações fora dessa faixa produzirão um preço sombra (equivalente por unidade) diferente.

TABELA 3 - Faixas de valores as quais o preço sombra permanecerá válido

\begin{tabular}{|c|c|c|c|}
\hline Quitandas & Mínimo & Atual & Máximo \\
\hline Pão de Queijo & 172,6 & 180 & Infinito \\
\hline Biscoito de Queijo & 10,75 & 20 & 235,75 \\
\hline Biscoito de Goma & 0 & 7,5 & 215,75 \\
\hline Broa de fubá de sal & 0 & 11 & 874 \\
\hline Broa de fubá de doce & 0 & 12 & 647,25 \\
\hline Polvilho & 16,44 & 120 & 124,44 \\
\hline
\end{tabular}

Fonte: Elaborado pelos autores

\section{CONSIDERAÇÕES FINAIS}

O objetivo inicialmente proposto pelo trabalho foi atingido. Foi realizada uma modelagem matemática usando programação linear, elaborada com base em dados reais e semanais de uma panificadora, através do software LINDO® puderam-se analisar os resultados obtidos por meio da aplicação da $\mathrm{PL}$, identificou-se quais as quantidades ótimas de quitandas que devem ser vendidas por semana para maximizar o lucro da empresa estudada. Aferiu-se, ainda, que a empresa deve comercializar todas as quitandas (disponíveis) analisadas por este trabalho.

Pode-se constatar que a ferramenta, programação linear, é de extrema valia para este modelo de problemática, pois é uma ferramenta que auxilia e facilita processos decisórios.
O presente trabalho pôde contribuir no meio empresarial, à medida que possibilitou uma maior divulgação da possibilidade do uso de modelos matemáticos em pequenas e médias empresas, como auxiliar na gestão de operação e no processo decisório das empresas. Houve uma contribuição para a empresa estudada que poderá utilizar os dados obtidos, a fim de amplificarem seus rendimentos. Sua contribuição para o meio acadêmico foi a de apresentar uma maior discussão a respeito das técnicas de Programação Linear e dos softwares que facilitam a resolução e análises dos problemas de PL.

Para trabalhos futuros sugere-se a aplicação desta técnica na empresa estudada, bem como, realizar melhorias no modelo apresentado e aplicar à realidade de outras empresas. 


\section{REFERÊNCIAS}

[1] ANDRADE, E. L. Introdução à pesquisa operacional: métodos e modelos para análises de decisões. 4. Ed. Rio de Janeiro: LTC, 2009.

[2] ARENALES, M.; ARMENTANO, V. A.; MORABITO, R.; YANASSE, $H$. $H$. Pesquisa operacional. Rio de Janeiro: Campus/Elsevier, 2007.

[3] BRYMAN, A. Research methods and organization studies. 1a ed. London: Uniwin Hyman, 1989.

[4] CAYRES, P. G.; PAULINO, M. V. R.; CERQUEIRA, C. G.; HERMOSILLA, J. L. G.; AMARAL, A. C. O aprendizado interdisciplinar através do desenvolvimento do produto: um estudo de caso envolvendo a área de fisioterapia. ENEGEP, 2005

[5] CAIXETA-FILHO, J. V. Pesquisa Operacional: técnicas de otimização aplicadas à sistemas agroindustriais. São Paulo: Atlas, 2004.

[6] CERVO, A.L.; BERVIAN, P.A. Metodologia científica. 3. ed. São Paulo: McGraw-Hill do Brasil, 1983.

[7] CORREAA, H. L.; GIANESI, I. G. N.; CAON, M. Planejamento, programação e controle da produção. 5aㅡ Edição. São Paulo: Atlas, 2009.

[8] FERREIRA, F. M.; BACHEGA, S. J. Programação linear: um estudo de caso sobre os custos de transporte em uma empresa do setor de confecções de Catalão-go. ENEGEP, 2011.

[9] JANTSCH, A. P.; BIANCHETTI, L. Interdisciplinaridade: para além da filosofia do sujeito. Editora Vozes, 4를 Edção, 2000.
[10] HILLIER, F.S.; LIEBERMAN, G.J. Introdução à pesquisa operacional. Porto Alegre: Bookman, 2010

[11] JESUS, R.J.B; TORALLES, R.P.; BEHRENS, P.A.C. Pesquisa operacional: uma ferramenta do processo decisório no setor de compras. ENEGEP, 2015.

[12] MESQUITA, M. A.; SANTORO, M. C. Análise de modelos e práticas de planejamento e controle da produção na indústria farmacêutica. Revista Produção, v. 14 n. 1, 2004.

[13] NICOLESCU, B. Transdisciplinarity: past, present and future. In: congresso mundial de transdisciplinaridade, 2, Vila Velha/Vitória, 2005.

[14] PRADO, D. S. Programação Linear. 6 Edição Belo Horizonte. Editora indg tecnologia e serviços Itda, 2010.

[15] PRADO, D. S. Programação Linear. Belo Horizonte, Minas Gerais: Editora de Desenvolvimento Gerencial, 1999.

[16] SILVA, E. M. Da; SILVA, E. M. Da; GONCALVES, Valter. Pesquisa operacional: programação linear, simulação. 3. ed. São Paulo: Atlas,2010.

[17] TAHA, H.A. Pesquisa operacional: uma visão geral. São Paulo: Pearson Prentice Hall, 2008.

[18] TRIVIÑOS, A. N. S. Introdução à pesquisa em ciências sociais: a pesquisa qualitativa em educação. São Paulo: Atlas, 1987.

[19] TUBINO, D. F. Manual de planejamento e controle da produção. $2^{a}$ Edição. São Paulo: Atlas, 2000. 


$$
\text { Alutary }
$$




\section{ADRIANO MENDONCA SOUZA}

Possui graduação em Matemática (Faculdade Imaculada Conceição- Santa Maria), Especialização em Estatística e Modelagem Quantitativa (Universidade Federal de Santa Maria Santa Maria) e Mestrado em Engenharia de Produção (UFSM). Doutorado em Engenharia de Produção (Universidade Federal de Santa Catarina - SC) e neste período atuou como pesquisador na Texas A \& M University (TX? USA), realizou post-doc no Instituto Superior da Ciência do Trabalho e da Empresa - ISCTE - Business School - Lisbon Institute Portugal. Atualmente é Professor Titular do Departamento de Estatística (UFSM) atuando nos curso de Especialização em Estatística e Modelagem Quantitativa (UFSM) e no Mestrado em Engenharia de Produção (UFSM) assim como nos demais cursos de graduação da instituição

\section{ALEXANDRE CARVALHO DANTAS}

Possui graduação em Ciências Econômicas pelo Instituto Superior de Ciências Aplicadas (1993) e graduação em Administração de Empresas pelo Instituto Superior de Ciências Aplicadas (1997). Atualmente é professor - Faculdades Integradas Einstein de Limeira e Gerente Geral de Agência no Banco do Brasil S.A.. Tem experiência na área de Administração e auditoria interna, com ênfase em Administração Estratégica, Gestão de Projetos e OSM, atuando principalmente nos seguintes temas: planejamento estratégico de sistemas de informação e BSC.

\section{ALINE PEREIRA SANTOS}

Graduanda de Engenharia de Produção pela Universidade do Estado do Pará.

\section{ÁLVARO DANIEL OLIVEIRA LOPES}

Possui graduação em Engenharia de Computação pela Universidade Federal do Rio Grande do Norte e atualmente cursa o Mestrado em Engenharia Elétrica na Universidade Federal do Espírito Santo.

\section{ANDERSON SENHORELI}

Graduado em Engenharia de Produção pela Pontifícia Universidade Católica do Paraná Câmpus Londrina (2017). Especialista em Administração e Finanças - Faculdade São Braz (2018). Atualmente está cursando MBA em Gestão da Qualidade - Ênfase em Seis Sigma e Lean Manufacturing - Unopar, atua como gerente de produção na empresa Alumpar Alumínios. Experiência em processos de fundição e fabricação de tarugos de alumínio, tratamentos térmico e termoquímicos.

\section{ANDRÉ LUIZ A. C. VENÂNCIO}

Pesquisador bolsista da CAPES, vinculado ao Mestrado do Programa de Pós-Graduação em Engenharia de Produção e Sistemas - PPGEPS da Pontifícia Universidade Católica do Paraná - PUCPR. Tem como principais áreas de pesquisa as temáticas: Indústria 4.0; Sistemas Legado e seu aprimoramento para interação com tecnologias e processos mais atuais; Interoperabilidade; e Métodos de Tomada de Decisão de Múltiplos Critérios. Cofundador da GO44, empresa anteriormente acelerada na Agência de Inovação da PUCPR e que atualmente presta serviços de análise de maturidade industrial para organizações que buscam a transformação digital pela implementação de tecnologias e processos referentes a Indústria 4.0. 


\section{BIANCO GALLAZZI DA SILVA LEITE}

Formado em engenharia mecânica plena pela Escola de Engenharia de Piracicaba em 2006, pós graduado em engenharia de petróleo e gás pela Universidade Federal Fluminense (UFF) em 2007, especializou-se em engenharia de soldagem na Unimep juntamente com o International Institute of Welding (IIW) e a Associação Brasileira de soldagem (ABS) em 2011, atualmente é aluno de mestrado em engenharia de produção na Unimep em 2016. No ambiente industrial tem mais de 13 anos de experiencia na gestao de equipes técnicas de inspeção e analises metalúrgicas. Responsável técnico perante o INMETRO na área de analises laboratoriais metalúrgicas. Lecionando a mais de 6 anos nas disciplinas de tecnologia de soldagem e materiais.

\section{CAMILA APARECIDA SOARES DE OLIVEIRA}

Graduou-se em Engenharia de Produção pela Pontifícia Universidade Católica do Paraná, na condição de bolsista integral, em 2016. Atuou como aprendiz e estagiária em multinacionais como Dixie\&Toga e Sonoco, nos setores de Controle da Qualidade e Planejamento e Controle da Produção respectivamente. Em pequenas/médias empresas, tem experiência na implantação de Sistemas de Gestão da Qualidade e certificação INMETRO. Cursou MBA em Gestão de Negócios e Estratégia Empresarial na Universidade Pitágoras Unopar (2018). Atualmente (2019), cursa Mestrado em Ciências e Engenharia de Materiais na Universidade Tecnológica Federal do Paraná e MBA em Gestão da Qualidade - Ênfase em Seis Sigma e Lean Manufacturing na Universidade Pitágoras Unopar.

\section{CAROLINE KUHL GENNARO}

Doutoranda em Engenharia de Produção (início: 2016). Mestre em Engenharia de Produção pela Universidade Metodista de Piracicaba (2016) e Graduação em Engenharia de Produção pela Universidade Metodista de Piracicaba (2013). Tem experiência na área de Engenharia de Produção, com ênfase em Sistema de Gestão da Qualidade, atuando principalmente nos seguintes temas: processos especiais, cqi, melhoria continua, melhoria focada e world clas manufacturing;.

\section{DANIEL RENÉ TASÉ VELÁZQUEZ}

Graduado em Engenharia Industrial (2012) pela Universidad de Holguín, Cuba. Desempenhou-se como Engenheiro Industrial (2012-2015) na Empresa Florestal de HolguínCuba atuando como Especialista em Gestão de Recursos Humanos (diretrizes NC ISO 3000 SGICH) e como membro do Comité de Implantação do SGQ com enfoque em processos (diretrizes da ISO 9001:2008). Mestrado em Metrologia (2017) pela Pontifícia Universidade Católica do Rio de Janeiro. Atualmente é Pesquisador-Doutorando do Programa de Pósgraduação em Engenharia de Produção na Universidade Metodista de Piracicaba (2018 2022) na área de concentração Engenharia do produto e do processo. Nesta área atua na linha de pesquisa Engenharia do processo voltada para o desenvolvimento de estratégias de fabricação de superfícies complexas no contexto da manufatura híbrida (combinação de processos aditivos e subtrativos).

\section{DANIELLE SARANH GALDINO DUARTE GARCIA}

Graduada em Engenharia Civil (UNICENTRO NEWTON PAIVA). Especialista em Perícia e Auditoria Ambiental (UNINTER). Mestranda em Engenharia Civil (CEFET-MG). Docente em cursos de Engenharia (FEAMIG E FASEH).

\section{DIEGO QUINELATTO ROSSI}

Possui graduação em Engenharia de Produção pela Universidade de Araraquara (2016). Tem experiência na área de Engenharia de Produção, com ênfase em Gestão da Qualidade, 
atuando principalmente nos seguintes temas: fast food, mapeamento de fluxo de valor, planejamento, processamento, treinamento e recursos humanos. Atualmente trabalha como consultor de operações nas áreas de planejamento e treinamento.

\section{EDUARDO DE FREITAS ROCHA LOURES}

Professor Titular vinculado ao curso de Engenharia de Controle e Automação e Engenharia de Produção da Escola Politécnica da Pontifícia Universidade Católica do Paraná - PUCPR. Atualmente é pesquisador permanente do Programa de Pós-Graduação em Engenharia de Produção e Sistemas PPGEPS, PUCPR. Diretor da ISA (International Society of Automation), Distrito 4 América do Sul, Seção Curitiba. Bolsista de Produtividade Desenvolvimento Tecnológico e Extensão Inovadora do CNPq. Coordenador de diferentes projetos PD\&I com iniciativa privada e pública em temáticas como a Indústria 4.0, Gerenciamento de Ativos e Manutenção, Interoperabilidade e Engenharia Organizacional.

\section{EDUARDO EZEQUIEL ZANIBONI}

Graduando em Engenharia de Produção pelas Faculdades Integradas Einstein de Limeira

\section{EVERTON DIAS DE OLIVEIRA}

É Engenheiro Eletricista, graduado pela Pontifícia Universidade Católica de Campinas (PUCCAMPINAS, 2013), Mestre em Sistemas de Infraestrutura Urbana (PUC-CAMPINAS, 2015), e Doutorando em Engenharia de Produção, atuando na linha de pesquisa: Meio Ambiente, Energia e Produção Limpa (UNIMEP, 2017-2020). Possui experiência profissional em designer de hardware em microeletrônica para sistemas ópticos, desenvolvimento de circuitos em hardware digital em VHDL, desenvolvimento, monitoramento e gerenciamento de sistemas de eficiência energética, e desenvolvimento em redes de sensores.

\section{FÁBIA MARIA DE SOUZA}

Doutora em Engenharia de Produção (UFSCar - 2013/2017); Mestrado em Educação (Universidade Adventista de São Paulo / 2003); Especialização em Tecnologias em Educação (PUC-RJ / 2007), Gestão Escolar (CESUP/2003); Orientação Educacional (UNIVERSO/1997) Graduação em Pedagogia - Habilitação Administração Escolar - (UEPA /1994). Experiência em Gestão Publica: Diretora da 15aㅗ Regional de Educação Pará (2001/2002), Coordenadora Geral Campus XV/UEPA/Redenção (dez.2009/jan.2014); Professora Assistente III e pesquisadora da Universidade do Estado do Pará (1995 a atualidade), atuando no Ensino, Extensão e no grupo de NUPAD - Núcleo de Pesquisas Aplicadas ao Desenvolvimento Regional (UEPA) É referee no evento SIMPEP.

\section{FERNANDA STEFFENS}

Concluiu o doutorado em Engenharia Têxtil pela Universidade do Minho, Guimarães, Portugal (2015). Possui Mestrado em Engenharia Têxtil e Confecção pela Technische Universität Dresden, Alemanha (2011). MBA em Gestão Empresarial pela Fundação Getúlio Vargas (2008). Graduação em Engenharia Industrial Têxtil pela Faculdade Senai-Cetiqt (2005). Além disso possui experiência na área industrial têxtil. Sua área de atuação consiste em Engenharia Têxtil e Confecção, no desenvolvimento de malhas com comportamento auxético, têxteis técnicos e inteligentes, materiais fibrosos e desenvolvimento de produto. Em 2015 iniciou suas atividades como Professora Adjunto com dedicação exclusiva no Departamento de Engenharia Têxtil da Universidade Federal de Santa Catarina. 


\section{FERNANDO DESCHAMPS}

Engenheiro de Controle e Automação Industrial (UFSC), Administrador de Empresas (UDESC), Mestre em Engenharia Elétrica (UFSC) na área de concentração em Automação e Sistemas e Doutor em Engenharia de Produção e Sistemas (PUCPR) na área de concentração em Gestão da Produção e Logística. É professor adjunto da PUCPR, vinculado ao Programa de Pós-Graduação em Engenharia de Produção e Sistemas e da UFPR, vinculado ao Departamento de Engenharia Mecânica. Tem experiência na área de automação e sistemas, com ênfase nas áreas de sistemas de informação industriais, avaliação de desempenho e engenharia de organizações (arquitetura, projetos e processos).

\section{FERNANDO DOS SANTOS FREITAS}

Graduando de Engenharia Química pela Universidade Tecnológica Federal do Paraná (UTFPR) e participante de Programa de Iniciação Científica nas áreas de Modelagem Matemática e Otimização Combinatória.

\section{FERNANDO RIBEIRO OLIVEIRA}

Possui graduação em Engenharia Industrial Têxtil pelo Centro de Tecnologia da Indústria Química e Têxtil (2003), mestrado em Química Têxtil (2009) e doutorado em Engenharia Têxtil pela Universidade do Minho (01/2013). Desenvolveu um projeto de pós-doutorado no Centro de Ciência e Tecnologia Têxtil na Escola de Engenharia da Universidade do Minho - Portugal (08/2013). Tem experiência de 04 anos na área industrial, atuando no desenvolvimento de produto, qualidade, programação e controle da produção na área Têxtil (2004-2007). Em Agosto de 2013 iniciou suas atividades como Professor de Magistério Superior com dedicação exclusiva no Departamento de Engenharia Têxtil da Universidade Federal do Rio Grande do Norte. Atualmente é Professor Adjunto nível 3 no Departamento de Engenharias, Campus Blumenau, da Universidade Federal de Santa Catarina.

\section{GABRIELA MAESTRI}

Cursa Engenharia Têxtil na Universidade Federal de Santa Catarina, onde participou de grupo de pesquisa em eletrofiação com ênfase em encapsulação e liberação de medicamentos. Atualmente estuda tecnologias de Indústria 4.0 e suas aplicações ao setor têxtil.

\section{GISELY LUZIA STRÖHER}

Doutora em Ciências pelo Programa de Pós Graduação em Química da Universidade Estadual de Maringá (UEM), mestre em Química pela Universidade Federal de Mato Grosso do Sul (UFMS) e bacharel em química pela Universidade Estadual de Maringá. É professora da Coordenação de Licenciatura em Química da Universidade Tecnológica Federal do Paraná (UTFPR) onde atua nas áreas de análises de qualidade, cromatografia, espectroscopia atômica e molecular.

\section{GUILHERME GUILHERMINO NETO}

Mestre em Modelagem Computacional pela UFJF, Especialista em Métodos Estatísticos Computacionais pela UFJF e bacharel em Engenharia de Produção pela Universidade Salgado de Oliveira - Juiz de Fora. Atualmente é doutorando em Modelagem Computacional pela UFJF e professor no Instituto Federal do Espírito Santo (Ifes), onde leciona disciplinas relacionadas à Engenharia de Produção, Estatística e Computação. Suas principais áreas de atuação são Ciência de Dados e Métodos de Previsão Quantitativa. 


\section{GUILHERME LOURO BREZINSKI}

Guilherme Louro Brezinski é Engenheiro de Controle e Automação pela UTFPR, pesquisador e mestrando vinculado ao Programa de Pós-Graduação em Engenharia de Produção e Sistemas - PPGEPS da Pontifícia Universidade Católica do Paraná - PUCPR. Desenvolve sua pesquisa na empresa Wert Solutions, com o sistema Manusis 4.0, tendo como principais áreas de atuação a manutenção industrial, o desenvolvimento da transformação digital (indústria 4.0) e a arquitetura organizacional. É co-fundador da startup de tecnologia Go44, que presta serviços de análise de maturidade industrial para organizações que buscam a transformação digital, onde atua como chefe de operações.

\section{GYLLES RICARDO STRÖHER}

Doutor e mestre em Ciências pelo Programa de Pós Graduação em Engenharia Aeronáutica e Mecânica pelo Instituto Tecnológico de Aeronáutica (ITA), mestre em Engenharia Química e Engenheiro Químico pela Universidade Estadual de Maringá (UEM). É professor da Coordenação e do Programa de Pós Graduação em Engenharia Química da Universidade Tecnológica Federal do Paraná (UTFPR), onde atua nas áreas de Dinâmica dos Fluidos Computacional e Otimização Numérica.

\section{HELDER ROBERTO DE OLIVEIRA ROCHA}

Possui Doutorado e Mestrado em Computação Cientifica e Sistemas de Potência - UFF, Especialização em Administração e Negócios - UCAM, Bacharelado em Administração UFRRJ e Graduação em Engenharia Elétrica - UFF. Tem experiência na área de Engenharia Elétrica, atuando principalmente nos seguintes temas: Estimação de Estado, Metaheurísticas, Sistema de Potência e Telecomunicações. Foi Tutor Presencial no curso de Tecnologia de Sistemas de Computação oferecido pelo CEDERJ, professor no Instituto Federal do Espirito Santo e do Departamento de Computação e Eletrônica do CEUNES/UFES. Realizou pesquisa no âmbito do programa Pós-Doutorado da CAPES na UFES. Ocupa atualmente o cargo de Professor Classe C - Adjunto II do Departamento de Engenharia Elétrica da UFES. É bolsista de Produtividade da Fundação de Amparo à Pesquisa e Inovação do Espírito Santo.

\section{HÉLIO RAYMUNDO FERREIRA FILHO}

Possui graduação em Engenharia Elétrica pela Universidade Federal do Pará (1982), Mestrado em Tecnologia da Informação - University of Nottingham (1990), Mestrado em Gestion de Systèmes dlnformation - Université Pierre-Mendès France (2000) e Doutorado em Ciências de Gestão - Université Pierre Mendès-France (2004), convalidado pela Escola de Administração da Universidade Federal do Rio Grande do Sul. Atualmente é Professor Adjunto IV da Universidade do Estado do Pará, Coordena o Curso de Especialização em Logística com ênfase em Sustentabilidade. Atua no Programa de Mestrado em Ciências Ambientais e no Curso de Engenharia de Produção da UEPA. Tem experiência na área de Administração, com ênfase em Sistemas de Informação, atuando principalmente nos seguintes temas: Tecnologia da Informação, Gestão do Conhecimento, Sistema Integrados de Gestão, Supply Chain Management, Logística e Logística Reversa. Possui artigos publicados em eventos e periódicos nacionais e internacionais. É referee nos eventos ENEGEP e SIMPEP.

\section{HENRIQUE STEINHERZ HIPPERT}

Doutor em Engenharia Elétrica pela PUC-Rio em 2001. Atualmente é Professor Associado no Depto. de Estatística da Universidade Federal de Juiz de Fora, onde leciona disciplinas relacionadas à Estatística, Séries Temporais e Inteligência Computacional. Suas principais áreas de atuação são os métodos de previsão (particularmente para previsão de cargas) e as redes neurais artificiais. 


\section{ÍCARO AGOSTINO}

Engenheiro de Produção pela Universidade Ceuma (2016). Mestrando em Engenharia de Produção pela Universidade Federal de Santa Maria (UFSM). Atualmente é Pesquisador Bolsista (CAPES) no Laboratório de Análise e Modelagem Estatística da UFSM. Tem experiência na área de Engenharia de Produção, com ênfase em Simulação de Eventos Discretos, Métodos Quantitativos para tomada de Decisão, Previsão Aplicada.

\section{IVAN CORRER}

Doutorando em Engenharia de Produção pela Universidade Metodista de Piracicaba (2017atual), Mestrado em Engenharia de Produção pela Universidade Metodista de Piracicaba (2006) e Graduado em Engenharia de Controle e Automação pela Universidade Metodista de Piracicaba (2014). Atualmente é sócio/proprietário da empresa Geotecno Soluções em Automação, na qual coordena a área de Pesquisa e Desenvolvimento de Novos Produtos voltados para otimização de processos de usinagem (desde 2006). Professor dos cursos de Engenharia de Produção, Engenharia de Controle e Automação e Administração de empresas (desde 2011), lecionando disciplinas de Administração da Produção, Automação da Produção, Gestão da Qualidade, Gestão da Produção, Introdução a Engenharia de Produção, Logística Industrial, Metrologia Industrial, Pesquisa Operacional, Projeto de Fábrica, Sistemas supervisórios, Tecnologia da Informação. Experiência tecnológica na área de Engenharia de Produção, Engenharia de Controle e Automação e Gestão Empresarial, com ênfase em Automação da Manufatura, Gestão da Produção, Administração, atuando principalmente nos seguintes temas: P\&D de Novos Produtos, Controle de Processos, Controle da Produção, Sistemas de Monitoramento, Redução de tempos de Setup.

\section{JARBAS ANCELIMO DA SILVA JÚNIOR}

Graduado em Engenharia de Produção pela Universidade Federal de Goiás.

\section{JOSÉ LEANDRO FELIX SALLES}

Possui graduação em Engenharia Elétrica pela Universidade Federal do Espírito Santo (1987) e doutorado em Engenharia Elétrica pela Universidade Estadual de Campinas (1999). Atualmente é professor Titular da Universidade Federal do Espírito Santo. Tem experiência na área de Engenharia Elétrica, com ênfase em Engenharia Elétrica, atuando principalmente nos seguintes temas: Controle de processos, Otimização, Controle preditivo e Séries Temporais

\section{KARINA SAYURI UEDA}

Engenheira de Alimentos pela Universidade Federal da Grande Dourados- UFGD. Atuou durante 1 ano como Diretora de finanças e 6 meses como Diretora de marketing na Empresa Junior de Engenharia de Alimentos- EJIPTA. Tem experiência na área de Ciência e Tecnologia de Alimentos, com ênfase em Ciência de Alimentos. Atuou como voluntária em projeto de obtenção e incorporação de extratos e óleo essencial de Romã em filmes biodegradáveis. Foi bolsista durante o período de 2 anos pelo Programa Institucional de Bolsas de Iniciação Científica, PIBIC (CNPq) desenvolvendo o trabalho de extração de nanocristais de celulose de diversas fibras.

\section{KAROLINE SILVA AMORIM}

Graduanda de Engenharia de Produção pela Universidade do Estado do Pará. 


\section{KATIANE DE OLIVEIRA COMACHIO}

Sou Bacharel em Engenharia de Produção e tenho Licenciatura em Física, ambos pela Universidade Tecnológica Federal do Paraná - Campus Medianeira. Estagiei na Pesquisa e Desenvolvimento de Produtos Lácteos, na Frimesa Cooperativa Central - Matelândia. Como colaboradora efetiva neste setor, atuei por 1 ano e 2 meses, acompanhando start-up de novas linhas de iogurtes, desenvolvendo novos produtos e verificando e melhorando processos de fabricação de queijos, queijos fundidos, iogurtes e produtos UHT. Fui encarregada (responsável) pelo Setor de Higienização da Unidade Frimesa Matelândia, contemplando higienização interna (ambiente e CIP), externa (pátio e vestiários), controle de pragas e lavanderia. Nesta função, implantei a lavanderia industrial na unidade, acompanhei start-up de novas linhas e implantei algumas melhorias no processo de limpeza CIP de algumas linhas. Atualmente, possuo duas pós-graduações em docência, sou professora PSS do Estado do Paraná e leciono a disciplina de física para turmas do Ensino Médio. Áreas de interesse: Física. Tecnologias computacionaispara otimização de processos. Gestão da produção. Desenvolvimento de produtos e processos. Qualidade de produtos agroindustriais.

\section{LARA CRISTINE PEREIRA DOS SANTOS}

Graduada em Engenharia de Produção pela Universidade Federal de Goiás.

\section{LORENA HERNANDEZ MASTRAPA}

Possui graduação em Engenharia Industrial - Universidade Oscar Lucero Moya (2013). Mestrado em Engenharia de Produção, na área de Transporte e Logística da Pontifícia Universidade Católica do Rio de Janeiro (PUC-Rio). Atualmente é doutoranda (stricto sensu) do Programa de Pós-Graduação em Engenharia de Produção da Universidade Metodista de Piracicaba, São Paulo. Tem experiência na área de Engenharia de Produção, com ênfase em Sistemas Logísticos.

\section{LUCAS DAVIS RIBEIRO DE PAULA}

Graduando em Engenharia de Produção (FEAMIG). Aluno de Iniciação Científica (FEAMIG).

\section{LUCAS EDUARDO BARBIERI}

Graduando em Engenharia de Produção pelas Faculdades Integradas Einstein de Limeira

\section{LUCIANA LIMA GONCALVES}

Bacharel em Administração pelo Centro Federal de Educação Tecnológica de MG - CEFETMG. MBA em Gestão Financeira, Controladoria e Auditoria pela Fundação Getúlio Vargas. Experiência em: Reestruturação Financeira e Comercial, Mapeamento e Redesenho de Processos. Monitoramento de KPI's, dashboards, budget, cash flow. Implantação de Gestão Matricial de Despesas e Receitas. Criação de ferramentas integradas de gestão e treinamento gerencial. Responsável pela análise de causa em casos de desvios de forecast. Utilização de ferramentas de gestão como MASP, PDCA, FMEA, PPAP, CEP. Atuação em auditoria interna da ISO 9001, TS 16949 e ISO 14001.

\section{LUCIANO DOS SANTOS DINIZ}

Doutor em Ciências Sociais, professor adjunto II do Departamento de Ciências Sociais Aplicadas do CEFET/MG, pesquisador dos grupos de pesquisa CITIES - Núcleo Interdisciplinar de Pesquisas em Cidades Inteligentes, Tecnológicas, Inovativas, Empreendedoras e Sustentáveis (CEFET-MG); NEPUR - Núcleo de Estudos e Pesquisa Urbana (PUC-SP) e LOGOS - Processos e Sistemas Decisórios em Arranjos Organizacionais (CEFET/MG) 


\section{LUCIMARA CARDOSO NICOLAU}

Graduada em Pedagogia pelo Centro Universitário Leonardo da Vinci, Cursando Especialização em Educação Infantil e Anos Iniciais com Ênfase em Ludopedagogia e Literatura Infantil. Professora de Ensino Fundamental Anos Iniciais no Colégio Marista Criciúma, Microsoft Innovative Educator (MIE Expert).

\section{LUIS GUILHERME ESTEVES LEOCADIO}

Possui graduação em Engenharia de Produção e mestrado em Engenharia Mineral, ambos pela Universidade Federal de Ouro Preto (Escola de Minas - Ufop). Cursou especialização em Logística na Universidade Federal de Minas Gerais (Escola de Engenharia - Ufmg) e cursa especialização em Engenharia de Segurança do Trabalho no Centro Universitário Newton Paiva. Foi professor da Universidade Presidente Antônio Carlos (Faculdade de Tecnologia e Ciências de Conselheiro Lafaiete - Unipac) e do Instituto Federal de Minas Gerais, Campus Bambuí (Departamento de Engenharia e Computação - Ifmg). Têm interesse nas seguintes áreas: logística e qualidade.

\section{MARCELA MONIQUE DONADELLI}

Graduada em Engenharia de Produção pelas Faculdades Integradas Einstein de Limeira

\section{MARCOS WAGNER JESUS SERVARE JUNIOR}

Possui graduação em Engenharia de Produção e mestrado em Engenharia Civil (área de concentração: Transportes) pela Universidade Federal do Espírito Santo. Atualmente cursa o Doutorado em Engenharia Elétrica na mesma Universidade. Atua em projetos na área de Otimização de sistemas de transportes e redes logísticas.

\section{MARIA JULIA XAVIER BELÉM}

Graduada em Engenharia Mecânica pela Universidade Metodista de Piracicaba - UNIMEP (2016). Atualmente, aluna de mestrado do Programa de Pós-Graduação em Engenharia de Produção (PPGEP) da Universidade Metodista de Piracicaba (UNIMEP).

\section{MARIA VERÔNICA MACEDO DE LIMA GALM}

Graduanda do Curso de Engenharia de Produção da Universidade do Vale do Itajaí.

\section{MATHEUS ADRIANO GODOY RAMOS}

Curso técnico em Logística pelo Serviço Nacional de Aprendizagem Industrial (SENAI) (2013-2014);- Acadêmico do curso de Engenharia Mecânica na Faculdade de Telêmaco Borba (FATEB) - (2015-2019)

\section{NATÁLIA CIBELE DE SOUSA SANTOS}

Graduada em Engenharia de Produção pela Universidade Federal de Goiás.

\section{NAYARA CRISTINA RAMIOS}

Possui graduação em Engenharia de Produção pela Universidade do Estado do Pará (2015). Especialista em Engenharia de Segurança do Trabalho (2016), CREA: 151.442.0309. Especialista em Engenharia de Produção (2017). Mestranda em Ciências Ambientais (UEPA, 2018) Servidora efetiva da Secretaria de Estado de Saúde Pública desde 2012. Almeja atuar nas áreas de docência e pesquisa. Docente horista no Campus XV da Universidade do Estado do Pará (UEPA) Redenção - PA. 


\section{PAULO FERNANDES SANCHES JUNIOR}

Professor Associado II do Centro Federal de Educação Tecnológica de Minas Gerais (CEFET$M G$ ). Doutor em Engenharia Civil pela UNICAMP, Mestre em Engenharia de Produção pela UFSC. Atua em estudos de Organizações, Logística e Qualidade.

\section{PETER HACHMANN}

Graduando do Curso de Engenharia de Produção da Universidade do Vale do Itajaí. Analista de projetos jr na empresa Algar Telecom.

\section{RAFAEL RODRIGUES BENELLI}

Graduado em Engenharia de Produção pelas Faculdades Integradas Einstein de Limeira

\section{RAQUEL FERREIRA DE SOUZA}

Graduada em Letras (PUCMINAS) e Direito (FAMIG). Especialista em Educação (UNISEB) e em Linguística (ESTÁCIO). Mba em Gestão de Negócios (UNOPAR). Mestre em Filosofia (FAJE). Adjunta do Programa de Pesquisa, Produção e Divulgação Científica (PPDC) (FEAMIG). Docente em cursos de Engenharia (FEAMIG E FASEH).

\section{RENAN MITSUO UEDA}

Engenheiro de Produção formado pela Universidade Federal da Grande Dourados (UFGD). É Membro fundador e Ex-Diretor Jurídico-Financeiro da Sigmax Engenharia Júnior, uma empresa de consultoria que presta serviços para toda a região da grande Dourados. Além disso, já participou de projetos vinculados ao Conselho Nacional de Desenvolvimento Científico e Tecnológico (CNPq).Atualmente é mestrando em Engenharia de Produção (PPGEP - UFSM), atuando em pesquisas nas áreas de Métodos Quantitativos para Tomada de Decisão.

\section{RODRIGO FREDI}

Engenheiro de Produção Mecânica, Engenheiro de Segurança do Trabalho, mestrando em Engenharia de Produção, Diretor de Serviço Administrativo ETEC (Centro Paula Souza), Docente nos cursos Técnico em Segurança do Trabalho e Administração. Conhecimentos em Custos e Orçamentos, Vendas, PCP e Recrutamento e Seleção.

\section{RODRIGO MONTANARI DA CUNHA}

Administrador de empresas, mestrando em Engenharia de Produção, MBA em Gerenciamento de Marketing e MBA em Gestão Comercial com extensão internacional. Consultor Empresarial nas áreas de controles financeiros e gestão de custos. Diretor Geral em indústria de manufatura têxtil no setor de cama e acessórios. Multinacionais do setor financeiro com foco em busca de resultado. Empresas de grande porte no setor de comunicação impressa (jornais e revistas) com foco em desenvolvimento de novos negócios. Docente de graduação no curso de Administração de Empresas. Sólidos conhecimentos em planejamento estratégico, gestão industrial, gestão de pessoas, administração financeira, administração de vendas e recrutamento/seleção de novos colaboradores.

\section{SILVANA LIGIA VINCENZI}

Professora titular e pesquisadora da Universidade Tecnológica Federal do Paraná - UTFPR, campus Medianeira. Possui experiência na área de Probabilidade e Estatística, com ênfase em Análise de dados, atuando nos seguintes tópicos: modelos para variável latente, Teoria de Resposta ao Item, pesquisa operacional. Possui graduação em Ciências pela Faculdade 
de Filosofia Ciências e Letras de Umuarama (1982), graduação em Matemática pela Faculdade de Filosofia Ciências e Letras de Umuarama (1984), graduação em Física pela Fundação Faculdade Estadual de Filosofia Ciências e Letras de Cornélio Procópio (1985). Especialização em Instrumentação Para o Ensino de Ciências pela Faculdade de Filosofia Ciências e Letras de Umuarama e Especialização em Matemática pela Universidade Estadual de Maringá. Mestrado (2003) e Doutorado (2010) pela Universidade Federal de Santa Catarina em Engenharia de Produção na área de inteligência organizacional. Atualmente é professora do Programa de Pós-Graduação em Tecnologias Computacionais para o Agronegócio, atuando na linha de pesquisa Tecnologias computacionais aplicadas a produção agrícola - UTFPR/MD e professora do Programa de Pós-Graduação em Métodos e Gestão em Avaliação - UFSC

\section{SILVIA MARIA MARTELLI}

Possui graduação em Engenharia de Alimentos pela Universidade Federal de Santa Catarina (2002), mestrado em Engenharia de Alimentos pela Universidade Federal de Santa Catarina (2005), doutorado em Biomateriais pela Universidade de Pisa (2007), Pós-Doutorado pela Ghent University (2008-2009) e Pós-Doutorado pela Universidade Federal de Santa Catarina (2010-2012). É Professora Adjunta da Universidade Federal da Grande Dourados, Coordenadora do Curso de Mestrado em Ciência e Tecnologia de Alimentos e Coordenadora do grupo de pesquisa em Embalagens e Alimentos Funcionais (MFBIOPACK - UFGD), integrante do Grupo de Pesquisa de Microbiologia Aplicada (UFGD)

\section{SIMONE CAVENATI}

Graduada em Engenharia Química pela Universidade Federal de Santa Catarina (1993), Mestre em Engenharia Química pela Universidade Federal de São Carlos (1996) e Doutora em Engenharia Química pela Faculdade de Engenharia da Universidade do Porto (2005). Fez dois pós-doutorados na Universidade do Porto (Portugal), um na Faculdade de Engenharia (LSRE/LCM) e outro no Centro Interdisciplinar de Investigação Marinha e Ambiental (CIIMAR). Trabalhou como professora substituta na Universidade Federal de Santa Catarina, onde lecionou por dois anos no Departamento de Engenharia Química e de Alimentos. Atualmente é professora na Universidade do Vale do Itajaí (UNIVALI) onde leciona nos cursos de Engenharia de Produção, Mecânica e Química.

\section{TELMA TAMIRES BARBOSA VIEIRA}

Graduada em Engenharia de Produção pelas Faculdades Integradas Einstein de Limeira

\section{TIAGO CESCONETO ROQUE}

Mestrando em Tecnologias da Informação e Comunicação (TIC) pela Universidade Federal de Santa Catarina (UFSC) e Bacharel também em Tecnologias da Informação e Comunicação (TIC) pela Universidade Federal de Santa Catarina (UFSC). Analista de Tecnologia Educacional no Colégio Marista de Criciúma e Microsoft Innovative Educator Trainer (MIETrainer).

\section{VANESSA MORAES ROCHA DE MUNNO}

Possui graduação em Ciências - Habilitação em Biologia pela Universidade Metodista de Piracicaba (2001) e mestrado em Odontologia/Fisiologia pela Universidade Estadual de Campinas (2006). Atualmente é docente -Colégio Jandyra Antunes Rosa na disciplina de Biologia (Ensino Médio) e docente nas Faculdades Integradas Einstein de Ensino lecionando as disciplinas de Gestão Ambiental, Trabalho de Conclusão de Curso, Metodologia Cientifica, Ergonomia nos cursos de Engenharia: Civil, Elétrica, Produção, Mecânica, Administração e Metodologia e Conteúdo de Ciências no curso de Pedagogia. 


\section{VICTOR DE SOUZA RIBEIRO}

Graduando do Curso de Engenharia de Produção da Universidade do Vale do Itajaí. Promotor de vendas na empresa Ontex.

\section{VIVIANE YUKARI YAMADA}

Concluiu graduação em Engenharia de Produção pela Pontifícia Universidade Católica do Paraná (PUCPR - Londrina), no ano de 2016. Atuou como estagiária nas empresas Sunyata Soluções Industriais e Due Vita, nos setores de Projeto e Planejamento e Controle de Produção respectivamente. Atualmente, ocupa o cargo de Encarregada de Análise de Projetos na empresa Microsens S/A. Tem experiência em projetos elétricos (as built) e desenvolvimento de projetos de vídeowall para instituições públicas e privadas. Cursou MBA em Gestão e Estratégia Empresarial na Unifil (2018). Atualmente, cursa MBA em Gestão da Qualidade - Ênfase em Seis Sigma e Lean Manufacturing (previsão de conclusão em 2020) na Universidade Pitágoras Unopar.

\section{WALTER SEGOND DE VASCONCELOS}

Mestre em Estruturas e Construção Civil pelo Departamento de Engenharia Civil e Ambiental da Universidade de Brasília (UnB). Especialista em Gestão Ambiental pela Universidade Federal de São Carlos (UFSCar). Especialista em Planejamento e Gestão Empresarial pela Universidade Católica de Brasília (UCB). Especialista em Engenharia de Segurança do Trabalho pela FUNDACENTRO. Graduado em Engenharia Civil pela Universidade de Brasília (UnB). Docente no curso de graduação em Engenharia Civil do Centro Universitário Planalto do Distrito Federal (UNIPLAN). Diretor da ENTEMPO Consultoria Organizacional e Ambiental Ltda, desde o ano de 2009. Consultor de empresas do setor da construção civil no desenvolvimento de atividades voltadas para a gestão da qualidade e produtividade de processos de produção de obras e serviços. Auditor líder de Organismos Certificadores de Sistemas, na condução de auditorias de sistemas de gestão da qualidade, desenvolvidos e mantidos em conformidade a norma NBR ISO 9001 e aos requisitos do Referencial Normativo SiAC/PBQP-H, como também, auditor do Selo de Excelência ABCIC. Organizador e instrutor de cursos voltados para a qualificação profissional de trabalhadores do setor de construção civil 
